\title{
State and Self-regulation of Civil Society Organizations in Context: A Case Study of Kenya
}

\author{
by \\ Jacqueline Wood
}

A thesis submitted to the Faculty of Graduate and Postdoctoral Affairs in partial fulfillment of the requirements for the degree of

Doctor of Philosophy

in

Public Policy

Carleton University

Ottawa, Ontario

(C) 2019, Jacqueline Wood 


\begin{abstract}
Much was made of the global associational revolution beginning in the 1980s, as civil society organizations (CSOs) increased in number worldwide. Since then, a paradox of competing trends has emerged. On one hand, considerable stock is held in the promise of civil society whereby CSOs are recognized as critical actors in economic, social, and democratic development. Governments have sought ways to enable vibrant and diverse CSO sectors through regulation, reflecting a diffusion of pro-CSO norms globally. Deviating from this trend, an associational counter-revolution has arisen whereby governments use regulation to constrain the space for CSO operations.

Advancing CSO accountability is a key rationale for many intensified forms of both enabling and constraining state regulation, and self-regulation. Theory suggests there is a trade-off between state and self-regulation, from which cycles of regulatory waves unfold.
\end{abstract}

This dissertation contributes to the CSO regulation literature, which has tended to focus on high-income countries, by developing and applying a conceptual framework of regulatory change drivers to a lower-middle income country, Kenya. Beginning in the late 1980 s Kenya was the first African country to significantly address CSO regulation and self-regulation, and has since undergone four phases of CSO regulatory change, sometimes more, sometimes less enabling of the sector. The dissertation draws from primary data in the form of 63 interviews, legislation, regulation, and media sources. Its conceptual framework can help anticipate state and/or self-regulatory change; the state 
and self-regulation interaction; their relationship to accountability; and the associational counter-revolution paradox.

This dissertation finds that the most important driver of regulatory change in Kenya's lower-middle income context is government's political agendas, hand-in-hand with the types of activities CSOs engage in. Donor country governments are also an important direct and indirect driver of regulatory change. While regulatory change occurs in 'waves', rather than interplay between state and self-regulation, it is the drivers of regulatory change and their interplay that move and shape the waves. Regulatory change may be turned to as a technical solution to various issues reflected in the drivers, even as it may not necessarily be the best, the only, or sufficient means to address them. 


\title{
State and Self-regulation of Civil Society Organizations in Context: A Case
}

\section{Study of Kenya}

\author{
(C) 2019, Jacqueline Wood \\ orcid.org/0000-0002-6841-7860
}

\begin{abstract}
Recommended citation:
Wood, J. (2019). State and Self-regulation of Civil Society Organizations in Context: A Case Study of Kenya (Unpublished doctoral dissertation). Carleton University, Ottawa, Canada. http://doi.org/10.22215/etd/2019-m17011
\end{abstract}




\section{Acknowledgements}

I would not have made it through the long and bumpy journey to this dissertation's completion were it not for the scholarly, professional and personal contributions and support of many.

Coming from a program and policy analyst background, my step into the academic realm took some getting used to. Throughout, my supervisor Susan Phillips has been a source of unflagging faith, intellect and kindness for which I am eternally grateful. To cite yet another reference: what Ken Dryden, professional hockey player turned Member of Parliament turned author wrote of his mentor (writer Don Coles) depicts Dr. Phillips' support perfectly. Dr. Phillips helped me believe that this dissertation was a worthwhile endeavour, that "no matter how ragged my work, there was something there. That I was getting there and would get there" (Martin, 2017, para. 15).

I cannot thank Edward Jackson and Douglas Rutzen enough for their willingness to participate in my committee despite busy schedules, for their patience through my dissertation process, and for their invaluable, insightful feedback.

Carleton's School of Public Policy and Administration has been a great home for me and for my research, thanks to the community of professors, helpful administrators, and my fellow SPPA students who made tackling the first year of course work feel do-able. A shout out goes to Saul Schwartz, especially but not exclusively for his guidance in navigating the system. I am also grateful for the camaraderie and insights from participants in the 2016 UPenn Summer Doctoral Fellows Program and its host, Dr. Peter Frumkin. The supportive environment and opportunities provided by the International 
Society for Third Sector Research 2014 Doctoral Seminar and subsequent conferences are also noteworthy. I also appreciate the financial support provided by the Ontario Graduate Scholarship Program as well as the Eileen Cox and Zuhair A. Hassan Graduate Scholarships.

I have been lucky to have many colleagues, friends and allies with a shared interest in (and responsibility for) the subject matter of this dissertation, who aided me in one way or another through this process. Thanks also go to them, including for putting me in touch with colleagues of colleagues of colleagues, friends of friends of friends, and acquaintances of acquaintances of acquaintances, around the globe.

To my dear parents (Jim and Margaret), sisters (Christina and Lynda), nephews (William and James), and in-laws (Jeffery) including the sadly departed (Mark), my partner (Réal), and my wonderful pals far and near (yogis included), ever-so-many thank yous for the various forms of support and encouragement you have provided. Thanks also for your patience with my distracted self over these years!

I am especially grateful to the many individuals in and outside of Kenya who agreed to participate in this research. Mabibi na Mabwana, na shukuran. I hope that my depiction of Kenya's CSO regulatory change story adequately reflects your experiences.

All that said, any errors or omissions in this research are mine alone. 


\section{Table of Contents}

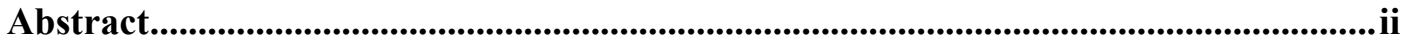

Acknowledgements ........................................................................................................................ v

List of Tables .......................................................................................................................................vviii

List of Figures.........................................................................................................................................viii

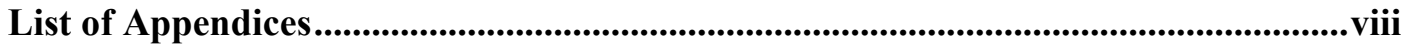

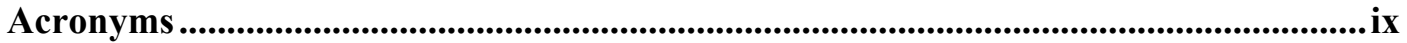

1 SETTING UP THE RESEARCH........................................................................... 1

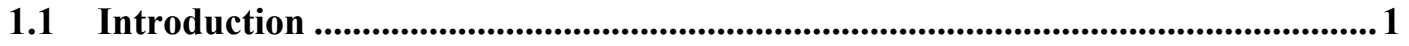

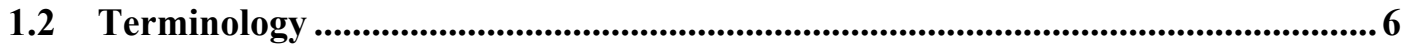

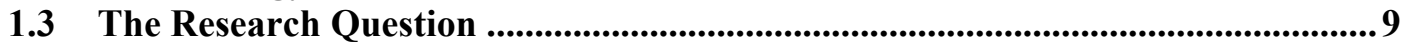

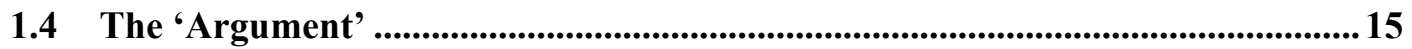

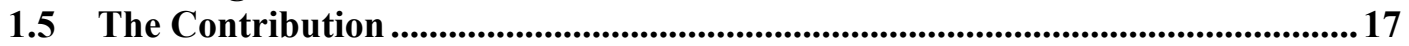

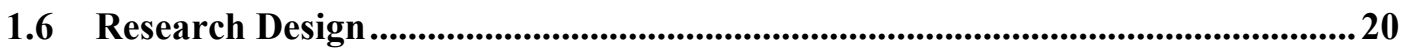

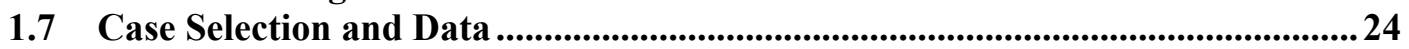

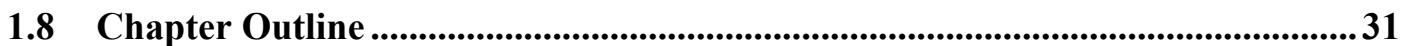

2 CONCEPTUALIZING STATE AND SELF-REGULATION AND

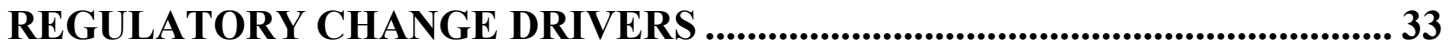

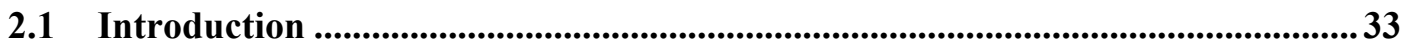

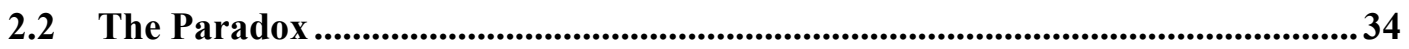

2.3 The CSO Accountability Challenge ....................................................................36

2.4 Responding to Accountability Challenges through Regulation............................. 40

2.5 State and Self-regulation: The Why, How and What, in Theory and Practice.. 42

2.6 Drivers of Regulatory Change - A Conceptual Framework .................................6 67

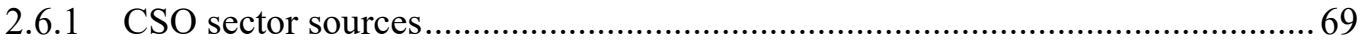

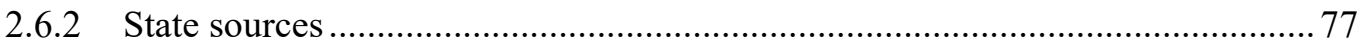

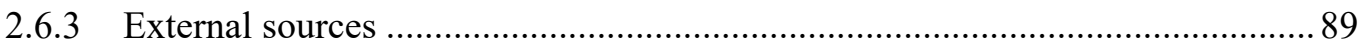

2.7 Lower and Middle Income Country Characteristics of Relevance to CSO Sector

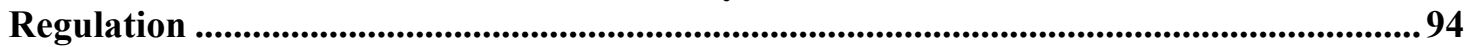

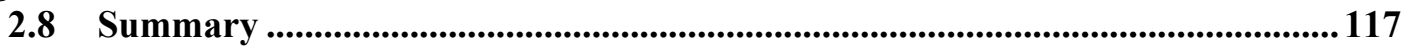

3 REGULATORY WAVE ONE, LATE 1980s TO 1999 - A RISING TIDE OF

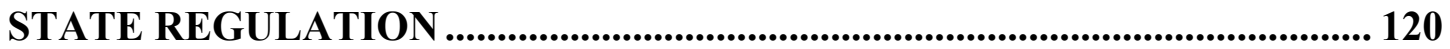

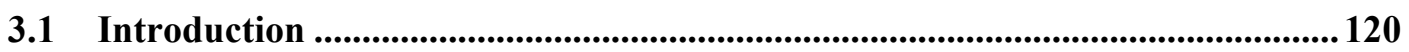

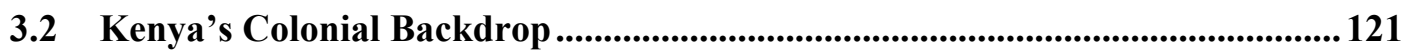

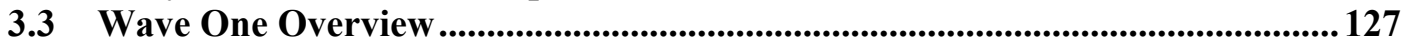

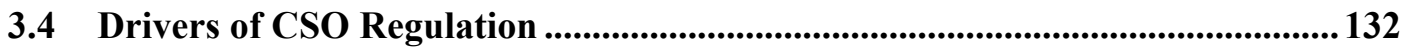

3.5 Regulatory Change Outcomes....................................................................................... 178

3.6 Analytical Summary ........................................................................................................... 194

4 REGULATORY WAVE TWO, 2000 TO 2007-STATE REGULATORY

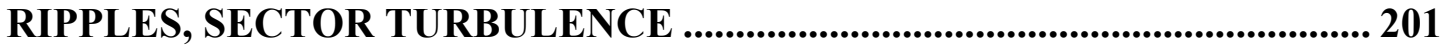

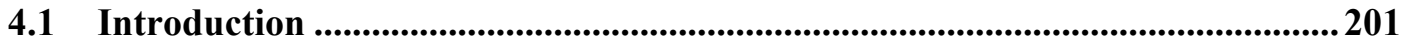

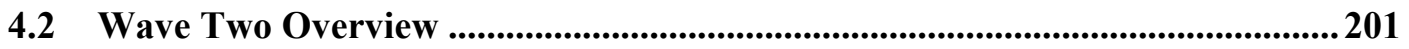

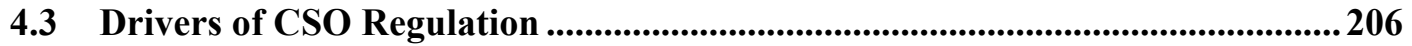

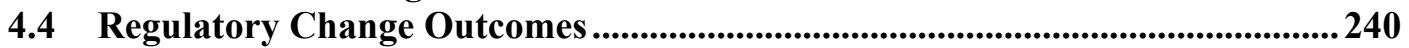

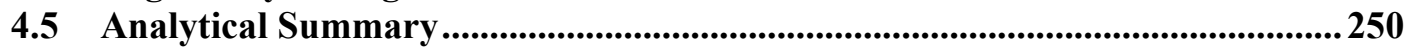


5 REGULATORY WAVE THREE, 2008 TO EARLY 2013 - CIVIL SOCIETY

ORGANIZATION REGULATORY UPSWELL ................................................. 256

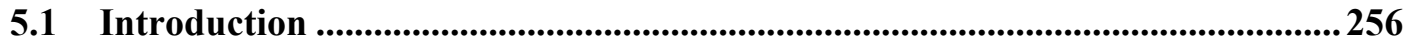

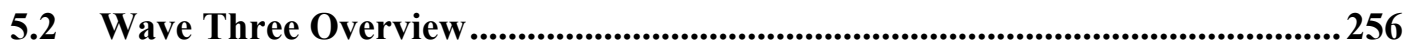

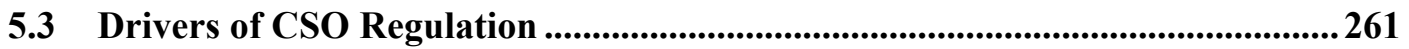

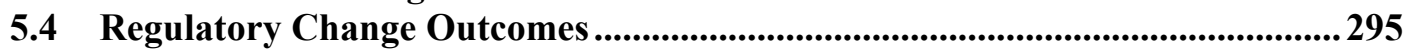

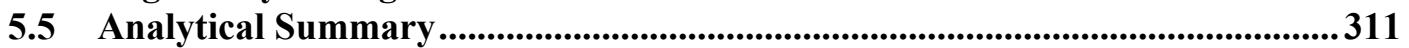

6 REGULATORY WAVE FOUR, 2013 TO 2017 - RISING TIDE OF

REGULATORY REFORM ATTEMPTS ......................................................... 317

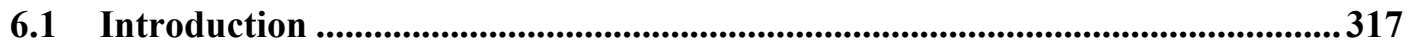

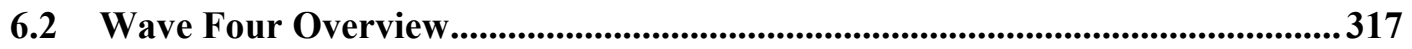

6.3 Drivers of CSO Regulation .............................................................................. 322

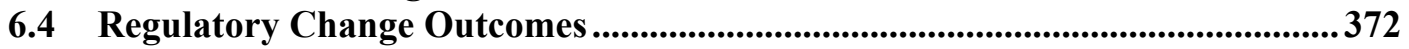

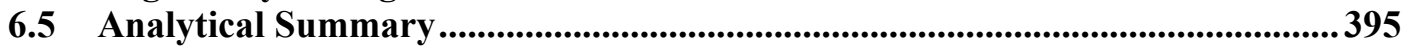

7 DISCUSSION - UNDERSTANDING THE DRIVERS OF REGULATORY

CHANGE IN LMI COUNTRY CONTEXTS ......................................................... 400

7.1 Drivers of CSO Regulatory Change: Lessons from Kenya.................................400

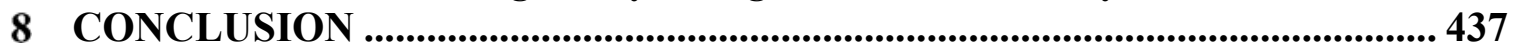

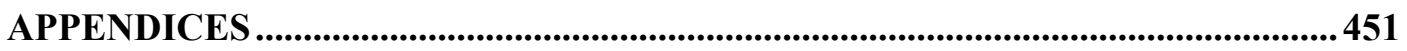

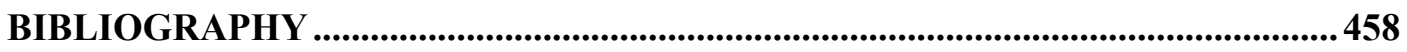

\section{List of Tables}

Table 1: Issues for CSO Regulation and Forms of Regulation..................................... 53

Table 2: Wave One Key Developments or Actions of Main Actors ............................. 130

Table 3: Wave One Key Regulatory Change Drivers............................................... 199

Table 4: Wave Two Key Developments or Actions of Main Actors.............................. 203

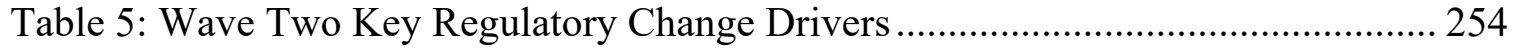

Table 6: Wave Three Key Developments or Actions of Main Actors........................... 258

Table 7: Wave Three Key Regulatory Change Drivers ............................................. 315

Table 8: Wave Four Key Developments or Actions of Main Actors ............................ 319

Table 9: Wave Four Key Regulatory Change Drivers .............................................. 398

\section{List of Figures}

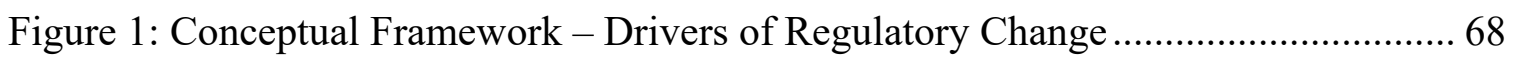

Figure 2: Wave One Timeline: Key Political and CSO Regulation Developments ....... 131

Figure 3: Wave Two Timeline: Key Political and CSO Regulation Developments....... 205

Figure 4: Wave Three Timeline: Key Political and CSO Regulation Developments.... 260

Figure 5: Wave Four Timeline: Key Political and CSO Regulation Developments ...... 321

Figure 6: Conceptual Framework - Drivers of Regulatory Change with LMI Country

Characteristics

\section{List of Appendices}

Appendix A: Research Participant Breakdown ..................................................... 451

Appendix B: DAC/G Official Development Assistance Disbursements....................... 453

Appendix C: DAC/G ODA Disbursements for CSOs ............................................... 456 


\section{Acronyms}

\begin{tabular}{|l|l|}
\hline ACNC & Australian Charities and Not-for-Profits Commission \\
\hline AfriCOG & Africa Centre for Open Governance \\
\hline AKDN & Aga Khan Development Network \\
\hline AU & African Union \\
\hline CCIC & Canadian Council for International Cooperation \\
\hline CEO & Chief Executive Officer \\
\hline CIPEV & $\begin{array}{l}\text { Commission of Inquiry into Post-Election Violence (Waki } \\
\text { Commission) }\end{array}$ \\
\hline CKRC & Constitution of Kenya Review Commission \\
\hline CLARION & Centre for Law and Research International \\
\hline CoE & Committee of Experts on Constitutional Review \\
\hline CORD & Coalition for Reform and Democracy \\
\hline CPI & Corruption Perceptions Index \\
\hline CRS & Creditor Reporting System \\
\hline CSO & Civil society organization \\
\hline CSORG & CSO Reference Group \\
\hline DAC & Development Assistance Committee \\
\hline DAC/G & Development Assistance Committee Government \\
\hline DPG & Development Partners Group \\
\hline ED & Executive Director \\
\hline eKLR & Kenya Law Reports (electronic database) \\
\hline ESAAMLG & Eastern and Southern Africa Anti-Money Laundering Group \\
\hline EU & European Union \\
\hline FAQ & Frequently Asked Questions \\
\hline FATF & Financial Action Task Force \\
\hline FH & Freedom House \\
\hline FIDH & FIDH: World Movement for Human Rights \\
\hline GDP & Gross domestic product \\
\hline GNI & Gross national income \\
\hline GoK & Government of Kenya \\
\hline GPEDC & Global Partnership for Effective Development Cooperation \\
\hline HAP-I & Humanitarian Accountability Partnership International \\
\hline HIPC & Heavily indebted poor countries \\
\hline HRW & Human Rights Watch \\
\hline ICC & International Criminal Court \\
\hline ICNL & International Center for Not-for-Profit Law \\
\hline IDLO & International Development Law Organization \\
\hline IDS & Institute of Development Studies (University of Kenya) \\
\hline IEBC & Independent Electoral and Boundaries Commission \\
\hline IFI & International financial institution \\
\hline IREC & Independent Review Commission \\
\hline KADU & Kenyan African Democratic Union \\
\hline
\end{tabular}




\begin{tabular}{|l|l|}
\hline KANU & Kenya African National Union \\
\hline KCS-CSP & Kenya Civil Society Competence and Sustainability Program \\
\hline KHRC & Kenya Human Rights Commission \\
\hline KNCHR & Kenya National Commission on Human Rights \\
\hline KNCSS & Kenya National Council of Society Services \\
\hline KPTJ & Kenyans for Peace with Truth and Justice \\
\hline KTJN & Kenya Transitional Justice Network \\
\hline LGBTQ+ & Lesbian, gay, bisexual, transgender, queer, plus \\
\hline LMI & Lower and middle income \\
\hline MHA & Ministry of Home Affairs \\
\hline MP & Member of Parliament \\
\hline MUHURI & Muslims for Human Rights \\
\hline NARC & National Alliance Rainbow Coalition \\
\hline NCCK & National Council of Churches of Kenya \\
\hline NCEC & National Convention Executive Council \\
\hline NCNGO & National Council of Non-Governmental Organizations \\
\hline NCVO & National Council for Voluntary Organizations \\
\hline NGO & Non-governmental organization \\
\hline NGOCB & NGOs Co-ordination Board \\
\hline NPM & New public management \\
\hline NPO & Non-profit organization \\
\hline ODA & Official development assistance \\
\hline ODM & Orange Democratic Movement \\
\hline OECD & Organisation for Economic Co-operation and Development \\
\hline OVP & Office of the Vice-President \\
\hline PAGVS & Panel on Accountability and Governance in the Voluntary Sector \\
\hline PBO & Public benefit organization \\
\hline PBOT & Public benefit organization Taskforce \\
\hline PEN & Poverty Eradication Network \\
\hline PEV & Post-election violence \\
\hline PoK & President of Kenya \\
\hline PRSP & Poverty Reduction Strategy Paper \\
\hline PSO & Private service organization \\
\hline SAP & Structural adjustment program \\
\hline Task Team & $\begin{array}{l}\text { Task Team on CSO Development Effectiveness and Enabling } \\
\text { Environment }\end{array}$ \\
\hline TI & Transparency International \\
\hline TJRC & Truth, Justice and Reconciliation Commission \\
\hline UK & United Kingdom \\
\hline UN & United Nations \\
\hline UNDP & United Nations Development Programme \\
\hline UNSR & $\begin{array}{l}\text { United Nations Special Rapporteur on the rights to freedom of } \\
\text { peaceful assembly and of association }\end{array}$ \\
\hline
\end{tabular}




\begin{tabular}{|l|l|}
\hline US & United States \\
\hline USAID & United States Agency for International Development \\
\hline USD & United States dollars \\
\hline VAT & Value-added tax \\
\hline WB & World Bank \\
\hline WMD & World Movement for Democracy \\
\hline
\end{tabular}




\section{SETTING UP THE RESEARCH}

\subsection{Introduction}

Much has been made of the global "associational revolution" Salamon (1994) observed beginning in the 1980s, as organizations of civil society (CSOs) increased in numbers and diversity, and expanded their roles and contributions worldwide. Across the globe, in countries ranging from the US to China, and at the global level, the CSO sector has continued to grow and diversify (Casey, 2016). CSOs are increasingly active and influential in roles from public service provision to policy engagement nationally and internationally (Lloyd \& Casas, 2005, para. 2).

Policy-makers and scholars alike have put considerable stock in "the promise of civil society", whereby CSOs are recognized as critical actors in economic, social, cultural and democratic development (Edwards, 2011, p. 4; Wiepking \& Handy, 2015a; World Economic Forum, 2013). Characteristics attributed to CSOs including cost-effectiveness; innovativeness and risk-taking; flexibility and responsiveness; and their linkages to and knowledge of the needs and priorities of people on-the-ground, has served to consolidate their place as key players in addressing persistent global, national and local challenges (Hulme \& Edwards, 1997, p. 6; Organisation for Economic Co-operation and Development $[\mathrm{OECD}], 2010)$. International declarations touting the importance of civil society and CSOs abound. CSOs are recognized by the international development community as independent actors "in their own right" (Global Partnership for Effective Development Cooperation [GPEDC], 2016, para. 11c), while the United Nations (UN) Agenda 2030 for Sustainable Development places civil society and CSOs as integral 
partners of government and the private sector to achieve the universal Sustainable Development Goals (United Nations [UN], 2015). National governments have been seeking ways to enable a vibrant and diverse CSO sector, through legislation, regulation and policies that, amongst other things, seek to incentivize CSO action and engagement and leverage philanthropic contributions to the sector (Phillips \& Smith, 2011b; Wiepking \& Handy, 2015; Casey, 2016, p. 20; McGregor-Lowndes \& Wyatt, 2017).

At the same time however, in recent years an "associational counter-revolution" has emerged (Rutzen \& Shea, 2006, p. 27, emphasis added). An ever-growing body of practitioner and scholarly sources shows governments using varied tactics to restrict the space available for CSOs to exist and operate, with tactics including overt ones such as harassment and extra-judicial killings of CSO representatives, to more subtle forms such as restrictions on internet communications or burdensome registration requirements (Carothers \& Brechenmacher, 2014; Rutzen, 2015b; Dupuy, Ron, \& Prakash, 2015a \& b; International Center for Not-for-Profit Law [ICNL], 2016; United Nations Special Rapporteur on the rights to freedom of peaceful assembly and of association [UNSR], 2013 \& 2014; CIVICUS, 2015b; CIVICUS, 2016). Notable among the tactics to constrain the space for CSOs is the use of state legislation, regulation and policies (ICNL, 2016; World Movement for Democracy [WMD] \& ICNL, 2012). Figures from the International Center for Not-for-Profit Law (ICNL) show that from early 2015 to mid2016, sixty-four laws, regulations, or other initiatives restricting the space for CSOs and for civil society more broadly had been enacted worldwide (ICNL, 2016, p. 2). 
These competing trends present a paradox. On the one hand, there is recognition of CSOs' importance alongside efforts to enable the sector's vitality and contribution through policy and regulatory means. On the other, there is a counter trend to restrict CSOs' operating space, also through policy and regulation. As highlighted by Dupuy et al., (2015a), the trend of restricting CSO space through regulatory means is a "remarkable, formal rupture" in the process of global diffusion of liberal democratic norms, administrative and legal standards, inclusive of "NGO-enabling legal environments" previously documented (p. 300).

A theme common to these two trends is the issue of accountability. Demands on CSOs to strengthen their accountability have persisted since the early days of the global association revolution (Edwards \& Hulme, 1996; Wapner, 2002; Ebrahim, 2003; Jordan \& van Tuijl, 2006; Burger \& Seabe, 2014), and are heard on both the 'enabling' and 'restricting' sides of the paradox. Scholars of CSO sector regulation note that the "perdurable interest in accountability.... is expressed through regulation" (Phillips \& Smith, 2011b, p. 10). Advancing accountability in the sector is a key rationale for many new and intensified forms of both state and self-regulation that are emerging worldwide (Rutzen, 2011, p. 269; Wiepking \& Handy, 2015b, p. 605; Jordan \& van Tuijl, 2006, pp. 5-7; Burger \& Seabe, 2014; Lloyd \& Casas, 2005, para. 3; Irvin, 2005; Phillips \& Smith, 2011b). Yet, the extent, nature and instruments of regulation give latitude or create constraints for different kinds of actors and actions.

Regulation is broadly understood as a means to shape and steer the behaviour of targeted bodies (industries or specific actors) in ways that address their accountability in 
the public interest (Baldwin, Cave, \& Lodge, 2010, p. 10; Baldwin, Scott, \& Hood, 1998, pp. 3-4). Regulation involves a suite of instruments and approaches and can involve varied actors from within and outside of government (Coglianese \& Mendelson, 2010, p. 146; Baldwin et al., 2010, pp. 8-9). When it comes to CSOs, states can regulate through legislation, regulation, policies, and practices that directly or indirectly target the sector. CSOs have also become their own regulators, through voluntary or enforced selfregulation such as codes of conduct or accreditation.

Recent regulatory theory suggests that, as regulation is used to shape behaviour toward greater accountability, there is a trade-off between state and self-regulation, with self-regulation seen as a proxy or alternative to state regulation and vice versa (Coglianese \& Mendelson, 2010, p. 147). In this vein, scholars of CSO regulation posit that a "wave" effect occurs, moving from state to self-regulation and back (Breen, Dunn, $\&$ Sidel, 2017b). ${ }^{1}$ The current research draws from and builds on this and other literature to develop a conceptual framework of drivers of regulatory change as a means to help us understand when and why state and/or self-regulation of the CSO society sector emerge or are altered, and whether and how they interact with each other. This research examines and rounds out the CSO regulation and change literature, which has tended to focus on the "welfare states" of high income, developed countries (Phillips \& Smith, 2014, p. 1142), by applying the conceptual framework to that of a lower-middle income country

${ }^{1}$ The term "regulatory waves" was popularized by authors on related panels at the 10th and 11th International Society for Third Sector Research conferences in 2012 and 2014, including articles that both preceded and followed these conferences, culminating in a 2017 publication edited by Breen, Dunn and Sidel (Breen et al., 2017b). 
case, that of Kenya. In so doing, it sheds light on the paradox in which CSOs are understood as significant contributors to social, economic and democratic development, while at the same time being constrained in their work through regulatory and other means. While the restricting trend is considered a global phenomenon also seen in high income countries, the data and examples indicate that it is nonetheless particularly prevalent in lower and middle income countries (Carothers \& Brechenmacher, 2014; Rutzen, 2015b; Dupuy et al., 2015a \& 2015b; ICNL, 2016; UNSR, 2013 \& 2014; CIVICUS, 2015b; CIVICUS, 2016).

Kenya was the first sub-Saharan African country to significantly address CSO regulation and self-regulation beginning in the late 1980s (Gugerty, 2010, p. 1097). Since then, the country has undergone four distinct phases of CSO regulatory development, implementation and reform, at times more enabling of the sector, at other times significantly less so. Currently Kenya is caught up in a period of restrictive regulation of the CSO sector emblematic of the experience in other lower and middle-income countries worldwide. This dissertation examines Kenya's regulatory change experience of the past thirty years to help us understand the factors driving regulatory change over time. In examining the change drivers, the dissertation further aids us in assessing the relevance of CSO accountability to regulatory change; the relationship between state and selfregulation, and in turn, the paradox of the trend toward restrictive regulatory change even as the contribution of CSOs is acknowledged. 
While recognizing that each lower and middle income country is distinct, with many sharing characteristics of the driving factors behind regulatory change as identified in this research, the Kenya case is useful to help understand regulatory patterns elsewhere.

\subsection{Terminology}

A few notes on terminology are necessary before proceeding.

Consistent with popular terminology, the term 'CSO' is used in this dissertation to refer to the range of non-profit distributing organizations in Kenya, although the main focus of regulatory coverage is more narrowly CSOs that are considered public benefit organizations (PBO). PBOs are non-profit distributing organizations the purpose and (all or most of) the activities of which are intended to benefit the public (Irish, Kushen, \& Simon, 2004, p. 115). Alternate terms such as non-governmental organization (NGO), non-profit organization (NPO), charity, or PBO are also used when that is the term that is used in a specific legislation, regulation, or citation. Other CSO types found in Kenya (e.g. non-public benefit CSOs) are also referred to in this research, as their regulation is part of the wider regulatory framework for the sector. The term civil society, also used on occasion in this research, is a wider concept than that of CSO in that it includes CSOs but is also comprised of non-organizational forms of associating such as seen in informal movements or other forms of informal citizen organizing. The focus of this research is on the organizational form of $\mathrm{CSO}$, though regulation affecting wider civil society is also touched upon in the empirical chapters.

Salamon et al. (1999) refer to NPOs - CSOs for our purposes - as being:

- Organizations, i.e., they have an institutional presence and structure; 
- Private, i.e., they are institutionally separate from the state;

- Not profit distributing, i.e., they do not return profits to their managers or to a set of "owners" (referred to by Hansmann (1980) as the "nondistribution constraint" (p. 835));

- Self-governing, i.e., they are fundamentally in control of their own affairs; and

- Voluntary, i.e., membership in them is not legally required and they attract some level of voluntary contribution of time or money. (pp. 3-4)

There has been some debate about the pertinence of the civil society and CSO concepts in Africa in particular, and the "Western and Northern bias" that permeates their study (Van Rooy, 1998, pp. 27-28; Lewis, 2002; Obadare, 2011; Fowler, 2012). However, while acknowledging the risk of such bias, authors also point to their global usefulness given their (near) global existence, and that the concepts help us understand societal relations (Lewis, 2002; Okopu-Mensa, 2009, pp. 2-4; Bratton, 1994, p. 52). Writing on Africa, Obadare (2014) notes the "powerful reality" of the concepts that are "indigenized and adapted to African politics and sociology" (p. 3) such that there is no need to shy away from their use or study on that continent.

As noted, regulation is a means to shape and steer the behaviour of targeted bodies (industries or specific actors) in ways that address their accountability in the public interest (Baldwin et al., p. 10; Baldwin et al., 1998, pp. 3-4). Regulation has come to be understood as encompassing not only the work of centralized state regulators but that of a range of non-state actors, including CSOs and other types of organizations, industries or bodies traditionally regulated by states but turning to self-regulation (also referred to as 'private regulation') (Baldwin et al., 2010, pp. 10-11; Coglianese \& Mendelson, 2010, p. 146). Regulation is also thus understood as involving varied mechanisms including those with a direct regulatory intent and those with an indirect regulatory effect (Baldwin et al., 2010, pp. 5-6). This research also understands regulation in these ways. For ease of 
reading, the term "regulation" is used in this research as a short form for legislation, regulation and self-regulation, and policy. The term 'regulatory change' encompasses the emergence of new state or self-regulation of CSOs, review of and revisions to current state or self-regulation, as well as changes in the way such regulation is implemented.

'Lower and middle income (LMI) countries' is used in this research to denote countries included in the Organisation for Economic Co-operation and Development's (OECD) categorization of countries and territories eligible to receive official development assistance (ODA), what the OECD calls "developing countries" (OECD, n.d.-a, para. $4 \&$ n.d.-d, para. 22). ${ }^{2}$ Official development assistance is "government aid designed to promote the economic development and welfare of developing countries" (OECD, n.d.-e, para. 1). Obviously, there is considerable variation across the 146 countries so categorized.

LMI countries are distinct from "developed countries" which are high-income countries, referred to in this research as $\mathrm{HI}$ countries, and which are members of the OECD's Development Assistance Committee (DAC) (OECD, n.d.-e, para. 1; OECD,

${ }^{2}$ This OECD list draws from data published by the World Bank (WB) and the UN and includes four categories: least developed, other lower income countries, lower middle income countries and territories, and upper middle income countries and territories (OECD, n.d.-a, para. 4 \& n.d.-b). In 2017 the OECD list included 146 ODA-eligible countries and territories (OECD, n.d.-b). The OECD list is slightly more inclusive than the 137 countries and territories categorized by the WB for 2017 as either low-income economies (less than USD 995/per capita gross national income (GNI)); lower-middle income economies (between USD 996 and 3, 895 per capita GNI); and upper-middle income economies (between USD 3,986 and 12,055 per capita GNI) (WB, n.d.-a) . 
2018b). ${ }^{3}$ Countries of the DAC channel ODA to LMI countries, as do the international financial institutions (IFIs), specifically the International Monetary Fund (IMF) and the World Bank (WB), and multilateral institutions such as UN bodies. When it comes to consideration of the influence of ODA and its providers, this research is concerned with ODA from DAC member country governments. Thus, the term "DAC/G" is used to denote DAC member government providers of ODA. ${ }^{4}$ Even as each DAC/G is distinct, it is beyond the purview of this research to examine each DAC/G's policy and practice separately.

The term Government of Kenya (GoK) is used in this dissertation, also as a short form encompassing all levels of the Kenyan Government, ministries, departments and agencies. This is done for convenience, while recognizing that the GoK is not a monolith. Different components of the GoK may have different relationships with or views on CSOs for example. GoK denotes the executive branch of government as well as the legislative branch, which, until Kenya's Constitution of 2010, did not enjoy much separation of powers. Even subsequent to the Constitution the separation of powers is tenuous.

\subsection{The Research Question}

An abundance of scholarly as well as global and national policy literature positions CSOs as significant actors in social, economic and democratic development, at global,

${ }^{3}$ The WB categorizes high-income countries as those with per capita GNI of USD 12,056 or more (WB, n.d.-a).

${ }^{4}$ Note that European Union institutions are included in the list of DAC members and thus also in this research's DAC/G category (OECD, 2018b). 
national, and local levels. The sector's financial contribution alone is noted, documented at on average 5 percent of gross domestic product (GDP) to OECD countries' national economies, equivalent to the contribution of major industries (Salamon, 2010, p. 198). In the international development sphere, over 17 percent of DAC members' 2016 ODA was channelled to and through CSOs, while CSOs raised 42 billion United States dollars (USD) in the same year (see Table C1 in Appendix C \& OECD, 2018a, p. 6).

The roles attributed to CSOs are varied and include providing social services; acting as a voice for the concerns of different communities and social groups; providing vehicles for citizen participation and citizenship; and collaborating in multi-stakeholder governance to help solve complex problems (Beer, Bartley, \& Roberts, 2012; OECD, 2010; Phillips, 2012). Edwards (2009) speaks of the sector's economic role in service provision and securing livelihoods; its social and cultural role nurturing (potentially) positive norms; and its political role as a counterweight to governments and the private sector (pp. 13-15). According to Casey (2016), belief in the sector's importance spans "seemingly opposing ideologies" which "now concur that they [CSOs] are necessary elements of the institutional frameworks for service delivery and policy-making, albeit with vastly different parameters" (p. 301).

Expectations of the sector have been (Salamon, 1994) and continue to be high, as demonstrated in their place as key partners in achieving the UN universal 2030 Agenda for Sustainable Development (UN, 2015). Yet the ability of the sector to meet these expectations is not solely a function of whether CSOs are particularly good or bad at what they do, but also of the space afforded to them by regulation and its implementation 
(Salamon \& Toepler, 2000, pp. 13 \& 15; Bloodgood, Tremblay-Boire, \& Prakash, 2014, p. 717). ${ }^{5,6}$ At the national level governments recognize this as seen in frequent incidences of regulatory change that have the primary intent of enabling the sector's functioning including helping to build public trust and confidence in it, and involving both state and self-regulation (Phillips \& Smith, 2011b; Wiepking \& Handy, 2015; Casey, 2016, p. 20; McGregor-Lowndes \& Wyatt, 2017).

Just as global declarations extol the virtues and values of CSOs and governments implement regulation to enable the sector, other governments are turning to regulation, and other policies and practices with the intent of restricting the sector (Carothers \& Brechenmacher, 2014; Rutzen, 2015b; Dupuy et al., 2015a \& 2015b; ICNL, 2016; UNSR, 2013 \& 2014; CIVICUS, 2015b; CIVICUS, 2016), which is occurring alongside the growth in CSO self-regulation initiatives (Mirza \& Obrecht, 2013; Sidel, 2010). While incidences of oppression of associational forces, including through regulation, are not new (e.g. see Fisher, 1998), their growing prevalence and the sophisticated use of regulatory measures is cause for concern. Data from the six year period between 2004

${ }^{5}$ The literature on the inherent "goodness" of civil society and CSOs has been accused of being overly normative (Lewis \& Opoku-Mensah, 2006, p. 669) and civil society and CSOs' potential for 'un-civility', remains a topic of debate e.g. see Berman, 1997, Lipschutz, 2005, Clifford, 2011. Assumptions about the valued characteristics of CSOs (e.g. innovativeness, cost-effectiveness, connectedness to poor or marginalized communities), are also a topic of debate e.g. see Edwards \& Hulme (1996b, pp. 4-7), Hellinger, Hellinger, \& O'Regan (1988, p. 100), and Mackintosh (2002, p. 80).

${ }^{6}$ The link between enabling environments and a thriving civil society has also come under question of late in a study by Kamstra, Pelzer, Elbers and Rubin (2016) which concludes that civil society in developing countries is strongest under restrictive environments. However, their study assesses civil society strength by looking at associational membership. This excludes the many organizational forms of non-memberbased CSOs that are subject to regulation and are the focus of this research. 
and 2010 show that over fifty countries contemplated or enacted such measures to restrict the space for civil society (Rutzen, 2015b, p. 30). Ongoing monitoring indicates that the rights of association, assembly and expression necessary for CSOs' functioning are "under renewed and sustained assault" (CIVICUS, 2016, p. 53). Such restrictions take varied forms including administrative hurdles hindering CSO formation and operation; constraints on the receipt of foreign funding; impediments to certain types of activities; restrictions on communication; and intimidation and harassment; amongst others (WMD \& ICNL, 2012).

In Kenya, the presence of CSOs is not a new phenomenon. Community support and self-help groups (harambee groups, meaning 'let's pull together') are an example of associational life that has been part of Kenyan culture and tradition prior to independence (Hornsby, 2012, pp. 84 \& 138; Kanyinga \& Mitullah, 2007, p. 7; Brass, 2012, p. 210). The sector's landscape is rich in organization types including community-based organizations, societies, companies limited by guarantee, foundations or trusts, and NGOs. According to NGO Council figures, CSOs registered as NGOs numbered over 8,000 in 2014 (National Council of NGOs [NCNGO], n.d.). ${ }^{7}$ The sector that these varied CSOs make up contributes variously to the country's social, economic and democratic development. Many CSOs engage in welfare service provision, including in collaboration with government (Brass, 2010; Brass, 2012, p. 209-210), supporting the livelihoods and welfare of millions of Kenyans (Poverty Eradication Network [PEN], 2014, p. 9). They are the primary providers of humanitarian relief in the context of famine and

\footnotetext{
${ }^{7}$ Note that this organization's website became un-operational some time around 2017.
} 
displacement in the region (Ndegwa, 1996, p. 21; Fowler, 1994, p. 130; Hornsby, 2012, pp. $346 \& 506$ ), or of violence and conflict such as followed the 2007 elections (Hornsby, 2012, p. 765; Kenya National Commission on Human Rights [KNCHR], 2008, paras. 2, $18,93)$. They have played a significant role in bringing about democratic reforms in the country (Maina, 1998, p. 166; Hornsby, 2012, p. 586), and at key junctures such as the 2013 elections, have also played a conflict-prevention and peace-building role (United States Agency for International Development [USAID], 2014, p. viii; Long, Kanyinga, Ferree, \& Gibson, 2013, p. 149). The economic contribution of the sector has been estimated at USD 800 million in 2012, at which time it employed over 1 percent of the labour force (CSO Reference Group [CSORG], 2013, p. 1). Further, the Constitution of Kenya (2010) carves space for citizen and CSO participation in the country's development (s. 87e). The country is also signatory to key UN covenants and declarations containing rights applicable to CSOs, and is a member of the African Union (AU) that has encouraged members to enable civil society's functioning.

Just as CSOs are not a new phenomenon in Kenya, neither is regulation of the sector. The oldest regulation of the sector, the Trustees (Perpetual Succession) Act, (1923) governing trusts and foundations, has been in operation (though subject to occasional amendments), since 1923. The period since the late 1980s saw an increase in regulatory activity involving both state and self-regulation of the sector. The Non-governmental Organizations Co-ordination Act (NGOs Co-ordination Act) (1990) was enacted in 1990 targeting these organizations that did not fall under the purview of pre-existing 
legislation. ${ }^{8}$ Amongst other things, this Act legislated self-regulation via a National Council of NGOs meant to oversee self-regulation's implementation (Gugerty, 2010, pp. 1093 \& 1098). Today, over twenty-five years since the Act's enactment, and with some amendments and regulatory change starts and stops over time, the Act remains in place though with uneven implementation, including of the self-regulation requirement.

This even while early in 2013, a new Public Benefit Organizations Act (2013), intended to provide a comprehensive regulatory framework to address gaps in and replace the NGOs Co-ordination Act, received Presidential assent (ICNL, 2014b, p. 1). The new Act contained provisions for self-regulation, while Kenyan CSOs had also taken independent steps to increase the rigour and scope of self-regulation. Since the PBO Act's assent, the GoK appeared intent to forestall its implementation, seen most clearly in five amendment attempts from mid-2013. Critics suggest that the most sweeping of these amendments had "the potential to completely mutilate not only the PBO Act but cripple PBOs; undermine the Constitution.... and.... critical service delivery to Kenyans" (CSORG, 2015b, p. 1). Various practices pursued by the GoK, including a public relations narrative depicting civil society as 'evil society' and agents of 'foreign masters', along with bouts of suspending CSOs' registration, added a restrictive air to this uncertain regulatory environment.

${ }^{8}$ This paper uses the more common spelling of coordinate versus co-ordinate, though coordinate is used when found in original text such as the NGOs Co-ordination Act. 
Kenya is a prime case of a country that poses a curious regulatory puzzle, responding "ambiguously" (Bratton, 1989, p. 576) over time such that Kenya has been caught in the paradox between embracing and constraining the CSO sector.

This research addresses the question of how the regulatory regime for CSOs has changed over time in Kenya and what the driving factors behind such change have been. This research asks what the drivers of regulatory change seen in Kenya can tell us about the paradox between CSO enablement and restriction. It also asks what is the relationship between state and self-regulation and whether there is, as hypothesized in the literature, a wave-like pattern as these two types of regulation interact. Findings are also used to explore what the relationship between regulation and accountability is in the Kenya context. This research investigates these questions by applying a conceptual framework of drivers of regulatory change developed from the literature on CSOs and CSO regulation, with consideration to LMI country characteristics that inform the drivers in particular ways.

\subsection{The 'Argument'}

This research shows that CSO regulatory regime change in Kenya has rolled out in a dynamic, wave-like process beginning in the late 1980s through 2017. Each of the factors driving regulatory change gleaned from the literature as presented in chapter two's conceptual framework feature in the Kenya case. These factors are organized by the source from which the factor emanates as follows: CSO sector sources, which include sector growth; type of CSO activities (social and economic development, civic and political engagement); mismanagement or misconduct in the sector; sector infrastructure 
and status of self-regulation; state sources which involve the status of state regulation; political agendas; public management agendas; security and terrorism concerns; and external sources including foreign states, foreign CSOs, and supranational bodies.

These driving factors comes into play in the Kenyan regulatory change story with recurring themes pointing to features that are particular to or particularly acute in LMI country contexts, as well as to the driving factors that are most influential. The latter are particularly states' political agendas - tied to CSO civic and political engagement activities - and foreign states in the form of DAC/G funding and policy influence. CSO sector growth, CSO mismanagement or misconduct issues, and the status of the state regulatory framework are also important to regulatory change. Rather than any purported interactive relationship between state and self-regulation, it is the various driving factors, their interaction and their particular LMI country manifestations that drive regulatory change in the Kenya case. The findings of this research make clear that while regulatory change may be rationalized as a "technical fix to a problem", such as the problem of CSO accountability, it is "inherently a site where different political and economic forces come into contest" (Baldwin et al., 2010, p. 4). Regulatory change is far less a technical domain in which state and self-regulation might logically interact in the pursuit of CSO accountability, but is instead a political domain in which change is driven by myriad factors.

The presence and recurrence of the driving factors in Kenya over a thirty-year period also shed some light on the paradox in which CSOs are at once recognized for their contribution, while efforts are put in place to restrict CSOs through regulation. Even as 
the sector's contribution is understood, states and the self-regulating CSO sector are nonetheless faced with various issues - the driving factors - for which regulatory change may be turned to as a technical solution, even if it may not necessarily be the best, the only, or sufficent means to address these issues.

\subsection{The Contribution}

This research contributes to literature on the government-CSO relationship as reflected in the regulatory realm. Interest in understanding trends and drivers in the regulation of CSOs, and the interplay between state and self-regulation, is evident in a growing body of CSO regulatory change literature (Gugerty, Sidel \& Bies, 2010; Dunn, Spencer \& Sidel, 2012; Sidel, Layton, Dunn, Limor, \& Brindt, 2014; Parachin, Breen, Barber, Farwell, Phillips, \& Smith, 2014; Breen et al., 2017b). This research adds to the nascent scholarly treatment of state and self-regulation of CSOs together, and of their interactions, rather than on one or the other regulatory form as has been the tendency (Breen, Dunn, \& Sidel, 2017a, p. 1; Dunn, Breen, \& Sidel, 2017, p. 222). It builds on this literature by examining the occurrence and significance of the drivers of regulatory regime change in one country through a thick qualitative study.

This research broadens and deepens the CSO policy and regulation literature, which has been dominated by coverage of HI countries, with an in-depth LMI country case covering thirty years. It offers a conceptual framework incorporating driving factors behind regulation/self-regulation gleaned from the literature, while interpreting these in a LMI country context and giving prominence to previously un- or insufficiently articulated factors that apply in such contexts. As many LMI countries share 
characteristics of the driving factors that this research examines, this study provides insight for middle-range theory development to help predict regulatory patterns in other LMI countries.

This study's contribution is timely. On one hand, there are high expectations of CSOs' roles in social, economic and democratic development. Yet enabling the sector to fulfill these roles requires appropriate regulation. Regulation of the sector is a dynamic phenomenon, with many countries subjecting it to review and tweaking over time. Questions of how to strike the optimum balance between regulatory oversight and independence of the sector are a going concern. Of late, this concern is fuelled by the global trend, prevalent in though not exclusive to LMI countries, toward restrictive legal, regulatory, policy and practice (Carothers \& Brechenmacher, 2014; Rutzen, 2015b; Dupuy et al., 2015a \& 2015b; ICNL, 2016; UNSR, 2013 \& 2014; CIVICUS, 2015b; CIVICUS, 2016). ${ }^{9}$ Regulation in these contexts is becoming a tool not to enable the sector, but to narrow the space in which it operates. Unpacking the drivers behind regulation of the sector, and the relationship between state and self-regulation, is a step toward understanding this trend from a conceptual perspective. The variation in regulatory contexts between HI and LMI countries (Estache \& Wren-Lewis, 2010;

${ }^{9}$ Each of these sources addresses the restrictive regulation trend. While the data and examples indicate the trend is particularly prevalent in LMI countries, sources also refer to it as a global phenomenon, e.g. see Dupuy et al., 2015a, p. $302 \&$ 2015b, p. 423; ICNL, 2016, p. 2; UNSR, 2013, para. 12; CIVICUS, 2016, pp. 129-135). Most recently, a report from ICNL (2018) points to increasing incidences of restrictions on CSOs in HI countries considered democratic (p. 10). 
Minogue \& Cariño, 2006b) also provide a rationale for research that examines and rounds out the CSO-related policy and regulation literature.

The regulation and treatment of CSOs is a topic of high interest to policy makers and practitioners today. While for a few specialist CSOs, issues of the sector's regulation has been central to their mandates, in recent years the issue has garnered the attention of more diverse CSOs and indeed has become the "hot topic" of the day (CIVICUS, 2016, p. 53). Among DAC/G aid providers and Ministries of Foreign Affairs, multi-lateral institutions and other official bodies engaged in development cooperation, the shrinking of civil society space and calls for "enabling environments" are increasingly on the policy radar (OECD, 2012; GPEDC, 2016; ICNL, 2016), especially as they have long touted the liberal democratic model with an important role for CSOs in its advancement and maintenance (Carothers \& Ottaway, 2000).

This research thus offers a practical contribution for policy-makers and practitioners from the CSO sector, from DAC/G and LMI country governments. It may aid them to understand regulatory drivers and the complexities of their direct and indirect influence on these drivers, toward potentially refining their efforts to achieve more enabling regulatory outcomes where that is their goal.

This research also offers an empirical contribution to the study of CSOs and CSO regulation in LMI countries, Kenya in particular. It has gathered ample primary data from 63 interviews with individuals from multiple stakeholder groups - CSOs, various levels of the GoK, elected officials and DAC/Gs, amongst others. This data, coupled with primary sources in the form of legislative, regulatory and policy documents and reports, 
also from these varied stakeholder groups, as well as print and online media, forms a solid body of empirical data covering thirty years.

\subsection{Research Design}

\section{The Case Study Method and Abductive Approach}

The case study method has been chosen for this research as it can "produce a holistic - that is, a richly or thickly contextualized and embedded - understanding of the phenomenon or system under investigation" (Snow \& Trom, 2002, p. 150). A further feature is case studies' utility in "capturing and analyzing social processes as they emerge and evolve over time" as this research undertakes (Snow \& Trom, 2002, p. 155).

This research is "confirmatory/disconfirmatory" in nature in that it seeks to assess the applicability of existing scholarly literature to the Kenya case of CSO regulation (Gerring 2004, p. 349). It is simultaneously "exploratory" in nature as it seeks to generate additional theory in relation to CSO regulation through the Kenya case (Gerring, 2004, p. 349). It seeks to verify whether explanatory factors (called 'driving factors' or simply 'drivers' in this research) behind CSO regulation identified in the literature come into play in the Kenyan context. But it also starts from the observable phenomenon - in this case the regulation of CSOs in Kenya - to identify particular LMI country characteristics of these factors, and to extrapolate additional explanatory factors, while identifying, of all factors, which are most influential. As such, this research combines both deductive and inductive approaches. Such an approach is common in qualitative research where, as Berg (2001) describes, there is merit in an iterative, non-linear approach with ongoing "interaction between theoretical concerns and empirical observations" (p. 248). It is also characteristic of case study research whereby an "open-ended, recursive process" allows 
the researcher to "adapt the methodology to the exigencies of the field... to new data sources and data-gathering opportunities as they arise" (Snow \& Trom, 2002, p. 153).

In essence this research uses the strategy of abduction characteristic of the grounded theory method. ${ }^{10}$ Abduction offers an alternative to traditional deductive or inductive reasoning modes that rely on "existing knowledge" or theory "to make predictions, construct explanations, and draw conclusions" (Taylor, Torugsa, \& Arundel, 2018, p. 207). Abduction is a way of "finding new knowledge" that involves a "deliberate and iterative process between actively studying the phenomenon at close range and thoughtful theory development" (Taylor et al., 2018, pp. 207-208 citing Peirce, 1955 \& Hanson, 1958). It is inspired by the iterative, "interpretive process" called for in grounded theory (Suddaby, 2006, p. 638). With grounded theory, ongoing data gathering, coding, and interaction with the data as well as purposive sampling accommodate the researcher's growing understanding of the phenomenon under study. Rather than generating universal laws or principles, this nature of research can produce theory that is verified for "soundness and probable usefulness rather than... generalizability" (Deloffre, n.d., p. 2 citing Strauss \& Corbin, 1994). Grounded theory is well suited to the type of qualitative research of complex processes, grounded in empirical data, undertaken for this study. Further, Taylor et al. (2018) have posited abduction as particularly relevant to research on

10 "Characteristic of" as the research process, particularly the coding layering from open to categorical to conceptual (Suddaby, 2006, p. 638) was not undertaken in pure grounded theory mode. Further, there remains some debate as to whether and the degree to which grounded theory can involve an element of deductive theory testing, again see Suddaby (2006). 
the CSO sector given its potential to generate knowledge based on realities of practice, to bridge the scholar - practitioner divide and generate research of use to practice (p. 208).

Case study research is often examined in this way to extend theory or to refine it, providing insight into how explanatory factors may "interact and combine" (Snow \& Trom, 2002, p. 165 citing Cress \& Snow, 2000). Single-n studies such as single case studies can offer "contingent generalizations" and "scope conditions" for theory (George $\&$ Bennett 2005, p. 77). Contingent generalizations are narrow in their applicability to limited types of cases (e.g. LMI countries with authoritarian tendencies) rather than to a broad population of cases (e.g. all LMI countries) (George \& Bennett, 2005, pp. 30-31). Scope conditions are conditions that determine the likelihood that a theory and its variables will apply (George \& Bennett, 2005, p. 75).

By using the abductive approach, this research's broad, deep and iterative exploration of possible explanatory factors, enlightened by a longitudinal perspective over thirty years, provides insight into the types of interactions, contingencies and conditions that case study researchers typically identify. It is an appropriate offering given that theory on explanatory factors behind CSO regulation is fairly nascent, thus inviting new research to generate additional insight or nuances to strengthen it. In the vein of Wacker (1998 citing Osigweh, 1989) therefore, this research seeks to contribute to middle-range theorizing. While not broadly generalizable, and acknowledging the specificities of the case, it can help theory move up the ladder of generalizability as the subject undergoes further research. By selecting a single case study, a choice has been made "between knowing more about less and knowing less about more" (Gerring, 2004, p. 348). This research 
does not set out to "prove" so much as to "learn", through the "force of example" as is appropriate in social science research where "hard theory" is difficult to come by (Flyvbjerg, 2006, pp. 230 \& 225 citing Eysenck, 1976).

\section{Data Sources and Method}

Case studies are conducive to the use of mixed research methods such as the primary document review and interview methods used here, which provide a level of "procedural triangulation" (Snow \& Trom, 2002, p. 151). The primary documents drawn from for this research included official and non-official policies, legislation, regulations, legal cases, reports, and briefing papers. Official documents were GoK sources as well as those from DAC/Gs and multilateral institutions, while non-official documents were primarily from CSOs. International and Kenyan print and online media sources were also drawn upon.

The interview method was used to gain deep insight into the phenomenon under study, particularly the "informal track" of the process of regulatory change (George \& Bennett, 2005, p. 103). Interviews were also deemed a suitable way to gather longitudinal data given the absence of a repository of archival data on this subject matter in Kenya, and the weak data management systems in the GoK and CSOs into the 2000s.

Interviews were semi-structured as appropriate when seeking rich data in the absence of prolonged field research and observation (Blee \& Taylor, 2002, p. 93). The flexibility built in to semi-structured interviews renders them especially "useful in studies where the goals are exploration, discovery, and interpretation of complex social events and processes and when combined with participant observation and/or documentary methods (Blee \& Taylor, 2002, p. 93, citing Morris, 1984, Fantasia, 1998, McAdam, 1988, 
Staggenborg, 1991, Whittier, 1995, Robnett, 1996, \& Ray, 1999). The interview guidelines contained questions informed by theory, but the interviews themselves were not constrained by the guidelines. This allowed construction of a narrative of CSO regulation in Kenya over the past thirty years reflecting interviewees' real and varied experiences, ideas and perceptions of the factors influencing CSO regulation over an unlimited range of options.

Interviewee sampling considered key stakeholder groups identified as having significant but different direct and indirect roles in and experiences of CSO regulation, as further explained below. Sampling thus included representatives from the GoK, DAC/Gs, CSOs, academics, and elected officials amongst others. This approached was deemed necessary to ensure a "multiperspectival orientation" (Snow \& Trom, 2002, p. 154) to the narrative and identification of explanatory factors.

\subsection{Case Selection and Data}

\section{Case Selection}

Kenya is the LMI country selected for this case study research. In keeping with Flyvbjerg's (2006) assertion that selection strategies of case types are not mutually exclusive (p. 235), it is selected based on two strategies.

First, Kenya can be considered a "paradigmatic case" in that it "highlights more general characteristics of the societies in question", in this instance, characteristics of LMI countries (Flyvbjerg, 2006, p. 234). Kenya is a relatively low-income country with a long history of the presence of $\mathrm{DAC} / \mathrm{Gs}$ (including through the colonial era). It experienced democratic transition as part of democracy's Third Wave, though its 
democratic transition is considered incomplete. The country is also characterized by high levels of corruption. Kenya also has an active civil society, and a relatively long history of CSO regulatory regimes to observe. It was the first in Sub-Saharan Africa to address regulation/self-regulation concomitantly beginning in the late 1980s (Gugerty, 2010, p. 1097), with other countries in the region following suit. Kenya is also an influential country in Sub-Saharan Africa, one that is often considered a 'model' or "exemplar" to which others turn (Ndegwa, 1996, p. 10). Kenya's relevance in the current era where there is an observable "contagion effect" (Moore \& Zenn, 2013, p. 74) in countries' approaches to CSO regulation is thus significant. And while the use of regulation to shrink the space for CSOs is considered a global phenomenon, that the African continent ranks among the highest for restrictive regulatory moves since 2012 (Rutzen, 2015b, p. 30) suggests an African country is a good case selection.

Second, Kenya can also be considered a "crucial" or "critical" case in which its "particular features or characteristics... make it an ideal or critical one for the set of issues or concerns in question" (Eckstein, 1992; Snow \& Trom, 2002, p. 159). According to Gerring (2007), "a case is crucial if the facts of that case are central to the confirmation or disconfirmation of a theory" (p. 231). Such cases provide an "ideal assessment of some observed or theorized principle", in this case, of the varied explanatory factors identified in the CSO regulation literature (Snow \& Trom, 2002, p. 157). While some of the specific happenings in the Kenya narrative, at specific points in time, appear extreme, the context of CSO regulation covered in the empirical chapters indicates that on the whole, Kenya ought not be considered an extreme case. Still, the risk of overestimating the 
significance of the explanatory variables examined here, as cautioned by (Collier \& Mahoney, 2010, p. 72) is recognized. For this research then, Kenya is categorized as a weak most-likely critical case, designed to test previously identified explanatory factors that themselves have not been claimed to have fully predictive power. Thus, it has been open to identifying additional plausible factors needing consideration in the quest to understand regulation in LMI country contexts.

The single case of Kenya has been selected based also on the type of pragmatic considerations common to case study research (Seawright \& Gerring, 2008; Gerring, 2004, p. 352-3). For one, time and financial resources are not unlimited in the context of $\mathrm{PhD}$ research, making the travel necessary for cross-case comparison based on empirical data unrealistic. Gathering a depth of understanding of the complex regulatory phenomenon over time has been chosen over breadth. Further, language barriers were not anticipated to be problematic in Kenya as document sources (including primary sources and media) were anticipated to be available in English, while interviewees were also expected to be fluent English language speakers. My basic knowledge of Kenya's second official language, Kiswahili, was also a consideration, as was my familiarity with the country based on previous visits and over three years spent living and working in neighbouring Tanzania.

While acknowledging that regulatory stories are best understood based on the "particular situations of individual nations" (Bies, 2010, p. 1058) and recognizing that the specific confluence of factors in the Kenya case will not be found in other countries, their existence and shared characteristics in other LMI countries suggest these factors are 
worth monitoring to account for regulatory developments elsewhere. In particular, while there is of course enormous variation across the social, economic and cultural contexts of LMI countries, there are also similarities that suggest a degree of generalizability in the study of CSOs in these contexts (Okopu-Mensa, 2009, p. 2 citing Lipton, 1989).

Finally, this case study research, having been undertaken by a non-Kenyan originating from an HI country, cannot be said to be devoid of Eurocentrism. There is a built in risk of such bias when country case research is undertaken by a non-resident from the 'West'. Effort was made, through many in-depth interviews with individuals originating from different stakeholder groups, and with the vast majority of interviews (84 percent) being with Kenyans, to minimize the bias. My experience living and working in neighbouring Tanzania as well as multiple visits to varied countries across the African continent over the years, including to Kenya, hopefully also tempered any Eurocentric bias. Use of the abductive method and its open, iterative approach to learning from on-the-ground realities also sought to minimize bias. Nonetheless, this research is admittedly located within "epistemic modes of Western intellectual thought" rather than an LMI country, or an African, "knowledge system" (Arowosegbe, 2014, p. 308).

\section{Data Collection and Management}

Most of the Kenya-specific primary literature sources were collected during three field visits to Kenya over the period from January 2015 to December 2016. Sources originated variously from GoK bodies, CSOs and DAC/Gs, many of them also interviewees for this study. Some primary GoK documentation was obtained from the National Council for Law Reporting website (also referred to as eKLR). A visit to the 
University of Nairobi library produced a handful of archival documents, though their availability was sporadic. Primary documents in the form of CSO or DAC/G policies was obtained directly from these organizations or from their websites.

For this research's second data source, 63 interviews were conducted between January 2015 and March 2018, the bulk taking place in $2015 .{ }^{11}$ A total of $68^{12}$ individuals were interviewed representing 53 different organizations. ${ }^{13}$ Of the 63 interviews: 15 were from the GoK (national and local government); 4 were elected officials (national or local); 11 were from DAC/Gs; 23 were from CSOs; and 10 were from other categories inclusive of, for example, national autonomous institutions or commissions established by Acts of Parliament, academia and the media. The majority of interviews, 56, representing 89 percent, took place in Kenya during three field visits. ${ }^{14}$ The remainder took place either in $\mathrm{DAC} / \mathrm{G}$ countries, with a few undertaken remotely by phone or Skype. Interviews lasted between 30 and 90 minutes, with the occasional interview extending to 120 minutes or more. A breakdown of interviews is presented in Appendix

${ }^{11}$ An initial 42 interviews were planned for. Additional interviews were pursued in pursuit of the "category saturation" necessary to uphold verifiability in grounded research (Suddaby 2006, p. 36 based on Srauss \& Corbin 1998). Though with 42 interviews completed the key analytic categories were close to being confirmed, additional interviews were pursued to ensure that saturation had indeed been reached, as well as to fill empirical data gaps and confirm a proper understanding of Kenya's regulatory developments. A few interviews were undertaken when opportunities arose in the course of my travel undertaken for other purposes.

${ }^{12} \mathrm{Six}$ of the 63 interviews included multiple participants. Four of the 63 interviews were with previous participants (i.e. second interviews). In total, the number of participants reached with the 63 interviews was 68 .

${ }^{13}$ Different ministries, agencies, and levels of Government are each considered individual Governmental organizations here.

${ }^{14}$ Two of these were by phone or Skype. 
A. Throughout this dissertation interviewee quotes are numbered and attributed by stakeholder type, so e.g. a GoK interviewee could be indicated as I9_GoK, a CSO interviewee as I2_CSO, etc..

The three field visits to Kenya took place in January/February 2015, June 2015, and December 2016 respectively. The first visit was a scoping one to get an initial lay of the land of potential individuals and organizations to be interviewed and their willingness to participate in the research; a sense of the accessibility of primary sources; and to apply and refine the interview guide. The guide, along with the recruitment letter and consent form, had first been reviewed and approved by Carleton University's Research Ethics Board. The bulk of interviews took place during the second visit, which included on-site interviews in four towns ${ }^{15}$ distant from Nairobi. The third visit involved a return to some interviewees past as well as new interviewees to validate the research's emerging findings and seek clarity on some outstanding questions. In keeping with the grounded theory approach (Charmaz, 2008, p. 204), analysis of the data began with the first set of interviews, which helped to refine and further focus the data gathering.

A purposive sampling method was used to select interviewees. The selection process began with a group of ten potential interviewees inclusive of or recommended by individuals in my professional network built over twenty-five years of working in the field of international development. From that initial group of individuals, interviewed in

${ }^{15}$ Laikipia, Nakuru, Kisi, and Kisumu were the towns visited. To balance ethnic representation, the dominant ethnic group of these towns covers the spectrum of Kenya's main ethnic groups. 
Kenya and Washington, DC, the snowball technique was applied to expand the interviewee list while I also continued to seek contacts via my professional network. The majority of interviewees were selected as their knowledge and experience deemed them able to provide an informed accounting of facts, and to hold perspectives in relation to CSOs and their regulation in Kenya. A number of interviewees were not experts in this subject matter, but worked with organizations with a potential stake or influence on CSO regulation. Purposive sampling was necessary also to capture the experience and perspectives of key organization types, including national and local/decentralized GoK officials and elected representatives, DAC/G officials, and Kenyan and international CSOs. This was combined with snowball sampling as interviews revealed additional organizations or individuals considered well informed on the research subject. To gather historical perspectives, 43 percent of the interviews involved individuals having either engaged in or observed the regulation of civil society for at least 15 years.

As the findings from this research reveal, the subject of CSO regulation in Kenya is a politically sensitive one. Interviewees were guaranteed confidentiality to protect their identities and allow them to speak from their personal rather than institutional perspectives if they chose. As such, interviewees are not named in this dissertation nor are their organizations identified; designation is provided by organization type only. Interviews were held in a location of the interviewee's choice. Interviewee consent was given prior to each interviewee including consent to audio record the interview. ${ }^{16}$ Notes

${ }^{16}$ Only one interviewee did not give consent to be audio recorded. A handful of other interviews were not audio recorded as they were impromptu, and in one case, due to 
were also taken by hand. Interview recordings, transcriptions and notes are maintained in a secure location, with electronic data password-protected.

A preliminary open coding of interview notes was done by hand, followed by more micro coding of transcription of the audio-recorded interviews using NVivo data management software.

\subsection{Chapter Outline}

The next chapter provides an overview of the literature that underpins this research. It also includes clarification of the terms used throughout the dissertation. Chapter two's main focus is presentation of a conceptual framework of the explanatory, or 'driving' factors of CSO regulation gleaned from the literature, followed by an overview of generalized LMI country characteristics deemed of particular relevance to CSO regulatory change.

Chapters three through six contain the empirical data on four successive phases in Kenya in which key regulatory developments occurred. In these chapters the data is interpreted against the conceptual framework outlined in chapter two. The first phase, or wave, begins in the late 1980s with instigation by the GoK of the NGOs Co-ordination Act (1990) in an effort to rein in the burgeoning CSO sector. This phase also covers the first decade of the Act's implementation through the 1990s. The second wave spans from 2000 to 2007 , a period in which the GoK took small steps toward regulatory reform, while the CSO sector suffered a crisis of confidence and self-regulation floundered. In the

security restrictions in the building that did not allow visitors entry with any type of information and communications technology. 
third wave, from 2008 to early 2013, CSO sector initiative led to new regulatory outcomes both in state and self-regulation, culminating with the PBO Act (2013) and an independent CSO self-regulation mechanism. The fourth wave follows, covering various GoK-initiated obstacles resulting in non-implementation of the new Act and a restrictive environment for the CSO sector through 2017.

Chapter seven pulls together and deepens the analytical highlights of the four empirical chapters against the conceptual framework. Finally, chapter eight provides a summary conclusion to this research, suggesting implications for further research, policy makers and practitioners from governments and civil society. 


\section{CONCEPTUALIZING STATE AND SELF- REGULATION AND REGULATORY CHANGE DRIVERS}

\subsection{Introduction}

CSOs face a seeming paradox: they are at once recognized as significant contributors to social, economic and democratic development, while at the same time being constrained in their work through regulatory and other means. This chapter first assesses the nature and implications of this paradox. It then outlines the complexity of CSO accountability, a concern on both sides of this paradox, the solution to which is often addressed by states through regulation and/or by CSOs through self-regulation, which are understood to interact in a wave-like manner of alternating emphasis. Drawing from the literature, the chapter presents current approaches to understanding state and selfregulation of CSOs and the anticipated relationship between them in the pursuit of CSO accountability.

In order to better understand the paradox, and to unpack the relationship between CSO accountability and regulation, this research explores the factors that drive regulatory change and help to explain the emergence or reform of regulation and/or of selfregulation over time. As to date there is no single conceptual framework of regulatory change drivers, this chapter proposes such a framework based on concepts and empirical findings gleaned from the literature. The chapter then puts forward highly generalized characteristics of LMI countries that are most relevant to and may influence how the drivers of regulatory change play out in practice in LMI country realities. 


\subsection{The Paradox}

The CSO sector has experienced considerable growth over the past four decades with an expansion of roles and influence from global to local levels. Expansion of the sector is expected to continue for various reasons as documented by Casey (2016), such as government retrenchment due to fiscal restraint; "privatized" solutions to public problems; growing middle classes with interest in engaging on global and local issues, and with income to support CSO activities; expanding funding opportunities (e.g. corporate or web-based giving); new technologies reducing start up and operating costs for CSOs; and a global spread of "non-profit mind-sets and toolkits" (p. 294).

As the sector grows and its influence amplifies, there is an accompanying recognition of its importance. In a 2017 report the UN Special Rapporteur on the freedoms of peaceful assembly and of association articulated the "intrinsic and instrumental" value of civil society and its organizations, documenting civil society's successes and achievements of recent years in various domains (UNSR, 2017, para. 8). Civil society and CSOs contribute to societal improvement by "protecting civil and political rights, advancing development objectives, moving societies towards freedom and equality, achieving and upholding peace, checking corporate behaviour, protecting the environment, delivering essential services, and advocating for economic, social and cultural rights" (UNSR, 2017, para. 8). Expectations of the sector's contribution are high, and span across political ideologies (Casey, 2016, p. 20). Reimann (2006) points to a "pro-NGO international norm" having proliferated globally beginning in the 1980s (p. 46), arguably part of democracy's third wave (Huntington, 1991) and the widespread uptake of liberal democratic norms and values (Dobbin, Garrett, \& Simmons, 2008). 
Yet, at the same time, there is a paradox. On the one hand, the importance of the actual and potential contribution of CSOs is acknowledged. On the other, there is a widespread phenomenon over the past ten-plus years whereby space for the sector's functioning has been shrinking in some countries. Though suppression of CSOs is not a new phenomenon, its incidence and the sophistication of approaches used by states to shrink CSO space - including regulatory approaches - has been on the rise (Carothers \& Brechenmacher, 2014; Rutzen, 2015b; Dupuy et al., 2015a; Dupuy et al., 2015b; ICNL, 2016; UNSR, 2013 \& 2014; CIVICUS, 2015b; CIVICUS, 2016). And while seen in countries worldwide including in HI countries, there is a higher prevalence of regulatory and other actions that shrink CSOs' space in LMICs (Carothers \& Brechenmacher, 2014; Rutzen, 2015b; Dupuy et al., 2015a \& 2015b; ICNL, 2016; UNSR, 2013 \& 2014; CIVICUS, 2015b; CIVICUS, 2016). ${ }^{17}$ The trend is puzzling given the recent decades of global diffusion of pro-CSO norms, alongside both the reputational risk faced by governments that implement measures restricting CSOs, and the risk of financial losses given the considerable resources CSOs contribute to development, including private and official flows (Dupuy et al., 2015a, p. 300). ${ }^{18}$

${ }^{17}$ As noted, each of these sources addresses the restrictive regulation trend. While the data and examples indicate the trend is particularly prevalent in LMI countries, sources also refer to it as a global phenomenon, e.g. see Dupuy et al., 2015a, p. 302 \& 2015b, p. 423; ICNL, 2016, p. 2; UNSR, 2013, para. 12; CIVICUS, 2016, pp. 129-135). Most recently, a report from ICNL (2018) points to increasing incidences of restrictions on CSOs in HI countries considered democratic (p. 10).

${ }^{18}$ Dupuy et al. (2015a) focus on the potential loss of foreign aid flows in the context of regulatory change specifically restricting such flows. However, any regulation that restricts CSOs' ability to operate has the potential to reduce the availability of financial contributions that would normally flow from or via CSOs. 
A common thread on both sides of the paradox lies the issue of CSO accountability. Since Naidoo (2004) wrote of "the end of blind faith" in the CSO sector, accountability pressures on CSOs have been and are expected to continue to rise, just as expectations of CSOs' contributions to development also rise. In a sense, the roles, contributions and influence of CSOs are "being undermined to some extent by the mantra for greater NGO accountability" (Charnovitz, 2006, p. 40). On one side of the paradox CSOs are generally trusted organizations but for which attention to accountability is necessary to ensure they can deliver the promise of their societal contribution in an effective manner. On the other side of the paradox there appears at times to be an assumption that CSOs, as non-elected bodies absent shareholders, are by definition not accountable and thus should only have a narrow space of operation. While concerns about CSOs' accountability are legitimate, they need to be understood in a way that reflects what is specific to accountability in the CSO sector.

\subsection{The CSO Accountability Challenge}

Accountability is a widely used concept but one that is "in motion.... discussed in a series of definitional whirlpools and from multiple directions" (Harrow, 2016, pp. 483484). The 1999 report of the Canadian Panel on Accountability and Governance in the Voluntary Sector defines accountability as "the requirement to explain and accept responsibility for carrying out an assigned mandate in light of agreed expectations" (Panel on Accountability and Governance in the Voluntary Sector [PAGVS], 1999, p. 11). 
The difference between CSOs' accountability relationships and those of the private sector or governments is well articulated by Gugerty and Prakash (2010). In summary, for private sector firms, accountability is primarily to shareholder 'principals' and clients, who respond to positive accountability signals with their investments. For governments, accountability is to the public - via elected officials - and the public responds to positive accountability signals by voting governments in and out of power. CSOs on the other hand may have many 'investors', that is, their donors, but unlike with firms for which the primary goal is profit making, CSOs' investors do not necessarily have the same goals. As well, CSOs' clients, or beneficiaries, do not have voting power.

Accountability is a particular necessity for CSOs to build and maintain the public trust so essential to the sector given the non-distribution constraint that characterizes them, i.e., that they do not distribute "net earnings, assets or profits to any founder, director, officer, member, employee, or donor" (ICNL \& United Nations Development Programme [UNDP], 2009, p. 17), in other words, to any "individuals who exercise control over it" (Hansmann, 1980, pp. 838 \& 896). The public trust is also essential given CSOs' self-promotion and associated societal expectation of them as altruistic dogooders. Due to their "normative goodness" (Bloodgood, 2013, p. 8), CSOs are held to a high standard of accountability (Naidoo, 2004, p. 18). Commenting on accountability pressures on the sector, McGregor-Lowndes and Wyatt (2017a) highlight this well with their suggestion that in the public perception, "It is one thing to be cheated by a business, but another to be taken down by a supposedly trusted pillar of society" (p. 264). 
Yet, an over-emphasis on accountability has been noted to have potential negative affects on the productivity and innovation potential of organizations in varied sectors (Thomas, 2015, para. 30). ${ }^{19}$ Accountability needs to be balanced against CSO autonomy and independence from the state. CSOs need to be accountable while retaining the ability to exercise "reasonable discretion" versus the "uniformity of government-directed action" (Brody 2006, p. 244), as it is such discretion that underlies sector attributes such as innovation, responsiveness, voluntarism, and the like.

Another CSO-specific accountability challenge is that, more so than private firms (Ebrahim 2003a, p. 814) or arguably governments, CSOs face multiple, sometimes competing accountabilities to varied stakeholders including to constituents or beneficiaries, private and public donors, boards and peers amongst others (Tenbensel, Dwyer, \& Lavoie, 2014; Najam, 1996). CSOs consider "mediating the tensions" between their varied accountability relationships as one of their key challenges (Burger \& Seabe, 2014, p. 80 citing Edwards \& Hulme, 1996, Christensen \& Ebrahim, 2006). The literature's various conceptualizations of CSOs' "multi-layered" or "multidimensional" accountabilities (PAGVS, 1999, p. 11) are summarized by Casey (2016, p. 266) as:

Upward (to donors, sponsors, and regulators), outward (to collaborators and peers), inward (to staff and members), or downward (to recipients and communities) (citing Ebrahim, 2003a)

Representative (to members), principal-agent (to donors and contractors), or mutual (to allies and peers) (citing Brown \& Jagadananda, 2010)

19 Thomas (2015) further notes that too much or the "wrong kind" of accountability measures can have the counter-effect of reducing trust in organizations in that they draw attention to errors and wrongdoings (para. 30). 
Constituency based (to the interests of beneficiaries), movement based (to the values of a movement), or mission based (to the expectations of affiliates and members) (citing Brown, Ebrahim \& Batliwala, 2002)

Functional (short-term accounting for resource use and outputs) or strategic (accounting for ongoing impact and relations) (citing Edwards \& Hulme, 1996)

Full (financial accounting of use of resource), explanatory (provision of information and explanation for action), or responsive (maintaining trust and faith) (citing Lewis, 2007)

Accountability in the CSO sector is further complicated by its vast diversity of organizations. Diversity in terms of size and scope of reach, budget, sources of funding, purpose and approach (PAGVS, 1999, p. 3; Harrow, 2016, p. 484) also render it difficult to envision a 'one-size-fits-all' response to CSOs' accountability pressures.

When it comes to the CSO sector, therefore, accountability challenges are multifaceted. So too are the origins of accountability demands on CSOs. They are partly a product of an era of fiscal constraint alongside implementation of the new public management (NPM) model in which CSOs are drawn into filling service functions traditionally performed by governments as these are privatized or decentralized (Brody 2002; Ebrahim, 2003a; Amstrong 2006; Naidoo, 2004; Smith, 2011; Williams \& Taylor, 2013, p. 561). This function not only increases CSOs' visibility (McGregor-Lowndes \& Wyatt, 2017a, p. 287) but also comes with pressures to demonstrate value-for-money, results and impact, often through performance-based contract or 'partnership' (usually co-funded) arrangements. Higher levels of professionalization and professionalism in the sector, which is not solely the site of volunteers organizing to 'do good', have led to both internal and external demands on the sector's accountability (Harrow, 2016, pp. 485-6). As CSOs' operations and sometimes their organizational forms have become hybridized and more business-like, for example in the arenas of social entrepreneurship or public- 
private partnerships (Harrow, 2016, p. 485; Skelcher, 2004; Smith, 2010), this too has increased accountability pressures on the sector. In addition, CSOs' increasing influence in the policy realm including their demands for accountability and good governance from both states and the private sector has come with calls on CSOs to ensure they have their own houses in order and are "modelling the values they espouse" (CIVICUS, 2011, p. 24; Jordan \& van Tuijl, 2006, p. 3). Of CSOs it is often asked "Who elected them?", highlighting that fundamental questions about CSO legitimacy also underpin accountability pressures (Amstrong, 2006, p. 63).

Further, the current era is one with high expectations of openness, transparency and accountability from all institutions (Phillips, 2013; Phillips, 2012, p. 812 \& p. 810 citing Jordana \& Levi-Faur 2004, p. 812). When combined with the effect of social and popular media coverage of actual or perceived wrongdoings by CSOs (amongst others) (Gibelman \& Gelman, 2004; McGregor-Lowndes \& Wyatt, 2017a), and a "backdrop of declining public trust and confidence in all social institutions, public, private, and voluntary" (Etherington, 2017, p. 75), accountability demands on the CSO sector are not expected to dissipate.

\subsection{Responding to Accountability Challenges through Regulation}

Globally, governments and CSOs alike are turning to new and intensified state and self-regulatory measures to addres accountability pressures. In the name of accountability however, regulation can be shaped to control the CSO sector, or, to enable it - regulation is not a neutral tool. For governments, regulation is the choice mechanism to address CSO accountability. Lack of or weak accountability is often used as a rationale for 
introducing or reforming state regulation (Rutzen, 2011, p. 269; Wiepking \& Handy, 2015, p. 605; Burger \& Seabe, 2014; (Lloyd \& Casas, 2005, para. 3; Irvin, 2005; Jordan \& van Tuijl, 2006, pp. 5-7). Governments tend to see that CSOs' accountability must first and foremost flow upwards to the state, where a responsibility to safeguard the public and private financing CSOs receive (Phillips \& Smith 2011b, p. 10), and ensure the legitimacy of these non-elected bodies (Burger 2012, pp. 101-102), also lies.

CSOs express interest in strengthening their accountability, but are simultaneously protective of their independence and their fundamental rights of association, assembly and expression (Jordan \& van Tuijl 2006, p. 6). Further, CSOs see their accountability relationship to governments as one amongst others. For CSOs, state regulation does not necessarily enable them to adequately respond to their multiple accountabilities, and may even undermine them. Thus, governments' interest in regulating the CSO sector is counter-balanced by CSOs' interest in protecting their independence, with self-regulation as one means to do so. CSOs may prefer to pursue self-regulation, or at least an approach that allows roles for state and self-regulation to co-exist. Self-regulation in various industries including in the CSO sector, has been a growing trend of interest to practitioners, policy-makers and academics globally (King \& Lenox, 2000, p. 698; AbouAssi, 2015, p. 1256; Gugerty et al., 2010, p. 1028).

A common conception in the broader regulation literature is that self-regulation offers an alternative to state regulation (Coglianese \& Mendelson, 2010, p. 147). In this vein, recent scholarship on CSO regulation posits that in the pursuit of accountability through regulation, a causal relationship exists between state regulation and self-regulation of the 
CSO sector, with a "seeming ebb and flow between the statutory and non-statutory regulatory cycles" as one alternates for the other in "cycles of regulation" (Breen et al., 2017a, p. 3). A trade-off between state and self-regulation is anticipated, with selfregulation a proxy to state regulation and vice versa, and a wave-like effect unfolding as they interact. The current research draws from and builds on this scholarship to analyze the relationship between the accountability imperative and state and self-regulation. It focuses on various drivers of regulatory change, and their manifestation in LMI country contexts, as a way to highlight the primacy of these drivers' influence on state and selfregulation above and beyond the theorized relationship between the two. In so doing this research seeks to shed light on the paradox wherein the CSO sector may be recognized and valued for its significant contribution to development, while the regulatory space for its operations shrinks.

Before proceeding to develop a conceptual framework of drivers of regulatory change this chapter provides an overview of the why, how and what of state and self-regulation of CSOs. The 'whys' covered here relate to the nature of CSOs as non-profit distributing organizations, and differ from the drivers of regulatory change which occur at a more meso-level of analysis as reflected in this chapter's conceptual framework.

\subsection{State and Self-regulation: The Why, How and What, in Theory and Practice}

To provide a basis for understanding the state and self-regulation domains, this chapter proceeds to detail the why, how and what of states' CSO regulation and CSO self-regulation. 


\section{Why and How do States Regulate?}

Ensuring accountability of CSOs is the fundamental rationale for state regulation. Simply put, this means that, through regulation, states seek assurance that CSOs are the organizational form they say they are, and do what they say they will do. CSOs come in varied organizational forms, but a defining attribute is what is called the non-distribution constraint. As noted, non-distribution means that any assets, earnings or profits held by the CSO cannot be distributed but are ploughed back into the organization for pursuit of its stated non-profit purpose. This constraint is a critical signal of CSOs' trustworthiness (McGregor-Lowndes \& Wyatt, 2017a, p. 262, citing Hansmann, 1981 \& 1996; Hansmann, 1980). States will regulate the CSO sector to signal or reinforce that the nondistribution constraint applies to the organizations being regulated.

From there, the "why" of state regulation varies for different CSO types. Of particular interest to this research is the public benefit form of $\mathrm{CSO}$, that is, non-profit organizations the purpose and (all or most of) the activities of which are intended to benefit the public (Irish et al., n, 2004, p. 115). Public benefit organizations are also often referred to as charities, and regulatory recognition of public benefit/charity status can come with "special benefits from the state", such as tax privileges (exemptions, reductions, or special rates), customs and duty benefits (customs-free imports, special rates), or other forms of government income (Irish et al., pp. 53-55; Pajas, 1999, p. 2). With these special benefits come "special obligations and requirements", usually additional regulatory burdens and scrutiny in the form of particular registration and reporting procedures (Pajas, 1999, para. 12; Irish et al., 2004, p. 54). When it comes to PBOs, states' interest in regulation is to ensure they are accountable in meeting the public benefit parameter, and 
where tax or other benefits are accorded, in accessing the public purse. Where a CSO is intended to fulfil some kind of benefit to the public, the public as consumer or beneficiary of the good or services provided needs protection and assurance. Where a CSO receives special benefits, they are considered a government investment in the form of (forfeited) tax revenues. Regulation is thus used as a way to protect this investment ensuring not only that the funds are used for the public benefit, but also, that there is no abuse of the tax privilege system.

It need be noted that conferring public benefit status does not necessarily entail also conferring tax exemptions or other benefits and associated regulatory requirements. Not all governments are prepared to forgo state income through tax privileges to CSOs, whether due to the former's limited resources, or lack of conviction the work of CSOs should be encouraged such as by incentivizing private giving to the sector (Bater, 2000, paras. 1-2). Equally, CSOs may prefer, and should be allowed, to opt out of such special benefits. As noted in the Open Society Institute's Guidelines for Laws Affecting Civic Organizations: "the PBO classification will ordinarily entitle a formal civic organization to special benefits, which bring with them additional regulatory burdens.... a civic organization should retain the freedom to decide whether to obtain this special status and subject itself to the additional regulatory burdens. (Irish et al., 2004, p. 54). There is, however, some debate on this regulatory tenet, leading to different approaches to the regulation of PBOs. Some states prefer CSOs to register as PBOs based on their purpose and activities to automatically be eligible for special benefits and the associated regulatory requirements. Others leave PBOs to elect, or not, to receive the benefits and 
thus be subject, or not, to the additional regulatory burden. Even with an elective option, states may impose the same regulatory burden on all PBOs based on the rationale that their intent to fulfil a benefit to the public merits regulatory scrutiny, with or without tax privileges. However, many in the $\mathrm{CSO}$ and human rights community argue that this approach goes against the right to freedom of association without government interference as enshrined in the international human rights legal framework. ${ }^{20}$

At the most basic level, states' regulatory approaches involve verifying eligibility of an applicant to form and operate as a $\mathrm{CSO}$, or a particular type of $\mathrm{CSO}$, through a cycle of monitoring and enforcement via reports and audits. Beyond those basics, differences arise whether a state sees its role as pursuing CSO accountability in the narrow sense of accounting for inputs and actions. Or, whether a state sees itself as having a role in advancing not only accountability, but more broadly in promoting public trust and confidence in the CSO sector.

Recent scholarship depicts these two different approaches to CSO regulation as, in the first instance, the individual accountability model, and in the second instance, the trust and confidence model (McGregor-Lowndes \& Wyatt, 2017a). In the former case, emphasis is on individual CSOs to comply with regulatory rules, and in so doing, to qualify as accountable organizations that individual members of the public - as donors

${ }^{20}$ Including the Universal Declaration of Human Rights, the International Covenant for Civil and Political Rights, the International Covenant on Economic and Social Rights, amongst other conventions, declarations, and case law (WMD \& ICNL, 2012, pp. 34-39; Irish et al., 2004, p. 20). Note further that the right to freedom of association allows for associating without the necessity of seeking legal entity status (WMD \& ICNL, 2012, p. 37). 
and as consumers - can inform themselves about, if they so choose. In the latter case, the regulatory rationale is "over and above" the pursuit of individual CSOs' accountability (McGregor-Lowndes \& Wyatt, 2017a, p. 261). Its reach involves protection and promotion of the sector as a whole, grounded in a belief that the sector is a significant contributor to society, one to which the public's financial, human (especially volunteers) and moral support, that is, the public trust, is essential (Etherington, 2017, pp. 61-62).

The individual accountability model follows a traditional "command-and-control" approach to regulation within which a set of prescriptive, targeted rules are enacted and enforced by states, with sanctions meted out for non-compliance (Baldwin et al., 1998, p. 3). The trust and confidence model falls into the realm of what is known as "responsive regulation" (Ayres \& Braithwaite, 1992). As per its name, responsive regulation calls for regulation that is "responsive to the regulatory environment and to the conduct of the regulated in deciding whether a more or less interventionist response is needed" (Braithwaite, 2017, p. 117). It is distinct from command and control regulation in that the triggers of a regulatory response, and the form of that response, can and should vary given that diversity - of capacity, budget, needs, and intentions - within an industry being regulated requires flexibility and responsiveness to varied levels of risk (Doern \& Johnson, 2006, p. 10). Responsive regulation assumes that, while the sector may be "vulnerable to individuals with nefarious motives" (Farrelly, 2017), the majority of those being regulated are well intentioned. They want to comply, but they may not have the information or awareness needed to do so. Further, the responsive model is not solely about accountability of individual CSOs but is about enhancing the "charity brand" 
(McGregor-Lowndes \& Wyatt, 2017a, p. 263). Responsive regulation sees the regulator's role as not being simply about oversight, but also about enabling the sector, which can include providing a "service" to the sector in the form of "communication, advice, and support" (Phillips 2006, pp. $136 \&$ 129).

Practice finds states' CSO regulation at either end of the spectrum of these two models with variations in between. Federal regulation in the United States (US) is cited as the typical individual accountability approach. There, CSOs seeking public charity status and the tax privileges that come with it (referred to as "501(c)(3)s, with reference to the relevant section of the Internal Revenue code), are regulated at the federal level by the tax agency, the Internal Revenue Service, ${ }^{21}$ with emphasis on oversight of CSOs as tax paying and tax concession-receiving organizations. In this case, "the regulation of charities is not perceived as having a unique character - charities being just another taxpayer, subject to the same classic command and control punitive [regulatory] tools" (McGregor-Lowndes \& Wyatt, 2017a, p. 272). This model is criticized for lacking the resources and design features such as proportionality that are necessary for a "fit-forpurpose" regulatory approach specific to CSOs (McGregor-Lowndes \& Wyatt, 2017a, pp. 272-273). Here, regulation is not concerned with building trust and confidence in the sector. Responsibility is instead left to CSOs through individual accountability or selfregulatory measures to demonstrate not only the sector's accountability but its value to society. In this vein, third party CSO watchdogs are increasingly involved in the US to

${ }^{21}$ In the US, the regulation of CSOs more broadly is undertaken, largely by Attorneys General, at the state level, where CSOs must legally incorporate (Owens, 2017, p. 84). 
provide data about CSOs' work and results. Self- and third party regulation under the individual accountability approach "becomes a necessary backstop to loss of not only donor dollars but also public trust in the sector" (Boris \& Lott, 2017, p. 107).

Responsive regulation of the CSO sector is demonstrated in Australia. Recent regulatory reforms there were grounded in a conviction that the sizable non-profit sector - with over 600,000 organizations and close to a 5 percent contribution to GDP required a more enabling regulatory regime that would increase public trust and confidence both in individual CSOs and in the sector (Australian Government the Treasury, 2012, pp. $2 \& 16$ ). The regulatory reform process involved extensive research, public consultation, and input from a cross-sectoral task force, believing that coproduction with the sector would provide a "gateway to compliance" (Baird, 2017). The consultative process led to establishment of a new Australian Charities and Not-forProfits Commission (ACNC) under its own Act, also supported by a new Charities Act. The ACNC is a relatively independent body that is overseen by two Ministries (Treasury and Small Business) and reports to Parliament (Pascoe, 2017, pp. 227 \& 229).

The ACNC applies a "graduated and proportionate" approach (Baird, 2017) based on a "regulatory pyramid of support and compliance" that balances the pursuit of CSO accountability and transparency with supporting and enabling the sector (Australian Government the Treasury, 2012, p. 5). ${ }^{22}$ The pyramid is one of escalating nudging and

${ }^{22}$ In its establishment phase, the ACNC prioritized regulation of charities specifically, with the intent to later broaden the ACNC's regulatory coverage to other types of non- 
pressure with opportunities for CSOs to self-correct, with sanctions for non-compliance implemented only once the top of the pyramid. The compliance pyramid exists alongside escalating supports or rewards to sector members for high performance or for the mentoring and guidance they provide to others in the sector (Braithwaite 2012, p. 5). The ACNC is resourced to be able to meet the varied demands on it moving up the pyramid, and invests in building its knowledge of the sector on an ongoing basis, with formal protocols and mechanisms in place to maintain independence from the sector (Pascoe, 2017, pp. $219 \& 223)$.

What this demonstrates is that there can be considerable variation in how states regulate CSOs, even as the reason for regulation as relates to CSOs' organizational form are fairly consistent.

In addition to CSO-specific regulation, $\mathrm{CSO}$ are also regulated by states, directly or indirectly, through regulation or policy whose primary target may not be CSOs, but that nonetheless affects them. A country's legal and regulatory framework as affects CSOs often includes the country's constitution, then various other regulations that can cover amongst others: counter-terrorism; the rights of specific groups such as ethnic groups or, lesbian, gay, bisexual, transgender, queer, plus (LGBTQ+) communities, whereby CSOs working in support of such groups and individuals in them become indirect regulatory targets; or procurement and contracting. In common law countries, the outcomes of legal cases also provide a form of regulation in the precedents of legal interpretation that they

profit organizations that, along with charities, make up the CSO sector. The regulatory pyramid concept and associated principles apply to the CSO sector writ large however. 
set. The main focus of this research is CSO-specific regulation, especially the regulation of PBOs. In order to depict the case study narrative in full, instances of indirect regulation of CSOs will nonetheless be covered in the empirical chapters on the Kenya case.

\section{What do States Regulate?}

From among the range of CSO policy and practice that governments might choose to regulate, due to the accountability areas of interest (the 'whys') listed above, when it comes to PBOs emphasis tends to be broadly on the regulation of:

i. Mandate/Purpose: Including mission or policy priority(ies) that is appropriately public benefit

ii. Activities: In keeping with the organization's mandate (and therefore with public benefit)

iii. Finances: Revenue and expenditure, with the latter in keeping with mandate and activities, and avoiding fraudulent practices

The first two of these three regulatory arenas are not as straightforward as they appear at first glance. The definitional issue of what constitutes 'public benefit', also referred to as "charitable purpose", has in common law countries been based on foundations provided by the English 1601 Statute of Charitable Uses, then by the also English 1891 Pemsel case which defined four public benefit categories: advancement of religion, relief of poverty, advancement of education, and other purposes beneficial to communities as defined by law. The four categories have evolved and expanded over time with variations on the public benefit theme seen across common law countries and other jurisdictions (Phillips \& Smith, 2016, p. 215), and a host of more specific activities defined as public benefit that range from the support of sports to the protection of human rights (Pajas, 1999, paras. 22-24). The basic four definitional parameters are also widely used in civil 
law countries, with variants and specificities, though civil law public benefit parameters tend to be wider than in common law countries (Irish et al., 2004, p. 55). Generally the public benefit test verifies that a CSO's mandate and activities are not a self-serving but instead target and reach the public or a section of the public. Within that broad(ish) parameter, variation is seen in whether public benefit is presumed or must be proven by the $\mathrm{CSO}$; whether scrutiny of mandate is adequate or a deeper dive into activities is required; whether the public benefit must be the exclusive or only the primary purpose of the organization; and the boundary between the "public" and "non-public" on the receiving end of the benefit (Pajas, 1999, paras. 1-4).

A related point of regulatory variance is seen in provisions for CSOs to engage in socalled "political activities". Both the nature of and degree to which public benefit CSOs are permitted to undertake public policy related activities is a point of ongoing debate in many jurisdictions. Generally, some form of public policy activity restriction is seen. Again English case law provided an interpretation in the 1917 Bowman's case, that the activity must not be of a partisan nature, or seeking to change a specific law or public policy (McGregor-Lowndes \& Wyatt, 2017a, p. 279). Since then, the political activities interpretation has become less narrow in the UK and elsewhere, with for example regulation stipulating that such activities must simply be ancillary and not dominant to meeting a CSO's mandate. Recent regulatory reform in Australia has set a precedent for modernizing the interpretation of political activity limitations exclusively to partisan political activities (McGregor-Lowndes \& Wyatt, 2017a, p. 281). In Canada in 2018, the Ontario Superior Court ruled that the long-standing ten percent limit on what a charity 
could expend from its budget on non-partisan political activities was a violation of the constitutionally protected freedom of expression (Canada Without Poverty v. AG Canada, 2018; Beeby, 2018a, para. 1). Subsequently, after stating it would revise the relevant legislation while challenging the court's ruling (Beeby, 2018b, paras. 7-11), the federal government revised the Income Tax Act, essentially removing the ten percent limit (Department of Finance Canada, 2018; Blumberg, 2018, p. 3).

The regulation of finances is straightforward though again there is variation in what is covered. Regulation is put in place to ensure sound accounting and prevention of funds misappropriation of other forms of fraud. Expenditure is looked at in relation to a CSO's public benefit purpose and possibly activities. As regards income, parameters are sometimes placed on, for example, whether CSOs are allowed to engage in what are deemed commercial or other types of income generating activities. Increasingly in an environment of fiscal constraint and innovation, CSOs are venturing into the profit making arena with activities ranging from sale of goods and services (e.g. t-shirts, printing, consultancy services) to property investment or public share portfolios for example (Garrett, 2017, p. 179). Where state regulation allows such activities, it seeks to ensure that the non-distribution constraint is met and profits be used for fulfillment of the public benefit mandate.

These are, broadly speaking, the minimum regulatory arenas covered by governments. Some will go further, implementing rules or guidelines depending on their relatively more prescriptive or responsive approaches. While arguably more appropriately left to CSOs' to self-regulate, whether individually or through collective self-regulation, 
where CSOs' internal management and governance involve interface with the public and/or where mismanagement can leave CSOs particularly vulnerable to loss of public trust (e.g. fundraising, board governance, disclosure and transparency), a state may opt to intercede in these areas with regulation. Also, as previously noted, various other laws, policies and regulations are used that, though not CSO-specific, may address or indirectly affect CSOs. Commonly regulated aspects of the CSO form, operations and actions as categorized by ICNL and UNDP (2009) are detailed below (p. 18).

\section{Table 1: Issues for CSO Regulation and Forms of Regulation}

\begin{tabular}{|l|}
\hline General life-cycle issues: \\
- Definition of CSO organizational type \\
- Establishment \\
- Registration \\
- Internal structure and governance \\
- Activities \\
- External supervision, including reporting \\
- Terd auditing \\
- Foreign civion, dissolution and liquidation
\end{tabular}

Fiscal Regulation:

- Public benefit (or charitable) status

- Income or profits tax exemptions for CSOs

- Income or profits tax preferences for donations

- Economic activities and the taxation of income from economic activities

- Value-added tax (VAT) and customs duties

- Government funding

- Investment income

- Fundraising (public collections) State/Civic Sector Relations:

- Registration

\section{Regulated potentially by:}

- Civil Code

- Specific legislation governing various organizational types (laws on associations and foundations, for example)

- Legislation governing companies or corporate forms

- Industrial relations acts (relating to trade unions)

- Licensing laws (for certain activities)

Regulated potentially by:

- Public benefit legislation

- Income tax law

- Law on VAT

- Law on customs duties

- Law on fundraising (public collections)

- Budgetary appropriations acts

- Finance and audit acts

- Land (duties and taxes) act

\section{Regulated potentially by:}

- All of the laws/regulations listed above 


\begin{tabular}{|c|c|}
\hline $\begin{array}{l}\text { - External supervision, including reporting } \\
\text { and auditing } \\
\text { - Public policy / political activities } \\
\text { - State subsidies, grants and contracts } \\
\text { - QUANGOs and GONGOs } \\
\text { - Policy documents for cooperation } \\
\text { - Liaison offices }\end{array}$ & $\begin{array}{l}\text { - Local government act } \\
\text { - Law on public procurement } \\
\text { - Laws on social assistance, healthcare, } \\
\text { education } \\
\text { - Laws establishing various kinds of not- } \\
\text { for-profit organizations, often considered } \\
\text { QUANGOs or GONGOs } \\
\text { - Policy documents for cooperation }\end{array}$ \\
\hline $\begin{array}{l}\text { Public Participation: } \\
\text { - Public policy/political activities } \\
\text { - Receipt of information } \\
\text { - Consultations } \\
\text { - Active participation }\end{array}$ & $\begin{array}{l}\text { Regulated potentially by: } \\
\text { - Freedom of information laws } \\
\text { - Acts on decisional transparency } \\
\text { - Legislative process rules } \\
\text { - Government policy }\end{array}$ \\
\hline
\end{tabular}

Evident from this list is that the many aspects of CSOs regulated by states can involve "a complex web of legal sources.... that will likely have direct or indirect influence on the existence, operations and activities of CSOs" (ICNL \& UNDP, 2009, p. 16). While the current research focuses primarily on CSO-specific regulation, it does so cognisant of, and where relevant speaking to, key laws and regulations of the wider regulatory framework (italicized in the above table).

\section{Why and How do CSOs Self-regulate?}

As with state regulation, accountability provides an over-arching rationale for CSO self-regulation (Lloyd \& Casas, 2005; Hammad \& Morton, 2011; Dunn et al., 2017, p. 222). The same aspects of CSOs' organizational nature and relationships - as public benefit organizations operating under a non-distribution constraint and with access to the public purse - that are of interest to states are also central to CSOs' rationale for selfregulation, and CSOs will turn to self-regulation in an attempt to stave of state regulation (Prakash \& Gugerty, 2010, p. 24; Ebrahim, 2003; pp. 820-821; Dunn et al., 2017, p. 223; Bies, 2010, p. 1069; Gugerty et al., 2010, p. 1028; Burger, 2012, p. 89). Their 
motivations to self-regulate may be "many and overlapping" however, (Sidel, 2010c, p. 1040) and extend beyond state regulatory requirements.

Self-regulation may be pursued by CSOs as a means of self-improvement. It can be seen as a means of strengthening the quality of the sector's governance, operations and activities; of coordinating a diverse and "unruly" sector; or of learning through self and peer assessments (Sidel, 2010c, p. 1040; Gugerty \& Prakash, 2010, p. 21), in these ways using self-regulation as an "instrument of professionalism" (Dunn et al., 2017, p. 222). As with state regulation, CSOs may turn to self-regulation to "shore up the [non-profit] sector's public profile" (Dunn et al., 2017, p. 222), in other words, to build public trust and confidence in the sector. CSOs may see self-regulation as a way of protecting or increasing public and private financial flows to the sector, as well as to individual CSOs as it can help to distinguish between "good apples" and "bad apples" in the sector (Prakash \& Gugerty, 2010, pp. 23-24).

CSOs also pursue self-regulation to address the "legitimacy dilemma" they face as they "straddle the boundary between public and private" domains (Williams \& Taylor, 2013, p. 570). Though legitimacy and accountability are not one and the same (Amstrong, 2006, p. 62), demonstrating accountability can provide assurance, shoring up CSOs' legitimacy claims that they are "authentic and... justified in [their] actions" (Naidoo, 2004, p. 14; Bies, 2010, pp. 1058 citing Harrow 2006, Svítková \& Ortmann, 2006, p. 1070). Self-regulation can send "signals" - to governments, donors, and the public - about the legitimacy, professionalism and trustworthiness of participating CSOs and the sector as a whole (Warren, Lloyd, \& Lingan, 2009, para. 7). Through self- 
regulation CSOs' legitimacy “is operationalized into practice” (Williams \& Taylor, 2013, p. 571 citing Brown, 2008).

At its most basic, self-regulation has CSOs establishing shared "norms and standards around to whom and for what they are accountable" (Lloyd \& Casas, 2005, para. 3). Alternatively, self-regulation can be more akin to "accountability clubs.... rule-based institutions that create standards for behaviour, regulate membership, and enforce compliance among members" (Gugerty \& Prakash, 2010, p. 5). These two definitions reflect that approaches to how to self-regulate are found along a spectrum of rigour, from the more light touch "aspirational" variety such as codes of conduct or guidelines, to more rigorous ones involving accreditation or certification (Lloyd \& Casas, 2005, para. 3; Gugerty, Sidel, \& Bies, 2010, p. 1030).

The codes of conduct approach to self-regulation offers standards for CSOs to aspire to, but leaves compliance in the hands of individual CSOs. These are generally considered the weaker form of self-regulation (Gugerty, 2010, p. 1108; Sidel, 2005, pp. 823, 828; Prakash \& Gugerty, 2010, p. 23; Lloyd \& Casas, 2005, paras. 5-7). On one hand it may be relatively easy to obtain wide sector agreement, or "sectoral acceptability" on the content of standards (Sidel 2010b, p. 1044; Gugerty et al., 2010, p. 1031) given that there is no need for sector members to prove their adherence to the code. On the other hand, they send a less robust signal to outsiders about the effort (behaviour change) required to participate, given their broad applicability to the sector without much in the way of proof of adherence required (Gugerty \& Prakash, 2010, p. 20). 
The US Principles for Good Governance and Ethical Practice, developed by the Independent Sector umbrella network in consultation with the sector, offer an example of this type of self-regulation scheme. The Principles, while comprehensive, are put forward as recommendations of "sound practice that should be considered by every charitable organization as a guide for strengthening its effectiveness and accountability", while organizations "can use these principles to evaluate their current practices", and set their own path to address areas in which they fall short (Independent Sector, 2015, p. 7). In response to demand from the sector for stronger signalling, to complement the Principles, the Independent Sector developed a Code of Ethics that CSOs can sign on to, with a list of signatories posted on the Independent Sector website (Gugerty \& Prakash, 2010, p. 29).

More rigorous approaches to self-regulation involve accreditation or certification such that CSOs move "away from a passive commitment to codes of conduct and standards towards an active demonstration of their implementation" (Callamard, 2006, p. 191). Such schemes will have more rigorous standards along with monitoring and enforcement mechanisms, and some for of sanction for non-compliance. They will be better at signalling, though will likely have a narrower sectoral acceptability and reach across a diverse CSO sector (Gugerty \& Prakash, 2010, p. 20; Gugerty et al., 2010, p. 1035), potentially excluding smaller or more nascent CSOs with limited resources or capacity to reach the standards (Brody, 2006, p. 257). Enforcement challenges may arise if the self-regulating body is reluctant to expose non-compliers, fearing that differentiating the "bad apples" may "weaken the reputation of the sector as a whole" 
(Gugerty \& Prakash, 2010, p. 22). However, in the absence of monitoring and enforcement, lower performing sector members may "free-ride" on the efforts of others, rendering participation symbolic and ultimately undermining the effectiveness and credibility of the self-regulation endeavour (King \& Lenox, 2000, pp. $698 \&$ 702).

The Humanitarian Accountability Partnership International (HAP-I) offers an example that demonstrates many of the above-mentioned features of an accreditation or certification model of self-regulation. HAP-I arose out of the felt need for greater accountability among humanitarian relief CSOs following the mid-1990s Rwanda crisis. With seven detailed accountability principles at its core, HAP-I was established in 2003 as a certification scheme, with its founding CSOs "insisted" on the rigour of "monitoring and performance assessment, complaints mechanisms and compliance" (Callamard, 2006, p. 190). Ascribing CSOs developed accountability work plans against which they reported and were monitored. Recertification under HAPS-I was required every 3 years, based on a compliance verification audit and mid term monitoring, with enforcement in the form of rescinding of HAPs-I membership. Significantly, reflected in the HAP-I standards was a concern for accountability to the disaster-affected communities ascribing CSOs work with. Members were required to establish complaint referral mechanisms within their organizations, and a Standing Complaints Committee of the HAP-I Board also served as a complaints referral mechanism (Callamard, 2006, p. 193). In 2014 HAP-I and two other self-regulation initiatives in the humanitarian sector (People in Aid's Code of Good Practice and the Sphere Core Standards) harmonized their efforts into the Core 
Humanitarian Standard, operating much as HAP-I did (Core Humanitarian Standard, n.d.).

In its pure form, self-regulation is understood to be sector-driven, "without direct intervention by the state" (King \& Lenox, 2000, p. 698). Hybrid forms of self-regulation are increasingly seen however that involve co-regulation, in some form of joint stateCSO sector regulatory endeavour. These vary in the "degree of involvement and discretion" of the state and the sector, and the "degrees of interdependence" between state and self-regulation (Phillips, 2012, pp. $813 \&$ 816). Sidel (2005) points to the risk that coregulation constitutes just another form of state regulation: "we must be cautious that self-regulation supported and incentivized by government does not become, in effect, a form of government 'nationalization' of non-profit governance and management through an ostensible 'self-regulatory' process" (pp. $809 \&$ 835). However, his study of selfregulation in Asia points to how co-regulation can be critical to "establish a stronger political basis for self-regulation", in other words, state (and public) buy-in for selfregulation (Sidel, 2005, p. 835). Moreover, with co-regulation, concrete, strategic incentives can be built into the mechanism to make the rewards of adherence more enticing, thus potentially resolving the trade off between rigour and reach to expand CSO participation. Incentives can be, for example: regulatory if adherence triggers clearance or approvals of compliance with state regulation requirements; tied to joint "learning opportunities"; or they can be financial if members of the public or government funders tie funding to a CSO's adherence to the self-regulation scheme (Phillips, 2012, p. 825; Sidel, 2005, p. 803). In an example of the latter, only CSOs adhering to the self- 
regulatory Code of Conduct managed by the Australian Council for International Development can apply for ODA funds from the state (Lloyd \& Casas, 2005, para. 4).

In choosing between a less rigorous 'codes' approach and a more rigorous accreditation one, a trade-off must be made, between, in the first instance, breadth of sector acceptance and potential coverage, and in the second, signalling high standards of accountability (Gugerty \& Prakash, 2010, p. 20). In choosing co-regulation, a trade-off is made between independence, and breadth of coverage, alongside high standards of accountability, and legitimacy through state buy-in. Tremblay-Boire, Prakash and Gugerty (2016) remind us that where there is already rigour in state regulation's monitoring and sanctioning, breadth of coverage rather than similar rigour and "signalling strength" may be the preferable self-regulation option (pp. 712, $715 \& 720$ ).

\section{What do CSOs Self-regulate?}

Self-regulation can seek to regulate CSO policy and practice in relation to mandate, activities and finances much as state regulation does. Its coverage will depend in part on the degree of comprehensiveness of state regulation's coverage. Self-regulation may seek to reinforce $\mathrm{CSO}$ policy and practice to meet state regulatory requirements - picking and choosing aspects of state regulation, perhaps going into greater depth and detail. Or, selfregulation schemes may target a broader range of CSO policy and practice than state regulation does.

Due to its voluntary nature versus the universal coverage of state regulation, it is in self-regulation that sensitivity to diversity in the sector, and to CSOs' multiple accountabilities, is especially seen. Self-regulation can also appropriately cover areas of 
CSO policy and practice in which discretion and protection of their independence is paramount, such as their values, self-governance, or their relationships with beneficiaries.

What self-regulation seeks to regulate varies considerably across mechanisms, including possibly:

i. Areas of day-to-day management or "operative accountability" (Williams \& Taylor, 2013, p. 570)

ii. Financing, including fund-raising

iii. High level values and principles

iv. Relationships with constituencies and beneficiaries

Self-regulation of CSOs' operative accountability looks into CSOs' "internal governance, administration and financial management" (Lloyd \& Casas, 2005, para. 13). This is a common arena of self-regulation which can include, for example, adherence to mission, governance by voluntary boards, human resource (staff and volunteer) management, fund-raising practices, monitoring, evaluation and reporting systems, quality and results of programming, amongst others. Self-regulation sometimes seeks to comprehensively cover all possible operative policies and practices, or, it can focus on one or a few. In an example of the former, a comprehensive list of thirty-three "principles of sound practice are found in the above-mentioned US Principles for Good Governance and Ethical Practice (Independent Sector, 2015, p. 7). The principles are organized into four categories of: legal compliance and disclosure; effective governance; strong financial oversight; and responsible fundraising (Independent Sector, 2015). In an example of the latter, self-regulation specifically of CSOs' fund-raising was established in the United Kingdom (UK) in 2006 with a voluntary code of conduct overseen by a 
Fundraising Standards Body, though this self-regulation was more recently transformed into a co-regulation scheme (Driscoll, 2017, p. 43).

Self-regulation can cover high-level values or principles that members of the sector are meant to adhere to such as human rights or non-discrimination, transparency, and of course accountability (Hammad \& Morton, 2011, p. 12). Mechanisms to regulate such values tend to be of the aspirational variety. They may come with guidance as to the kind of policies and practices that would reflect the values, but self-regulation is left to individual CSOs rather than requiring monitoring and enforcement. The ten Istanbul Principles for CSO Development Effectiveness offer an example of this type of valuesbased self-regulation, cover: human rights and social justice, gender equality, and environmental sustainability, amongst others (Open Forum for CSO Development Effectiveness, 2010). Rather than an accountability mechanism per se, these Principles are primarily intended to stimulate reflection and build CSOs' understanding of values that must be upheld to be considered an effective CSO (Hammad \& Morton, 2011, p. 18).

Both self-regulation of internal governance and management, or of values and principles, may include coverage of CSOs' relationships with their constituencies or beneficiaries, often referred to as 'downward' accountability. Accountability to constituencies and beneficiaries is an important aspect of CSOs' legitimacy and can enhance their responsiveness to constituents and beneficiaries real needs and priorities (Burger \& Seabe, 2014, p. 80). The above-referenced Istanbul Principles include one on pursuing "equitable partnerships and solidarity", with references to relationships involving "organizational autonomy, long-term accompaniment, solidarity" (Principle 6). 
The US Independent Sector's Principles cover downward accountability only with reference to the need for whistle-blowing policies. CSOs' self-regulation has been criticized however for a lack of emphasis on this kind of downward accountability provision (Lloyd \& Casas, 2005, paras. 15-18; Hammad \& Morton, 2011, pp. 15-16). Responsiveness to constituents/beneficiaries often receives a notional or vague reference, perhaps as they are the least powerful and influential among CSOs' multiple accountability targets (Lloyd \& Casas, 2005, paras. 14, 16-18; Hammad \& Morton, 2011). The power imbalance challenges self-regulation of this policy and practice area also as constituents/beneficiaries may be reluctant to raise gaps in downward accountability for fear of losing access to CSO services (Hammad \& Morton, 2011, p. 17).

\section{How do State and Self-regulation Differ?}

While states and CSOs share a broad interest in the rationale of regulation for accountability, or even for building trust and confidence in the sector, significant differences remain in the rationales for, targets and means for regulation and selfregulation (the why, what and how) that will come to bare on their respective relevance and interaction. While, as noted, the approach and coverage of either state or selfregulation varies across countries, some generalizations can be made.

First, state and self-regulation can overlap in key regulatory target areas of mandate/purpose, activities and finances as described above. Beyond that, the targets of self-regulation tend to be both broader and deeper than state regulation, though there are some blurred boundaries where states step into the details of CSO practice. We have seen 
that the "what" of self-regulation ranges from values and principles, to day-to-day operational/administrative and/or organizational governance issues. State regulation, which comes with prescriptive rules to ensure consistency of their universal application, is not an appropriate nor sufficient means of regulating such a broad and deep range of organizational and operational targets in a sector as diverse as civil society. The "more complex objectives, lack of uniform means of achieving them and higher costs" (Phillips, 2012 , p. 814) that come with monitoring such a range of organizational and operational targets are not well suited to state regulation. Whereas, where CSO attributes and behaviours are particularly vulnerable to loss of public trust - say financial mismanagement or fraud - state regulation is a more appropriate mechanism of accountability.

Second, self-regulation tends to be voluntary and therefore does not have the universal coverage nor coercive power of state regulation. As regards coverage, selfregulation may be national or international in scope, or may cover a sub-set of CSO types (e.g. international CSOs under the International NGO Accountability Charter) ${ }^{23}$ or of CSOs operating in particular thematic area (e.g. international development CSOs under the Canadian Council for International Cooperation's (CCIC) 2009 Code of Ethics and Operational Standards. As a result, multiple self-regulation initiatives may simultaneously exist, and compete, in one country (Sidel, 2010c, p. 1052).

${ }^{23}$ Established in 2008, the Charter now goes under the name Accountable Now (Accountable Now, n.d.). 
As regards coercive power, as noted, exceptions exist where self-regulation is actually co-regulation, with adherence a requirement to access some form of state benefit or "license to operate" (Phillips, 2012, p. 814). Otherwise, self-regulation targets CSO principles, practice and behaviour to send a "signal [to donors, members and clients] that [CSOs] uphold certain values and pledge to behave in certain ways" (Bloodgood, 2013, p. 14), and as such serves as a "hallmark of quality" (Phillips, 2012, p. 814). Further, its success in so doing in some respects relies on a strong commitment to accountability in the first pace. As noted by Etherington (2017) commenting on CSO self-regulation in the UK, it "can only be successful if those it is intended to regulate want it to be"; there can be no "disconnect between the ethos and values of [CSOs] and their... practices" (p. 71).

Third, for CSOs, self-regulation can be seen as means to protect their fundamental rights to freedom of association and expression, amongst others. Self-regulation is attractive as it comes with a degree of discretion that state regulation does not offer (Coglianese \& Mendelson, 2010, p. 151). There is a school of thought that any state regulation is an "intrusion[s] on freedom of association" that is only justifiable where there is a legitimate government or public, interest (Amstrong, 2006, p. 70), though what makes for 'legitimate' interest is too often too open to interpretation. Naidoo (2004) calls on CSOs to pay heed to the rising demands for CSO accountability by stepping up selfregulation and other accountability measures, but to do so while continuing to "defend the rights of citizens and their organisations to participate actively in public life [as they] have fought long and hard to create the space to practise active citizenship" (p. 24). Smith (2011) maintains that US CSOs need to up their commitment to self-regulation "if we 
hope to maintain our eroding freedom of association in an era of terrorism" (p. xvi). Thus, for CSOs, self-regulation is not just about the pursuit of accountability but also about asserting their legitimacy, their right to exist and operate with the discretion accorded to them by the international human rights legal framework.

Fourth, while self-regulation offers a mechanism by which CSOs pursue accountability collectively, it is additional to and does not substitute for CSOs' implementation of individual accountability mechanisms such as for example meeting program monitoring, evaluation and reporting requirements that usually accompany donations from non-individual sources (e.g. from governments, foundations, corporations), or implementing participatory processes of constituency and beneficiary engagement including social auditing (Ebrahim, 2003). Instead, self-regulation can demonstrate that systems are in place to address these various accountabilities. When the prescriptive requirements of state regulation are combined with self-regulation requirements and CSOs' individual accountability pursuits, the accountability landscape can become quite muddy and demanding. In the absence of joint efforts, or the possibility, given different aims, to harmonize and streamline the accountability requirements to CSOs' varied stakeholders (Sidel, 2010b, p. 1053), CSOs are pulled in varied directions to meet multiple and sometimes competing accountability pressures.

These differences between state and self-regulation suggest the need to further investigate the notion of a trade-off between the two, where one acts as a proxy or alternative to the other. One way to do so is by probing the array of factors that are said to drive the emergence or reform of regulation and self-regulation, i.e. of regulatory change. 
This chapter proceeds to present such driving factors gleaned from the growing body of literature on CSO regulation and self-regulation. It then outlines generalized characteristics of LMI countries to enrich our understanding of what these factors might look like in such countries and how regulation and self-regulation might also interact there.

\subsection{Drivers of Regulatory Change - A Conceptual Framework}

Underneath the purported interplay between regulation and self-regulation, a series of factors that spur states and/or CSOs to step up, or down, their regulation and/or selfregulation initiatives can be gleaned from the literature. A conceptual framework of the driving factors, or simply drivers, of regulatory change is presented here, with the organizing concepts illustrated through country examples. The framework is intended as both a contribution to theory development, and as an analytical device of convenience recognizing that "life is not so easily compartmentalized in practice" (Turner \& Hulme, 1997, p. 25). Given this research's interest in understanding regulatory change drivers in LMI countries in particular, a selection of generalized LMI country characteristics is also presented as these characteristics affect how the drivers of regulatory change are manifest in LMI country contexts. The conceptual framework is depicted in Figure 1 below. The framework is then applied to the Kenya case in subsequent chapters.

To an extent each of these drivers can be categorized by source, that is, by the type of actor from which the driving factor emanates - from the CSO sector, from the state, or from external sources - and they are organized as such below. Most of the drivers can bring about changes in either state or self-regulation unless indicated otherwise. 
Figure 1: Conceptual Framework - Drivers of Regulatory Change

\section{Regulatory Change Drivers and their Sources}

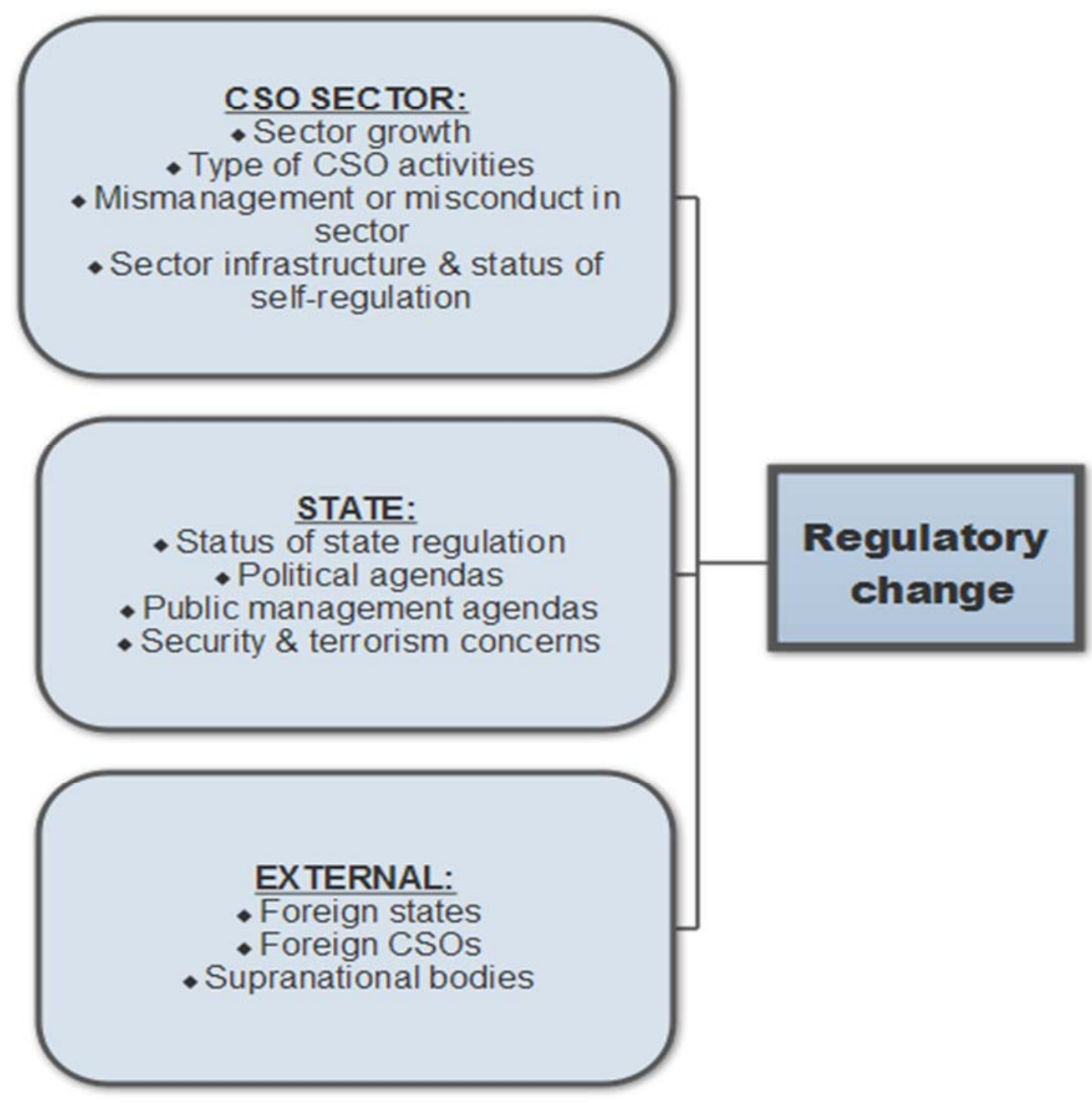




\subsubsection{CSO sector sources}

Characteristics of or activities within the CSO sector can provide a source of regulatory change. There are four regulatory change drivers emanating from the CSO sector: sector growth, the type of CSO activities, CSO mismanagement or misconduct in the sector, and sector infrastructure, inclusive of the status of self-regulation implemented by that infrastructure.

\section{Sector Growth}

Growth in CSO numbers can drive the state and/or the sector to turn to regulation or self-regulation. With growth the sector becomes a more visible part of a countries' institutional landscape and the opportunities and challenges associated with it also become more visible and ripe for regulation. What is considered the earliest CSO regulation, England's 1601 Statute of Charitable Uses arose due to a vastly growing secular charitable sector and the government's felt need to better track and ensure the appropriate (charitable) use of private donations going to it (Robbins, 2006, pp. 24-25).

In more recent examples, a sense of lack of understanding and oversight of a rapidly growing sector is noted by Gugerty (2010) and Sidel (2010b) as having contributed to the rise of both state and regulation and self-regulation in Africa and Asia since the 1990s. The above-mentioned case of HAP-I and associated self-regulation initiatives in the humanitarian CSO sector was driven in part by the massive influx of CSOs responding to crises in Rwanda, Haiti, Pakistan, and to the 2004 Asian tsunami (Callamard, 2006, p. 183).

These are just some examples of how the sector's growth and regulatory change can go hand in hand. 


\section{Type of CSO Activities}

The type of activities CSOs engage in is another source of regulatory change. Typically CSO activities fall along a spectrum between social and economic development service delivery to "civic and political engagement", that is public policy engagement and influencing activities (Frumkin 2002, pp. 165). CSO activities on both ends of the spectrum can provide impetus for regulatory change, though the latter is more fraught.

Regulation provides a tool for governments to ensure that CSOs' service providing activities meet the public benefit test. It can also be turned to as a tool to foster CSOs' service-oriented activities, and relatedly to help government identify potential partners to implement social and economic development programs and policies. In Hungary for example, one (certainly not the only) driver behind state regulatory change was the economic crisis of the early post-Communist era in which CSOs were stepping in to fill gaps in services once provided by the state (Kuti, 2011, pp. 150-151). In numerous HI countries, the trend influenced especially by NPM (discussed further below), of "quasimarketization" of social service provision through CSOs and other non-state actors also drove (and was driven by) changes in states' regulation of the sector (Bode, 2011, p. 116).

Frumkin (2002) draws attention to the fact that CSOs' civic and political engagement can give rise to the perception that CSOs are acting in a partisan or otherwise overly selfinterested manner rather than acting for the public benefit for which they are granted tax and other privileges (pp. 165-167). Such activism can also fuel state discontent or suspicion of the sector and a subsequent regulatory response (Jordan \& van Tuijl, 2006, 
pp. 6-7; Gugerty et al., 2010, p. 1029). While regulation denying CSOs the possibility of engaging in partisan political activities is commonly seen in HI countries, from there, where the boundary is drawn between CSOs' civic and political engagement and other types of activities differs between jurisdictions and can be a moving target. Country cases demonstrate the variance across jurisdictions. Under the US tax code, 501(c)(3) public charities can engage in non-partisan civic and political activities with limits imposed on the amount of time and resources so dedicated (Frumkin, 2002, p. 56). Yet another category of CSOs in the US, referred to as 501(c)(4)s or social welfare organizations, also enjoys some tax privileges (though less than the 501(c)(3)s), and these CSOs allowed to engage substantially in civic and political activities (Frumkin, 2002, pp. 54-56). ${ }^{24}$ A 2010 US Supreme Court decision (Citizens United v. Federal Election Commission) increased the limit on 501(c)(4) political activities, giving greater allowance for partisan political activities (Boris \& Lott, 2017, p. 110; McGregor-Lowndes \& Wyatt, 2017a, p. 282). The UK relies on common law precedent inclusive of the afore-mentioned Bowman case and subsequent cases, complemented in 2008 by Guidance on Campaigning and Political Activities by Charities prohibiting partisan political activities but allowing "political activity to secure or oppose a change in the law or central or local government policy or decisions" (Morris, 2016, p. 110).

${ }^{24}$ There are numerous categories of organizations in the US that could be considered as CSOs, with varying tax privileges, regulatory oversight, and allowance to engage in civic and political activities of a non-partisan or partisan nature, the latter including the controversial political action committees (Boris \& Lott, 2017, p 100). 
The "sector-politics charity boundary" between what constitutes "political activity" tends to be a sight of regulatory hand wringing in many and varied jurisdictions, the "running sore" of many a regulatory regime (McGregor-Lowndes \& Wyatt 2017a, p. 283 \& 2017b, p. 9). Even where a "hard metric" provides clear parameters on CSOs' political activities (McGregor-Lowndes \& Wyatt 2017a, p. 280), the range of CSO activism when faced with an equal range of government tolerance for it means CSOs' civic and political engagement is a frequent driver of regulatory change, subject also to states' Political Agendas as discussed below.

As one example, long-standing debate on the subject and dissatisfaction with where the boundary lay led to recent regulatory reform in Australia that extended the definition of acceptable CSO civic and political activities to all policy engagement that is nonpartisan (McGregor-Lowndes \& Wyatt, 2017a, p. 281). In another example, Canada's regulatory reform in the guise of the 2001 Accord between the Government of Canada and the Voluntary Sector gave rise to a Code of Good Practice on Policy Dialogue (Voluntary Sector Initiative, 2002). That the Code was one of the first outputs of the Accord was testament to the importance for both the government and the sector of protecting and enhancing the space for CSO civic and political engagement. On the other hand, a 2013-2014 study covering twelve LMI countries noted that the "blurred line between political activism and the social justice work of many NGOs creates tensions with state authorities", tensions that were shown to spur state regulatory change in countries covered by the study (Hayman et al., 2014, p. 3). Also, when CSOs recognize that their presence and influence as civic and politically engaged organizations puts them 
under scrutiny and comes with "increased responsibilities and public accountabilities", this can lead to a self-regulatory response (Naidoo, 2004, p. 16).

The range of CSO activities along the spectrum from service delivery to civic and political engagement therefore are known to drive regulatory change, with the latter activity area being especially subject to regulatory debate.

\section{Mismanagement or Misconduct in the sector}

Often, issues of mismanagement or misconduct in the CSO sector will provide impetus for regulatory change. The concepts of mismanagement and misconduct cover a broad range of potential CSO challenges. These can include, for example "exaggerated claims of performance" (Ebrahim 2003, p. 820); what Naidoo (2004) has called "fragility in NGO practice", that is, financial mismanagement or fraud (p. 18); "self-dealing" such as in the form of over-paid executives or personal use of CSO assets (Sidel, 2005, pp. 804-805); and various other governance and management issues (Gibelman \& Gelman, 2004). Some authors include in the mismanagement, or even "corruption" category the "deviation from mission" that occurs as CSOs pursue (or accept) funding for projects not in keeping with their missions or expertise, or local priorities (Edwards \& Hulme, 1996, p

4; Hellinger, Hellinger, \& O'Regan, 1988, pp. 107-108). Even when CSO management and conduct issues may arise from a few 'bad apples,' or 'rogue' CSOs, regulatory responses can ensue.

State or self-regulation are especially spurred on if some kind of scandal or disaster arises and puts CSO management issues in the limelight, thus undermining public trust in the sector. This is not exclusive to the CSO sector. The broader regulation literature notes 
the tendency for an industry disaster, such as seen with the environmental catastrophes in the chemical and nuclear industries in the US in the 1970 s and 80 s, to spur these industries' self-regulation (Coglianese \& Mendelson, 2010, p. 160). The US CSO sector experience in the early 2000s provides an example wherein a few high profile cases of misconduct in well-known CSOs triggered both a tightening of regulation by the state and by the sector. Prompted by an invitation from the US Senate Finance Committee, an invitation accompanied by the threat of tighter state regulation, CSOs were triggered to initiate a self-regulation effort under the umbrella of the Independent Sector CSO apex body (Smith, 2011, pp. xiii-xiv).

In another example, in the UK, the CSO umbrella National Council for Voluntary Organisations (NCVO) responded in 2013 to media-fuelled public, and to some degree the state regulator's outcry at high levels of Chief Executive pay in the CSO sector. Though the issue "revealed once again a mismatch between the public's perceptions of charities" as purely voluntary, do-good organizations rather than the reality of the sector's diverse make up inclusive of professional and technical organizations, NCVO implemented an independent inquiry into the issue; developed guidance for boards on establishing pay levels; and implemented a transparency requirement for CSOs of a certain size (Etherington, 2017, pp. 67-69). The more recently revealed case of sexual exploitation by OXFAM-UK aid workers spurred a multi-pronged state regulatory response, with the UK's Department for International Development reviewing CSO partners' "safeguarding" mechanisms beginning in 2018, and talk of establishing a global registry of aid workers (Dearden, 2018, paras. 7-8). The OXFAM case also prompted 
CSOs in various jurisdictions to better address safeguarding in their self-regulatory initiatives. As one example, the US coalition of international development CSOs, InterAction, established a CEO Pledge on Preventing Sexual Abuse, Exploitation and Harassment by and of NGO Staff that, amongst other things, commits members to develop (or review) appropriate policies and confidential reporting mechanisms (InterAction, 2018).

Mismanagement or misconduct in the CSO sector, widespread or narrow, real or perceived, is thus a driver of regulatory change.

\section{Sector Infrastructure and Status of Self-regulation}

The existence and strength of the CSO sector's infrastructure in the form of a national umbrella membership body (an 'apex' or 'peak' body) is also known to be a driving source behind self-regulation in particular, but also potentially state regulation. A strong apex body can provide convening power and resources to generate and implement a selfregulation scheme, such as the above-cited example of the UK NCVO's Chief Executive pay initiative. In Canada, the growing strength of the apex body Imagine Canada contributed to its move from a codes of conduct self-regulation approach to a comprehensive, "world-class" certification scheme (McGregor-Lowndes \& Wyatt, 2017a, p. 264; Phillips, 2012, pp. 811 \& 822). A study covering six sub-Saharan African countries found that the pre-existence of such CSO infrastructure gave impetus to the emergence of self-regulation (Gugerty, 2014, p. 10). A lack of or weak CSO infrastructure has also been shown to impede self-regulation initiatives in countries ranging from Ireland (pre-2000) to China to Mexico (Dunn et al., 2017, p. 235). In each 
case, self-regulation arose to fill a gap either due to its absence or to weaknesses in existing self-regulation schemes. In some, such as the NCVO Chief Executive pay initiative and the sub-Saharan African cases, changes in self-regulation came about not because, or solely because of self-assessed felt need in the sector, but due to an actual or perceived threat of restrictive state regulation - which is discussed further below under Status of State Regulation.

A strong apex body can also play a role in influencing, if not driving, state regulatory change via evidence-based proposals and advocacy. Apex bodies existed in Australia in the 1980s and 1990s, but these were subsector-specific and thus not geared to address issues common to the whole sector, nor were they active in regulatory matters (Stephens, 2017, pp. 234-235). In 2004, faced with the risk of restrictive state regulatory change, the Australian CSO sector established a National Roundtable of Non-profit Organizations to, however, its impact was mitigated due to challenges of inclusively and capacity gaps (Stephens, 2017, pp. 238-239). In 2011 a new, more robust and inclusive body, the Community Council for Australia was established to represent and advocate for the sector (Stephens, 2017, pp. 245-246). It did so successfully in support of a 2013 Charities Act; the creation of the ACNC; and later to thwart a (new) government's regulatory reform efforts to dissolve the ACNC (Stephens, 2017, pp. 246, 248 \& 250-251). As another example, despite the noted positive developments as regards the main Canadian apex body, Imagine Canada, the question has been raised as to whether it would be able to take advantage of the (then) incoming government's seeming openness to policy dialogue to put forward sound proposals and press for long-overdue regulatory reform given its 
precarious funding and fairly narrow membership relative to the sector's size (Wyatt, 2016, pp. 153-154).

Both of these country examples also point to the fact that the inherent diversity in CSO sectors in terms of organizational size, purpose, strategy, location, can plague the sector's ability to establish and sustain an apex body whether for self-regulation or to influence state regulation.

Finally as regards the status of self-regulation, there is some evidence that a sound self-regulation scheme can have an impact on state regulation. In England, CSOs were tasked by the state to self-regulate fund-raising with the state intending to step in with regulation only if self-regulation were to fail (Dunn et al., 2017, p. 226). The Australian Council for International Development's self-regulation ended up serving as a state-

endorsed substitute for state regulation (Dunn et al., 2017, p. 227). However, the existence or effectiveness (i.e. the status) of self-regulation appears to drive stateregulatory change far less than the reverse, that the status of state regulation drives changes in self-regulation as is discussed below.

\subsubsection{State sources}

There are also four drivers of change in state and/or self-regulation that emanate from states: the status of state regulation, political agendas, public management agendas, and security and terrorism concerns.

\section{Status of State Regulation}

The status of state regulation of CSOs is a driver of regulatory change that though obvious, is worthy of inclusion in this conceptual framework. Status issues can include 
the non-existence of, gaps or weaknesses in state regulation. Weakness can manifest itself if regulation is found to be unable to address one of the other drivers, such as rapid expansion of CSO numbers, or occurrences of mismanagement in the CSO sector.

New Zealand provides a case of minimal charity regulation providing a significant driver of regulatory change. What regulation there was existed under the Internal Revenue Department, with CSOs self-assessing to qualify for tax privileges, no registration requirement, minimal reporting requirements, and no monitoring by the regulator (Barker, 2017, pp. 184-185). Information on the sector was thus scanty, while concerns grew across the sector and in government about the possibility that CSOs were, knowingly or unknowingly, breaching the regulations for example through fraud or tax evasion (Barker, 2017, p. 186). A Charities Act (2005) was thus introduced that would establish a Charities Commission to administer registration, monitoring and reporting of charities, thus tightening the regulatory framework for CSOs with the related intent of building trust in the sector that would amongst other things foster charitable giving (Barker, 2017, p. 186).

Alternatively, it may also be the case that state regulation exists and is not necessarily flawed in its design, but its implementation is lacking. This was exemplified in the case of Mexico where state regulation underwent reform to address gaps in relation to tax provisions and philanthropic flows. Subsequently in response to "government ineptitude" in implementation of the reformed state regulation, CSOs established a self-regulatory Funds in Plain Sight initiative, hoping to fill the state's implementation gap (Dunn et al., 2017, p. 223). 
Self-regulation has arisen elsewhere, driven by weaknesses or gaps in state regulation. Bies (2010) points to the emergence of self-regulation in four Western European countries (Germany, the Netherlands, Switzerland and Austria) to supplement state regulation by providing information and/or accreditation mechanisms to help private donors distinguish “'bona fide' and deserving" CSOs, and assure protection of donors' contributions (pp. $1070 \&$ 1073). An alternate commonly occurring scenario is when the CSO sector turns to self-regulation in response to an actual or perceived threat of pending state regulation, with the intent of shaping state regulation, or staving off restrictive regulation (Prakash \& Gugerty, 2010, p. 24; Dunn et al., 2017, p. 223; Bies, 2010, p. 1069), an experience seen in various LMI countries such as Kenya, India, Cambodia, Uganda, and the Philippines (Gugerty et al. 2010, p. 1028; Sidel 2010c; Burger 2012, p. 89; Ebrahim 2003; pp. 820-821). Sometimes self-regulation emerges in response to already existing restrictive state regulation as seen in China and Vietnam (Dunn et al., 2017, p. 223). Noteworthy also is the experience of highly restrictive or extensive state regulation having a "crowd out" affect on self-regulation as evidence from some countries such as Israel, China and some in sub-Saharan Africa points to (Dunn et al., 2017, pp. 223-224).

Through these examples we see that the status of state regulation can provide impetus for changes in state or self-regulation.

\section{Political Agendas}

States' political agendas, sometimes overt, sometimes masked, drive changes in state regulation in particular. Other of the factors driving regulatory change are sometimes 
categorized as political agendas in a sense. Some would, for instance, label the NPM public management agenda discussed below as having a political aspect in that it is linked to agendas of smaller government as promoted by the more conservative side of partisan politics. NPM came in on a wider political, and economic, agenda steeped in the "supremacy of markets and of private sector-based transactions" over public sector involvement (Breen et al., 2017a, pp. 14-15; Reichard, 2010, p. 1030; Dunn et al., 2017, p. 236). Relatedly, politically motivated reform agendas can follow partisan political cycles. Changes back and forth between more liberal and more conservative governments have brought reform, or at least attempts to reform state regulation and self-regulation of the sector in, for example, Australia, New Zealand, England and Wales, with more liberal governments supportive of, for example, independent charity commissions and more conservative ones wishing to do away with or rein in these supposedly costly regulators amongst other reductions in state interventions (McGregor-Lowndes \& Wyatt 2017a, pp. 266-267; Breen et al., 2017a, p. 15). In the US, Congressional partisan political pressures to reduce the Internal Revenue Service's resources dedicated to charity oversight have influenced the implementation of regulation (and lack of regulatory change) there (Owens, 2017, p. 90; Boris \& Lott, 2017, p. 101). The late 2017 Tax Cuts and Jobs Act, deemed highly partisan, contained provisions that were anticipated to reduce the incentive for individual charitable giving (Gleckman, 2018, para. 3; Rogers, 2018, para. $6)$.

In another vein, sometimes a state's regulatory response is seen as 'playing politics' when a regulatory change is initiated in response to real or possibly manufactured public 
pressure to address an equally real or inflated issue of CSO mismanagement or misconduct. For example, media-fuelled public outcry over CSOs' fundraising practices in the UK led the state to step in with regulatory measures aimed at bolstering CSOs' self-regulation of fundraising (Etherington, 2017, pp. 69-72). While the sector's fundraising practice challenges were real, the state's response was somewhat a political show of responding to public outcry.

The issue of a regulator's "independence from political direction" has been of concern in a number of $\mathrm{HI}$ countries of late; regulators need to be and to be perceived as being "governed by the rule of law not by the rule of the figure in power" (McGregorLowndes \& Wyatt, 2017a, p. 283). Where responsibility for the sector's regulation lies with the tax authority, as in Canada and the US, there is a perception of reduced independence of decision-making related to tax privileges for charities, and to the associated charity-politics boundary, "in favour of the fisc" and therefore of conservative political agendas (McGregor-Lowndes \& Wyatt, 2017a, p. 283). Phillips and Smith (2016) also speak to the "the incursion of domestic partisan politics" straining the government-CSO relationship in the UK, the US, and Canada (p. 224), with regulatory reform ensuing.

Political agendas can of course become manifest when political antagonisms arise between the state and CSOs due to the latter's civic and political engagement activities. This was the case under the most recent Conservative government reign in Canada whereby, in 2012, the government launched a new "political activities audit project" and associated reforms in political activities reporting (Wyatt, 2016, p. 149). Accusatory 
statements from government officials made it clear that these initiatives were driven by the state's displeasure with CSOs, especially but not exclusively environmental CSOs actively opposing fossil fuel pipeline developments, the latter a favoured project of the government (Wyatt, 2016, pp. 148-149; Phillips \& Smith, 2016, p. 223). As audits were launched, concerns were soon expressed that the selection of CSOs to be audited was based on "direction from politicians" (Wyatt, 2016, p. 149). The state in this case attempted to disguise their political motivations by manufacturing concern over the fact that CSOs were in receipt of foreign funding, despite that such funding, minimal in volume, was not a new phenomenon and was allowable under state regulation (Wyatt, 2016, p. 149).

Beyond such cases where specific CSO civic and political activity areas raise the ire of a particular government in power, a state may be motivated to regulate the CSO sector because it is more generally opposed to civic and political activism on the part of CSOs such as when CSOs engage in "monitoring, commenting on otherwise attempting to influence the market, political processes or the government and its authorities" (Jordan \& van Tuijl, 2006, p. 6).

These cases point to the fact that the political agendas driver of regulatory reform can involve - but is more complex than - the "political muddle" (McGregor-Lowndes \& Wyatt, 2017a, p. 279) of the moving and often blurry boundary between CSOs' civic and political engagement activities and the public benefit imperative. Political agendas can be more or less overt, partisan or not, and can drive changes especially in state regulation. 


\section{Public Management Agendas}

Regulatory change is often driven by trends in public management paradigms. A public management paradigm may itself be driven by certain pressures, such as fiscal austerity, but the prevailing paradigm is what pushes (or pulls) changes in regulation or self-regulation.

NPM for example was the dominant paradigm emerging in the late 1970s and carrying through to today, though its manifestations changed over time. It grew out of a felt need to shrink the post-World-War II welfare state which had become both a fiscal burden and a bureaucratic, administrative burden on citizens, businesses, and the state itself (Reichard, 2010, p. 1031). Though a "loose term", NPM saw states seeking to roll back their role, implement market-based solutions, automate transactions, orientation toward clients ("customers", or "citizens") amongst other NPM-type reforms (Hood, 1991; Reichard, 2010, p. 1031). There was widespread adoption of the NPM model across HI nations, though the degree of uptake varied across countries (Hood, 1991, pp. 3-4; Hood, 1995; Pollitt, 2010, pp. 7-8). Over time, NPM "re-balancing" saw a move toward a middle ground acknowledgement of the important roles of both free markets and of the state, and other actors (Pollitt, 2010, p. 3; Turner \& Hulme, 1997, p. 138). Yet another public management model emerged, that of "governance" or "relational governance" (Osborne, 2010; Phillips \& Smith, 2011, p. 2). With greater emphasis on interdependence, collaboration, partnerships and network relationships across states, the private sector, and CSOs, this model arose in part to counter some of the deficiencies of NPM and new challenges that it created (or exacerbated) such as by addressing fragmentation of service provision; reducing the "NPM bureaucracy" and "red tape" that 
arose to administer, oversee and monitor complex delivery systems (Reichard, 2010, p. 1033); fostering innovation, and accountability including through greater citizen engagement (Phillips \& Smith, 2011, p. 3).

Regulatory changes that come about due to particular public management agendas can be ones that directly target CSOs, or CSOs can also be affected by the ways in which a public management paradigm influences broader regimes that CSOs interact with. As regards the latter, NPM shifted some of the state's traditional responsibilities in social and economic service delivery to CSOs and other actors, often through contracts with stringent performance measurement and reporting requirements that put CSOs under new pressures (Reichard, 2010, p. 1032). In the UK for example, NPM's approach of contracting traditional state service provision to CSOs led to a tightening of the states' regulation of the sector in ways designed to ensure such contracting was to "reliable and functioning nonprofits" (Breen et al., 2017a, p. 15). This public management approach co-existed with the government's steps towards a relational governance approach that led to establishment of the Compact on Relations between Governance and the Voluntary and Community Sector comprised of a shared vision and principles, and leading to five codes of practice to guide the state and CSOs in their relationship (Morris, 2011, pp. 47, 53-54). In Australia with the aim of administrative simplification and reducing the (NPM-induced) regulatory burden both on the government and on the CSO sector, the ACNC implemented a Charity Passport, a database of key data on CSOs accessible to all departments and levels of government to ease administrative interactions with CSOs (Pascoe, 2017, pp. 224-225; Phillips \& Smith, 2016, p. 224). 
States are influenced in their reform approaches by the public management paradigm of the day. More specific drivers will be part of the language and modus operandi of that paradigm - fiscal efficiency, reducing red tape, client responsiveness and the like, but the over-arching driving force is the prevailing public management agenda. Public management agendas primarily drive state regulatory change but are also seen in relation to self-regulation.

\section{Security and Terrorism Concerns}

Security and terrorism concerns have spawned regulatory moves in many countries worldwide especially since the terror attacks of September 2001 in the US. Typically security issues would have been addressed by regulation distinct from CSO regulation, but increasingly post-9/11, regulatory change driven by security and anti-terror concerns affects CSO-specific regulation as well as more-broad based regulation to which CSOs are also subject (Bloodgood \& Tremblay-Boire, 2011). The impetus is based on fears that terrorists are "using or duping" CSOs to channel resources to terrorist activities (McGregor-Lowndes \& Wyatt, 2017a, p. 276), with regulatory change often focused on non-domestic funding flows to CSOs and/or on non-domestic CSOs including domestic CSOs' overseas affiliates (other CSOs, communities, staff).

Regulation of CSOs has been affected by the requirements of the Financial Action Task Force (FATF). FATF is a multilateral body comprised of (currently) 180 states, established in 1989 to ensure ascribing states comply with its standards designed to combat money laundering and terrorism financing (Financial Action Task Force [FATF], 
n.d., para. 1). ${ }^{25}$ In 2001 the terror financing risk was added to FATF's mandate. A series of Special Recommendations on Terrorist Financing were published in 2003, then revised and the FATF's guidance updated and elaborated leading in 2012 to a set of International Standards on Combating Money Laundering and the Financing of Terrorism and Proliferation (FATF, 2012). Among the Special Recommendations was one specifically targeting CSOs as potential conduits for terror financing. Recommendation 8 reads, in short: ${ }^{26}$

Countries should review the adequacy of laws and regulations that relate to entities that can be abused for the financing of terrorism. Non-profit organisations are particularly vulnerable, and countries should ensure that they cannot be misused. (FATF, 2012, p. 13)

In a number of countries FATF pressures have contributed to regulatory change that, again though not necessarily CSO-specific, still affected CSOs, often in relation to nondomestic CSOs, to CSOs external funding, as well as to CSOs' overseas affiliates as noted above (Rutzen, 2011, p. 271; Hayes, 2012, pp. 30-35). Sidel (2010b) documents how FATF requirements drove regulatory change that affected CSOs in India, members of the European Union (EU), and to a degree Canada (pp. 80, 92 \& 57). In New Zealand and Australia, changes to state regulation of the sector had various rationales and had been under consideration for some years prior to 9/11 (Barker, 2017, p. 187; Stephens, 2017). Terrorism was thus not a primary driver of state regulatory change but cited as a

${ }^{25}$ FATF is thus an external source of regulatory change, however, given its specificity to security and terror it is included in this category of the drivers of regulatory change framework.

26 The FATF recommendations were re-numbered in 2012 such that Special Recommendation VIII on non-profit organizations became Recommendation 8. 
"corollary reason" for such change including establishment of charity commissions and charity registries in line with FATF requirements (McGregor-Lowndes \& Wyatt 2017a, pp. $276 \& 266)$.

Examples of terror concerns, FATF-inspired or otherwise, being behind regulatory change are found in countries ranging from Germany to Japan to Zimbabwe amongst many others (Sidel, 2006, p. 203; Bloodgood \& Tremblay-Boire, 2011; McGregorLowndes \& Wyatt, 2017a, p. 276; Sidel, 2010b). In Canada, the passing in 2001 of the Anti-terrorism Act also created the Charities Registration (Securities Information) Act through which a security certificate can be issued against a CSO suspected of financing or engaging in terrorism, thus (at minimum) denying it registration (Bloodgood \& Tremblay-Boire, 2011, p. 158). In another example, anti-terror regulation dating back to the 1993 World Trade Centre bombing was supplemented following 9/11 by two new 2001 legislations in particular - Executive Order 13224 and the Patriot Act - that were not CSO-specific but applicable to CSOs (Sidel, 2010b, p. 15). A CSO-specific state regulatory initiative was seen with the 2002 US Treasury publication of Anti-Terrorist Financing Guidelines: Voluntary Best Practices for US-Based Charities, to which CSOs responded with their own self-regulatory Principles of International Charity (Bloodgood \& Tremblay-Boire, 2011, pp. 151-152; Sidel, 2010b, p. 18). At the level of the EU, a regulatory change effort was instigated following the 2004 and 2005 terrorist attacks in Madrid and London, leading to the European Commission's Recommendation and Framework for a Code of Conduct followed by a set of five guiding principles (Sidel, 2010b, pp. 93-94 \& 96 citing Vellenga, 2008). The Recommendation, which called for a 
balanced approach between state and self-regulation, met resistance and scepticism from CSO sectors across the EU that, though expressing a shared interest in preventing terror financing via CSOs, also drew attention to issues such as the lack of evidence on a terrorCSO link, and the already growing and burdensome counter-terror regulations and other measures they had to contend with (Sidel, 2010b, pp. 97-99 citing Vellenga).

It needs be noted that, in response to the influence of FATF, a Global NPO Coalition on FATF was established in 2012 and has drawn attention to the unintended consequences of FATF's Recommendation 8. Specifically, the Recommendation has contributed to, amongst other things, "the creation of onerous and restrictive laws, rules and regulations for the sector" (Global NPO Coalition on FATF, n.d.-a, para. 2). The coalition consistently called for an evidence-based approach, noting that non-profits are "not a significant source of terrorist financing" and that "the frequency and severity of such abuses is very low" (Global NPO Coalition on FATF, 2014, p. 2). As a result of the Coalition's evidence and advocacy, Recommendation 8 and its interpretive note were revised in 2016 such that the Recommendation no longer states that CSOs are "particularly vulnerable" to abuse for terrorism purposes (Global NPO Coalition on FATF, n.d.-b, para. 1).

On the whole, security and terror concerns are mainly a driver of change in states' regulation of CSOs, change that can either be to CSO-specific regulation or to broader regulation that applies to CSOs. Terror concerns are less a driver of self-regulation. 


\subsubsection{External sources}

Changes to state and self-regulation of CSOs can come about not only due to domestic drivers, but to non-domestic ones. In particular, foreign states, foreign CSOs, and supra-national (i.e. regional or international) bodies can be drivers of regulatory change.

A useful source to draw from in explaining this driver is the literature on policy transfer. Dolowitz and Marsh (2000) define policy transfer as a "process by which knowledge about policies, administrative arrangements, institutions and ideas in one political system (past or present) is used in the development of policies, administrative arrangements, institutions and ideas in another political system" (p. 5). They distinguish four types of transfer that happen along a continuum from voluntary "lesson-drawing" through "policy convergence", "policy diffusion" and imposed "policy transfer" (p. 5). Policy, and regulatory models can thus be purposefully copied, absorbed, or actively imposed in a country from sources outside of its borders. External sources can also directly influence regulatory change by providing financial resources to fund it. Between HI countries, policy transfer without accompanying financial resources is more common, while external sources will often finance policy and regulatory change efforts in LMI countries.

For the purposes of this conceptual framework of regulatory change drivers, the type of transfer is not the focus so much as is the source from which the policy or regulatory influence or change emanates, as noted, foreign state sources, foreign CSO sources, and supra-national sources. 


\section{Foreign States}

Policy transfer between states in the area of CSO regulation of the 'copy' or 'adapt' variety is common as it is in other policy and regulatory realms. For example, an International Charities Regulators group comprised of heads of charity regulators from HI countries meets approximately every eighteen months to share regulation experiences, ideas and directions, providing a channel for policy transfer. As a country-level example, establishment of Charity Commissions in New Zealand and Australia benefitted from the experience of the Charity Commission for England and Wales which included a former senior staff from the England and Wales Commission filling a commissioner position in the Australian Commission (McGregor-Lowndes \& Wyatt, 2017a, pp. 268-269). The UK's process toward and 1998 establishment of the Compact on Relations between Government and the Voluntary and Community Sector also provided a source of inspiration to Canada when it came to establishing the 2001 Accord between the Government of Canada and the Voluntary Sector (Phillips, 2011, pp. 229-230).

In another part of the world, Howell, Ishkanian, Obadare, Seckinelgin, and Glasius (2008) draw attention to the tendency of former Soviet states to adopt policies and regulation similar to those of Russia, as evidenced in the mid-2000s with the emergence of (restrictive) regulatory change targeting CSOs in a number of Central Asian countries (p. 85). Koesel and Bunce (2013) suggest the adoption of Russian-style CSO regulation extends more broadly to countries such as China and Venezuela as a "diffusion-proofing" tactic to mitigate the counter-authoritarian risk of the colour revolutions and Arab spring (pp. $754 \& 758)$. 


\section{Foreign CSOs}

Cross-border policy transfer is also seen coming from foreign CSOs between and among CSOs. There are relatively few CSOs specialized in CSO regulation doing this, with ICNL, which collaborates with both governments and CSOs in legislative and regulatory technical support and capacity development, a notable exception. There is however a growing body of CSOs working both internationally and with local counterparts in specific countries to draw attention to the proliferation of regulatory restrictions on civil society and CSOs and in so doing, seeking to influence regulatory change in more enabling directions. ${ }^{27}$

CSOs also share models of self-regulation with each other across borders. For example, in Canada, CCIC's Code of Ethics and Operational Standards, first developed in 1995, evidently drew from the US coalition InterAction's Private Voluntary Organisation Standards first published in 1993 (Ebrahim, 2003, p. 820). More recently, CCIC adopted a Leader's Pledge on Preventing and Addressing Sexual Misconduct similar to InterAction's above-referenced CEO Pledge (CCIC, 2018).

In their policy transfer efforts foreign CSOs will often share not just models of and expertise on state and self-regulation across borders, but also financial resources. Indeed, foreign CSOs are important channels of both private and official funding of CSOs with transfers especially occurring from CSOs in HI countries to those in LMI countries.

${ }^{27}$ These include amongst others WMD, CIVICUS, Article 19 and ACT Alliance. 


\section{Supra-national bodies}

Supra-national external sources tend to be a source of influence rather than a driver of CSO regulatory change. An exception is seen in relation to the global effort to combat money laundering and terror financing which, especially in the wake of $9 / 11$, was a driving force beginning with states' efforts to comply with UN Security Council Resolution 1373 (Hayes, 2012, p. 22; Sidel, 2010b, p. 54). FATF requirements are also a source of external pressures that can drive regulatory change, as discussed under the Security and Terrorism Concerns driver.

Another supra-national source of influence is the UN international human rights legal framework and its regional complements. ${ }^{28}$ Drawing from the full framework, two CSOs, the World Movement for Democracy (WMD) and ICNL, developed a set of International Principles Protecting Civil Society (WMD \& ICNL, 2012, pp. 34-52). They lay out in a comprehensive manner, with specific reference to the framework, regional complements, and case precedents, six principles that if respected could guide regulatory change to enable civil society and the CSO sectors globally. Additional UN-based sources of

${ }^{28}$ The most relevant human rights instruments pertaining to civil society and CSOs' functioning include the Universal Declaration of Human Rights (1948); the International Covenant on Civil and Political Rights (1966); and the General Declaration on the Right and Responsibilities of Individuals, Groups and Organs of Society to Promote and Protect Universally Recognized Human Rights and Fundamental Freedoms (1999). Many civil society-relevant rights are also articulated in numerous other UN instruments (e.g. on the rights of women, children, and persons with disabilities amongst others). They are complemented by a host of regional instruments, the content of which generally mirrors UN instruments while being tailored to geographic and cultural specificities, such as the African Charter on Human and People's Rights (1981) or the European Convention for the Protection of Human Rights and Fundamental Freedoms (1950), amongst others, and the case law that has ensued from these instruments. 
potential influence on CSO regulatory change exist such as the Universal Periodic Reviews undertaken by the UN Human Rights Council, and the UN Special Rapporteur on the Freedoms of Peaceful Assembly and of Association recommendations and country reports produced since the creation of this UN mandate in 2010. Sources of external influence also include regional ones, such as the AU's African Peer Review Mechanism that is intended to assesses AU states' progress in areas of democratic governance (Gyimah-Boadi, 2015, p. 103).

Unlike the global anti-terror framework however, the UN-based international human rights legal framework does not appear to provide a driver of CSO regulatory change, at least, there is little evidence to that effect. The framework is not binding in nature but constitutes 'soft law', more like standards and norms than obligations. Universal Periodic Reviews for example offer "a platform for UN member states to make recommendations to fellow states on how to improve their promotion and protection of human rights" (McMahon, 2012, p. 3), but there is a dearth of evidence on whether such recommendations lead to specific changes in CSO regulation. The soft law status also holds true of FATF, but its members and associated regional bodies seem largely to have embraced its policy-making and enforcement role despite that it is not formally constituted via a treaty, convention or the like (Hayes, 2012, pp. 13, $18 \& 24$ ). Where external (global, regional) mechanisms do seem to drive change in states' regulation of CSOs is when there is a clear incentive, such as has been seen in countries of Central and Eastern Europe and Eurasia that have aspired to join the EU (USAID, 2017a, p. 3). Otherwise, CSOs will use the international human rights legal framework and relevant 
regional instruments in their policy advocacy efforts to influence regulatory change, while the framework can also inform CSOs' approach to self-regulation.

This section has provided a conceptual framework of driving factors behind changes in state or self-regulation of CSOs as a tool for organizing how we might think of, and possibly even anticipate, changes in such regulation, and by extension, how state and self-regulation interact, or not. The next section presents a selection of generalized LMI country characteristics to aid us in putting these drivers into the LMI country context of interest to this research.

\subsection{Lower and Middle Income Country Characteristics of Relevance to CSO Sector Regulation}

As with any conceptual framework, the framework of drivers of regulatory change as presented above is limited by the need to consider contextual, political and historical factors and how they manifest themselves in different countries (Dunn et al., 2017, p. 228). Indeed, CSO regulation is considered to be one of the few regulatory fields "that remains largely place-based", given that, unlike with regulation of the private sector or particular industries, incentives for "regulatory competition" are not present, and an international mechanism to encourage or compel harmonization of CSO regulation is absent (Phillips \& Smith, 2014, p. 1145). Though the international human rights legal framework and related soft law provisions apply to CSO regulation, and international treaties protecting financial investment do have some applicability to CSOs, CSO regulation has been "neglected by the architects of global governance" (Peterson \& Gallus, 2007, p. 48). 
While recognizing therefore that regulatory shifts are best explained "by the particular situations of individual nations" (Bies, 2010, p. 1058), generalizing characteristics of LMI country contexts can help further our understanding of the drivers behind changes in state and/or self-regulation and how they may play out in those countries. In this vein, LMI country characteristics as most relevant to regulation of the CSO sector are presented below. The characteristics as presented are highly generalized and will feature in LMI countries to varying degrees. Though aspects of them will also be found in HI countries, again generalizing, they will be less pervasive and acute. These characteristics include: authoritarian propensities; uneasy relationships between governments and CSOs; weak CSOs and CSO sectors; CSO sector dependency on nondomestic funding; pronounced influence of DAC/Gs via funding and policy engagement; capacity and quality challenges of state regulators; and, neo-patrimonialism and corruption.

\section{Authoritarian Propensities}

Huntington's (1991) writing on the third wave of democratization that began in the mid-1970s came about in an era of aspiration that many LMI countries were on a path of transition to the liberal democratic model of the Western world. Countries of Eastern and Central Europe had for decades been subject to authoritarian rule under Soviet dominance. Others in Africa, Asia, and Latin America had similarly operated under authoritarian rule for various historic reasons including in some cases the omnipotent state approach inherited from their former colonial oppressors. 
It did not take long however before deficiencies in the 'democracy rising' argument were revealed, with the study of newly defined "hybrid regimes" or "illiberal democracies" pointing to the often partial, choppy nature of recent democratic transitions in many LMI countries (Zakaria, 1996; Karl, 1995; Carothers, 1997). Levitsky and Way (2002) cautioned against a "democratizing bias" as countries could not be assumed to be on a linear path of democratization (p. 51). They drew attention to the post-third wave emergence of what they called "competitive authoritarian" regimes, in which "formal democratic institutions are widely viewed as the principal means of obtaining and exercising political authority.... [but] incumbents violate those rules so often and to such an extent.... that the regime fails to meet conventional minimum standards for democracy" (pp. 51-52). These were countries that had undergone a degree of democratic transition, but had "transitioned as far as they were inclined to go" in the democratization process (Rutzen, 2015b, p. 29). "Democratic backsliding" measures were being implemented by autocratic incumbents to retain power in less-than-democratic ways (Haggard \& Kaufman, 2016, p. 133).

Diamond (2015) suggests that a period of "democratic recession" has been underway since 2006 with reversals, or perhaps stasis, in democratic development in many countries worldwide (p. 144). Alongside other evidence, he points to Freedom House's (FH) freedom in the world rankings of political rights and civil liberties as having peaked in 2005 (Diamond, 2015, pp. 141-142). His analysis includes not only outright antidemocratic incidences such as coups, but also the occurrence of "subtle and incremental degradations of democratic rights and procedures" (Diamond, 2015, p. 144). "Instability 
and stagnation" in and of democracies, "deepening authoritarianism" elsewhere, and a "decline in the functioning and self-confidence of the world's established, rich democracies" are all characteristics of the democratic recession (Diamond, 2015, p. 142). It appears that democratic space is at once opening and closing, both within and across countries globally, as the 2017 Freedom in the World report also attests (Freedom House [FH], 2017).

Authoritarian tendencies are therefore far from an exclusively LMI country phenomenon. Still, it is evident from the literature and from global rankings that a higher proportion of countries in the LMI category are considered as not full democracies but are in one way or another, or in many ways, tending toward authoritarianism (Maeda, 2010; Diamond, 2015, p. 145; International Institute for Democracy and Electoral Assistance, 2017, Table A.5). Writing on Africa for example, Gyimah-Boadi (2015) notes that while "there has not yet been a case of permanent reversal to the status quo ante of robust authoritarianism", "the harvest of African democratization" has been of the "low-hanging fruit", such as elections, constitutions, and the expansion of media and associational freedoms (pp. 102-103). In much of Latin America, while Pousadela and Cruz (2016) suggest that while democracy "eventually prevailed", concerns remain about its quality such that 'the democratic experience has fallen short of citizens' expectations and human rights violations have persisted even in democratic contexts" (p. 608). Of the 136 LMI countries included in the 2017 Freedom in the World report, ${ }^{29} 79$ percent are

${ }^{29}$ The data in the 2017 Freedom in the World report covers the calendar year 2016, in which a total of 195 countries (and 14 territories) were ranked. 
ranked as either partly free or not free, of which 69 percent are considered partly free and 31 percent not free (FH, $2017 \& 2018)$.

This is not to suggest that levels of economic development necessarily have a causal effect on democratic development and consolidation, a question around which there is also a considerable body of literature (Haggard \& Kaufman, 2016, p. 129 citing Przeworksi et. al, 2000, Boix \& Stokes, 2003, Epstein et al. 2006, Kennedy, 2010, Boix, 2011). It is also not to state a rule - that LMI countries are not full democracies while HI countries are - but simply an observation of the preponderance of authoritarian tendencies among LMI countries relative to HI countries.

\section{Uneasy Relationships between Governments and CSOS}

Coston (1998) posits a continuum of government-CSO relations, from repression through rivalry, competition, contracting, third party government, cooperation, complementarity, to collaboration (pp. 361-362). Najam (2000) organizes the relations in "four-Cs": cooperation, confrontation, complementarity, and co-optation (p. 375). Breen et al. (2017a) propose three "relationship stages" between governments and CSOs challenging, cooption, and collaboration - that provide the context for and shape the CSO regulatory environment (pp. 6-11). In HI countries, the relationship between government and CSOs is not without contention and certainly has its ups and downs. Still, broadly speaking, in HI countries the relationship tends more toward the cooperation/complementarity/collaboration end of the spectrum, grounded in a belief in the societal value of CSOs. The value-added of CSOs can be seen as both "functional" in relation to provision of services, and also "democratic", such as by raising public 
consciousness or engaging in public policy discussion, even while it remains "contested terrain" (Bode \& Brandsen 2014, pp. 1057-1058). That said, the democratic value of CSO civic and political engagement is not necessarily nor always welcome in HI countries. ${ }^{30}$ However it is conceptualized, collaborative, competitive, or otherwise, the government-CSO relationship in any country, HI or LMI, will fluctuate over time.

In LMI countries, the relationship between governments and CSOs is more inclined to tip toward one of tension and mistrust. The nature of the relationship may be due to cultural, political factors or historical factors (Breen et al., 2017a, p. 10), the latter including the legacy of imperial or colonial state omnipotence in the face of alternate societal forces. Though LMI country governments may be open to the social and economic development roles played by CSOs, their tolerance of CSOs' policy and advocacy-related work is more likely to be limited (Hayman et al., 2014; USAID, 2014, p. xvii), which readily translates into a wariness of the whole sector. A prevailing perspective in sub-Saharan Africa for example is that CSOs are meant solely to be "operational" and "charitable" organizations (Burger \& Seabe, 2014, p. 86). Thus the line between CSOs' small-p (civic and) political engagement whether in the realms of human rights, accountable governance, or democratic development, and what is perceived as large-P partisan political activism provides a source of tension between government and CSOs (Hayman et al., 2014, p. 3). Tolerance for such activities which tend to be critical

${ }^{30}$ There is a risk of negative attitudes toward and reduced tolerance of CSO civic and political engagement in HI countries in the context of rising populism and autocratic forms of government globally (FH, 2017). 
of the government in power's decisions or behaviour can be rather limited (Mirza \& Obrecht, 2013, p. 4).

Such tension is particularly acute in LMI countries with the "regime vulnerability" that comes with questionable, possibly fraudulent election processes and associated authoritarian or otherwise anti-democratic practice (Rutzen, 2015a, p. 41 citing Christensen \& Weinstein, 2013). That civil society and its organizations have played, or attempted to play, a role in pushing for democratic reform - fundamentally small-p political transitions but that entail large-P partisan political transitions, beginning with independence movements, and more recently the various "colour revolutions" or the “Arab spring”, is not lost on such regimes (Rutzen, 2015a, pp. 6-7; Hayman et al., 2014, p. 33). In LMI countries that are fragile democracies - if democracies at all - concerns that CSOs and civil society activists may be "potential challengers in political or policy terms" (Sidel, 2010a, p. 52) have a distinct affect on government-CSO relations.

\section{Weak CSOs and CSO Sectors}

The CSO sector globally has experienced growth over the past few decades, with the fastest growth rate attributed to LMI countries (Braithwaite, 2006 citing Commission on Global Governance 1995, p. 33; Gugerty et al., 2010, p. 1028; Pousadela \& Cruz, 2016, pp. 608-609). There is considerable literature on the contributions this growing sector makes to social, economic and democratic development in LMI countries (e.g. Brass, 2012; Salamon, Sokolowski, \& Associates, 2004; Fisher, 2013; Risley, 2015). Yet still, LMI country CSO sectors tend to be deemed nascent and lacking capacity relative to their HI country counterparts, even as issues of CSO mismanagement or misconduct are far 
from limited to LMI country CSOs (Naidoo, 2004, p. 18; Prakash \& Gugerty, 2010, p. 23). Low and middle income countries' CSO sectors have grown stronger, and in them are found many CSOs that are effective in different ways, with knowledge and expertise on particular issues, geographic areas, or methods; adeptness in service provision; or outspokenness in civic and political engagement (see regional chapters in Heinrich \& Fioramonti, 2008; USAID, 2017a, b, c \& d). However, just as with other institutions in LMI countries, heightened capacity challenges characterize the CSO sector (see regional chapters in Heinrich \& Fioramonti, 2008; USAID 2017a, b, c \& d).

In Asia, the sector is large, growing and vibrant, and playing an important role in areas from rights promotion to filling service gaps, though simultaneously it is "regarded... as a haven of murky deals, unsavoury connections to government, and often unabashed commerciality" (Sidel, 2005, p. 810). Particularly, though not exclusively, the many smaller CSOs outside of capital cities face organizational challenges such as in human resource capacity/retention, financial sustainability and management, long-term planning and constituency building (USAID, 2017a, p. vii). CSO sectors in the Middle East and North Africa showed signs of strengthening organizational capacity in 2016, despite the mitigating circumstances of conflict and insecurity, but still face considerable capacity challenges (USAID, 2017d, pp. v). In Central Europe and Eurasia, CSO sectors show considerable divergence in capacity, with some countries seeing improvements and others deterioration in 2016 (USAID, 2017b, p. 7). Notably, in all of the regions covered by the above-referenced USAID CSO Sustainability Indices, legal and regulatory environments for CSOs are a consistent impediment to CSOs' capacity to be effective 
development actors and to their sustainability. ${ }^{31}$ Latin America and the Caribbean is considered a middle-income region though with great variance in income levels within and across countries, and over half of the region's countries found on the OECD's list of ODA-eligible countries (OECD, n.d.-b). Still, while organizational capacity challenges seem less prevalent in Latin American CSO sectors, the capacity issue of financial sustainability is felt across the region (Pousadela \& Cruz, 2016, p. 614).

Typically in sub-Saharan Africa the sector's weaknesses revolve around challenges of human resource capacity, financial sustainability and management, mission drift, infrastructure, internal governance, and public image including community/constituency connectedness (Mirza \& Obrecht, 2013, pp. 14, 17 citing Gyimah-Boadi 1996, Robinson 1995, \& Makumbe 1998; USAID, 2016, pp. vii, ix, xiv-xv; USAID, 2017c, pp. x-xi \& xv). The term "briefcase NGO", that is, NGOs made up of one individual and a briefcase that "exist mainly to promote the wealth of one or two individuals, without regard to the wider constituency" originated in sub-Saharan Africa (Dicklitch, 2002, p. 31). Commenting on African CSOs, Obadare (2011) notes the critique that the sector is weakened by an "organizational culture... [that] bears an uncanny resemblance to the verticality and personalism that characterize existing political culture at large" (p. 189).

Peak bodies, where they exist in LMI countries, may have limited membership, in part due to the financial constraints they face, but also due to the challenges of diversity, and of outreach to rural CSOs where communications and other infrastructure may be

${ }^{31}$ USAID does not produce a CSO Sustainability Index for Latin America therefore other sources are used for that region. 
lacking (Mirza \& Obrecht, 2013, p. 17; Gariyo, 1996, p. 160). There is a growing interest and occurrence of self-regulation in LMI countries (Warren, Lloyd, \& Lingan, 2009, paras. 14-15), but their application and effectiveness is not widespread. In Asia for example there is continued experimentation to address various challenges of implementation, compliance and enforcement (Sidel, 2010c, p. 1053). In Central Europe and Eurasia, CSO sectors have "failed to embrace transparency and self-regulation measures in a significant way" (USAID, 2013, p. 5). Self-regulation in sub-Saharan Africa is "mostly undeveloped" (USAID, 2016, p. xv). An overview of self-regulation across Africa by One World Trust suggests such mechanisms tend to fall short of addressing "well-defined challenges of African civil society" such as corruption or disconnectedness from communities or other intended beneficiaries (Mirza \& Obrecht, 2013, p. 15), and therefore lack the relevance and legitimacy needed to address CSO accountability challenges.

\section{CSO Sector Dependency on Non-domestic Funding}

In HI countries there is considerable variation in CSOs' reliance on different sources of funding. In the UK in 2014-2015, for example, individual private giving was the primary funding source for CSOs registered as charities, standing at 45 percent of these organizations' revenue, followed by contracts and grants from all levels of government at 34 percent (National Council for Voluntary Organizations [NCVO], 2017). The main additional sources included foundations (or other types of grant-making/philanthropic organizations) and the private sector. Writing in 2011, Smith pointed to a growing dependency of social service CSOs in the US and other HI countries on domestic government funding (citing Gidron et al. 1992, Kramer et al., 1993, Rekart, 1993, \& 
Smith \& Lipsky, 1993). Charities in the US relied on grants and contracts from all levels of government for 33 percent of their revenue in 2012, with 47 percent of revenue coming from fee-for-services and 13 percent from individual donations (Boris \& Lott, 2017, p. 99 citing Pettijohn et al., 2013). In Canada in 2015, 67 percent of charities' revenue came from various levels of government (Blumberg, 2017a).

Though studies of philanthropic giving do not often specify whether and how much of the giving might involve non-domestic sources (e.g. see Wiepking \& Handy, 2015a; Jung, Phillips, \& Harrow, 2017), on the whole, even with much cross-country variance in relative share of revenue sources there is evidence of considerable domestic sources of support for CSOs in HI countries, manifest as a combination of domestic government; fee for service; private individual, corporate and other philanthropic sources. That in HI countries three-quarters of philanthropic giving comes from individuals (Jung \& Phillips, 2017, p. 11 citing Anheier, 2014 \& Giving USA, 2014) suggests high levels of domestic sourcing. In Canada, non-domestic sources accounted for only approximately 0.8 percent of charities' total revenues in 2015 (Blumberg, 2017a), with a heavier reliance on foreign funding seen by international development and humanitarian oriented CSOs with operations focused outside of Canada (Blumberg, 2017b).

A distinctive feature of CSOs in LMI countries is the paucity of domestic funding sources available to them and thus a reliance on financial flows from non-domestic sources. Since the 1980s, foreign institutions have been the "patrons" of CSOs working in LMI countries, channelling significant funds whether in the form of ODA from multilateral bodies or $\mathrm{DAC} / \mathrm{G}$ governments, or from foundations, inclusive of that which 
flows to LMI countries through DAC country or international CSOs (Reimann, 2006, pp. 48-54; Vernon, 2009, p. 29; Guerrero, 2004, p. 221). Funding from domestic government sources in the form of grants or contracts remains relatively low in LMI countries (Guerrero, 2004, p. 224; Suarez \& Gugerty, 2016, p. 2634). This is slowly changing in some contexts, as more ODA-recipient states graduate to higher income status, and DAC/Gs reduce (or eliminate) their financial support. Across Latin America for example, CSOs are increasingly in receipt of domestic sources of government funding (though this includes ODA funding received by these governments), as well as of corporate funding, though foreign flows remain CSOs' primary source of financing (Pousadela \& Cruz, 2016, pp. $607 \&$ 609-611). While the middle class in LMI countries is growing, this growth is not necessarily translating to increased philanthropic flows to CSOs beyond localized community or kin-based organizations (Salamon, Wojciech Sokolowski, \& List, 2004, p. 47). In addition, the type of tax privileges and other benefits to incentivize domestic private giving (individual or corporate) found in the majority of $\mathrm{HI}$ countries is less common in LMIs and where it exists can be cumbersome to access (Rutzen, 2011, p. 268; Pousadela \& Cruz, 2016, p. 610).

In sub-Saharan Africa the sector is heavily dependent on foreign funding sources (Okopu-Mensa, 2009, p. 4; Burger \& Seabe, 2014, p. 83). CSOs on the continent "continue to rely on short-term international donor funding, while such funding continues to decline... and... local sources of support... are not common" (USAID, 2014, p. iv). Dependency on foreign funding is also an issue in Asia, Central and Eastern Europe and 
Eurasia, and the Middle East and North Africa (Atia \& Herrold, 2018, p. 8; USAID, 2017a, p. viii; USAID, 2017b, p. 6; USAID, 2017d, pp. 14, 23, 32, 51 \& 61).

This landscape of CSO dependency may change also due to increasing incidences of state regulatory restrictions on CSOs' receipt of foreign funding (Rutzen, 2011, p. 269; Dupuy et al., 2015a, p. 299). This, along with decreasing ODA flows to some regions, is prompting CSO efforts to diversify their funding base (Pousadela \& Cruz, 2016, p. 614; USAID, 2017d, p. ix; USAID, 2017b, p. 6; Appe \& Pallas, 2017, p. 252), but such diversification is a slow process and alternate funding sources are not expected to resolve the dependency issue soon.

\section{Pronounced influence of DAC/Gs via Funding and Policy Engagement}

All countries of the world are host to the official presence of other countries in their borders. Ministries of foreign affairs will have a presence through embassies that pursue a range of mandates inclusive of diplomatic, trade, and security ones. A key distinction in LMI countries is the financial resources in the form of ODA and the policy influence that come with HI countries' presence. These have gone together as ODA has been at once an instrument of foreign policy, but also a means to promote social, economic and democratic development that was particularly deficient in LMI countries at the beginning of international development cooperation post-World War II.

As a financier of development, DAC/Gs' contributions have been significant. Since 1960 net ODA disbursements increased from USD 32 billion to 120 billion in 2016 (see 
Table B1 in Appendix B). ${ }^{32}$ While these figures mask changes over time and debates on what can be reported as ODA, the figures are substantial. On the recipient end, the level of ODA varies considerably across countries, as does the importance of the flows in relation to a recipient country's gross national income (GNI). In general, excluding humanitarian or political crises that have increased flows to particular countries in particular years or time periods, LMI countries' ODA to GNI ratios have reduced over time. In 1986, LMI countries' received on average 1.1 percent of their GNI from DAC/G ODA, compared to 0.5 percent of their GNI in $2016{ }^{33,34}$ On average, countries in the least developed country category received 7.2 percent of their GNI from DAC/G ODA in 1986 and 3.4 percent in 2016, while those in the upper middle income category received 0.2 percent and 0.1 percent in the same years respectively (see Table B2 in Appendix B).

Various channels are used by DAC/Gs for ODA delivery, which can flow directly to LMI country governments, to CSOs in DAC countries for use in LMI countries, to CSOs

${ }^{32}$ Note that Table B1 figures only begin in 1986, which coincides with the first year of this research's Kenya coverage. The 1960 and other pre-1986 figures are available from the DAC database, DAC2a - Aid (ODA) disbursements to countries and regions, accessed at https://stats.oecd.org/. Last accessed October 8, 2018. Figures are in constant 2016 USD prices. Note also that while this dissertation's research extends up to 2017, at the time of its completion OECD figures were only available up to 2016.

${ }^{33}$ Figures on DAC/G ODA to GNI ratios are from the DAC database, DAC2a - Aid (ODA) disbursements to countries and regions, accessed at https://stats.oecd.org/. Last accessed on October 8, 2018.

${ }^{34}$ These ratios cover ODA disbursements by the DAC/Gs. When other ODA sources (from non-DAC donors and from multilateral institutions) are included the ratios increase somewhat. Including all ODA sources the share of GNI for all LMIs was 1.5 percent in 1986 and 0.64 percent in 2016. It was 10.8 percent and 5 percent in 1986 and 2016 respectively for least developed countries. These figures also sourced from DAC2a data. 
in LMI countries, and to multilateral development institutions, amongst others. ${ }^{35}$ There are variations in the mix of channels (or 'actors') over time, across $\mathrm{DAC} / \mathrm{Gs}$ and across recipient countries. LMI country governments have typically been primary recipients of ODA. Approximately 52 percent of DAC/Gs' gross ODA disbursements went to LMI country governments in 2010 , increasingly to 55 percent in 2016, with fluctuations in between. ${ }^{36,37}$ This figure under-estimates ODA amounts disbursed to LMI governments however, as it does not include flows shared with other actors in the form of publicprivate partnerships, nor funds that flow to governments via multilateral institutions.

Beginning in the 1980s DAC/Gs began to channel more funding to the CSO sector in part due to dissatisfaction with the performance of inefficient and corrupt recipient states, in part due to a newfound belief that CSOs would help unlock stalled democratization

${ }^{35}$ In addition to a plethora of delivery channels, ODA flows in different forms including not only grants but also, for example, soft or concessional loans, and technical assistance (OECD, n.d.-e, para. 1). This research is not concerned with the form of ODA so much as with the level and channel of flows.

${ }^{36}$ Figures are from the OECD Creditor Reporting System (CRS) database, accessed at https://stats.oecd.org/qwids/. These figures last accessed October 8, 2018. Note that the OECD maintains two datasets known as the DAC and the CRS datasets. DAC data as in the above-referenced DAC2a is focused on high-level data, while the CRS data is focused on detail, down to the individual project level. Though in principle the data should match there are acknowledged discrepancies in the historical data contained in these two databases. See Frequently Asked Question [FAQ] 4.3 at OECD (n.d.-c). In addition, the DAC2a source gives values in net ODA disbursements while the CRS uses gross disbursements. Gross disbursements become net disbursements when principal on loans and other offsets are made. See FAQ 3.2 at OECD (n.d.-c).

${ }^{37}$ Data on disbursements to public institutions is available in the CRS database from 2003. However, DAC member reporting on data by channel, including the public institutions channel, and thus reporting quality in the early years was deficient. Data from 2003 for example shows only USD 2.1 billion gross ODA flowing to public sector institutions, which would represent an implausible 0.003 percent of ODA in that year. For comparative purposes with the flows for CSOs covered in the next paragraph the data provided here is from 2010 to 2016. 
processes (Turner \& Hulme, 1997, pp. 206-207; Carothers \& Ottaway, 2000). The increased funding to CSOs represented a unique "conjunction of ideas" in that it brought together ideologies of the 'right' in support of a smaller state through privatization of service delivery, and the 'left' in support of CSOs as a force for citizen participation and empowerment (Bratton, 1989, pp. 569-570). Until 2010, DAC/G ODA flows for CSOs had not been well tracked (Smillie, 1995, p. 271; Van Rooy \& Robinson, 1998, p. 34). ${ }^{38}$ In 2010 these disbursements amounted to USD 19.4 billion, and almost USD 23 billion in 2016. ${ }^{39}$ They represented 17.9 percent and 17.2 percent of gross ODA disbursements in 2010 and 2016 respectively (see Table C1 in Appendix C).

More recently DAC/Gs have turned to the private sector as critical to further development progress, which has included the use of ODA to leverage investment by DAC/G country private sector firms (Kindornay \& Reilly-King, 2013, p. 31). In 2016 DAC/Gs' ODA disbursements to private sector institutions and public-private

${ }^{38}$ The OECD began requiring DAC members to report specifically on their ODA disbursements to and through CSOs in 2002. While data is therefore available in the CRS database from that year, as noted, prior to 2010 the quality and consistency of DAC/G reporting by delivery channel was considered poor. The OECD considers that the quality of all DAC/Gs' reporting on their CSO flows to be good beginning in 2010 (DAC statistician, personal communication, August 1, 2018).

${ }^{39}$ Figures are in constant 2016 USD prices, from the CRS database. Last accessed October 8, 2018. Note the CRS provides data on gross disbursements, whereas the DAC database provides data on net disbursements. The DAC database provides more historic data and is therefore used in this research for the previous paragraph's data on ODA flows, though it does not provide data on the CSO channel or other channels. Therefore the CRS data is used for the channel data. 
partnerships combined amounted to approximately 5.2 percent of gross bilateral ODA disbursements. ${ }^{40}$

As regards the policy-influencing role of $\mathrm{DAC} / \mathrm{Gs}$, funding to specific actors or groups of actors is used as an indirect means to influence policy. A more direct policyinfluencing role is also seen when DAC/Gs engage with LMI country governments to advocate for certain policy changes. Part of this equation includes the imposition of conditionalities on funding whereby the allocation of ODA is conditional upon a recipient government meeting certain policy reform requirements. Such requirements range from, for example, macroeconomic ones such as currency devaluation; institutional (and economic) ones such as reducing public expenditure; and political ones such as holding elections, the latter having come into DAC/Gs' practice especially in the post-Cold War era (Turner \& Hulme, 1997, p. 228). While the application of conditionalities and associated sanctions is inconsistent - across DAC/Gs, across recipient countries and within recipient countries over time - they continue to be part of DAC/Gs' toolbox.

High-income country governments will of course seek to influence the policies of other HI countries, and will also disburse funds in other HI countries. The difference is the scale of financial flows, as well as the strength of the influence that grew out of a paternalistic international development paradigm.

${ }^{40}$ Figures in constant 2016 USD prices, from the CRS database. Last accessed October 8, 2018. Data on ODA flows to private sector institutions has only been collected in the CRS since 2016. 
As funders of CSOs, DAC/Gs also impose conditionalities of a sort through their financial support modalities. Dominant modalities have see DAC/Gs' funding CSOs as implementers of DAC/G-defined programs, sometimes focusing on (or requiring) particular target groups, activity area and approaches, accompanied by monitoring and reporting requirements that, combined, have been said to transform CSOs into "technical instruments" to meet DAC/G agendas (Howell \& Pearce, 2000, p. 75; Hulme \& Edwards, 1997, pp. 8-9; Atia \& Herrold, 2018, p. 1). In the OECD Creditor Reporting System a distinction is made between ODA that flows "to" CSOs and "through" CSOs, the latter constituting the dominant modality of funding CSOs as implementing instruments. The OECD defines funding "through" CSOs as "funds channelled through CSOs and other private bodies to implement donor-initiated projects (earmarked funding)" and funding "to" CSOs as "core contributions and contributions to programmes [sic]. These aid funds are programmed by the CSOs" (OECD, 2018a, p. 1). Between 2010 and 2016 the share of DAC/G ODA disbursements that flowed through CSOs ranged between a low of approximately 85 percent to a high of approximately 90 percent, with the balance flowing to CSOs (see Table C1 in Annex C).

A similar phenomenon of utilizing CSOs as implementing instruments is experienced by government-funded CSOs in HI countries, though the above-mentioned relationship of LMI country CSO financial dependency on DAC/Gs combined with sometimes weak(er) CSO sectors means the $\mathrm{DAC} / \mathrm{G}$ influence as donor is more pronounced. 


\section{Capacity and Quality Challenges of State Regulators}

Much of the literature on regulation, as also the efforts at policy transfer from HIs to LMIs, is based on "an idealised model rooted in developed country practice", the understanding of which is "transplanted" to LMI country contexts (Minogue \& Cariño, 2006a, p. 7). However, the idealised attributes of regulators may be lacking in LMI countries. According to the WB Worldwide Governance Indicators, low and lowermiddle income countries tend to score low on the "regulatory quality" measure (World Bank [WB], n.d.-b). In particular, the capacity and independence that regulators need to perform their function of protecting the public interest cannot be assumed to be present (Minogue \& Cariño, 2006a, p. 9).

Estache and Wren-Lewis (2010) point to a number of critical issues that reflect differences in the "nature and quality" of LMI country regulators and regulation (pp. 374 \& 376-377), ${ }^{41}$ beginning with the issue of capacity. Highly skilled, professional staff with deep technical capacity in the form of knowledge of the industry or sector under regulation, its forms, needs, approaches, and constraints, are considered by these authors as "scarce" in LMI countries (Estache \& Wren-Lewis, 2010, p. 377; Minogue \& Cariño, 2006a, p. 9; Minogue, 2006, p. 78 citing Hyden, Court \& Mease, 2004). A sixteencountry study by Hyden et al. (2004) identified amongst other challenges that LMI country bureaucracies were "incompetent, poorly performing, and politically

${ }^{41}$ Estache and Wren-Lewis's (2010) contribution is focused on 'network industries' which include amongst others transport, telecommunications, and information technology, however their findings are echoed in the broader literature on regulation in LMI countries e.g. Minogue \& Cariño (2006b); Hyden, Court, \& Mease (2004). 
compromised" (Minogue, 2006, p. 78; Hyden et al., 2004, pp. 121-141). Braithwaite (2006) suggests that LMI country regulators may lack organizational capacity and human resource capacity in the form of the "analytic resources" necessary to implement a "reflexive approach" to regulation involving appropriate risk assessment and responsiveness to that risk (p. 889). Also contributing to human resource and related technical capacity limitations, LMI country regulators may also face budgetary constraints. Overall state budget shortages may be the reason for such constraints, or the state may be disinterested and therefore not prioritize the regulator's funding, or funding may be "deliberately withheld.... as a means of undermining the agency" (Estache \& Wren-Lewis, 2010, p. 377).

A further LMI country regulatory constraint is a lesser degree of "underlying commitment" to contracts (Estache \& Wren-Lewis, 2010, p. 377). Agreements on paper may not necessarily carry the same weight as they would in HI countries and are more likely to be renegotiated, reinterpreted or reneged upon, leaving them open to abuse and creating uncertainty for those being regulated. Onoma (2010) uses the example of land documentation in Kenya to point to wholesale "fraudulent exploitation" of the system of land titles over time by political and economic elites determined to gain private benefit from these supposed inviolable regulatory tools of property ownership (p. 66).

LMI country regulators, along with other institutions, are also found to be less accountable, with discretion to pursue objectives that may not be in the public interest, which renders them vulnerable to collusion and corruption (Estache \& Wren-Lewis, 2010, p. 377; Minogue, 2006, p. 78 citing Hyden et al., 2004). Collusion is typically 
discussed as occurring between the regulator and the industry or sector being regulated, amounting to regulatory capture, or outright corruption, that can influence regulation's shape and implementation in favour of the industry being regulated (Estache \& WrenLewis, 2010, p. 380). This reduces efficiency given decisions made and effort spent on “creating rents" (Estache \& Wren-Lewis, 2010, p. 381). The issue of corruption, which is not the exclusive domain of regulators, is further discussed in the next sub-section.

In LMI countries, regulators often suffer from a lack of independence in that they do not have the requisite "insulation from both political and industry pressures" to promote and protect the public interest (Minogue \& Cariño, 2006a, p. 10). A regulatory commission that is not attached to a particular ministry or department will generally have a greater likelihood of political independence, while the higher up the bureaucratic hierarchy a regulator is placed, the less independent it is likely to be (Minogue \& Cariño, 2006a, p. 10). The challenges of lack of accountability and independence are inter-linked in LMI countries where the risk of regulatory capture is not only, or even necessarily, that of capture by the industry/sector being regulated but by governments, or the regulators themselves, who may be "private-regarding", an "interested party" (Minogue \& Cariño, 2006a, p. 11) as rent seekers or with other interests that have the potential to distort regulation.

Given these various considerations, while HI and LMI countries may have similar regulatory goals, the "weights" and "constraints" driving regulatory design and implementation choices, and thus regulatory change, may differ (Estache \& Wren-Lewis, 2010, p. 373). 


\section{Neo-patrimonialism and Corruption}

Reference is made in the literature to the presence of neo-patrimonial states among LMIs (Turner \& Hulme, 1997, pp. 50-52). Unlike the Weberian modern rational-legal state, the neo-patrimonial state operates with "the trappings.... of the impersonal universalistic systems and rules of the rational-legal" but that these "have been employed for private, particularistic purposes" (Turner \& Hulme, 1997, p. 51 citing Findlay, 1991, p. 18). Hornsby (2012) defines the neo-patrimonial state as one where "despite the formal structures of modern bureaucracies, the state operates on patrimonial principles, with personalised political authority, weak checks on private appropriation of public resources and pervasive clientelism" (p. 829). Neo-patrimonialism contributes to the features of LMI country regulators as discussed above, but they are not just issues of regulators and bureaucracies.

Common to neo-patrimonial states are practices of corruption, clientelism, and patronage, all found especially in LMIs (Turner \& Hulme, 1997, pp. 50-52 \& 66; Hyden et al., 2004, p. 48). While definitionally distinct (Obong'o, 2013, pp. 28-29), corruption, clientelism and patronage share common features. They institutionalize informal rules and practices that go against the public interest and the policies and regulations meant to serve it (Hyden et al., 2004, p. 94; Turner \& Hulme, 1997, pp. $51 \&$ 61). They involve "particularistic exchanges", usually between those of unequal power, of goods or a favour for which the recipient offers allegiance or some other form of support (Obong'o, 2013, pp. 28-29). 
Minogue (2004) uses the example of corruption, "perhaps the defining limit of a range of governance pathologies" to illustrate the shortcomings of policy transfer attempts from HIs to LIs (p. 173). Much of the study of corruption in LMIs takes an economic perspective, seeing corruption as reflecting "opportunistic" and "selfinterested" public officials seeking and extracting rents in the context of the particular "bureaucratic pathologies of the 'third-word' state" (Minogue, 2004, p. 173 citing Broadman \& Recanatomom, 2002, Rose-Ackerman, 1999, Gray \& Kaufmann, 1998, Klitgaard, 1988). Based on their 2004 research, Hyden et al. note that "nepotism and various forms of corruption continue to affect the civil service in many countries" ( $p$. 127). Yet, as Minogue (2004) points out, corruption in LMI countries needs to be understood in the context of poverty, inequality, culture, alongside the challenges faced by LMI country regulators and public service agencies more broadly as described above, that make up corruption's "deeper structural causes" (Minogue, 2004, p. 176 citing Khan, 1998). An anthropological perspective broadens what is considered as corrupt behaviour beyond that which is practiced by public office holders to practices that are ingrained and considered acceptable in certain social relationships (Minogue, 2004, p. 175 citing Sissener, $2001 \&$ Ledevena, 1998). Corruption, and the related practices of patronage and clientelism as seen in the neo-patrimonial state do not only entail theft of public resources by office-holders. Indeed they can involve grand corruption involving high-level politicians and large corporations, or day-to-day bribery and extortion between public officials and individuals, but also private regarding, rent-seeking practices by all types of individuals and organizations, including not just the state and state resources but CSOs and other resources. 
That corruption is endemic in LMI countries is a commonly cited refrain, backed by data (Turner \& Hulme, 1997, p. 100; Hyden et al., 2004, pp. 48 \& 94). Figures from Transparency International's (TI) Corruption Perception Index (CPI), though they assess perceived levels of public sector corruption specifically, are telling. The CPI for 2017 shows the lowest scoring countries are to be found in the LMI countries of Asia and the Pacific, the Americas (inclusive of Canada and the US), Eastern and Central Europe, with the sub-Saharan Africa region scoring the worst (Transparency International [TI], 2018b). The Worldwide Governance Indicators back this up, with the lowest scores for the control of corruption measure showing in low and lower-middle income countries (WB, n.d.-b).

Corruption, clientelism and patronage practices are therefore particularly characteristic of LMIs and, when pursued by different actors, can affect how regulation is designed and implemented, and incentives for regulatory change.

This section has demonstrated that the study of state and self-regulation of CSOs needs to be contextualized to LMI countries with consideration of these LMI country characteristics' affects on how the drivers of regulatory change are manifest, and which are most influential.

\subsection{Summary}

This chapter has provided the theoretical and conceptual foundation underpinning this research with explanation of the paradox of the trend toward both enabling and restricting the CSO sector, often through regulation; the common thread of accountability; the response to accountability challenges through both state and self-regulation of CSOs; and 
the purported relationship between state and self-regulation. It has proposed a conceptual framework of drivers of regulatory change based on the literature and pointing to examples from various countries. It has then generalized LMI country characteristics of particular relevance to the study of state and self-regulation in such country contexts.

In the following four chapters, the conceptual framework is applied systematically to data from Kenya, with the LMI country characteristics integrated through the coverage of data for each driver of regulatory change and the subsequent analysis.

Note however that while three external sources - foreign states, foreign CSOs, and supra-national bodies - are described in the conceptual framework, the literature shows they are intertwined and interdependent forces, and conceptually difficult to distinguish. For example, the norms and frameworks of supranational bodies are influenced by and draw from, foreign states (and foreign CSOs). Foreign CSOs sometimes influence the position of foreign states on CSO regulation issues, but are also themselves very much influenced by foreign states that are their funders. The difficulty of separating these external sources was demonstrated to be the case in practice when applying the framework to the Kenya case. Interviewees for this research, themselves, did not make distinctions between these three foreign sources. In fact, in applying the framework to the data it became clear that the dominant external source of regulatory change was foreign states in the form of DAC/Gs' funding and policy engagement. The data found virtually no reference to supra-national bodies as a driver of regulatory change in Kenya. As regards foreign CSOs, with the exception of some specific incidences of foreign CSOs in collaborative, facilitative roles with Kenyan counterparts, the data found little in the way 
of distinctions being made between foreign and domestic CSOs. Foreign CSOs were considered part and parcel of other regulatory change drivers emanating from the CSO sector. Thus, in the empirical chapters the external driver focuses on the foreign state external source of regulatory change in the form of DAC/Gs. 


\section{REGULATORY WAVE ONE, LATE 1980s TO 1999 - A RISING TIDE OF STATE REGULATION}

\subsection{Introduction}

The present chapter begins with a brief synopsis of Kenya's colonial history, the legacy of which is relevant to the four regulatory waves covered by this research. An overview of regulatory wave one is then provided (also summarized in Table 2) along with a timeline (Figure 2) before the chapter proceeds to detail the CSO regulation story in Kenya over this first wave beginning in the late 1980s through to 1999. The story of this first period opens with coverage of the political environment backdrop to provide context to this wave, then the key driving factors behind state and self-regulation through this period, followed by the regulatory change outcomes. The outcomes are organized starting with the development and negotiation of this wave's focus, the 1990 NGOs Coordination Act and its self-regulation provisions, then the Act's implementation. A table (Table 3) completes the chapter with a summary of this wave's drivers of regulatory change.

Each of the four chapters covering the empirical data from Kenya is organized in this way. The periods, or waves, covered by these chapters are not tightly and neatly bounded, as there is some overlap between them. However, each wave is book marked by important regulatory transition or change.

The factors driving regulatory change are organized according to the categories of the conceptual framework developed in chapter two. As explained in that chapter, there are linkages between the varied factors and thus the narrative is not strictly bounded. 
Coverage of one factor can also be seen in coverage of a separate, but linked, factor. For example, the growth in CSO numbers is one driving factor, itself influenced by the influx of $\mathrm{DAC} / \mathrm{G}$ funding to the sector, but since the $\mathrm{DAC} / \mathrm{G}$ factor holds other influences than simply the affect on sector growth, it is also treated as a separate factor. As another example, CSO activities, specifically their civic and political engagement, can themselves inform GoK political agendas but such agendas are not only fuelled by CSOs' civic and political engagement.

As also explained in chapter two, the focus of the external sources driver is on foreign states in the form of DAC/Gs. To aid the narrative flow, given the above-mentioned interlinkages between the factors, coverage of the $\mathrm{DAC} / \mathrm{G}$ external driving factor is located in between drivers emanating from the CSO sector and drivers emanating from the state.

\subsection{Kenya's Colonial Backdrop}

A fulsome recounting of the country's colonial history would go beyond the space limitations of this dissertation. Therefore, only a brief overview of some of the attributes of colonial Kenya that left their mark post-independence in ways that would influence the drivers of CSO regulation is provided here.

Kenya was a British protectorate between 1895 until 1920 when it was declared a British colony and so remained until independence in 1963. The British vision for Kenya was as a settler colony (per South Africa, Zimbabwe or Canada). The granting, leasing, renting and sale of vast swaths of the territory to settlers with little to no consideration for the original inhabitants sowed seeds of dependency, as well as of future chronic conflicts over land. Land alienation and associated shortages for the African population, combined 
with restrictions on cash crop production, the imposition of taxes and legislation such as the Native Labour Ordinance (1919) and kipande passes of Native Identification, contrived indirectly and directly to force Africans into wage labour and the settler economy more broadly (Amutabi, 2006, p. 92; Hornsby, 2012, p. 33). Reserves established to house displaced African populations were largely organized on an ethnic basis (Kanyinga, 2004, p. 12).

Maintenance of the colonial system of rule required the British colonizers to exercise not only economic and military hegemony but political hegemony as well (Amutabi, 2006, p. 93). Coercion, control and marginalization of the African population were paramount, and critical roles of the paternalist colonial state (Amutabi, 2006, pp. $93 \&$ 100-101). Rather than a contemporary understanding of government as an "impartial institution that could be counted on to safeguard [the populations'] interests", the colonial state was understood and experienced by those colonized as an "instrument of African control and domination" (Amutabi, 2006, p. 100). A system of Local Native Councils combined with Provincial and District Administrations provided representation of the African population through appointed African chiefs. However, the administrative structure was used for "deflecting African demand for participation" in centralized decision-making, as the "chief instrument for colonial domination and control of the Africans", and a way of "preempting [sic], containing and controlling African resistance" (Amutabi, 2006, pp. 95-96). Other colonial methods of domination included, legislation, as well as the use of force, and the dispensation of patronage to those loyal and compliant among the African population (Amutabi, 2006, p. 101). 
When it came to CSOs, the colonial state welcomed the efforts of religious/missionary-based social and economic development interventions as well as those of foreign organizations such as British OXFAM or the American CARE (Amutabi, 2006). Social and cultural welfare associations of an "ethnic character" existed (Kanyinga, 2004, p. 12), some over time also putting forward political demands such as for the return of Africans' land (Hornsby, 2012, p. 33). The colonial state sought to maintain these as regional or ethnic, rather than national groupings, in the spirit of the British "divide and rule" approach to colonial hegemony (Kanyinga, 2004, p. 12, Hornsby, 2012, p. 33). Restrictions were placed on them at various times in various locations, through for example legislation restricting public meetings, movement, or outright bans (Hornsby, 2012, pp. 34, 37, 41 \& 51). Trade unions were legalized in the early 1940s, and though following mass strikes many were banned and trade unionists detained, they became a powerful force for change with financial and moral backing from outside of the country (Hornsby, 2012, pp. $42-43 \& 51-53$ ).

Cracks in the colonial political hegemony were showing with unrest in the late 1940s and 1950s stemming from both the settler and African population, the latter epitomized in the Mau Mau movement against "foreign rule, land alienation and political and economic inequality" (Hornsby, 2012, p. 44; Amutabi, 2006, p. 103; Kanyinga, 2004, p. 103). Mau Mau, a largely Kikuyu revolt, though one that also pitted Kikuyu against Kikuyu, was a violent affair. It was equally violently repressed by the British colonial forces, inclusive of mixed race police and security forces and a "Home Guard" Kikuyu "self-defense force" (Hornsby, 2012, p. 45). In 1953 six of Mau Mau's purported leaders were arrested, 
including future independence President Kenyatta, and what had become a civil war effectively ended by 1955 (Hornsby, 2012, p. 45 and 47). The Mau Mau movement which purportedly used the Kenya African Union, the first African small-p "political organization", established in 1944, "as a cover" - combined with the adoption of nationalist agendas by some key religious and ethnic-based social welfare organizations, led the colonial state to increase its surveillance and control of African associational life (Hornsby, 2012, pp. 40 \& 43; Kanyinga, 2004, p. 12).

Even so, in the post-World War II environment; under pressure from liberals in Britain and internationally; with growing demands for political representation and nationalism across the African continent including among those having received some form of education and/or having served alongside their colonial rulers in World War II; and fear of further insurrection, the British colonial state began a process of adjustment and reforms that would eventually, if reluctantly, lead to Kenya's independence (Amutabi, 2006, pp. 103-104; Hornsby, 2012, pp. 39, 46, 55 \& 59). As a first step, a 1954 constitution formalized multiracialism and granted limited voting rights to Africans (Hornsby, 2012, p. 53). Still, to prevent the emergence of nationalist liberation movements, African political parties were initially allowed only at the district level ${ }^{42}$ (Hornsby, 2012, p. 53). A 1950 Public Order Ordinance and 1952 Societies Ordinance were tools through which the colonial state did its utmost to control the unfolding political engagement of Africans (Hornsby, 2012, p. 54).

${ }^{42}$ With the exception of Kikuyu districts, given the Kikuyu role in the Mau Mau revolt. 
Once Africans were in 1957 elected for the Legislative Council they used this new official recognition, including boycotting their actual participation in the Council, to push for sweeping reforms beyond multiracialism to uhuru, independence (Hornsby, 2012, p. 55). National parties formed, at first surreptitiously then legally. These were fractious, with multi-faceted divisions including, amongst others, between the more hard-line confrontational opponents to the colonial state and those more moderate (Hornsby, 2012, p. 56). A key source of polarization in the nationalist movement revolved around the preferred system of government, whether a federal one that would better represent regional and ethnic diversity, or a more centralized one (Kanyinga, 1998, p. 48). In 1960 a path to majority rule and independence was agreed upon between Britain and the African representatives, followed by elections in 1961 in which two parties, the Kenyan African Democratic Union (KADU) and the Kenya African National Union (KANU), dominated the African vote (Hornsby, 2012, pp. 61-62). Given the numbers of its ethnic base, KANU would have formed government however refused to do so unless Kenyatta was released from detainment (Hornsby, 2012, pp. 66).

From there the path to the independence elections of 1963 involved much to-ing and fro-ing, influenced by the colonial and other foreign states' Cold War considerations and support for the various factions, and British fears of civil unrest, until Kenya obtained self-government in 1963 (Hornsby, 2012, pp. 70-72 \& 89). The new country inherited the British bicameral political model and common law legal system, and a made-for-Kenya federalist constitution that would, it was thought, avoid over-centralization of power 
(especially in the hands of the rebellious Kikuyu), and potentially conflict (Hornsby, 2012, pp. 68, 70-72). ${ }^{43}$

The independence government under the leadership of the ultimately released Kenyatta (and the KANU party) took quick steps to consolidate and centralize power, such as reverting the constitution to a centralized model (Hornsby, 2012, pp. 85, 90-91, 94-95, \& 100). Rule was highly personalized around Kenyatta, his ethnic group and "others whose interests he assisted" (Hornsby, 2012, p. 107). The exchange of gifts and favours was consolidated as the norm, providing a means to maintain control amidst divisiveness and an uncertain post-independence path. As described by Hornsby (2012): "Political leaders would seek support locally and reward it through the channelling of resources to their clients, while the leadership in the centre (Nairobi), as personalised in its central party officials, ministers and civil servants, would maintain the support of key communities by allowing their representatives access to the opportunities that the centre controlled" (p. 111). The legislative framework inherited from the colonial state, including such tools as the above-mentioned Societies Ordinance, provided a further means of control while the colonial power's "repressive attitudes to dissent" were also retained (Hornsby, 2012, p. 109). Organizations of civil society were closely monitored with the help of infiltrators from the ruling party (Wamucii, 2014, p. 122 citing Kanyinga, 1998).

${ }^{43}$ That this is an extreme over-simplification of the independence struggle and transition cannot be over-emphasized. See Hornsby (2012), chapter two, "Independence!" for a detailed account. 
Thus, in a nutshell, the colonial period in Kenya left a legacy that combined a hegemonic approach to state rule aided by tools and tactics such as divide and rule, constraints on citizen associations, patrimonialism and patronage, all alongside a colonial-rooted legislative framework.

\subsection{Wave One Overview}

This period involves both state regulation and self-regulation imposed on a growing CSO sector via the 1990 NGOs Co-ordination Act. ${ }^{44}$ Critical drivers of regulatory change in wave one can be summarized as the GoK's politically-motivated desire to control an increasingly large, influential, civic and politically-active DAC/G-funded CSO sector in an authoritarian era with slow democratic opening. Clear gaps in both state and selfregulation of CSOs also drove this wave's regulatory change.

In the late 1980s the CSO sector was experiencing a growth spurt as many such organizations stepped in to fill gaps in social and economic service provision left by a weak and corrupt GoK. Under the one party state system and a repressive GoK, CSOs were also forming or consolidating as channels for people's civic and political activism. An influx of DAC/G funding for the sector helped fuel this growth, with DAC/Gs turning to CSOs as an alternative to the state in service provision and as allies in the pursuit of democratization in Kenya.

${ }^{44}$ Through this research both the terms CSO and NGO are used. The NGO term is used when speaking to this CSO type, as the term was common in the wave one era and is found in the literature, and in GoK statements. These organizations were the ones ultimately regulated under the NGOs Co-ordination Act. However, the broader CSO sector was subject to or involved in the various drivers of regulatory change, as well as in the process of negotiations on the Act. 
This growing CSO sector was not well organized, and no form of self-regulation was in place. Sporadic incidences of misconduct in the sector specifically related to abuse of tax privileges accorded to CSOs with non-profit status were seen. At the same time, the pre-existing regulatory framework for CSOs was weak, with a number of different legislations intended to regulate varied CSO forms in place.

Most importantly, the GoK of this wave was a nervous one following a 1982 coup attempt, and growing signs that the its overtly repressive tactics were alienating the population, including those represented by CSOs, as well as the community of DAC/Gs the funding from which the GoK relied on. While DAC/G funding for CSOs was growing, the DAC/Gs were increasingly prone to use the threat of political and economic reform conditionalities tied to their funding flows to the GoK. Amidst GoK public verbal attacks against the sector and accusations that CSOs were a threat to national security, the GoK initiated legislation targeting NGOs, with the stated intent of 'coordinating' the sector. However, all signs indicated that "political exigencies" rather than coordination of NGOs' development work were the order of the day for a GoK also jealous of DAC/Gs' CSO funding (Ndegwa, 1996, p. 36). For this funding not only fuelled CSOs' civic and political engagement activities, but also negatively affected the GoK's profile as omnipotent provider and relatedly, the availability of DAC/G funding for GoK political patronage purposes (Ndegwa, 1996, p. 36; Maina, 1998, p. 151).

The hasty passing in Parliament of the new 1990 NGOs Co-ordination Act saw CSOs equally hastily organize themselves into a new apex body to push for amendments to mitigate the Act's most controlling aspects. The GoK did concede some critical 
amendments, faced as it was with a political imperative to demonstrate, if unenthusiastically, an opening of democratic space. In 1991 DAC/Gs had also suspended aid to the GoK as a means to push for the key political reform of multiparty-ism prior to the 1992 elections. Pressure from CSOs, from the broader public, and from DAC/Gs, including aid suspension, prompted the GoK to reform the Constitution, making Kenya a multiparty state. Opposition political parties, now legal, sided with the CSO sector and DAC/Gs in relation to the Act's amendments, which were emblematic of a broader democratization push. Ultimately, the Act was a product of GoK political agendas, first to quell a growing and increasingly active CSO sector, then to appease it and its allies in an environment of reluctant but incremental democratic opening.

The regulatory framework provided by the Act, under which NGO 'self'-regulation was a statutory requirement, remained consistent through this wave though with some implementation tweaks along the way. However, after only a few years of the Act's implementation, a seed for regulatory change was planted by the regulator, the NGOs Coordination Board, which called for a national NGO policy to underpin the Act. This recommendation arose in part as, while the NGOs Co-ordination Act provided a regulatory means for the GoK to intervene in the evolving CSO landscape by, for example denying registration or deregistration, CSOs continued to seek registration under the alternate regulation options that continued to exist. Wave one closes just prior to convergence between the GoK and CSO sector on the need for regulatory change, slow steps toward which then begin in the next wave. 
Table 2 summarizes key developments within or actions of the main players influencing the CSO regulation and self-regulation landscape.

Table 2: Wave One Key Developments or Actions of Main Actors

\section{GoK:}

- Regulatory change preceded by era of repressive actions (e.g. constitutional reform to single-party state) and treatment of individuals, organizations (e.g. harassment, imprisonment, torture)

- Accuses CSOs of subversion and threatening national security

- Initiates NGOs Co-ordination Act to regulate: eligibility/registration; NGO activities and the coordination thereof; NGO financial accounting; tax/duty-free privileges

- Legislates self-regulation under the Act

- Reluctant and incremental democratic opening though no transition to a new GoK through two elections (stalled democratic transition)

CSO sector:

- Largely social and economic development service oriented sector

- Seek democratic reform from GoK in form of transition to multiparty-ism

- Minimally organized and coordinated at first

- Absent self-regulation, proposal for light self-regulation rejected by GoK

- Organize to influence NGOs Co-ordination Act toward less controlling, more enabling Act, with partial success

- Take up legislated self-regulation under new legislated NGO Council, largely designed to encourage upholding of certain norms and values by CSOs, but still Council deemed strong in representing the sector

- Civic and political activism growing

- Continued registration under regulatory regimes other than NGOs Co-ordination Act

DAC/Gs:

- Post-Cold War context push for democratic reforms from GoK

- Political and economic conditionalities applied to aid leading to reduced funding for GoK

- Increase aid to CSOs including but not limited to civic and political activism for democratic reform

- Financial, policy and moral support to CSOs' negotiations on NGOs Co-ordination Act 
Figure 2: Wave One Timeline: Key Political and CSO Regulation Developments

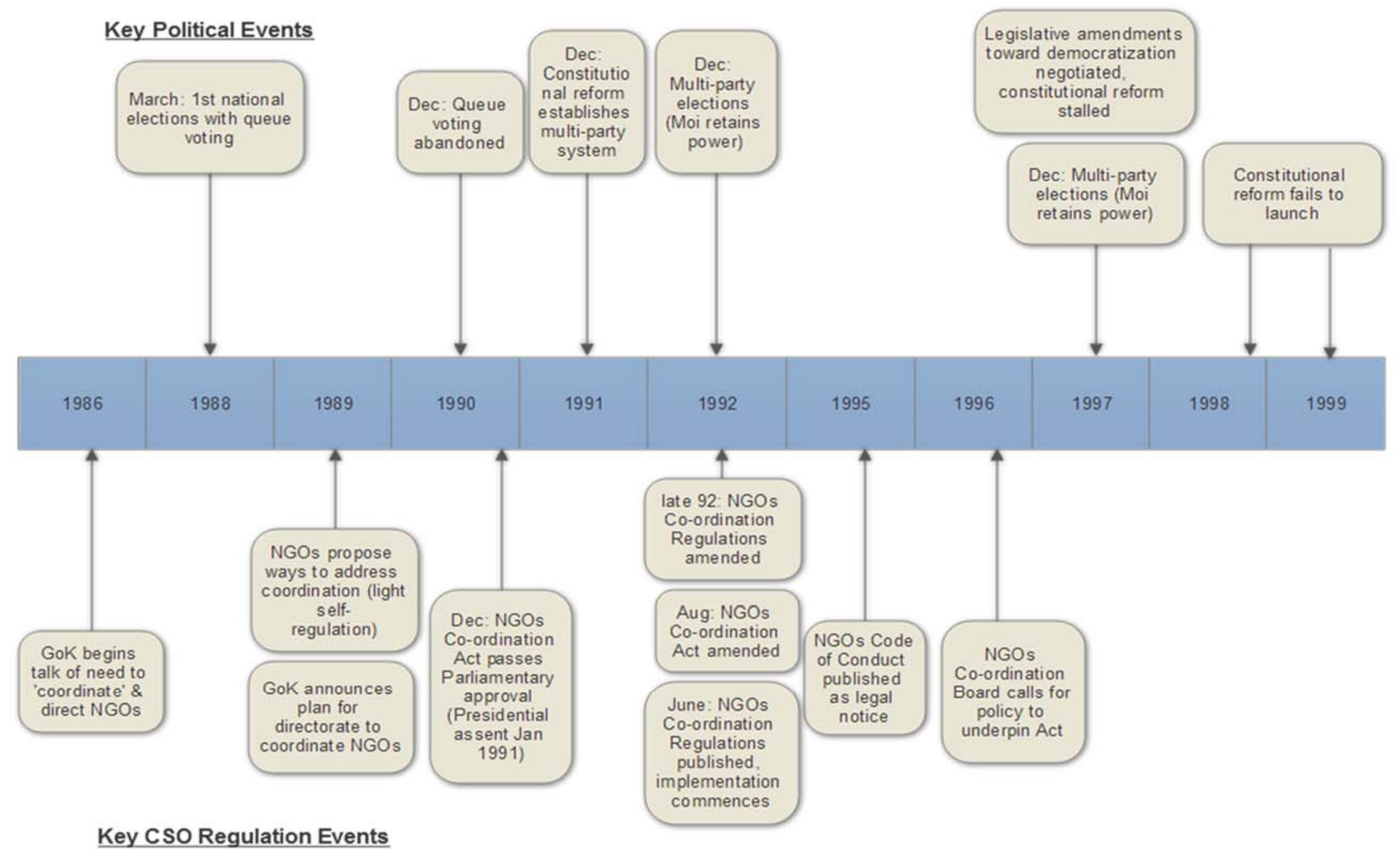




\subsection{Drivers of CSO Regulation}

\section{In Focus: Perspectives on Regulatory Change Drivers}

The number of NGOs in Kenya mushroomed.... the government, concerned by the growing influence and independence of NGOs, began to talk of registration and monitoring. (Hornsby, 2012, p. 449)

The NGOs Co-ordination Act was enacted due to a realization on the role of NGOs. Most were working in service delivery but the influence of advocacy types was increasing. Government was trying to find a platform to control the advocacy NGOs and their funding flows. (I47_CSO)

The emergence of the regulation of $N G O$ sector in Kenya.... coincides... [in] the late '80s.... [with] a feeling in Government that the reduced direct aid to the Government was actually matched directly with the increase of the NGO funding.... So there was almost alarm in the eyes of the Government that "We're now being pushed to the periphery and NGOs are getting an ascendance”. (I39_Other)

The motivation behind the Act is... a preoccupation with all forms of control. (I55_CSO)

I'll never forget, January 14th of 1991 [the Act] received Presidential assent.... the resistance to the NGO Co-ordination Act in 1990, started in my office..... [CSO leaders] met.... and talked about what is the effect of this and none of us knew a lot. So we decided we'll go and consult our lawyers.... we decided this is potentially dangerous for us and for the whole community. And we very quickly built up a movement against the NGOs Co-ordination Act.... we started resisting from there.... We managed to get the ear of the Government because of the next Paris Club meeting, we had talked to several [DAC/Gs] who then went and raised that at the Paris Club meeting. They [then] said [to the GoK], "We're very concerned.... this NGOs Co-ordination Act is going to basically cripple the operations of NGOs"..... because [the GoK] needed the money, they were willing to listen. (I12_CSO)

The critical voice that came after the fall of the Berlin Wall was not there before. The greater threshold for accountability was not there before. So, with the advent of multiparty-ism, which came due to pressure from civil society and the opposition politicians, this created a space for Kenya to transact political business, and then a greater scrutiny of Government started at that time. So, we had civil society that were now closely looking at the Government, the way Government was operating. (I16_DAC/G) 


\section{Political Backdrop: From authoritarianism to a slow, stubborn process of democratization}

By the time of entering this regulatory wave in the late 1980s, Kenya's political environment, continuing in the pre and post-independence vein, was nothing short of authoritarian. President Moi, who had served as Kenya's vice-president and Minister of Home Affairs since 1967, succeeded President Kenyatta after his death in 1978. Kenyatta's choice of Moi as his successor had been informed in part by the fact of Moi's originating from a small tribe of the Kalenjin ethic group. Moi was not considered a threat to Kenyatta, a Kikuyu, and his Kikuyu loyalists as he did not come to the political scene with a large ethnic group backing, nor was he a Kikuyu competitor; Moi offered Kenyatta a conservative and loyal ally (Hornsby, 2012, p. 165). Despite divisions between (Kikuyu-led) pro and anti-Moi factions of the ruling party, KANU, over succession, a combination of strong party support for Moi relative to other contenders; media suppression; fear of detention; and the absence of opposition parties in this singleparty $^{45}$ state placed Moi in the presidential seat (Hornsby, 2012, pp. 327-329).

On coming to power Moi promised a policy of following in the footsteps of his predecessor (nyayo, literally 'footsteps' in Swahili) (Hornsby, 2012, p. 332). Indeed, the Moi GoK entrenched characteristics of the political environment that had been seen under his predecessor: "Moi inherited and adapted [Kenyatta's] model of authoritarianism and

${ }^{45}$ Even prior to full independence, Kenya was "showing signs of moving towards a oneparty state" as members crossed the floor so as not to miss out on the rewards potentially available in the independent state (Hornsby, 2012, p. 86). Later, the logic of national unity to counter perceived tribal threats was used in Kenya (and elsewhere on the continent) to suppress opposition parties, and by 1964 KADU dissolved (Hornsby, 2012, p. 95). 
the administrative structures that supported it" (Hornsby, 2012, p. 12). One aspect of this model was centralization of power and personalization of the "omnipotent "big man"" presidency (Hornsby, 2012, p. 347) ${ }^{46}$ This contributed to a perception that politics was a zero-sum game in which access to patronage and other resources would only be available to the President's ethnic group (Commission of Inquiry into Post-Election Violence [CIPEV], 2008, p. 23), a perception maintained through a constant and calculated ethnic balancing act in the meting out of political positions and other patronage.

The far-reaching patron-client system was also key to the maintenance of loyalty. As described by Hornsby (2012), "patron-client relations were visible in every aspect of society, but were most obvious in the political sphere", where "an informal asymmetrical exchange of goods and services formed the basis of most political activity" (pp. 260261). Resources such as money, jobs, and political appointments or endorsements, as well as physical security, were offered to clients by the patrons - politicians, senior civil servants, and business leaders - in a vertical system of patronage from the President as "super-patron" or "patron in chief" down to communities and the harambee communitybased organizations (Hornsby, 2012, pp. $347 \&$ 260-261). Alongside and fostered by this system of patronage, a culture of "hand-out[s]" and "acquisitiveness" bloomed (Hornsby, 2012, pp. 262-263). Expectations of chai (literally translated as 'tea' but meaning a bribe) accompanied many a transaction, small or large (Hornsby, 2012, p. 346).

${ }^{46}$ One of the more harmless examples of how this was done was the 1973 ban on use of the title of 'president' for any head of an organization (Hornsby, 2012, p. 258). 
The highly centralized Presidency also meant a weakening of the authority and legitimacy of state institutions (CIPEV, 2008, p. 23), exemplified in the habitual resorting to constitutional amendments as a means of maintaining the status quo. At the other end of the spectrum of powerful tools of repression, detention without trial, harassment, and torture were used to punish any form of dissent (Hornsby, 2012, pp. 165, $254 \& 258$ ). Both the Kenyatta and Moi GoKs, in a Cold War alliance with the West, accused perceived challengers to their authority of Marxism or radicalism, amounting to sedition (Hornsby, 2012, pp. 288, 341, 347, 374, \& 388). Despite these leaders' publicly stated preference for a post-colonial "Africanisation" versus either capitalist or socialist ideologies deemed as foreign, they maintained Western alliances while Moi developed a "particular ire" for the Marxist-leaning thinking coming out of Kenya's universities (Hornsby, 2012, pp. 121, $341 \& 347$ ).

The maintenance of Kenya as effectively a single party state was also a powerful control tool maintained through a variety of means. Theoretically, registration of political parties was allowed under the colonial-era Societies Ordinance ${ }^{47}$ of 1952 , but the registrar simply rejected parties' registration applications (Hornsby, pp. 54 \& 154). An effort to establish a second party began around 1966 when a KANU faction considered "radical" due to its redistributive bent and opposition to the GoK's conservative, (stateled) capitalistic, and pro-West allegiance left KANU through a combination of manipulation and choice (Hornsby, 2012, p. 159). Though a new party led by Oginga Odinga (a Luo) did manage to form, it faced obstacles as the GoK implemented an array

${ }^{47}$ Which became the post-colonial Societies Act. 
of tactics to undermine it, including delaying its registration, banning branch meetings, and a constitutional amendment that prohibited Members of Parliament (MPs) from crossing the floor (Hornsby, 2012, pp. 160-164). Ultimately the party was banned in 1969 as a "subversive organization", and candidates in the 1969 elections could only be KANU members (Hornsby, 2012, pp. $214 \& 215$ )

Later, in 1982, another effort was launched, again by Oginga Odinga and now also his son Raila, to establish an opposition party ${ }^{48}$, the platform of which was strongly anticorruption and pro-democracy, combined with a socialist/Marxist redistributive bent (Hornsby, 2012, p. 374). The GoK undermined this effort in a broad sweeping way through a constitutional amendment. Amendment 2A of 1982 outlawed political parties other than KANU, and was accompanied by other constitutional and legislative amendments with the threat of detention for MPs who would dare oppose them (Hornsby, 2012, p. 375). In this manner the KANU-led GoK "legalise[d] its monopoly on power" (Hornsby, 2012, p. 374).

Left with little recourse, in the same year Kenya experienced a coup attempt led by members of the air force, with links to the rebels of the banned opposition group; father and son Odingas were placed under house arrest and jailed respectively (Hornsby, 2012, p. 377). As a result of the coup attempt, previously evident "authoritarian and paranoid

${ }^{48}$ As a result of his reformist stance, Odinga was increasingly sidelined from KANU, though he was "nominally a member" (Hornsby, 2012, p. 373). In 1982 he attempted to establish a new CSO, though registration was refused (Hornsby, 2012, p. 373). 
aspects of the president's personality became dominant" and the authoritarian tendencies of the Moi GoK reached peak levels (Hornsby, 2012, p. 380).

This was, however, not only due to fear of this opposition group and its supporters, but to the factions and tensions growing within the ruling party itself, including among prominent Kikuyu who had seen Moi as merely an interim leader until the Kikuyu could again gain power (Hornsby, 2012, p. 331). Moi, like his predecessor, had done his due diligence in maintaining loyalty through skilled manipulation of the "arithmetic of ethnicity", imparting patronage across ethnic groups, each maintaining a "kitchen cabinet" of influential and loyal inner circles (Ndegwa, 2003, p. 150; Hornsby, 2012, pp. $261,373 \& 382)$. Once in power, Moi over time implemented an implicit policy of "deKikuyuisation", removing Kikuyu, the majority ethnic group ${ }^{49}$, from senior civil service and parastatal positions they had been granted under Kenyatta, though he did so while maintaining key Kikuyu allies in top positions of his coterie and otherwise finding ways to "placate" this economically and politically powerful ethnic group (Hornsby, 2012, pp. $334,338 \& 346)$. But as time passed, this strategy was proving insufficient for Moi to maintain loyalty. At the time of the coup it was rumoured that at least one, possibly two

${ }^{49}$ Kikuyu make up approximately 25 percent of Kenya's population, followed by the Kalenjin and Luo at approximately 12 percent each (Ndegwa, 2003, p. 150). These are considered to be Kenya's three main ethnic groups. Other, smaller groups are seen as similar, and/or allied with one of the three main groups though alliances shift over time. Thus the term "Gema" is used to cover Kikuyu (or Gikikuyu in formal Swahili) but also the smaller Embu and Meru groups as well as the Mbeere and Tharaka, while the term "Kamatusa" is used for the grouping of Kalenjin, Masai, Turkana and Samburu tribes (Hornsby, 2012, pp. 10 \& 22). 
other coup plots had been in the works prior to this unsuccessful attempt, and that top army officials had been aware of the pending coup (Hornsby, 2012, p. 378).

Moi's reaction to the coup plot(s) included sackings, passport seizures, closing of the University of Nairobi and Kenyatta College for a year, detentions and imprisonments without trial, and torture (Hornsby, 2012, p. 379). GoK actions forced dissenters underground, or into exile, though the repressive tactics spilled broadly across Kenyan society (Branch, 2011, pp. 162, 163, 165 \& 167). An informal group, Mwakenya ${ }^{50}$ emerged, comprised of anti-government dissidents with Marxist influences that distributed anti-GoK literature and allegedly engaged in nefarious activities such as sabotaging of rail and phone lines (Hornsby, 2012, pp. 414-15). Though considered largely "ramshackle" and "ineffectual", the Moi GoK used its existence to exaggerate the threat to "national security" and justify repressive tactics (Branch, 2011, pp. $163 \&$ 168; Hornsby, 2012, p. 416). The post-coup period of Moi's rule is considered among the darkest in Kenya's history.

The clampdown on the university... lecturers were detained without trial and including the present Chief Justice and other people.... then dissent went underground.... you'll find this underground movement called Mwakenya.... it was clamped down very seriously, a lot of people were taken to court and tortured.... institutionalization of torture [became] a means of investigation with building of Nyayo House torture chambers.... So, there was that whole sense of.... "We [GoK] don't want... dissent and we are going to clamp down on dissent", which took dissent underground. (I11_Other)

Later, the Moi GoK implemented a new means of controlling election outcomes by introducing a system of queue voting (mlolongo in Swahili, meaning 'sequence' or

${ }^{50}$ Mwakenya stood for Muungano wa Wazalendo wa Kukomboa Kenya which translates to Union of Patriots for the Liberation of Kenya (Hornsby, 2012, p. 414). 
'order'), first for the $1985 \mathrm{KANU}$ elections then for the 1988 general elections (Hornsby, 2012, pp. 399 \& 408). According to Branch and Hornsby, and to the interviewee quoted below, this move was a source of "widespread disgust" and was the last straw that led to CSO and citizen agitation for democratic reform toward a multiparty system (Branch, 2011, p. 177; Hornsby, 2012, p. 408).

In 1988 Moi changed the election system from secret ballot to queuing up, what we call mlolongo. Yои queиe up behind the picture of your candidate... his argument was this is.... the African way of elections which is transparent, but then it became a farce because you line up behind a person and then they announced the other guy whose got three people in his line as the winner. So, it just created so much dissent.... [yet] it was meant for Moi to be able to manipulate the election of people into parliament the way he wanted them, to get rid of those who were dissenting. (II1_Other)

The introduction of queue voting was not the only source of demand for change. Successive acts of overt or covert GoK tyranny had "alienated too many Kenyans", not least of which the 1990 messy cover-up of the murder (and alleged torture) of a prominent post-independence civil servant then MP (Branch, 2011, pp. 176 \& 190-193, I11_Other). ${ }^{51}$ Further, the patronage that had helped sustain Kenyatta then Moi's leadership was becoming more difficult to come by as the country's economy faltered, and as DAC/Gs' conditions under structural adjustment programs (SAPs) reduced public spending (Branch, 2011, p. 176). Adding to this, civil society in Kenya, and a growing political opposition, were emboldened by the success of democracy movements in Eastern Europe as the Berlin Wall fell (Branch, 2011, pp. 182-185; Hornsby, 2012, p.

${ }^{51}$ The victim, Robert Ouko, had developed a view contrary to that of Moi and others in his coterie, that corruption in the GoK needed to be reined in to maintain relations and thus funding flows from DAC/Gs (Branch, 2011, p. 190). His murder was seen as a Moi GoK assertion of its supremacy amidst growing opposition (Branch, 2011, p. 190). 
463). While per the ethnic order of things in Kenya the not-yet-permitted opposition was dominated by the Kikuyu and Luo ethnic groups (Branch, 2011, p. 199), such was Kenyans' alienation with the Moi GoK that the opposition, citizen protestors, and CSOs crossed ethnic lines. ${ }^{52}$

Under great pressure and amidst growing domestic unrest, the Moi GoK slowly came to terms with the fact that "the long-established tactics for suppressing dissent and seeing off the challenge of rivals were out of date", and that a new approach was required (Branch, 2011, p. 193). The change in strategy was not immediate however. Mass prodemocracy demonstrations were crushed by state-sponsored violence, and yet another repressed attempt at establishing an opposition party, with supporters from all walks of Kenya's ethnic spectrum, was repressed (Branch, 2011, pp. 193-195). Still, step-by-step, the Moi GoK began to concede reforms, including abandoning queue voting in 1990 (Hornsby, 2012, p. 479). In December 1991, after a meeting of the Consultative Group on Kenya in Paris, this 'Paris Club' group of multilateral and bilateral donors' suspension of aid $^{53}$ in the absence of both economic and political reforms led Moi to announce that multiparty-ism would be implemented, which it was through a constitutional amendment before the year's end (Branch, 2011, p. 196; Hornsby, 2012, pp. 486-487).

${ }^{52}$ See for example Branch's coverage of the protests following the 1988 elections and of the 1990 Saba Saba (7/7 for July 7) mass rally (2011, pp. 176-178 \& 193-195).

${ }^{53}$ The term "suspension of aid" is used here and throughout this thesis to simplify the intricacies of DAC/Gs' manipulations of the varied aid and related tools at their disposal, in collaboration with the IFIs. In this instance balance of payment support - the primary macro-economic support tool at the time - was suspended, as were discussions and decisions on new or pipeline support (Hornsby, 2012, p. 486). Generally when DAC/Gs suspended aid it was ODA, loans or credit to the government, while humanitarian assistance and project aid tended to continue. 
Despite the successful reform to a multi-party system, the business of democratization in Kenya remained unfinished. Throughout this wave, Moi's incumbent KANU party managed to stay in power through elections in 1992 and 1997. Opposition political parties struggled to remain internally united or to join forces and gain a foothold (Hornsby, 2012, pp. 531 \& 604; Branch, 2011, p. 208; Ndegwa, 2003, p. 146). Also, the Moi GoK maintained various means of tilting electoral outcomes - including election rigging, neglecting to pursue critical institutional pro-democracy reforms, and fomenting ethnic divides (Hornsby, 2012, pp. 530-536). The advent of multiparty-ism in 1991 heightened ethnic tensions and violence. Long-standing divisive issues in particular in relation to land, and relatedly, to devolution were trotted out as GoK loyalist MPs who feared a loss of KANU's power under multiparty-ism, or who were seeking to gain power, "orchestrated" ethnic-based conflict, aided and abetted by provincial administrations and GoK security and police forces (Branch, 2011, pp. 198 \& 201). When it came time for the 1992 elections (and later for the 1997 elections), politicians continued this pattern of ethnic divisiveness and incitement to violence - including by state police and security institutions - between Kenya's main ethnic groups with "grievances about historical injustices", as they sought to hold onto or gain power (CIPEV, 2008, pp. 22-23; KNCHR, 2008, p. 24). Conclusions and recommendations from various domestic inquiries and reports were not heeded, contributing to a growing culture of impunity in the country (CIPEV, 2008, p. 22).

KANU's 1992 election win was also aided by the use of state funds and a corruptly acquired "war chest" for campaigning and patronage purposes (Branch, 2011, p. 219; 
Hornsby, 2012, pp. 508, $520 \&$ 534). In 1993 the Goldenberg scheme was revealed, the Goldenberg company having been established, and granted a monopoly over gold and diamond exports, for the benefit of its owners and GoK friends. Hundreds of millions of US dollars were skimmed through exploitation of an export credit and bonus scheme, the spoils of which were enjoyed, as it turned out, not only by the incumbent GoK but also by political opponents (Branch, 2011, pp. 219-221). Kenya, included in TI's fourth-ever CPI in 1998, ranked $74^{\text {th }}$ out of 85 countries assessed, with a score of 2.5 out of 10 (TI, 1998).$^{54}$ By the end of this wave in 2002 Kenya's CPI rank was 96 out of 102 countries covered by the index, with a lower score than in 1998, at 1.9 out of 10 (TI, 2002).

As the 1997 elections approached, opposition parties desperate for change began to work together with a growing civic and politically active segment of the CSO sector to push the Moi GoK on additional constitutional and other reforms felt needed for a more level and democratic playing field. A Citizens Coalition for Constitutional Change CSO that had formed following the 1992 elections convened an assembly of $600 \mathrm{CSO}$, civil society and opposition party representatives in a National Convention Assembly (Hornsby, 2012, p. 597). ${ }^{55}$ The group elected a National Convention Executive Council (NCEC) to represent them in pushing demands forward (Hornsby, 2012, p. 597). With a long-term goal of constitutional change, in the short-term the group's pre-election red line was for a series of legislative changes that, though less ambitious, would loosen the ruling party's grip on power (Hornsby, 2012, p. 597). Mass NCEC-incited protests,

${ }^{54}$ The most corrupt country in 1998, Cameroon, scored 1.4 out of 10. In 2002 the most corrupt country, Bangladesh, scored 1.2 out of 10 .

${ }^{55}$ This initiative was partially funded by a US foundation (Hornsby, 2012, p. 597). 
which turned violent when disrupted by police and security forces and pro-KANU "vigilantes", coupled with pressure and some aid suspension from DAC/Gs, led the Moi GoK to concede the need for some level of reform though Moi was only prepared to discuss these with elected leaders, and not with non-elected representatives in the NCEC including from the CSO sector (Hornsby, 2012, p. 597-599; Kanyinga, 2004, p. 19).

From this point, the NCEC movement split between the more hard-line and moderate reformers. Dissatisfied with the initial reform offerings made by the Moi GoK as well as by the absence of dialogue to reach reforms, NCEC hard-liners incited a general strike, which led to clashes and the death of 40 people (Hornsby, 2012, pg. 600). On the other side, moderate MPs from the opposition and KANU formed an Inter-Parties Parliamentary Group, coming up with compromised, but still significant reforms that were passed in Parliament and welcomed by the DAC/G community fearful of further instability (Hornsby, 2012, p. 600; Katumanga, 2004, p. 49; I55_CSO). Through these reforms, state authority would be reduced through repeal or revisions to a number of repressive laws. These reforms saw, amongst others, abolishment of preventative detention and the sedition prohibition, and, a time limit for the Registrar of Societies to respond to registration requests under the Societies Act, while electoral regulations were also revised (Hornsby, 2-12, pp. 600-601). A Constitution of Kenya Review Act (1997) would establish a commission (Constitution of Kenya Review Commission or CKRC) with nominees put forward by political parties and CSOs, though disagreement over the membership and objectives of the Commission stalled its establishment through to 2000 (Hornsby, 2012, pp. 601 \& 624-625). 
While these reforms "permitted a significant opening of political space", the encumbent Moi would again win the elections in 1997 (Hornsby, 2012, p. 601). Oppostion parties remained divided both internally and among themselves, while the preelection reforms negotiated by the Inter-Parties Parliamentary Group proved inadequate to diffuse the election incumbents' power and privileges (Branch, 2011, pp. 227-228). While there was not a sense that the elections had been rigged outright, they were manipulated in many more or less subtle ways (Branch, 2011, p. 228).

Following publication of the election results and associated ethnic voting patterns, some parts of the country fell into ethnically-charged violence of score-settling and retaliation (Branch, 2011, pp. 229). Those participating from the Kikuyu, Kalenjin and Luo and their affiliated ethnic groups were actively supported by "politicials, KANU officials, district officers, district and provincial comissioners and officers in the security forces" (Branch, 2011, p. 231). Over the 1990s, these actors had not only participated actively in the violence, but tapped into, fomented and "sponsored", "private armies and militias" for the purposes of protection and retaliation (Branch, 2011, p. 237). The tendency to resort to violence and unrest was aided by the economic situation in the country which had deteriorated due to economic policies, some implemented as part of DAC/Gs' SAP requirements to liberalize Kenya's economy, that saw rising food prices, low incomes, and increasing unemployment (Branch, 2011, pp. 232-234). By the end of this wave, there was no shortage of Kenyans who had come to "believe that the only hope for the rebirth of their country lay in the fall of KANU and Moi” (Branch, 2011, p. 244). 
Over the period of this wave the Moi GoK's relationship with CSOs remained acrimonious. From the beginning the GoK's authoritarian nature meant a reluctance to move the country on a path of genuine democratization. It was only under pressure from CSOs, the official political opposition, and DAC/Gs, working together and separately, that a slow path to reform was trod. For the Moi GoK, as its overtly repressive tactics of suppressing opposition whether from the CSO sector or otherwise became increasingly difficult to sustain in the post-Cold War era of democratization, other, more legitimate means of controlling the sector were needed. The NGOs Co-ordination Act was in part intended to and did, as will be seen, somewhat serve this controlling purpose, though it was not adequate to fully stymy the voices of CSOs and others demanding change.

\section{Sector Growth: Burgeoning NGO numbers}

The 1980s and 1990s saw a burgeoning of CSOs across Kenya, inclusive of both indigenous Kenyan and international ones (Kanyinga, 1995, pp. 79, 100-102), pursing both what Hornsby calls "developmental" goals - social and economic development - as well as "political" goals - civic and political engagement (2012, p. 449). Numbers more than tripled from an estimated 125 CSOs in 1974 to 400 in 1987, then representing the greatest concentration of CSOs in an African country (Bratton, 1989, p. 571 citing USAID, 1986 \& Kenya National Council of Society Services [KNCSS], 1987). By 1990 the figure reached an estimated 500 (Ndegwa, 1996, p. 19), continuing to increase to 836 by 1997, and 1,234 by 1999 (Kisinga, 2009, p. 57).

Ndegwa (1996) attributes the sector's early growth to Kenya's presence as a regional hub including for international organizations (such as DAC/Gs and international CSOs); 
its well-developed communications network; and the tradition of harambee that was conducive to CSO formation (p. 9). Harambee was a form of associational life that had been encouraged and flourished by the Kenyatta GoK at independence as a form of nation building (Hornsby, 2012, pp. 84 and 138). Through harambees people pooled effort and resources to implement local development activities or provide assistance to members in need, usually within a particular locality (Office of the Vice President and Ministry of Home Affairs [OVP \& MHA], 2006, p. 8; Brass, 2012, p. 210). Harambees were also a site of political patronage, used by the GoK to drum up loyalty at decentralized levels (Ndegwa, 1993, p. 10). This meant a relatively "amenable political environment" for the formation and operation of CSOs, at least of social and economic development-oriented ones, under President Kenyatta's reign (Fowler, 1994, p. 130; Ndegwa, 1996, p. 9).

Under his successor President Moi, the political climate became less amenable, with the single-party state actively repressing civil society and CSOs (Ndegwa, 1996, pp. 2627). Still, CSO numbers continued to grow under this increasingly authoritarian regime, which "reflected the difficulties of seeking change through formal politics, and the resulting diversion of political energies into NGOs, churches and professional associations" (Hornsby, 2012, p. 449). The sector's growth thus occurred both despite and because of years of post-Independence success, especially under the single-party regime format, in deregistering, proscribing, and otherwise eliminating a vast swath of CSOs of various natures as well other forms of independent voice or action (Ndegwa 1996, pp. 26-27; Kanyinga, 2004, p. 14). CSOs were seen "by many.... as.... the way 
forward for taking action on matters affecting the lives of the people" (Kameri-Mbote, 2000, p. 3) including all manner of economic, social, civic and political ills.

A critical ingredient of the sector's growth through the 1980s and onward through wave one was the influx of DAC/G financing for CSOs, with a new emphasis on CSOs' civic and political engagement, as is discussed separately under the DAC/G section below.

\section{Type of CSO Activities: Service orientation dominant, civic and political activism growing bolder}

Social and economic development and associated service-related activities was the "primary concern" for most of the CSO sector entering this wave (Fowler, 1994, p. 165), though the civic and politically engaged segment of the sector was growing and increasingly active.

In the colonial era Kenya's CSO sector was dominated by organizations involved in social and economic development work, whether for public or member benefit. These included the harambee self-help groups, occupational or professional associations, and religious and secular service providing CSOs (Kameri-Mbote, 2000, p. 2). Amutabi (2006) points to the role of (then) social and economic development NGOs such as OXFAM and CARE, as well as philanthropic bodies such as the Rockfeller Foundation, in the provision of services such as in agriculture and health, both to the settler and African population (pp. 88-89 and 101). Certain colonial era CSOs had been civic and politically active, even as such activities were largely banned but ultimately impossible to 
fully contain. Some of the first Kenyans to become members of the colonial Legislative Council, and ultimately the independence movement, were affiliated with such CSOs. ${ }^{56}$ As noted however, post-independence, civic and political activism by CSOs or otherwise was not tolerated.

The sector's social and economic development activities continued and expanded post-independence, including CSOs' prominent role as first responders to various humanitarian crises such as drought and famine in Kenya during the mid-late 1970s, and later, in the 1984-86 Ethiopia famine (Fowler, 1994, p. 130, Hornsby, 2012, pp. 346 \& 506; Ndegwa, 1996, p. 21). Supported in their humanitarian work by vast private donations and ODA from DAC/G countries, some foreign CSOs stayed on in Kenya after the humanitarian crises ended, either working in refugee or internally displaced persons camps, with many transitioning to social and economic development programming (Ndegwa, 1996, p. 21 citing Kanyinga, 1993). The sector's social and economic development role was for the most part welcomed by the GoK as a contribution to "nation building", and for the political gains for politicians' whose constituents were being served by CSO projects (Fowler, 1993, p. 130). Estimates for 1990 suggest CSOs were contributing 35 percent of health services and 40-50 percent of education services in Kenya (Robinson, 1997, p. 74 citing Mushi et al., 1992).

\footnotetext{
${ }^{56}$ Two of the first elected non-European Legislative Council members, Oginga Odinga and Tom Mboya, were respectively prominent within the Luo Union, an ethnic-rooted social welfare and cultural CSO, and the Kenya Federation of Labour (Hornsby, 2012, pp. 54-55).
} 
At the same time, the growth in CSO numbers brought on by the diversion of political energies to CSOs, as noted by Hornsby (2012) meant growing incidences of their civic and political activism, and influence, as CSOs called out increasingly intolerable GoK abuses and pushed for democratic reforms. Most notably in 1986, and much to the GoK's consternation, the National Council of Churches of Kenya (NCCK) and its members, as well as the Catholic church took a lead in the (eventually successful) stand against Moi's introduction of a queue (mlolongo) versus secret ballot method of voting (Ndegwa, 1996, p. 34; Hornsby, 2012, p. 409). ${ }^{57,58}$ According to Hornsby (2012), "the introduction of queue voting... proved the foundation of civil society's engagement in active politics" ( $p$. 408). The NCCK and other civil and politically engaged CSOs were later pivotal in applying pressure on the GoK to repeal the single party state clause $2 \mathrm{~A}$ of the Constitution, pressure to which Moi ultimately succumbed in 1991, thus opening the country to its first genuine multi-party election in 1992 (Maina, 1998, p. 166; Bratton, 1994; Hornsby 2012, p. 586). Non-NCCK churches, as well as professional associations specifically the International Commission of Jurists Kenya chapter and the Law Society of Kenya were also "at the forefront of the democratic campaign" (Maina, 1998, p. 151). Another historically significant instance of CSO civic and political engagement was seen

${ }^{57}$ Note that civic and political activism, as well of course as proselytization, were not the only activities the churches were involved in. The churches, and other religious organizations, were also typically involved in social and economic development, sometimes with dedicated departments or affiliate organizations (Kanyinga, 1995, p. 103).

${ }^{58}$ Not all of the churches, NCCK members or otherwise, joined the condemnation of queue voting; some pro-Moi GoK churches disassociated themselves from the anti-queue voting movement (Hornsby, 2012, p. 409). 
in the Green Belt Movement's environmental activism. This peaked in 1989 with the Green Belt's launch of the first CSO court case against the GoK in opposition to the latter's effort to replace central Nairobi's only public green space, Uhuru Park, with a private media complex (Ndegwa, 1996, p. 35; I39_Other). ${ }^{59}$ Later the Green Belt Movement would broaden its activism, for example pushing for an end to political imprisonments (Branch, 2011, p. 189).

That these CSOs were willing to engage in such political advocacy despite the highly repressive environment is attributed to a sense of protection due, in the case of the NCCK, to Kenyan's "religiosity"; Moi "could hardly be seen to be gagging the clergy" (Branch, 2011, p. 180). It is also attributable in part to these CSOs' international networks and connections, and the financing that came with it (Ndegwa 1996, p. 37; Fowler 1994, p. 203). International CSOs such as Amnesty International were also a source of solidarity for Kenyan civil society within an "emerging transnational human rights network" that helped monitor and publicize the situation in Kenya (Hornsby, 2012, pp. $417 \& 463)$.

In the 80 s the work that Amnesty International had done.... exposing human rights violations, the work that Africa Watch... had done in 1991 again in documenting these things was very, very powerful.... [human rights] became.... a narrative that was available and so the whole concept of human rights as an avenue for dissent and for challenging became clear to people in this country. (I11_Other)

59 The case was dismissed on the grounds that it had no right to be heard (locus standi), though the park was saved due to added pressure from protesting DAC/Gs concerned not only with environmental considerations but the high cost of the construction project in an era when the GoK expected DAC/Gs to fill the country's budget gaps (Hornsby, 2012, p. 464; Branch, 2011, p. 186). 
As this wave evolved, CSOs continued to focus primarily on social and economic development work. However, in the post-Cold War context, with political space slowly opening following the 1991 constitutional amendment, and the re-election of Moi in the following year, the number of civic and politically active CSOs grew (Hanmer, Ikiara, Eberlei, \& Abong, 2003, p. 95), equally intransigent in their demands for democratic reform and the upholding of rights as the GoK was intransigent in its refusal to enact changes. A Kenyan civil society leader and activist from early in this wave reflecting on the CSO sector's activities and capacity in that era notes:

A lot of things have been done by civil society, so it's being very successful.... We've got a lot of people who in service delivery have been excellent.... about the accountability groups [civic and political CSOs]. The capacity has been good, but something happened. The first years of civil society and human rights work, pro-democracy work, were quite tough and people - there was quite a lot of risk to be taken, so actually there was a smaller group of people and they [were] dedicated - some not very professional - but.... there was much more courage, passion, commitment. (I11_Other)

DAC/Gs were also a significant source of growth in the civic and politically active segment of the sector, with DAC/Gs increasing funding flows to CSOs as critical actors and $\mathrm{DAC} / \mathrm{G}$ allies in the push for democratic reform in Kenya (and elsewhere in the developing world). For the GoK, these DAC/G-funded CSOs were becoming a threatening force to be reckoned with. In the words of a GoK interviewee:

The fall of the Berlin Wall opened the floodgates. Now you found so many NGOs [working] on human rights and democracy. So Government woke up and thought maybe we need to start regulating the sector. (I45_GoK)

CSOs engaged in areas such as civic education, human rights and gender equality; they advocated for reduced presidential powers; further constitutional reform; changes to the electoral system and boundaries to level the playing field across regions and ethnic 
groups; and various other revisions to repressive legislation such as to the colonial era Public Order Act (1950) that were seen to hinder democratic expression (Hornsby, 2012, pp. $587 \& 597) .{ }^{60}$ While the official opposition was failing to coalesce or obtain muchneeded reforms from the Moi GoK, CSOs, with funding from DAC/Gs and Western foundations, "helped sustain opposition politics", bringing the formal opposition along with them (Hornsby, 2012, p. 587). In the ongoing struggle for democratic reform that characterized this wave, CSOs played a pivotal role, using "shuttle diplomacy" to foster inter-party dialogue and becoming the "intellectual wing of the opposition" (Kanyinga, 2004, p. 22; Ndegwa, 2003, p. 152). The National Convention Assembly's NCEC for example was, strategically, led by civil society representatives, and its members produced models of reform bills that, eventually, formed the basis of GoK legislative review (Hornsby, 2012, pp. 597-599). A number of CSO representatives moved into party politics in the late 1990s as a more formal means to influence democratic change, according to Hornsby, "NGO activists were the aspiring politicians of the 1990s" (2012, p. 628).

Later in this wave, again DAC/Gs influenced CSOs toward civic and political activism, supporting its expansion beyond advocacy for democratic reform. In 1996 the IFIs along with $\mathrm{DAC} / \mathrm{Gs}$ and other creditors launched the heavily indebted poor countries (HIPC) initiative through which qualifying countries needed to meet various conditionalities for debt relief. In 1999, conditionalities for HIPC2 as well as for broader loan, credit and ODA flows began to include countries' development of Poverty

\footnotetext{
${ }^{60}$ Formerly the Public Order Ordinance.
} 
Reduction Strategy Papers (PRSPs). PRSPs were essentially national development plans intended to ensure that financial resources received or freed up from debt relief would be allocated to growth, poverty reduction and development ends. Amongst others, a principle behind PRSPs was that they were to be developed in a participatory manner (Hanmer et al., 2003, p. 7). Though Kenya was not among HIPC qualifying countries, its debt levels not reaching the criteria threshold, it succumbed to IFI and DAC/G pressures and initiated a PRSP process in 1999.

A study on Kenya's PRSP process suggests that it had positive outcomes in building the sector's experience of engaging beyond service delivery or democratic and constitutional reform, into the realm of national and sectoral-level policies for poverty reduction (Hanmer et al., 2003, p. 99). The study further suggests that, after years of friction between the GoK and CSOs, the PRSP process not only gave "indications that [such] attitudes are changing", but also "added force" to the movement for democratic reform and inclusiveness (Hanmer et al., 2003, pp. 105-106 \& 114 ).

\section{Mismanagement or Misconduct in the Sector: Incidences of abuse}

Early in this wave, the CSO sector was not suffering from the type of chronic mismanagement or misconduct, actual or perceived, which would come to plague it in later waves. However, some incidences of abuse of tax privileges were seen prior to enactment of the NGOs Co-ordination Act. Gaps in CSO financial management capacity became evident later as some CSOs grappled with or disregarded management requirements that came with $\mathrm{DAC} / \mathrm{G}$ funding they were so enticed by, while CSOs' programming also became influenced by $\mathrm{DAC} / \mathrm{G}$ priorities. 
In the mid-late 1980s there were incidences of misuse of the 'nonprofit' status and associated tax exemptions. Some CSOs, or individuals associated with CSOs, were for example accused of "capitalizing on duty-free privileges" such as by importing goods for other than the intended development purposes (Fowler, 1994, pp. 152-153 \& 200; I56_Other). A notorious incident purportedly by a faith-based CSO, involved importation of bows, arrows, and uniforms labeled as relief food, thus also contributing to Moi's general sense of unease that followed the 1982 coup attempt against him (Kameri-Mbote, 2000, p. 27; I56_Other). Such incidents prompted new, arbitrarily applied denial by the GoK of duty-free imports for CSOs and work permits for foreign staff (Ndegwa, 1006, p. 35; I56_Other).

The growth in numbers in the sector was not necessarily accompanied by a growth in CSO capacity, at least in the capacity to manage funds, a factor that became increasingly evident with the inflow of DAC/G funding to the sector through the 1990s. Interviews with DAC/Gs in 1996/97 revealed a dominant perception that CSOs in Kenya were "poorly managed", lacking in "financial probity and discipline" (Maina, 1998, p. 157). Maina (1998) refers to CSO "rent-seeking activities" such as inflated invoicing or overcounting seminar participants, especially where a CSO, or more specifically, a CSO leader, had either "captured the donor or.... been captured by the donor" such that donor oversight became "too-friendly" (p. 161 citing Ngunyi, 1996). Incidences of "My Own NGO" and "Non-governmental Individuals", that is, CSOs overly dominated by their leaders, with inadequate governance and management systems in place began to be seen (Maina, 1998, p. 163). 
On the other hand, Maina's (1998) research also found that, in CSOs' perception, $\mathrm{DAC} / \mathrm{G}$ requirements could be "too focused on reports and financial accounting and less on programme $[$ sic $]$ quality and impact" (p. 157). The experience of DAC/Gs' having an inordinate influence on CSOs' programming priorities with the process of discussion and proposal revisions leading to programs that "belonged to the donor, not the NGO" was also identified and became a growing concern as this wave progressed and into later waves (Maina, 1998, p. 157). The risk that DAC/G funding could cause CSOs to become more responsive to $\mathrm{DAC} / \mathrm{G}$ needs and priorities versus those of the people CSOs intend to serve or represent was a cause for concern early in this wave, as noted by Fowler (1994): "increased aid from northern governments [is] making PSOs [private service organizations] less "civic" because they increasingly fulfill.... donor agendas.... official aid to PSOs may be reducing their ability to function as genuine expressions of Kenya's civil society" (p. 300).

\section{Sector Infrastructure and Status of Self-regulation: Initially weak sector organization transformed}

The CSO sector entered this wave "feebly organized" (Ndegwa, 1996, p. 35; Fowler, 1994, p. 148). Early on in this wave however the sector rallied to form an effective apex body, the NGO Network, to influence the NGOs Co-ordination Act, and then to implement self-regulation as the NGO Council. The sector also became increasingly organized over this wave to push the GoK toward democratic reform.

The organizing structure that existed entering this wave was in the form of the Kenya National Council of Society Services (KNCSS). Established in 1963 with financial support from a UK foundation, the KNCSS was meant to be the societies' umbrella 
organization and act as interlocuteur between the sector and the GoK, particularly the Ministry of Culture and Social Services (Fowler, 1994, p. 193). The UK financial support ceased in the mid-1960s and the newly independent GoK began to provide nominal funding and seconded staff (Fowler, 1994, p. 193). Though registered as a CSO, the KNCSS was effectively a "quasi-governmental" umbrella of societies housed under the Ministry of Culture and Social Services (Kameri-Mbote, 2000, pp. $2 \& 27){ }^{61}$

The KNCSS did not prove an adequate organizing infrastructure for the sector. It suffered from a shortage of funding given a minimal allocation from the GoK, and no funding from its members or from DAC/Gs. Its sector coverage was limited as while it included some NGOs, and CSOs registered as societies, other CSOs such as trusts and foundations or companies limited by guarantee were not among its members (Ndegwa, 1996, p. 34). Moreover, its quasi-governmental status meant it did not truly represent the sector. In the repressive environment at the outset of this wave, any kind of "assertive actions" by CSOs or other actors were a risky affair, and the KNCSS was not a body prepared to take such risks (Ndegwa, 1996, p. 35). The KNCSS was disbanded in 1990 (Kameri-Mbote, 2000, p. 2).

As will be seen below in the section on the development and negotiation of the NGOs Co-ordination Act, in the face of the regulatory threat posed by the Act, the sector organized itself, creating a new infrastructure in the form of the NGO Network that demonstrated considerable strength in its mandated role of influencing the Act's

${ }^{61} \mathrm{KNCSS}$ was registered as a company limited by guarantee, a form of CSO regulated under the Companies Act of 1962. 
development. With the Act, the Network's leadership body, the NGO Standing Committee, became the interim NGO Council with a role in aiding the GoK to implement regulation under the Act and responsibility for the sector's self-regulation. The NGO Council effectively fulfilled these roles through this wave before faltering in the subsequent wave. Financing for both the Network and the Council came from DAC/G sources, both directly and indirectly via their members.

The sector was also increasingly organized in its civic and political activism in this wave, as was discussed above in the Political Environment section. The NCEC coalition that worked with opposition political parties to push hard for democratic reforms around the 1997 elections included, but was not led by the National Council of NGOs. Effective at its peak, the NCEC weakened when its more radical and more moderate elements were divided on whether to go along with the Moi GoK's concession to negotiate reforms directly with the opposition parties (Hornsby, 2012, p. 598-600; Kanyinga, 2004, p. 19). In the PRSP process that came later, the NGO Council represented CSOs, facilitating the outreach for this DAC/G-funded consultative process involving national level, decentralized and thematic group consultations across the country (Hanmer et al., 2003, pp. 98, 104, 111 and 116).

\section{DAC/Gs' Funding and Policy Engagement: Fuelling sector expansion, penalizing the GoK}

This first wave saw a trend of increased DAC/G financial flows to the CSO sector alongside on-off aid suspensions to the GoK as DAC/Gs used aid to pressure the GoK to implement economic and democratic reforms. DAC/Gs' investments in CSOs' prodemocracy civic and political activism were felt by the GoK as a threat, while the GoK 
also coveted DAC/G flows to CSOs. Further, aspects of DAC/Gs' CSO funding requirements such as the steering of programming areas and emerging application of results-based management began to be felt by CSOs as constraining their autonomy.

In the lead up to and through this wave, the growth in numbers of CSOs, including those working in social and economic development and in civic and political engagement, was very much a reflection of the availability of $\mathrm{DAC} / \mathrm{G}$ funds flowing to the sector (Bratton, 1989, p. 571; Kanyinga, 1995, p. 100). This occurred in the context of the neo-liberal paradigm of the late 1980s into the 1990 s, central to which were policy conditionalities requiring states in Africa and elsewhere to roll back their reach in social service provision and other arenas. Structural adjustment programs became the overarching model for aid espoused by the IFIs and adopted by DAC/Gs. In part this model was intended to shrink the corrupt and mismanaged African state and "find a better balance between the state and what was becoming known as "civil society"' (Hornsby, 2012, p. 449). Government corruption, mismanagement and democratic shortfalls led DAC/Gs to turn to CSOs to meet development objectives, with CSOs seen as "efficient, less bureaucratic, grassroots oriented, participatory, and contributing to sustainable development" (Ndegwa, 1996, p. 20). In Kenya as elsewhere, DAC/G ODA flowed to CSOs as providers of services able to fill gaps left by the combination of GoK inability (or unwillingness) to provide them combined with active state retrenchment under SAPs, such that CSOs were becoming DAC/Gs" primary "agents of development administration" under a model that preferred a "privatization of development 
interventions" through CSOs and other non-governmental actors (Ndegwa, 1996, p. 33; Bratton, 1989, p. 570).

The West's post-Cold War neo-liberal paradigm also saw a "democracy aid boom" whereby DAC/Gs began to invest their aid in ways aimed at spurring or consolidating democratic transitions, in Kenya and beyond (Carothers \& Ottaway, 2000, p. 5). The 1990s thus saw DAC/Gs turning to CSOs as "an alternative tool to influence domestic politics" in Kenya, with ODA being routed "to NGOs, Christian development organisations and charities and building up civil society as an alternative source of influence", an influence facilitated by the CSOs' dependence and the project-based approach (Hornsby, 2012, pp. 630-631). According to Hornsby (2012), in the 1990s virtually all civic and politically-engaged CSOs in Kenya were funded by "Western donors" (p. 587), though as in the mid-1980s, this was the case for the sector as a whole regardless of CSOs' activity type ${ }^{62}$ Looking at both service and civic and politically active rights and democracy CSOs, by the 1990s, all were reliant on foreign funding sources, included as channelled to Kenyan CSOs via international CSOs or other intermediaries (Fowler, 1994, p. 135; Ndegwa, 1996, p. 24; Maina, 1996, p. 137). One estimate suggests a reliance on foreign funding sources for 90 percent of CSOs' capital and operating expenses (Bratton, 1989, p. 576 citing Mwangi, 1986), another estimates a

${ }^{62}$ Note that DAC/G donors almost exclusively do not fund the formal political engagement avenue of political parties. There are some foreign foundations that do, such as the German party political foundations, and have done so in Kenya such as during the 1992 multi-party elections (Hornsby 2012, pp. 510, 586-587, \& 865). 
dependency on foreign aid of between 80 to 95 percent, inclusive of funds received "second or third-hand" via intermediaries (Hulme \& Edwards, 1997, p. 7).

As noted in the CSO Mismanagement and Misconduct section, as the DAC/G-CSO relationship grew so too did concerns regarding CSOs' vulnerability to the influences of $\mathrm{DAC} / \mathrm{G}$ funding modalities and the associated 'projectization' of CSOs' work. The influence of DAC/Gs' preoccupation with performance management to demonstrate the results of their investments that arose in the early to mid-1990s in Kenya (I51_Other) and elsewhere, which, though not described as such in the international development literature, can be considered part of the NPM paradigm, was one such concern. This $\mathrm{DAC} / \mathrm{G}$ preoccupation arose in response both to domestic pressure in $\mathrm{DAC} / \mathrm{G}$ countries and a collective self-reflection on the need to better demonstrate the impact of almost four decades of international development cooperation (Maina, 1998, p. 158). ${ }^{63}$

The ensuing implementation by DAC/Gs of results-based management with its linear approach to development "as a set of predictable outcomes to be achieved through the ordering of project inputs and outputs", and concomitant application of logical framework analyses and associated indicators began to be seen for its potential negative influence on CSOs, stifling creativity and "limiting them to ready-made policy options" (Biggs \& Neame, 1996, pp. $40 \& 47$ ). A CSO leader of the era reflects below on how DAC/Gs' approach to accountability for results was incongruous with the work of civic and politically engaged CSOs in Kenya.

${ }^{63}$ Official Development Assistance's identity crisis is reflected in, for example, OECD (1996), Shaping the $21^{\text {st }}$ Century: The Contribution of Development Co-operation. 
Donors.... then began now bringing the development paradigm into human rights and democracy.... asking for log frames.... asking for measurements.... asking for results in a year or two.... it's a stupid approach to governance and democracy and human rights and I think it hurt... civil society not just in Kenya but across the world.... Because you can do all this work for five years, ten years you want to see some results, but I cannot guarantee you that in five years - unlike.... if I distribute mosquito nets in a particular area for five years, I can guarantee you almost that we'll have malaria going down by 60 percent... but I cannot guarantee you that in five years people will stand up and start demanding their rights.... I went to Poland and I met Solidarity people and they told me, "Oh, in fact without the West, we'd never have survived as a union doing the work we were doing." There [were] no log frames. None.... was there some pilfering?... Probably there was. Not much.... I think the problem began when the West, in a sense, decided to turn democracy and change into a project like... provision of water. (I11_Other)

Also as part of the neo-liberal paradigm and emboldened by the West's Cold War victory as well as by domestic pressures, DAC/Gs opted to no longer overlook the repressive methods of the Moi GoK, their erstwhile Cold War ally. While previously "Cold War Realpolitik had trumped democracy and human rights at every turn" (Branch, 2011, p. 185; Hornsby, 2012, p. 417), DAC/Gs were now ready to push the GoK to reform. Through policy advocacy, economic and political aid conditionalities, and via funding for CSOs, the DAC/G community squarely "entered the political fray" in Kenya in the early 1990s (Hornsby, 2012, p. 565). Kenya had been a "favoured nation" of the DAC/Gs (Hornsby, 2012, p 359) with ODA levels increasing year-by-year between 1986 and 1990 (see Table B1 in Appendix B). But come 1990, key donors began to play their conditionality hand seriously, threatening to suspend aid to the Moi GoK in the absence of political and legal reform while aid to CSOs would continue, and even increase (Maina, 1998, p. 154; Hornsby 2012, p. 587). Late in 1991, that "the patience of most donors was exhausted" led to "one of the first (near-) united uses of aid to drive political reform in Africa" (Hornsby, 2012, p. 486). DAC/Gs suspension of balance of payments was the "trigger" for the GoK's repeal of the single party state clause of the Constitution 
and other reforms (Hanmer et al., 2003, p. 93; Hornsby, 2012, pp. 485-487; Maina, 1998, p. 166). Despite that throughout his rule Moi expressed disquiet with "'foreign ideologies", and advocated for, if not actually identified and implemented African solutions to the country's and the continent's challenges (Hornsby, 2012, pp. $347 \&$ 631), in this instance the stick of aid conditionality, along with domestic pressures from reformist voices in civil society and beyond, proved too strong to defy.

As noted, as DAC/Gs suspended aid flows to the GoK, their tendency was to maintain and even increase flows to CSOs. Writing in 1996, Ndegwa cites a figure of USD 35 million a year in ODA received by NGOs for work in Kenya, or 18 percent of all ODA going to the country (p. 20). While a not insignificant portion of ODA thus continued to flow (on and off) to the GoK, nonetheless the GoK coveted the foreign aid flows to the CSO sector. A veteran of Kenya's CSO sector links the increased flows of DAC/G financing for CSOs to the emergence of regulation:

The Government [woke] up to the reality that there are NGOs out there who are about to receive many lucrative receipts, so they're competing for whatever it is that they'll get. That then translated to the interest of Government in the NGO sector.... Government started asking, "Okay, so who the hell are these NGOs, and how do they operate.... and if they're going to get all this money, how do we make sure that that money comes through Treasury?" The very first ideas about how to control NGOs actually involved suggestions like [that]. (I12_CSO)

Throughout this wave DAC/Gs continued a dance with the GoK, using aid flows and conditionalities to pressure for economic and political (democratization) reforms. Having suspended critical aid to Kenya in 1991, it was restored late in 1993 with a GoK promise 
of a raft of economic and political reforms, but suspended again in $1997^{64}$ amidst large scale unrest in the country in the absence of constitutional and other reforms to render that year's elections more free and fair (Hornsby, 2012, pp. 560-561, 599, \& 629), restarting, and then stopping again in 2000 (Hanmer et al., 2003, pp. 91-92). Despite such measures, there were limits to DAC/Gs' use of the aid stick. Brown (2001) draws attention to the fact that, despite flaws in the rules and set up of both the 1992 and 1997 elections, as well as irregularities in their execution, the DAC/G community nonetheless endorsed the election outcomes - apparently withholding evidence of election flaws - as DAC/Gs" "primary concern appeared to be the avoidance of any path that could lead to a breakdown of the political and economic order" (p. 726).

Over this wave therefore Kenya's ODA levels and aid dependency fluctuated but reduced over time. In 1990, the year prior to aid suspensions that triggered constitutional reform to a multiparty system, DAC/G net ODA amounted to almost 9.5 percent of Kenya's GNI. In 1991 DAC/G ODA was reduced to 1987 levels at approximately USD 800 million, though with a higher ratio to GNI was at 8 percent, attributed also to the country's poor economic performance. By 1999, with DAC/Gs having continuously upped the ante of their aid conditionalities while the GoK resisted or was slow to reform, ODA to Kenya was close to its lowest level in a decade, down almost 60 percent from

${ }^{64}$ The 1997 suspension was of IMF concessional financing through the Enhanced Structural Adjustment Facility, and cancellation of existing agreements between the GoK, IMF and World Bank, with many $\mathrm{DAC} / \mathrm{G}$ bilateral contributions also suspended (Hornsby, 2012, p. 599). 
1991 levels to USD 326 million, amounting to approximately 2 percent of GNI (see Tables B1 and 2 in Appendix B for the data in this paragraph).

Thus, as DAC/G financial aid to CSOs flourished, the reluctant-to-reform GoK was increasingly hamstrung by pressure from DAC/G corners. Jealous of CSOs' funds, and perturbed by CSOs' DAC/G-funded civic and political engagement, the GoK's view of CSOs did not improve. At the same time, the CSO sector began a relationship of dependency on DAC/G funding that would leave it vulnerable going forward.

\section{Status of State Regulation: Multiple regulatory entry points for the sector}

The NGOs Co-ordination Act of 1990 did not emerge in a regulatory void. Different legislations along with other regulating arrangements, some dating from the colonial era, existed to regulate various types of CSOs, as well as other organization types. This made for a fragmented regulatory framework, and rendered it difficult to have a complete picture of the CSO sector in Kenya. Meanwhile, the granting of tax and other exemptions involved yet other, separate legislation.

Prior to the NGOs Co-ordination Act, various legislations and their regulations were in use under different GoK Ministries to regulate various CSO types including trusts and foundations, companies limited by guarantee, societies, and community-based organizations. These included: the 1923 Trustees (Perpetual Succession) Act for the regulation of trusts and foundations; the Companies Act of 1962 covering companies 
limited by guarantee; and the Societies Act of $1968 .{ }^{65}$ Community based organizations and self-help groups meanwhile were regulated by the Department of Social Services and could register at centralized levels, closer to where they operated. A select few CSOs, such as the Kenya Red Cross Society and the Law Society of Kenya, enjoyed an organization-specific legislated mandate. In addition, some CSOs were regulated via memoranda or protocols with specific Ministries, including the Ministry of Foreign Affairs for some international CSOs, as well as line Ministries.

Entering this wave, Kenya's regulatory framework for CSOs suffered somewhat from its colonial inheritance in different ways. For one, CSOs faced a "limiting legal structure [that] was a legacy of the colonial laws based on restrictive associational rights" (KameriMbote, 2000, p. 1). For example, the colonial-era legislation of the Societies Act (previously Ordinance) had set a precedent for the use of regulation to control associational life. The Societies Act not only required that any society of ten or more persons be registered under the Act, but provided the responsible Minister the ability to declare as unlawful any society he/she deemed as "dangerous to the good government of the Republic" (s. 4), while the "Special Branch" security and intelligence service was called upon to aid in vetting of applicants (Kameri-Mbote, 2000, p. 27). Secondly, independent Kenya inherited a somewhat incoherent regulatory framework for CSOs with multiple regulation options, none specific to public benefit CSOs. Even within the CSO categories covered by the varied regulations there was variance in the type of CSO each covered, while they also covered other organization types, and not all of the CSOs

${ }^{65}$ The Societies Act replaced the Societies Ordinance of 1952. 
so regulated necessarily worked for the public benefit. The societies category for example covered member-based organizations, ${ }^{66}$ including professional clubs and associations working for members' benefit, as well as churches, mosques and temples (I42_GoK; Kisinga Gitonga, 2010, p. 26). The 1968 Societies Act defined societies as "any club, company, partnership or other association of ten or more persons, whatever its nature or object, established in Kenya or having its headquarters or chief place of business in Kenya" (s. 2). Trusts were originally mainly established "to hold and manage assets" for the benefit of a particular group of individuals, including families, making them a form of mutual benefit organization though they could also operate for the benefit of the wider public (ICNL, 2015a, p. 8; Kisinga Gitongo, 2010, p. 24). The breed of CSO that became known as NGOs were not necessarily member-based as were societies, nor did they possess or hold land or other immovable property and associated shareholders (or trustees) for which the trust identity was relevant. NGOs were distinct in their formation as "development agents" largely established to operate for public benefit, whether in social services, in pushing for "socio-political change", or facilitating people's participation in the development process (Kameri-Mbote, 2000, p. 3).

The breadth of organization types regulated under different regulatory frameworks made it challenging to have a complete picture of the CSO sector, and official data on the

${ }^{66}$ The Societies Act also covered political parties, at least until the Political Parties Act of 2011 was put in place. 
sector, even when available, was unreliable (Fowler, 1994, p. 153) ${ }^{67}$ An early rationale for the NGOs Co-ordination Act was to address the diversity of regulatory frameworks and associated inconsistency in CSO sector regulation by providing a "central reference point for registration" inclusive of NGOs and other CSO types (Jillo, 2009, p. 41). Regulation under one Act by one regulatory entity that "should understand PSOs [public service organizations] and be more professionally able to deal with them" (Fowler, 1994, pp. 199 \& 201; I55_CSO) was a desired outcome. Centralizing jurisdiction of the sector would also centralize authority over it while giving a "comprehensive overview or register of which PSOs were operating and what they were doing" (Fowler, 1994, p. 131).

The regulatory framework for CSOs in Kenya was further complicated by the fact that yet other legislation regulated CSO charitable, tax-exempt status. Registrants under the existing Acts or conventions could apply to qualify as "non-profit" or "charitable" entities, a status that if conferred by the Kenya Revenue Authority could make them eligible for various tax and import duty exemptions, and for work permits for expatriate employees (Fowler, 1993, pp. 130-131; Kisinga Gitonga, 2010, pp. 34-36; I61_Other). Such charitable status was delineated under the Income Tax Act of 1973, whereby a registered organization could apply to qualify for tax exemption if they were: "of a public character established solely for the purposes of the relief of poverty or distress of the public, or for the advancement of religion or education" (i.e. charitable/public benefit purposes); established in Kenya or with a regional headquarters in Kenya; and the income

${ }^{67}$ From the first to the fourth wave covered by this research, it was not possible to obtain disaggregated data on societies or trusts/foundations to be able to determine the number of public benefit CSOs among them (I61_Other; I41_GoK). 
of which would benefit the residents of Kenya (sched. 1, part 1, s. 10). Income derived from commercial activities by tax-exempt organizations would also be exempt under the Act if it met conditions of: being applied to charitable purposes; being generated through activities related to the organization's charitable purpose; or being generated by the organization's beneficiaries (sched. 1, part 1, s. 10). Organizations with tax-exempt status could also apply separately for exemptions from customs, duties, VAT, and for work permits for expatriates, also covered by varied legislations including the Value Added Tax Act of 1993, the Customs and Excise Act of 1978, and the Immigration Act of 1985 (Kisinga Gitonga, 2010, pp. 34-36).

\section{Political Agendas: Multi-faceted GoK discomfort with the oppositional force of the CSO sector in a repressive environment}

For the GoK, the 'NGO question' was one needing resolution for political reasons. CSOs' civic and political activism demanding democratic reform and accountability from the GoK was certainly seen as an explicit threat to GoK power throughout this wave. The growing sector, in all its domains of work, also provided an implicit form of political challenge, given CSOs' access to $\mathrm{DAC} / \mathrm{G}$ resources and their ever-expanding reach in social and economic development arenas. Mixed in with the Moi GoK's political agenda to control, or at least quell the CSO sector were elements of ethnicity and personal politics as well.

Especially following the 1982 coup attempt, Moi was nervous of any form of potentially dissenting voice, including those of his erstwhile close allies, which were viewed with suspicion as potential coup collaborators or empathizers (Fowler, 1994, pp. 197-199; Hornsby, 2012, p. 382). The GoK of the 1980s was "extremely dictatorial, 
autocratic, [with] hundreds of thousands of arrests, and clamp down on civic bodies like unions, teachers, workers, student unions, and so on" (I13_CSO). CSOs' pushback against mlolongo queue voting, then their demands for restoration of multiparty-ism were extremely threatening to the GoK. Since independence CSOs had been accepted by the GoK "as instruments to supplement the development programme of the public service" (Kameri-Mbote, 2000, p. 2), with the memory of pre-independence CSOs' role in pushing for radical change a fairly fresh one. CSOs' civic and political activism contributed to a perception by "certain important figures" in the Moi GoK (Kanyinga, 1995, p. 114), that these organizations were a threat to the GoK's power, a threat for which it had little tolerance. The GoK's leadership was becoming increasingly "suspicious" of CSO activism, seeing these organizations as fronts for their political opponents" (Hornsby, 2012, p. 587), and as fronts for the DAC/ powers so keen on democratic reform in the country. According to one CSO working with the NCCK at the time, "Moi, was fond of saying, 'Look, this civil society, it just gets money from Europe and from America and [they] come and push their agenda here"” (I26_Elected). The GoK's politically motivated backlash spread across the sector, also affecting CSOs operating in the areas of social and economic development such that the sector was subject to "loud condemnation and.... vilification" by the GoK (Ndegwa 1996, p. 53). Moi was heard to accuse CSOs of being involved in "subversive activities", a typical example of use of state propaganda to discredit the sector (Ndegwa, 1996, p. 34 citing Daily Nation, December 14, 1986; Matanga, 2000, pp. 29-30). The Church of the Province of Kenya, an active member of the NCCK whose reform activism placed it in opposition to provincial authorities, was nicknamed the "Church of Politics of Kenya" 
while the churches more broadly were dubbed, by "politicians close to the centre", as "agents of foreign masters" (Kanyinga, 1995, pp. 103 \& 115) - no light accusation given Kenya's colonial history.

Multiple authors as well as interviewees for this research equate the NGOs Coordination Act's emergence with the Moi GoK's political agenda of tamping down the sector's reformist power. According to Hornsby (2012), as CSO numbers and engagement in social and economic development as well as civic and political arenas grew alongside their access to $\mathrm{DAC} / \mathrm{G}$ funding, "the government, concerned by the growing influence and independence of NGOs, began to talk of registration and monitoring" (p. 449). According to Maina (1998), many public officials "saw the [NGOs Co-ordination Act] as giving the government the statutory framework to check the growing power of those NGOs funded by donors" (p. 162). CSOs' civic and political activism, even as it was concentrated in a small portion of the sector, sewed "a seed of doubt within the regime [GoK] about the assumed palliative nature of PSO development action" (Fowler, 1994, p. 199). This in turn "underscored the political imperative of controlling NGOs and triggered concerted efforts to rein in the NGO sector through legislation" (Ndegwa, 1996, p. 35).

Now Moi creates the [NGOS] Co-ordination Act in order to control, to find out how much are they getting. Because at that time there's a perceived threat. It is a perceived threat because NGOs are saying they [Kenyans] need to know their rights. They need to be educated about their rights, about obligations, about privileges.... So they are basically questioning the regime at that time and asking for more space for people to participate.... that therefore questioned the very existence of Moi's regime. And therefore, they [the GoKJ need to control what NGOs are spending, where they're getting money from and so on. (139_Other) 
The GoK's political agenda was not solely related to CSOs' oppositional power, but also to its need to practice the political patronage that was the norm for a GoK seeking to maintain power and legitimacy (Ndegwa 1996, p. 37). Kanyinga (1995) documents the importance of such patronage that was well integrated from national through to local levels. Relationships of political patronage at local levels were complicated ones. On one hand, local politicians and their allies in the civil service would use harambee gatherings to dole out gifts from the President and his close political associates (Kanyinga, 1995, p. 79). Though not regulated by the NGOs Co-ordination Act, harambee groups were very often NGOs' local partners. On the other hand, where an NGO was seen to be overly active and popular, thus undermining the "omnipotent image" of local politicians, the latter could undermine the NGO by replicating its activities, or finding ways to shut them down (Kanyinga, 1995, pp. 114-115 \& 112). Concern that the growing number and influence of DAC/G-funded NGOs, working in partnership with harambee groups or otherwise, "could undermine the power of the politicians at the grassroots" was a source of "considerable friction between the politicians, the civil service and the NGOs and civil society organisations" (Hanmer et al., 2003, p. 105).

In light of these GoK's political motivations, it is not surprising that the GoK felt a need for regulation to gain "better insight into what PSOs are doing" and "a better basis for screening" NGOs (Fowler 1994, p. 200). Some aspects of the GoK's conundrum in the face of a growing and increasingly influential sector are articulated by one interviewee: 
A parallel system sprouts up, and is very active and engaging and almost fighting with you [GoK] over development. It's biting some of your constituency in terms of engaging in development activities.... So all of a sudden.... you [GoK]are being blamed for not doing your part.... So when you start being blamed, you also start becoming defensive. The state becomes very defensive, and starts asking whose mandate the civil society is speaking on? On whose behalf are they [NGOs] speaking and are they accounting? So the question of the accountability starts being raised..... We [GoK] are wanting them to be accountable and [to be] reporting. We want to know that they're registered.... who you [NGO] are, and who you speak for, and who gives you money.... They [NGOs] were becoming many, many, many. You hear names you don't know... So at the end of the day, who are you [NGO] was a big issue. So then comes the NGO Act so that order can be brought into this big sector that is not known and is very amoebic. You don't know it. It's just fragile there, and it is talking on behalf of who? (151_Other)

Further, GoK political motivations may not have been devoid of ethnic considerations since the "ethnic-laden politics of Kenya" imply that "shades of ethnic meanings" permeated, or were at least ascribed to, both state and CSO actions (Ndegwa 1996, p. 37). Fowler (1994) suggests that some impetus for the 1990 NGOs Co-ordination Act stemmed from Moi's agenda to "change the ethnic pattern of leadership" in the country (p. 197). From the beginning of his rule Moi, a member of the Kalenjin ethnic group, had sought to disrupt the legacy pattern of majority Kikuyu domination left behind by President Kenyatta. This pattern, most evident in GoK, was seen to be mirrored in the CSO sector (Ndegwa 1996, p. 37; Fowler, 1994, pp. $129 \&$ 197-198), though the Luo ethnic group also featured prominently among CSO leadership (Hornsby 2012, p. 587). Thus, according to Fowler (1994), "the perception that PSOs were being led by the ethnic opposition provided a spur to new legislation" (p. 198). Reflecting back from today to her real time observations of and work with the sector early in wave one, an interviewee disputes this analysis however: "I don't buy that argument. It wasn't so deep.... Because at that time.... there were few NGOs during the '80s. They were not as many as they became in the '90s and 2000s.... They were not even really dominated by one ethnic 
group" (I51_Other). Later in this wave as more civic and politically-active human rights and governance CSOs formed, these were dominated by the Luo and Kikuyu ethnic groups however (Hornsby, 2012, p. 631), which, especially when combined with the pressures they exerted on the GoK to reform, would not have endeared them to Moi. ${ }^{68}$

This political imperative to control the sector through legislation also held aspects of personal vendettas. Politics was highly personalized under both Kenyatta and Moi, and the GoK "was known to institute legislation or policy to counter specific individuals" (Ndegwa, 1996, p. 37) ${ }^{69}$ What developed into a personal battle between the Green Belt Movement's Wangari Maathai and President Moi apparently "convulsed" the NGOs Coordination Act's evolution, specifically its hasty transfer to the Office of the President at a time in its drafting that coincided with a peak point of the "Moi-Maathai spat" (Ndegwa, 1996, p. 37; I12_CSO). ${ }^{70}$

\section{Public Management Agendas: DAC/Gs lay the ground}

As in other LMI countries in this era, models of public management entered Kenya from outside, especially from the $\mathrm{DAC} / \mathrm{G}$ countries, the aid flows of which came

${ }^{68}$ Hornsby (2012) actually refers here not to the Kikuyu but to the Gema grouping, which is dominated by the Kikuyu (p. 631).

${ }^{69}$ The highly personalized nature of politics and use of legislative measures to settle personal scores is also documented by Hornsby (2012), see for example pp. 259 and 460.

${ }^{70}$ Maathai (a Kikuyu) had previously been an outspoken Chair of the National Council of Women in Kenya whom the GoK had banned from running in a by-election in 1981 (Hornsby, 2012, p. 355). She again became active in party politics in the 1990s when she participated in movements that sought to unite the opposition against KANU's ongoing hold on power. She eventually ran and won an MP seat in the 2003 elections. Maathai later won the Nobel Peace Prize in 2004 for her environmental activism. Though it is difficult to know whether and the degree to which this type of personal acrimony affected the NGOs Co-ordination Act's development, a similar personalized use of legislative tools is seen again in wave four. 
wrapped in the international development paradigm of the day, itself a product of the public management paradigm of the day. Though, as noted, Moi publicly expressed distrust in and did what he could to resist what he considered as foreign models (Hornsby, 2012, p. 347), they nonetheless permeated Kenya's public management landscape.

For almost the first two post-colonial decades the reigning public management model had been one of national planning. This was based on a view that, in the words of the India's then Prime Minister Nehru, development was a "mathematical problem" whereby proper planning would inevitably lead to newly independent countries down a developmental path similar to that of the developed nations (Turner \& Hulme, 1997, p. 133). Projects, also detailed in their planning though at a smaller scale, were also introduced to supplement national plans (Turner \& Hulme, 1997, pp. 133-134). In the 1980s, the planner's model fell into disfavour, taken over by a decidedly free market, anti-planning approach influenced by what became know as NPM (Hood, 1991), with emphasis on liberalizing economies and rolling back the state (Turner \& Hulme, 1997, p. $134 \& 138)$.

NPM was adopted in different ways and to different degrees in public management circles in virtually all HI countries through the 1980s, 1990s and into the 2000s (Hood, 1995; Pollitt, 2010). As a result, NPM principles were also applied to DAC/Gs' development aid (Naudet, 2012, p. 13), largely entering Kenya through DAC/Gs' influence. Thus, at the macro level, the introduction of SAPs in the 1980s had NPM characteristics such as its emphasis on liberalizing the Kenyan economy in favour of 
market forces and solutions, privatisation and the outsourcing of service provision, and downsizing of the public service (Schoeman, 2008, p. 32; Polidano \& Hulme, 1999, p. 122). ${ }^{71} \mathrm{DAC} / \mathrm{Gs}$ provided financial support for NPM initiatives, such as for a Civil Service Reform Program launched in 1993, largely focused on reducing the size and costs of the public service (Hope, 2013, p. 130). ${ }^{72}$ Even so, the Moi GoK's resistance to implementing the kinds of reforms SAPs called for meant through this wave DAC/Gs implemented on and off aid suspensions as SAP-related conditionalities were or were not met.

However, DAC/Gs' turning to CSOs as alternate implementers of development cooperation, in a sense privatizing development, was also indicative of their application of NPM in Kenya. In Kenya therefore, NPM was not so much an express public management agenda adopted by the GoK but by DAC/Gs, while its influence on CSO regulation was less a direct than an indirect one. First, because the application of NPM by $\mathrm{DAC} / \mathrm{Gs}$ contributed to the proliferation of CSOs in Kenya, which was a motivating factor for the GoK's introduction of the NGOs Co-ordination Act. Second, because it shaped the funding relationship and arrangements between DAC/Gs and the GoK, and DAC/Gs and CSOs, inspiring the GoK to seek to control the CSO sector now in receipt

${ }^{71}$ Literature does not always categorize these policy moves as NPM, but rather, refers to for example simply to neo-liberalism, or to the Washington Consensus (Polidano \& Hulme, 1999, p. 130).

72 This program and its second phase launched in 1999 were ultimately assessed as "unsatisfactory" in their results due to a variety of issues including lack of commitment on the part of the GoK (Hope, 2013, p. 133). Obong'o (2013) attributes lackluster public sector reform in Kenya to resistance by "vested political interests" needing to maintain a system of "patronage appointments" (p. 27). 
of considerable and growing $\mathrm{DAC} / \mathrm{G}$ funding flows, through regulation. Ironically, in a sense, through the Act the GoK itself was desirous of continuing in a planner's mode of public management, seeking to "'coordinate" and direct [CSOs] toward its own vision of state-coordinated development" (Ndegwa, 1996, p. 33). Third, as this wave progressed, DAC/Gs' adoption of NPM-style performance management measures such as resultsbased management and the associated logical framework analyses (Naudet, 2012, p. 10) that they began to apply to their CSO funding mid-to-late in this wave laid the ground for the doubting of CSOs' legitimacy and accountability that would grow through subsequent waves. Treating CSOs as private contractors or partners to implement DAC/G programs, applying performance management methods that treat development as a predictable and linear process rather than the messy one it is, when combined with CSOs' dependency on DAC/G funding began to undermine CSOs' credibility as independent domestic actors.

While DAC/Gs' turning to NPM provided an indirect driver of CSO regulation, NPM methods did inform aspects of the NGOs Co-ordination Act's design. Establishment of a (semi) autonomous agency in the form of the NGOs Co-ordination Board was typical of the "agentification or corporatization" of public services under NPM (Polidano \& Hulme, 1999, p. 123).

Later in this wave, the beginnings of DAC/Gs' aid effectiveness paradigm began to be seen in Kenya. This again represented somewhat of a public management "rebalancing" in that it was based on a planner's model with a more significant role accorded to the state in addressing the welfare of its citizens. Here too the Moi GoK was averse to this public management model and its planning requirements of which PRSPs 
were emblematic: "Moi did not like PRSPs, he did not like planning but preferred to rule by favour" (I1_DAC/G). In the Moi era, such prescriptive models were shied away from given the preference for the kind of discretion of choice and decision-making necessary to run the state as a machine of patronage.

All told, the public management agendas that came into play in this wave were a result of DAC/Gs' adoption of NPM-associated approaches in Kenya, and with a largely indirect influencing effect on state regulation of CSOs.

\section{Security and Terrorism Concerns: CSOs deemed a threat to national security}

Terror concerns were not yet particularly on the international or on Kenya's domestic agenda at the outset of wave one. National security was nonetheless a prominent feature of the national policy landscape, as would be expected in an authoritarian state where heavy investment in the military, police and secret intelligence forces were the norm as were, especially following the 1982 coup attempt, detention without trial and other forms of security enforcement.

National security concerns came to bear on the GoK's attitude toward CSOs, as seen with the afore-mentioned incidences of CSOs' abuse of tax exemption privileges, which triggered Moi and his officials to characterize the sector as a "security threat" (KameriMbote, 2000, p. 27). However, the expression of such security concerns in this era was more in passing "conspiracy theory" imaginings of a paranoid Head of State rather than part of a grand anti-CSO narrative (I56_Other). Nor were they linked to terrorism concerns as they would be in later waves. As noted by one interviewee commenting on 
security concerns in wave one: "in those days, threatening national security wasn't really threatening national security. Instead, it was threatening the Moi state” (I8_Other).

The terror risk did become a prominent national issue later in this wave following the 1998 US embassy bombing, responsibility for which was claimed by Osama bin Ladenlinked operatives (Hornsby, 2012, p. 660). This incident consolidated an anti-terror alliance between Kenya and the US (Hornsby, 2012, p. 661). The GoK punitive reaction to the 1998 bombing targeted Arab and Muslim minorities in the country, with indiscriminate deportation of resident Somalis fomenting (further) tension with these minority groups. The GoK attempted to implicate CSOs as part of the terror threat, deregistering six Muslim CSOs (Hornsby, 2012, p. 661), though these de-registrations were rescinded due to lack of evidence (Kameri-Mbote, 2000, p. 14).

\subsection{Regulatory Change Outcomes}

\section{Development and Negotiations: The NGOs Co-ordination Act (1990)}

Rumblings of a regulatory wave begin in 1986 with GoK publically articulating the need to "coordinate" the "burgeoning NGO sector" in order to "direct them toward its own vision of state-coordinated development" (Ndegwa, 1996, p. 33). NGOs were called on to seek GoK clearance for all projects and budgets and to liaise with local district development committees that were, in effect, local arms of the ruling party, with Moi also announcing that NGO funding would have to be the channelled through the GoK budget (Ndegwa, 1996, pp. 33-34). Come 1989, President Moi announced that a directorate would be established to coordinate NGOs and to-be-developed NGO-specific legislation (Ndedgwa, 1996, pp. 34-35). Registration, import duty exemptions and work permits for 
expatriate staff that were already subject to uncertainty and erratic application became more firmly restrictive following this announcement (Ndegwa, 1996, p. 35). The sector was not entirely surprised as, "prompted by the demand by Government that they pay tax", it had been calling on the GoK to develop "enabling policy legislation for development"(I56_Other).

Still, that these various initiatives were coming from the President himself and from the Internal Security department of the President's Office was disconcerting for the sector. Predictably, the CSO sector, inclusive of but not limited to NGOs, was thus spurred to consider some form of self-regulation as a means "to forestall stringent government control" (Ndegwa, 1996, p. 35). Spearheaded in 1989 at a seminar organized by the KNCSS and the University of Nairobi's Institute of Development Studies (IDS), which had previous experience in policy research and analysis in collaboration both with the GoK and CSOs, this effort led to a proposal aimed at improving coordination within the sector and with the GoK (Ndegwa, 1996, p. 35). ${ }^{73}$

The proposed light self-regulation initiative was put forward to an inter-Ministerial committee - comprised of various Ministries with which the sector had traditionally interacted as well as the President's Office - that that had been established by the GoK to develop NGO legislation (Ndegwa, 1996, p. 35). In December 1990 the NGOs Coordination Bill passed through Parliament with unusual speed, with the Act receiving the

${ }^{73}$ According to Kameri-Mbote (2000) the Ministry of Culture and Social Services tabled a paper on coordinating the sector already in 1986 (p. 4). Though the literature provides different years - 1986 in this Ministry's case and 1989 in the KNCSS's case - these are likely one and the same paper, noting the KNCSS's affiliation to the Ministry. 
required Presidential assent in January 1991 (Ndegwa, 1996, pp. 37-38). ${ }^{74}$ Eager to ensure legislation to fit his purpose and demonstrating the personalized nature of this regulatory event, drafting of the Bill had been taken over (or "hijacked") by the President's Office (Ndegwa, 1996, p. 36). The Act did not reflect the sector's coordination proposals, and the Parliamentary debate on the Act clearly "betrayed the Government's intention to control NGOs in the name of coordination" (Ndegwa, 1996, pp. $36 \& 38)$.

With financial support from the Ford Foundation and the United Nations Development Fund, a second of a total of four seminars was organized by the University of Nairobi's IDS following Presidential assent of the Act, in February 1991 (Ndegwa, 1996 pp. 38 \& 51). ${ }^{75}$ Though the seminar, also with GoK representatives in attendance, had been arranged to familiarize attendees with the new Act, CSOs in attendance were vocal about their dissatisfaction with the Act. The speed with which the Bill had been developed and assented, as well as its content, was a cause of alarm in the CSO community. They felt it imperative to establish a focused, built-for-purpose coalition to push for amendments to the Act and input into the development of regulations anticipated to guide its implementation. The KNCSS's efforts to influence the state's regulation through light self-regulation overtures and otherwise had been unsuccessful, and overall

${ }^{74}$ Once a Bill is tabled in Parliament, the legislative process requires Parliament to pass the Bill, at which time it becomes an Act. Following its passing parliamentary approval an Act requires Presidential sign-off, or assent. Notification of all new legislation is then published in the Kenya Gazette

75 The ongoing involvement of IDS and its academics played a role in boosting the NGO Network's capacity to engage on the regulatory front. 
the KNCSS was seen to have "poorly fulfilled" its role in "representation of [CSO] interests towards the government" since independence (Fowler, 1994, pp. 192-193; Kameri-Mbote, 2000, p. 2). And whereas the KNCSS's approach to regulatory events had been also hindered by the "national political context" of repression that "would not bear... assertive actions" by CSOs (Ndegawa, 1996, p. 35), the common threat of the Act, combined with incremental changes in the political environment toward some semblance of democratization, emboldened the sector and provided impetus for a collective effort among CSOs that had previously been largely absent (Fowler, 1994, p. 306).

From the second seminar therefore, agreement was reached to establish a new builtfor-purpose coalition, the NGO Network, specifically to continue with collective analysis of the Act, and to engage with Government and with DAC/Gs on the Act via an elected NGO Standing Committee of the Network (Ndegwa, 1996, p. 40). This nature of organizing and joint action had up to this point been rare in the sector, but interest was so keen that the IDS seminars were the most widely attended meetings of the sector to that date (Fowler, 1994, p. 305). The work of the Standing Committee and its Network were to be financially supported by the sector (Fowler, 1994, p. 305). The ten-member Standing Committee was comprised of a representative of IDS and of some of the largest and most prominent Kenyan and international CSOs with varying mandates. These ranged for example from the faith-based coalition the NCCK; the community development CSO the Udungu Society of Kenya; the women's rights CSO FEMNET; the Aga Khan Foundation; and ActionAid (Ndegwa, 1996, p. 41). 
The Network and its Committee worked with increasing sophistication, specialization and "organizational acumen" it its analysis and lobbying, detailing their concerns regarding the Act and even developing a complete alternative legislation (Ndegwa, 1996, pp. $44 \& 47)$. It shared its proposals with the $\mathrm{DAC} / \mathrm{G}$ community which also expressed concerns about the Act publically and to the GoK, much to the latter's chagrin, with the GoK in turn requesting CSOs to cease lobbying DAC/G officials (Ndegwa, 1996, pp. 44 \& 50-52). DAC/Gs also supplemented Network members' financial contributions with financial support for the Network's discrete activities around the Act, ultimately providing support to a Network secretariat, though the source providing the initial financial contribution to establish the secretariat did so anonymously (Ndegwa, 1996, pp. $40,46 \& 51) .{ }^{76}$ Indirect DAC/G support was also available through their continued aid flows to a number of the larger national and international CSOs engaged in the Network (Ndegwa, 1996, pp. 40-41).

Besides NGOs' over-arching concerns about the GoK's intent in implementing the Act, a number of specific CSO concerns about its content were raised. These included: the implicit threat in having the Act administered by the Internal Security department; the

\footnotetext{
${ }^{76}$ According to a CSO interviewee active in the Network at the time, the GoK also initially undertook to thwart such $\mathrm{DAC} / \mathrm{G}$ funding. It did so apparently with a threat to withdraw the work permit of a representative of the first $\mathrm{DAC} / \mathrm{G}$ that began funding discussion with the Network. Called to a meeting by the Internal Security department of the President's Office, the DAC/G representative was told: "'Mr. So-and-So, I gather you're the ones who are giving these guys [NGOs] the sense of arrogance so that they can attack us.... I understand they're getting their strength from funding that you guys are proposing to give them.... I just wanted to remind you that if that were the case, it doesn't take too much to ask my friend here [from the Ministry of Foreign Affairs], to.... give you letters to ask you to leave this country'" (I57_CSO).
} 
absolute powers the Act accorded to the responsible Minister including approvals of registration, deregistration, customs and duty exemption and the like; lack of dispute or recourse mechanisms in the case of e.g. registration denial or de-registration; a requirement for re-registration very five years versus perpetual succession; vague definitions including the NGO definition itself; an a lack of provisions for financing implementation of the Act (Ndegwa, 1996, pp. 38-39). The sector was also concerned with what the status of CSOs' previously approved income tax and duty exemptions, and work permits, would be under the new Act (Ndegwa, 1996, p. 39).

Further, the NGOs Co-ordination Board that would be established to implement the Act, (with support from a secretariat, later called bureau), would be dominated by GoK appointees, with minimal, NGO representation (Ndegwa, 1996, p. 39). Notable also were the conditions proposed for the creation and operation of a so-called self-regulatory body, the National Council of NGOs, that would assumedly replace the KNCSS (Ndegwa, 1996, p. 39). ${ }^{77}$ Membership in the Council was to be accorded to the first 100 NGOs registered by under the Act, NGOs that would then develop a code of conduct, for approval by the Minister, that all registered NGOs would be bound to adhere to (Ndegwa, 1996, p. 39). The Act provided considerable oversight of the legislated Council to the new NGOs Co-ordination Board ensuring that the Council would not be "independent from government interference" (Ndegwa, 1996, p. 38).

${ }^{77}$ Initially called the National Council of Voluntary Agencies. 
After initial firm GoK resistance to any amendments to the Act, then verbal indications from GoK officials that the various concerns raised by CSOs would being taken into account, the Network's amendment proposals largely fell on "deaf ears" (Ndegwa, 1996, pp. 41 \& 45). In June 1992 the GoK published subsidiary legislation in the form of the Non-Governmental Organizations Co-ordination Regulations, followed by announcement of the Act's commencement in the same month (Ndegwa, 1996, p. 46). The Network used national newspaper advertising to spread a call to CSOs to boycott registration under the Act (Ndegwa, 1996, pp. 46-47 \& 52). The sector's concern “was not so much that you shouldn't regulate", but that the Act was "draconian" in its treatment of the sector (I55_CSO).

Here still the Network was emboldened by the slow shift in the political climate in favour of democratic opening, specifically the late 1991 (re)instatement of multiparty-ism and other slow-moving democratic reform concessions. Subsequently between mid- and late-1992 of this first genuine multi-party election year, the GoK conceded a series of critical amendments to the Act and accompanying regulations that the NGO Network had been advocating for (Fowler, 1994, p. 305). ${ }^{78}$ Contributing to CSOs' successful coordinated advocacy was the parallel policy influencing efforts of DAC/Gs, as well as that of opposition political parties now allowed to legally operate under the multi-party system. Opposition parties aligned with the CSOs' positions against the Act, with one stating their intent to repeal the Act in favour of the CSO-developed alternate version

${ }^{78}$ An additional factor that may have come into play in bringing about the amendments was the presence of a new Permanent Secretary in the President's Office and a new Attorney General with ties to the CSO community (Fowler, 1994, p. 305). 
were the opposition to gain power (Ndegwa, 1996, p. 51; Fowler, 1994, p. 301). Opposition parties “embraced the NGOs' cause as a contributory part of the broader objective of democratizing the state" (Ndegwa, 1996, p. 51). With these three forces combined - the CSO sector, DAC/Gs, and opposition parties - rallying against the Act, the amendments were one among other concessions that the GoK offered as part of its forced, incremental democratization process.

Key amendments to the Act included a right of appeal to the court in the case of disagreement with rulings by the NGO Board, and removal of the requirement for NGOs to re-register every five years (Fowler, 1994, pp. 305-306). The NGO definition was broadened and clarified to "a private voluntary grouping of individuals or associations not operated for profit or for other commercial purposes but which have organized themselves nationally or internationally for the benefit of the public at large and for promotion of social welfare, development, charity or research in areas inclusive of, but not limited to, health, relief, agricultural, education, industry and supply of amenities and services" (NGOs Co-ordination Act, 1990, s. 2).

The Act's amendments also served to grant the Council a greater degree of independence and discretion in fulfilling its legislated role as "a collective forum of all the voluntary agencies registered under this Act" (s. 23(1)). The Act saw the role of the Council, backed by a (legislated) Non-governmental Organizations Council Code of Conduct (1995) as covering self-regulation "on matters of activities, funding programmes, foreign affiliations, national security, training, the development of national manpower, institution building, scientific and technological development and such other 
matters as may be of national interest" (NGOs Co-ordination Act, 1990, s. 24(1)). The GoK accepted the sector's proposal that the NGO Network's Standing Committee would operate as its main interlocutor and a substitute for the NGO Council only until such time as the NGO Council leadership would be constituted through an election process (Ndegwa, 1996, p. 50; Fowler, 1994, p. 306). For the CSO sector, it was hoped that selfregulation would be a means through which to minimize state regulatory actions, which were "perceived a control to be kept away as far as possible" (PEN, 2007a, p. 14). However, there was no allowance for voluntary membership in the Council; all registered NGOs would be members of the Council and subject to its self-regulatory Code of Conduct (Gugerty, 2014, p. 16). The GoK also maintained considerable Council oversight including: presence of a Ministerial delegate at the first Council meeting adopting the Council structure and procedures; Board approval of a Council Code of Conduct for NGO self-regulation; and Board approval of rules and procedures for NGO account audits (NGOs Co-ordination Act, 1990, ss. 23(2) \& 24(2-4)). The Code of Conduct would become law in 1995 in the form of Legal Notice 306, later appended to the Act's regulations in the form of the NGOs Coordination Regulations (1992).

What resulted from the various amendments was an NGOs Co-ordination Act considered more benign than the original controlling version. Overall it was "less threatening" to the CSO sector (Ndegwa, 1996, p. 52) and "more democratic in [its] effects" (Fowler, 1994, p. 306). While the sector still chaffed at the GoK's controlling intent that the messaging and process around the Act's development had revealed, there 
was a sense that "[the Act] is something we negotiated until we were satisfied.... We made legal history, actually”(I12_CSO).

\section{Implementation: The NGOs Co-ordination Act's First Decade}

For the sector, a first task toward operationalizing the Council as established by the Act was to develop its constitution and several committees to attend to various areas of Council responsibility, including a Regulatory Committee, which led in designing the Council's self-regulation mechanism. Sector self-regulation under the Council would come to involve a Code of Conduct (1995), which became subsidiary legislation to the NGOs Co-ordination Act. The Code was designed as "an expression of the ethos of every registered organization" to be observed by them all (s. 3). Operating by the Code, registered organizations would exercise the "cardinal values" of probity, self-regulation, justice, service, cooperation, prudence, and respect (s. 7). "Self-regulation" here referred to regulation by individual NGOs of their own organization, each guided to "strive for self-determination; appraise and evaluate its conduct periodically; be open to learning and change; and be self-reliant and vigilant" (s. 9). The monitoring system would rely solely on follow-up to public complaints launched against a Council member which would be examined by the Committee (s. 19; I55_CSO). The Regulatory Committee of the Council was empowered to pursue sanctions including verbal sanctions or fines, or recommend suspension to the NGOs Co-ordination Board (ss. 15 \& 20).

Accounts suggest that, in its early years from its formal establishment in 1993 the Council was "fairly active and united" (I1_DAC/G), effectively fulfilling its role as a collective forum for registered NGOs in Kenya as the Act intended. The Council was 
funded through the membership fees that all registered NGOs were required to pay, while it also received substantial DAC/G financial support: "there was unlimited donor funding during that era of the 1990s to 2003, though the process was endogenous" (I56_Other; I57_CSO). In the words of a CSO and an academic equally active on sector issues in that era:

[Regarding] the capacity to self-regulate.... we were managing that before very well, through the NGO Council.... That doesn't necessarily mean that you captured all the civil societies [CSOs], but organizations in the NGO Council were self-regulating. And that used to work well. (I6_CSO)

The first Council was actually very strong in terms of self-regulation.... even the second [Council].... it fostered democratic tendencies within the sector... [it] had a very strong membership, and spoke very well about the sector. (I56_Other)

The backdrop of democratic opening, in which CSOs had and were continuing to play a key role, was significant to the Council's strength for CSOs apparently recognized that they could not "preach water and drink wine at the same time" (I56_Other). Other Committees established additional to the Regulatory Committee, such as a Networking and a Peace Committee, were deliberately open to CSOs other than those registered under the Act in an effort to reflect a democratic and inclusive approach (I55_CSO).

In terms of.... self-regulation.... [the Council] actually played its role..... ensuring that the civil society, the CBOs, the NGOs were working within the regulations set for them.... regularly you would have meetings where people would come together and discuss what it is that we would want to as a civil society? What are some of the things we are facing as a nation that we need to work on together? And that really.... help[ed] us to speak with one voice.... We would also.... report in terms of our activities, what is it that we were doing, how much money did we collect... to share information to say what activities is [CSO X] implementing. When we printed publications we would share with them so that they would actually be able to see what we were researching on and what our findings are, and how we are using those findings. And occasionally they would also come around and visit when we have activities. So I think that really contributed in [self-]regulating. Putting order, making sure that people are working towards a common goal. (I54_CSO) 
Implementation of the Act provided the GoK with the regulatory weight it had sought to screen NGOs applying for registration, and to monitor NGO activities and financial status through annual reporting to the Board. An 18-20 member NGOs Co-ordination Board (supported by a staffed Secretariat) ${ }^{79}$ held responsibility for implementation of the new Act and its regulations. All Board members would be either GoK representatives (including a Permanent Secretary from the President's Office, the Treasury, and others) or Presidential appointments, including five NGO representatives recommended by the Council (NGOs Co-ordination Act, 1990, s. 4). According to the Act and its Regulations, the Board's functions included: coordinating and facilitating the work of NGOs; maintaining and regular review of the register of NGOs; receiving and discussing NGOs' reports; advising the GoK on NGOs' activities and roles; providing policy guidelines to NGOs for harmonizing with GoK development plans; approving reports of the NGO Council, advising the Council on its activities, and approving the Council Code of Conduct; prescribing and implementing registered NGOs' requests for duty and tax exemption and work permits for expatriates (NGOs Co-ordination Act, 1990, s. 7; NGOs Coordination Regulations, 1992, ss. 28-30).

The initial fears of the Act providing the GoK with a mechanism for controlling the sector were somewhat founded. For example, when it came to seeking exemptions from customs, duties and VAT, the Regulations stipulated that registered NGOs needed to apply through the NGOs Co-ordination Board (ss. 29 \& 30). NGOs were "not in practice

${ }^{79}$ The term Board and Secretariat (the Bureau) tend to be used inter-changeably in Kenya. In the same vein, the term 'Board' is used throughout this dissertation with specification only when a separation of the two is evident. 
exempt", with many opting to not pursue the application process which was "tedious and confusing", with a positive recommendation from the Board far from guaranteed (Jillo, 2009, p. 49). Also, the 1973 Income Tax Act's "public character" criteria for exemption relief of poverty or distress, religious or educational advancement - was narrower than the NGO definition in the NGOs Co-ordination Act, with discretion used by the Commissioner of Income Tax in interpreting this criteria (sched. 1, part 1, s. 10; Kisinga Gitonga, 2010, p. 34). When it came to duty exemption, the criteria needing to be met according to the 1992 NGOs Co-ordination Regulations, that the foreign currency used to purchase the imported good was not raised in Kenya, demonstrated the GoK's concern with preservation of foreign currency, ironically the same largely DAC/G-sourced foreign currency flowing to CSOs that was a cause for GoK consternation (sched. 1 s. 29; Kameri-Mbote, 2000, p. 11; Jillo, 2009, p. 49).

Further, despite the presence of Council members on the NGOs Co-ordination Board and the legislated roles of the Council overall, there was a growing sense through the 1990s that the Council's "rights" were "on paper only" (Kameri-Mbote, 2000, p. 14). Still, the Act now at least provided a regulatory site of contestation regarding what constituted legitimate NGO activities, and the Council's presence on the Board helped inform that debate. Based on the NGO definition in the Act, allowable activities by these organizations could have been interpreted in a manner limited to social and economic development (s. 2). Instances of the Board seeking to proscribe NGOs aiming to engage in civic and political activism included the case of the Kenya Human Rights Commission (KHRC). Established by Kenyan political exiles in 1991-92, this CSO's mandate of the 
pursuit of human rights, democracy and good governance in Kenya (Hornsby, 2012, p. 587) led to near denial of its registration application. Debate in the Board saw the "government side... bent on not registering the KHRC" which it deemed a "political body" (I55_CSO). Ultimately the KHRC was registered based on an argument - by one of the NGO Council members of the Board - that a line could not be drawn between "where the political and civil rights stop and the economic and social rights begin" (I55_CSO). The influence of DAC/Gs was also likely brought to bear in this case given DAC/G financial support for the organization, and the KHRC founders' Western connections and profile garnered from their exile years.

The conclusion of this NGO's case and the CSO sector's growing prominence in the country did not see the issue fully resolved however. The sector remained subject to "hostility and threats" from the GoK (Kameri-Mbote, 2000, p. 13). The Act was susceptible to use by the GoK as a tool to silence CSOs such as by denying their registration applications (Kanyinga, 2004, p. 22). The sector in this era continued to be subject to "close scrutiny, supervision, constant harassment and often deregistration" the latter without discussion with the NGOs Council despite it being a legal requirement (Kameri-Mbote, 2000, p. 8; Kanyinga, 2004, p. 22). In one instance, the Centre for Law and Research International (CLARION), an NGO engaged in rights and democracy promotion activities, was abruptly deregistered in 1996 based on a notification from the Board's Chair (rather than from the full Board as was legally required), and without the opportunity for a hearing as is was also a legal requirement (Kameri-Mbote, 2000, p. 14). The grounds of "unlawful activities" cited for deregistration were that CLARION was in 
violation of its terms of registration under the Board, and had published and disseminated harmful materials (Kameri-Mbote, 2000, p. 14). The fundamental issue at hand was that this CSO had published research on corruption in the GoK, "the first ever research on corruption in Kenya ... and when we published that .... the Government was very unhappy. Very unhappy" (I54_CSO; I51_Other).$^{80}$ The NGO Council decried the deregistration, as did the DAC/G community, particularly its Nordic members (Kameri-Mbote, 2000, p. 14; I51_Other). ${ }^{81}$ The deregistered CLARION sought redress in the courts and eventually their deregistration was rescinded by the NGOs Co-ordination Board and firmly restored following a High Court ruling (Kameri-Mbote, 2000, p. 14).

Regardless of the positive outcome for CLARION, the power of the Act to control CSO activities, particularly their civic and political engagement, had been made obvious. Such signals continued to be sent, especially to the civic and politically active segment of the sector. The abrupt deregistration of six NGOs for alleged involvement in the 1998 US embassy terror attack for example was seen as a case of the GoK sending "a clear message to policy-focused NGOs that they were being closely monitored" (KameriMbote, 2000, p. 14). Again the NGO Council decried these de-registrations, which were rescinded based on a High Court ruling which found no evidence linking the NGOs to terrorism (Kameri-Mbote, 2000, p. 14; Kaberia, 2014, para. 12).

${ }^{80}$ CLARION chose to have the publication printed outside of Kenya (I54_CSO).

${ }^{81}$ A considerable portion of CLARION's funding came from the Danish official funding agency, Danida. 
Despite a broadening interpretation of the types of CSOs that could be registered under the Act, that its concept of "NGO" was not sufficiently comprehensive as to clearly cover all non-profit organizations working for public benefit "forced" some CSOs to register elsewhere rather than risk coming up against a potentially narrow interpretation of the definition by the NGOs Co-ordination Board (Jillo, 2009, p. 48). Ironically, experiences such as that lived by CLARION led CSOs to seek registration under one of the alternative regulatory options that remained following the Act's implementation, despite the initial stated intent that the Act would provide one coherent regulation to cover the CSO sector broadly. In a sense, use of the Act for its perceived primary GoK purpose of controlling the sector backfired.

People felt that going to the NGO Board was going to.... make your work a bit difficult because anytime you appear to very critical of the Government of the day, they'll use the NGO Board to curtail your activities.... They will freeze your bank accounts. They will.... fix some charges against your Director, and this kind of thing. So people shied away from that framework, because it could easily be used to frustrate your work. (I29_CSO)

Relatedly, CSOs opting for registration under regulatory options other than the Act were motivated by the fact that the registration was more navigable, and reporting procedures under these alternative mechanisms relatively light of touch (I20_CSO; I40_Elected; I36_CSO; I41_GoK). Further, NGOs were experiencing registration delays as the Board struggled to keep up with applicant numbers (Kameri-Mbote, 2000, p. 29).

Why people went to these other regimes was the difficulty in getting registered as an $N G O$ - that was the most difficult.... So people opted to exist in other forms that were easy. It was easy to register as a CBO. It was easy to register as a trust because the trust was under the Ministry of Lands.... Companies, [and] societies.... under the Societies Act, which were less restrictive....[and] are not very rigid.... the level of the scrutiny is not that strict. (I29_CSO) 
Some of these issues, including the narrow NGO definition, and the ongoing existence of multiple regulatory regimes for CSOs, led the NGOs Co-ordination Board in 1996 - only four years after full implementation of the Act - to express that a national NGO policy was needed to provide a framework of reference for implementation of the NGOs Co-ordination Act (Kisinga, 2009, p. 57). Concrete steps in this direction would not be taken until wave two however.

Through the 1990s the GoK also continued to use alternative, non-regulatory means of oppression. CSOs, their staff and others associated with their activities were still at times subject to intimidation and harassment.

Police would be sent to disrupt civic education meetings... [they would] beat people up and throw them out of the meeting rooms... if you traveled, say, to another place, not Nairobi .... to have a meeting.... the district officers and.... the provincial officers.... they would pour askaris [security guards] all over the place so that you're not even able to assemble. (I54_CSO)

Katumanga (2004) speaks of the GoK inciting factions within society "to mete violence on civil society activities opposed to the state" (p. 49). Harassment of CSO representatives, CSO office break-ins and even fire-bombings were the purview of "persons believed to be acting for the government" (Kameri-Mbote, 2000, p. 14), providing a complement to the NGOs Coordination Act.

\subsection{Analytical Summary}

Both state and CSO self-regulation emerged in this wave due to a confluence of factors. Self-regulation was absent, with CSOs motivated to pursue self-regulation only under the threat of potentially controlling state regulation. Though state regulation of various CSO types was in existence at the beginning of this wave - much of it a colonial 
inheritance - it was fragmented, with numerous legislations governed by different Ministries or other GoK bodies. Existing state regulation was also inadequate to address the rapid growth in CSO numbers inclusive of CSO forms, specifically NGOs, not well covered by the pre-existing regulation. The GoK sought a means to vet, track and purportedly coordinate the activities and financial flows, much of it from DAC/Gs, of this burgeoning sector.

Weakness in the sector was initially seen in discrete incidences of misuse of nonprofit tax privileges, prompting greater GoK scrutiny of these privileges, though the sector was not plagued with widespread mismanagement or misconduct, or perceptions thereof. As the sector grew in numbers, with increasing access to $\mathrm{DAC} / \mathrm{G}$ financing, deficiencies in CSO financial management and internal governance began to show. The sector also began to see cases of 'briefcase' NGOs with NGOs being created as vehicles for rent seeking, though these issues did not appear to influence regulatory change in wave one.

At the beginning of the wave the sector did not have infrastructure in the form of an apex body capable of addressing CSO self-regulation or of engaging with the GoK on regulatory issues such as the emerging NGOs Co-ordination Act. A new body in the form of the NGO Network needed to be created to fulfill this role. It did so ultimately aided by alliances with the DAC/G community, which provided financing and support via its own policy influencing efforts with the GoK on the Act. The Network's strength and astuteness grew quickly. While the sector previously lacked cohesion, its success in organizing to influence the Act showed an enhanced "capacity for collaboration" 
(Fowler, 1994, pp. 201 \& 306). Fowler's (1994) question of whether a strong representative CSO body would endure once the common cause of influencing the Act passed was answered in the affirmative as the NGO Council that succeeded the NGO Network effectively represented the sector through this wave (p. 306).

In the post-independence era up to this wave CSOs had largely been focused in the social and economic development realm. The GoK had learned from its colonial history and independence struggle both the practice and norm of controlling civic and political engagement activities of CSOs and others, and the potential political power of such activities. In this wave, CSOs became a conduit for civic and political engagement where other means were not readily available. Through the Act the GoK sought to address the arising political threat CSOs were seen to pose. While CSOs and the DAC/Gs that funded them were not pursuing per se partisan political aims, their calls for reform toward a more democratic political system were equated with opposition politics and in a single party state, amounted to as much, as did their intermediary role in seeking unity among opposition parties following re-establishment of multiparty-ism.

The GoK's discomfort with the sector's growth and influence was not solely due to its civic and political engagement however. CSOs were also deemed a source of competition for $\mathrm{DAC} / \mathrm{G}$ resources, and a threat to the system of patronage that served to keep the Moi GoK in power. Ethnicity was a related though minimal consideration given the inextricable link between politics and ethnicity in Kenya and the perception at least early in the wave for CSO leadership to be dominated by ethnic groups other than Moi's. Personalized politics also made an appearance in this wave in as much as the friction 
between the Green Belt Movement's Wangari Maathai and President Moi triggered hasty transfer of responsibility and development of the NGOs Co-ordination Act to the President's Office.

An important factor in regulatory change, in various respects, was the DAC/Gs. For one, DAC/Gs' preference for supporting CSOs while penalizing the GoK with the aid conditionality stick contributed not only to the rapid increase in CSO numbers, but also was felt as an insult by the GoK, while fuelling a GoK jealousy over these flows to CSOs. Secondly, the post-Cold War influx of DAC/G financing for CSO civic and political activism also caused consternation given the threat that such activism posed to a GoK reluctant to undertake democratic reform and determined to hold onto power. Third, the CSO sector in this wave began to be affected by the availability of DAC/G funding with some degree of 'mission drift' as they responded to $\mathrm{DAC} / \mathrm{G}$ priorities and requirements such as the NPM-inspired application of results-based management, and as noted, the occurrence of rent-seeking and CSOs driven by self-interest than by developmental aims. Though this third element of DAC/Gs' influence was not a contributing factor to the emergence of the NGOs Co-ordination Act, its impact on CSOs' legitimacy is a recurring theme in future waves. Fourth, financial support to the NGO Network and its Secretariat was directly or indirectly sourced from DAC/Gs even as the GoK sought to dissuade such financing. The flow of DAC/G funding to the NGO Council that succeeded the Network was important to the Council's success. Member fees would not have been adequate to cover an active Council, nor was GoK financing an option provided for by the Act or its regulations. Finally, DAC/Gs' weighed in on the 
policy debate about the NGOs Co-ordination Act in support of amendments demanded by the $\mathrm{CSO}$ sector.

The security/anti-terror agenda also came into play somewhat in this wave though it was not a regulatory driver of significance. In the early part of this wave, the GoK raised security concerns in relation to CSOs. However, in question was not so much securing the country against a terror threat, but against opposition to the Moi government. The deregistration of a half dozen NGOs following the 1998 US Embassy bombing was seen as a fear tactic with no real link to the country's terror threat. Equally, the accusations of CSOs as threats to national security were fabrications of a paranoid authoritarian leader.

The act of legislating self-regulation under the NGOs Co-ordination Act showed that the GoK had little faith in the sector's capacity for independent self-regulation. Such lack of faith was understandable given the absence of self-regulation by the sector up to that point. At the same time however, the driving factors behind the Act suggest that selfregulation, independent or otherwise, would not have sufficed to meet the GoK's regulatory aims of gaining control over the sector.

The wave one narrative points to political agendas as the primary drivers behind state regulation in the authoritarian context of this era, at first with the aim of controlling CSOs' activities, civic and political engagement and otherwise, and funding. The NGOs Co-ordination Act offered a subtler means to exert control over a growing NGO sector than the long-standing methods of repression through violence, intimidation, imprisonment or exile that had reached peak heights under Moi's rule but were no longer proving viable in the face of both domestic and international pressure on the Kenyan state 
to democratize. Then, amendments to the Act were abetted by developments in Kenya's political context as incremental democratic opening both emboldened the sector to take a hard line against the Act, and deterred the GoK from completely ignoring CSOs', DAC/Gs', and newly legal opposition party positions demands. A political agenda of self-preservation led the GoK to accept amendments to the Act.

Table 3: Wave One Key Regulatory Change Drivers

\begin{tabular}{|c|c|}
\hline $\begin{array}{l}\text { Drivers emanating } \\
\text { from CSO sector }\end{array}$ & Characteristics \\
\hline Sector growth & $\begin{array}{l}\text { - Rapid growth in number of CSOs including: national, } \\
\text { international; social and economic development-oriented, civic } \\
\text { and politically active }\end{array}$ \\
\hline Type of CSO activities & $\begin{array}{l}\text { - Dominance of social and economic development services } \\
\text { - Ever-increasing civic and political engagement }\end{array}$ \\
\hline $\begin{array}{l}\text { Mismanagement or } \\
\text { misconduct in the sector }\end{array}$ & $\begin{array}{l}\text { - Sporadic incidences of abuse of tax exemption privileges at first } \\
\text { - Capacity weaknesses coming to light over time amidst abundance } \\
\text { of DAC/G funding and high CSO dependency } \\
\text { - Degree of mutual CSO-DAC/G capture and CSO rent-seeking } \\
\end{array}$ \\
\hline $\begin{array}{l}\text { Sector infrastructure and } \\
\text { status of self-regulation }\end{array}$ & $\begin{array}{l}\text { - Initial absence of self-regulation and weak apex body } \\
\text { - New body formed to negotiate NGOs Co-ordination Act, then } \\
\text { implement self-regulation and represent sector }\end{array}$ \\
\hline $\begin{array}{l}\text { Drivers emanating } \\
\text { from DAC/Gs }\end{array}$ & Characteristics \\
\hline $\begin{array}{l}\text { Funding and policy } \\
\text { engagement }\end{array}$ & $\begin{array}{l}\text { - Increasing financial support fuelling CSO sector growth } \\
\text { - Ongoing funding to CSO social and economic development } \\
\text { service work, new and growing financial support to CSO civic and } \\
\text { political engagement } \\
\text { - Threat of and actual decreasing financial support to GoK with } \\
\text { conditionalities tied to democratic (and economic) reform } \\
\text { - Financial and policy support to CSO apex body seeking to } \\
\text { influence Act } \\
\text { - (Somewhat NPM-inspired) CSO support modalities and } \\
\text { performance management requirements introduced, influencing } \\
\text { CSO programming priorities, responsiveness to } \\
\text { constituents/beneficiaries }\end{array}$ \\
\hline
\end{tabular}




\begin{tabular}{|c|c|}
\hline $\begin{array}{l}\text { Drivers emanating } \\
\text { from GoK }\end{array}$ & Characteristics \\
\hline Status of state regulation & $\begin{array}{l}\text { - Non-cohesive regulatory framework for CSOs with multiple } \\
\text { legislations, in part a colonial inheritance } \\
\text { - Combined with growing sector, non-cohesive regime rendering it } \\
\text { difficult for GoK to understand sector scope, interventions } \\
\text { - Lack of clarity on CSOs' civic and political engagement role in } \\
\text { Act }\end{array}$ \\
\hline Political agendas & $\begin{array}{l}\text { - Control of reformist voices } \\
\text { - Competition for DAC/G funding for profile and patronage } \\
\text { purposes } \\
\text { - (Possible) political-ethnic motive to weaken sector deemed } \\
\text { dominated by certain ethnic groups } \\
\text { - Elements of personal acrimony between GoK and (certain) CSO } \\
\text { leadership } \\
\text { - Reluctant, wavering and incremental democratic opening }\end{array}$ \\
\hline $\begin{array}{l}\text { Public management } \\
\text { agendas }\end{array}$ & $\begin{array}{l}\text { - NPM permeates via DAC/Gs' first in form of SAPs, then } \\
\text { increasing 'privatization of development' through use of CSOs as } \\
\text { implementers }\end{array}$ \\
\hline $\begin{array}{l}\text { Security and terrorism } \\
\text { concerns }\end{array}$ & $\begin{array}{l}\text { - Incidences of CSO abuse of tax privileges lead to accusations that } \\
\text { CSOs are threat to national security } \\
\text { - Attempted implication of half-dozen Muslim CSOs in } 1998 \text { US } \\
\text { embassy bombing }\end{array}$ \\
\hline
\end{tabular}




\section{REGULATORY WAVE TWO, 2000 TO 2007-STATE REGULATORY RIPPLES, SECTOR TURBULENCE}

\subsection{Introduction}

This chapter details the CSO regulation story in Kenya over the second wave from 2000 to the end of 2007. It covers the main regulatory changes in the form of a $2006 \mathrm{GoK}$ Sessional Paper No. 1 (OVP \& MHA, 2006) on NGOs, and the demise of self-regulation through the NGO Council.

\subsection{Wave Two Overview}

The second regulatory wave was one in which the GoK led steps toward regulatory change with publication of the 2006 Sessional Paper No. 1 intended to provide a policy backing to revise the NGOs Co-ordination Act, while the CSO sector failed in selfregulation. Critical driving factors included gaps in existing state and self-regulation, the latter particularly acute due to political interference in the NGO Council, interference motivated by a multiplicity of political agendas.

A key turning point for the country and the sector came with what was deemed the first genuinely democratic election in 2002 leading to Kenya's 'Second Liberation'. This transition held unanticipated destabilizing repercussions for the sector that, at least initially, suffered from an identity crisis as the pro-democracy rallying cry that had helped unite it over the previous decade and more no longer seemed pertinent. The sector floundered also as key CSO leaders were drawn into GoK positions, and as DAC/G financing for CSOs dipped in favour of the new GoK. Signs of mismanagement and misconduct in the sector were beginning to show, with concerns regarding CSOs' rent- 
seeking behaviours surfacing, all in an era when issues of CSO accountability were a growing concern globally.

However, less than two years following the 2002 elections, the still new GoK in which so much hope had been placed became enmeshed in grand corruption scandals, and failed to adequately deliver on various reforms, particularly the country's longawaited constitutional reform. Disillusioned DAC/Gs applied economic and political aid conditionalities to try to influence the GoK, though these were not exercised with the severity that they had been previously. The new GoK's relative economic growth success, the strategic anti-terror alliance with Kenya especially following $9 / 11$, and the increasingly significant relationship between Kenya and alternative financiers such as China, mitigated DAC/Gs' influence.

Notably, CSO civic and political activism during the first part of this wave was weakened. The sector that had worked so hard for Kenya's Second Liberation was divided in how to contend with the disappointing performance of the new GoK. Divisions were exacerbated to the point of the NGO Council's demise in the face of GoK political interference in the Council. This interference was said to have been largely motivated by a GoK intent on undermining both CSOs' civic and political activism, as well as any chance of self-regulation.

Prior to the 2002 elections, both the GoK and CSOs via the NGO Council had reached agreement on the need for a policy to guide the NGOs Co-ordination Act's implementation and provide a basis for review of the Act. The drivers then had more to do with addressing gaps in the wider CSO regulatory framework given the Act's limited 
coverage to registered NGOs, as well as with clarifying the legitimacy of CSO civic and political engagement under the Act. Ironically, in the absence of an effective NGO Council, the sector was unable to input into the policy but still the GoK published Sessional Paper No. 1 on NGOs in 2006. The Paper chastised the NGO Council for its internal wrangling, calling for an enforcement of self-regulation and an important role for the NGOs Co-ordination Board in this regard, the latter instituted with revisions to the NGOs Co-ordination Act in 2007.

A segment of the CSO sector responded to the uncertainties surrounding the GoK's regulatory intent with the Sessional Paper and to the absence of self-regulation under a viable NGO Council, by launching a new independent self-regulation initiative. Simultaneously a small group of CSO leaders began meeting to envision what the content of a revised NGOs Co-ordination Act ought to contain.

This wave closes as the 2007 elections violence rocked the nation. Its aftermath would have repercussions, at first, positive in wave three then negative in wave four, for CSO regulation.

\section{Table 4: Wave Two Key Developments or Actions of Main Actors}

\section{GoK:}

- Intent to develop NGO policy to underpin NGOs Co-ordination Act

- Democratic 2002 "Second Liberation" election replaces former repressive GoK with new leadership on reformist platform

- New GoK caught up in grand corruption, fails to meet demand for constitutional reform toward further democratization

- Mix of disillusionment with and support for GoK leads to ethno-political divisions in the country, including in CSO sector, leading to fraught 2007 elections with repercussions for subsequent waves

- GoK political interference in NGO Council

- Otherwise, eventual collaborative engagement with sector including civic and 
politically-active segment

- Publishes Sessional Paper No. 1 on NGOs (2006)

- Revises NGOs Co-ordination Act giving GoK greater control of self-regulation

CSO sector:

- Support and advocate for an NGO policy to underpin NGOs Co-ordination Act

- Continue to seek democratic reform from GoK, strongly support Second Liberation election win by new GoK

- NGO Council splits, rendered ineffective in representing sector

- Already weakening self-regulation fails

- Subject to polarization, divisions along with wider Kenyan society in wake of GoK corruption scandals, constitutional reform fail

- (Some) civic and political activism proceeds in collaborative mode with GoK

- Organize to initiate independent self-regulation, influence NGOs Co-ordination Act revisions

DAC/Gs:

- Strongly support Second Liberation election win by new GoK

- Initially reduce ODA to CSOs while increasing to Second Liberation GoK

- Political and economic conditionalities applied to aid means on/off aid to GoK, though largely on in face of competing DAC/G priorities

- Uptick in aid to CSOs

- Financial support to NGO Council dwindles; financial support provided to new CSO network targeting self-regulation 
Figure 3: Wave Two Timeline: Key Political and CSO Regulation Developments

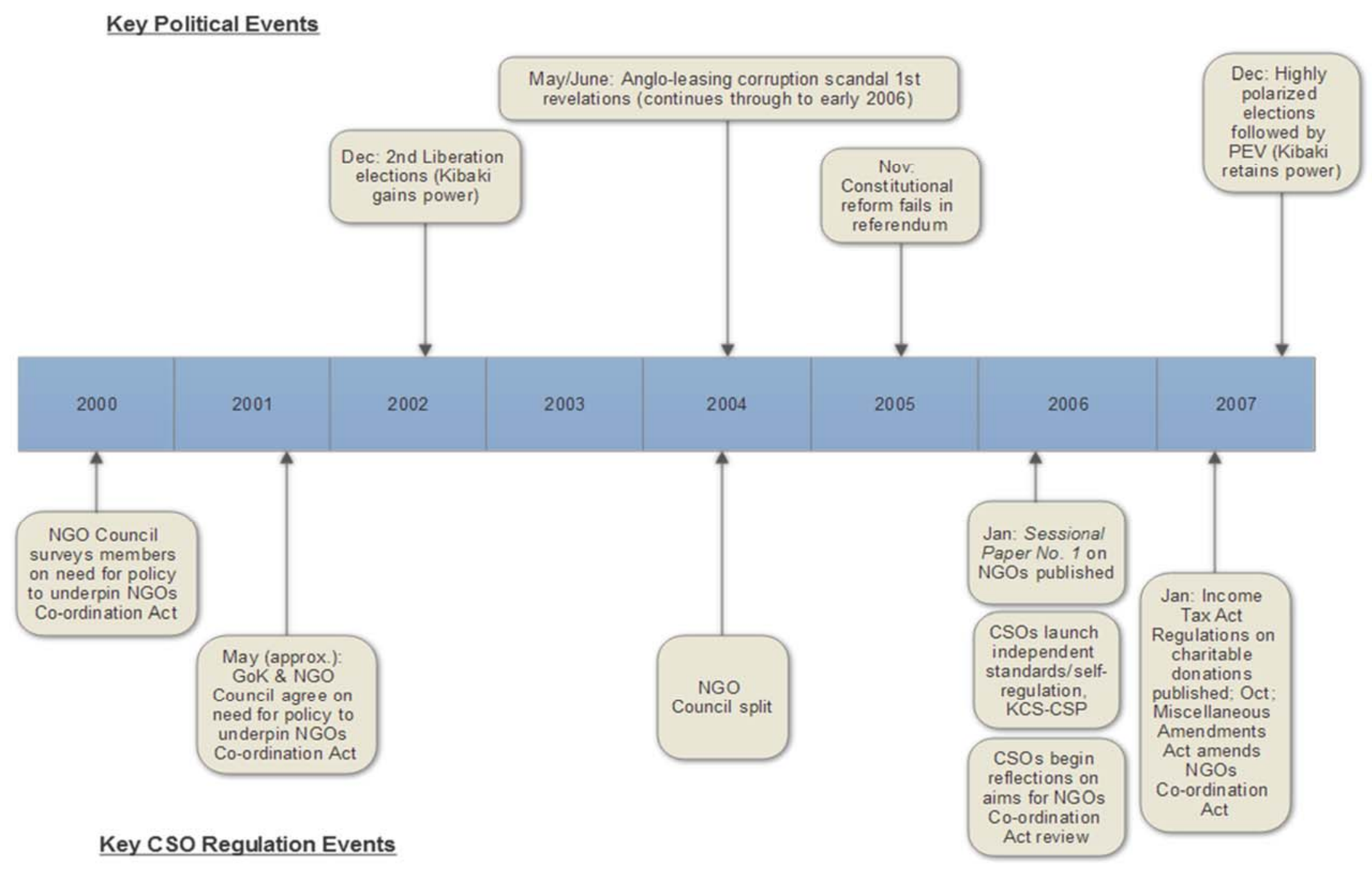




\subsection{Drivers of CSO Regulation}

\section{In Focus: Perspectives on Regulatory Change Drivers}

In the 2002 elections.... the opposition... they got into Government. It was like euphoria you have never seen. (I15_DAC/G)

In 2002 after the elections, the NARC administration.... co-opted a number of civil society leaders into Government. That had a serious impact on the civil society sector.... They [CSOs] did not have a proper transitional plan in place. So when the key operatives within civil society left and joined Government, the civil society became weak. (I16_DAC/G)

Everyone [DAC/Gs] was like "Now... our funding needs to go to Government because they are really good. They've got credibility, they have transitioned, they know how civil society operates".... So [funding] went really down for civil society. (I15_DAC/G)

Civil society is on a loose footing, trying to get their way again.... The thing is, the environment had also changed for civil society. Before, it was, "Let's change the Constitution. Let's change the political leadership and everything." That suddenly shifts, so, "What are we clamouring for?" So, they sort of lost footing and focus. "What do we do now? Who's going to lead us?" So, they go through a very loose period. (I15_DAC/G)

Government could have stage-managed these divisions to ensure that the sector loses legitimacy in the eyes of the public. That way, they [GoK] were able to ensure that they are able to control and inhibit [CSOs'] ability to contribute significantly especially on the governance issues. (I29_CSO)

There was a time.... post 2000, when NGOs tended to be falling prey to the political tunes. (I51_Other)

A new Government had come into force in 2003 and they were looking for an alternative relationship with NGOs that was not based on suspicion and control.... [they] wanted a different mechanism within which they could work with NGOs.... [Sessional Paper No. 1] definitely is positive, it's a step forward. (I13_CSO)

The need for self-regulation of the sector arose out of the realization that the sector was not getting all the services that they expected to get from the Council. (I20_CSO) 


\section{Political Backdrop: Second Liberation GoK's euphoric reception short-lived}

After a decade of a stalled democratic transition, a new GoK came into power early in this wave following the 2002 elections. This changed Kenya's political environment considerably even as some of the old political personages and habits remained. The new GoK was not of the repressive variety as was the wave one GoK. However, issues of corruption, political-ethnic competition and divisions, and a slow pace of reform continued to characterize the political landscape. This backdrop helped shape some of the key drivers behind regulatory reform in Kenya in wave two. In particular, the political environment had an influence on the CSO sector's coherence and activities, as well as on $\mathrm{DAC} / \mathrm{G}$ funding. The sector's infrastructure and associated self-regulation were also directly influenced by suspected GoK political interference as discussed separately below under the Political Agendas driver.

As discussed under wave one, the period of the 1990s was one of considerable unrest in Kenya as the renewed multi-party system in place from the 1992 election had not served either to oust Moi nor, initially, to significantly temper his repressive modus operandi. A turning point for the country came with the December 2002 national elections. In the two "dubious" national elections since the 1991 constitutional reform had established a multi-party system, Moi and his KANU party had managed to retain power, making Kenya one of the continent's "best-known cases of stalled transition" (Ndegwa, 2003, p. 145). Now the 2002 elections were won by a "grand opposition alliance" in the form of the National Alliance Rainbow Coalition (NARC) (NCNGO, 2004b, p. 89). Leading figures in this coalition included some who had defected from 
KANU in protest against Moi's having "hand-picked" his successor in the form of Uhuru Kenyatta, son of Kenya's first President. The NARC party was led by Mwai Kibaki ${ }^{82}$ with Raila Odinga ${ }^{83}$ his second-in-command (Ndegwa, 2003, p. 147; Hornsby, 2012, pp. 675-680). The election results showed strong support for NARC among Kenyans with Kibaki winning a firm 61 percent of the presidential ballot and NARC winning 125 of 210 elected seats in the National Assembly under this "Third Republic" (Ndegwa, 2003, p. 145; Hornsby, 2012, p. 690).

Kenya was deemed victorious, "now a true democracy" due to this "most significant political event in the history of Kenya since British colonial rule formally ended" (Hornsby, 2012, p. 696; Ndegwa, 2003, p. 145). Indeed, the Kibaki/NARC win was domestically dubbed Kenya's 'Second Liberation', the first liberation having been from colonial rule. Kenya's 2002 election was seen to have brought Kenya squarely if belatedly into Huntington's (1991) third wave of democratization. Free and fair elections, a smooth transition, and a new GoK elected on a reformist platform with commitments to end corruption, strengthen Parliament over the executive, reinvigorate institutions of the state including an independent judiciary, and renew the economy, all had awakened hope in the nation (Hornsby, 2012, pp. 696-697).

In the context of positive democratic evolution for the country, and also given the considerable alignment between CSOs' platforms leading up to the election and those of

${ }^{82}$ Formerly a cabinet minister under Kenya's first two Presidents, this was Kibaki's third attempt at the Presidency.

${ }^{83}$ Odinga, a Luo, had also unsuccessfully run for President in the 1997 election, and, as seen, his father had been a prominent reformist politician (Branch, 2011, p. 246). 
the now victorious opposition (NCNGO, 2004b, p. 89), it would have been easy to assume that the CSO sector would thrive under the new dispensation. Certainly, at the outset of this wave, "for the first time", the GoK-CSO relationship "wasn't adversarial" (I15_DAC/G). The reigning perspective was that the new GoK was "arguably and normatively committed to civil society ideals" (NCNGO, 2004b, p. 89), and that it had won the election with the "tacit or implicit support of quite a good section of civil society" (I8_CSO). However, wave two reveals some unanticipated repercussions that hit the sector in this era such that, in the early part of this wave, it became "ironically weakened by the success of the multiparty effort" (Branch, 2011, p. 256).

The fragility of this democratic transition, of the united front for change, revealed itself as this wave progressed, with the polarizing potential of personalities, ethnicity and patronage so firmly entrenched in the past ever-present (Hornsby, 2012, p. 627). While the Second Liberation GoK's first eighteen months in office was a period of “openness... renewal and optimism", less than two years following the December 2002 elections the Kibaki-led NARC began to splinter (Hornsby, 2012, p. 705 \& 710). That the NARC coalition was merely "an alliance of convenience" formed to ensure electoral victory for an alternative to KANU under the leadership of Moi's ally and successor Kenyatta, the NARC party's basis for unity was shallow (Hornsby, 2012, p. 680). Infighting slowed the pace of reform while evidence of corruption emerged, such that glaring holes fairly soon shone through NARC's winning anti-corruption and reformist platform (Hornsby, 2012, p. 710). One particular case of grand corruption, the AngloLeasing scandal, involved billions of Kenyan shillings caught up in invalid procurement 
processes, inflated pricing, fake companies, countless GoK officials, and evidence that much of the misappropriated monies were intended to fund the NARC GoK's re-election in 2007 (Hornsby, 2012, pp. 726 \& 743-744). Uncovering of this and other scandals by a new Anti-corruption Commission ${ }^{84}$ led to such pressures on the Commission's Head, John Githongo that, fearing for his life, he went into exile in early 2005. By the end of this wave in 2007 the CPI ranking for Kenya was 150 out of 179 countries ranked with a score of 2.1 out of 10 , not much of an improvement from 2002's 1.9 out of 10 score at the end of the previous wave (TI, 2007).

According to Hornsby (2012), amidst "widespread public shock and anger" the corruption scandal "nearly brought it [the GoK] down and permanently tarnished its reputation" (pp. 725-726). Still, a segment of Kenyans either seemingly wanting to give the relatively new GoK a chance, or, for whom corruption and patronage had become understood as simply the spoils of victory, continued their support for the Kibaki regime. Politics had become more deeply ethnicized since reintroduction of a multi-party system in the previous wave, and electoral victories had come to be seen as an "ethnic zero-sum game" with the victorious ethnic group expected to benefit (KNCHR, 2008, p. 23). ${ }^{85}$ As

${ }^{84}$ Under DAC/G pressures, the Moi GoK had established the Kenya Anti-Corruption Authority in 1997 (Hornsby, 2012, pp. 630 \& 633-634). Following its full operationalization in 1999 the Authority had some short-lived success in identifying and prosecuting corrupt officials, however, resistance from within the GoK and Parliament and an inadequate legislative backing limited its reach and led to its dissolution (Hornsby, 2012, pp. 633-634 and 636).

${ }^{85}$ This attitude is exemplified in the Kiswahili statement ni zamu yetu ya kula, which translates to "it's our turn to eat". It's Our Turn to Eat: The Story of a Kenyan Whistleblower is the title of a 2009 book by Michela Wrong on the Anti-corruption Commission Head John Githongo's experience that led him to flee Kenya in fear for his 
the NARC's Second Liberation GoK became increasingly divided, "the split in Government in 2005 spilled over to every part of society including civil society" (I56_Other). The NARC split had a further "polarizing and ethnicizing” effect on Kenya, and "civil society took sides" (I1_DAC/G).

In parallel to the Anglo-Leasing scandal unfolding, the reinvigorated effort at constitutional reform, which had been part of the NARC GoK's winning electoral platform, was underway and also proved divisive. The CKRC initiated in wave one had, between 2001-2002, undertaken a nation-wide consultation process leading to publication of a new Constitution prior to the 2002 elections as per its mandate (Hornsby, 2012, p. 669). The document, "informed by a strong decentralising and human rights spirit", would have upended the status quo, requiring a "radical restructuring" and changing "the nature of politics and the apparatus of government fundamentally" (Hornsby, 2012, p. 670). It faced considerable resistance from Moi and his KANU allies however, leading Moi to call the elections early thus dissolving Parliament (Hornsby, 2012, pp. 670). Parliament's dissolution eliminated the possibility of the next step required to finalize the Constitution in the form of deliberations by the 600 odd-member National Constitutional Conference comprised of all MPs, other political party representatives, delegates from the districts, CSOs and religious organizations that had been part of the constitutional review process legislated in wave one (Hornsby, 2012, pp. $670 \& 722$ ).

life. From exile he further exposed corruption in the GoK supported by tape-recorded conversations in which this attitude is starkly evident (Hornsby, 2012, p. 743). 
Constitutional reform was then a key component of NARC's winning electoral platform. The National Constitutional Conference began deliberation on the CKRC's 2002 version not long after Kibaki took power in 2003 (Hornsby, 2012, p. 722). By March 2004 this "Bomas conference" process reached a draft constitution that, amongst other significant changes that had widespread popular support, devolved the GoK, reduced Presidential power and control, and created the position of Prime Minister (Hornsby, 2012, pp. $722 \&$ 724). Agreement on this draft was far from attained however, with some MPs in favour of a less reformist, status quo constitution walking out of the process (Hornsby, 2012, p. 724).

Following the stalemate the NARC GoK itself revised the Bomas draft in favour of a status quo constitution, and discord ensued in the country with demonstrations ${ }^{86}$ and some violence. The NARC constitution was ultimately rejected in a 2005 referendum, with a 58 percent "no" vote reflecting a strong popular will for reform (Hornsby, 2012, pp. $724 \& 740$ ). Entering the referendum "the country was deeply divided both on the merits of the new constitution and the process by which it had been cobbled together" (Hornsby, 2012, pp. 739-740).

Credibility and support for Kibaki's GoK reached a low point in 2006 and Kibaki's effort to revisit constitutional reform as well as his renewed pledge to address corruption were not given much credence, though actions were taken including the forced resignation of some cabinet ministers against whom the evidence of corruption was

${ }^{86}$ Though, harkening back to the Moi era, in 2004 the NARC GoK had banned demonstrations (Hornsby, 2012, p. 739). 
unassailable (Hornsby, 2012, p. 743). The constitutional experience exacerbated the growing polarization in Kenya in this wave that contributed to a December 2007 election enmeshed in crisis and followed by violence (what became known as the post-election violence or PEV) (Long et al., 2013, p. 143).

The December 2007 elections were "the most closely contested, controversial and violent in Kenya's history", with the vote count showing victory for the incumbent President Kibaki only in the final hour of vote counting; "the result was uproar" (Hornsby, 2012, p. 751 \& 759). It had taken the Electoral Commission of Kenya three days to announce the results, three days during which the media had pre-emptively declared a win by the main opposition party - the Orange Democratic Movement (ODM), established following the constitutional split and led by NARC defector Raila Odinga based on early and unofficial vote counts (Branch, 2011, pp. 269-270). Evidence pointed to elections that were, "at best marked by significant irregularities.... at worst they had been fixed" (Branch, 2011, p. 271). According to one interviewee, "Raila's victory was stolen by the other side, by Kibaki and his cronies" (I4_DAC/G). Over 1,100 Kenyans were killed, $350,00^{87}$ displaced, and countless others subject to violence, rape, and destruction of property in the two months immediately following the elections (Hornsby, 2012, p. 765; Branch, 2011, pp. 271 \& 276). Protests and other forms of civil disobedience at first incited by the losing opposition were supressed by police and security forces using excessive and indiscriminately targeted force (Branch, 2011, p.

${ }^{87}$ Branch (2011) provides a figure of 500,000 displaced though Hornsby (2012) uses 350,000 , which is the official figure provided by the $\operatorname{KNCHR}(2008$, p. 8). 
272). Armed militia also launched ethnic-based attacks, with Kalenjin militia focusing attacks on Kikuyu civilians, and Kikuyu militia focusing attacks on Kalenjin and Luo civilians (Branch, 2011, pp. 273-277). In the final reckoning, members of Kenya's three main ethnic groups were victims, and also perpetrators with weapon of choice ethnicallyascribed according to an interviewee: "The Luos had stones, the Kikuyu had pangas [machetes], and the Kalenjin had spears" (I30_CSO). The PEV and the behind-thescenes political forces behind it, and the mood and moves toward reconciliation following the 2007 elections, come significantly into play in the third and fourth waves.

While this second wave opened on a high note in terms of the relationship between the incoming GoK and the CSO sector, high expectations followed by unmet promises of the Second Liberation GoK soured the GoK's relationship, not only with CSOs but with the broader citizenry. Further, as Kenyans became divided over their support for GoK, the sector also suffered from divisions and was fragile in this wave.

\section{Sector Growth: Exponential expansion}

The growth in CSO numbers had continued through the 1990s, with 1, 234 registered NGOs by 1999, representing a two-and-a-half-fold increase from the 1990 estimated figure of 500 (Kisinga, 2009, p. 57). By the late 1990s, Kenya still had the highest concentration of NGOs in any sub-Saharan African country (Hornsby, 2012, p. 587). Numbers continued to increase exponentially during the second wave reaching 4,500 by 2006 (Kisinga, 2009, p. 57).

Virtually the same reasons cited for continued sector growth in the previous wave were present at the outset of this second wave. These include Kenya's tradition of 
harambee; the continued inability of the state to meet basic service needs (Kanyinga \& Mitullah, 2007, p. 7); and role CSOs were increasingly able to play in pushing for further advances in democratization, human rights and good governance (Kanyinga, 2004; Ndegwa, 2003). The continued and ever-increasing flow of DAC/G funding to CSOs, despite an initial downward dip early in this wave, was a further contributing factor to the sector's “mushrooming” (Kanyinga \& Mitullah, 2007, p. 7).

\section{Type of CSO Activities: Continued dominance of social and economic development, more collaborative civic and political activism}

Growing CSO numbers in this wave included both social and economic development oriented CSOs as well as those working in civic and political engagement. While social and economic development CSOs still made up the bulk of the sector (Kanyinga \& Mitullah, 2007, p. 12), the proportion of the CSO sector engaging in civic and political activism to push the GoK toward further reforms that had grown through wave one continued to grow in this wave (Hanmer et al., 2003, p. 95), evolving over time to contribute collaboratively in a variety of policy reform arenas.

CSOs civic and political activism for a democratic 2002 election as seen late in wave one continued into the beginning of wave two. Given that the sector was pushing also for a change in political leadership away from Moi and his cronies, this activism spilled into the formal political realm. Such was the popular desire for change, the sector made "no attempt to hide [their] allegiance” (I25_GoK), though "at some point, the Kenya Human Rights Commission.... got into trouble for very openly supporting the NARC campaign" (I8_Other). Then, following the NARC GoK's election win, the sector's activism waned as it took time to figure out what its approach to the new GoK, with which it seemingly 
held a natural affinity, ought to be. The sector's civic and political activism reignited over time however, as CSOs found opportunities to be active in a manner that was more collaborative with the GoK than in the previous wave:

2002 really was the beginnings of the substantive openness within the society, where a number of NGOs were able to now do work much more openly and begin to engage the Government.... like on human rights, governance, law and order (I13_CSO).

Collaborative approaches were not necessarily the rule however. For example, that CSOs "became tougher on corruption" after the Anglo-Leasing scandal was revealed, soured the GoK-CSO relationship (I1_DAC/G).

Further, CSO civic and political activism in this wave diversified from the a focus on the democratic reforms that had been needed to oust Moi to other policy arenas. A specific example of such diversifying was that of CSO engagement in the Forests Act of 2005. This was considered a progressive legislation, shaped by the former head of the Green Belt Movement, now head Assistant Minister for Environment and Natural Resources, Wangari Maathai, working closely with the her former Green Belt colleagues and others in the CSO sector (Taylor, 2013, pp. 184-185). Another was the Governance, Justice, Law and Order Sector Program, launched in 2004 which brought together various GoK institutions and involved CSOs as implementing partners and as a policy voice (USAID, 2010, p. 76). CSOs were, along with other actors and citizens, also active in the consultative process established by the GoK to elaborate the national development strategy, Kenya Vision 2030 (Government of the Republic of Kenya, 2007; Wamucii \& Idwasi, 2010, pp. 264; USAID, 2010, p. 76). In another example, cooperation between CSOs working on land issues (particularly the Kenya Land Alliance coalition) and the 
Ministry of Lands led to development of Sessional Paper No. 3 on National Land Policy first submitted to Cabinet in 2007, and ultimately to the Land Act of 2012 (Ministry of Lands, 2009; USAID, 2010, p. 76).

The constitutional reform debate in which CSOs were very active was a more divisive than collaborative affair, pitting some segments of the CSO sector against some segments of the GoK, while aligning them with other segments as the split within NARC became more entrenched. CSOs had been agitating for constitutional reform for some time such that "for the most part it was a civil society agenda" (I8_Other). The CSO sector, and DAC/Gs, had largely sided against the status quo constitution that eventually was quashed in the 2005 referendum (I25_GoK; I56_Other; Hornsby, 2012, p. 739), though in the sector as in society there were divisions along constitutional and ethno-regional lines (Hornsby, 2012, p. 724; I16_DAC/G; I56_Other).

\section{Mismanagement or Misconduct in the Sector: CSO accountability, $D A C / G-d r i v e n$ nature a growing concern}

In this wave, the sector was on the one hand seen to be becoming more mature and professional (I25_GoK). At the same time gaps in the governance, management and transparency in the sector with its ever-growing access to DAC/funding were being revealed (Aulick, 2013, p. 1) as highlighted by the following interviewee:

There are cases that were quoted where people were found to have, claimed to have organized public meetings, a conference in Homa Bay or somewhere in Kenya, and that conference never took place, but it was well accounted for to the donors. So a lot of those were there in the press.... where people have been blamed for not managing efficiently, and abusing resources from the development partners [DAC/Gs]. (I51_Other)

Questions about whether and to whom the sector was accountable were beginning to arise as CSOs were quick to take up short-term, DAC/G-defined projects and priorities in 
order to access funding (Aulick, 2013, p. 1), which was not forthcoming from the GoK (Kanyinga, 2004, p. 17). Even as CSOs experienced the fickleness of on-and-off DAC/G funding in this wave, more and more CSOs were "popping up to access donor money" for "rent seeking purposes", or even using CSOs as a platform "for launching political careers" (I56_Other; Kanyinga, 2004, p. 17). While CSOs were forming because "people want to contribute", CSOs were also seen as an "income generating opportunity, because jobs are scarce" (I54_CSO). A 2002 survey on the sector reported that "corruption, nepotism, and authoritarianism and other features characteristic of the state institutions are now increasingly used to describe CSOs in Kenya" (Kanyinga, 2004, p. 17). Meanwhile, DAC/Gs' financing fickleness also contributed to an environment of competition among CSOs, which ate into the sector's potential for networking and coordination (Kanyinga, 2004, p. 23).

The Kenyan experience coincided with a global trend wherein the sector was experiencing "a loss of public trust" and associated pressures for greater transparency and accountability (Burger \& Seabe, 2014, p. 77; Naidoo, 2004; Ebrahim, 2003, p. 813; Gibelman \& Gelman, 2004). Discourse among academics and practitioners alike was beginning to question whether the various expectations placed on CSOs as forces for democratization or servers of the poor and marginalized had been "overrated", and whether the increased contracting of CSOs to deliver programs, usually on behalf of governments, inclusive of DAC/Gs, was undermining the sector's integrity (Edwards, 1998, p. 55). In Kenya, by the early 2000s the "euphoria" about CSOs' transformative potential was beginning to fade (Hornsby, 2012, p. 627). 


\section{Sector Infrastructure and Status of Self-regulation: Lack of direction and divisions taking hold}

This second wave was one in which the CSO sector went through considerable turmoil as it struggled to determine its position in the new and changing political context under the Second Liberation GoK. Loss of sector leadership, an initial reduction in DAC/G funding, the demise of the NGO Council and self-regulation under it, followed by political (and related ethnic) divisions, all characterized a rocky period for the sector.

From the late 1980s up to the outset of this wave, a critical mass of CSOs in Kenya had shared democratization as a common concern. Even among those not civic and politically active, and even as there were divisions between more conservative and radical reformers, there was widespread interest in a change to the political landscape. In the lead up to the 2003 elections the CSO sector was considered largely united, as were opposition parties and the general public, against Moi and his KANU party that had ruled since Independence (I1_DAC/G;I16_DAC/G). Now, in the face of success, "you've got people even thinking that we no longer need civil society" (I8_Other). CSOs experienced an "identity crisis" (I25_GoK) and "confusion of agenda" (I8_Other), beginning a period of struggle to find meaning, and eventually, unity. Following the Second Liberation CSOs entered a period of "complacency and confusion" (Ong'wen, 2004, para. 12). The sector began to fall into some disarray as a key common raison d'être of fighting for freedom from Moi's autocratic tyranny no longer provided a unifying rallying cry. This was a critical time for CSOs with much existential hand wringing about the sector's existence. Indicative of this was that almost immediately following the 2002 elections, in January 2003 the NGO Council hosted a conference, Civil Society in the Third Republic, 
as an opportunity for the sector, inclusive of Council members and beyond, to reflect on their roles and strategies under the new dispensation in Kenya (NCNGO, 2004a). Among CSOs, and their DAC/G donors, "for the first time.... there's some really deep questions about what the future of civil society in Kenya is" (I8_Other). This juncture of uncertainty rendered the CSO sector, inclusive of the NGO Council, vulnerable to disruption.

The CSO sector was also weakened in the aftermath of the Second Liberation as a number of influential CSO staff, who had been active in the movement to end the Moi era, were drawn into working for the new GoK (Kanyinga, 2004; p. 23; KNCHR, 2008, para. 89; I8_Other; I5_CSO; I15_DAC/G; I12_CSO; I25_GoK; I56_Other). Prominent examples included TI's Nairobi-based regional office loss of their leader, John Githongo, to the newly established quasi-independent Anti-corruption Commission; the KHRC's loss of its leader Maina Kiai to the newly established Kenya National Commission on Human Rights (KNCHR); and the NGO Council's loss of its Chief Executive Officer to the Ministry of Culture and Social Services. The sector suffered a "brain drain" that "weakened the quality of civil society leadership" (Branch, 2011, p. 256) and left it in a state of “temporary disorientation” (Wamucii \& Idwasi, 2010, p. 265).

A lot of civil society leaders jump into government... and there was a collapse in civil society leadership.... There was no change management.... It sort of caught them by surprise. $\left(I 15 \_D A C / G\right)$

Further, in 2004, the NGO Council became subject to serious disruption as battles within and between its Chair(s), Executive committee and staff ensued. The GoK having brought the popular and well-reputed Council Chair into its staff, elections were held 
among Council members to identify a replacement. To the surprise of many, the newly elected Chair was a virtual unknown from outside the sector (I56_Other; I57_CSO; I54_CSO). Apparently, through a combination of manipulating electoral rules and mobilizing many smaller NGOs nationwide to pay for Council registration, thus in a sense buying voting eligibility, this unknown candidate won the Chair seat. Her unfamiliarity in the CSO sector, and the manner in which this new Chair gained power gave rise to suspicion that her candidature was evidence of the GoK seeking to infiltrate and destabilize the Council, of which more is said below under Political Agendas.

The Council suffered tremendously as a result of this leadership transition. The new Chair's legitimacy was constantly questioned based on a perception that she was "in bed with powers" (I12_CSO). Further, this Chair was deemed an aggressive and fractious character who did not want or failed to understand the Chairing role to the point that she effectively closed the separation of powers between the Board and Executive such that "you'd think she was bordering on being the Chief Executive Officer" (I51_Other). The Council "became less accountable" to its members (I56_Other), while a vast contingent of Council members slowly lost interest and withdrew altogether (I5_CSO). Accounts are given of the Chair's total take-over of the Council's infrastructure: "She took over the office and she began to live there and it was like her personal property. So people couldn't come in and work even. Even .... the new Director who was coming in couldn't.... work there. So that is how the split began because now a new office had to be found" (I54_CSO). The Council temporarily split into three splinter groups, each claiming to be 'the' Council (I12_CSO). 
As a result of the Council's disruption, through the remainder of this wave it limped along with limited presence and actions of note, certainly very little that would fall under the guise of self-regulation or other efforts to speak for or strengthen the sector. Granted, self-regulation under the NGO Council had already been struggling prior to the 2002 elections, as noted in one of the NGO Council's 2003 conference background papers, the "absence of internal good governance and adequate financial probity among CSOs is a major concern.... Self-regulation has failed" (Owiti, Aluoka, \& Oloo, 2004, p. 86). One study suggests that CSOs were no longer motivated to self-regulate in the Second Liberation era, that with a new democratic GoK CSOs would no longer be playing the "moral counterfoil" role as they had done under the Moi GoK, thus eliminating the necessity for the sector to uphold accountability standards for itself (PEN, 2007a, p. 20). While this consideration did not trigger the Council's demise, it may well have been an underlying reason as to why the sector took some years before taking steps to address the self-regulation gap. Ultimately, in 2006, the absence of a self-regulation option under the NGO Council provided inspiration for the sector to instigate a new, independent, selfregulation scheme, discussed under the Outcomes section below.

The Council's funding in the form of membership fees dropped significantly due to member disengagement, as did DAC/G sources (I56_Other). Later in this wave, in 2007/08, one of the Councils able to continue to demonstrate legitimacy, particularly through control of the original Council's bank account, received DAC/G funding via an intermediary international CSO headquartered in the DAC/G country. This was following the divisive Chair's departure, when this Council "made some very frantic effort to put 
their house in order. They even bought an office and everything was funded by [the $D A C / G$-funded CSO]" (I53_GoK). Not long after however, indications of funds misappropriation were uncovered and the intermediary CSO and DAC/G began to take steps to recover the funds (I60_DAC/G). This Council "could not account for most of the funds, and since that time, none of these donor organizations have wanted to fund them again" (I53_GoK).

Having gone through a period of identity crisis, then the Council rupture that reverberated across the CSO sector, the sector also then got caught up in the divisions manifesting on the political landscape as the honeymoon period with the Second Liberation GoK waned and the NARC coalition, though continuing to exist on paper, crumbled. Kenyans, inclusive of CSOs and the wider public, became caught up on one side of the split or the other in a context in which "their faith betrayed their aspirations" (I16_DAC/G; I1_DAC/G; KNCHR, 2008, para. 89).

So Kenya has believed that at last we've arrived. The days of negative ethnicity has ended. The days of corruption have ended. We have popular government. We have Kikuyus and Luos working together, so we have a united country. But two years into that, cracks started developing within politics and also betrayal, in terms of grand corruption again emerging. So at that point, you find civil society taking sides, depending on which ethnic group or political persuasion you belong to. (I6_DAC/G)

As described by Hornsby (2012), the CSO sector was uncertain how to adapt to the deteriorating Second Liberation political situation such that it "gradually bifurcated between those who believed that the NARC represented the best available option for Kenya, and those who held to the same precepts of challenge that had motivated their opposition to KANU" (p. 715). This bifurcation was complicated by the fact that some of those involved in the new GoK's power abuses originally hailed from the CSO sector, a 
development that also ate away at the sector's unity and credibility in this era (Branch, 2011, p. 257). Interviewees shared their observation that CSO representatives moving into the GoK were found to abandon, to greater or lesser degrees, reformist platforms as they took up the business of government: ${ }^{88}$ "all of us are asking what happens to you when you get in to Government.... there seems to be a real like transformation in a lot of those people” (I12_CSO). Even while qualifying that such behaviour is human nature, "it's human beings. It's not the civil society, it's the humanity", there was disappointment in the outcome: "When they got into Government, they didn't become good at accountability.... So that was really unfortunate that they moved on to be part of Government, and to just sing the same songs that they were against”(I51_Other).

\section{DAC/Gs' Funding and Policy Engagement: Flip flopping financial support between CSOs and the GoK}

A repercussion for CSOs of the Second Liberation election was an initial loss of $\mathrm{DAC} / \mathrm{G}$ financing due to $\mathrm{DAC} / \mathrm{Gs}$ ' perception that the sector's role in pushing for democratic reform was no longer necessary now that Kenya had gone through a democratic transition. This perception was short-lived however, and their financing for CSOs resumed, alongside a continuation of a largely on though sometimes off again

${ }^{88}$ Interviewees also noted that the experience of CSO leaders changing attitude once they get into government was common in any of Kenya's four waves, but was not observed across the board. Those that continued to uphold the reformist principles of their CSO days tended to not pursue long-term careers in the GoK. Some, such as John Githongo and Maina Kiai were said to have done an "exemplary job", continuing to push a reformist agenda during their relatively short stints working from within the GoK (I26_GoK). 
funding relationship with the GoK, amounting to an overall increase in ODA flows to Kenya in this wave.

Over the period of the 1990s DAC/Gs' financial flows to CSOs had continued on and off, while they had also carried on applying conditionalities to their aid flows as a stick to prompt democratic reform. DAC/Gs had also invested heavily in pursuit of a transformative 2002 elections including via CSO-led civic education and monitoring (Hornsby, 2012, p. 683). In the lead up to the elections DAC/Gs became "overtly involved in Kenya's internal politics" by taking sides in the reform debates (Hornsby, 2012, p. 629). With the NARC win, on a platform that included a commitment to meet DAC/G conditionalities (Hanmer et al., 2003, p. 92), DAC/Gs' optimism led them to begin diverting funding from CSOs to the GoK, including to the latter's new institutions mandated to tackle corruption and advance human rights, roles that on the surface seemed no longer necessary for CSOs to fill (Hornsby, 2012, p. 728). Such was the optimism among $\mathrm{DAC} / \mathrm{Gs}$ that, for a brief period, they put a hold on, reduced or eliminated their CSO support; "donors were moving money to Government" (I25_GoK; I8_Other; I61_Other; I15_DAC/G).

So he [DAC/G representative] comes one day into my office and tells me, ".... I think what we should do now that you guys have a more democratic government, is we should just abolish this civil society fund, and put all the money in the government fund.".... finally Moi is gone and you've got people even thinking that we no longer need civil society, including [DAC/G representative]. (I8_Other)

Though it did not take long for the optimism to wane, in the early years of this wave, diminished $\mathrm{DAC} / \mathrm{G}$ funding was a significant preoccupation in the sector, which was now forced into an awareness of its vulnerability to "donors' patronage" (Kanyinga, 2004, p. 
23). At this point CSOs maintained an estimated 90 percent dependency on $\mathrm{DAC} / \mathrm{G}$ funding to cover their budget needs (Kanyinga, 2004, pp. 17).

Amidst the emergence of corruption allegations including the Anglo-Leasing scandal, the early honeymoon between the DAC/G community and the Second Liberation GoK faded fast. During 2004, DAC/Gs engaged in loud condemnations and threatened to or actually suspended aid to the GoK or components thereof, even while DAC/Gs were not forthright in acknowledging that their own aid funds and private firms held a role in the scandal (Hornsby, 2012, pp. 727-728). After having levelled off between 2000 and 2003, DAC/G funding to Kenya increased considerably in 2004 and continued to do so year-byyear through the remainder of this wave. Between 2003 and $2004 \mathrm{DAC} / \mathrm{G}$ funding to Kenya increased by close to 44 percent and 63 percent between 2004 and 2007 respectively (see Table B1 in Appendix B). The DAC/Gs' reacted publicly to corruption and to the slow pace with which the GoK was implementing the reforms it had committed to, both on the political front such as constitutional reform, and the economic front such as privatization of GoK industries. However, typically DAC/Gs' use of the aid stick was "contradictory and inconsistent" due to the oft-conflicting aims of influencing both the country's political and economic outcomes (Hornsby, 2012, p. 728). Despite slow reforms in many areas, an overall liberalization of the economy, improved administration and public as well as private domestic investment contributed to "reignite[d]" economic growth, though not for the country's poorest (Hornsby, 2012. pp. 731-732). 
Mitigating concerns additional to Kenya's economic and political performance were also coming into play in this wave. For one, the growing import of the anti-terror agenda for DAC/Gs, in which Kenya was an important ally, further complicated their relationship with and messaging to the GoK. Secondly, the GoK's success in attracting investment, trade and aid from China - "with fewer strings attached than the more squeamish West" - from 2002 onwards led DAC/Gs to begin to "fear[ed] both the loss of their 'soft' power in Africa and a hardening of state resolve against their aid conditionalities" (Hornsby, 2012, p. 730; Branch, 2011, p. 299). DAC/Gs were being vocal in their condemnation of the GoK, but were inconsistent in their use of the aid tool, which meant "a confused message from donors" (Hornsby, 2012, p. 745).

DAC/Gs' early questioning in this wave of the need for a CSO role in democratization and governance was short-lived, and their investment in CSOs, including in civic and political engagement, continued. As noted, toward the end of wave one DAC/Gs' development paradigm had begun to place emphasis on CSO engagement with the GoK to develop more inclusive policies, and to promote CSOs' voice in holding governments to account. This approach was a continuation of DAC/Gs' post-Cold War emphasis on CSOs' role in democratication, but it was also part of an emerging DAC/G agenda of "aid effectiveness" as reflected in the Paris Declaration on Aid Effectiveness ("Paris Declaration," 2005)("Paris Declaration on Aid Effectiveness," 2005). The paradigm evolved out of a recognition that DAC/Gs needed to do more to harmonize and coordinate their efforts in ways that would reduce the transaction costs for aid-recipient governments associated with multiple DAC/G interactions. DAC/Gs would harmonize, 
amongst other ways, by pooling their resources together and aligning the resource allocations with aid-recipient government national development plans (i.e. PRSPs) and sector (i.e. education, health) wide strategies. The aid effectiveness model, which focused primarily on $\mathrm{DAC} / \mathrm{Gs}$ ' funding relationships with governments, also articulated a role for civil society in holding aid-recipient governments to account ("Paris Declaration", 2005, paras. 3.iii, $14 \& 48)$.

An example of an "aid effective" approach of harmonized DAC/G support to a sector wide strategy was the previously-referenced Governance, Justice, Law and Order Sector Program launched in 2004. The multi-DAC/G program, housed in the Ministry of Justice and Constitutional Affairs, aimed to "promote good governance, respect for human rights, equal access to justice and respect for the rule of law in Kenya" (Republic of Kenya, 2007, p. iv). Reform of the relevant GoK institutions and practices was targeted as was the development of a "more informed and participatory citizenry and non-state actors" (i.e. CSOs), activities under which, though achieved with mixed success, included, amongst others, support to CSO engagement in the constitutional reform process (I13_CSO; Everatt \& Kanyinga, 2007, p. 17).

At the same time as aid effectiveness meant DAC/G support to CSOs' civic and political engagement role, it also, in some countries, began to narrow $\mathrm{DAC} / \mathrm{G}$ 's funding to CSOs' initiatives only if those fully aligned with government strategies and plans. ${ }^{89}$

${ }^{89}$ This phenomenon is not very well documented though reference is found in policy papers, see for example OECD (2010, p. 34) and Task Team on CSO Development Effectiveness and Enabling Environment [Task Team] (2011, p. 14). Findings of specific 
There is no clear evidence that this was a trend that affected Kenya's CSO sector in an enduring way. Indeed, Kenya was a country in which DAC/Gs did not pursue the aid effectiveness model to the same degree as was pursued in other aid recipient countries. The model, which required considerable confidence in an aid recipient government's accountability, was challenging for DAC/Gs in Kenya given their ever-present concerns with corruption and other governance issues (I3_DAC/G). That said, in this wave DAC/Gs continued to shape CSOs' programming by, as introduced in the previous wave, pre-defining programming priorities and through the application of results-based performance management.

Overall in this wave, DAC/Gs' policy conditionalities and funding to the GoK reflected "greater trust in the government's probity and capacity [which] inspired stronger support for state-led development (rather than via NGOs)", however, GoK corruption, the slow pace of reforms, and the internal divisions in the NARC GoK that became increasingly obvious over this wave was a source of $\mathrm{DAC} / \mathrm{G}$ frustration (Hornsby, 2012, pp. 727-728). After an initial dip, DAC/Gs continued their considerable funding flows to CSOs.

use of the language of aid effectiveness in CSO regulation reform are also found in WMD \& ICNL (2012, pp. 17-18). 


\section{Status of State Regulation: Ongoing fragmented state regulatory regime}

Despite, as seen in wave one, the stated intent for the NGOs Co-ordination Act to provide one coherent regulatory framework under which to consolidate all CSO types, the Act was not proving a replacement for the varied regulatory regimes.

CSOs continued to pursue the alternate registration options in part, as noted, as these other options were deemed administratively easier to contend with than the NGOs Coordination Act as it was being administered under the Office of the President, and without the risk of punitive targeting that registered NGOs or those seeking registration sometimes faced. Registered NGOs' experience of being "subjected to close scrutiny, supervision, constant harassment and often deregistration by the National Intelligence Service and the [NGOs Co-ordination] Bureau without consultation with the NGO Council as required by law" was a contributing factor in CSOs' decision of where to register (Kameri-Mbote, 2000, p. 8). According to research conducted by two Kenyan scholars in the mid-2000s, between 1997 and 2005 there was on average a three-fold increase in CSO numbers, with NGOs showing a five-fold increase, and CSOs registered as trusts or foundations showing a thirteen-fold increase (Kanyinga \& Mitullah, 2007, p. $6)$.

The situation of ongoing multiple registration options for CSOs was attributed by Kameri-Mbote as due to "lack of co-ordination between the Government departments that administer those Statutes and the NGOs Co-ordination Board", with a hint that consensus across these departments on harmonization was lacking (2000, pp. 10-11). This meant also an ongoing "dearth of comprehensive and coherent empirical 
information" on the sector as a whole (Kameri-Mbote, 2000, p. 2). Further, multiple regulatory regimes limited the scope of self-regulation, which only covered those CSOs registered with the Board as NGOs, and thus members of the NGO Council.

\section{Political Agendas: Manufacturing an NGO Council fracture}

Aspects of the second wave point to political agendas interfering in the sector, specifically in the NGO Council, in ways that undermined self-regulation and eventually informed state regulatory reform.

As noted, the NGO Council was subject to disruption in this wave. The changed political environment following the Second Liberation election had left the sector vulnerable due to loss of CSO leadership to the GoK; an identity crisis in the face of a new dispensation; and a reduced funding from $\mathrm{DAC} / \mathrm{Gs}$. There is also widespread belief that the new GoK took purposeful, politically motivated steps to undermine the sector's effectiveness and credibility.

Some observers characterized the recruitment of CSO leadership as a deliberate "coopting" of the CSO sector by the new GoK (Wamucii \& Idwasi, 2010, p. 265), undertaken either simply to bolster its own position vis-à-vis the sector, or to neutralize it. The recruitment amounted to a "merciless raiding" of CSO leaders into the GoK's fold, leading one CSO staffer at the time to question whether the GoK was implementing a "grand scheme" to destabilize the sector (Ong'wen, 2004, paras. 3-4). Others saw it as a natural fit given these CSO leaders' role in bringing the democratic transition that brought the Second Liberation GoK to power: "It was not calculated to undermine the sector, it was a natural process of coalition building.... a very good natural evolvement 
of the period" (I56_Other). However deliberate a co-optation or otherwise, the movement of CSO leadership "arguably compromise[ed] their [NGOs'] ability to critically engage government" (Wamucii \& Idwasi, 2010, p. 265).

As regards the demise of the NGO Council, the dominant narrative is that the NGO Council was subject to divisive GoK intervention, with the appearance of efforts beginning in 2003 to "infiltrate" the Council (I15_DAC/G). It is believed that the GoK "sponsored the scuttling" of the Council (I47_CSO; I12_CSO), including financial backing to help a GoK-planted candidate, a virtual stranger to the sector, garner (or "bankroll") the votes needed to win the Council's Chair position (I51_Other). Suspicions were fuelled when the new Chair's votes included many newly paying Council subscribers, the legitimacy of whose membership was deemed questionable, yet while "the Government knew of some illegally existing groups but they did not do anything.... They turned a blind eye despite knowing that these guys were masquerading to be in the Council”(I53_GoK).

Though the degree to which the Council's demise were a calculated political move by GoK operatives or simply the result of divisiveness in the growing sector is virtually impossible to fully ascertain, the source of the scuttle was one of political agendas. At the individual level, the incoming Council Chair was perceived as being motivated in her pursuit of the Chair position both by "self-interest" and "political ambitions", seeing the Chair role as a "platform" from which to achieve them (I56_Other; I57_CSO). And in an environment where political power was accessible through patronage, the incoming Chair along with those purportedly supporting her behind the scenes and otherwise "wanted to 
put her fingers on some of that money" that was at the time flowing to the Council from DAC/Gs and other sources (I57_CSO).

At the level of the GoK, there are a number of feasible and mutually reinforcing motivations for Council interference that are evident from the literature and research data. For one, the objective of Council infiltration may have been to gain the control over the Council that had been sought via the initial, pre-1992 amendments incarnation of the NGOs Co-ordination Act. From the outset, the Council's presence in the Act "made the government uncomfortable" (Kameri-Mbote, 200, p. 9). This possibility is further backed by Maina's (1998) suggestion that registration of an estimated 200 NGOs over two years in the mid-1990s by GoK officials and cabinet ministers may have been "a strategy... to ensure that the government has a large enough majority to take over the NGO Council itself" (p. 151). A CSO leader active also in this era even suggests that the Council scupper was a somewhat ethnically-motivated, and thus, in Kenya, politically motivated move to dominate the Council (I55_CSO).

Secondly, if indeed "Government brought in their own people to destroy the Council" (I15_DAC/G), it could have been designed to demonstrate that CSOs, through the Council or otherwise, were unable to self-regulate, thus planting seeds of justification for tighter state regulation. The GoK at this time was already "busy tightening the screws" in implementation of the NGOs Co-ordination Act through the introduction of new fees and more stringent reporting requirements (I55_CSO).

Third, the GoK may have been motivated to disrupt the Council as a way of dulling CSOs' civic and political activism. It is possible that the new GoK, inclusive of former 
CSO leaders that had now joined it and who "played a role in splintering this NGO Council" was interested in a quieter CSO sector: "the fact that NGOs were.... remaining critical of Government left Government feeling like.... NGOs should leave us alone for awhile to do what we need to do" (I57_CSO; I15_DAC/G). This cynical view is not implausible, as the method of "interference with internal organizational dynamics" to curtail CSOs was a tried and true approach demonstrated by the previous GoK, members of which were also present in the Second Liberation GoK (Wamucii \& Idwasi, 2010, p. 251). The use of divide and rule tactics involving "engineering Trojan factions" to "beat back" CSOs (Maina, 1998, p. 151) was not unfamiliar territory as a means "to kill any independent voice" (Ong'wen, 2004, para. 3).

If NGOs are fighting, it distracts them from lobbying. That is why Government scuttled the Council.(I47_CSO)

Some of these things were either engineered by Government just to destabilize the sector.... the Government possibly supported a particular faction to ensure that constantly we are fighting, and to see that therefore we are not able to put our eyes on the prize, the issues. (I29_CSO)

The officials running the organization [Council] were not elected as per the NGO Act... [but] the Government never acted.... they just wanted them [CSOs] to be divided. (I53_GoK)

Speaking more specifically to the "cooption" of CSOs by the GoK, Ong'wen (2004) implies that it is no coincidence that the Council was unable to provide leadership for the sector to meaningfully contribute on key national debates during the first eighteen months of the Second Liberation GoK (para. 227). Certainly the NGO Council ruptures impeded the sector's ability to effectively influence development of the national NGO policy developed in this wave. Further, it may not be a coincidence that, entering 2004 the shine on the Second Liberation GoK was already dulling amidst rising charges of GoK 
misdemeanours of a nature that a strong and united CSO sector would typically have rallied against.

Whichever story of the machinations behind the NGO Council split hold most water, all scenarios point to its very damaging affect on the Council's ability to effectively represent the sector. Entry of the new and controversial Council Chair in 2004 "was actually the beginning of the death of the NGO Council", which left a "vacuum" in the CSO sector's infrastructure (I54_CSO). The split also greatly weakened the sector's reputation, and the NGO Council's ability to implement self-regulation.

All that said, the GoK's NGO Council scupper was a fairly isolated, if devastating, case of GoK interference with the CSO sector. On the whole, the Second Liberation GoK was not overly pre-occupied with finding ways to control the sector through regulation, nor did it seek to sully the sector's reputation with some of the type of propaganda seen early in wave one: "Kibaki's era, he was not necessarily pro-civil society, but there was some collaboration there. And not a lot of meddling, nor propaganda" (I5_CSO); "we saw a lot of reprieve” (I7_CSO); “Kibaki was not a dictator” (I25_GoK). The second wave's GoK took a more hands-off approach to CSOs and their regulation, as described by one veteran CSO activist turned GoK public servant turned CSO activist:

[Under] Kibaki, in terms of civil society there was space, it may have been the weakness
of civil societies themselves that did not take advantage of it, but.... in terms of human
rights groups, operating was easy. There was no problem about it... generally
speaking... what you saw with Kibaki... he didn't bother.... he was laissez-faire in his
approach in many things, but they were not bad years.... if you were in an organization.
(II1_Other)


This is not to imply that the GoK-CSO relationship was entirely congenial; "strained relations" continued to exist (Wamucii \& Idwasi, 2010, p. 266). As discussed, there was no shortage of sources of disagreement and division on corruption, constitutional reform, and the like. This had devastating effect in 2009 when an activist working with a CSO offering free legal aid and also monitoring the GoK (especially police and security forces) and calling out accountability lapses was gunned down (Wamucii \& Idwasi, 2010, p. 266). However, the GoK demonstrated more openness to CSOs contributions than had been seen in the past, such as noted for example with development of Kenya's Vision 2030. The Vision document itself called for a strategy of "open engagement between government and civil society", and close collaboration in both implementation and monitoring of the Vision (Government of the Republic of Kenya, 2007, pp. 25-26; Kisinga, 2009, p. 59).

\section{Public Management Agendas: Not driving but shaping}

The NPM paradigm was present in this wave, not solely due to its application by DAC/Gs but as a public management approach adopted by the GoK, though it was not a driver of CSO regulatory change so much as a light shaper.

President Kibaki was "a believer in economic rationality" and had come to power on a platform with some NPM-like characteristics including a strong market orientation and economic growth focus, a commitment to deal with corruption and inefficiencies in the GoK, and "better planning and modernization" (Hornsby, 2012, p. 700; I1_DAC/G). The new GoK's Economic Recovery Strategy for Wealth and Employment Creation 20032007 published early in this wave contained elements of the NPM model, though not 
explicitly stated as such (Government of Kenya [GoK], 2003). The Kibaki GoK undertook selective NPM-type reforms such as "cleaning up the civil service", sometimes to remove the Moi-allied guard, but also to meet DAC/G pressures on the GoK to reduce public expenditure (Hornsby, 2012, pp. $704 \&$ 733). Examples of NPM application by the GoK included the introduction of performance contracts for senior bureaucrats, some parastatals, ministries and departments, and the use of information technology including in some GoK institutions "to improve services and reduce corruption" (Hornsby, 2012, p. 704; Obong'o, 2009, p. 78).

The Economic Recovery Strategy called on "civil society, labour, the private sector, and all development partners" to help mobilize resources for the Strategy's implementation (GoK, 2003, p. vi). The Economic Recovery Strategy also referred to the need for "an appropriate institutional framework" for GoK ministries and departments to implement the Strategy, "and which facilitates the active participation of the private sector, civil society, and communities" (GoK, 2003, p. 46). In turn, Sessional Paper No. 1 on NGOs referred to the need for a regulatory framework for NGOs that would facilitate their ability to contribute to the Economic Recovery Strategy. Aspects of the Sessional Paper reflected the Recovery Strategy's NPM orientation, particularly its intention to improve performance in service delivery to Kenyans (Obong'o, 2009, p. 67). Through the Sessional Paper the GoK called for review of the NGOs Co-ordination Act and its Regulations, partially with the aim of facilitating CSOs "to play a greater role in the economy" (OVP \& MHA, 2006, p. 13). At the same time, the Sessional Paper called on CSOs to "embrace" the NPM paradigm in their work, including applying commercial 
principles such as performance objectives; competitive procurement; increased involvement of service users; and training CSO staff in NPM principles (OVP \& MHA, 2006, pp. 12-13). NPM therefore contributed to shaping the 2006 Sessional Paper, though the Paper's origins pre-dated the Second Liberation GoK era.

As noted, CSOs were significant players in social and economic development services in the country, virtually all of which was through projects, and contracts, not funded by the GoK but by DAC/Gs under an NPM mode of privatizing services. That the DAC/G funding boom for CSOs through the previous wave had helped fuel sector growth and was beginning to be a source of scepticism about CSOs' accountability and credibility meant DAC/Gs' NPM practices could be said to have also had an indirect affect on state regulatory change as in Sessional Paper No. 1 the GoK sought to prescribe NPM principles to CSOs' DAC/G-financed programming. Also as noted, one aspect of DAC/Gs' aid effectiveness model that was gaining currency in this wave saw a role for CSOs in GoK planning processes and in holding the GoK to account, which somewhat reflected NPM thinking in relation to a "customer orientation" and the importance of accountability to stakeholders for performance (Obong'o, 2009, p. 66; Naudet, 2012, p. 10). It is conceivable that this mode of NPM-style thinking had an effect on the Sessional Paper's recognition of just such a role for CSOs.

All told the public management agendas of both the GoK, the latter especially NPMoriented, and DAC/Gs played a shaping role in CSO regulatory change in this wave. 


\section{Security and Terrorism Concerns: CSOs unscathed, for now}

Following the previous wave's 1998 US embassy bombing, terrorism was a growing concern in Kenya. Though in this wave there was no obvious direct influence on CSO regulation, the growing importance of the anti-terror agenda influenced $\mathrm{DAC} / \mathrm{G}$ behaviour and brought Kenya more firmly into the global terror battle.

Kenya was both a site of terror in this wave, including in 2002 the bombing of a hotel in Mombasa and a failed attempt missile shooting of a passenger jet, and, following its having joined the war on terror under the previous GoK following the 9/11 terror attack in the US, an "anchor state" for anti-terror operations in the region (Branch, 2011, pp. 250; Hornsby, 2012, pp. $661 \& 728-729$ ). The country continued to be a "reliable ally" in the global anti-terror realm, and received training for security forces and other types of security-related assistance and collaboration from the US and the UK, in exchange for permission to maintain security and military operations in the country (Hornsby, 2012, p. 729; Branch, 2011, p. 267). As noted, the significance of Kenya's collaboration on security issues meant that, for a country like the US, concerns over other issues such as corruption or by extension other rights and democracy-related reform issues "often conflicted with this close security engagement" (Hornsby, 2012, p. 728).

Though not specific to Kenya, the potential for regulatory influence from the global body FATF needs mentioning. From its establishment in 1989, FATF had largely been a Western, DAC/G country inter-governmental body established to address the threat that money laundering posed to the banking system and to other financial institutions (FATF, n.d., para. 1). Various regional groups were also established to implement the FATF 
recommendations, including in 1999 an Eastern and Southern Africa Anti-Money Laundering Group (ESAAMLG) in which Kenya is a member.

This research did not uncover any evidence that Kenya's membership in ESAAMLG and the associated imperative to implement FATF Recommendation 8, which implicates CSOs in terror financing, influenced the GoK's approach to its regulation and treatment of CSOs in this wave. However, the Recommendation's statement, that non-profits, i.e. CSOs, were "particularly vulnerable" to terror influences normalized this kind of attitude that, even in the absence of evidence of a credible CSO-terror link, emerges in later waves.

\subsection{Regulatory Change Outcomes}

Development and Negotiations: Sessional Paper No. 1 on NGOs and the Kenya Civil Society Competence and Sustainability Program

Early on in this wave steps began to be taken to address the need articulated by the NGOs Co-ordination Board in wave one for regulatory change to address weaknesses in the NGOs Co-ordination Act. A national policy was seen as necessary backing for the Act, to provide "a general framework to which to refer" in addressing areas that the Act was silent or insufficiently clear on such that there was confusion in implementation (Kisinga, 2009, p. 57). Specifically, a policy would provide the basis to, amongst other things, "harmonize the relevant Acts and seal the existing loopholes" (Kameri-Mbote, 2000, pp. 10-11; Kisinga, 2009, p. 57). A key 'loophole' stemmed from the fact that, while requiring all NGOs to register under the Act, the NGO definition and regulation provisions were not adequately inclusive of the nature and modus operandi of each of the varied CSO types operating in the country. Thus, the issue was not that non-bona fide 
CSOs were being registered, but that they were registering under the regulation options other than the NGOs Co-ordination Act. Based on input from a sector survey it conducted in 2000, the Council backed the Board's original (1996) call for a national policy, also advocating for the policy to provide a basis for review of the NGOs Co-ordination Act itself (I56_Other; Kisinga, 2009, p. 57).

In 2001 the GoK initiated steps toward policy development. Perhaps having learned a lesson from the protracted negotiations with CSOs around the 1990s Act, while finding it increasingly untenable to resist demands for greater transparency and reform in the country, the GoK initially chose an unusually collaborative approach to this policy's development. The GoK's first step was to invite CSOs to a consultation, after which a concept note outlining a strategy for development of an NGO policy was drafted. The NGO Council held lead responsibility for the process of drafting the concept note. A Steering Committee comprised of NGO Council members, as well as representatives from the NGOs Co-ordination Board, the Vice President's Office, and other GoK officials, as was a Technical Committee. There was at this point apparently "general agreement" between the NGO sector and the GoK "that a comprehensive policy would facilitate the formulation of a sound legislation on the NGO sector" to replace the NGOs Co-ordination Act (Kisinga, 2009, p. 58).

Development of the policy itself proceeded through 2002 with the GoK in the lead but seeking NGO input through the Council. A consultant was recruited to draft the policy based on the various inputs from the concept paper and reports from GoK - NGO dialogues. A draft was presented to the NGOs Co-ordination Board which then held 
responsibility for taking further steps of ongoing consultation with the sector and within the GoK to obtain the necessary approvals and finalize the policy (Kisinga, 2009, p. 58).

However, Kenya's Second Liberation elections at the close of 2002 effectively put further development of a policy on hold for a period as the new GoK reorganized its priorities and approach to its dealings with the sector. The Council's split also meant that, though invited to do so by the GoK, the sector was "not able to effectively mobilize themselves in the policy making process, right through to the end" (I56_Other; Kisinga, 2009 , p. 58) such that the policy's development was not a collaborative affair as was initially intended. After a long hiatus where attentions were also distracted by the constitutional debates and 2005 referendum, in January 2006 the policy was released in the form of Sessional Paper No. 1 on Non-governmental Organizations (2006).

The 2006 Paper stated its intent of providing a policy framework constituting "the government's first step towards developing conducive legal administrative guidelines to govern the NGOs for optimal operations" with a review of the NGOs Co-ordination Act to follow (OVP \& MHA, 2006, pp. 2 \& 22). With implicit reference to the varied Acts governing CSOs in Kenya, the Paper lamented the "fragmented and uncoordinated legal and institutional framework" for NGOs, which "makes coordination difficult" (p. 22). The Paper called for a "harmonization" of these various frameworks and an overall review of the NGOs Co-ordination Act to follow the Paper (OVP \& MHA, 2006, p. 22).

Justification for the Paper included explicit recognition of the "important role" of NGOs in Kenya's social and economic development, especially in service delivery, but also, in a notable departure from the NGOs Co-ordination Act, of their role in democratic 
development, "lobbying, advocacy and human rights" (OVP \& MHA, 2006, pp. 2, 7 \& 9). Still, the Paper placed particular emphasis on NGOs' service delivery role and the need to enhance the efficiency and quality of services provided by NGOs (OVP \& MHA, 2006, pp. 2, 9 \& 12). The need to enhance coordination among CSOs and with the GoK, as well as to promote a partnership approach between the GoK and NGOs in implementing GoK national development strategies and programs, such as the 2003-2007 Economic Recovery Strategy for Employment and Wealth Creation was also articulated in the Paper (OVP \& MHA, 2006, pp. 2, 9 \& 11). A section of the Sessional Paper framed the need for greater coordination and partnership with the GoK as part of the GoK's pursuit of the NPM model (OVP \& MHA, 2006, pp. 11-13).

Though not articulated as such in the Paper, the emerging aid effectiveness paradigm being promoted by DAC/Gs was coherent with NPM in its pursuit of a coordinated and harmonized approach to aid provision in support of aid-recipient governments' national development strategies. Though also not stated as such in the Sessional Paper, its push for greater coordination and partnerships reflected the GoK's ongoing challenge of understanding the full scope of $\mathrm{DAC} / \mathrm{G}$ contributions to CSOs and the manner in which these were being used and accounted for. According to a 2003 study of aid management and the PRSP process in Kenya, "the volume of foreign exchange brought in through NGOs is significant enough to effect macro balances and there is concern, among other things, to be able to collate the information on these inflows and ensure that funds are used transparently by all recipient organisations (Hanmer et al., 2003, p. 95). 
The Paper also defined a mission for the NGOs Co-ordination Board of providing "efficient services in the coordination and facilitation of the NGOs/CSO sector in order to support and enhance the contribution of the sector in the socio-economic development and improvement of the welfare of the people" (OVP \& MHA, 2006, p. 5).

Further justification articulated for the Paper was the growing number of NGOs and associated need for enhanced transparency and accountability (OVP \& MHA, 2006, p. 9). The Paper called for improved self-regulatory measures along with the need to address a dysfunctional NGO Council subject to "internal wrangling" (OVP \& MHA, 2006, pp. 6 \& 9). More specifically, the Paper required all NGOs "to work under the auspices of the Council", with the Council in turn required to "enforce self-regulation in the sector", specifically to enforce the Code of Conduct with the help of a strengthened selfregulatory committee (OVP \& MHA, 2006, pp. 15 \& 20). The NGOs Co-ordination Board would however "retain(s) the role of managing self-regulation", playing a "supervisory" role "to ensure self-regulation takes place in an effective manner" (OVP \& MHA, 2006, pp. 15-16). As articulated in the NGOs Co-ordination Act mandate for the Council, the Paper reiterated the Council's role in capacity building and networking with the sector (OVP \& MHA, 2006, pp. $26 \& 18$ ).

The Sessional Paper was met with some scepticism in the CSO sector, scepticism fuelled by CSOs' experience with GoK's alleged role in undermining the NGO Council and the sector more broadly, as well as by fear grounded in the uncertainty of what changes the Paper would mean for the NGOs Co-ordination Act. 
What happened after 2002 is.... the new Government, it seems like there were players in there who wanted to basically erode the credibility and the grip that the NGO Council had on it's membership.... the sum total of the result of all the that happened is there ended up coming into the field three NGO Councils.... that left it for Government to decide which one it's in bed with at which time... that of course, eroded the credibility of the whole sector. So, Sessional Paper No. 1... was supposed to be basically saying look, we need to put things back in order, we need to strengthen the sector.... all the high sounding stuff that the Government could just say.... making it appear as if they had the interest of the sector at heart. (I12_CSO)

Not all reviews were so sceptical however. After all, the sector had originally supported and indeed advocated for an NGO policy as the basis for revising the NGOs Co-ordination Act (I56_Other: Kisinga, 2009, p. 57). Though the Paper's focus on coordinating the sector and better harnessing its contributions to national development plans may have seemed to some too close a harkening back to the cover that the use of "coordination" provided to the wave one GoK seeking control of the sector through regulation, for others the Paper represented a positive GoK effort to build a more collaborative relationship with the sector (I13_CSO). Further, certain aspects of the Paper's content signalled a GoK aim of creating a more enabling regulatory environment for CSOs. This included for example a statement to the effect that the GoK would engage NGOs in policy-making, inclusive of support to "the nascent consultative framework" developed through the PRSP process initiated in wave one (OVP \& MHA, 2006, pp. 1415). The fact that the Paper also contained explicit recognition of the range of CSO roles inclusive of civic and political activism; that it outlined the rights to freedoms of speech, assembly and association articulated in the Constitution; and referred to the international and regional instruments ratified by Kenya, was also considered a good sign (OVP \& MHA, 2006, pp. 21-22). 
Uncertainty and some trepidation as to what nature of revisions or replacement to the NGOs Co-ordination Act would be forthcoming in the wake of the 2006 Sessional Paper took hold in the sector, especially given the Paper's recommendation for a stronger managerial role for the Board in self-regulation, and for self-regulation to continue through the NGOs Council. Further, whichever more or less sceptical perspective on the Sessional Paper members of the CSO community held, the sector could not deny that it faced an uphill battle to redeem itself, the sector having suffered severely in more ways than one in this era. The CSO sector was increasingly viewed as being characterized by "declining standards and professionalism", which combined with the "long, drawn-out leadership wrangles and warring factions", had "dented [its] image and credibility" (Kisinga, 2009, p. 60).

Lacking "a legitimate and credible institution to organize CSOs and monitor standards in Kenya" (PEN 2007a, p. 6; I20_CSO; I55_CSO; I12_CSO), rather than work through a Council with unsalvageable credibility, CSOs were motivated to revisit the possibility of independent self-regulation through a body other than the Council. Financial support and the organizing impetus to take steps in this direction came from a well-respected international CSO, the Aga Khan Development Network (AKDN). In 2006 AKDN had commissioned a CSO, the Poverty Eradication Network (PEN), to undertake a study to identify what could be considered "standards and qualities of an exemplary CSO", and to map out the lay-of-the land in capacity building services, needs and gaps for CSOs (PEN, 2007a, p. 6). Amongst other findings, the study concluded that there was need in the sector to "establish clear standards and qualities for CSOs, promote 
best practices, provide holistic capacity building and establish mechanisms for ensuring compliance" (Viwango, 2011b, p. xii). This conclusion reflected the fact that the valuesbased self-regulation under the Council as reflected in the Council's Code of Conduct had proven "insufficiently significant on their own" while the Code lacked monitoring and compliance mechanisms, relying instead on "wilful obedience and adherence" (PEN, 2007a, p. 15). Amongst other sources, the study included findings from a "strategic thinkers" forum of CSO leaders to consider necessary next steps. Out of the forum came an idea to establish a harmonized set of CSO accountability standards and tools essentially a self-regulation mechanism - and an institution focused on their promotion and implementation (Aulick, 2013, p. 2).

In follow-up, a series of six CSO-led initiatives with the objectives to "enhance the competence, credibility and sustainability of CSOs' initiatives and to promote acceptable standards and practices within the civil society sector" joined to form the Kenya Civil Society Competence and Sustainability Program (KCS-CSP) (Viwango, 2011b, p. ix). ${ }^{90}$ The KCS-CSP was thus a new, built-for-purpose networked formed to address CSO accountability, legitimacy and capacity issues through strengthened self-regulation. Financial support for KCS-CSP came primarily from DAC/Gs via AKDN and other international CSOs (Viwango, 2011b, p. viii). DAC/Gs' investment reflected not only an interest in supporting CSOs' to enhance their accountability, but also, the KCS-CSP

${ }^{90}$ There is a minor variance in the actual number of initiatives referenced as having been involved in establishing the KCS-CSP. Aulick (2013) refers to seven participating initiatives (p. 2), whereas Viwango (2011b, p. xi) refers to six. 
model of a coordinated and harmonized multi-CSO initiative fit well with the aid effectiveness model of the 2005 Paris Declaration.

The KCS-CSP began late in wave two to launch a broad consultation on what the standards and tools ought to look like. Though the NGO Councils were not a member of this new CSO network, they did participate in this consultation process. Ultimately the KCS-CSP institutionalized the self-regulation mechanism developed in a body called Viwango, of which more is said in wave three.

CSOs, including some of those involved in the KCS-CSP, also recognized the missed opportunity to contribute to the Sessional Paper due in large part to the sector's disorganization, as well as the potential threat of pending revisions to the NGOs Coordination Act, and thus the need for the sector to step up its game on regulatory matters. After the Paper's release therefore, in 2006 a small group of CSO leaders began to regularly convene to discuss and document what an enabling regulatory framework for the sector would look like: "We were so audacious as to call ourselves the Committee of the Wise... we said, "Let's develop ideas... that would then provide a basis for debate with whoever else about why should the law have these things in it" (I12_CSO). This small group's efforts in the arena of state regulation would expand considerably in the third wave.

\section{Implementation: Amendments to the NGOs Co-ordination and Income Tax Acts}

Amidst the initiation of CSO efforts to re-establish some semblance of credible CSO infrastructure that could play a role in regulatory affairs, the GoK, apparently without consulting the sector, made two significant revisions to the NGOs Co-ordination Act via 
The Statute Law (Miscellaneous Amendments) Act of 2007 (Wamucii \& Idwasi, 2010, p. 262). One such revision addressed self-regulation by handing responsibility for revising the Code of Conduct to the NGOs Co-ordination Board, to be done in consultation with the by now much-maligned Councils (The Statue Law (Miscellaneous Amendments) Act, 2017, p. 225; NGOs Co-ordination Board [NGOCB], 2009, p. 42). Another was to, on the one hand, reduce the number of Ministerial appointments and experts to the NGOs Coordination Board, and on the other, reduce the number of Board members required to achieve quorum in decision-making while eliminating the need for any of the NGO members to be present to achieve quorum (Wamucii \& Idwasi, 2010, p. 262). These changes were considered a "set back" for the sector as they "curtailed their powers to self-regulate as well as their representation at NGO Board meetings, thus limiting their leverage in decision-making processes" (Wamucii \& Idwasi, 2010, p. 262).

In another step in follow-up to Sessional Paper No. 1, the NGOs Co-ordination Board initiated a survey of the sector to better understand the landscape and provide a further basis for informed regulatory reform. A survey tool was piloted in 2006 and data collection ran through 2007 and 2008 with delays due to the PEV (NGOCB, 2009, p. 22).

Sessional Paper No. 1 had articulated concern about CSOs' financial sustainability, but had been fairly silent on how it could be addressed, beyond the suggestion that the NGO Council needed to encourage NGOs to pursue financial support from the business sector (OVP \& MHA, 2006, p. 26). According to one interviewee, the CSO sector, cognisant of the need to find ways to diversify their funding sources beyond $\mathrm{DAC} / \mathrm{Gs}$, pushed for solutions via the Income Tax Act (I61_Other). A positive regulatory 
development came in the form of publication of the Income Tax (Charitable Donations) Regulations in 2007. With these new regulations, 100 percent of individual or corporate donations to CSOs having successfully been granted tax-exempt status would be tax deductible (Kisinga Gitonga, 2010, p. 35). However, this new provision still came with some limitations and an administratively burdensome process requiring, for example, that donations be solely by cash or cheque, and that the CSO supply the donor with a written declaration that the funds would be used for public benefit/charitable purposes only (Kisinga Gitonga, 2010, p. 36).

Any further state or self-regulatory steps toward implementation, or staving off Sessional Paper No. l's recommendations were interrupted by the 2007 elections and ensuing PEV, the aftermath of which, as will be seen in waves three and four, contributed to a fundamental shift in the GoK's relationship with CSOs with associated regulatory implications.

\subsection{Analytical Summary}

State regulatory change in this wave, mainly in the form of Sessional Paper No. 1 on $N G O s$ was initially conceived to provide a policy backing for the NGOs Co-ordination Act, evolving to provide a policy basis for review and revision of the Act. Both the GoK and CSOs shared the view that revisions were needed to address weaknesses in the existing state regulation regime as identified in the previous wave, and by extension in self-regulation under the Act. With CSO numbers growing, many were registering under regulatory options other than the NGOs Co-ordination Act. The continued existence of multiple regulation options for CSOs meant inconsistency in the way CSOs were being 
regulated, as well as limits to self-regulation, which only applied to CSOs registered with the NGOs Co-ordination Board and thus members of the NGO Council. Continued growth in the sector further made it difficult for the GoK to have a complete picture of the sector and its operations. Growing concerns about CSOs' financial probity, DAC/G dependence and rent-seeking behaviours in the sector pointed to the need for to revisit state and self-regulation scheme, all in a global environment of scepticism about CSOs' roles, and demands for greater CSO accountability.

Though the door had thus opened for regulatory change, a weakened sector and sector infrastructure impeded CSOs' ability to shape the change. Ironically, the political development of Kenya's Second Liberation left CSOs with an identity crisis, loss of key CSO leaders to the GoK, and (initially), financial vulnerability as DAC/Gs temporarily turned to the newly elected GoK as their primary aid partner. The sector was then undermined when an alleged politically motivated infiltration of the NGO Council dealt it a blow leading to a Council split. A partial motivation for undermining the NGO Council, and its ability to implement self-regulation, was seemingly to provide justification for stronger state regulation and greater state involvement in self-regulation, as was eventually reflected in the 2006 Sessional Paper No. 1 and the 2007 amendments to the NGOs Co-ordination Act. Another motivation was to render the Council, and by extension the sector, less capable of the type of CSO civic and political engagement that had helped the Second Liberation GoK come to power, the Council's infiltration thus amounting to a non-regulatory means of controlling the sector. 
The political agendas influencing regulation and self-regulation present in this wave differed from the previous wave in intensity and tone. Alleged efforts to undermine the sector via the Council were a covert political tactic, much subtler than the repression CSOs experienced under Moi including but not limited to use of the NGOs Co-ordination Act. On the whole however, the Second Liberation GoK was more open to collaboration with the sector, collaboration that did take place including constructively in the policy arena. Behind the collaboration though, a political backdrop of increasing polarizing developed in the face of disillusionment especially with the GoK's grand corruption and failure to advance the type of constitutional reform process and outcome that much of the country had been asking for to put it more firmly on a path of democratization and reform. The CSO sector itself got caught up in the political-ethnic divides of this wave.

GoK and CSO motivations behind the idea of a regulatory change for the sector evolved over time between the initial late-wave one discussions and release of Sessional Paper No. 1 in 2006. After the experience with NGO Council interference, the failure of self-regulation and awareness of the sector's accountability challenges and waning credibility, and wariness about some of the Paper's content, a faction of leaders in the sector set out not only to establish a new independent self-regulation scheme, but also to reflect on what new state regulation ought to look like. For the GoK, the motive of improving the regulatory framework for CSOs by harmonizing the varied CSO regulations the sector remained. However, the GoK's emphasis as reflected in the Sessional Paper appeared to be not only coordination of a CSO sector now numbering in the many thousands, but also strengthening the sector's service delivery contribution. 
DAC/Gs' NPM-influenced continued financing of CSOs was thus an indirect shaper of regulatory change, though more evident from the Paper was a GoK interest in using regulation to better harness CSOs as DAC/G-funded contractors and contributors to the GoK's NPM-styled Economic Recovery Strategy.

Though security was definitely on the international and Kenya's national agenda especially following $9 / 11$, and was a confounding consideration for $\mathrm{DAC} / \mathrm{Gs}$ when it came to application of economic and political conditionalities on the GoK, there was no obvious immediate impact on CSO regulation in this wave. The Second Liberation GoK's more measured approach to dealing with the sector was not compatible with the use of security concerns to camouflage other motives for CSO regulation.

This wave highlighted some interesting interaction between state and self-regulation. At the outset of this wave the GoK and CSOs shared an interest in state regulatory change to address gaps in the existing framework. The CSO sector anticipated a collaborative effort to achieve regulatory change as per the plan developed with the GoK and expectations of a Second Liberation GoK's inclusive modus operandi, thus lessening any threat of regulatory overreach the sector might otherwise have felt. However, that selfregulation's demise came about due to the GoK's political interference in the Council raised concern in the sector about the potential threat of stricter state regulation, and selfregulation given the legislated marriage between the two. This newly-felt threat, alongside the sector's recognition of its weaknesses, as expected led it to reignite selfregulation through a new independent initiative, while also readying itself to shape state regulatory reform. 
Table 5: Wave Two Key Regulatory Change Drivers

\begin{tabular}{|c|c|}
\hline $\begin{array}{l}\text { Drivers emanating } \\
\text { from CSO sector }\end{array}$ & Characteristics \\
\hline Sector growth & $\begin{array}{l}\text { - Continued rapid growth in number of CSOs including: } \\
\text { national, international, social and economic development } \\
\text { and democracy/rights oriented }\end{array}$ \\
\hline Type of CSO activities & $\begin{array}{l}\text { - Ongoing dominance of social and economic development } \\
\text { services } \\
\text { - Civic and political engagement helped bring Second } \\
\text { Liberation GoK to power } \\
\text { - (Initially) civic and political engagement wanes, then re- } \\
\text { ignites including in collaborative mode with GoK }\end{array}$ \\
\hline $\begin{array}{l}\text { Mismanagement or } \\
\text { misconduct in the sector }\end{array}$ & $\begin{array}{l}\text { - Growing incidences of financial mismanagement and } \\
\text { misconduct } \\
\text { - Actual and perceptions of rent-seeking amidst continued } \\
\text { high CSO dependency on DAC/Gs }\end{array}$ \\
\hline $\begin{array}{l}\text { Sector infrastructure and } \\
\text { status of self-regulation }\end{array}$ & $\begin{array}{l}\text { - Self-regulation proving less than effective } \\
\text { - NGO Council splits, unable to represent sector or } \\
\text { implement self-regulation } \\
\text { - New infrastructure emerges for self-regulation and } \\
\text { targeting state regulation }\end{array}$ \\
\hline $\begin{array}{l}\text { Drivers emanating } \\
\text { from } \mathrm{DAC} / \mathrm{Gs}\end{array}$ & Characteristics \\
\hline $\begin{array}{l}\text { Funding and policy } \\
\text { engagement }\end{array}$ & $\begin{array}{l}\text { - Pro-Second Liberation GoK stance leads to increased } \\
\text { financial support to GoK, decrease to CSO sector } \\
\text { - Threat of decreasing financial support to GoK with } \\
\text { conditionalities tied to GoK anti-corruption, constitutional } \\
\text { reform, though support to GoK largely continues to flow } \\
\text { - Inconsistent application of conditionalities given strategic } \\
\text { priority of Kenya in anti-terror alliance; rise of China } \\
\text { influence } \\
\text { - Resume financial support to CSO sector }\end{array}$ \\
\hline $\begin{array}{l}\text { Drivers emanating } \\
\text { from GoK }\end{array}$ & Characteristics \\
\hline $\begin{array}{l}\text { Status of existing state } \\
\text { regulation }\end{array}$ & $\begin{array}{l}\text { - Non-cohesive regulatory framework for CSOs with } \\
\text { multiple legislations continues } \\
\text { - Combined with continued sector growth sector, non- } \\
\text { cohesive regime rendering it difficult for GoK to } \\
\text { understand sector scope and interventions } \\
\text { - Sessional Paper No. } 1 \text { implies possibility of greater GoK } \\
\text { regulatory control measures }\end{array}$ \\
\hline Political agendas & - (Initial) political intervention to weaken sector cohesion \\
\hline
\end{tabular}




\begin{tabular}{|l|l|}
\hline & $\begin{array}{l}\text { and civic and political activism, and undermine self- } \\
\text { regulation } \\
\text { - Collaborative approach to policy development with CSOs } \\
\text { evolves, laissez-faire President }\end{array}$ \\
\hline $\begin{array}{l}\text { Public management } \\
\text { agendas }\end{array}$ & $\begin{array}{l}\text { Informs GoK approach seen in Economic Recovery } \\
\text { Strategy (2003), possibly more 'partnership' oriented } \\
\text { approach to CSOs } \\
\text { - Reflected in Sessional Paper No. 1 } \\
\text { - DAC/Gs continue use of CSOs as implementers and } \\
\text { application of performance management to CSO funding }\end{array}$ \\
\hline $\begin{array}{l}\text { Security and terrorism } \\
\text { concerns }\end{array}$ & $\begin{array}{l}\text { War on terror of increasing import but no discernable } \\
\text { affect on CSO regulation }\end{array}$ \\
\hline
\end{tabular}




\section{REGULATORY WAVE THREE, 2008 TO EARLY 2013 - CIVIL SOCIETY ORGANIZATION REGULATORY UPSWELL}

\subsection{Introduction}

The CSO regulation story of the third wave, from 2008 immediately following the late December 2007 elections to the 2013 elections is covered in this chapter. It addresses regulatory changes in the form of a new PBO Act as well as a new independent CSO selfregulation initiative called Viwango.

\subsection{Wave Three Overview}

This period was a wave in which both the threat and the opportunity presented by the previous wave's state regulatory opening in the form of Sessional Paper No. 1, and demise of the NGO Council's self-regulation, were seized upon by CSOs to advance regulatory change. Not relying solely on improvements in self-regulation as a means to stave of state regulatory change and address the mismanagement and misconduct issues arising in the still-growing sector, CSOs took the initiative to also shape state regulation in the form of the PBO Act. That state regulation developed under CSO leadership and was ultimately enshrined into law was possible due to an environment in which political agendas were geared toward dialogue and reconciliation following the PEV of 2007/08.

The CSO sector had continued on its path of ever-expanding numbers. With this growth also came incidences of CSO misconduct and mismanagement, a cause for concern within a sector still facing a fractured NGO Council ineffectual in selfregulation. At the same time, the PEV provided an opportunity, if a tragic one, for CSOs 
to demonstrate their value-added not only in social and economic development via their humanitarian response to the crisis, but also in civic and political engagement. The sector's civic and political engagement was pivotal in many ways including in helping to shape the dialogue and reconciliation agenda and then implement it.

The DAC/Gs also played a role, using the threat of permanent aid suspension if a political settlement was not reached, and, once reached, putting their financial support behind both the GoK and CSOs in implementing the dialogue and reconciliation agenda. Although continued GoK corruption was at times penalized by DAC/Gs, their dominant interest was in political and economic stability, and collaboration with the GoK on the counter-terror agenda.

The continued existence of multiple regulatory regimes for the CSO sector remained a challenge for state regulation and one articulated, as it had been in Sessional Paper No. 1, in a National Survey of NGOs Report (NGOCB, 2009). The report, undertaken by the NGOs Co-ordination Board, was intended to inform review of the 1990 NGOs Coordination Act. The report also suggested that regulation needed to address CSOs' vulnerability as conduits for terrorism.

Meanwhile, CSOs were making inroads to address gaps in their infrastructure and in both self- and state regulation. The KCS-CSP coalition launched in wave two established a comprehensive self-regulation scheme under an independent institution called Viwango (meaning 'standards'). With Viwango intended to fill the self-regulation gap, rather than wait for regulatory reform from the GoK, CSOs developed state regulation to replace the NGOs Co-ordination Act. New infrastructure in the form of a CSO Reference Group 
(CSORG), introduced this new regulation in Parliament. Collaboration with the NGOs Co-ordination Board and a Parliamentary Committee saw revisions to the Bill such that the PBO Act (2013) was assented into law in this wave.

With the PBO Act CSOs had seized a new opportunity for the recognition of human rights and participatory legislative renewal provided by a new 2010 Constitution. The Constitution was a product of the political settlement that followed the PEV under a Kenya National Dialogue and Reconciliation process. The political environment was a conciliatory one in which numerous legislative and policy developments toward truth, justice and reconciliation were the order of the era. This period of CSO sector organizing; the GoK's openness to CSO civic and political engagement in the state regulation realm; and the ultimate assenting into law of the PBO Act coincided with the conciliatory political agenda of the power-sharing GoK. Meanwhile, as this more collaborative GoKCSO relationship evolved, CSOs' civic and political activism in relation to PEV followup was laying the ground for entirely different political agendas in the fourth wave under a different GoK.

\section{Table 6: Wave Three Key Developments or Actions of Main Actors}

\section{GoK:}

- Following on Dec. 27, 2007 elections PEV, Kenya National Dialogue and Reconciliation lays ground for more conciliatory political environment, with coalition GoK, investigative commissions and other institutions, legislative and policy initiatives or reforms, or commitments

- Launches constitutional reform and associated consultations leading to promulgation of progressive, citizen-oriented 2010 Constitution

- Instigates steps toward CSO regulatory reform in follow up to Sessional Paper No. 1, in the form of NGOs Co-ordination Board 2009 survey, craft Charities Bill

- Presidential assent of CSO-led PBO Act, which legislates voluntary self-regulation 


\section{CSO sector:}

- Continued growth in numbers

- Continued high level of engagement in service delivery

- Highly engaged in addressing and follow-up to PEV: humanitarian response; pursuit of truth, reconciliation and justice; constitutional and other policy initiatives and reform

- Issue of accountability, transparency, governance, financial dependency on DAC/Gs heightened

- Inactive NGO Council(s)

- Develop and formalize new independent self-regulation initiative, Viwango

- Lead development of PBO Bill and negotiate with GoK until PBO Act assented

DAC/Gs:

- Engage in and back post-PEV political mediation, threatening aid withdrawal in absence of mediated agreement

- Provide financial support to Kenya National Dialogue and various investigative commissions and other institutions, institutional reforms including constitutional reform

- Some DAC/G-specific suspensions of aid or other penalties due to GoK corruption

- Early reduction of financial support to CSOs due to DAC/Gs' financial crisis, but flows continue including for CSO engagement in post-PEV truth, justice, reconciliation including constitutional reform

- Provide financial support to Viwango and to CSORG for work on PBO Act 
Figure 4: Wave Three Timeline: Key Political and CSO Regulation Developments

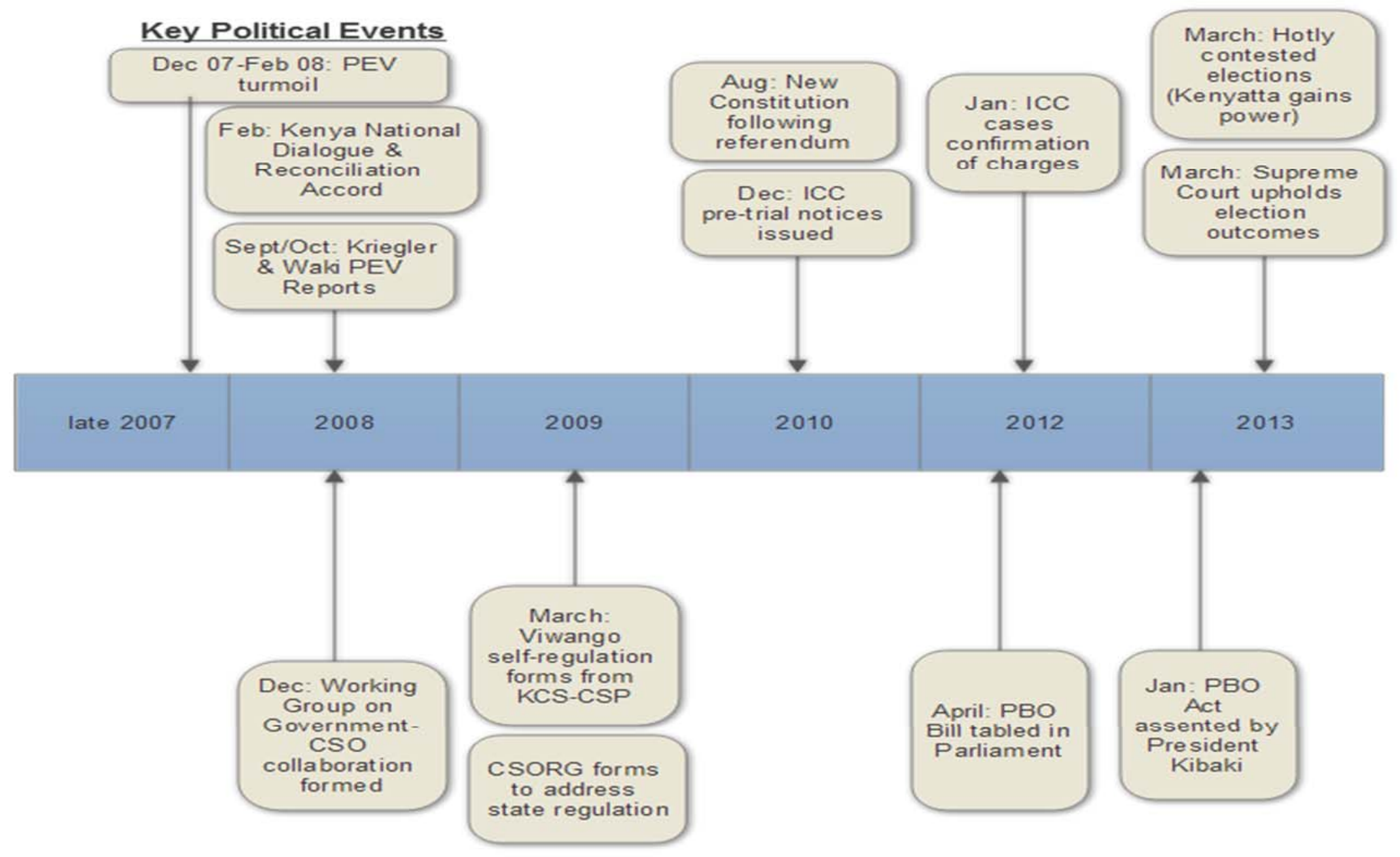

Key CSO Regulation Events 


\subsection{Drivers of CSO Regulation}

\section{In Focus: Perspectives on Regulatory Change Drivers}

[At the] 2007.... elections. The country splits up. Civil society kicks in.... in in a big way, but mainly doing humanitarian work. Peace and reconciliation starts. It was a lot of service provision then. Advocacy is big with this whole mediation support. (I15_DAC/G)

....CSOs were dealing with [PEV] witnesses.... [CSOs were] part of the push for accountability, for declaring these as crimes against humanity. (I25_GoK)

The 2008 PEV. That's where you began to see the beginnings of a rebuilding of Kenyan law and political relationships that led to the Constitution in 2010. (I13_CSO)

The.... Government, it was going somewhat in the right direction and especially with the hopes.... raised when the Constitution in 2010.... was approved with a vast majority of the population that voted yes to the new constitution, over 70 percent.... and of course this was just after a very violent, almost civil war-like situation in 2008, so the hopes were raised. I think there was positive development between 2009 and 2011. (I4_DAC/G)

The survey confirmed the diversity of NGOs in terms of their activities, size and access to resources. Further, it established that NGOs were present even in the most far flung of places in Kenya providing... a wide range of public benefit interventions.... It would appear that a number of NGOs had difficulty in meeting the transparency and accountability test.... This diversity clearly demonstrates that the NGO sector in Kenya has evolved considerably since enactment of the NGOs Coordination Act..... There is therefore an urgent need to review the legislative and regulatory framework.... (NGOCB, 2009, pp. 16-17)

The need for self-regulation of the sector arose out of the realization that the sector was not getting all the services they expected to get from the Council.... [then] when the new Constitution was passed.... there was a provision that actually us citizens could participate in legislation.... So the civil society sector, what they did is they went out and collected views about how they want the sector to run, how it would look like and all that. That is how they developed a PBO Act, which was passed in January 2013. (I20_CSO)

When KANU [Moi] lost, the situation significantly improved during the early days of the national Government and the leadership of Mwai Kibaki. And even the Kibaki second regime, when they shared power with the opposition, the situation significantly improved.... The situation was bad.... in the late days of the Moi regime, the situation was critical. There was a lot of political imprisonment, assassinations, and these kinds of things. But for the ten years when we had the Kibaki rule, the situation significantly improved.... because ultimately, what we got from the Kibaki regime was this PBO Act. It's Kibaki who assented to it. So things were really improving. (I29_CSO) 


\section{Political Backdrop: The 2007/08 post-election violence and aftermath}

At the outset of wave three Kenya was rocked by the PEV that had begun once the late December 2007 election outcomes were announced. For two months following the election the country was in disarray. A political settlement was reached only when an external panel of eminent African persons forged a compromise that would involve power sharing between the incumbent President Kibaki and the opposing Raila Odinga. Beyond this power sharing, the mediation process committed this GoK to an agenda designed to address critical issues underlying the PEV. Concrete actions toward truth, justice and reconciliation, inclusive of constitutional and various legislative and policy initiatives and reforms characterized the political backdrop of this wave. The pinnacle of the truth and justice movement was the eventual pursuit by the International Criminal Court (ICC) of cases against two of Kenya's long-standing MPs, and political leadership contenders, for their alleged roles in inciting the PEV in 2007/08.

Following wave two's highly divisive 2007 elections Kenya experienced a "sudden descent into anarchy" through close to two months of PEV and general chaos (Hornsby, 2012, p. 765). The incumbent President Kibaki and his supporters maintained that he'd won the elections fairly, while the opposing candidate Odinga and his supporters cried foul. A Kenya National Dialogue and Reconciliation process was established under external and internal pressures, leading to a February 2008 power sharing agreement reached with herculean effort by a team of a Panel of African Eminent Personalities headed by Kofi Annan (Branch, 2011, pp. 278-279). 
Under the agreement eventually reached, a coalition government was formed. A new post of Prime Minister was created for Odinga as were two Deputy Prime Minister posts, while an expanded Cabinet would see an equal allocation of Ministerial posts to the President and Prime Minister's parties (Branch, 2011, p. 278). The resulting 42 Minister configuration was "the largest Cabinet since independence" (Hornsby, 2012, p. 770). Through the mediation process it was also agreed to establish two commissions of inquiry: what became known as the Kriegler Commission into the conduct of the election (formally the Independent Review Commission or IREC), and the Waki Commission to investigate the origins of the PEV (formally the Commission of Inquiry into PostElection Violence or CIPEV) (Branch, 2011, pp. 278-279). A Truth, Justice and Reconciliation Commission (TJRC) made up of Kenyan and international experts was also established under an October 2008 Truth, Justice and Reconciliation Act (Truth, Justice and Reconciliation Commission [TJRC], 2013). The TJRC - which had originally been called for both by CSOs and a GoK Task Force at the outset of the Second Liberation GoK's reign (KNCHR, 2008, para. 730; Hornsby, 2012, p. 707) - was tasked with gathering evidence of gross human rights violations in Kenya dating back to independence up to 2008; explaining the causes of these violations; and recommending prosecution and reparation (Kenya Transitional Justice Network [KTJN], 2013, p. 6). ${ }^{91}$ The TJRC's backward lens to independence was an acknowledgement that the roots of the PEV ran deep.

${ }^{91}$ The TJRC was established in August 2009 and published its final report over four years later in May 2013 (TJRC, 2013, p. ii; KTJN, 2013, p. 6). 
Granted, the conciliatory spirit of the settlement and PEV follow-up reforms was forced, and the coalition GoK's genuine commitment to reforms that would address the systemic political, ethnic and impunity issues behind the 2007 election crisis deemed lackluster. Still, the GoK forged ahead with these initiatives even if driven in part by "the short-term political expedient of keeping the coalition together, thus preventing the immediate return to conflict" (Branch, 2011, p. 279). In some respects it was business as usual under the coalition GoK. From 2009 on, corruption scandals plagued the coalition GoK and became highly public matters given evidence and allegations revealed via WikiLeaks (Hornsby, 2012, p. 776; Branch, 2011, p. 285). What was unusual was the occurrence of MPs being suspended or forced to step down, ${ }^{92}$ brought on in part by the public availability of evidence, ${ }^{93}$ by the necessity of seeking compromise under a coalition GoK format, and by the involvement of DAC/Gs in revealing and penalizing the scandals which had grown to include money-laundering, and drug smuggling (Hornsby, 2012, pp. 776-778). By the end of this wave in 2012 some improvements had been made such that the country's CPI reached a still very low score of 27 out of 100 (ranked at 139 out of 176 countries), up from the 21 out of 100 of 2008 (TI, 2012; TI, 2008).

A particularly significant outcome of the National Dialogue and Reconciliation commitments in this wave was, after years of false starts, the promulgation of a new

${ }^{92}$ Including in 2010 the Minister for Agriculture and wave four Deputy President William Ruto in relation to suspect land deals and skimming of agricultural subsidies (Hornsby, 2012, p. 776).

${ }^{93}$ In addition to WikiLeaks, a Kenya version called Mars Group was undertaking similar online release of classified and unclassified documents, while an initiative called Mzalendo was also active in monitoring parliament (Hornsby, 2012, p. 888), the latter supported indirectly by $\mathrm{DAC} / \mathrm{G}$ funding and other largely foreign sources. 
Constitution in 2010. What was called Agenda Four ${ }^{94}$ of the dialogue outcomes involved steps to address long-term issues and solutions, specifically, to implement various legal and institutional reforms, not least of which was a new Constitution. A Committee of Experts on Constitutional Review [CoE], made up of Kenyan and international experts, was struck in March 2008 with the mandate of designing and implementing a constitutional review process. Constitutional review and amendment was legislated through a new The Constitution of Kenya Review Act of 2008 in December of that year. Rather than starting from scratch, and given the outstanding tensions around previous constitutional reform efforts, the Committee was required to consider previous Constitution drafts and issues arising (Hornsby, 2012, p. 777). A first draft was produced by November 2009, revised by a Parliamentary Select Committee by February 2010, and then passed in Parliament in April of that year. Its parliamentary approval occurred less because of its widespread, cross-coalition appeal to MPs, but rather, because of the inability of any MP or coalition to gain the necessary quorum to amend it (Hornsby, 2012, p. 778).

The new Constitution was deemed a "reasonable compromise" which garnered considerable support, including from CSOs, as "the last opportunity for meaningful reform" (Hornsby, 2012, p. 780; Branch, 2011, p. 282). The Constitution enshrined reform in key areas of long-standing contention among politicians, CSOs, and the

94 The Kenya National Dialogue and Reconciliation had a four-part agenda: 1) Immediate action to stop the violence and restore fundamental rights and liberties; 2) Immediate measures to address the humanitarian crisis, and promote healing and reconciliation; 3 ) How to overcome the political crisis; and 4) Addressing long-term issues (Kofi Annan Foundation, 2009, para. 6). 
populace including: some reduction to presidential powers inclusive of parliamentary oversight of presidential appointments; ministers, now called cabinet secretaries, would not be elected MPs; a Senate with special seats for women, youth, and disabled people; new and more equitable constituency boundaries; and dissolution of the independence, ethnic-based provincial boundaries to create 47 county governments, thus creating a twotiered, semi-devolved government (Hornsby, 2012, pp. 777-778; Branch, 2011, pp. 281 282).

Finally, after much debate and division surrounding the previous failed attempts at constitutional reform the Constitution was passed through an August 2010 referendum with a 70 percent voter turn out and close to 70 percent of those voting in the Constitution's favour (Hornsby, 2012, p. 779). ${ }^{95}$ Support for the Constitution was quickly expressed by the DAC/Gs, and most CSOs were also jubilant (Hornsby, 2012, pp. 778779). ${ }^{96}$ Both the process of consultation on the Constitution and the Constitution itself were touted as among the most comprehensive and citizen-oriented in the world, with ample room for public participation and a solid Bill of Rights (ICNL, 2015a, p. 4; Houghton \& Muchai, 2014, para. 6). Kenya's 2010 Constitution was and is considered "an incredibly progressive document", and Kenyans' pride in it is palpable (I3_DAC/G; I4_DAC/G). The process did not end with promulgation of the 179-page Constitution

${ }^{95}$ Its passing was supported by Kibaki, Odinga, and Kenyatta, with Ruto, though a member of Kibaki's party, campaigning for the "no" side (Branch, 2011, p. 283).

${ }^{96}$ CSOs were not entirely unified in support of the new Constitution. Specifically, some churches and faith-based organizations opposed it due to its recognition of Islamic khadis' courts, deemed as privileging the Moslem faith over Christianity, as well as its allowance for abortion (in cases where the mother's life was endangered) (Hornsby, 2012, p. 779; Branch, 2011, p. 283). 
however as the coalition GoK thereafter faced the "daunting task of crafting 49 pieces of complex legislation" required to implement it (Hornsby, 2012, p. 778 \& 780).

Another significant outcome of the Dialogue and Reconciliation process was agreement to investigate and try those found guilty of perpetrating the PEV. Authors of the Waki Report, released in October 2008, uncovered but chose not to publicize alleged perpetrator names, instead submitting their list of key inciters of violence, a list inclusive of MPs and GoK officials, in a sealed envelope with supporting evidence to the mediating Panel (Hornsby, 2012, p. 773; CIPEV, 2008, p. 18). ${ }^{97}$ Per the mediated PEV agreement, perpetrators were to be tried and prosecuted. The Waki Report recommended establishment of a special domestic tribunal, with recourse to the ICC if necessary (Hornsby, 2012, p. 773; CIPEV, 2008, p. 18). Through over a year of parliamentary deliberations, no agreement to establish a domestic tribunal was reached, with the contingent of MPs refusing to support the domestic tribunal idea holding conflicting motivations. Some resisted a domestic tribunal "to protect the guilty", based on an assumption that the ICC "will not materialize in our lifetimes", and that if it did materialize it would target "them, not us" (I22_CSO; Hornsby, 2012, p. 773). Yet others resisted it "to ensure that the guilty would be tried in The Hague [at the ICC]", based on the assumption that an ICC trial would be less subject to manipulation (Hornsby, 2012, p, 773). On the whole, the coalition GoK, "an extremely fragile, extremely fractious entity"

${ }^{97}$ The KNCHR also wrote an investigative report, which included a longer list of alleged perpetrators of PEV ranging from MPs to schoolmasters (KNCHR, 2008, pp. 168-221). The full version of the report including this KNCHR list was embargoed by the Waki Commission, but was leaked and is readily accessible on the web. 
was fundamentally not interested in any pursuit of accountability given the political threat accountability implied to many of those in the coalition (I22_CSO). Polling in 2010 and 2011 however showed that a majority of the Kenyan public (60 percent) supported the ICC route for Kenya (Menya, 2011, paras. 2-3).

In the meantime, the ICC, also in receipt of the Waki Report and list of suspected perpetrators, and cognizant of the lack of progress in establishing a domestic tribunal within the one year time frame recommended by the Panel, had begun investigations in Kenya. In December 2010 the ICC issued public pre-trial notices to six Kenyans on the Waki list deemed having committed crimes against humanity for their roles in the PEV. Among the six summoned to the ICC were Deputy Prime Minister Uhuru Kenyatta (allied with Kibaki's Party of National Unity) and Education Minister William Ruto (allied with Odinga's ODM party), accused of having incited, organized, and financed the PEV in what amounted to crimes against humanity (International Criminal Court [ICC], 2015; ICC, 2016; KNCHR, 2008, pp. $172 \&$ 175). ${ }^{98}$

Faced with this new reality the GoK sought to withdraw from the ICC, and lobbied the $\mathrm{UN}$ and the $\mathrm{AU}$ in hopes of delaying the investigations so that a domestic tribunal could be established (Hornsby, 2012, p. 773). The ICC trials proceeded however, beginning in this wave and continuing into wave four. In two separate cases, Ruto and Kenyatta's summons to the ICC were issued in March 2011 and their charges were

98 Neither Kibaki nor Odinga were identified as perpetrators in the post-PEV investigations, nor by the ICC's investigations. It has been suggested that Kenyatta and Ruto both "had help" in the KNCHR that produced the first PEV investigative report, each to ensure that the other was subject to blame (Kiai, 2015, paras. 11-12). 
confirmed in January 2012 (ICC, 2015; ICC, 2016). The ICC cases provided a layer of malcontent underlying the generally more conciliatory and reformist political environment of this wave.

The crisis of the post-2007 election violence precipitated critical reforms in Kenya, reinvigorating the country's movement in the democratizing direction that the 2002 Second Liberation elections had portended. These reforms, along with a conciliatory post-PEV environment - however forced - boded well for a more collaborative relationship between the coalition GoK and CSOs in this wave.

\section{Sector Growth: Expansion continues}

As noted, during the second wave NGO numbers had continued to increase, reaching 4,500 by 2006 . The growth in numbers persisted in the third wave, increasing to 6,075 registered with the NGOs Co-ordination Board by August 2009, then 8,430 in 2011/12, representing 35 percent and 39 percent increases over each of the three year periods since 2006 (NGOCB, 2009, p. 12; NGOCB, 2015, p. 3; Otini, 2012, para. 13). The NGOs Coordination Board was, however, beginning to doubt its figures.

In 2009 the NGOs Co-ordination Board fulfilled an infrequently met requirement under the NGOs Co-ordination Act to validate its registry regularly, undertaking a national survey of NGOs that would, amongst other things, "update and validate data on all NGOs" (NGOs Co-ordination Act, 1990, s. 7(a); NGOCB, 2009. p. 16). One of the survey's findings was that, though the sector was indeed continuing to grow, there was a discrepancy between the Board's registration numbers and actual NGO numbers. When seeking site visits and interviews with NGOs for the survey, the Board was apparently 
only able to reach 22 percent of the NGOs in its registry (NGOCB, 2009, p. 24). This led the Board to conclude that the remaining NGOs had either ceased operations without fulfilling the legal requirement to inform the Board; had not provided accurate contact information in their registration with the Board; or had become inactive (NGOCB, 2009, p. 25). Two stated limitations of the survey would have also contributed to the gap between the registered and the reachable NGOs. First, that contact information for some NGOs and individuals representing them may have been inaccurate due to mass of internal displacements due to the PEV during the study's data gathering, ${ }^{99}$ and second, possible reluctance among NGOs to participate due to a perception that the survey was in fact an audit of registered NGOs (NGOCB, 2009, p. 23).

With each of these scenarios feasibly contributing to the gap, the survey report did not attempt to conclude what the real gap between the official and actual numbers was, while the sector continued to grow. The further increase in registered NGOs to 8,430 in 2011/12 occurred even as, following the Board's 2009 survey findings, 1,250 NGOs were de-registered in 2010 due to failure to submit annual returns (Eastern and Southern Africa Anti-Money Laundering Group [ESAAMLG], 2011a, p. 177).

\section{Type of CSO Activities: Heightened civic and political engagement in relation to $P E V$}

A social and economic development orientation continued to dominate the CSO sector's activities in this wave. At the same time, CSOs' civic and political engagement,

${ }^{99}$ As noted, over 350,000 people were displaced due to the PEV, including in provinces with a high NGO presence, with many never returning to their homes or businesses, some of which had been destroyed during the violence and unrest (KNCHR, 2008, paras. 1-2). 
especially around the PEV truth, justice and reconciliation process and related reforms such as development of a new Constitution, was highly visible and effective in this wave.

The Board's 2009 survey report clearly acknowledged the sector's growth and diversity, and its positive contribution in many and varied sectors of Kenyan society and economy, including an "immense contribution" to the country's GDP (NGOCB, 2009, pp. 16-17 \& 57). ${ }^{100}$ According to the survey, social and economic development dominated the sector's activities, with 91 percent of NGOs surveyed involved primarily in service delivery (53 percent) or capacity development ( 38 percent), and the remaining 9 percent involved in advocacy (NGOCB, 2009, p. 29).

CSOs played a significant role spearheading the humanitarian response to address the needs arising from the PEV during which, as previously noted, over 1,100 people were killed, 3,500 injured, and over 350,000 displaced (Hornbsy, 2012, p. 765; KNCHR, 2008, paras. 2, $18 \&$ 93). CSOs' interventions were many and varied, not solely providing relief supplies to the victims of displacement and violences but also "secure passage, rescue centres with counsellors, psychiatrists... identifying [internally displaced] people and relocating them" (I30_GoK), and later, advocating for reparations for PEV victims (USAID, 2014, p. 68).

A segment of the sector was also active in advocating for an end to the PEV, for truth, peace, and also justice for the victims - and the country - as well as a negotiated political settlement following the violence. A coalition of CSOs and individuals, called Kenyans

${ }^{100}$ A figure of 68 billion Kenyan shillings (approximately 500 million USD) is cited as having been "spent in various projects across the country" (NGOCB, 2009, p. 57). 
for Peace with Truth and Justice (KPTJ) formed in the aftermath of the PEV for this purpose, working closely with the KNCHR (KNCHR, 2008, paras. 90-91). ${ }^{101}$ The KPTJ appealed to the African Commission on Human and People's Rights to intervene to put an end to the violence and human rights abuses, while other CSOs used various channels to draw international attention to the crisis (KNCHR, 2008, paras. 90-92). It was apparently one of the KPTJ members, the Kenya chapter of the International Commission of Jurists, from which the political power-sharing arrangement following the PEV originated (I22_CSO). Understanding the significance of CSOs' varied PEV roles is aided by the following interviewee description of the PEV weeks:

So you have a humanitarian crisis, you've got an information gap that builds and is always expanding, then you've got a legitimacy crisis in government. Kibaki is visibly no longer in charge of the entire country. There's a section of the country that has accepted the results. There's a large part of the country.... that just rejects the results, and rejects Kibaki, and rejects the legitimacy of anything called government. So, CSOs stepped into these gaps in different ways... a group of people had started meeting at the KNCHR offices. And the meeting was of people who had shared concerns about the crisis that was unfolding, and about which there was no response.... So what the initial activity in the group that started meeting was to exchange information. What's going on in different parts of the country? Just so that we update, we created a way of sharing information, and remember also, which we didn't know immediately - we were also choking the region. We were choking Uganda, we were choking Rwanda, we were choking South Sudan because they all.... depend on Kenyan supply lines.... People just came around [to the KNCHR office] and started saying what they knew.... Different CSOs but ordinary citizens also.... And so we start putting out information about what's going on in the country. There's humanitarian need, and also the issue of [the] international community needing interlocuteurs, who to engage with that wasn't too extreme and that was sort of still credible. The Kenyan government was on one fringe extreme, and the opposition was on the other fringe extreme. And so all these groups of people coming into the country want to help, want to do something, want somebody to talk to, somebody to plug in to, and so we [CSOs] provided that. (I22_CSO)

${ }^{101}$ The KNCHR was at this time led by Maina Kiai, one of the civil society activists recruited by the GoK at the time of the Second Liberation. 
CSOs also played a role in awareness raising of victims and witnesses to voluntarily give testimony to the official PEV investigations called for as part of the truth, justice and reconciliation process, including those of the KNCHR, the Waki Commission, and ultimately the ICC (I16_DAC/G; I22_CSO; I25_GoK). They were in a good position to do so given CSOs' on-the-ground presence in the immediate PEV aftermath. The Waki Commission's report articulated its deliberate collaboration with Kenyan CSOs, as well as the KNCHR, both of which provided "information, contacts, and expertise in areas related to post-election violence" (CIPEV, 2008, p. 5). Their contributions are listed in the report as:

- Providing background material and reports concerning the history and patterns of human rights violations in Kenya. This helped the Commission establish a foundation from which to proceed;

- Giving access to their records, often including statements from witnesses they had interviewed and helping map out geographic regions that should be the focus of investigations;

- Providing contacts with local community leaders, individual victims, and other key contacts in communities where they had established trust and credibility;

- Assisting and providing victims the Commission interviewed in public and in private with emotional support, based on long established relationships with them; and

- Offering various types of assistance to victims, including medical services, counselling, and various types of community support. (CIPEV, 2008, p. 6)

All of CSOs' actions following on the PEV were critical in aiding Kenya to move out of the 2007 election and PEV quagmire. Also of note is that CSO civic and political activism saw them supportive of the ICC's involvement as a critical component of the pursuit of justice for PEV victims and for Kenya more broadly, or which more is said below under Political Agendas. 
As part of their involvement in PEV-follow-up, CSOs also continued their activism from the previous waves in the arena of constitutional reform. CSOs had played a significant role in lobbying for the Constitution and shaping its content through the various means available such as oral presentations at regional hearings, written submissions, participation in thematic and sector-specific consultations of the CoE, and hosting CoE participation at CSO-led fora (Committee of Experts on Constitutional Review [CoE], 2009, pp. 19 \& 68-71; I9_GoK; I12_CSO). Following the Constitution's promulgation in August 2010, CSOs continued to be actively engaged in a variety of policy and regulatory realms, often in close collaboration with the GoK, to design the various legislation and bodies necessary for the Constitution's implementation (Hornsby, 2012, p. 781; USAID, 2014, p. 66). These included for example a revamped Supreme Court, a new Independent Electoral Boundaries Commission, and a Commission for the Implementation of the Constitution (Hornsby, 2012, p. 781). As with previous elections of the multi-party era, CSOs also provided substantial civic and voter education programming in the lead up to the 2012 elections, especially significant to disseminating information on rights and procedures under the new Constitution ${ }^{102}$ (USAID, 2013, p. 76).

Altogether during this wave, and despite the accountability and legitimacy challenges experienced by CSOs alongside a fractured and inactive NGO Council as discussed below, the sector's civic and political engagement proved it had moved past the crisis it

102 Civic education by CSOs was supported by DAC/G funding channeled through the GoK, as well as some direct $\mathrm{DAC} / \mathrm{G}$ and private foundation funding to CSOs. 
had faced through much of the second wave: "concerns over a weakened civil society.... have been diluted by the continued visibility of NGOs as mobilisers for key policy reforms" (Wamucii \& Idwasi, 2010, p. 267).

\section{Mismanagement or Misconduct in the Sector: A going concern}

The Board's 2009 survey affirmed perceptions carried over from the previous wave that accountability in the sector was falling short, and that NGOs were prone to misconduct. The sector itself was cognizant of these perceptions, but also of the fact that the sector was indeed facing accountability challenges, including due to the high level of dependence on $\mathrm{DAC} / \mathrm{G}$ funding.

In its survey report the Board laid blame on the NGO sector for its data collection challenges, which "had not been successful due to low compliance" by NGOs in submitting their annual returns (NGOCB, 2009. p. 16). Interviewees for the Board's survey from decentralized levels of government referred to a "lack of transparency and accountability among NGO officials" and unspecified "cases of embezzlement of funds" (NGOCB, 2009, p. 55). The survey report went on to mention questionable, rent-seeking type practices such as recruitment favouring NGO officials' family members, and NGO leaders' use of project funds for personal purposes (NGOCB, 2009, p. 55). Other issues cited included NGOs working in isolation rather than coordinating and collaborating among themselves and especially with the GoK, and relatedly, duplication of activities by NGOs (NGOCB, 2009, pp. 54-55). The sector's dependency on foreign funding was also cited as indicative of a lack of NGO sustainability and thus a cause for concern (NGOCB, 2009, p. 57). 
As noted, in coverage of its limitations, the survey report suggested that some NGOs' reluctance to participate in it or to provide the full information requested by the Board may have been due to their perception that the Board's intent was not a study, but NGO audits. This Board hypothesis raises the question of the degree to which reluctant NGOs may have feared an audit due to their knowingly engaging in fraudulent conduct or to simple neglect and mismanagement. Neglect and mismanagement would have been a factor given the study's finding that 22 percent of survey respondents stated they were simply unaware of their legal requirement to submit annual returns, though this also reflects the Board's shortfall in providing guidance to the sector, which the survey report also acknowledged (NGOCB, 2009, pp. 58 \& 55).

Even as the NGOs Co-ordination Board survey report was raising concerns about the sector's challenges, the sector itself was well cognizant of the issues both of perception of CSO management and accountability gaps and real gaps in practice. Writing in 2010, a Kenyan legal expert stated that: "Issues of transparency and internal governance especially in NGOs are in dire need of being addressed" (Kisinga Gitonga, 2010, p. 37). Findings from the AKDN-commissioned studies by the PEN at the end of wave two remained pertinent heading into wave three. Governance standards in the sector had been "consistently falling" with instances of, for example: numerous so-called briefcase NGOs; absence of Board meetings and engagement; absence of systems and policies; and failure to file financial reports with the NGOs Co-ordination Board as per the legal requirement (PEN, 2007a, p. 20). As with the Board's study, the PEN studies also referred to NGOs' operating without informing, engaging, or otherwise coordinating with 
the GoK on their activities, with an associated risk of duplication of effort, poor quality programming, and lack of sustainability (PEN, 2007b, p. iv). And while an independent study released in 2009 indicated higher levels of public trust in NGOs than in the GoK's executive branch (USAID, 2010, p. 78), gaps in CSOs' linkages to their constituencies were a point of concern, attributed by some to CSOs' dependency on foreign funding leading them to undertake "donor driven projects" and thus undermining CSOs" "loyalty for their constituents" (PEN, 2007a, p. 27).

Indeed, while the sector experienced fluctuations in the levels of funding coming from DAC/Gs, an "almost overwhelming dependency" of NGOs on "funding from the North" had become a serious cause for concern in the sector due largely to the associated issues regarding the "sustainability and legitimacy of these organizations" (PEN, 2007a, pp. 6 \& 26; USAID, 2013, p. 74). While CSOs receiving DAC/G funding certainly had to meet these donors' often strict accountability requirements, the dependence on external funding sources left CSOs vulnerable to the push and pull of $\mathrm{DAC} / \mathrm{G}$ priorities, sometimes at the expense of CSOs" organizational "aspirations", "values and principles" (PEN, 2007a, pp. $6 \& 20$ ). Moreover, despite the unpredictability of DAC/G funding, perceptions of the sector were that it was "an employment opportunity or a gateway to riches" such that the original "ethos" of the sector, grounded in "voluntarism" and "making a real difference in people's lives" had become compromised (PEN, 2007a, p. 25). 


\section{Sector Infrastructure and Status of Self-regulation: Multiple floundering Councils, fresh self-regulation}

This wave saw a continuation of the state of multiple ineffective NGO Councils, while the sector worked toward filling the self-regulation gap left by the Council's demise.

By 2009 the three NGO Councils that had surfaced following the 2003/04 Council rupture were now down to two factions representing themselves as 'the' Council, though neither of them were fulfilling the Council's legislated self-regulation role (Kisinga, 2009, p. 70). Still, one of them appeared to have sufficient credibility to have continued to play some degree of representation role, for example, by participating in a Working Group on Government-CSO collaboration established in 2008 (and of which more is said below) (Kisinga, 2009, p. 59). Writing in 2010, Kisinga Gitonga noted however that the Council's Regulatory Committee had not convened "for a long time" (p. 32). By this point the NGO Councils had minimal legitimacy both within the sector and without. Indeed, the "the long, drawn-out leadership wrangles and warring factions of the NGO Council" deemed it as having "weakened the NGO sector", contributing both to a lack of sector coordination and cohesion, and to tarnishing the reputation of the sector as a whole (Kisinga, 2009, p. 60).

Further, leadership wrangles and management issues aside, it had become evident that the self-regulation model instituted under the NGOs Co-ordination Act was no longer an adequate tool for enhancing and signaling the sector's accountability and legitimacy. Having been "tested to the limit" in wave two during the NGO Council crisis, selfregulation under the Council had proven "largely ineffective" (PEN, 2007a, p. 15). The 
absence of a sound monitoring and enforcement mechanism and thus the expectation of voluntary compliance with the Code of Conduct had proven ineffectual. Leaders in the sector were now questioning "whether in fact, the presumption that led to the development of the Code of Conduct, i.e. that CSOs intrinsically behave ethically, is still sufficiently important to promote best practices in the sector", a sector that had grown not only in numbers but become became more diverse "in structure, size and focus" and increasingly lacked cohesion (PEN, 2007a, pp. 6 \& 25).

That said, it was not that there was a complete absence of self-organizing in the sector. The kind of theme-specific coalition building that had begun in wave one especially on democratic reform-related issues, then in wave two on a broader range of topics and more frequently in a collaborative mode with the GoK, continued in this wave (Wamucii \& Idwasi, 2010, pp. 264-266). Notably also, in response to the sector's accountability challenges and self-regulation shortfalls, CSOs were building new infrastructure in the form of the new CSO-led self-regulation initiative, the KSC-CSP, that had been launched toward the end of wave two and picked up speed in this third wave, as is discussed in the Development and Negotiations section below. So too did CSO organizing to address state regulation in the form of a new coalition, the CSORG, also discussed below.

\section{DAC/Gs' Funding and Policy Engagement: Investing in reconciliation through the GoK and CSOs, conundrum of DAC/Gs, competing interests}

In this wave DAC/Gs' stood firmly behind the coalition GoK, providing financial support both to the GoK and CSOs for various initiatives in the truth, justice and 
reconciliation process. Faced with highly publicized corruption scandals, some DAC/Gs implemented punitive measures but these were short-term, and ODA flows to Kenya increased markedly in this wave.

As noted, the political power-sharing settlement that followed the 2007 elections and PEV was reached in no small part due to pressure from the international community. While the settlement was brokered by the Panel of African Eminent Personalities, DAC/Gs were warning of the possibility of a permanent end to their aid if the mediation process was not successful (Hornsby, 2012, p. 769). Thereafter, considerable DAC/G financing came into play in this wave - both to the GoK and CSOs - to support key initiatives related to reforms toward truth, justice and reconciliation intended to address the underlying and systemic causes of the PEV. A multi-DAC/G Trust Fund for National Dialogue and Reconciliation supported, amongst other things, the work of the CIPEV; (initially) the TJRC established to follow up on the PEV; and the Constitution consultation process; as well as GoK institutions that were either newly established or bolstered to support the Constitution's implementation (CIPEV, 2008, p. 1; Hornsby, 2012, p. 810; USAID, 2013, p. 71).

Hopes were raised when the Constitution in $2010 \ldots$. was approved with a vast majority of the population that voted yes.... Of course, $[D A C / G X]$ and $[D A C / G Y]$, and other countries have been supporting this process of getting the Constitution and the consultation around the Constitution. We have supported it very actively, and through civil society, but also through the good forces in government. (I4_DAC/G)

After the reduction in $\mathrm{DAC} / \mathrm{G}$ funding flows to CSOs in the early days of the second wave, flows to the sector mostly recovered though dipped in the early part of this third wave. The dip is attributed in part to the financial crisis that hit many DAC/Gs in 2008, 
though there is also a suggestion that the "perceived credibility of the Kenya Government due to the ongoing reforms" following the PEV and new 2010 Constitution "contributed to the diversion of donor funds [from CSOs] to the central government" (Otini, 2012, paras. $15 \& 17$ ). Flows to CSOs began to rise again, in part attributable to investments in CSOs' involvement in the various PEV reform processes, as well as civic education in preparation for the early 2013 election (Otini, 2012, paras. $11 \&$ 15; USAID, 2013, p. 74). Between $2010^{103}$ and $2012 \mathrm{DAC} / \mathrm{G}$ funds for CSOs increased by 45 percent (based on Table C2 in Appendix C). The vast majority of this, between approximately 93 (2010) and 95 (2012) percent, was in the form of earmarked funding flows through CSOs (see Table C2 in Appendix C). DAC/Gs' also provided critical financial support to the two CSO coalitions undertaking self-regulation and state regulation initiatives in this wave.

Meanwhile, DAC/Gs' funding to the GoK continued its up and down pattern, though not to the degree that it had in wave one, and overall between 2008 and 2012 DAC/G funding to Kenya increased considerably from approximately USD 1 billion to almost USD 1.8 billion (a 78 percent increase) (see Table B1 in Appendix B). Of the major DAC/Gs, the US increased funding early in this wave, in part based on a desire to bolster the fragile but stable post-PEV coalition GoK that the US had had a hand in brokering (Hornsby, 2012, pp. $769 \&$ 783). This was important for the US as Kenya continued to be a geo-politically strategic partner in the war on terror, as well as a location of security concerns given the growth in Islamic fundamentalism - itself partly due to this minority

${ }^{103}$ As noted in chapter two, the OECD considers its CRS data on flows for CSOs to be of good quality from 2010, hence the figures provided here start in 2010 rather than at the beginning of this wave in 2008 . 
population's unease with Kenya's active engagement in the war on terror (Hornsby, 2012, p. 661).

As noted, DAC/Gs continued their pressures on the GoK to address ongoing corruption issues, though seemed to be moving toward a more case-by-case punitive approach rather than that of tying conditions to a broad anti-corruption agenda. Corruption continued to be one among other concerns in DAC/Gs' basket of interests including not only the anti-terror agenda, but political and economic stability. Thus, while the US, for example, publically praised the coalition GoK, as revealed in a series of Wikileaks releases between 2010 and 2011, the US was well aware and highly contemptuous of the corruption that continued to be rampant under the coalition GoK, with the then US Ambassador calling it "a rogues' gallery" of corrupt officials (Hornsby, 2012, pp. 783 \& 776). In 2010 another major DAC/G donor, the UK, suspended any new aid following discovery of massive aid funds misappropriation in the education sector between 2005 and 2009 (Hornsby, 2012, pp. 776-777). The US and UK went so far as to ban over a dozen GoK officials and members of cabinet due to corruption charges, and in the US case, to evidence of links between GoK officials and MPs and international drug trafficking (Hornsby, 2012, pp. 776-777).

Still, DAC/Gs' continued contradictions and inconsistencies in their approach to the GoK remained and became increasingly challenging. Their interest in Kenya's economic stability and continued growth following positive performance in the previous wave was increasingly informed by a development paradigm that elevated the role of the private sector in achieving development outcomes (e.g. see "Busan Partnership", 2011). The 
promotion of the private sector became central to the majority of DAC/Gs' development policies in this wave, with economic opportunities for $\mathrm{DAC} / \mathrm{G}$ domestic firms and investors more or less explicitly part of this equation (Kindornay \& Reilly-King, 2013). Further, DAC/Gs faced stiff competition on both the trade and aid fronts due to the GoK's successful courting of non-DAC/G funds, with China having become by 2011 “Kenya's new preferred aid and trade partner" (Hornsby, 2012, pp. 783-784).

\section{Status of State Regulation: Continued fragmentation plus Board capacity challenges}

The existence of various parallel regulatory regimes for the CSO sector continued through this wave. Also in this wave, the NGOs Co-ordination Board began to articulate concerns regarding its capacity to effectively regulate the ever-growing NGO sector.

The Board's 2009 survey pointed to the regulatory gap that still had multiple regulatory regimes available for different types of CSOs, suggesting the survey could help "determine a case for bringing all organizations that are charitable in nature under one regulatory body" (NGOCB, 2009, pp. $21 \& 18$ ). This situation of "multiple and overlapping governing acts and legal forms" was proving challenging for the GoK, impeding development of "harmonized, systematic and coordinated plans and approaches to civil society, as there is no cooperation and much duplication among the various regulatory agencies" (Kisinga Gitonga, 2010, p. 26; Jillo, 2009, p. 50). Many CSOs continued to find it "politically or functionally expedient" to register themselves under the alternatives to the NGOs Co-ordination Act, and no effort had been made, either by the GoK or the CSO sector, to encourage CSOs to seek registration under the Act (Kisinga Gitonga, 2010, p. 26). This continued to provide a motivation for regulatory 
change that would see the Act as the "central reference point for registration of all NGOs", bringing together "all NGOs under a single definition and a consistent regulatory regime" (Jillo, 2009, pp. 41, $42 \&$ 47).

The Board's 2009 survey report also acknowledged weaknesses in implementation of the Act due to inadequate Board capacity, noting that growth in the sector had "not been matched by a concomitant growth in the capacity of the NGOs Co-ordination Board... to effectively regulate the sector" (NGOCB, 2009, p. 12). The Board's budget and staff numbers at the time - a total of 50 to oversee the over $6,000 \mathrm{NGOs}-$ as well as its lack of specialized technical capacity and knowledge of the sector, and its centralization in Nairobi, was only sufficient to implement its registration function and offer "minimal post-registration services", excluding therefore any kind of awareness-raising or guidance on regulatory requirements, monitoring, or research on the sector (NGOCB, 2009, pp. 12 \& 58; Jillo, 2009, p. 49).

Though not addressable by revising legislation, insufficient technical staff and equipment were affecting the Board's ability to play its oversight role of this increasingly large and diverse sector. The 2011 ESAAMLG Mutual Evaluation Report on Anti-Money Laundering and Terrorism in Kenya noted that the Board was challenged to maintain upto-date information, and to monitor NGOs and enforce regulatory requirements due to "lack of enforcement measures regarding information submissions obligations by the NGOs, large volume of stored in a manual filing system and shortage of personnel" (ESAAMLG, 2011a, pp. 180 \& 181). An increase in Board staff numbers to 55 by 2012 was still deemed "skeletal" relative to the ever-growing NGO numbers (E. Mutai, 2012, 
paras. $10 \& 19)$. Noteworthy is that the ESAAMLG report noted similar challenges for the Registrar of Societies and proclaimed inadequate regulatory measures also in place regarding trusts and companies limited buy guarantee (ESAAMLG, 2011a, pp. 21, 172 \& 181).

\section{Political Agendas: Conciliatory mode but festering hostilities}

This third wave did not see the kind of politically driven GoK anti-CSO agenda that prevailed in wave one, nor as seen in wave two whereby a politically driven GoK agenda interfered with the NGO Council. Instead, the post-PEV political agenda of reconciliation and reform characterized this wave, building also on a more collaborative approach to GoK-CSO relations that 2006 Sessional Paper No. 1 had clumsily called for. The consultative process toward and the participation and rights orientation of the new Constitution were emblematic of the more collaborative, conciliatory political agendas of this wave. At same time however, a whole other level of anti-CSO political agenda was rearing its head as the ICC opened cases in follow-up to certain Kenyan politicians' alleged involvement in the 2007/08 PEV.

On the whole this wave saw greater openness and more collaborative GoK undertakings when it came to CSOs. Even as a level of "suspicions and mistrust" and "animosity" between the GoK and CSOs - especially when it came to the GoK and civic and politically active CSOs - continued to exist, the coalition GoK was not inclined to stigmatize or undermine the sector, but to find ways of working with it (Kisinga Gitonga, 2010, p. 37; USAID, 2010, p. 76). Advancing over this wave the GoK was found to 
"invite[s] CSOs to contribute to the development of policies in many fields" (USAID, 2013, p. 7) in a more collaborative environment as described by an interviewee below:

The sector was viewed more like a partner, and they were invited to various platforms and encouraged to participate and to contribute and so that was quite productive period for NGOs. So by the time, the PBO Act was being passed in 2012, I'd say the sector had enjoyed quite a bit of support from the regime then. Or at least there was not - the interference was not at the level that it has reached right now. (I61_Other)

In part this was attributable to the foundations for a changed relationship that Sessional Paper No. 1 had sought to establish, even as the Paper projected an instrumentalist attitude to the sector's contribution to the country, and was a source of nervousness in the CSO sector about the nature of regulatory reform that would follow.

A major period in the history of the NGO sector... starts.... with the enactment of the new Sessional Paper.... which enshrined the concept of complementarity and collaboration between the NGO sector and the state, and also for the first time tried to bring together the different [CSO] roles from relief to development to governance in one framework. (I13_CSO)

Documentation of growing collaborations in the realm of service provision showed growing incidences of the GoK and CSOs working "hand-in-hand" (Brass, 2010, p. 2; PEN, 2007b). Concerted effort was also dedicated in this wave to addressing animosities and the challenges to a constructive GoK-CSO relationship. Sessional Paper No. I's stated interest in a partnership approach provided a policy foundation for such effort, as did a CSO study ${ }^{104}$ on CSO-GoK collaborations also provide an evidence base given its finding that the lack of a policy and legal framework was impeding GoK-CSO

${ }^{104}$ This was another AKDN-commissioned study undertaken by PEN, the same group that had undertaken the study that informed establishment of the KCS-CSP selfregulation initiative in wave two. 
collaboration, leaving it ad hoc, informal, and tenuous (PEN, 2007b, pp. iii-iv). A significant example is seen in the GoK's acceptance of an invitation to participate in a new Working Group on Government and CSO Collaboration, initiated by an international CSO, PACT and launched in December 2008 (Kisinga, 2009, p. 59). ${ }^{105}$ The aim of the Working Group was to guide a process to establish a policy-type framework for GoK CSO collaboration that would strengthen the relationship and "enhance partnerships" (USAID, 2010, p. 77; Kisinga Gitonga, 2010, p. 37). Though the Working Group's efforts did not lead to policy or regulatory reform per se, through 2008-2009 it developed a series of principles for effective government-CSO collaboration which were eventually reflected in the PBO Act developed in this wave (CSORG, 2014c, p. 8).

Government actually seconded several representatives and civil society.... also had.... representatives who came together and formed this round table on Government and civil society collaboration and they had various discussions that took about one year [on].... the challenges or the barriers to better Government and civil society collaboration.... They identified what would be viewed as the best solutions to some of these barriers..... One of the proposals that came out as a result of those discussions was.... to come up with principles for government and civil society collaboration. And so they were able to discuss and propose and formulate these principles, which.... ended up being incorporated in the PBO Act. So at the back of the PBO Act you will find what you call the Principles of Government and Civil Society Collaboration and that was the result of the [round table's] discussions. (I61_Other)

Beyond any inspiration provided by Sessional Paper No. 1, the GoK's more positive outlook on and approach to the CSO sector was attributable to a political agenda of reconciliation following the 2007/08 PEV. CSOs found themselves in "a favourable

${ }^{105}$ At the time PACT's focus in Kenya was CSO capacity development, and it was one of the founders of the KCS-CSP self-regulation initiative launched in the previous wave. This Working Group initiative was part of PACT's DAC/G-funded Government-CSO Collaboration Program. 
political environment" within which receptivity to CSOs, including to their civic and political engagement, was becoming more the norm (USAID, 2010, p. 70). In a sense, CSOs had shown their mettle in response to the PEV and in the truth, justice and reconciliation processes that followed, making it difficult to ignore their potential to contribute positively to the nation in their varied roles. Most significantly however, the coalition GoK knew it could not fail at the post-PEV commitment to attain, as much as possible, national agreement on a new Constitution.

Though the constitutional development process was not without obstacles and critiques, a conciliatory political imperative guided its development. A consultative process of constitutional development was seen as indicative of GoK "goodwill... [and] willingness to provide space for NGOs to engage and participate in activities that promote the public good" (Kisinga, 2009, p. 58). ${ }^{106}$ CSOs were hopeful also that the new Constitution would "improve the overarching constitutional framework for CSO formation and activities" (Kisinga Gitonga, 2010, p. 38). Certainly the Constitution provided a "boost" for CSO-led state regulatory reform in this wave (CSORG, 2014c, p. 3). More specifically, that the Constitution included allowance for direct citizen engagement in the Parliamentary process of legislation and regulation-making inspired CSOs to take a lead in developing legislation that would replace the NGOs Co-ordination Act, rather than wait for next steps from the GoK. Article 119 of the 2010 Constitution states that:

${ }^{106}$ Hornsby (2012) details some of the critiques, including initial CSO resistance to a GoK-led process rather than reverting to the previously established, multi-stakeholder National Convention on the Constitution (pp. 779-780). 
119. (1) Every person has a right to petition Parliament to consider any matter within its authority, including to enact, amend or repeal any legislation.

119. (2) Parliament shall make provision for the procedure for the exercise of this right.

Thus the Constitution opened the door for CSO-driven regulatory change.

They promulgated a new Constitution in August of 2010... and this was the beauty of itthe new Constitution did have in it a clause that says that, "Citizens who have an interest in a particular law have the possibility of initiating the making of that law". (I12_CSO)

Amidst the more conciliatory and collaborative political agendas in this wave, CSOs were not immune to politically motivated threats, harassment, and even killings. Writing for Human Rights Watch (HRW), Lanser (2012) cites, for example, harassment of staff with the Gay and Lesbian Coalition of Kenya; of other organizations involved in exposing corruption; and the killing of two activists calling out police abuses (pp. $8 \&$ 11). Moreover, through this third wave a second layer of political agendas brewed in parallel to the broader more conciliatory agenda. This because aspects of CSOs' role in follow-up to the PEV was causing consternation among some in the GoK who may have had reason to fear that the path beyond simple reconciliation to truth and justice was a destruction one for political careers.

In particular, the two MPs indicted to the ICC, Uhuru Kenyatta and William Ruto, "began to attack civil society soon after the ICC issued its summons for the two men to appear in The Hague in December 2010" (Human Rights Watch [HRW], 2013, para. 12). As the ICC process unfolded, they began accusing CSOs of having "coached" witnesses (Menya, 2014, para. 8; I7_CSO; I14_GoK; I22_CSO). These accusations implied that CSOs' role in having helped inform and mobilize witnesses to give testimony to the various investigations amounted to coaching. That a small contingent of CSOs helped 
protect and relocate at least one witness receiving death threats, also informed the coaching accusation (I25_GoK; I8_ Other). CSOs were said to have offered payment or other "incentive $[s]$ " to witnesses, with protection itself being considered an incentive (I6_CSO; I25_GoK). While, based on CSOs' recounting of their PEV activities, the logic and legitimacy of such accusations does not hold much water, once the ICC cases became a reality CSOs' PEV activities were viewed by those facing (or fearing) ICC indictments as a political threat. Interviewee descriptions of CSOs' PEV involvement are provided below to complement the Waki Commission report list cited above under CSO Activities.

What I know, civil society mobilized people and created awareness that you need to give your views to this investigation.... Kriegler.... Waki, and the.... Kenya National Commission on Human Rights.... [the] Waki Report was also informed by submissions from the National Intelligence Service. So, I mean, accusing coaching on the civil society, I think it is just a creation of those who are not comfortable with civil society. Most Kenyans spoke openly. Some of the things which were happening were public information.... [But] You can't, you can't [specify which CSOs]. This commission was collecting views from across Kenya. So when they went to Kisumu, civil society in Kisumu were mobilizing. When they were in the Rift Valley, civil society in the Rift Valley were mobilizing. When they went to Coast or Nairobi, it is local civil society mobilizing. So, you can't say specifically which number. But they were working in coordination to mobilize people. Also, the civil society leadership were providing their views, information on what they witnessed. (I25_DAC/G)

An ICC investigation takes the form of an external entity called the ICC investigators and the court, coming into a country that is either ambivalent to that investigation or actively threatened by it. The ICC.... there was no natural support for it within the Kenyan government so the civil society became its natural ally supporting the investigation ever so strategically. It can't be said anywhere and I can't find any proof that there was coaching of witnesses or any of the outstanding claims that have been made. All that was done on behalf of Kenyan civil society.... with the court, was to give it the kind of support that a cooperating government ordinarily should to ensure that it can carry out investigations in the country providing keys to analysis of Kenya's political history. Who are the actors in Kenya? What are their real intentions? What really threatens them? Because when you come as an ICC investigator, you don't understand this place. (I22_CSO) 
The political threat seen to be posed by CSOs was much like that posed by PEV witnesses. The environment for witnesses deteriorated rapidly as the reality of the ICC indictments took hold, with incidences of intimidation and even witness elimination through suspected extra-judicial killings (BBC News, 2013, para. 14; Office of the Prosecutor of the ICC, 2014, para. 7). Despite establishment of a Kenyan Witness Protection Agency in November 2009 as called for under the Witness Protection Act of 2006 (Igunza, 2012, para. 2) as well as the ICC's own witness protection system, the witnesses, "victims who had voluntarily come to testify to Waki" were increasingly fearing for their lives (I30_GoK; Hornsby, 2012, p. 773).

Politicians implicated in the PEV were also building a politically motivated grudge against CSOs in this wave due to the latter's pro-ICC position. According to Branch (2011), human rights CSOs had early on appealed to the ICC to investigate the PEV and associated crimes against humanity especially as perpetrated by state security forces and "some of the ODM's leaders" - the ODM having, officially, been the losing party in the 2007 elections (p. 283). According to the interviewee quoted below, for the CSOs involved, support to the ICC process was not their starting point but a natural progression from their early role in response to the PEV. Either way, CSOs' endorsement of an ICC process for Kenya contributed to an emerging politically motivated backlash against the sector.

When the ICC option results from the mediation process, [to support the ICC process] was really a progression of our sector's involvement.... because it was logical. We have had a mediation process. It has put in place several logical proposals. One proposal has been agreed on. So let's support that because it was possible to have a different option..... When the country politically opted for ICC justice we said, if that is the one that we have 
to live with, then let see how best it's going to work and let's support it. So really, it's a role that has grown. The involvement starts with plugging into the initial crisis, supporting the mediation process by putting out options for the resolution of the various aspects of the crisis. But then when those options are agreed on, supporting implementation of those options. (I22_CSO)

That CSOs, nor the DAC/G community, were supportive of the GoK's efforts to delay the ICC investigations in hopes of (finally) instating a "more malleable" domestic tribunal also did not endear them especially to politicians fearing ICC investigation outcomes (Hornsby, 2012, pp. 773-774). Moreover, DAC/Gs' financing of CSO activities was used to discredit CSOs' PEV activism.

Then 2007, post election crisis. Then one side of political divide started saying, "Civil society is the mouthpiece of the West." And that narrative has been repeated, repeated, repeated, and sustained up to today, that civil society in Kenya, especially those around governance and advocacy, are serving the interest of the West.... that narrative.... was there during Moi era, but it went during the first phase of Kibaki, the NARC administration. But after the post election crisis, then it started emerging. It became amplified when the ICC issue came out that a few Kenyans have been found to have issues at ICC. So, the role the civil society played in mobilizing people, that was, again, civil society are funded by development partners, by donors. They rely on donor funding. So, that group started saying that it was civil society who are given money by Western countries to fix them. Procure witnesses, coach them and all this, and that [narrative] has been around since [the] ICC began. (I16_DAC/G)

\section{Public Management Agendas: Less NPM, more 'governance'}

NPM continued to have an indirect affect in as much as DAC/Gs' NPM-styled

reliance on the CSO sector had and continued to contribute to the sector's growth. However, the NPM-style references of Sessional Paper No. 1 were seeming to be supplanted in this wave with the emerging "governance" paradigm with its "horizontal" and "relational" approach to public management in which the interdependence of governments, CSOs, and other sectors, is recognized (Phillips \& Smith, 2011, pp. 2 \& 4 citing Hood, 1991, Osborne, 2010, Rhodes, 1996, Salamon, 2002). While the Sessional 
Paper's calls for GoK-CSO partnerships to deliver national development goals remained salient, a more collaborative, relational GoK approach to CSOs and their regulation characterized this wave as evidenced for example in GoK participation in the Working Group on Government and CSO Collaboration. Certainly the principles for collaboration developed by the Working Group reflected this with their reference to, amongst others, principles of: dialogue and communication; learning and sharing; joint initiatives; and equity and equality in partnerships (see PBO Act, 2013, sched. 1).

In harmony with the governance paradigm the GoK seemed to be desirous of moving toward a more responsive regulatory model. This was reflected in the NGO Coordination Board's 2009 survey report reference to the need for regulatory reform that, rather than continue with the uniform approach to the sector's regulation, would be "risk based and proportionate" given the heterogeneous nature of the sector (NGOCB, 2009, pp. $17 \& 57)$. That the survey report also introduced the idea that regulatory reform ought to not only regulate, but also enable the sector, and relatedly, that the Board needed to play a role in providing services to the sector, also reflected a shift toward a more responsive regulatory model (NGOCB, 2009, pp. 14, 57 and 13).

\section{Security and Terrorism Concerns: Risk of sector-terror linkages enters the policy debate}

While wave two's 2006 Sessional Paper No. 1 had not made reference to issues of terrorism in relation to the CSO sector, the NGO Co-ordination Board's 2009 survey report introduced a potential terror-CSO link, pointing to the sector's growth as a security risk: 
.... the expansion brings with it high risks of potential abuse both for the public who interact with these organizations on a day to day basis as well as overall national security and economic stability. Activities of rogue NGOs pose a threat to public safety and can also impact negatively on the economy inter alia through acts of fraud, money laundering and financing of terrorism. (NGOCB, 2009, p. 12)

The specter that foreign flows to CSOs "could be used as a conduit for money laundering, funding terrorism or espionage" were reiterated late in this wave in Parliamentary debate urging revisions to the NGOs Co-ordination Act (E. Mutai, 2012, paras. 1, $4 \& 5$; Otini, 2012, paras. $6,7 \& 10$ ). The emergence of this type of language, if not in the NGOs Co-ordination Board's 2009 survey report but in later Parliamentary debate, may have been fuelled by the ESAAMLG 2011 Mutual Evaluation of Kenya's performance in anti-money laundering and combatting terrorism in relation to the FATF recommendations, the first such report on Kenya. The Mutual Evaluation Report, which looked at the regulations covering companies (including those limited by guarantee), trusts, societies and NGOs, concluded that adequate measures were not in place to prevent the potential use of CSOs registered under these regimes for money laundering or terrorism purposes, nor outreach to help them protect themselves against such abuse (ESAAMLG, 2011b, pp. 10-11). Specifically, The ESAAMLG's 2011 report called on Kenya to "expeditiously take necessary steps to ensure that the NPO sector is subject to CTF [counter-terror financing] obligations consistent with Special Recommendation VIII [Recommendation 8]" (ESAAMLG, 2011a, p. 183).

Notably, issues of terror more generally were of increasing concern to the GoK in this wave. For years, insecurity in Somalia had spilled across the border into Kenya, combined with incidences of insurgencies from Somalia - which claims ownership of a large swath of Kenya's (then) North Eastern province (Branch, 2011, p. 169). Drought in 
the region in 2010-11 led to border crossing by hundreds of thousands of Somalis into Kenya, amongst them purportedly some affiliated with militant Islamic groups deemed a terror threat (Hornsby, 2012, p. 784). In collaboration with the Somali military, Kenya sent troops into Somalia in 2011 as part of a US and UK backed mission to counter AlShabaab militants, a mission that in 2012 was merged with the wider AU Mission to Somalia (Achuka, 2018, para. 12).

\subsection{Regulatory Change Outcomes}

\section{Development and Negotiations: Viwango and the PBO Act}

The effort launched by CSOs toward the end of wave two to develop a new selfregulation scheme for the sector under the KCS-CSP program advanced considerably in wave three leading to the establishment of a new self-regulation institution, Viwango. While the GoK was taking some behind-the-scenes steps to devise new state regulation to replace the NGOs Co-ordination Act, CSOs were developing the PBO Act, which received presidential assent as this wave closed.

Development of the KCS-CSP self-regulation initiative initiated at the end of wave two proceeded apace in wave three. Committed to a participatory process that would tap into "as wide a perspective as possible", the KSC-CSP implemented "a collaborative and inclusive process to develop sector-wide standards involving the larger civil society constituency in Kenya" (Viwango, 2011b, p. 11). The GoK through the NGOs Coordination Board also engaged in this process, its NGO of the Year Award ${ }^{107}$ being one

${ }^{107}$ At the time being managed in partnership with the international CSO called the resource alliance. 
of the parallel standards-related initiatives that was part of the KCS-CSP (Viwango, 2011b, p. 11; Aulick, 2013, p. 2). In March 2009, the KSC-CSP and various collaborating national and international CSOs that had been involved in the consultation and design process that had launched in 2006 formalized the self-regulation scheme by establishing an institution called Viwango ('standards' in Swahili) (Viwango, 2011b, p. v). ${ }^{108}$ CSOs hoped that the Viwango initiative would demonstrate that they "appreciate the grave need to put their houses and the sector in order" thus signalling to the GoK and other actors their intent to behave professionally and demonstrate accountability, which would "lay the foundation for improved relationships between CSOs and the Government" (Kisinga Gitonga, 2010, pp. 38-39).

Through development of the Viwango self-regulation mechanism its designers did not lose sight of conclusions from the 2007 PEN study that there was need in the sector to “establish clear standards and qualities for CSOs, promote best practices, provide holistic capacity building and establish mechanisms for ensuring compliance" (Viwango, 2011b, p. xii). Viwango therefore was comprised of a set of CSO Standards; a Code of Practice; and an Organizational Capacity Assessment Tool with a peer certification process (Viwango, 2011a, 2011b, \& 2011c). The package of Viwango tools sought to address a number of the real "credibility gaps" experienced by Kenyan CSOs (Mirza \& Obrecht,

108 Viwango's institutionalization was then formalized through registration in 2011 as a non-profit company limited by guarantee (Aulick, 2013, p. 1; I20_CSO). Registration as a non-profit company was deemed by the KCS-CSP as most appropriate given Viwango's business model of selling services to the sector, while other considerations included the lighter regulatory burden than that posed by the NGOs Co-ordination Act, as well as to the uncertainties regarding transition from the latter Act to the PBO Act that KCS-CSP members were involved in developing (I20_CSO). 
2013, p. 19). The Code included a number of commitments addressing 'downward accountability' to CSOs' constituents such as for example through participatory monitoring and evaluation and feedback mechanisms (Viwango, 2011b, $8.1 \& 8.10$ ), that could help address the perception that CSOs were insufficiently connected and responsive to the people they serve or represent (I2_CSO; I5_CSO; PEN, 2007a, p. 27; USAID, 2014, p. 64). The Code also committed its adherents to pursue projects and programs aligned with CSOs' missions, goals, objectives and strategies rather than be swayed by donor financing, as well as to seek to diversify their financial resources (Viwango, 2011b, 6.1, 6.4, $6.13 \& 6.14$ ). The challenge raised by the GoK of lack of coordination among CSOs and with other actors was also addressed in the Code, which called for avoidance of duplication, collaboration and cooperation (Viwango, 2011b, 4.5, 4.15, $7.1 \&$ 7.2). The Code further addressed GoK concerns regarding CSOs' civic and political engagement by restricting its adherents from engaging in party politics while maintaining their independence to conduct "political and legislative activities... within the confines of our missions and stated objectives" (Viwango, 2011b, 2.9). Transparency was also called for in the Code, on financial resource mobilization and utilization and in other areas (Viwango, 2011b, 6.7, 7.8, $7.9 \& 8.4$ ).

The Viwango institution would oversee CSO certification and support compliance. In its early years, including the transition period from the KCS-CSP program to the standalone Viwango, the initiative was housed within a secretariat at PEN. Financial support from DAC/Gs was critical to first the KSC-CSP and then Viwango's Secretariat operations as were contributions from a small group of international NGOs, most notably 
the Aga Khan Foundation (Viwango, 2011b, p. 7). In a bid toward sustainability, a fee based business model was developed such that CSOs applying for certification would pay a fee that varied by organization size, and also covered the costs of volunteer peer assessors who support the pre-certification assessment process. Three levels of certification were established - gold, silver and bronze - leaving room for certification of CSOs with lower capacity but a willingness to improve and an associated development plan. Regarding compliance, a mechanism was established whereby Viwango-certified organizations would submit annual status reports and improvement plans, to be validated by Viwango (Viwango, 2015; I20_CSO).

The relevance and comprehensiveness of Viwango's approach gained recognition as it evolved. For example, a new USAID-funded CSO capacity development program turned to Viwango to help design its second phase in 2010. The new program, Fanikisha, drew heavily on Viwango's Standards, Code and Assessment Tool. Ultimately however, the executing agency awarded the Fanikisha implementation contract was not interested in direct collaboration with Viwango but instead opted to establish its own separate system and tools for the program (Aulick, 2013, pp. 3-4). Effectively, this led to creation of a competing set of CSO standards, launched in wave four (Mutheu, 2014).

At the level of state regulation, the GoK had implemented some steps in follow up to Sessional Paper No. 1 of 2006. As noted, at the end of wave two, the NGOs Coordination Act was revised in ways that strengthened the GoK's control over the Board and the Council's self-regulation. The NGOs Co-ordination Board also took steps beginning late in 2006 in follow up to the 2006 Sessional Paper, launching a national 
survey of NGOs that was eventually published in 2009. The study was intended as a next step toward regulatory reform, providing "the basis for improved regulation and enablement of the sector.... in order to increase their effectiveness and improve public trust and confidence in them" (NGOCB, 2009, pp. 13 \& 16). Otherwise, two amendments to the NGOs Co-ordination Regulations were made, in 2010 then in 2012, though these simply revised registration and other forms and fees.

Following the Board's survey, the GoK initiated efforts to develop a Charities Bill that would replace the NGOs Co-ordination Act. ${ }^{109}$ Development of the Bill was first mandated to the Kenya Law Reform Commission, and later, taken on by the NGOs Coordination Board itself. The CSO sector was purportedly not consulted during development of the Bill, which apparently, "never saw the light of day", overtaken as it was by a CSO-led PBO Bill (I61_Other). Little is known about the Charities Bill and no copy is attainable. Additional to considerations provided by the 2006 Sessional Paper and the Board's 2009 study, amongst other things the Bill may have been seeking to address gaps in the Board's functions as prescribed in the NGOs Co-ordination Act, and its actual powers to carry them out - a gap remarked on in the EASSMLG's 2011 report on Kenya (ESAAMLG, 2011a, pp. 176-177).

With the GoK working incrementally and in isolation on a replacement for the NGOs Co-ordination Act, beginning in 2009 the small group of CSO leaders, the so-called Committee of the Wise that had begun to convene late in wave two reignited its efforts,

${ }^{109}$ The Charities Bill is elsewhere referred to as the NGO Bill (ICNL, 2013, p. 6). 
and the CSO sector more broadly, to also address state regulatory reform. Reflections from the KCS-CSP/Viwango process had made clear that, even with a critical mass of CSO interest in rejuvenating self-regulation demonstrated through establishment of Viwango, self-regulation efforts would be hindered without an enabling state regulatory framework. As the 2007 PEN study on CSO competence and sustainability had highlighted, "gaps that exist in the legislative and policy framework.... hinder the implementation of standards" (2007a, p. 25). Further, the ongoing uncertainty regarding the GoK's intended follow-up to Sessional Paper No. 1 spurred the sector to take steps toward strengthening state regulation.

In addition, as noted, impetus came from the opening and more collaborative political space, which leant optimism to the prospect of constructive regulatory change, as noted by one interviewee:

We realized that the NGOs Coordination Act was not very progressive. Instead of facilitating NGO work, it was inhibiting NGO work. So there was every need to develop a progressive legislation that will give the civil society sector an environment that will enable them to supplement the Government, to operate well, and even to gain some legitimacy in its activities. (I29_CSO)

The opening political space was seen in the constitutional reform process and the Constitution itself, which provided a "springboard" for CSO-led regulatory efforts. The sector began to put more concerted effort into the design of what it deemed enabling legislation, in which self-regulation would have pride of place. The Committee of the Wise and CSO leaders from Viwango and beyond - including some that had been involved in the early 1990s NGO Network that had pushed for amendments to the NGOs Co-ordination Act - convened a meeting in 2009 to "define what we'd like to see" in new 
legislation (I12_CSO I55_CSO; I56_Other; I6_CSO; I61_Other). The intent was also to take a collaborative approach with the GoK, which was represented at the 2009 meeting. A key meeting outcome was the decision to establish a new "broadly inclusive, loosely structured" CSO coalition, the CSORG, specifically to work on regulatory reform (CSORG, 2014, p. 5).

When.... the Sessional Paper was passed in 2006, it.... was clear.... the Government was going to revise the NGO Act. And so civil society knew it needed to get organized, so that it could engage in the process of revising the NGO Act... So in 2009, there was.... a national meeting which brought together a lot of civil society actors including the different factions of the NGO Council, and the NGO Board, to discuss the best way to go about in collaborating on the revision of the NGO Act. So at the end of that meeting, [it] was proposed that civil society could mobilize itself using a CSO Reference Group. So it was set up basically to try and mobilize civil society and get their views, and ensure that their ideas were integrated, and also heard during the review process. (I61_Other)

So.... we got the material we've been putting together about enabling environment and we called ourselves the CSO Reference Group, because we wanted to be a point of reference for talking about this stuff. We then got a lawyer and we said, "We want to you to reduce this stuff into a draft law for us. (I12_CSO)

The presence of one international CSO at the 2009 meeting, ICNL, is noteworthy. ICNL played an important advisory, technical support, and honest broker role, through the regulatory review process. In Kenya, as it does in other countries ${ }^{110}$, ICNL sought "to support all the different actors whether civil society or Government to ensure that they come up with enabling or conducive laws and policies for civil society" (I61_Other). Part of ICNL's contribution to the process involved simultaneous fellowships for a lawyer

110 The Kenya experience reflects ICNL's approach elsewhere. This CSO does not maintain offices in LMI countries but collaborates with local actors, offering technical support and guidance on international best practice. It also serves as a neutral party to help local actors, be they governments or CSOs or otherwise, to develop enabling CSOrelated legislation. 
representing CSOs, and an NGOs Co-ordination Board representative at ICNL's Washington office in 2009, "to try and see how collaboration could take place between the two and so that we would come up with the best and most enabling law for the sector" (I61_Other). In addition to this nature of support for the regulatory reform process, members of the CSORG brought financial resources to the table from their $\mathrm{DAC} / \mathrm{G}$ and other funding sources, including $\mathrm{DAC} / \mathrm{G}$ funding dedicated specifically to the regulatory reform initiative (I12_CSO; I61_Other). ${ }^{111}$

After initial collaborative engagement between the CSORG and the NGOs Coordination Board however, "at some point", for reasons that are not clear, "both the sector and the Government went separate ways in terms of trying to come up with a draft law for civil society" (I61_Other). Perhaps this was due to the momentum building behind the ever-enlarging CSORG as it took the lead in convening sub-national and thematic workshops and consultations with CSOs, conferring also with the GoK including the NGOs Co-ordination Board and the Kenya Law Reform Commission, toward drafting a new NGO law (CSORG, 2014c, pp. 5-6). Eventually in 2011, the CSORG recruited the support of an MP, the Honourable Sophia Noor to table the new PBO Bill in Parliament as a private member's Bill. It was brought to Parliament in April 2012.

${ }^{111}$ As a non-registered entity the CSORG could not receive funds directly, 
At first the NGOs Co-ordination Board was not pleased with this degree of CSOs proactivism in the state regulatory realm. According to a CSO representative active in the CSORG at the time, when the PBO Bill was tabled in Parliament:

The Board then contacts us and says we need to meet, and we go to meet with them, and they say, "Look you guys, okay, we've heard you now. We understand that you're taking this thing seriously. Why don't we suggest, go and withdraw your draft Bill, and we will bring ours in ... you must. Law making is the job of the Ministry”. (I12_CSO)

The CSORG did not withdraw the Bill, though in the process of parliamentary review the two parties were called on to work together to revise it. Thus, come mid-2012 the CSORG and the Board, on behalf of the GoK, reached agreement to establish a Joint Committee to advance the Bill, a move that "powerfully leveraged key competencies from both sectors towards the attainment of the common goal" of a "conducive legal environment for NGOs in Kenya" (ICNL, 2013, p. 6). According to one interviewee, in this brief period the Board and the sector saw "quite a bit of collaboration ... they both worked together to actually come up with a draft that would be acceptable to both parties"(I61_Other).

The CSORG and Board developed "joint proposals" to revise the PBO Bill, tabling these for review by a Parliamentary Committee at a stakeholder's retreat in August 2012, with the Committee thereafter continuing to receive amendment proposals from various stakeholders (CSORG, 2014c, p. 6). ${ }^{112}$ Some of the amendments that would increase GoK oversight were seen by the sector as less than preferable, but were acknowledged by

112 This was the Parliamentary Committee for Labour and Social Welfare (CSORG, 2014c, p. 6). 
both the CSOs and the Board as necessary in order to ensure parliamentary and GoK support for the Bill (ICNL, 2013, pp. 5-6). The Bill was passed in Parliament in December 2012, and was quickly thereafter assented by President Kibaki, therefore becoming law in the form of the PBO Act in January 2013. The following interviewee quote shows the CSO sector's leadership in the process of the PBO Act's development and negotiations, the somewhat forced CSORG-Board collaboration, and both parliamentary and Presidential receptivity to the Act:

[The PBO Act] was actually a civil society initiative.... And the idea was now that we are about to get a new Constitution, and it will likely be written in such a way as to usher us into the new Kenya, how do we take advantage of this to come up with a better regulatory framework for the work that CSOs [are] doing? I think we were really successfully pushing it through .... it was like a five year process, beginning with the early discussions in civil society.... then putting together a draft, and then convincing Sophia to actually table it as a private member's Bill. And it gets way ahead of Government....

The Government then, through the NGOs Coordination Board had wanted to pass their Charities Act, so by the time they got to the House, Sophia's Bill was well past the second reading. And so they [the Board] were told, "Why don't you get together with Sophia, because it seems as if you've got two Bills here with different names, but the subject matter is the same. Go somewhere and hammer a compromise. If you can get back to this House with that compromise we will pass the law." So at that point, one of my colleagues in civil society told me this is what was happening. I said, "You're in the best of circumstances now, because first, you have wrong footed the government. Your Bill is the one ahead. And they're being told to talk to you, so that you can strike a compromise - be magnanimous. Welcome the opportunity. Get them into a meeting. Have some constructive dialogue. There's no way you can come out of it with a bad legislative product.".... So [a DAC/G-funded parliamentary support program] paid for the expenses of the committee and a number of other people who needed to be in that discussion.... When they came back with the compromise they had struck, it moved through the House like a hot knife through butter, and it was one of the Bills that was passed just before the last Parliament disbanded. (I8_Other)

Armed with lessons from two decades of experience of regulation under the NGOs Co-ordination Act, the PBO Act was designed to address many of the former's weaknesses or gaps, and was considered a comprehensive improvement on the 1990 Act 
(ICNL, 2015a). A particular gap issue noted was the narrow definition of NGO in the NGOs Co-ordination Act compared to the various CSO types and activities operating for public benefit in the country. The PBO Act of 2013 defined a PBO as a "voluntary membership or non-membership grouping of individuals or organizations, which is autonomous, non-partisan and non-profit making" inclusive of those operating locally, nationally or internationally (s. 5(1)). A public benefit activity was defined as "an activity that supports or promotes public benefit by enhancing or promoting the economic, environmental, social or cultural development or protecting the environment or lobbying or advocating on issues of general public interest or the interest or well-being of the general public or a category of individuals or organizations" (s. 2). The PBO Act's Sixth Schedule contained a list of twenty-eight eligible public benefit "areas", from disaster prevention to human rights, while an opening paragraph references "lobbying or advocating on issues of general public interest" as being in the public benefit (sched. $6 \&$ s. 2).

The narrow NGO definition had also made it "difficult to identify and prescribe universal standards for the entire sector" (PEN, 2007a, p. 25; Jillo, 2009, pp. 47-48). Creating a public benefit organization definition broadened the Act's coverage beyond NGOs. In so doing, the PBO Act was meant to facilitate eventual harmonization of the disparate regulations covering trusts, foundations and companies limited by guarantee, at least as pertained to organizations so registered and working in the public benefit, which would be eligible to register under the PBO Act. The Act would thus provide "an umbrella that can deal with all the public benefit organizations" (I36_CSO; I5_CSO; 
I6_CSO). ${ }^{113}$ In theory, this would facilitate monitoring and coordination of the sector, while harmonizing regulatory requirements so that all public benefit CSOs would be required to meet the same standards - thus addressing the perception that such requirements for CSOs registered elsewhere than the NGOs Co-ordination Act were relatively lax (I20_CSO; I40_Elected).

Notably, the PBO Act did not make it mandatory for these other CSO types to migrate from under their current regulatory regimes to the new Act, as mandatory migration would be in violation of the freedom of association as is enshrined in Kenya's Constitution (I44_Other). Instead, the PBO Act was designed to incentivize voluntary migration (Houghton, 2015, para. 19).

The idea.... was that the PBO Act would be so attractive - and that's the way it was designed to be ....to CSOs that they would feel that if they compared it to any of the other regimes, they would rather operate under it. And part of that attractiveness would come from Government working closely with the sector to come up with, for example, incentives that would enable those organizations that are registered under that PBO regime to receive certain, for example, tax incentives, access to certain, I'd say, contracts, training. And this would definitely be the case because the law itself would ensure that those who are operating under it are more accountable. (I61_Other)

As regards coverage of self-regulation in the PBO Act, "the role, and even existence, of the NGO Council was the single most contentious issue" in the early part of the regulatory reform discussions (USAID, 2010; pp. 24-25). Ultimately, the Act maintained

${ }^{113}$ As noted, societies are not considered public benefit but member benefit CSOs, thus they would not fall under the PBO Act (s. 5(2)(e); CSORG, 2014c, p. 3). At 70,000 registered societies, this was the largest CSO category in 2010, inclusive of approximately 40,000 churches, temples and mosques (Kisinga Gitonga, 2010, p. 25; I42_GoK). Community-based organizations including harambee groups, also not intended to be covered under the PBO Act given their member benefit nature, was the first largest (s. 5(2)(i); Kisinga Gitonga, 2010, p. 25). 
a Council-like body called the PBO Federation, but allowed for voluntary rather than obligatory membership in the Federation, and for the possibility of multiple and again voluntary self-regulation initiatives - though these would need formal "recognition" by the PBO Authority (replacing the NGOs Co-ordination Board) (ss. 20, 21(1)-(2) \& 23; CSORG, 2014c, pp. 16-17). With these provisions the Act responded to the sector's interest in "greater CSO choice and reduced government involvement" in self-regulation (USAID, 2010, p. 25).

In another deviation from the NGOs Co-ordination Act, the PBO Act addressed the "excessive discretion" of the Board to register or deregister a CSO or otherwise impinge on its operations (Jillo, 2009, p. 48). The PBO Act laid out clearer guidelines on grounds for refusal of registration or deregistration, and established an independent PBO Disputes Tribunal authorized to deal with appeals brought forward by either the PBO Authority or the PBO Federation (ss. 50-55; CSORG, 2014c, pp. 4 \& 13). A 60-day time limit was also placed on the new PBO Authority to process registration applications as were other steps in the registration and related procedures time bound, whereas the NGOs Coordination Act had been silent on timeframes (PBO Act, 2013, s. 9; CSORG, 2014c, p. 13). The PBO Act also sought to boost the Authority's neutrality by requiring meritbased appointment of Board members through transparent procedures (ss. $35 \& 36$; USAID, 2013, p. 71). The PBO Act was also more explicit than the NGOs Co-ordination Act in stipulating that, while PBOs were not to engage in party politics, engagement on policy issues was legitimate CSO purview (ss. 66(1)-(3); CSORG, 2014c, p. 14). Further, the First Schedule of the Act contained the Principles for Effective Collaboration 
between the Government and Public Benefit Organizations that had been developed by the joint GoK-CSO Working Group for Government-CSO Collaboration (sched. 1; CSORG, 2014c, p. 8).

The Act also sought to address CSOs' dependence on DAC/G financing with various provisions designed to help CSOs "to have a balanced and reliable revenue stream" (Kisinga Gitonga, 2010, p. 36). The provision for CSOs to undertake income generating activities for public benefit purposes was enunciated more clearly in the PBO Act, specifically allowing income generation through "lawful economic activities" if the income earned is used for public benefit (s. 65; CSORG, 2014b, p. 4), while the Act also encouraged GoK funding of CSOs via grants and contracts (sched. 2, ss. $2 \& 3$; CSORG, 2014c, pp. 4 \& 8). ${ }^{114}$ The Act's Second Schedule, Benefits of Registration, listed the various means of indirect GoK support to be provided to all CSOs registered under the Act, inclusive of various tax and duty exemptions as well as "incentives for donations by legal and natural persons" (sched. 2, ss. $6 \& 1$ ).

In automatically conferring these indirect support benefits to all PBO Act registrants (CSORG, 2014c, p. 8; USAID, 2013, p. 72), the Act veered substantially away from the NGOs Co-ordination Act's elective approach to benefits. As noted under wave one, though allowed for under the Income Tax Act (1973) and Custom and Excise Act (1978), tax-exempt status involved a long and cumbersome procedure with arbitrary decisions

114 The NGOs Co-ordination Act itself was silent on NGO income generation, though the accompanying Regulations referred to income generated as an area for possible tax exemption for NGOs having been granted tax-exempt status (s. 30(1)(b)). 
sometimes made. In 2010 a new requirement was imposed for renewal of tax exempt status every three years, with decisions becoming even more arbitrary and exemptions "almost impossible to access", such that exemption claims began to decrease (USAID, 2013, p. 72; USAID, 2014, p. 64). Also as noted in wave two, the Income Tax (Charitable Donations) Regulations (2007) had provided for corporate and individual donors to receive tax deductions for donations to a CSO with tax-exempt status. However, the challenge of obtaining exempt status had continued to be an impediment, while CSOs and potential donors remained largely unaware of and thus did not utilize this provision (USAID, 2013, p. 72; USAID, 2014, p. 64; Ochido, 2013, p. 70).

The PBO Act did not explicitly specify that more rigorous regulatory requirements would ensue in exchange for the benefits that would now be automatically conferred on all registrants. Annual financial and program reporting to the new PBO Authority would, for example, remain more or less as under the NGOs Co-ordination Act (PBO Act, 2013, ss. $30 \& 31$ ). However, the PBO Act contained more detailed eligibility and compliance requirements, with room for more as regulations would be developed, in a consultative manner (s. 69). Further, the requirements of the PBO Act were more rigorous than under other of the Acts under which some PBOs were also registered. CSOs could continue to be registered under the other Acts, but if registered under the PBO Act would have access to the tax and other benefits (Council on Foundations, 2018, p. 6).

\section{Implementation: $\mathrm{PBO}$ Act awaits enactment, slow start for Viwango}

The PBO Act was enacted into law in January 2013 when, following Presidential assent, it was published publically, or 'gazetted' as an Act of Parliament. However, the 
PBO Act's gazette did not stipulate a commencement date for the Act but rather stated the commencement date would be "by notice" (see PBO Act, 2013, "commencement date"). This was not unusual in and of itself. However, despite the Constitutional requirement for a law to commence within 14 days of being gazetted, which could be done via an announcement by the relevant Cabinet Secretary, ${ }^{115}$ this step to begin implementation of the new Act was not taken prior to the March 4, 2013 elections. The reason for this was likely that once the election campaign opened very shortly after the January 25 gazetting, GoK activities were put on hold. The March 2013 elections brought in a new GoK leadership, which through the fourth wave, failed to implement the PBO Act, leading one CSO interviewee to note:

One thing I can say for the Kibaki regime before it [left] office is it allowed the passage of the Public Benefit Organizations Act. If they were still around I would like to wager you my last shilling that at least they would be implementing it. Probably not perfectly, but they would be implementing it. (I8_Other)

This also meant that the regulations to support operationalization of the new PBO Act were not developed.

As regards self-regulation, from its formalization as an institution in 2009, Viwango continued to consult on and refine the design Standards and Code, certification and monitoring mechanisms (USAID, 2013, p. 78). By May 2012, 105 CSOs, either Viwango members or their program implementation partners, had been trained in the Standards and associated mechanisms, while the certification process itself was in 2013 being piloted,

${ }^{115}$ At the time, the Cabinet Secretary for the Ministry of National Heritage and Culture (CSORG, 2014c, p. 5). 
with continuous refinement to the scheme into 2013 based on lessons from the pilots (Aulick, 2013, p. 3). A self-regulation system was well in place by the end of this wave, though its implementation in the CSO sector had still a ways to go.

\subsection{Analytical Summary}

In follow-up to the 2006 Sessional Paper No. 1, the GoK took steps toward regulatory change in the form of the NGO Co-ordination Board's 2009 sector survey, as well as initiating steps to develop a Charities Bill, though the Bill was overtaken by CSO-led regulatory efforts. Indeed, regulatory change in this wave was largely initiated and driven by the CSO sector, leading to the Viwango self-regulation initiative and the PBO Act.

On the GoK side, the 2009 survey report reaffirmed the intent to revise (or replace) the NGOs Co-ordination Act to address outstanding regulatory weaknesses including the continued existence of multiple regulatory regimes for CSOs. Further, the survey report articulated that the Act was no longer proving adequate to meet the regulatory needs of a sector that had grown so significantly in numbers and diversity since 1990. The survey report also pointed to the Board's lack of human resource, technical and financial capacity to adequately fulfill its regulatory role - though falling short of stating that the Act's implementation was proving to be a bigger obstacle than the Act itself was to effective CSO regulation. The NPM-tone seen in Sessional Paper No. 1 was not echoed in the survey report, rather, a tone of responsive regulation was seen in for example in the report's reference to the need for a proportionate and risk-based approach to reformed CSO regulation. 
The survey further found that CSOs were failing to meet, or even be aware of, their obligations under the Act to submit annual returns and were deemed overall insufficiently accountable. CSOs meanwhile were themselves aware that the sector faced accountability challenges, exacerbated by the absence of self-regulation given the NGO Council's demise in the previous wave. The Board's survey also commented on CSOs' dependency on $\mathrm{DAC} / \mathrm{G}$ funding and the negative implications for the sector's sustainability, which the sector itself was sensitive to. Access to $\mathrm{DAC} / \mathrm{G}$ funding over the years had left the impression that the CSO sector was a site for money making, which left the sector vulnerable to rent-seeking behaviours. The $\mathrm{DAC} / \mathrm{G}$ funding relationship with CSOs was increasingly proving itself a mixed blessing.

DAC/G's funding to the GoK in this wave was not as on-again-off-again as it had been in previous waves, though corruption scandals did lead to some $\mathrm{DAC} / \mathrm{G}$ punitive measures. DAC/Gs were highly supportive of a political settlement following the PEV and invested both via the GoK and CSOs in the truth, justice and reconciliation process, including constitutional and other policy and legislative reforms. Their interest in maintenance of the political settlement and associated stability, along with other interests including the anti-terror agenda, economic growth and private sector investment in competition with China as the emerging economic foreign power in Kenya, left DAC/Gs challenged to implement a consistent approach to the GoK.

CSO activities continued to focus on the social and economic development realm, however, their civic and political activism in this wave heightened and was critical in follow up to the PEV. CSO activities included the provision of humanitarian relief but 
also raising awareness with victims and witnesses of their rights and opportunities to provide testimony; securing passage for victims and internally displaced persons; collaborating with the various PEV-investigations; and advocating for justice for victims, ultimately through the ICC.

The type of GoK political motivation to control the sector through regulation or other means was not evident in wave three as it had been in wave one in particular. Instead, wave three saw more conciliatory political agendas given the imperative of implementing and sustaining the post-PEV political settlement and related reforms. This was most evident in the Constitutional development process and ultimately the content of the 2010 Constitution. However, CSO activism in relation to PEV follow-up and the ICC cases was fomenting antagonism between segments of the GoK facing or fearing post-PEV repercussions for their political futures, antagonism that would have significant impact on state and self-regulation in wave four.

CSOs, via a newly formed CSORG, developed and negotiated new state regulation in the form of the PBO Act, responding not only to apprehension about the potential for regulatory overreach following Sessional Paper No. 1 and the Board's survey, but also to the opportunity presented by the GoK's conciliatory political agenda, and the specific allowance for citizen engagement in the legislative process seen in the new Constitution. The more conciliatory GoK was receptive to the CSO-led PBO Act more so than would have been the case in previous waves.

The Viwango self-regulation initiative took root in this wave through a consultation process contributing to the development of a comprehensive set of standards for 
certification, monitoring and compliance tools and processes. This initiative was pursued both to address gaps in CSO self-regulation left by an ineffective NGO Council, as well as to stave off the regulatory threat posed by Sessional Paper No. 1 and the Board 2009's survey. The establishment of Viwango also motivated CSOs to turn their eye to state regulatory reform as they felt Viwango sent a signal that they were taking their accountability and transparency challenges seriously. That said, there is no indication that Viwango's existence had an effect on the GoK's receptivity to the PBO Act per se, though it likely contributed to inclusion of the Act's allowance for CSO self-regulation under multiple voluntary self-regulation regimes versus solely under a legislated PBO Federation.

The risk of CSOs being used as conduits for terrorism or otherwise posing a security threat, absent from Sessional Paper No. 1, was raised officially for the first time in the Board's 2009 survey report. However, this was more as passing reference, attributing the risk to 'rogue NGOs', rather than it being a key cause for concern to be resolved through regulatory reform. That this risk arose in parliamentary debate in 2012 likely reflected the GoK (and DAC/Gs') mounting preoccupation with terrorism as evidenced in Kenya's 2011 military incursion into Somalia to counter Al-Shabaab. This preoccupation coincided with the ESAAMLG's 2011 Mutual Evaluation Report on Kenya that, amongst other things, identified weaknesses in the country's CSO regulation. Counter-terror was thus increasingly on the GoK's agenda, but this did not have any immediate repercussions for the CSO sector in this wave. 
In a sense, wave three closed on a positive note for CSO state and self-regulation. Even though Viwango had yet to take off with its self-regulation certification process, as regards state regulation, Presidential assent of the PBO Act in January 2013 was a high water mark for the sector. This wave showed CSOs' motivation to self-regulate not only due to a threat of state regulatory overreach, but also due to a genuine interest in addressing growing CSO accountability challenges. It also demonstrated that, whatever the relationship between state and self-regulation, the opening provided by a conciliatory political agenda was critical to the introduction of enabling CSO regulation.

\section{Table 7: Wave Three Key Regulatory Change Drivers}

\begin{tabular}{|l|l|}
\hline $\begin{array}{l}\text { Drivers emanating } \\
\text { from CSO sector }\end{array}$ & Characteristics \\
\hline Sector growth & $\bullet$ Continued rapid growth in number of CSOs of all types \\
\hline Type of CSO activities & $\begin{array}{l}\text { - Continued dominance of social and economic development } \\
\text { - High levels of effective civic and political engagement }\end{array}$ \\
\hline $\begin{array}{l}\text { Mismanagement or } \\
\text { misconduct in the sector }\end{array}$ & $\begin{array}{l}\text { - Recognition of growing challenge of accountability and } \\
\text { transparency gaps in sector }\end{array}$ \\
\hline $\begin{array}{l}\text { Sector infrastructure and } \\
\text { status of self-regulation }\end{array}$ & $\begin{array}{l}\text { - NGO Councils (2) considered ineffective } \\
\text { Independent self-regulation infrastructure consolidated in } \\
\text { form of Viwango }\end{array}$ \\
\hline $\begin{array}{l}\text { CSORG forms focused on replacing NGOs Co-ordination } \\
\text { Act, effectively develops and negotiates PBO Bill to PBO } \\
\text { Act }\end{array}$ \\
\hline $\begin{array}{l}\text { Funding and policy } \\
\text { engagement }\end{array}$ & $\begin{array}{l}\text { Characteristics } \\
\text { Threat of (permanent) aid suspension in absence of } \\
\text { mediated political solution to PEV } \\
\text { Selected funding suspension to GoK due to corruption } \\
\text { - Keen interest in maintenance of economic and political } \\
\text { stability in Kenya, and of related interests including private } \\
\text { sector investment and anti-terror imperative } \\
\text { - Funding to GoK and CSOs for post-PEV processes and } \\
\text { various institutional, policy and legislative reforms } \\
\text { • Funding to CSOs for self- and state regulation initiatives }\end{array}$ \\
\hline
\end{tabular}




\begin{tabular}{|c|c|}
\hline $\begin{array}{l}\text { Drivers emanating } \\
\text { from GoK }\end{array}$ & Characteristics \\
\hline Status of state regulation & $\begin{array}{l}\text { - Non-cohesive regulatory framework for CSOs with } \\
\text { multiple regulations } \\
\text { - NGOs Co-ordination Act, but also Board capacity, not } \\
\text { keeping up with sector growth and diversity } \\
\text { - } 2009 \text { Board survey reiterates need for new/revised } \\
\text { regulation while calling out CSOs mismanagement and } \\
\text { misconduct, sustainability issues } \\
\text { - Draft Charities Bill subsumed by CSO-led PBO Bill }\end{array}$ \\
\hline Political agendas & $\begin{array}{l}\text { - Conciliatory political agendas following PEV } \\
\text { - Significance of CSOs' roles in pursuit of national } \\
\text { development inclusive of post-PEV truth, justice and } \\
\text { reconciliation recognized positively } \\
\text { - } 2010 \text { Constitution epitomizes conciliation imperative }\end{array}$ \\
\hline $\begin{array}{l}\text { Public management } \\
\text { agendas }\end{array}$ & $\begin{array}{l}\text { - } 2009 \text { Board survey references need for proportionate, risk- } \\
\text { based regulation in spirit of governance/responsive } \\
\text { regulation }\end{array}$ \\
\hline $\begin{array}{l}\text { Security and terrorism } \\
\text { concerns }\end{array}$ & $\begin{array}{l}\text { - } 2009 \text { Board survey makes explicit link between terror } \\
\text { threat and CSO proliferation } \\
\text { - Pre-occupation with anti-terror agenda evidenced by } 2011 \\
\text { incursion into Somalia } \\
\text { - ESAAMLG } 2011 \text { Mutual Evaluation of Kenya critiques } \\
\text { GoK for inadequate anti-money laundering and anti-terror } \\
\text { measures including as regards CSO regulation }\end{array}$ \\
\hline
\end{tabular}




\section{REGULATORY WAVE FOUR, 2013 TO 2017 - RISING TIDE OF REGULATORY REFORM ATTEMPTS}

\subsection{Introduction}

This chapter details the CSO regulation story in Kenya over the fourth wave covering the 2013 pre-election and election periods, to the end of 2017. In this wave state regulation under the NGOs Co-ordination Act was implemented with vigour, while attempts were made by the GoK to amend rather than implement the PBO Act. Selfregulation of CSOs was largely stalled.

\subsection{Wave Four Overview}

This period came in on a peak of state regulatory change with a new PBO Act at the ready for implementation, as well as an independent self-regulation scheme, Viwango, poised to complement the Act. Yet wave four brought the key driver of political agendas into sharp focus under a new authoritarian-leaning GoK hostile toward CSOs and DAC/Gs. Through this wave the GoK proved unwilling to implement the PBO Act while pursuing amendments that would render it less enabling of the sector. It used the NGOs Co-ordination Act and a captured, rent-seeking Board to crack down on the CSO sector while building an anti-CSO and anti-DAC/G narrative, peppered with accusations of CSO terror affiliations. In parallel, CSO self-regulation, for which there was no motivation in this environment, stalled.

In the fourth wave, NGO numbers appeared to be stabilizing. Perceptions of CSO misconduct, that CSOs were money chasers rather than promoters of the public good remained present, though the appeal of CSOs as an income source was waning. The 
sector's infrastructure was a mixed bag. At any given time in this wave at least two NGO Councils continued to exist though with insignificant membership, legitimacy, or selfregulation role. At the same time, while self-regulation under Viwango did not pick up speed, the CSORG represented the sector in relation to state regulation as best it could under the circumstances.

Non-implementation of the PBO Act, five amendment attempts including a proposed 15 percent ceiling on foreign funding to CSOs that would have crippled the sector, and an increasingly aggressive, and over-reaching implementation of the NGOs Co-ordination Act were notable regulatory changes in this wave. These occurred alongside a narrative emanating from the GoK that demonized the sector including accusations that CSOs were, amongst other things, conduits for terrorism as well as agents of 'foreign masters'. The regulatory changes were largely attributable to political agendas of a new GoK that took power in 2013, then again in 2017, both times with questionable legitimacy following marginal and hotly contested election wins.

The GoK's political agendas were linked to CSOs' civic and political engagement activities as well as that of DAC/Gs in the previous and current wave. When it came to CSOs' activities wave three had seen receptivity to CSOs' civic and political engagement and the CSO-GoK relationship had been evolving in a positive, collaborative direction, epitomized by the PBO Act's enactment. However, in words and deeds the new and increasingly authoritarian-leaning GoK was set on implementing restrictive regulatory control while fomenting a climate of mistrust and fear among CSOs and DAC/Gs. Both CSOs' and DAC/Gs' actual and perceived support for and role in bringing the wave four 
GoK's leadership to the ICC on charges of crimes against humanity for their alleged role in the PEV, alongside CSOs' and DAC/Gs' resistance to the wave four GoK leaders' 2013 election candidatures, then CSOs' role in calling out irregularities in the contested 2017 elections, were sources of contention. As this wave progressed, the CSO sector faced fear and uncertainty, while their DAC/G supporters and allies were seen as cowed by a hostile GoK forging stronger links with alternate aid providers and investors. The interest of DAC/Gs in security, stability and economic growth for Kenya (and by extension, themselves) seemed to over-ride interests in a democratic Kenya.

The NGOs Co-ordination Board succumbed to the GoK's political agenda, captured as it was by the new GoK. The Board regulated with a heavy hand and with virtual impunity in suspending hundreds of CSOs and generally operating beyond its regulatory purview, including penalizing CSOs not even registered under the NGOs Co-ordination Act. The Board fell into a state of disarray while signs of rent seeking from the CSOs it was meant to regulate emerged.

At the end of this wave none of the PBO Act amendment efforts had resulted in regulatory change, though they had fomented a chilly climate in the sector reinforced by the manner of implementation of the NGO Co-ordination Act.

\section{Table 8: Wave Four Key Developments or Actions of Main Actors}

\section{GoK:}

- March 2013 election of new GoK

- Explicit anti-CSO, anti-DAC/G narrative emerges

- Overall authoritarian tendencies of new GoK, suffering from legitimacy crisis in evidence

- Resistance to civic and political engagement role for CSOs in relation to implementation of 2010 Constitution including devolution, other legislation 
- Attempts to amend and failure to implement PBO Act

- Use of NGOs Co-ordination Act and NGOs Co-ordination Board rogue Executive Director to suspend CSO registrations, amidst accusations of CSO engagement in money laundering, terrorism, acting as foreign agents

- 2017 election highly contested, CSOs engaged in civic education, monitoring, penalized through registration suspensions and other means

CSO sector:

- Numbers stabilize

- Some continue follow-up on pursuit of justice re 2007/08 PEV and ICC cases

- Continued high level of engagement in service delivery, also civic and political activism regarding implementation of Constitution commitments including devolution, other legislation

- Resist Board overreach through court system

- CSORG activism opposing PBO Act amendment proposals and Board over-reach

- NGO Council(s) in disarray

- Independent self-regulation via Viwango stagnates

DAC/Gs:

- Suspend aid following new GoK following 2013 election win; CSO flows also briefly affected

- Backed selves into corner due to 2013 election positions taken re ICC indictees now leading the GoK

- Democracy and rights agenda a lesser priority relative to other interests and concerns: private sector development, competition with China, stability and anti-terror agenda

- Continued financial support to Viwango and to CSORG for work on PBO Act implementation 
Figure 5: Wave Four Timeline: Key Political and CSO Regulation Developments

\section{Key Political Events}

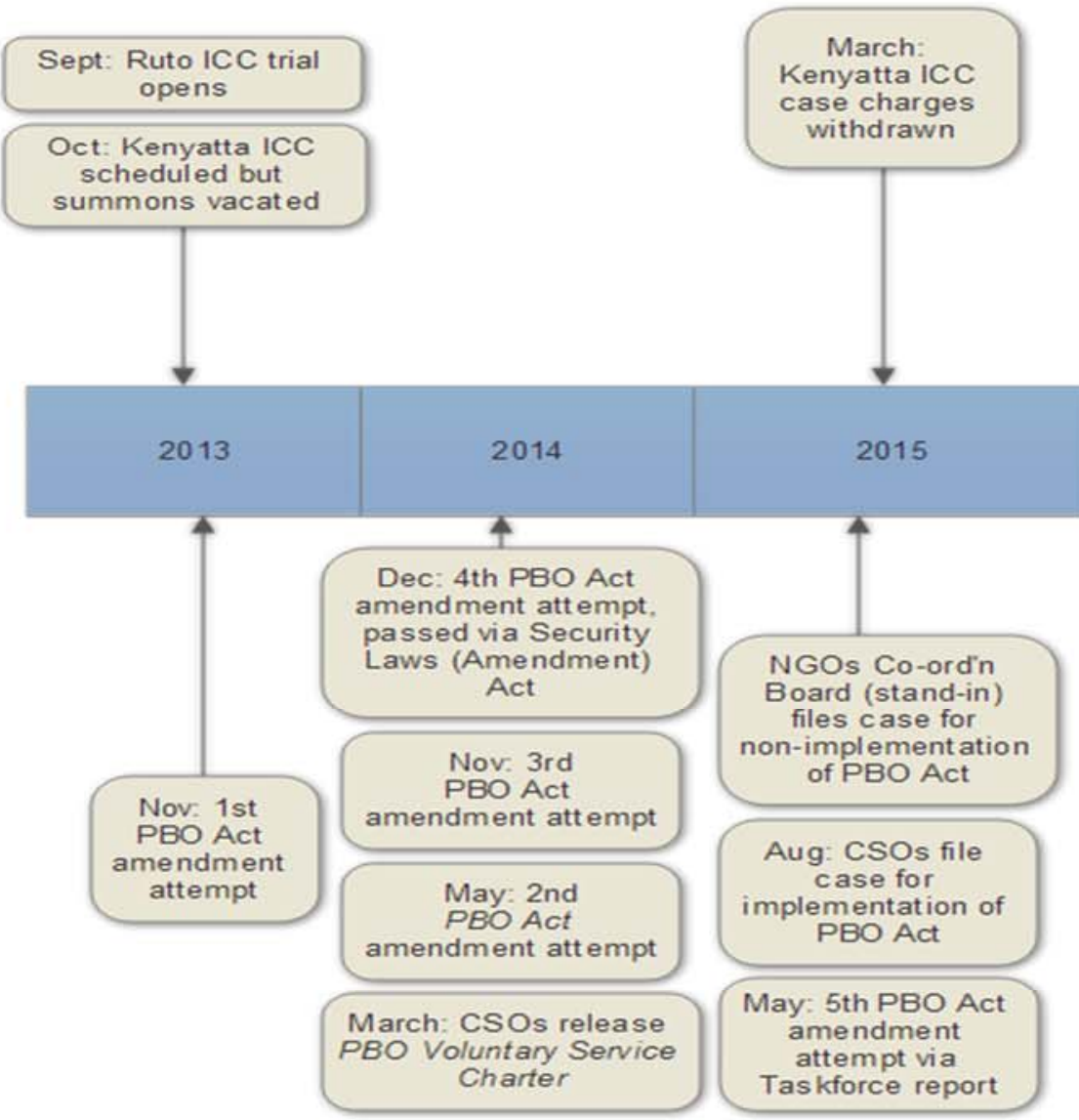

Key CSO Regulation Events
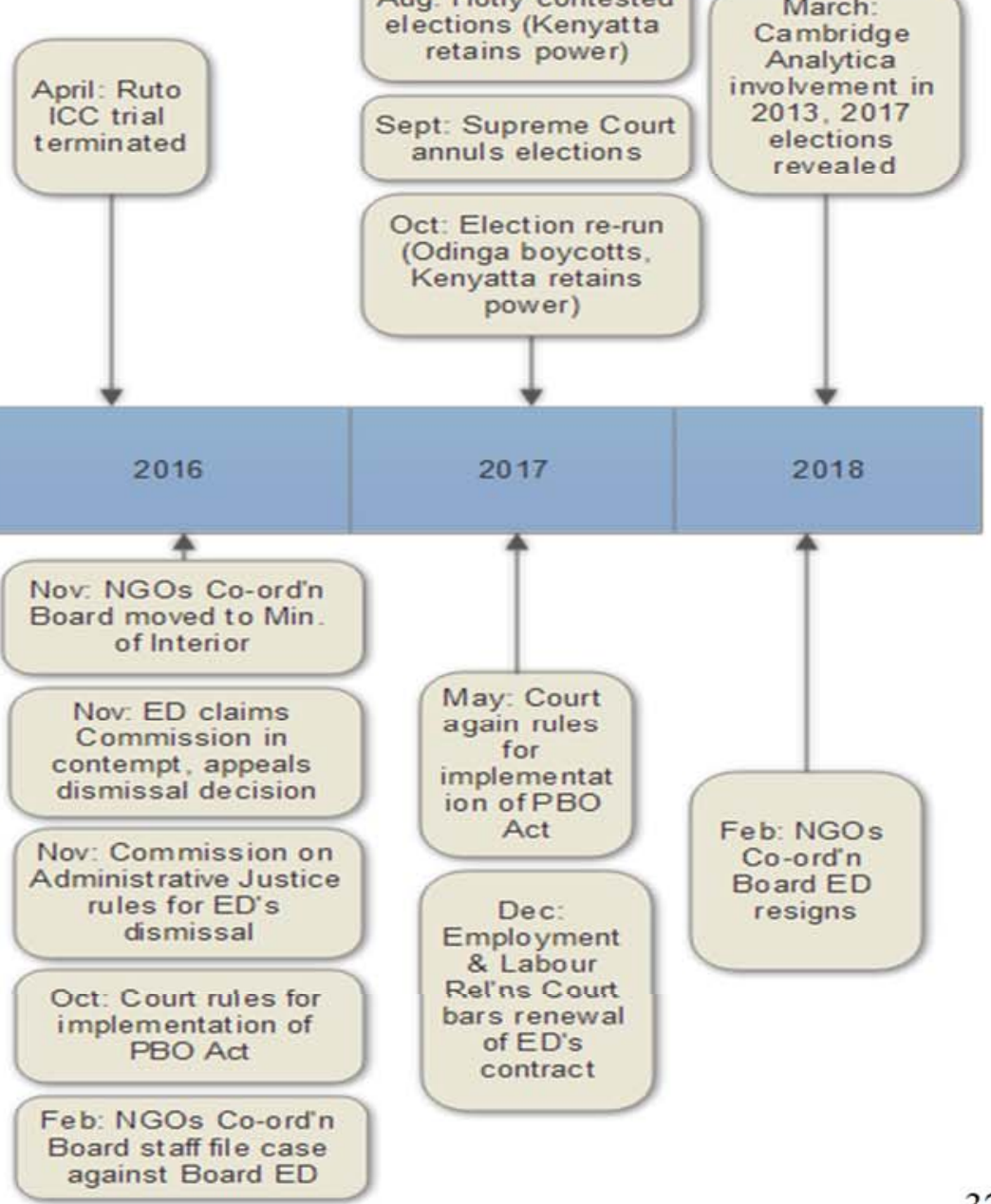


\subsection{Drivers of CSO Regulation}

\section{In Focus: Perspectives on Regulatory Change Drivers}

CSOs need to convince the public that they're doing the right thing. Right now when the public looks at CSOs and Government, they see the same thing. They see corruption. They see inefficiencies. They don't see anything new. And the onus then would be on the CSOs to do something different. (I59_DAC/G)

I highly doubt that it is the issue of capacity [to self-regulate] that is creating the demand for the current legal framework that is being proposed.... I think the legal reform that is being proposed at the moment is political, and does not seek to promote the development of the sector.... the legal framework [is] being tilted to meet certain political objectives, rather than being supportive of [CSOs'] various roles. (I6_CSO)

It is not very easy to discern why Government is not comfortable with civil society working around accountability and oversight. We tend to reach the issue of ICC, because when you listen to those who matter in Jubilee.... they made it very clear from the beginning that they're not comfortable with civil society operatives who took their leadership to ICC. So, you may not say whether it is the ICC that is making them a bit uncomfortable, or whether they just fear to be audited by the public through civil society.... But I'm persuaded to believe [the] ICC is at the center of the strange relations between the civil society and Jubilee administration.... that is the main reason. (I16_DAC/G)

[The PBO Act amendments], it's political agendas.... driven from the top. (I14_GoK)

The main motivation is that they [GoK] want to silence a few of these kind of pain-in-theneck NGOs.... that are openly criticizing Government and exposing Government when they do bad things. And there are a few of them. They are not many, if you look at the whole totality of all the NGOs, the thousands of NGOs that are around. Most of them are working on social service delivery and capacity-building in social development and economic development. The number of NGOs that would be labeled as activist, democracy, human rights defending NGOs are very few and those are the ones they want to nip in the bud. (I4_DAC/G)

$[D A C / G s]$ have been intimidated by Government... they are on the defensive and ceding ground. (I16_DAC/G)

I personally don't see how PBOs cause insecurity.... I believe the harassment of MUHURI [a CSO], and the rest of them may be in preparation for justifying some bad law. But that's our country. That's our politics.... and then you proceed and de-register and take away licenses of organizations. But those are organizations that have also pointed out the government excesses. (I21_Other) 


\section{Political Backdrop: A new GoK with old baggage}

This wave began with a political transition to a new GoK led by President Uhuru Kenyatta and his Deputy President William Ruto. Unlike in 2007, the 2013 election was a peaceful one though the losing side, again led by Raila Odinga, unsuccessfully disputed the outcome at the Supreme Court. Since coming to power this GoK demonstrated the authoritarian tendencies of old. While Kenyans' rights were protected under the 2010 Constitution, in a variety of ways this GoK operated in ways not in keeping with the Constitution's spirit, or at times, the Constitution's letter. Come 2017 Kenya again faced an election battle between the incumbents and Odinga. This time the Supreme Court nullified the elections citing irregularities, though it dismissed petitions disputing the rerun, leaving Kenyatta and Ruto's Jubilee party to continue to lead the GoK.

The 2013 elections political slate was an odd one. As a result of the 2011 ICC indictments, Kenyatta and Ruto, in wave three members of opposing political parties and facing trial for having incited violence against each others' supporters, formed a "pariahs' alliance" against those who opposed them, putting the "the enemy of my enemy is my friend" proverb into practice (Hornsby, 2012, p. 774; I25_GoK). While it had been anticipated that these men, both with Presidential aspirations, would be opposing contenders for the Presidential position in the 2013 election (Hornsby, 2012, pp. 686-687, $773 \& 750$ ), they joined forces in an unlikely alliance, establishing a new Jubilee Coalition alliance of parties with their eyes on the 2013 election. Despite their erstwhile enmity, the ICC issue unified these accused: "their motivation for coming together was to get office and impunity" from the ICC, and to "marginalize and push back these charges" (I12_CSO; Hannan, 2015, 5:09-5:27; Long et al., 2013, p. 145). Their ethnic origins 
meant another "ethnic head-to-head" election between the Kikuyu Kenyatta (with Ruto, a Kalenjin), and the Luo Odinga (Hornsby, 2012, p. 784). Changes to the election parameters brought about by the 2010 Constitution and subsequent legislation including a Political Parties Act (2011) and changes to electoral constituency boundaries, though intended to reduce ethnic considerations in the voting process (Lanser, 2012, pp. 6-7), did not, in this round, break Kenya's ethnic divides.

Yet Kenya's 2013 election was a peaceful one due to concerted and collaborative effort on the part of all sectors and the public to make it so; Kenyans did not want a repeat of the 2007/08 devastation from which it was in many respects still recovering (USAID, 2014, pp. viii \& 62; Long et al., 2013, pp. 149 \& 152). As in 2007, the 2013 results were hotly contested, with Kenyatta the declared Presidential winner garnering a very slim margin with 50.07 percent of the vote (Long et al., 2013, p. 140). The elections were deemed free and fair despite the re-occurrence of previous elections' challenges such as the misuse of public funds, voter intimidation and harassment, as well as breakdowns in the Independent Electoral and Boundaries Commission's (IEBC) voter registry and a new Electronic Voter Identification system (Ebole \& Odhiambo, 2016, p. 2). ${ }^{116}$ The results were challenged in the Supreme Court by the Odinga-led coalition party ${ }^{117}$ and two CSOs (Long et al., 2013, pp. 151 \& 153). The Court, while acknowledging flaws in the election process, ruled in Kenyatta's favour and Odinga accepted defeat, all the while appealing to his supporters to remain peaceful (Long et al.,

116 The IEBC was another 2010 constitutional creation, replacing the Electoral Commission of Kenya that had lost credibility due to the 2007 election debacle.

${ }^{117}$ Coalition for Reform and Democracy (CORD), established for the 2013 elections. 
2013, pp. 149 \& 150). Following the 2007/08 PEV experience, "Kenyans above all seemed to hope for peace in 2013 - so much so that many voters were willing, if necessary, to sacrifice having a fair electoral result in order to ensure peace" (Long et al., 2013, p. 151). ${ }^{118}$

The new GoK faced a political environment in which the promises of the 2010 Constitution were becoming reality as various new or reformed policies and legislations began implementation. Arguably the most significantly reform, devolution, launched in earnest in 2013 with the establishment of country governments and associated supporting systems and structures in keeping with the Urban Areas and Cities Act of 2011, the Transition to Devolved Government Act of 2012, the County Governments Act of 2012, and the Public Finance Management Act of 2012. ${ }^{119}$ Technically, devolution reduced the power of the central GoK and the Presidency, with both resources and decision-making devolved to 47 newly-established county governments led by an elected Governor (Lanser, 2012, pp. 4 \& 6-7). Further, the "commitment to citizen participation in the planning, delivery of services, budgeting and monitoring is well articulated" across devolution's legislative framework (Nizam, Muriu, \& International Budget Partnership, 2015, p. 1). The process of devolution was slow and rocky in this wave, with challenges in relation to the transfer of functions from national levels, the (im)balance of ethnic

${ }^{118}$ Long et al. (2013) offer an excellent in-depth analysis of the 2013 election, while a Kenyan CSO, InformAction, produced a video documenting in real time the flaws claimed to have mired the election process (Hannan, 2015).

119 These are the main new or amended laws in which devolution is addressed. 
representation, debates over revenue allocations, and evidence of "rampant corruption" at county government levels (Ebole \& Odhiambo, 2016, p. 4).

In spite of, and partially because of the expectations and requirements of the GoK under the 2010 Constitution, the Jubilee rulers of this wave proved themselves adept strategists prepared to use and amend legal requirements to curtain freedoms and quell opposition, leading one commentator to note that: "The ease with which the government is clawing back on fundamental freedoms that Kenyans have defended for decades is disconcerting, and questions the Kenyatta administration's willingness to put its citizens' interests before its own" (Mwiti, 2014, para. 9). Freedoms existed, but the combination of corruption, state overreach, and "repressive impulses", "prevent[ed] the full promise of Kenya's legal and institutional framework from being realized" (Ebole \& Odhiambo, 2016, p. 2). The Jubilee GoK's "legitimacy crisis" following its very slim win in the contested 2013 (and then 2017) elections, elections in which “they can't demonstrate that they actually won" exacerbated the autocratic tendencies of this GoK (I22_CSO; I7_CSO).

Both Kenyatta and Ruto's early political careers were honed under the tutelage of wave one's President Moi, such that they were referred to as "Moi's boys" and appeared to prefer Moi-style repressive political tactics (I4_DAC/G). In this wave, the GoK applied more nuance than Moi had, not daring for example to seek to amend the iconic 2010 Constitution, nor to re-open the Nyayo House torture rooms. Instead, legislative means and more covert punitive measures were often called upon. For example, in December 2013, access to information and media freedoms were constrained via 
amendments to the Kenya Information and Communications Act of 1998 and a new Media Council Act of 2013, the latter amounting to "draconian changes to the media freedoms allowed in the new constitution that would negate the progress made in the last decade" (Mwiti, 2014, para. 9; Committee to Protect Journalists, 2013; para. 1). In another example, a highly controversial The Security Laws (Amendment) Act of 2014 imposed severe restrictions on peaceful assembly, expression and the media, provoking a physical brawl in Parliament (BBC News, 2014). The anti-democratic nature of these and other moves by the GoK were not lost on Kenyans with high expectations of their constitutional protections, as highlighted by one interviewee:

To me this is a bad sign; it's not a healthy sign for a country that has struggled to where it is, to begin to make some sense in terms of democratization, freedom of expression, and basic human rights. Instead of now progressing, we're retrogressing. (I7_CSO)

As a result, the mettle of Kenya's High and Supreme Courts was tested to the maximum in this wave. For example, sections of the Information and Communication Act (1998) amendments and Security Laws (Amendment) Act (2014) were deemed unconstitutional by the Court (Ebole \& Odhiambo, 2016, p. 3; CIVICUS, 2015a, p. 4). Also having been subject to reforms to align with the 2010 Constitution, through most of this wave the judicial system was independent and powerful enough "to check executive excesses", though at the same time, it was not unusual for court orders to be ignored, and the judiciary became subject to GoK criticism and fearful as this wave progressed (Ebole \& Odhiambo, 2016, pp. 4 \& 9).

The political environment characterizing this wave was well demonstrated also through the GoK leaders' (and allies) handling of the ICC cases they faced. First, since 
their indictment, the Jubilee GoK leaders had sought to propagate a view at home and with members of the AU that the ICC was a Western construct with no place in the continent's affairs, accompanied by threats of withdrawal. ${ }^{120}$ In its attempts to discredit the ICC, the GoK "spent millions of taxpayers' dollars in an effective shuttle diplomacy campaign to portray the current ICC trial as an imperialist and racial agenda by the West against Africa" (Mwiti, 2014, para. 3). Second, the cases ended without prosecutions due to various hindrances by a non-cooperative GoK and alleged illegal actions impeding the procedures. In December 2014 the ICC's Chief Prosecutor withdrew the charges against Kenyatta stating there was "no alternative but to withdraw the charges against Mr. Kenyatta, given the state of the evidence in this case" (ICC, 2015, p. 2). ${ }^{121}$ The ICC case against Ruto was terminated in April 2016 amidst similar allegations (ICC, 2016; Allison, 2016, para. 4). The GoK had impeded the presentation of evidence, and was accused of obstructing investigations by not responding to requests for documentation, as well as bribery, intimidation, and possibly killing (or incitement to killing) of witnesses (Bowcott, 2014; Koskei \& Ollinga, 2015). In both cases the termination did not preclude

${ }^{120}$ In mid-2014 Kenya was the first to sign on to the AU's Malabo Protocol which would, once ratified by the necessary minimum 15 member states, essentially establish a Union-based court substitute for the ICC in trying African cases by expanding the African Court of Justice and Human and People's Rights to include international crimes. The Protocol contains an immunity clause excluding any head of state, deputy or other senior officials from being tried during their tenure (Kikechi, 2015, para. 4; African Union [AU], 2014, p. 6). Early in his tenure in November 2013, President Kenyatta had failed in an attempt to have a similar clause added to the ICC Statute (Affa'a-Mindzie, 2014, para. 6), following which he called for a mass withdrawal from the ICC by AU members, without success (Boru Halakhe, 2014). Though Malabo has yet to receive the necessary minimum signatures, it had adequate support to stand at the AU, including from another ICC-indicted African leader, the President of Sudan.

${ }^{121}$ The decision on withdrawal of charges was issued in March 2015 (ICC, 2015, p. 1). 
appeals nor future prosecution, domestically or at the ICC (ICC, 2015; ICC, 2016). Commenting on the Kenya cases, the Chief Prosecutor expressed that "the level.... of witness interference is unprecedented.... We have been able to see that there's a scheme.... in which several people were involved.... The witnesses are under siege" (InformAction, 2015, 03:34; 03:50 \& 04:45).

Also through this wave, corruption continued largely with impunity and thus without fear. Kenya's CPI ranking by the end of this wave was $143^{\text {rd }}$ out of 180 ranked countries with a score of 28 out of 100 , very marginally improved over the $136^{\text {th }}$ out of 177 countries ranking in 2013, scored at 27 out of 100 (TI, 2018b; TI, 2013). Corruption was both grand and petty in scale. Regarding the former, in 2015 GoK officials were caught in a massive corruption case involving more than USD 1 billion of funds pilfered in a scandal involving Eurobonds (USAID, 2016, pp. 96-97). Regarding the latter, "Kenyans pay more frequent bribes for business and informal fees for basic services like education and health than in many other countries" (Finch \& Omolo, 2015, p. 5).

An interviewee active in the CSO sector since the first CSO-published corruption monitoring report in the mid-1990s, when interviewed almost four years into the Jubilee GoK's mandate expressed exasperation with the never-ending anti-corruption battle:

I think the government has kind of become immune to the critiques, you know? Because it has been criticized a lot concerning corruption. People have talked about it a lot until now they $[G o K]$.... don't really care. That is why even when you continue talking about something that is happening now and happens tomorrow, then the day after, there is more corruption being discovered. (I54_CSO)

The same interviewee predicted that corruption issues would not see the Jubilee GoK suffer at the polls in the pending 2017 elections as "a lot of money has gone into people's 
pockets"; through patronage, political support is easily bought (I54_CSO). Relatedly, Kenyans, it seems, continue to be swayed by ethnic affinities.

Many people, they have such allegiance to their community, ethnic affiliation.... and that interferes with their.... reasoning and their capacity to really make decisions that are.... based on merit. People will base their decisions on, "Who am I voting for? Is it someone from my tribe?" And this idea of, "If my tribesman is eating it's good. There's no problem with it... My time will come." So people will not see it as a very bad thing if one of them is eating. So they will still vote for that person.... irrespective of the fact that I am corrupt, they still vote for me..... It keeps happening. (I54_CSO)

Also noteworthy in relation to the political environment in this wave were pressures on various institutions of democracy such as CSOs (discussed under the Political Agendas, Negotiation and Implementation sections below), but also the media. The media faced not only legislative reforms such as the above-mentioned amendments to the Kenya Information and Communications Act restricting the freedom and independence of the media, but also harassment and both physical attacks as well as verbal ones by the GoK (Ebole \& Odhiambo, 2016, pp. 6-7). Notably, impunity in the use of excessive and indiscriminate force by police, security and intelligence forces also characterized this wave (Ebole \& Odhiambo, 2016, pp. 7 \& 12).

The 2017 elections shared features of the 2013 one. This time however there were protests, violence, and deaths - the bulk inflicted by Kenya's police forces - though not to the level as was experienced in 2007 (Epstein, 2017, para. 27; Moore, 2018, para. 3). Kenyatta the incumbent again won against his main opponent, again Odinga, in a very close August 2017 race. Kenyatta was declared winner with 54.27 percent of the vote (Kimutai \& Okumu, 2017, para. 2). The result was disputed by Odinga on the grounds that the electoral system had been hacked (Kimutai \& Okumu, 2017, para. 8). This did 
not seem an unlikely claim, given that the IEBC's head of information technology had been tortured and murdered a week prior to the election (Burke, 2017), alongside other signs of irregularities (Epstein, 2017). As in 2013, Odinga again went to the Supreme Court to contest the results, with the Court ruling in his favour and, per constitutional requirements, calling for a re-run of the election 60 days following its ruling (Moore, 2017b, para. 4). Deeming the time available inadequate to overhaul the flawed election system, Odinga eventually withdrew his candidature and called on his supporters to boycott the re-run (Moore, 2017b, para. 5). ${ }^{122}$

Ultimately following the October re-run, Kenyatta was declared the victor with 98 percent of the vote, based on a 39 percent voter turnout, a poor comparison to the 77 percent turn out for the August elections (Miriri, 2017, para. 1; Africa Centre for Open Governance [AfriCOG], 2017, para. 3). At the August election, the head of the IEBC had wavered on whether or not the voting system had been hacked, though eventually declaring that there had been no hacking (Kimutai \& Okumu, 2017, para. 92). At the October election, the IEBC warned that the election's credibility was being compromised due to political interference while one of the commissioners fled the country in the face of death threats (Moore, 2017a, para. 8). And while two petitions to the Supreme Court contesting the October election were this time overturned, Odinga refused to accept the election outcome (Moore, 2017b, paras. 1 \& 4).

${ }^{122}$ Initially Odinga attempted to obtain agreement for a later election date, boycotting the October election only once he failed in this attempt. 
Again, despite Kenyatta's win on paper, his GoK with Deputy President Ruto also still sharing the helm, entered their second tenure facing a legitimacy crisis, and anger at the various institutions that had sought genuinely free and fair elections. The GoK's backlash against these institutions was quick. For example, following the Supreme Court's ruling that annulled the August 2017 election results, the GoK accused the judiciary of being unduly influenced by foreign donors and by CSOs through which their funding flowed (Githae, 2017, paras. $1 \& 10$ ). ${ }^{123}$ This notwithstanding that this same foreign funding supported the work of many and varied GoK Ministries, and that the main international CSO source supporting the Supreme Court also supported the GoK in developing the 2010 Constitution (Owino, 2017, para. 13).

As was revealed early in 2018, for both the 2013 and the 2017 elections, the Jubilee party (or the GoK proper given blurred separation between the two) had recruited the UK data mining and public relations firm, Cambridge Analytica, to help with its election win (Solomon, 2018 paras. 1 \& 10-13; Kiai, 2018, paras. 3 \& 4; Epstein, 2017, para. 25). ${ }^{124}$ With its parent company, the firm "ran the Kenyatta campaign" in 2017, exploiting societal divisions and fears in ways that swayed "an unknown number of voters, but enough to make an impact" (Solomon, 2018, paras. 8, 10 \& 26). Even had the result been different, that Kenya's political leaders resorted to the Cambridge Analytica tactics was

123 Kenya's judiciary receives financial and technical support from DAC/Gs and international foundations (some via an international CSO).

${ }^{124}$ Kenyatta and Ruto also employed UK lawyers to defend them at the ICC (Boru Halakhe, 2014, para. 19). 
testament to the lengths to which they were prepared to flout the democratic process so as to first obtain then maintain power, with or without legitimacy.

Within this political context, the GoK and the CSO sector's relationship suffered considerably relative to the high water mark reached in the previous wave. Outright hostility toward the CSO sector as well as other organizations and institutions daring to project an independent voice were a prevailing feature of this wave.

\section{Sector Growth: Stabilizing?}

According to an NGOs Co-ordination Board report released in 2015, by 2013/14 the Board had registered 9, 728 NGOs, representing another 15 percent increase in the two years since the figure of 8,430 in $2011 / 12$ (NGOCB, 2015, p. 3). However, only 74 percent of these, approximately 7, $250 \mathrm{NGOs,} \mathrm{were} \mathrm{deemed} \mathrm{by} \mathrm{the} \mathrm{Board} \mathrm{as} \mathrm{active} \mathrm{at} \mathrm{the}$ end of the 2013/14 period (NGOCB, 2015, p. 3).

This figure of 7,250 suggests that the upswing in number of NGOs Kenya experienced through the 1990s and 2000s may have been beginning to stabilize in this fourth wave. Though in the absence of 'active' versus 'registered' figures for previous years it is not possible to conclude this with certainty, expert estimates for 2017 put the number of registered NGOs at "6,500+", lower even than the Board's 7,250 active NGOs figure for 2013/14 (ICNL, 2017, para. 8).

Among the considerations pointing to a possible stabilization in numbers include a dip in the availability of DAC/G funding starting in 2013 when many DAC/Gs put financial flows to Kenya, including CSOs, on hold as they awaited implementation of key reforms scheduled to kick-in following the first election under the 2010 Constitution, and 
also assessed how to adjust to a new, ICC-indicted GoK (I36_GoK). While DAC/G funding to CSOs picked up to reach a high point later in 2013, thereafter it did not grow as it had previously. The combination of an initial reduction and CSO competition for a finite amount of resources may have led to the closure of some CSOs while prevented new ones from forming. According to one observer: "NGOs are dying because they are not getting enough funding" (I52_CSO).

Further, the anti-CSO stance of the wave four GoK and associated restrictive regulatory and extra-regulatory measures either discouraged CSOs from forming and registering, or motivated them to register under the alternative regulatory regimes available. The mere fact of the regulatory uncertainty while awaiting the transition to the new PBO Act could have contributed to stabilizing NGO numbers, as noted by one interviewee:

There's really lack of clarity when it comes to the registration framework. Because you have this law [the PBO Act] that is supposed to be commenced, and it still hasn't been commenced. And then nobody really knows whether the other one [NGOs Coordination Act] was revoked or whether it continues to operate. So that confusion has probably made quite a number of people to either prefer other alternatives or just wait and see how things will go before they make their decision to register. (I61_Other)

Also, from 2014 the efficiency of the Board's operations was less than optimal, slowing down the process of registration and associated administrative steps and approvals, as explained by a GoK interviewee:

Even other little services like, normally... [the Board] recommends to the banks about opening.... accounts for new NGOs or any NGO that wants to open a bank account, [the Board is] supposed to give information about the official members of the organization. So [the Board is] supposed to recommend to the bank that this is a valid, registered NGO with bona fide officials.... But the way [the Board is] doing it at the moment is very lousy. There's a lot of delay and this is affecting donor remittance of funds. (I53_GoK) 
The combination of these various wave four developments therefore contributed to stabilization in CSO numbers relative to the sector growth of previous waves.

\section{Type of CSO Activities: Ongoing dominance of social and economic development, civic and political engagement diversifying}

The activities of CSOs in this wave continued in both the social and economic development and civic and political engagement realms. Though the latter realm continued to be the focus of a small portion of the sector, the number of CSOs thus engaging showed signs of increasing particularly at decentralized levels. Civic and political activism by CSOs also continued to target PEV-follow up and election monitoring.

In social and economic development, CSOs in this wave were active in the fields of health, education, water and sanitation, amongst others, as the majority of them had been for decades. For a smaller portion of the sector, hovering between 9 and 5 percent of NGOs registered with the NGOs Co-ordination Board between 2009 and 2015, civic and political engagement (i.e. governance, rights and advocacy) was their primary objective (NGOCB, 2009, p. 32; I47_CSO). ${ }^{125,126}$ These CSOs continued to push for various rights and reforms to ensure compliance with the 2010 Constitution, contributing to a plethora of quotas and Acts, and court cases defending and promoting such rights, thus placing

125 The Board's Annual Sector Report for 2013/14 put the share of NGOs focused on "governance" at 3.6 percent, with those focused on "governance" and "peace building" combined at 8.4 percent (NGOCB, 2015, p. 5).

${ }^{126}$ Though the wider CSO sector share would be larger given the multiple registration regimes and the tendency as previously noted for civic and politically active CSOs to choose the registration options alternative to the NGOs Co-ordination Act. 
greater and greater demands on the GoK (I39_Other; I34_GoK). Illustrative examples include CSOs' advocacy to amend the Persons With Disabilities Act of 2003; their push to have the dedicated seats for women and youth in Parliament and the Senate filled; provision of training on and engagement in county-level budgeting and audits; and on various other legislative and policy developments in which CSOs pursued "constitutional accountability" (USAID, 2014, pp. 63 \& 66).

The portion of civic and politically engaged CSOs was said to be on the rise in this wave in the context of Kenya's devolution, which began to roll out in 2013. As noted, devolution enshrined a significant role for citizens and CSOs representing them in the pursuit of accountability and transparency from devolved government. For example, the County Governments Act (2012) dedicates a section to citizen participation and contains specific references to CSOs (referred to as "non-state actors") including their role in decision-making and government oversight (s. 87(e); USAID, 2014, p. 63). As a result, more and more social and economic development focused CSOs undertook capacity development with citizens and sought opportunities to engage in policy dialogue and the pursuit of accountability from decentralized levels of government, with $\mathrm{DAC} / \mathrm{Gs}$ supporting this engagement (I47_CSO; I32_CSO; USAID, 2013, p. 73). CSOs increasingly mixed civic and political activism with a service orientation in the devolution process, training CSOs and county government officials and elected members of county assemblies in the new devolved system and their responsibilities under it, while also actively inputting and reviewing county plans and budgets (USAID, 2014, p. 66). 
Notable CSO civic and political activism in relation to the PEV truth, justice and reconciliation process that occurred in the previous wave carried through into wave four. This activism included CSOs protesting Kenyatta and Ruto's election candidatures "arguing that they did not meet the standards of leadership and integrity established in the constitution" (USAID, 2014, pp. 63). CSOs were also active in civic education, monitoring and follow-up of both the 2013 and 2017 elections. Following the 2013 elections not only did the losing party file a petition with the Supreme Court disputing its legitimacy but so to did two CSOs, the Africa Centre for Open Governance (AfriCOG) and the Kenya Asia Forum, petition the Court with a claim that the elections did not meet Constitutional requirements (Long et al., 2013, pp. $151 \&$ 153; Wanyeki, 2015, p. 18).

Prior to and throughout the process of the 2017 election, a handful of CSOs and their coalitions were engaged in investigations tracking and contesting the results. For example, the IEBC initially declared a 46 percent voter turnout in the October 2017 election, whereas the CSO count, specifically that of the coalition Kura Yangu, Sauti Yangu (meaning 'My Vote, My Voice'), came to 38 percent as finally officially declared by the IEBC (Moore, 2017a, paras. $9 \& 13$ ). CSOs had also questioned the IEBC's preparedness for the election, and raised concern about the senior IEBC official's torture and murder, (Rajab \& Awich, 2017, paras. 17 \& 18).

In the wave four political environment, $\mathrm{CSO}$ civic and political activism in relation to the ICC, the elections, and in other arenas, fuelled a GoK perception that the sector was "collaborating with the opposition party, thereby reinforcing the notion that CSOs are opposed to the government" (USAID, 2014, p. 63). 


\section{Mismanagement or Misconduct in the Sector: Strong negative perceptions, rent seeking in abeyance?}

Issues related to CSO mismanagement and misconduct continued to plague the sector in the fourth wave, though deciphering between perception and reality was not easy in an environment dominated by the GoK's anti-CSO rhetoric. CSOs continued to be swayed in their strategies and priorities by the DAC/G funding upon which the sector remained dependent. With a more precarious environment for CSOs overall, coupled with the perception that CSOs were no longer a preferred source of income relative to other pursuits, the sector's attraction as a source for potential rent seeking seemed to diminish in this wave.

According to the NGO Co-ordination Board's 2013/14 sector report, a shockingly low 2,846 of the NGOs deemed by the Board as active, i.e. only 39 percent, submitted annual returns as required under the NGOs Co-ordination Act (NGOCB, 2015, p. 15). This figure was highly suspect, even as non-submission of returns was a regular occurrence especially when CSOs lacked funding and had ceased operations (USAID, 2014, p. 65). The estimate that close to 4,500 registered NGOs did not submit returns was incomparable to the 2010 figure of 1,250 non-return submitting NGOs, or to the Board's reported figures of 450 in 2013 and 510 in December 2014 (USAID, 2014, p. 65; Jamah, 2014, para. 16). It suggested a Board exaggeration to justify the regulatory overreach that it exercised in this wave. Other concerns raised in the report included in relation to NGOs' "over-reliance.... on donor funding from Western countries"; weak NGO board governance; and insufficient coordination with the GoK (NGOCB, 2015, p. 15). A lack of collaboration with the GoK and coordination within the sector was an ongoing concern 
given the both for potential duplication of effort and for gaps in coverage, with GoK Ministries and Departments expressing that they were often not aware of what CSOs were doing and where (I14_GoK; I40_Elected; I46_GoK).

Kenya... has a very vibrant civil society... a big variety of organizations working on a number of things and with relatively good capacities. But that also means that to a certain extent, maybe you end up with the.... problem where there's maybe too many organizations and everyone wants to start their own organization. Maybe there needs to be more coalition building around particular sectors or.... priorities. (I3_DAC/G)

That negative perceptions of CSOs were commonly voiced by interviewees, including from within the sector, indicates that CSOs had considerable work to do in this wave to get their houses in order and to demonstrate as much. According to one interviewee, "CSO accountability varies greatly. A few national human rights ones are very much so [accountable] because they know they are under observation..... [but] there's a lot of dirt in the sector" (I56_Other). CSOs were seen to "answer to themselves only" (I40_Elected), whereas "NGOs should be accountable too, especially as they do more and more oversight work" (I33_Elected). When it came to meeting regulatory requirements, "many comply, but some don't" (I59_DAC/G). Recurring themes included perceptions of corruption and mismanagement in the sector, or that CSOs' motives were not the altruistic ones society expects: "Not all CSOs are there for good reasons" (I29_CSO). CSOs were sometimes seen as "just looking for money" (I2_CSO), and were themselves seen as "cash cows" (I52_CSO). Still, the actual incidence of mismanagement or fraudulent behaviour is difficult to gauge amidst such perceptions, as corruption may be assumed "just because someone is driving a new car" (I51_Other), or because CSO staff were "well remunerated" (I40_Elected). 
Further, the sector was criticized for lacking clarity of purpose and conviction about their work: "Sometimes civil society is not clear on their agenda" (I26_Elected). As a result, CSOs, in their pursuit of $\mathrm{DAC} / \mathrm{G}$ funding, were seen to be readily swayed by DAC/G agendas: "Donors dictate the help they give [to CSOs] whereas it may not be a priority area for the community" (I17_Other; I40_Elected). They continued to be easily influenced by $\mathrm{DAC} / \mathrm{G}$ geographic and thematic priorities more so than community priorities (USAID, 2014, p. xv). This reflected the perpetual dependence of the sector on $\mathrm{DAC} / \mathrm{G}$ and other non-domestic financial flows. According to the NGOs Co-ordination Board (2015) a total of 81 percent of NGO funding came from external sources in 2013/14 (p. 12). These organization's main sources of funds were: 34 percent from "foreign government agencies", 29 percent from "affiliates of NGOs"; 16 percent from "international NGOs/foundations/trust", and another 7 percent from UN agencies (NGOCB, 2015, pp. 10-11).

Notable in this period however were changing perceptions of CSOs as a potential source of riches. In previous waves, this view had contributed to entry into the sector of CSOs more interested in donor rents than public benefit, whereas in wave four: "old perceptions of NGOs being money minters are receding in public consciousness" (Mohammed, 2015, para. 11). This change in perception may have had less to do with any particular improvements in CSOs' governance and management, and more to do with the influence of other actors. A levelling off of DAC/G financial flows available to a growing sector in this wave and thus the reduction in rent-seeking opportunities via CSOs was one element. So too was the weight of a punitive regulatory environment for the 
sector counterbalancing the appeal of establishing a CSO, combined with the appeal of the relatively more lucrative public sector rife with rent-seeking opportunities. Public sector, not CSO sector employment, "particularly in procurement and finance" were increasingly seen as "the sure ticket to quick riches" (Mohammed, 2015, para. 11).

Still, the sector was also affected by the formation of CSOs by politicians or their close affiliates, blurring the line between CSO small-p and large-P partisan political engagement. Politicians or aspiring politicians were seen to register NGOs and use them to channel money for political purposes (I62_GoK). According to one interviewee: "People use the sector to popularize themselves, for political and self-actualization" (I52_CSO). Perceptions of CSOs' neutrality were not helped when CSOs with such political affiliations were hit by scandal, as occurred in this wave. The Evans Kidero Foundation, purportedly a separate entity from Mr. Kidero himself who was then Nairobi Governor, was under investigation in this wave for not having submitted annual returns and for an alleged amount of funds in its account that well surpassed its annual budget (Kamau, 2016, paras. 1-2).

All told, the CSO sector in Kenya in this wave was suffering from a variety of challenges in CSOs' management and conduct, even as the Board tended to exaggerate these challenges to justify its actions.

\section{Sector Infrastructure and Status of Self-regulation: Confusion and self-perpetuation versus self-regulation}

The NGO Council(s) continued on its beleaguered path through wave four. CSOs continued to organize to address both state and self-regulation, though these organizing 
efforts did not did not serve to fulfill the role that the Council had played through the 1990s.

As this wave progressed the woes that hit the Council in wave two were not resolved. There were numerous indications of this, including when at a global CSO conference in Johannesburg in 2014, a Kenyan CSO representative was approached by two different individuals, each with a different NGO Council business card, each claiming to represent the Council (I5_CSO). By late 2016 there apparently remained “many Councils”, making it difficult to distinguish if any could be considered as having the capacity or legitimately to represent the sector (I50_CSO).

Early in 2014 the Chair of one Council was placed under internal investigation followed by suspension due to allegations of mismanagement and corruption (Koech, 2014, para. 1). A replacement Chair was subsequently elected, with GoK involvement in the vetting in a process that formalized this particular Council as the official Council operating under the NGOs Co-ordination Act (Makabila, 2014, para. 18). Under the new Chair, perceptions in the wider CSO sector were that this Council was "dancing the tune of Government" (I37_CSO). The Council certainly seemed to be onside with the new GoK with its new Chair's foreboding public statement advising NGOs that they "must co-operate with the government of the day" rather than "undermining the state", and that the Council would "co-operate with the government to weed out suspect NGOs" (Makabila, 2014, paras. 4, 1 \& 10). Thereafter, the Council spoke out publically against the first round of proposed amendments to the PBO Act in May 2014, specifically opposing the proposed 15 percent cap on foreign funding to CSOs (Matara \& Mwajefa, 
2014, para. 1). Yet, later in the same year, the Council collaborated with the GoK to develop a (leaked) memorandum detailing some 54 amendments to the Act (CSORG, 2014b, p. 1), while it was also assigned to participate in the GoK-initiated PBO Act Taskforce launched in 2015.

There was a perception that this Council's collaborative efforts with the GoK on PBO Act amendments were aimed at achieving its main interest of "self-perpetuation" (I13_CSO). For on the whole though the Council came off in this wave as "in disarray", demonstrated by a series of back-and-forth court petitions (I13_CSO). For example, mid2014 a lawsuit seeking injunction orders was filed by the Council against its new Chair and its Chief Operating Officer (National Council of Non-Governmental Organisations v Wilson Kipkazi \& another, 2014 [2017]), both of whom were later suspended (along with others considering themselves as representing the NGO Council), and ordered by the High Court to cease representing the Council (Peter Ntoyian Ole Mesei \& 11 others $v$ Non Governmental Organizations Council, Civil Appeal No. 31 of 2016, 2016). As they then continued to operate as Council representatives, in March 2016 the High Court reissued orders requiring that those suspended cease "carrying out the business of the Council until matters pending before the Court are heard and determined" (Cabinet Secretary Ministry of Devolution and Planning, 2016, para. 4). Come March 2017, the original 2014 lawsuit was dismissed by the High Court due to delays and "want of prosecution" (National Council of Non-Governmental Organisations v Wilson Kipkazi \& another, 2014 [2017], s. 7). 
With the exception of individuals directly involved with the Council, both participants in and observers of the CSO sector saw the NGO Council as "as good as dead" (I35_GoK). The sector's minimal engagement with the Council diminished over time such that by mid-2015 the Council's membership was limited to "a few hundred" NGOs (I17_CSO) rather than the over 8,500 referred to on the Council's website, a figure that represented an out-dated tally of NGOs registered with the Board. ${ }^{127}$ It remained very "under-resourced", reliant on "well wishers" for resources in cash or kind and minimal membership fees given that CSOs had for over ten years not paid fees as they saw in the Council "neither vision, services or a leadership that represents the sector" (I13_CSO; I17_CSO; CSORG, 2014b, p. 4). The DAC/Gs were largely disinterested in funding a Council troubled by serious legitimacy issues. One DAC/G that had since 2007/08 been unsuccessfully pursuing the Council for alleged funds misappropriation opted in 2016, after close to ten years of follow-up, to forfeit the funds and close the file (I60_DAC/G).

Meanwhile, the CSORG, though never intending to replace the Council, provided an organizing infrastructure for a segment of the sector specifically focused or otherwise interested in CSO regulation. In wave four it remained an unregistered open platform of a core group of approximately 45 international and national CSOs and coalitions and upwards of 200 affiliate CSOs (I12_CSO). Cognizant of the growing sensitivity around foreign funding flows to CSOs under the wave four GoK, the CSORG was "selective in who they get funding from" (I12_CSO), while minimizing exposure of their funding

${ }^{127}$ At some point in 2017 the NGO Council's website ceased to exist. 
sources in an effort to protect both their own sense and perceptions of their being locallydriven, if foreign funded (I6_CSO).

Meanwhile, through this wave Viwango did not prove itself as the substitute for selfregulation under the NGO Council as had been envisioned with its creation. Viwango continued to exist, but with limited uptake from the CSO sector of its accreditation offerings. This was in part attributable to capacity challenges inherent in the Viwango mechanism. For while it continued to receive funding from DAC/Gs (including via intermediary CSOs), its reliance on peer review certification and monitoring, while cost saving, limited the availability of volunteer peer reviewers (I20_CSO). According to the USAID CSO Sustainability Index assessment of Kenya for 2015, "CSOs have yet fully to embrace self-regulation, and they are not committed to adopting codes of ethics to demonstrate transparency in their operations" $(2016$, p. 102). Exacerbating this may have been that in the wave four environment in which CSOs felt there was a "witch-hunt" against them (Rajab \& Awich, 2017, para. 4), they feared that the costs of exposure were too high. Viwango's wave four experience was that CSOs "may be enthusiastic at first but then back off" as they "fear exposure" (I20_CSO).

On the whole, since the Council's demise in wave two, the CSO sector continued to "lack [a] unified forum" (I53_GoK) with broad reach and scope, while the Viwango selfregulation scheme lacked adherents.

\section{DAC/Gs' Funding and Policy Engagement: Funding flows levelling off, $D A C / G$ influence waning amidst competing priorities}

In this wave, following an increase in DAC/G funding to Kenya from 2012 to 2013, Kenya began to experience reductions in $\mathrm{DAC} / \mathrm{G}$ funding flows and a levelling off of 
flows to CSOs. Even while DAC/G priorities continued to influence CSO programming, DAC/Gs appeared to be shying away from their close and supportive relationship with CSOs due to various inter-related considerations including concern with CSOs' domestic accountability, an altered landscape of $\mathrm{DAC} / \mathrm{G}$ influence, and competing $\mathrm{DAC} / \mathrm{G}$ priorities.

Early in the 2013 year DAC/Gs' suspended or slowed funding to Kenya purportedly as they sought to reconfigure their funding profiles to align with the process of devolution that began to be operationalized in 2013 with the first post-Constitution election of county governors, along with other legislative reforms kicking in in follow-up to constitutional commitments (USAID, 2014, p. 65). These were not the only DAC/G considerations however, as the "election-related hiatus in funding" (USAID, 2014, p. 65) was attributable also to DAC/Gs taking time to figure out how to deal with a situation in which the 2013 election candidates that DAC/Gs, and CSOs, had opposed based on their ICC indictments were now in power (I30_GoK). While some major aid flows intended for the GoK remained suspended or their implementation delayed (I3_DAC/G), eventually in 2013 DAC/G funding flowed to Kenya such that DAC/G disbursements levels surpassed the previous year, though thereafter reduced year-by-year amounting to approximately a 28 percent decrease between 2013 and 2016 (see Table B1 in Appendix B).

According to the NGOs Co-ordination Board, flows to NGOs increased between 2012 and 2014 (USAID, 2014, p. 65; NGOCB, 2015, p. 10). This only partially coincided with OECD data, according to which DAC/G funding for CSOs increased between 2012 and 
2013, then reduced in 2014, more-or-less levelling off up to 2016 (see Table C2 in Appendix C).

Certainly over this wave the level of $\mathrm{DAC} / \mathrm{G}$ flows was perceived as having diminished from previous waves:

Donor funding is shrinking.... so... NGOs are suffering. (I59_DAC/G)

Ten years ago the civil society had a lot of money. It was easier to access resources. But now access to resources has become difficult. (I54_CSO)

Funding for NGOs is decreasing. The sector has been growing but donor money not increasing concomitantly, so CSOs feel a squeeze. (I56_Other)

The perception of reduced DAC/G funding was attributed by USAID, at the beginning of this wave, as having been due to growth in number of CSOs not being matched by funding growth (USAID, 2014, p. 65), though as noted, CSO sector growth appeared to begin to level off as this wave progressed. It is true though that after 2013, DAC/G funding levels for CSOs did not grow as they had previously. Between 2010 and $2013 \mathrm{DAC} / \mathrm{G}$ disbursements to the sector increased by approximately 63 percent, whereas between 2013 and 2016 disbursements decreased by approximately 19 percent (based on Table C2, Appendix C). As DAC/G funding for Kenya decreased however CSOs' share remained high at approximately 27 percent of Kenya's ODA in 2013 and almost 29 percent in 2016 (see Table C2 in Appendix C).

As noted, DAC/G funding priorities continued to steer CSOs' work, with CSOs' strategic plans sometimes "shaped by donor expectations" and CSOs funded "for projects they are not adequately prepared to implement" (USAID, 2016, pp. 98 \& 99). While more flexible institutional support that enables CSOs to pursue self-defined priorities was 
never the dominant $\mathrm{DAC} / \mathrm{G}$ mechanism in Kenya (or elsewhere), according to the USAID CSO Sustainability Index for 2016, DAC/Gs virtually ceased providing such support to CSOs (2017, p. 106). Data from the OECD for this wave continued to show the highest proportion of $\mathrm{DAC} / \mathrm{G} \mathrm{CSO}$ flows going 'through', versus 'to' CSOs, at between approximately 94 and 93 percent in 2013 and 2016 respectively (see Table C2 in Appendix C).

Another aspect of the DAC/G-CSO funding relationship was increasing $\mathrm{DAC} / \mathrm{G}$ sensitivity both to the GoK's animosity toward the CSO sector and DAC/Gs' funding of it, and to the sector's management and governance challenges, as elaborated by a $\mathrm{DAC} / \mathrm{G}$ representative:

I think that was the clash that the Government has had with the donors is supporting CSOs with huge amounts of money. Some CSOs don't even have capacity to absorb that money. Let's call it what it is. Kenya was number 138 out of 168 in this year's Transparency International report on corruption. It would be folly, pure folly, for us to just think.... [that it's only in Government].... If you give me one billion shillings and.... I didn't bother.... even all the people I hired the basic pay, returns were not submitted for that team that I am with, let alone any audits, then I think we are out to then set up some extra incentive on this corruption refusing to go, some fertilizer. So it's only logical for us to want the CSOs that we are engaging with.... to abide fully with the law that has been stipulated. [Submit] your returns, have the audits done. If you're meant to, submit them at the AG's [Attorney General's]. If the Ethics and Anti-corruption Commission has a query, then they come in and ask for your reports, you should be ready... to respond to their questions. What we have seen is most CSOs then would be, "No, why are you doing this? You are harassing us"... but as the civil society.... they should be the ones showing the Government.... how this is done, so that by the time you [CSO] come to tell us that the Ministry stole this amount of money.... They [CSOs] are then able to.... say, "For us, this is how we do it." But what has happened, the Government has called out the CSOs on their issues and they cannot be able to defend themselves. (I59_DAC/G)

While such an overt articulation of these concerns was unusual, it did appear in this wave as though $\mathrm{DAC} / \mathrm{Gs}$ were becoming more cautious about their CSO funding decisions, and more willing to be swayed by GoK pressures on the subject. An example 
of how this was demonstrated was in the case of $\mathrm{DAC} / \mathrm{G}$ funding for $\mathrm{CSO}$ engagement in civic education for the August 2017 election. By December 2016 none of the DAC/Gs that had previously announced their intent to provide such support had launched that support, despite the pending elections (I54_CSO). CSOs suspected the reason was GoK influence:

Many of the donors have kept pushing the call-release dates.... They've kept shifting. I think there's a way that the Government is also trying to regulate when funds are released.... directly with the donors who are concerned.... there's increased control where the Government wants to really take the money, there are more regulations.... it's influencing [so donors release] late. So that whatever we [CSOs] do eventually is not effective. (I54_CSO)

As this wave progressed, DAC/Gs seemed to be more firmly on a path that affected their willingness to try to exercise their policy influence on the GoK when it came to issues of rights and democracy, including as related to CSOs and their regulation. As was already becoming evident in wave three, this path reflected evolving DAC/G interests and priorities, and a felt need on the part of DAC/Gs to stay on the GoK's 'good side', in part to protect DAC/Gs' diminishing influence.

The reasons for this were many. ${ }^{128}$ For one, because of DAC/Gs having so firmly taken sides in the lead up to the 2013 elections, they had to about-face with the Jubilee GoK win. Unprepared to stay out of the fray, the UK and other EU members had publically stated they would limit contact with a President and Deputy facing ICC charges, with the US in turn famously stating to the Kenyan electorate that "choices have consequences" (Jacinto, 2013, para. 33). None of this sat well with the Jubilee leadership

${ }^{128}$ These findings have previously been presented in Wood (2016). 
contenders, nor that matter for sections of the Kenyan public, which also had implications going forward: "it created a siege mentality... [and] resentment. If they [DAC/Gs] had not taken sides it [the 2013 election] might have played out differently" (I25_GoK). DAC/Gs then found themselves backed into a corner following the Jubilee GoK election win in 2013.

Second, the country's reliance on DAC/G financing, while fluctuating over time, had diminished considerably, also impacting DAC/G influence. By 2013 the DAC/G ODA to GNI ratio for Kenya had reached a relatively high 4.2 percent compared to the 2.3 percent of ten years earlier. By 2016 it had reduced to 2.2 percent (see Table B2 in Appendix B). Even while Kenya remained a leading recipient of $\mathrm{DAC} / \mathrm{G}$ funding to Africa (African Develoment Bank Group, OECD \& UNDP, 2016, pp. 65-67), Kenya's dependence on ODA was decreasing.

Third, with Kenya ranked as Africa's fifth largest economy and reaching the WB's lower-middle income status in 2014 (WB, 2014), the country was becoming not only less reliant on $\mathrm{DAC} / \mathrm{G}$ aid, but fertile ground for $\mathrm{DAC} / \mathrm{G}$ countries' pursuit of private sector development using aid funds or otherwise. Though not from DAC/G sources exclusively, foreign direct investment in Kenya doubled between 2013 and 2014 and was projected to keep growing (Masinde, 2015a, paras. 1 \& 7). The African Development Bank's 2015 Economic Outlook for Africa pointed to Kenya as a "favoured business hub" in investment areas of information and communication technology, manufacturing, transport, and oil and gas exploration (Masinde, 2015b, para. 7). Increasingly, the strength of DAC/Gs' voice on controversial issues of governance, rights and democracy 
was seen to quieten, trumped perhaps by interest in Kenya's economic growth and stability and in rebuilding then maintaining positive relationships with the GoK along with fertile ground for private sector investments. As articulated by interviewees:

They [DAC/Gs] have compromised.... because some of the donors.... [have] a lot of interests in Kenya in terms of other programs [they] support[s]. Apart from governance work they have also gone into mining. They have gone into.... infrastructure. (I54_CSO)

I think they [DAC/GS] are torn between having the ear of this administration and doing business with them, and reminding it [the GoK] of its duties including respect for human rights. (I8_Other)

This compromising of DAC/Gs' traditional position of influence was exacerbated by a newly competitive environment, in which new players, in particular China, held increasing sway. Kenya's relationship with China as an alternative financier blossomed in this wave, evident in the growing Chinese presence in many sectors of Kenya's economy, from telecommunications to infrastructure, the latter including the massive USD 4 billion Standard Gauge Railway project (York, 2015b, para. 13). Though Kenya's main “investors are Western capital, not China” (I16_DAC/G), China was nonetheless a much welcomed contributor to Kenya's economy, one that came without the pesky conditionalities and "moralizing" (I39_Other) that traditionally emanated from the DAC/G community. ${ }^{129}$ The GoK's quick use of a "turning to the East" veiled threat to DAC/Gs was, in the eyes of some merely "meant to hoodwink and cajole" Kenya's traditional DAC/G allies (Obala, 2014, p. 1; I39_Other). Whereas, according to others,

129 The official welcoming stance was not without controversy, with the ever-growing Chinese investment and modus operandi not embraced by Kenya's domestic business sector. For example, hackles were raised over the importation rather than local sourcing of tons of cement for the railway line (Malingha Doya, 2015). 
"the Chinese have won the first round in the battle for business as their 'ask-no-questions' and 'bribe-all-who-matter' model has stumped their Western competitors" (Menya, 2014, para. 33).

DAC/Gs' interest in Kenya's role in the war on terror seemed also to compromise DAC/Gs' willingness to attempt to wield policy influence in defense of the rights and democracy realm (Menya 2014, par. 32).

Governance issues, human rights issues. I think that civil society is the only voice that's really bringing these issues up to the surface. The donor community... hasn't been so explicit about these issues with Kenya. Obviously Kenya does have some elements like terrorism.... that concerns the broader international community, [and] that seems to dominate.... in the bilateral discussions and so on. (I18_CSO)

While none of these $\mathrm{DAC} / \mathrm{G}$ interests were new, they were elevating in priority in this wave. DAC/Gs' reaction to the 2017 election exemplified their position. Despite early indications of tampering, foreign election observers and $\mathrm{DAC} / \mathrm{G}$ diplomats were quick to endorse the August election results as free and fair and thus in favour of the incumbent (Epstein, 2017; Ratcliffe, 2017, para. 11), back-tracking only after Kenya's Supreme Court annulled the August election round. Epstein's (2017) comment on the possibility that the US "wants Kenyatta to stay in power at the expense of democracy" due to the counter-terror allegiance with Kenya and Kenyatta's strong anti-terror stance could be extended to other DAC/Gs with shared interests (paras. 12, $13 \& 15$ ). Commenting on DAC/Gs' stance in relation to the 2017 elections, one interviewee noted the effect of DAC/Gs' private sector interests:

They [DAC/Gs] are just after their own investment interests. When everything was revealed, they backtracked. It's about FDI [foreign direct investment]. If the system fails, their companies' interests will be affected. (I62_GoK) 
Finally, when it came specifically to DAC/Gs' engagement with the GoK on the subject of CSO regulation, there was a real possibility of "PBO Act fatigue" given donors' growing sense that their words were falling on deaf ears (I24_DAC/G). Some DAC/Gs it seems were "displaying a cynicism" in relation to this and other rights and democracy related challenges in Kenya (I57_CSO).

All told, while DAC/Gs' financial flows and policy engagement remained a direct and indirect driving factor in Kenya's fourth wave, the strength and nature of the influence was changing.

Status of State Regulation: Perpetuation of multiple regulatory entry points for CSOs and NGOs Co-ordination Act implementation with rent seeking

Regulatory gaps that existed in the previous waves continued. These included the existence of multiple regulatory options for the CSO sector, and a lack of capacity and coordination across GoK regulators. A degree of regulator interest in maintenance of the status quo of a non-harmonized regulatory framework for the sector became evident.

The CSORG estimated that up to 350,000 CSOs that could be considered as operating in the public benefit were registered under the various regulatory regimes available in 2014 (CSORG, 2014b, p. 1), inclusive of over 300,000 community based organizations registered at decentralized levels of government (USAID, 2014, p. 61). As from wave one, figures on the number of organizations registered under these different regimes that were public benefit types of CSOs were not available. An interviewee working with or researching the sector for some time noted that gathering disaggregated figures is: 
.... very difficult.... because.... they hardly keep the disaggregated records to show you which of those groups are civil society, for example under the societies or the trusts, because in there you find a range of organizations, some which are public benefit, and others which are mutual benefit. I think the regulators really have not-basically.... the systems that exist do not make coming up with those figures very easy. (I61_Other)

Understanding the full sector landscape, and even coordinating CSOs, as was the GoK's purported original aim of the NGOs Co-ordination Act, continued to be a challenge due to the existence of multiple regulation options. However, this challenge also continued to be one of capacity, a gap that the Board itself acknowledged in its 2009 survey report and was reinforced by an interviewee:

The problem hasn't really been that there are many organizations.... registered outside the NGO Act. Even those who are registered within the NGO Act, the regulator keeps saying that they have not been able to effectively regulate them. So it's probably an issue of the capacity of the regulator. (I61_Other)

As an example of the Board's capacity challenges, apparently up to 2017 it continued to lack a fully computerized system to manage information on its NGO registrants, and thus no electronic database to help track their annual financial reports (I62_GoK). The Board's capacity to implement the Act was increased with a staff contingent up from the approximately 50 of 2009 to 63 in 2015 (I9_GoK), though financial and technical capacity remained an issue (Ochido, 2013, p. 70), and the staffing figure was a moving target with staff taking leave or being forced out in a hostile Board environment (I53_GoK).

Further, addressing the challenges posed by multiple regulatory regimes for the sector, whether under the NGOs Co-ordination Act or in the transition to the new PBO Act, would have required dedicated capacity to coordinate, not only on the part of the Board but other regulatory bodies as well. In the words of one interviewee, the existence 
of multiple regimes "does not mean the different regulators cannot work together to ensure those registered under them are accountable. Coordination is an issue of the capacity of the regulators" (I61_Other). Regulators other than the Board also confirmed that they faced capacity challenges, including insufficient human resources to monitor organizations once they are registered, and inadequate data management (I41_GoK).

Noteworthy also was that the regulators of trusts, societies, and companies limited by guarantee were not necessarily on board with the aim of the PBO Act to entice (or, under proposed amendments, require) all public benefit CSOs to be registered under it. Ministries responsible for these regulations - specifically the Attorney General's office and the Ministry of Lands - "don't expect to see migration" of their registrants to the PBO Act (I42_GoK). In a sense, the Act was seen as unwelcome "competition" in their regulatory domains, domains designed to meet specific needs of specific organization types that the PBO Act would not meet, such that "if you delete the [Trustees (Perpetual Succession)] Act you leave a gap" (I41_GoK). Equally, CSOs registered under these different regimes for their part had no strong individual organizational motivation to migrate from regulation that had served them adequately well "based on their objectives and nature of operations" (CSORG 2015b, p. 12). Among these CSOs were those that would have opted to skip the tax privileges and other benefits accorded to registered PBOs, preferring their chosen regulatory option and electing whether or not to seek taxexempt status.

Issues of Board vested interests not obvious (though not necessarily absent) in previous waves that contributed to Board interest in maintaining the status quo of the 
NGOs Co-ordination Act also became evident. On one hand, according to some interviewees Board staff was apparently concerned with their job security if with enactment of the PBO Act and the associated establishment of a PBO Authority Board staff would lose their jobs - though the Act articulated that Board staff would continue in their positions under the new PBO Authority (sched. 5, ss. 6(3) \& (8)). Some of the early PBO Act amendment proposals were focused on transitional provisions to secure Board staff positions under a new Authority because "the Board, as far as they understand it, the Board ceases to exist and has to be re-constituted", thus "the transitional provisions are the key, because they think that the PBO Act is going to put them out of business" (I50_CSO; I57_CSO).

Not only jobs, but rent-seeking opportunities apparently available for the NGOs Coordination Board also worked in favour of the status quo. It was rumoured that the Board's Executive Director (ED) working with close Board associates found ways to use their positions to extort financial gains from the CSOs the Board was meant to regulate (I53_GoK; I50_CSO).

The story that's been passed on to me is he's [a Board staff] now developed a racket whereby he, on behalf of [the ED], is raising all of these compliance issues with different $N G O s$. He's saying either new $N G O s$ or existing ones... they're non-compliant for $X, Y$, or $Z$ reasons. But then he.... as a private attorney, he set up a consultancy service whereby, for a fee, he will help you get your documents in order. (I50_CSO)

The Board's capacity challenges over this wave reflected the inefficiencies of a highly centralized management style exacerbated by this type of rent seeking. 
The regulation work that [the Board] undertake[s], at the moment, is not very efficient because of the management of the organization. [The Board] ha[s] a director who has not made the work environment as good as it should be. The people [the Board] serve[s], and mainly the NGOs, are feeling very frustrated from the... nature and quality of [Board] services.... One key area is the recommendation of work permits. [The Board] make[s] recommendations to [the] Immigration department about.... those seeking work permits for.... the expats. So [the Board] make[s] recommendations that this is justified by.... the level of expatriate staff they have, that kind of thing. But at the moment, there is no objectivity. You'll find that even an organization that has more than one hundred Kenyans, and only one expatriate, they're not getting that recommendation.... some of them, they are being forced to pay money, to bribe their way to get that kind of recommendation. (I51_GoK)

Political vested interests also became more evident in this wave as the Board was clearly not operating independently of the GoK's political leaders. Obstructionism in implementing the PBO Act including disregard for High Court rulings calling for its implementation, as well as regulatory overreach in implementing the NGOs Coordination Act, pointed to a Board, or at least a Board ED, "operating at the behest of the highlight level" of the GoK (I61_Other). As this wave progressed and the Board's transgressions ramped up, it became clear that "there is no way they [the Board] could be so bold unless they had the backing of the highest offices. There is no way any other official or institution could operate like this" (I61_Other). This politicization of CSO regulation is discussed in depth below both under the Political Agendas and the later Negotiation and Implementation sections.

\section{Political Agendas: Grudges and baggage fuel GoK backlash}

This wave saw the rise of a fervent anti-CSO stance on the part of the GoK. This stance formed part of a clear political agenda, not only to silence but seemingly to punish the CSO sector, and its $\mathrm{DAC} / \mathrm{G}$ supporters, for their roles in relation to the ICC cases. More generally, the GoK's political motivation to stymy CSOs' pursuit of accountability 
from the GoK fuelled the anti-CSO backlash. Ethnicity also came into play in as much political motivations in Kenya are underpinned by ethnic considerations.

As seen, the third wave had witnessed an increasingly cooperative and consultative relationship between the GoK and CSOs, building on the 2006 Sessional Paper No. I's explicit acknowledgement of CSOs varied roles and the rights that underpin them; CSOs' critical role in the PEV follow-up toward truth, justice and reconciliation; and in the constitutional and related reform processes. The type of political motivation to quell the CSO sector seen earlier was on the wane such that, "the natural progression would have been ongoing and increased collaboration" between the GoK and CSOs (I5_CSO).

That progression faltered badly under the new Jubilee GoK however, as noted by an interviewee: "with the [2013] coming of the Jubilee government.... we've seen that we've lost a lot of ground in terms of goodwill" (I29_CSO). On paper, the pre-2013 election Jubilee Coalition Manifesto had positive things to say about the sector. Under the Manifesto's third pillar, Uwazi (meaning 'openness'), a Jubilee GoK would seize the opportunity of the "valuable role [NGOs have] to play in monitoring Government and helping to strengthen the social infrastructure in our country" (Jubilee Coalition, 2013, p. 65). ${ }^{130}$ According to the Manifesto, "the influence of civil society has expanded over the years to the point where the various Civil Society groups play an important role in the country's political and economic development" (Jubilee Coalition, 2013, p. 65). From early on in this wave however, the new GoK, authoritarian-leaning and suffering from a

130 The Uwazi pillar also included commitments to combat corruption and fully implement devolution as per the 2010 Constitution. 
legitimacy crisis dating from even before their election win given the ICC cases, consistently demonstrated, through regulation and otherwise, a politically-driven animosity toward the sector. In words and actions the GoK made its discomfort with CSOs clear.

As raised in wave three, the new GoK came into power in 2013 ill at ease with the sector, especially with its civic and political engagement role and more specifically with its role in relation to PEV follow-up and the ICC. The new GoK also came to power perturbed with $\mathrm{DAC} / \mathrm{Gs}$ given the latter's pre-election stance regarding Kenyatta and Ruto's candidatures. As soon as the reality of the ICC cases hit home, beginning in the previous wave these candidates lost few opportunities to blame the CSO sector, along with DAC/Gs, for their predicament. Lashing out in 2011 for example, Ruto declared that: "NGOs should stop interfering with government matters, writing letters to their donors abroad to support the ICC intervention and compiling reports about post-election violence. It is none of their business" (HRW, 2013, para. 20). The Jubilee election campaigning included accusations against $\mathrm{DAC} / \mathrm{G}$ governments, their political opponents, and CSOs of using the ICC cases to prevent them from running (HRW, 2013, para. 11).

It was widely believed, across all stakeholder groups in Kenya interviewed for this research, including from within the GoK, that the GoK leadership's backlash against CSOs, regulatory and otherwise, was largely politically-motivated and driven by the ICC cases: "The ICC cases have warped the entire [GoK-CSO] relationship... the President and Deputy President have taken this personally" (I3_DAC/G). The role that CSOs, and 
DAC/Gs, were seen to have played in bringing the ICC cases to fruition, and then in challenging the legitimacy of Kenyatta and Ruto's candidatures, raised the ire of these GoK leaders. According to CIVICUS, "Sensitivities about these [ICC] proceedings being brought against the people in power would seem to be one driver of the government's increasingly negative attitudes towards civil society and the media" (CIVICUS, 2015b, p. 219). Indeed, in Kenya the sentiment was widespread that "without the ICC things would be different in Kenya today" (I7_CSO), and that "there is a general distrust on the part of Government that is independent of reality" (I2_CSO).

The political backlash against the CSO sector was evident in a propaganda campaign, an "effective narrative" of negativity against CSOs mounted by the GoK inclusive of a public discrediting of individual civil society activists (I3_DAC/G). The term "evil society" was coined to substitute for "civil society" (I3_DAC/G; I5_CSO). In one example, the President's director of digital media blogged a list of civil society, and opposition leaders' names, describing these individuals as belonging to the "evil society" supporting the ICC process (HRW, 2013, para. 8). References were also made to CSOs as foreign agents speaking the voice of their "foreign masters", which critics saw as one means by which the GoK sought to "stigmatize dissent" (CIVICUS, 2015a, p. 1; I38_GoK; I11_Other). Barely veiled criticism of CSOs and their DAC/G supporters was heard in a 2014 Presidential speech in which "those abroad" that "fund and nurture various outfits", were accused of putting Kenya's destiny "in the hands of unelected, unaccountable institutions that answer to elsewhere" (President of Kenya [PoK], 2014, para. 25). Critics suggested that the speech "was reminiscent of former President Moi's 
numerous attacks on nonprofits and civil society" that were one component of his "suffocating" "crackdown on dissenting voices", and that if the GoK made good on the President's threats "Kenya will have regressed 20 years overnight" (Kaberia, 2014, paras. 3- $4 \& 6)$.

It is worth noting that Kenyan citizens are not so concerned with the origins of CSOs' funding: "Government will express foreign funding concerns, but not the people" (I33_Elected; I32_CSO; I35_Elected; I40_Elected; I41_GoK). An exception was seen with the LGBTQ+ cause that, in highly conservative and devout Kenyan society, was an issue area in which CSOs were said to "propagate foreign ideas" (I32_CSO; I28a_GoK; I10_DAC/G; Laing, 2015). This perspective was evident when, following a 2015 High Court ruling in favour of an LGBTQ + CSO denied registration by the Board, according to one interviewee, an MP accused the High Court of being funded by foreign sources (Gitari v NGOs Co-ordination Board and Attorney General, 2015; I28a_GoK). ${ }^{131}$ Notably also, the PBO Taskforce report released in 2017 categorized under "national security" that regarding "respect for cultural values", "gays and lesbians should be looked

${ }^{131}$ The CSO was denied registration on the grounds that it sought to protect the rights of gay and lesbian persons. Homosexuality is criminalized in Kenya's Penal Code of 1930 (ss. 162-165). And though the 2010 Constitution defends the rights of "vulnerable groups" including "minority or marginalized communities" (s. 21(3)), sexual orientation is not specified in the list of grounds for non-discrimination (s. 27(4)). The April 2015 High Court ruling should have an impact on future constitutional interpretations however given its conclusion that the Constitution protects the rights of all persons living in Kenya regardless of sexual orientation (Eric Gitari v NGOs Co-ordination Board \& 4 others, 2015, s. 148(i)). For example, in 2018 a court ruled against censorship of an acclaimed Kenyan movie with an LGBTQ+ theme following its banning by the Kenya Film Classification Board (York, 2018b). A court challenge to the penal code is ongoing (Eric Gitari v Attorney General \& another, 2016; Bearak \& Ombuor, 2018). 
into keenly as the same erode the African values system" (PBO Taskforce, 2015, p. 34).

In its recommendations the Taskforce called for the PBO Act to be amended "to prohibit registration of any public benefit organisation that is involved in promotion and advocacy of indecent acts", 'indecent acts' being code for homosexual acts (PBO Taskforce, 2015, p. 37).

The anti-CSO narrative of this wave also implicated the sector in terrorism. Shortly after the Garissa University terror attack in April 2015, two CSOs - Haki Africa and Muslims for Human Rights (MUHURI) - were included in a GoK gazette notice "List of Entities Suspected to be Associated with Al-Shabaab", requiring those on the list to demonstrate within twenty-four hours why they should not be so specified (The Kenya Gazette, Vol. CXVII - No. 36, 2015). ${ }^{132}$ The list, signed by the Inspector General of Police with reference to the Prevention of Terrorism Act of 2012, was comprised of 80 entities, inclusive of the likes of Al-Shabaab and Boko Haram, as well as many money transfer businesses and individuals. The bank accounts of all entities on the list were frozen.

The terror accusation was seen by many as a reprisal for these CSOs' civic and political activism. ${ }^{133}$ That Maina Kiai, "one of the most strongest government critics" was a MUHURI Board member, fuelled scepticism about the validity of the terror

${ }^{132}$ A third CSO was also included on this list. There was no apparent follow up from this organization that, according to its website, worked largely in the humanitarian arena with Somali populations in and outside of Kenya (http://apd.or.ke/).

${ }^{133}$ Notably the MUHURI offices had recently been broken into and "vital information" removed (KNCHR, 2015a, para. 7). 
accusation: "People saw a lot in that. They read other mischief in that" (I39_Other). Notably, Mr. Kiai was a long-time civil society and democracy activist who led the KNCHR in the early days of its evidence-gathering on the PEV.

According to a GoK interviewee, the terror affiliation was lobbed as Haki Africa apparently "stood surety to an Al-Shabaab suspect", that is, funded the bail of at least one individual imprisoned on suspicion of terrorism (I45_GoK), while MUHURI was accused of spreading extremism (Katana, 2015, para. 3). Haki Africa had raised awareness of human rights violations by Kenyan policy and security forces in the Coast region as had MUHURI (BBC News, 2015, para. 9; I36_CSO). According to MUHURI's ED "A lot of extra-judicial killings took place, and we were the ones criticizing the government, so they don't like it. Anyone who dissents is considered a 'radical.' It is criminalized" (York, 2015a, para. 19). Not having been given advance notice and an opportunity to defend themselves (KNCHR, 2015a, para. 7; FIDH: World Movement for Human Rights [FIDH], 2015, para. 6), these organizations filed a court case that ultimately found a violation of the "rights to fair administrative action" amounting to lack of evidence to declare them as terrorist organizations (though on a technicality the CSOs' bank accounts were not immediately unfrozen) (BBC News, 2015, para. 4; Muslims for Human Rights \& another $v$ Inspector General of Police \& 5 others, 2015, s. 197).

The GoK leadership's animosity toward the sector, and its DAC/G funders, continued throughout the wave, even after the ICC case proceedings were terminated in 2014 (Kenyatta) and 2016 (Ruto), compounded in the latter half of this wave by the 2017 elections. The anti-CSO narrative was seen clearly by some to have arisen "because the 
leadership is angry with the West", as well as with CSO sector that was largely Westernfunded; it appeared to be "payback time" for their stances in relation to the ICC and the 2013 elections (I38_GoK; I20_CSO). The ICC was a central driver behind the actions of Kenya's leadership to the point that "Government domestic development policy was being blindsided by the ICC process" (Houghton \& Muchai, 2014, para. 19). There was a deliberateness to the narrative, to undermine CSOs' credibility as well as that of the DAC/Gs that funded them. For example, representative of the "latest onslaught in President Uhuru Kenyatta's war on NGOs", especially civic and politically engaged ones, the President's 2016 Jamhuri (Independence Day) speech called out “money coming into Kenya from abroad in the guise of supporting good goverance or civic education", the "true intention" of which is to "influence our electoral choices" (Rajab \& Awich, 2017, paras. 5 \& 29; PoK, 2016, para. 9). The speech urged Kenyans "to reject such interference", as "no one should ever try and control our choices for their selfish interests" (PoK, 2016, para. 9).

While the ICC was a principle political driver for the GoK of this wave, there was also a strong sense that the GoK was averse to CSO civic and political activism more generally. In a 2015 speech the then Cabinet Secretary for the Ministry of Devolution and Planning (then responsible for the NGOs Co-ordination Board) suggested that given Kenya's democratic progress, CSOs' civic and political activism role in pushing for democratic reform and rights was no longer necessary. For the past 20 years, the speech stated, civil society "preoccupied itself with the push for civil and political rights and the expansion of political space in Kenya", and was now needing to "adopt a more diverse 
agenda, one that is reflective of the new realities we live under" (Onyando, 2015, para. 8). This kind of public statement backs an interviewee's sentiment that: "NGOs they have problems, serious problems.... Because.... they try to check the Government..... The Government is never comfortable with that.... That's why you find sometimes their [CSOs'] accounts are frozen" (I41_GoK). Of CSOs the statement was heard that "Kota futa makosa" - they, CSOs, are witch hunting (I32_CSO; I46_GoK). As a result, the PBO Act amendments were seen to be "symptomatic of a growing obsession to control institutions that contribute to checking excesses of the state" (Houghton \& Muchai, 2014, para. 19). ${ }^{134}$ More generally, the GoK backlash against CSOs was seen as aversion to the new constitutional space accorded to citizen participation and the CSO sector (I32_CSO). According to one interviewee, this aversion combined with a GoK interest in stemming CSO funding, whether in the hopes of accessing that funding, or simply to quiet the sector.

The Government.... doesn't like what the civil society does.... Monitoring what the Government is doing. Talking about things that are going wrong. Mobilizing the masses to talk about it and to say, "No, we really want change here." Getting people to participate.... And that is why they try to stop it. Because the civil society will ensure there is accountability. They do not want to have accountability. [And] they want to take all the money there is for them to take. So that has actually been a motivation to make sure the Bill [PBO Act] doesn't pass, [that] the civil society is denied, even in terms of the funding we get. (I54_CSO)

${ }^{134}$ As discussed in the Political Environment section, such institutions were not limited to CSOs. For example, a Public Audit Bill was introduced in 2015 that would have strengthened the check and balance role of the Auditor General's office. After receiving Parliamentary approval, the President refused to assent the Public Audit Act, demanding considerable amendments that would purportedly weaken it substantially (I43_Other). The modified Act was eventually assented into law late in 2015. 
The deliberateness of the Jubilee GoK's political agenda against the CSO sector was evident in its approach to and use of the NGOs Co-ordination Board since coming into power. The sitting ED of the NGOs Co-ordination Board resigned seven months into the new GoK's tenure as he apparently "felt the Government would be better to articulate their views through different leadership" (I47_CSO), or in other words, he was unwilling to succumb to "pressure from Government on the foreign agents argument" (I30_GoK). The subsequent ED on the other hand rose to the occasion, evident from the the manner and tone with which he implemented the NGOs Co-ordination Act as is discussed in further detail in the Implementation section below. The ED, rumoured to be an agent of Kenya's secret service (I50_CSO; I57_CSO; I53_GoK), was able to implement the NGOs Co-ordination Act with an iron fist, while maligning and threatening the CSO sector at every turn. The NGO Co-ordination Board's actions under this ED, including numerous registration suspensions, seemed designed not only to penalize the CSOs specifically targeted, but also to "foster a climate of insecurity and fear among CSOs", and among their DAC/G funders (CIVICUS, 2015b, p. 89).

Even when the Board's actions clearly demonstrated regulatory overreach, the ED survived and thrived with impunity, both, it would appear, despite and because of his "overzealous" approach to regulation (I53_GoK). ${ }^{135}$ There were, apparently, "a few people protecting him", people to whom the ED also sought to demonstrate his effectiveness by cracking down on CSOs; "he believes that he has to be more effective by

${ }^{135}$ The ED eventually resigned from his post in February 2018, effective April 1, 2018 (Obura, 2018, para. 11). 
being very difficult on NGOs" (I53_GoK). Apparently a senior GoK official quietly encouraged CSOs to make efforts to 'out' the ED toward having him replaced, as the official felt that the hands of the Ministry responsible for the Board were tied given that the ED's real 'boss' was to be found elsewhere in the GoK (I50_CSO).

It's still an open question as to who is really calling the shots.... [But] what is particularly distressing is that Fazul [the Board ED] seems to operate by a different set of rules. (I50_CSO)

It needs also to be noted that ethnicity remained a strong undercurrent to so much of Kenya's political landscape, and certainly come election time, ethnic identities often overrode considerations of performance or integrity. That said, while ethnic mathematics continued to inform the formation of political oppositions and alliances, including the Kenyatta-Ruto alliance against the Odinga opposition, the animosity between the GoK and the CSO sector in this wave could not be said to have been based on a scenario of opposition based on different ethnic identities of the GoK and the CSO sector as was proposed by some observers in wave one. In wave four, "you can't say that the NGO sector is dominated by Luo, or Kikuyu, or Maasai.... the NGO sector is many different groups..... very diverse” (I54_CSO).

The animosity was ethnic-based however in as much as civic and politically active, reformist CSOs found themselves in opposition to the GoK, and thus de facto aligned with the political opposition dominated by ethnic groups not enjoying political power. Where the root of the animosity was CSO activism in relation to the PEV and ICC cases, ethnicity was an underlying layer, but still tied to the drive to maintain political power. Asked whether today an ethnic divide is coming into play as a factor dividing the GoK 
and CSOs, interviewees responded: "No, no, no, no, it's not like that" (I51_Other); "the backlash against civil society isn't ethnic. There is much diversity in the sector regarding leadership" (I56_Other). In fact, many of the CSOs and activists that irk the GoK are from President Kenyatta's ethnic group, as noted by interviewees these CSOs: "supported the ICC, and they continue to complain that these people ought not to have led the Government. And [yet] they belong.... to the President's ethnic group" (I51_Other), and "these are people who believe on justice, and that is what they've been advocating for consistently" (I25_DAC/G). For example, Maina Kiai, a Kikuyu and long-time civil society activist who led the KNCHR in the early days of its' evidence-gathering on the PEV, was at times referred to as a "traitor" to other Kikuyus (I3_DAC/G; I11_Other; I25_DAC/G).

The clear influence of political agendas on CSO regulation in this wave was further evidenced in the ways in which the NGOs Co-ordination Act was implemented, covered in further detail in the Implementation section below.

\section{Public Management Agendas: Not discernably present}

There was little in the way of public management agendas as a driver of the GoK's approach to CSO regulation in this wave. Only DAC/Gs' NPM-style methods of privatizing service provision through CSOs, as well as performance management requirements that emphasized the DAC/G-CSO accountability relationship can be said to have continued to have an indirect affect on CSO regulation in Kenya.

As regards the GoK's public management agendas, the main public management project in this wave was implementation of the 2010 Constitution's devolution 
commitment as noted. Amongst other aims, devolution was meant to improve public service delivery performance by bringing it closer to the clients, and involving them, directly and through CSOs, in both defining and monitoring service needs. In this way, devolution may also have indirectly contributed to the GoK's approach to CSO regulation in this wave in that the GoK was uneasy with the civic and political engagement role for CSOs' devolution demanded. Though this type of role and overall a more governanceoriented, collaborative approach between the GoK and CSOs was seen emerging in wave three, in this wave it fell by the wayside.

\section{Security and Terrorism Concerns: Bolstering the clampdown on CSOS}

Terrorism was a growing concern in Kenya in this wave and the GoK responded in a heavy-handed manner, with a "crackdown" on the terror threat launched in 2013 (Ebole \& Odhiambo, 2016, p. 8). As regards CSOs, the official GoK position increasingly associated the sector with Kenya's terror threat.

With 140 terrorist attacks of one shape or form taking place in the two-year period up to December 2014, the terror threat was a significant preoccupation for the Jubilee GoK (I4_DAC/G). Since Kenyan troops entered Somalia in 2011, Al-Shabaab had been on the offensive, escalating attacks including amongst others: the siege of Nairobi's Westgate Mall in September 2013; attacks on police and civilians in the Kenyan coastal town of Mpekatoni in 2014; and the April 2015 attack at Garissa University in which non-Muslim students were separated and shot point blank. Threats to Kenya's security also stemmed from the coastal independence faction led by the banned Mombasa Republican Council. Kenyan security and intelligence forces' anti-terror capacity was increased to handle 
these threats, with the financial and technical support of the US and UK in particular, who together with other DAC/Gs shared an interested in Kenyan success in combatting the terror threat.

However, commentators suggested that the Government's approach had been heavyhanded, with the KNCHR issuing in 2015 a damning report warning of the "error of fighting terror with terror" (KNCHR, 2015b). Indiscriminate deportation of resident Somalis; raids and temporary closure of Mosques and arrests of Imams; the use of "excessive force" and "the rhetoric of blanket condemnations" (York, 2015a, paras. 5 \& 10), were fomenting further tension with Arab and Muslim minorities. ${ }^{136}$ In this wave, the CSO sector was on the receiving end of such blanket condemnations, also fomenting tensions there: "the rise in terror-attacks on Kenya is witnessing the already love-hate government/civil society relationship worsen, with the government linking some of these entities" to terrorist activities (Katana, 2015, para. 1). This was evident in a December 2014 statement by the NGOs Co-ordination Board ED, made upon the registration

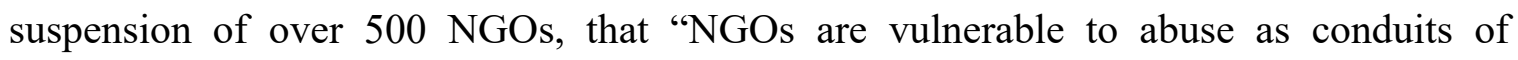
terrorism financing and money laundering" (Jamah, 2014, para. 1), as well as in regulatory actions against particular CSOs discussed in the Implementation section below. The GoK's justification for some PBO Act amendments included non-specified terror-related concerns (Houghton \& Muchai 2014, para. 19), with the terror threat used to "demonize and vilify" the CSO sector (I39_Other), whereas "whenever the Government has tried to use that [terrorism] as an excuse there is never any hard

${ }^{136}$ Deportation of Somalis dated back to the post-1998 US embassy bombing period. 
evidence" (I61_Other). In this wave, an anti-CSO narrative became part and parcel of official concerns over Kenya's terrorism threat.

It is conceivable that the imperative of complying with the FATF international standards on money laundering and terrorism financing were a motivating factor for the GoK. As noted in wave three, in 2011 the ESAAMLG assessed Kenya as inadequately addressing the potential use of CSOs for terror and money-laundering purposes. However, none of the interviewees for this research pointed to FATF/ESAAMLG compliance as an overt driver. ${ }^{137}$ It may well have been a behind-the-scenes consideration, but the degree to which FATF compliance was a concern was not obvious. Rather, the common thread was that the terror threat was being "used to try and more or less bolster the justification for making certain proposals that would encumber the sector" (I61_Other). If compliance with FATF were a driving factor, one would have expected to see a concerted approach to regulatory change rather than the mud-slinging and selective punitive measures implemented in this wave.

Further, the PBO Act itself, if implemented, was said to provide an appropriate regulatory complement to the regulatory framework designed to address the terror risk in Kenya, inclusive of laws such as the Proceeds of Crime and Anti-Money Laundering Act of 2009 and the 2012 Prevention of Terrorism Act. Notably also, the PBO Act, while originating from the CSO sector, was subject not only to parliamentary debate but to review and negotiations between the CSORG, the NGOs Co-ordination Board, and

${ }^{137}$ Interviewees included two employed in one way or form on the security and antiterror file in Kenya. 
Parliamentarians amongst others, at which time the already-released ESAAMLG recommendation would, presumably (though granted, not necessarily), have been considered.

I'm sure.... that our Government has been under pressure to implement the FATF recommendations. But.... I'd say that our laws and especially currently the PBO Act is really a very comprehensive framework that would, combined with several of the other laws that we have in place, on money laundering and anti-terrorism.... all be very good frameworks to address the issue of.... terrorism. It's not that we lack the frameworks. We have great laws in place, which only require to be implemented. So for them to propose additional laws to address any risk of the abuse of NGOs [for terror purposes] would really .... be overreach. (I61_Other)

Thus, in this wave, security and terror concerns somewhat drove regulatory change attempts in the form of the PBO Act amendments. However, the language used to justify a certain approach to regulation's implementation and the overall approach suggested the manufacturing of a terror-CSO link to justify regulatory actions.

\subsection{Regulatory Change Outcomes}

\section{Development and Negotiations: PBO Act Amendment attempts}

Though the PBO Act had received Presidential assent prior to the fourth wave transition to a new GoK, the Act was not implemented but instead was subject to multiple GoK-initiated amendment attempts. Through this wave there was virtually no movement in CSO-led self-regulation.

As noted, the Jubilee Coalition's pre-election Manifesto included coverage of regulatory change for the $\mathrm{CSO}$ sector, with commitments to:

Introduce a Charities Act to regulate political campaigning by NGOs, to ensure that they only campaign on issues that promote their core remit and do not engage in party politics. This will also establish full transparency in funding both for NGOs and individual projects. 
Establish a Charities Agency to provide an annual budgetary allocation to the NGO sector.

Promote accountability and coordination between the NGO sector and national and county Governments.

Develop strong partnership with the NGO sector that enhances the country's development agenda and promotes the interests of the people of Kenya. (Jubilee Coalition, 2013, p. 65)

The commitment to introduce new charities legislation was notable given that at the time of the Manifesto's publication the PBO Act had already passed through parliamentary debate and been assented to by President Kibaki. While it is far from unusual for a new government to upend legislation enacted by its predecessor, in this instance, this GoK leadership's distrust and even disdain for the CSO sector, and for their $\mathrm{DAC} / \mathrm{G}$ funders, in hindsight, belied a more nefarious intent. So too did the reference to a Charities Act focused on limiting CSOs' political activities, implying Jubilee's preference for a narrow and traditional charity-focused role for the sector (I61_Other). The Jubilee GoK did not take steps to introduce new charities legislation. Nor did it taken steps to implement the PBO Act, despite that the Act addressed, amongst other things, regulatory areas of concern highlighted in the Manifesto including issues of sustainability of CSO financing; transparency, accountability and coordination; and refraining from party politics.

Instead, the GoK made five attempts to amend the PBO Act, directly or indirectly via other legislation, since it came to power in 2013. These attempts put forward through two The Statute Law (Miscellaneous Amendments) Bills, of 2013 and of 2014, a (leaked) internal memorandum (CSORG 2014b), The Security Laws (Amendment) Act (2014), and the PBO Act Taskforce established to review and consult on the Act, each varied in 
the breadth and depth of amendments proposed. By the end of this wave, only the Security Laws amendments had been implemented.

The first set of 13 amendments was published on October $30^{\text {th }} 2013$ as part of The Statute Law (Miscellaneous Amendments) Bill of 2013 (pp. 977-986). The most concerning amendment proposed was a 15 percent ceiling on the receipt of foreign funding by CSOs, which, given the sector's known dependency on foreign funding, was said by some to be "designed to kill off the sector" (Kiai, 2013, para. 22). Other amendments included considerable discretionary powers to the new PBO Authority in granting or denying registration; reduced independence of the Authority from the executive; and a requirement for all CSO funding to flow through the new PBO Federation (replacing the NGO Council) (CSORG, 2013, p. 1; HRW, 2013, para. 18).

That these amendments were defeated in Parliament was attributed in part to the focused advocacy efforts of the CSORG alongside "other groups sympathetic to the cause" (CSORG, 2015b, p. 1; USAID, 2014, pp. 66-67). CSOs drew attention to the potential impact of a 15 percent foreign funding cap in terms of jobs lost (estimated at almost 250,000 individuals, mostly Kenyans, directly employed by the sector); an estimated USD 800 million in foreign flows potentially lost annually; negative implications for the value of Kenya's currency; and the loss of critical social services to millions of Kenyans (CSORG, 2013; Houghton \& Muchai, 2014, para. 13). The sketchy logic of the 15 percent cap proposal, seen alongside the public relations narrative of CSOs as foreign agents, was a source of puzzlement in many Kenyan quarters, as articulated by the following interviewee: 
It doesn't make sense, because, let's say... take even an example of, you want to do your financing of a certain individual project. I have only 15 percent of the total cost of my project; I get 85 percent from somewhere, like from a bank. That doesn't make me now part of the bank shareholding because now I got it from the bank, yeah? So it's like you're saying, if I'm getting money maybe from Canada to do a project in Kenya, more than.... 80 percent of my funding coming from Canada. That doesn't make me a Canadian, for me now to be called I'm not a Kenyan? I'm still a Kenyan by birth and by everything. So the mere fact I'm getting support from outside, which even Government gets... that doesn't make us look at the sovereignty of the Government. (I14_GoK)

Parliamentarians were also quick to realize that a cap would be of direct harm to their constituents given CSOs' active engagement in humanitarian work and service provision (I8_Other; USAID, 2014, p. 67), especially since in some parts of Kenya “citizens only know CSOs" as successive GoKs neglected to reach them with basic service provision (I9_GoK). One MP was quoted as saying "this Bill is Parliamentary suicide for us" (Houghton \& Muchai, 2014, para. 13). MPs' opposition to the amendments was also attributed to the fact that many Kenyan politicians "themselves have NGOs" (I41_GoK), and that over a third of MPs in Parliament were former employees or beneficiaries of CSOs (Houghton \& Muchai, 2014, para. 14). Concerns were also voiced in the parliamentary debate about the constitutionality of the proposed amendments given the lack of consultation with the CSO sector or the public prior to their introduction, as well as with the use of a Miscellaneous Amendments Bill to implement changes of such breadth and depth (ICNL, 2014, p. 6). At the end of the year, the PBO Act amendments were withdrawn from the Bill.

Notably, the amendments were defeated in Parliament by only a small majority of 10 votes (Houghton \& Muchai, 2014, para. 20). However, that nearly 50 percent of MPs were not present for this vote indicated a stronger majority. Given that at the time the 
ruling party controlled Parliament, it has been suggested the high level of absenteeism was purposeful, whether because absent MPs were genuinely not supportive of the amendments, or because they had been instructed to be absent (I7_CSO; I8_Other). If the latter, the amendment proposals and parliamentary vote were mere "theatre", designed as a warning to the CSO sector and their DAC/G funders (I7_CSO). Indeed, "CSOs interpret[ed] the proposal as indicative of a lack of political will to implement the PBO Act and a sign of possible future restrictions on CSOs" (USAID, 2014, p. 64).

Beyond their expressions of opposition to the amendments, in March 2014 CSOs, through the CSORG, published a PBO Voluntary Service Charter (CSORG, 2014a) that reinforced key requirements of the sector as contained in the PBO Act. The Charter was a move by the sector to illustrate their self-regulation intent as articulated by an interviewee below.

[The PBO Voluntary Service Charter].... was for us a precursor to the self-regulating mechanism that's in the PBO Act, right? And the idea was to say, "Look. We are committed to meeting the standards that will be expected of a sector like ours in the area of self-regulation."... we said, "This is how we'd like to be judged."... It was almost making a formal statement that we do believe that we are accountable. There are laws in this country that demand that we practice certain.... that we stay within certain parameters in terms of our practice and our performance. And going further than that, here is a statement of our intent. (I57_CSO)

A second set of amendments to the PBO Act was put forward in a second The Statute Law (Miscellaneous Amendments) Bill on May $30^{\text {th }} 2014$, this time without the 15 percent cap. This Bill may have been put forward in an attempt to quell the ongoing outcry over the 15 percent cap amendment attempt, as most of the other controversial amendments seen in the 2013 Miscellaneous Amendments Bill remained (ICNL, 2015a, p. 6). CSOs and DAC/Gs responded to the May 2014 amendment proposals by 
welcoming the critical change to the cap amendment, but again registering their concerns on various other amendment proposals (ICNL, 2014, p. 6). Notably, a DAC/G-sponsored workshop on international good practice in CSO regulation, attended by many MPs as well as GoK officials and CSOs was held in the month of May prior to release of the 2014 Amendments Bill (I3_DAC/G; Development Partners Group [DPG], 2015, p. 1). The Parliamentary Committee on Justice and Legal Affairs' report on the workshop concluded that any proposal to cap foreign funding, or for DAC/Gs to channel all CSO funding through the GoK, had no legitimate basis (DPG, 2015, p. 2). ${ }^{138}$ The DAC/Gs had clearly communicated at the workshop that any funds freed up from a foreign funding cap would not be redirected to the GoK (I3_DAC/G).

Again, the PBO Act amendment elements of the Bill did not pass successfully through parliamentary debate. Six months later however, the Ministry with authority for the NGOs Co-ordination Act, the Ministry of Devolution and Planning, ${ }^{139}$ jointly with the NGO Council, prepared a (leaked) Memorandum containing 54 amendment proposals. In the words of the CSORG, this latest series of amendments had "the potential to completely mutilate not only the PBO Act but cripple PBOs; undermine the Constitution

${ }^{138}$ It is not clear at what point the idea to channel CSO funding through the GoK arose, or whether the 2013 amendment proposal to channel funding for CSOs through the PBO Federation, i.e. the Council's replacement, was being interpreted as channeling funds through the GoK.

${ }^{139}$ In 2013, Ministerial authority for the NGOs Co-ordination Board was transferred from the dissolved Ministry of National Heritage and Culture to the Ministry of Devolution and Planning. There was some speculation that the choice of Ministry may have been informed by the President's rumoured intimate relationship with the Devolution and Planning Minister (Nairobian Reporter, 2015), who was considered reliably willing and able to deal with the sector as the GoK's political leadership thought fit (I61_Other). 
and gains made in the last decade; and hence undermine critical service delivery to Kenyans" (CSORG, 2015b, p. 1). Other commentators suggested they represented an indication that Kenya was "taking... the Rwandan, Ethiopian and Ugandan way" in the form of "suppressed civil liberties" (Kiplagat, 2014, para. 19).

Resurfacing among these controversial proposals was the 15 percent foreign funding cap, or, where foreign funding exceeded 15 percent, the requirement to apply for registration as a foreign PBO (ICNL, 2015a, p. 6). The Memorandum also proposed to remove the section of the $\mathrm{PBO}$ Act dedicated to indirect GoK support to all registered PBOs through various tax exemptions and incentives for private donations, which had been included in the original PBO Act as a step toward reducing dependence on foreign funding (CSORG, 2014b, p. 10; Houghton, 2015, para. 15). Here, it is possible that the amendment was motivated by a desire to maintain the NGOs Co-ordination Act elective approach to tax-exempt status due to trepidation about the potential cost to the GoK of forfeited tax income given eternal pressures to increase, not reduce, tax collection (USAID, 2013, p. 72). However, the GoK's apparent willingness to forfeit ample foreign funding receipts, even as these would flow via CSOs, suggests that income concerns were not at the forefront of the amendment attempts, except inasmuch as that with a nonelective approach, all PBOs inclusive of those undertaking policy advocacy as per the Act's PBO definition would have automatically been granted tax-exempt status. ${ }^{140}$

${ }^{140}$ Not one of the interviewees for this research, including those from the GoK and elected officials, raised the potential tax income losses by the GoK as a rationale for PBO 
Other of the 2013 amendments in relation to discretionary powers of and executive control over the PBO Federation remained. The Memorandum further proposed to impose membership in the new $\mathrm{PBO}$ Federation rather maintain the voluntary membership and the possibility of multiple self-regulation regimes allowed for under the original PBO Act (CSORG, 2014b, p. 4). Finally, the Memorandum made migration to the new Act compulsory for all type of PBOs (e.g. including those registered under other regulations as trusts or companies limited by guarantee) rather than voluntary (Houghton, 2015, para. 20).

Again, the CSORG responded to the Memorandum, this time stating an amendmentby-amendment position with justification and alternatives proposed for those amendments they did not support. For example, they argued: to retain the section on tax and other benefits to incentivize the sector's work and private giving to the sector; for voluntary membership in the PBO Federation, citing the failure of the legislated Council in the self-regulation realm; the preference for an incentive-based versus legislated system of self-regulation; and that forced membership runs counter to the freedom of association as enshrined in the Constitution. In their response the CSORG also proposed additional amendments to enhance sector transparency and accountability (CSORG, 2014b).

Following further outcry against this latest set of proposed amendments and in an effort to uphold Constitutional requirements for public participation, the Ministry of

Act amendments and non-implementation, nor was it an issue arising in the PBO Taskforce report covered in further detail below. 
Devolution and Planning constituted a Taskforce on the Proposed Amendments to the PBO Act in December 2014 (Abdi, 2015a). The Taskforce, comprised of representatives from the GoK and CSOs, including the NGOs Co-ordination Board, the NGO Council and CSORG amongst others, undertook consultations across Kenya over approximately a three-month period. This process included hearings in ten of Kenya's urban centres that were attended by members of the public, CSOs, local and central GoK representatives and elected officials, and DAC/Gs. The Taskforce also held a meeting with DAC/Gs, whose joint written submission reiterated good practice as covered at the May 2014 workshop; provided assurance that $\mathrm{DAC} / \mathrm{Gs}$ practice due diligence to ensure CSO accountability for the funds they receive; and encouraged a better balance to enable the independence and work of CSOs while also ensuring accountability and transparency to prevent illicit activities via CSOs (DPG, 2015, pp. 2-3).

The Taskforce submitted its report to the Ministry of Planning and Devolution, the Attorney General, and the Clerk of the National Assembly in May 2015, which was then made publicly available approximately three months later (PBO Taskforce, 2015). Observers from within and outside of the CSO sector did not expect much in the way of enabling outcomes for the CSO sector to come from the report. For some, the Taskforce's efforts were seen as "a bundle of madness" (I40_Elected), another kind of "theatre" (I6_CSO), set up by a GoK that would ultimately impose whatever amendments to the Act it would see fit. The report was largely a recounting of positions heard, many of them contradictory along with ten recommendations of varying degrees of specificity. Taken together, the report's recommendations did not resolve many of the controversial 
amendment proposals seen over the 2013-14 period, which was not surprising given the many and often conflicting views, as well as that the report required sign off by Taskforce participants. The report's recommendations did however highlight the key outstanding issue of the existence of multiple regulatory regimes for CSOs. It recommended a clearer definition of "PBO", and for their registration under a single legislation, "bearing in mind that such harmonization requires broader consideration as it has implications on other legislation" (PBO Taskforce, 2015, p. 37).

Since the PBO Act's assent in 2013 and as part of the Taskforce consultations, CSOs, DAC/Gs, and some MPs had called for the Act to be implemented, in its original incarnation prior to seeking any amendments, even while acknowledging that the Act had some grammatical errors as well as "inconsistencies with existing legislation" (CSORG, 2015b, p. 4; CSORG, 2015a; ICNL, 2015b, p. 7; PBO Taskforce, 2015, p. 29; DPG, 2015, p. 2; I6_CSO; I40_Elected). The logic was that enactment would "enable a proper evaluation of the successes and shortcomings of the Act before any proposals for its amendment can be made", or in the words of one interviewee, "what are you amending when you've not even seen the flaws... first... give it life" (CSORG, 2015b, p. 4; I40_Elected). Mid-2015 an MP who had been involved in the initial 2012 negotiations on the Act prepared a Bill to amend the Act to include an immediate commencement date, though it did not receive parliamentary approval (The Public Benefit Organizations (Amendment) Bill, 2016; I40_Elected; I50_CSO). On the whole though, many MPs, it seemed, preferred the status quo, perhaps because as previously noted, some MPs maintained CSOs, and perhaps preferred to avoid the deeper scrutiny of their CSOs that 
would have come with implementation of the PBO Act. According to one interviewee: "some of the current politicians have several NGOs.... and they misappropriated.... monies. And they have poor leadership. So that's why you find they are causing confusion on the way forward"' (I41_GoK).

By virtue of its ten recommendations the Taskforce report called for amendments, a call reinforced following the report's release when the Taskforce Chair issued a public statement specifying that the Taskforce nonetheless recommended amendments preimplementation (Abdi, 2015b). Prior to public release of the report, CSOs including from the CSORG and purportedly the NGOs Council - both of which were Taskforce members - denied that the report specifically called for amendments pre-implementation (Wafula, 2015, para. 4). In effect, the report was somewhat contradictory, on the one hand making recommendations that amounted to amendments, on the other, including in those recommendations that the Act be implemented as per the 2010 Constitution's article 116 requiring commencement of all laws within 14 days of issuance of its publication in the Kenya Gazette as an Act of Parliament (s. 116(2); PBO Taskforce, 2015, p. 37).

By the end of this wave, no amendments had been made to the PBO Act, nor had it been implemented, despite the report's recommendations, and despite that the Act had been published in the Gazette in January 2013 following Presidential assent. The sole amendment was The Security Laws (Amendment) Act (2014), which modified the as yet to be implemented PBO Act to require "classification" of PBOs registered with the PBO Authority, with the classification criteria to be determined by the Cabinet Secretary 
responsible for the Act (The Security Laws (Amendment) Act, 2014, s. 96). This amendment was purportedly made to enable a distinction between service-oriented PBOs and those undertaking civic and political engagement, the latter deemed a security threat (I5_CSO). The PBO Act amendments were not part of the afore-mentioned partially successful Supreme Court challenge to the constitutionality of The Security Laws (Amendment) Act.

Absent a resolution on the various proposed amendments or implementation of the PBO Act, the Act, and the NGOs Co-ordination Board that continued to administer the NGOs Co-ordination Act, went through a "comically complicated" saga as various parties vied for either the PBO Act's implementation or otherwise (I50_CSO). The CSORG's shadow report to the Taskforce's report stated that views heard during the Taskforce consultations included that non-commencement of the Act violated the Constitution given that: a) the Act had not come into force within 14 days of its Gazette publication, and b) that delayed implementation was "not fair administrative action (i.e. expeditious, efficient, lawful, reasonable and procedurally fair)" (CSORG, 2015b, p. 4). In follow up, in August 2015 the CSORG worked with a Kenyan CSO to file a lawsuit against the Cabinet Secretary of the Ministry of Devolution and Planning - under which the NGOs Co-ordination Board then sat - to commence implementation of the Act (I50_CSO; I57_CSO). The suit also claimed that any and all of the attempts to amend the PBO Act, including establishment of the Taskforce, and equally any actions taken by the Board since the March 2015, held no authority given that the Act had yet to be commenced. 
In a counter-move, a petition was apparently filed at the High Court, purportedly by a stand-in recruited by the NGOs Co-ordination Board ED and his allies, against commencement of the PBO Act on the grounds of it being un-Constitutional, and with amendments pending (Achieng, 2017, para. 4 citing CSORG, n.d.; I61_Other; I50_CSO). ${ }^{141}$

This case argued that.... the PBO Act Taskforce had produced a set of amendments that were supposed to be implemented, and that in any case parts of the PBO Act.... are inconsistent with the Constitution and inconsistent with each other, and that the court should block the Cabinet Secretary from commencing the Act.... This [case] is [brought forward by] a private individual.... folks within the NGO Bureau staff... referred to it as, "Our case," thereby unintentionally admitting that they're the ones behind it.... they didn't file it as the Bureau or the Board. They found sort of a strongman to file the case on their behalf because there's no end to the skullduggery. (I50_CSO)

Responding to this court filing, CSOs petitioned the court to hold off on hearing this latter case until a ruling on the initial CSO case calling for implementation of the Act. In October 2016 the High Court ruled in favour of the CSOs' case, calling for a commencement date to be set (Trusted Society of Human Rights v Cabinet Secretary Devolution and Planning and 3 others, 2016), and opting to not hear the alternate case against the Act's implementation (I61_Other). Notably, the ruling drew amply from the 2010 Constitution, declaring that: "Legislation should not be suspended indefinitely as that is the mischief that Article 116(2) [of the Constitution] sought to cure" (Trusted

${ }^{141}$ In the course of this research a copy of this particular petition was not retrievable; it was superseded by the previous Trusted Societies petition to have the Act implemented. The latter court ruling simply states that the respondent (Cabinet Secretariat Devolution and Planning and 3 others) "opposed the Petition" for the Act's implementation (Trusted Society v Cabinet Secretary Devolution and Planning and 3 others, 2016, s. 3). 
Society of Human Rights Alliance v Cabinet Secretary Devolution and Planning and 3 others, 2016, s. 85).

Then, in September 2016 and prior to the High Court's ruling, the Ministry of Planning's new Cabinet Secretary announced his intent to commence implementation of the Act without further delay (I50_CSO; I57_CSO; FH, 2016, para. 1). This new Cabinet Secretary replaced one with, as noted, close and long-standing ties to the President but who was forced to resign late in 2015 due to public and opposition outcry over corruption scandals tied to her and her Ministry (Okumu, 2015, paras. 1 \& 7). The September 2016 announcement by her replacement that the Act would be implemented forthwith may have been a calculated move by a Cabinet Secretary who could see the writing of the Court's ruling on the wall. Or it may have simply been a gesture of "goodwill" from a (naive) Cabinet Secretary prepared to operate with more independence from the GoK's leadership than the previous one (FIDH, 2017, para. 3). ${ }^{142}$

Meanwhile, following the High Court's October 2016 ruling in favour of the PBO Act's implementation, the NGOs Co-ordination Board and associated responsibility for the PBO Act was put under the watchful eye of the Ministry of Interior and Coordination, which sat in the President's Office (I50_CSO). In the words of the CSORG, this "underhand manouevre(s) to undermine justice" rendered the Court order "inapplicable" (Achieng, 2017, para. 5 citing CSORG, n.d.; FIDH, 2017, para. 2). Subsequent to the High Court's first ruling of October 2016 but with the Act now under the Interior

${ }^{142}$ Not long after, the Cabinet Secretary in question was re-assigned to the Ministry of Agriculture, considered a demotion. 
Ministry, CSOs launched a contempt of court suit against the Ministry of Devolution and Planning and the Attorney General (Otwala, 2017, para. 4). In May 2017 again the Court ruled in favour of implementation of the PBO Act stating that the GoK "was clearly in contempt of court over its failure to comply with a similar ruling eight months ago" (FIDH, 2017, para. 1; Trusted Society of Human Rights Alliance v Cabinet Secretary for Devolution and Planning \& 3 others, 2017). Still, the ruling was disregarded, making it clear that "the Government is not interested in implementing the PBO Act" (I40_Elected).

In parallel to these lawsuits, actions were launched against the Board's ED. First, two of the Board's staff filed a petition challenging the ED's qualifications, some of which he had allegedly falsified (I40_CSO; Muhindi, 2016). ${ }^{143}$ As the Commission on Administrative Justice investigated the ED and his appointment, the ED was briefly sent on administrative leave (Mutambo, 2016, para. 8). In November 2016 the Commission recommended that the ED should be dismissed and not be permitted to hold public office based on their findings that, not only had he falsified his qualifications, but he was "culpable of abuse of power and misconduct" (Mutambo, 2016, para. 5; I53_GoK). ${ }^{144}$ The ED claimed the Commission had violated a court order temporarily banning release of the findings and pursued a petition against the Commission (Mutambo, 2016, paras. 9 \& 14); and apparently appealed the Commission's decision (I53_GoK; Republic v

${ }^{143}$ The two staff were apparently operating not only on behalf of themselves but also of other Board staff (I53_GoK).

${ }^{144}$ As noted, the ED eventually tendered his resignation in February 2018. 
Commission on Administrative Justice Ex parte Yusuf Mahamed Fazul, 2017). ${ }^{145}$ Another case targeting the ED, this one filed in the Employment and Labour Relations Court against the Cabinet Secretary of Interior, was not concluded in this wave though in December 2017 the court issued an order disallowing renewal or extension of the ED's contract which technically ended in November (Kakah, 2017, paras. 4-5).

Throughout this period of lawsuit and counter-lawsuit, despite a brief suspension, the ED remained at the Board's helm while Board fell into disarray and those staff not under the ED's wing worked in fear: "staff are terrified" (I53_GoK). This wave's ED was:

.... flying off the handle. He's demanding bribes. It's like the Wild West. He's threatening people's safety, threatening their registration.... he sent a lot of the reasonable staff to the far corners of the country, and has sort of stacked the head office with his cronies... there's.... a new level of rent seeking and intimidation.... it's so brazen. (I50_CSO)

Since October 2016, there was no actual Board of Directors guiding the NGOs Coordination Board, such that there was apparently no oversight of the ED. The ED, apparently a former employee of the Interior Ministry prior to his move to the Board (Menya, 2014, para. 24), was seen instead to be both taking direction and receiving "protection from some quarters"; he "has support from the Interior Ministry. That we guess give [him] some instructions" (I53_GoK).

Finally in this section some mention needs to be made of CSOs' self-regulation. In mid-2015 the NGO Council was rumoured to be exploring establishment of a certification mechanism, a move emblematic of its interest in self-perpetuation. The CSO

${ }^{145}$ Rulings on the matter by the Commission of Administrative Justice were not publicly available at the time of writing. 
sector was largely sceptical of any such self-regulatory effort by the Council given the perspective that "the NGO Council and NGO Board are one and the same" (I20_CSO). Meanwhile, the Viwango self-regulation initiative appeared to be continuing to refine its mechanism to find ways to attract interest from the sector (I20_CSO).

\section{Implementation: Viwango and NGOs Co-ordination Act continued....}

While the PBO Act remained in limbo, a heavier hand was increasingly evident in the implementation of the NGOs Co-ordination Act in this wave. In some respects this suggested that the GoK was "informally" implementing "certain provisions of the PBO Act, including stricter controls on NGOs' reporting requirements and adherence to laws and regulations under the NGO (sic) Co-ordination Act" (USAID, 2017d, p. 104).

The heavy-handedness was most evident beginning in December 2014 with the first official act of the newly-appointed ED of the NGOs Co-ordination Board who implemented a sweep of the Board's registry (CSORG, 2017, p. 1). Over 500 NGOs were notified that, due to non-compliance with reporting requirements, their registration was suspended and bank accounts frozen, with registration to be fully revoked if they failed to meet said reporting requirements (Jamah, 2014, para. 1; I9_GoK). ${ }^{146}$ The Board also threatened repossession of these NGOs' assets, and required all of the NGOs with expatriate staff to validate the necessity of employing foreigners (Jamah, 2014, paras. 1213). In contravention of procedures required under the NGOs Co-ordination Act,

146 According to a GoK interviewee de-registration was averted in the majority of these cases as within some five weeks of the notification, $60 \%$ of the NGOs concerned had submitted reports with more anticipated (I9_GoK). However, this was disputed by a DAC/G source (I59_DAC/G). 
apparently the notification of suspension was first communicated via the media (CSORG, 2017, p. 1). Of those suspended, 15 were unnamed due to ongoing investigations of alleged links to "terrorism and criminal activity" (Jamah, 2014, para. 3). The announcement also "put on notice donors who do not demand accountability from the NGOs they fund" (Jamah, 2014, para. 27). A further close to 1,000 NGOs were similarly suspended by the Board, via the media with a similarly menacing tone, in October 2015 (Wanzala, 2015). This notification of suspension was quickly repealed by the Devolution and Planning Minister following "overwhelming complaints" from the affected NGOs, giving the latter more time to meet the regulatory requirements they were accused of breaching (Mohammed, 2015, paras. 2 \& 6; USAID, 2016, p. 97).

The NGOs Co-ordination Board also used its regulatory power to penalize the two CSOs previously noted as ending up on a list of suspected Al-Shabaab associates. Following initiation of court action by Haki Africa and MUHURI in protest of their listing, the NGOs Co-ordination Board issued notifications that the CSOs would be deregistered based on a series of purported non-compliance issues including tax evasion and operating without proper registration (Katana, 2015, para. 4). This piqued further scepticism about the terror accusations: "They have no evidence of terrorism so are turning to administrative issues" (I36_CSO). Scepticism was also expressed by the KNCHR, which noted that the accusations came "hot on the heels of the.... systematic campaign against civil society organizations speaking against the State and leaves one wondering whether the naming of the two vibrant human rights organizations is not a continuation of the same" (KNCHR, 2015a, para 10). The KNCHR called on the Kenyan 
state to "cease[s] the continued criminalization of legitimate civil society organizations" (KNCHR, 2015a, para. v). In the words of one long-time expert on civil society in Kenya, some CSOs are:

.... being victimized because terror seems to be the alternative to Marxism. In the past if the government didn't like you they used Marxism, but now it seems.... to antagonize you in the eyes of the West, they have to link you with terrorism. In the past they linked you with Marxism. (I39_Other)

In yet another show of muscle flexing by the Board, in April 2016 it issued a circular addressed to NGOs in Kenya, intended to reinforce implementation of the NGOs Coordination Act and the Kenya Citizenship and Immigration Act (2011) provisions regarding expatriate staff permits. Specifically, for the Board to recommend work permit approval to the Immigration Ministry, the NGOs Co-ordination Act's Regulations required demonstration that the expatriate staff were necessary to the NGO's functions; or, that there were no personnel available locally to fill the position; or, that the expatriate staff would undertake to train Kenyans (s. 28). While these were not new provisions, ${ }^{147}$ the circular represented regulatory overreach in that, for one, it required compliance with the second and third criterion, ignoring the first criteria, and that only one of the criteria needed to be met. It also introduced a requirement for NGOs to "immediately initiate the process of harmonizing the salary discrepancies between International and local staff employed in the same category with comparable skills and qualifications" (Ministry of Devolution and Planning, 2016, p. 3).

${ }^{147}$ And were also contained in the PBO Act. 
As pointed out by the CSORG, the targeting of expatriate staff in the CSO sector, when no similar moves were being made for other sectors of the economy, was suspect (CSORG, 2017, pg. 2). Moreover, apparently the Board's decision-making regarding whether or not to forward permit applications to Immigration had become an arbitrary matter: "At the moment, there is no objectivity.... It's just somebody making an individual decision. And that is.... the Director himself" (I53_GoK).

The NGOs Co-ordination Board also took actions both punitive and preventative in nature against CSOs active in civic education, monitoring and calling the GoK out on issues related to the running and results of the 2017 election. Late in 2016 the Board ordered the International Foundation for Electoral Systems to cease its operations including a new USAID-funded Kenya Electoral Assistance Program (Republic v NonGovernmental Organisations Co-ordination Board EX Parte Okiya Omtatah Okoiti \& 2 others, 2017, para. 2). The Court ruled against the Board, based amongst others on the fact that the CSO, registered as a company limited by guarantee, did not fall under the Board's regulatory jurisdiction (Republic v Non-Governmental Organisations Coordination Board and 2 others, 2017, para. 24). In other instances, in the week following the August election, the CSO the KHRC was issued a deregistration notice on the basis of administrative and tax violations, and AfriCOG was also threatened with closure and arrest of its Directors for criminal activity, while a failed attempt was made to search their office (L. Mutai, 2017, paras. 1-3). Both CSOs' bank accounts were frozen (Rajab \& Awich, 2017, para. 6). It was seen as no coincidence that the Board's efforts came two days before the deadline to submit petitions to the Court against the election results 
(Rajab \& Awich, 2017, paras. 7-8). When the Supreme Court suspended the Board's actions, the Interior Ministry's Cabinet Secretary called for further investigations into the cited regulatory issues, despite that in the KHRC's case the issues had already been dismissed by the High Court in a separate 2016 ruling (Kenya Human Rights Commission [KHRC], 2017, p. 1; L. Mutai, 2017, para. 5).

In early November, again days before the deadline for submitting petitions, this time in relation to the October election re-run, three other CSOs engaged in election monitoring (including MUHURI, referenced above) were accused by the Board of being in breach of regulatory requirements and/or of money laundering (Abdullahi, 2017, paras. 1-2). Two others, including the Kura Yangu, Sauti Yangu coalition along with another such coalition, We the People, were effectively banned by the Board also for alleged regulatory breaches including engaging in "political activities" (Abdullahi, 2017, para. 3). The latter two cases provide an example of the Board's regulatory overreach, and confusion, in that on the one hand, the coalitions were accused of "political and flagitious operations in Kenya", yet, the Board's rationale for its authority over the coalition was that that are "engaged in activities that fall within charitable objectives as is encapsulated under the NGOs Co-ordination Act 1990 and therefore under the jurisdiction and regulation of the NGOs Co-ordination Board" (Mahamad, 2017, p. 1). Yet another CSO, the International Development Law Organization (IDLO) that provided financial and technical support to the judiciary such as to fulfill its function to follow-up on electionrelated petitions - specifically, purportedly, in relation to the Supreme Court's ruling 
nullifying the August election - was threatened with suspension in October (Abdullahi, 2017, para. 8; Owino, 2017, para. 14).

The timing, targeting and nature of these various Board actions led the KHRC's ED to proclaim that: their "brazen nature... calls to question whether this errant public officer [NGOs Co-ordination Board ED] enjoys political support to undertake such abuse of office" (Rajab \& Awich, 2017, para. 38). It did not go unnoticed that the Board was technically reaching outside of its rubric, given for example that AfriCOG was registered as a company limited by guarantee, not as an NGO under the Board. Nor that the Board felt empowered to invoke criminal law in calling for the arrest of CSO officials, nor that it was capacitated to send the revenue and tax authority to search AfriCOG's office. Referencing previous rulings on the Board ED's qualifications, it was noted that though he was "one of the few people in public service jobs without the pretense of academic qualifications.... he can countermand a Cabinet Secretary", and "clearly takes orders which he goes overboard to fulfill" (Kiai, 2017, paras. 3-4). In the case of IDLO, it was the Ministry of Foreign Affairs that in September 2017, within days following the Supreme Court ruling annulling the August elections, revoked its Host Country Agreement with the CSO. In short order, a letter from the Board's ED suspended IDLO's activities and had its bank account frozen claiming, amongst other things, that the CSO was using its funds for "nefarious operations" (Republic v Fazul Mahamed and 3 others, 2017, s. 28; Owino, 2017, paras. 7-9). After which, the High Court ruled, in essence, that the ED's actions went beyond the remit of the Board and were in violation of the Constitution (Republic v Fazul Mahamed and 3 others, 2017) 
All told, the various actions toward amendments and lawsuits alongside the continued regulatory overreach by the NGOs Co-ordination Board pointed to a "regulatory, compliance and enforcement policy that has gone terribly wrong, and completely hijacked by a regime that has dropped any more pretenses to the rule of law as a constitutional value and principle of governance" (CSORG, 2017, p. 3).

As regards self-regulation, there was not much in the way of implementation in this wave. It was clearly not happening under the NGO Council plagued by lawsuits, nor did it appear likely to launch any time soon. Even following the Council's potential legislative revitalization under the PBO Act, the Council, it was felt, would continue to "exist theoretically, but may remain irrelevant" (I47_CSO).

While Viwango was never meant to be a substitute for the NGOs Council in representing the sector, it was meant to offer a self-regulation mechanism, a "standards consultant... [like] Charity Navigator... in the States" (I57_CSO). Through much of this fourth wave however it had not succeeded in garnering subscribers. By mid-2015, Viwango had managed to attract just over 40 CSOs to its self-regulation initiative, including some 30 having participated in the pilot phase (I20_CSO). While the Viwango assessment process was lined up for an additional 50-plus CSOs in 2015 (I20_CSO), the pace of uptake was proving slow as the state regulatory framework remained uncertain, as highlighted by an interviewee:

What's the point of this, we don't even have a law in place so help me. So Viwango I think is an idea which would have worked perfectly had everything else been in place. So to some extent, it's an idea whose time had not yet come in Kenya. And now it's struggling to stay alive while all these other things.... are happening. (I57_CSO) 
With all of the commotion around the PBO Act amendments, there was too much uncertainty about what the Act's requirements would entail on the self-regulation side; "people are waiting" (I36_CSO). The following comment from the DAC/G perspective provides a revealing take on CSOs' lack of incentive to self-regulate in this wave:

Really, our understanding is that [CSO accountability is] an ostensible rationale on the part of the Government. But no amount of self-regulation is going to be sufficient, because that's not the real reason for putting forward these [PBO Act] amendments for trying to control the space. It's a political issue. It's not a technical issue. (I3_DAC/G)

In such an environment, the threat of state regulatory overreach was insufficient to motivate widespread CSO uptake of self-regulation.

\subsection{Analytical Summary}

At the outset of this wave, one could have interpreted the initial round of registration suspensions implemented by the NGOs Co-ordination Board as a legitimate effort to clean up the Board's registry of defunct organizations, as well as to remind active ones of their reporting obligations. Even the public nature and accusatory tone of the Board's ED could have been attributed to the over-enthusiasm and misunderstanding of a novice ED. As this wave evolved however it would have taken a generous interpretation to see the multiple PBO Act amendment attempts, the stalling on implementation, and the Board's aggressive tactics and actions as those of a neutral regulator. Various Board actions media announcements of mass registration suspensions, the targeted suspensions of civic and politically active CSOs, and public declarations associating CSOs with terrorism were all indicative not only of politically-motivated effort to penalize individual CSOs for their civic and political activism, but as part of a wider effort both to instil fear in and demonize the sector. The Board's ED appeared to be doing his best to fulfill orders 
coming from the highest levels of a GoK angered by CSOs' engagement in relation to the ICC cases and then the 2017 elections. That this wave's GoK had to contend with the roll out of various 2010 constitutional commitments, including that of devolution in which CSOs were legislated to have a prominent role, further fuelled this GoK's discomfort with CSOs as an alternate voice and source of power.

Authoritarian tendencies of this wave's GoK leadership were exacerbated by the narrow margins by which the hotly contested 2013 and 2017 elections were won. Its use of an anti-West, turning-East narrative went hand-in-hand with an anti-CSO, 'foreign agent' narrative that saw the traditional influence of $\mathrm{DAC} / \mathrm{Gs}$, also pre-occupied with private sector and counter-terror interests, diminished. Amidst DAC/G changing and sometimes conflicting priorities, $\mathrm{DAC} / \mathrm{Gs}$ were also sensitive to the risk that any attempts to wield policy influence could backfire both on DAC/Gs and on CSOs. Both DAC/Gs' willingness and ability to influence Kenyan policy on matters related to human rights, democracy, good governance, and as part of that, CSO regulation, appeared to be changing from the wave one days.

CSO numbers, at least those registered with the NGOs Co-ordination Board, seemed to be stabilizing in this wave. Competition for DAC/G financing was one likely source of this stabilization along with a changing perception of the CSO sector as no longer a prime opportunity for rent seeking. Further, motivation to form or perpetuate CSOs was diminished due to the unpredictability surrounding the GoK's refusal to implement the PBO Act, combined with obstructions and delays at the Board level, and the general antiCSO sentiment emanating from the GoK. 
The regulatory gap in the form of multiple regulatory regimes covering the CSO sector continued to exist in this wave. That CSOs were registered under these varied regimes was not, however, an impediment to the use of regulation to penalize or restrict the sector given the NGOs Co-ordination Board operating as if it was the sole authority over all things CSO-related. One could cynically think that the GoK would have had an interest in implementing the PBO Act to move toward bringing all public benefit CSOs under one regulatory regime, officially empowering the Board to continue operating with its heavy hand. But the GoK seemed to prefer to operate in the mayhem of regulatory overreach and impunity, ignoring court rulings and perhaps content with the chill effect on the sector and on the sector's DAC/G financiers. The Board through its actions demonstrated an interest in maintenance of the status quo through which staff positions, and opportunities for rent seeking amidst the chaos and environment of impunity, were maintained.

Moreover, the idea of a harmonized regulatory regime for all PBOs did not necessarily have full support of the GoK institutions with authority over the alternate regimes, nor from the full CSO sector. The tax privileges and other benefits conferred on all CSOs to be registered under the new Act was likely not going to be sufficient to entice these other CSOs to the PBO Act. Certainly not under the circumstances of the proposed removal of these benefits via amendments, whatever the motivation - income-related or political - to remove the benefits from Act was. And while an amendment for mandatory registration of all CSOs working in the public benefit also met opposition, the resulting 
two-tiered system allowing some elective benefits and others not, would not have helped meet a goal of harmonizing the regulatory regime for PBOs.

As for developments in self-regulation, it appeared that the threatening wave four environment, rather than motivating CSOs to self-regulate, had the opposite effect. As the prospect that self-regulation would deter the GoK's regulatory overreach appeared slim, for CSOs, absorbing the actual and potential costs of self-regulation would hardly have seemed worth it.

This fourth wave brought into sharp focus the myriad of factors influencing state and self-regulation, and the ways in which these factors can undermine the anticipated logic of the relationship between state and self-regulation. That the potential for regulatory renewal posed by the PBO Act was not seized upon demonstrated that regulation was less seen as a means of strengthening sector accountability, but rather, a means to fulfill other, more political agendas. And despite the threat posed by state regulation, self-regulation would not take firm hold given that it would not resolve the sector's regulatory challenges, which were less based less on technical issues of CSO accountability however present such issues were - than on political ones.

Table 9: Wave Four Key Regulatory Change Drivers

\begin{tabular}{|l|l|}
\hline $\begin{array}{l}\text { Drivers emanating from } \\
\text { CSO sector }\end{array}$ & Characteristics \\
\hline Sector growth & $\begin{array}{l}\bullet \text { No further growth, stagnation toward reduction in } \\
\text { numbers }\end{array}$ \\
\hline Type of CSO activities & $\begin{array}{l}\text { - Continued dominance of social and economic } \\
\text { development } \\
\text { - High levels of civic and political engagement by small } \\
\text { portion of the sector, but growing in context of } \\
\text { Constitution, devolution }\end{array}$ \\
\hline
\end{tabular}




\begin{tabular}{|c|c|}
\hline $\begin{array}{l}\text { Mismanagement or } \\
\text { misconduct in the sector }\end{array}$ & $\begin{array}{l}\text { - Continued challenge of accountability and transparency } \\
\text { gaps in sector }\end{array}$ \\
\hline $\begin{array}{l}\text { Sector infrastructure and } \\
\text { status of self-regulation }\end{array}$ & $\begin{array}{l}\text { - NGO Council(s) remain largely ineffective in self- } \\
\text { regulation, though participate in PBO Act amendment } \\
\text { proposal debates } \\
\text { - Independent self-regulation via Viwango not taking hold } \\
\text { - CSORG active resisting PBO Act amendment proposals }\end{array}$ \\
\hline $\begin{array}{l}\text { Drivers emanating from } \\
\text { DAC/Gs }\end{array}$ & Characteristics \\
\hline $\begin{array}{l}\text { DAC/G funding and } \\
\text { policy engagement }\end{array}$ & $\begin{array}{l}\text { - Minimal aid to GoK especially early in post-2013 } \\
\text { election phase due to ICC cases } \\
\text { - Resume aid to GoK as ICC cases terminated but slowly } \\
\text { decreasing } \\
\text { - Overall aid dependency of GoK decreasing } \\
\text { - Continued keen interest in maintenance of economic and } \\
\text { political stability in Kenya, and of related interests } \\
\text { including private sector investment and security } \\
\text { - Growing concern following attacks (Westgate, Garissa), } \\
\text { thus anti-terror imperative continues to shape alliance } \\
\text { with GoK } \\
\text { - Funding to CSO sector reducing in volume } \\
\text { - Funding continues for CSO state and self- regulation } \\
\text { initiatives (CSORG and Viwango) }\end{array}$ \\
\hline $\begin{array}{l}\text { Drivers emanating from } \\
\text { GoK }\end{array}$ & Characteristics \\
\hline Status of state regulation & $\begin{array}{l}\text { - Non-cohesive regulatory framework for CSOs with } \\
\text { multiple legislations }\end{array}$ \\
\hline Political agendas & $\begin{array}{l}\text { - Significance of CSOs' roles in pursuit national } \\
\text { development inclusive of post-PEV truth, justice and } \\
\text { reconciliation recognized negatively } \\
\text { - Penalizing CSOs (and supporting DAC/Gs) portrayed as } \\
\text { responsible for ICC cases, and for civic and political } \\
\text { activism more generally related to } 2013 \text { elections, } 2017 \\
\text { elections } \\
\text { - Resistance to requirements for CSO civic and political } \\
\text { engagement called for by Constitution, devolution }\end{array}$ \\
\hline $\begin{array}{l}\text { Public management } \\
\text { agendas }\end{array}$ & - Not in evidence \\
\hline $\begin{array}{l}\text { Security and terrorism } \\
\text { concerns }\end{array}$ & $\begin{array}{l}\text { - Growing concern following attacks (Westgate, Garissa) } \\
\text { addressed in heavy-handed manner } \\
\text { - Narrative linking CSOs to terrorism }\end{array}$ \\
\hline
\end{tabular}




\section{DISCUSSION - UNDERSTANDING THE DRIVERS OF REGULATORY CHANGE IN LMI COUNTRY CONTEXTS}

\subsection{Drivers of CSO Regulatory Change: Lessons from Kenya}

This chapter provides a summary analysis of the drivers of change in state and selfregulation, highlighting the features revealed from the Kenya case and that have some generalizability to LMI country contexts that share the characteristics outlined in chapter two. Connecting the data and the conceptual framework in this way helps elaborate on the framework for particular LMI country relevance as illustrated in Figure 6 below.

The story of state and self-regulation of CSOs in Kenya covering four waves of change since the late 1980s provides lessons for understanding such change in LMI country contexts, and by extension, for understanding the relationship between state and self-regulation, accountability, and the paradox of the associational counter-revolution.

\section{Sector Growth}

Growth in the number of CSOs making up the sector drives regulatory change. The global associational revolution documented by Salamon et. al. in 1999 had been building over more than a decade prior to their writing, prompting regulatory change in numerous jurisdictions (Salamon \& Toepler, 2000). A feature of this regulatory change driver particular to LMI countries has been the exponential growth in CSO numbers over the last thirty years, (Braithwaite, 2006 citing Commission on Global Governance, 1995, p. 33; Gugerty et al., 2010, p. 1028; Pousadela \& Cruz, 2016, pp. 608-609), fuelled in part, in some places in large part, by DAC/G funding. 
The driving factor is not necessarily based on a concern that sector growth is problematic or should be stopped or managed toward an optimum number of CSOs for any given country. There is no such optimum number, and sector growth is to be anticipated when there are, as there always will be, felt needs and priorities that are not being addressed at all or adequately by other actors. Individuals and groups of people desirous of exercising their rights and abilities to pro-actively help address these needs and priorities - whether in the social and economic services or policy realm - will always organize into what we know as CSOs. In the words of one Kenyan interviewee, "human beings will come together.... around things they care about.... Whether it's a sewing club, it's a village education association, or it's a funeral association", it is "a natural function of the fact that in unity we find strength.... civil society can be ad hoc, it can be structured, it can be long term, it can be short term.... it will always exist" (I11_Other). This phenomenon is not specific to HI or LMI countries.

What is specific to LMI countries, however, is that CSO sector growth has been funded in large part by $\mathrm{DAC} / \mathrm{G}$ countries, including both by official $\mathrm{DAC} / \mathrm{G}$ donors directly or indirectly via intermediaries such as, $\mathrm{DAC} / \mathrm{G}$ country or international CSOs. Especially in the context of the later phase of SAPs and early post-Cold War era beginning as covered by this research in wave one, $\mathrm{DAC} / \mathrm{G}$ funding has been responsible for the high rate of growth in CSO numbers in LMI countries. Though associations of civil society pre-date DAC/G funding, that funding fuelled growth in the formalized form of CSOs given the need for an association to have legal status in order to receive DAC/G funding, particularly direct funding but also sometimes indirect funding via 
intermediaries. Where existing state regulation is not geared for the emerging organizational form, as was the case in Kenya in wave one, or the regulator does not have the capacity to deal with the levels of growth, as was articulated in Kenya going into wave three, regulatory change likely ensues.

\section{Type of CSO Activities}

The type of activities CSOs implement - social and economic development types of activities in more of a service delivery mode, or civic and political engagement activities - also drive regulatory change. Both of these activity areas can be perceived by the state as a threat and thus be regulation-inducing.

Though CSOs' social and economic development role is less contentious, more generally accepted in both HI and LMI countries, it can still provide impetus for regulatory change. The age-old issue of CSOs' social and economic development activities undermining government responsibility as the primary "custodians of development" (Amutabi, 2006, p. 201) is more present in LMI than HI countries, the latter generally having a firmer grasp and performing relatively effectively in that custodian role. The high prevalence of CSO's in service delivery, especially when funded by DAC/Gs based on the perception of CSOs' "comparative advantage" over states, "has a corollary of state failure" that can negatively affect governments' view of this CSO role (Turner \& Hulme, 1997, p. 210). Governments of LMI countries, particularly those with an authoritarian bent, often see CSOs as a "necessary evil - necessary because they increasingly represent a means by which the work of development can be delegated, and an evil because NGOs have never been within the government's control" (Amutabi, 
2006, p. 194). The Kenya case shows how high numbers of CSOs with wide-spread social and economic development activities, funded by DAC/Gs, can inspire an LMI country government to turn to regulatory change as a way to understand the sector's contribution to national development, and/or to coordinate it. This was the primary rationale provided by the GoK for introduction of the NGOs Co-ordination Act, even as in the authoritarian political environment the GoK conflated the concepts of 'coordinate' and 'control'. It arose later too in wave three's Sessional Paper No. 1's emphasis on the need for more 'partnerships' with CSOs, as well as the CSO-initiated Working Group on Government and CSO collaboration, and the Viwango self-regulation initiative.

More contentious and inspiring of regulatory-change is CSOs' civic and political engagement activities. As noted in chapter two, the boundary between CSOs' public benefit and political activities is at best a "muddle" at worst a "running sore" of many a CSO regulatory regime in HI countries (McGregor-Lowndes \& Wyatt, 2017b, p. 9; McGregor-Lowndes \& Wyatt, 2017a, p. 279). Whatever boundary is set, and it varies across countries, in HI countries regulation is meant, amongst other things, to provide a means to ensure that the financial contributions public benefit CSOs receive in the form of tax or other benefits, are utilized by CSOs primarily for activities in the public benefit. The public benefit character of social and economic service provision is relatively easy to identify whereas civic and political engagement is less so.

In LMI countries, the incentive to set boundaries around the public benefit nature of CSOs is present, but is less tied to protecting financial contributions from domestic taxpayers. In an LMI country context such as Kenya, there has to date been little in the 
way of government funding for CSOs, directly or via tax privileges. There has also been little in the way of private funding for CSOs due to income constraints of potential private givers, combined with the absence of or challenges in obtaining tax deductions on charitable giving. Instead, CSOs are dependent on $\mathrm{DAC} / \mathrm{G}$ financing, which is a complicating factor in regulatory change in LMI countries. The delinking of domestic financial contributions from protection of the public benefit does not mean that LMI country governments do not seek to regulate to control CSOs' civic and political engagement activities, but that such regulatory motives are less tied to protecting domestic resources. Instead, the motivation to regulate arises more out of limited tolerance of, or even acrimony toward, CSOs as alternate voices to that of governments, especially in authoritarian political environments. For some LMIs, a colonial legacy of repression of CSO civic and political engagement may well carry through postindependence.

CSOs' dependency on DAC/G funding also comes into play due to the risk that CSOs' civic and political engagement can be perceived, or manufactured by wary governments as, based on 'foreign agendas'. This arose in Kenya prior to the NGOs Coordination Act, appearing again in the most recent wave of regulatory stalling and overreach. Kenyan CSOs, and likely most Kenyan citizens would argue that it is "insulting to every Kenyan citizen" that "democracy, human rights, accountability, freedom of association and a host of other issues advocated by "some NGOs" are "foreign" values", as indeed such values are embedded in Kenya's Constitution (Kiai, 2013, para. 23). Moreover, selectivity in which 'foreign agendas' are acceptable makes 
the accusation difficult to take seriously in Kenya and other LMIs, where governments "don't have a problem with capitalism, which is as Western as the human right. They are fine with it.... They're fine with foreign funding for the state. They're fine with foreign funding for their companies... The powers that be like to say that human rights is foreign... but when you ask them, 'What is the African thing?' they have no answers" (I11_Other).

Still, some CSO activism pushes tolerance levels in LMI countries when human rights encounters traditional or conservative societies, such as activism around LGBTQ+ rights, and gets branded with a 'foreign agents' label that provides handy justification for regulatory change. This is not to suggest that CSOs should avoid civic and political activism on any contentious issues, but it highlights the role of such activism as a potential regulatory trigger, even if the activism becomes an excuse for far-reaching regulatory change in LMI country contexts where governments remain ill at ease with CSOs' civic and political role. As noted by one interviewee, CSOs are "becoming more and more effective at holding governments to account and governments aren't liking that. So we see increasing [regulatory] restrictions" (I3_DAC/G).

Thus, in LMI countries, governments can turn to regulation as one way to control CSOs' activities both in the social and economic service realm and in civic and political engagement, with the considerations of $\mathrm{DAC} / \mathrm{G}$ financing and authoritarian political environments complicating the public benefit-political activities muddle. 


\section{Mismanagement or Misconduct in the Sector}

Changes in state and self-regulation are often spurred by evidence or perceptions of CSO mismanagement or misconduct, especially when a scandal is revealed. In LMI country contexts this driver needs to look beyond the incidence of high profile scandals given the relative nascency of the sector and associated capacity issues, its dependency on $\mathrm{DAC} / \mathrm{G}$ funding, and the wider political environment.

CSO sectors in LMI countries have grown not only in size but also in capacity and professionalism. In some respects however, capacity has not kept up with growth. Issues of weak governance, human resource management, financial management, monitoring of results achieved, connectedness to communities or other constituents, transparency, all challenge LMI country CSOs, and provide rationales for both state and self-regulatory change. In Kenya as seen, impetus for the NGOs Co-ordination Act was due less to evidence or perceptions of widespread CSO capacity issues but rather a few incidences of abuse of tax privileges. As time passed, capacity challenges in the growing sector became more of a concern. By the mid to late 2000s, both the Board in its 2009 national survey report intended to inform review of the NGOs Co-ordination Act, and CSOs as seen in the PEN 2007 study on CSO competence and sustainability that informed the Viwango self-regulation initiative, decried the sector's many capacity gaps that left it vulnerable to mismanagement or misconduct.

A recurring theme is the absence of financial sustainability and CSOs' high level of dependence on $\mathrm{DAC} / \mathrm{G}$ funding which has many implications. The $\mathrm{DAC} / \mathrm{Gs}$ ' turning to CSOs as implementers of social and economic development and democracy programs in 
the 1990 s and through the 2000 s was so marked as to feed a perception that CSOs were a source of easy money. In a sense CSOs became a source of rent seeking of $\mathrm{DAC} / \mathrm{G}$ financing, exacerbated by corrupt practices that pervaded in many LMI countries and extended across all institutions, inclusive of CSOs. In the words of One World Trust authors, "the investment of large sums of money from international donors.... has created opportunities for a few civil society organisations to deliberately misuse funds, generating calls for some means to regulate them" (Mirza \& Obrecht, 2013, p. 2).

Further, when DAC/Gs' tendency is to set the priorities for the CSO programming they finance $(\mathrm{OECD}, 2011$ \& 2018a) tempted by the resources are often prepared to follow those priorities rather than those set in CSOs' own strategies, and relatedly, one hopes, the priorities of CSOs' constituents and beneficiaries. Caught up in DAC/Gs' patronage, CSOs will "cater to donor priorities rather than adhere to their own missions" (Atia \& Herrold, 2018, p. 6). This can negatively affect CSO performance if they enter into programming realms for which they are not well equipped, and also shapes perceptions of CSOs legitimacy gaps, both fuelling the felt need for regulation and selfregulation to address the issue. In Kenya the perception of CSOs as rent seekers is widespread. For example, it appeared that some in the CSO sector in wave four held a greater interest in maintenance of the regulatory status quo than in implementation of a stronger regulatory framework in the form of the $\mathrm{PBO}$ Act, due to a preference to avoid scrutiny that might uncover that "NGOs don't stick to their strategies but follow the money" (I62_GoK). 
This is not an LMI country phenomenon alone. CSOs globally faced a period of trust issues and challenges to their legitimacy and accountability in the 2000s. According to the Edelman Trust Barometer, although between governments, business, and the media, NGOs remain the most trusted institution, trust in the sector has been on a downward trend globally in recent years (Edelman Trust, 2017). Amongst others, concerns are expressed that CSOs are "too focused on money, losing touch with the public, using public funding poorly, corrupt, or incompetent" (Goldsmith, 2015, para. 6; Edelman Trust, 2017). With $\mathrm{DAC} / \mathrm{G}$ funding of CSOs in LMI countries, there is a such a "disconnection" between "those who pay... and those who benefit" (Naudet, 2012, p. 5) that such concerns are heightened. In LMI countries, CSOs' dependency on DAC/G funding leaves them prone to neglect domestic relationships of accountability, a phenomenon raised by multiple interviewees and also not limited to Kenya. A vicious circle ensues as CSOs "largely depend on gifts given anonymously by donors in faraway countries" which tends to "alienate them from the communities that they seek to serve" and, in turn, makes "the communities feel absolved from a sense of responsibility to support the NGOs" (Ochido, 2013, p. 70). Funding from DAC/Gs and the emphasis on 'upward' accountability that goes with it enables CSOs to neglect rather than build their accountability relationships with constituents and beneficiaries.

Relatedly, reliance on funding from $\mathrm{DAC} / \mathrm{Gs}$ ' empowers $\mathrm{CSO}$ to distance themselves from government rather than to invest in that relationship. CSOs "have funding coming in, so they do not necessarily need the Government. They don't have to engage with the Government for anything.... overall they made a choice not to.... the 
responsibility then falls back on the CSOs to change this narrative" (I59_DAC/G). Rather, CSOs can be quick to cry 'harassment' when they are pursued to fulfil basic regulatory requirements, a cry more easily made as the global narrative of shrinking space for civil society gains ever-more traction.

These kinds of actual and perceived management and misconduct issues in the CSO sector are deep-seated. Even if not the source of high profile public scandal, they provide fodder for LMI country governments to rationalize changing regulation to address them, as well as for CSOs to self-regulate, even as they may not in reality be the main reason for regulatory change efforts. And for CSOs dependent on unpredictable but still available $\mathrm{DAC} / \mathrm{G}$ financing, the "prospects of enhanced reputation and greater credibility" do not "provide sufficient incentives of themselves" (Morris, 2011, p. 60) to spur self-regulation due in part to the distance between funder and CSOs' domestic relationships.

\section{Infrastructure and Status of Self-regulation}

The existence and strength of the CSO sector's infrastructure can drive regulatory change in different ways. A CSO apex body can present a coordinated voice of the sector to influence state regulatory change efforts, while equally its absence can leave a state to forge ahead with regulatory change exclusive of CSO inputs. A strong and representative CSO apex body is also seen as critical to driving the establishment of self-regulation, promoting its coverage across the sector and its legitimacy. Lessons from the Kenya case suggest considerations to apply to avoid over-simplification of the relationship between 
CSO infrastructure and regulatory change. The first two of these are not LMI country specific but worth highlighting.

First, sector infrastructure does not have to pre-exist regulatory change to have an influence but can be created, often specifically to address such change. Gugerty (2014) suggests that in Kenya the existence of the KNCSS was an important rallying point for CSOs' to address regulation in wave one, however, the pre-existing KNCSS was in some respects an early impediment to CSO engagement in state regulatory change due to its limited membership and timid approach. The NGO Network that, after some struggle, managed to influence the NGOs Co-ordination Act then later become the NGO Council did not pre-date the Act but was created in response to it and was a completely separate entity from the KNCSS. Equally, the KCS-CSP that became Viwango was created afresh and separate from the NGO Council, as was the CSORG. Second, not just any CSO infrastructure is equipped to address regulation issues. The NGO Network/NGO Council, KCS-CSP/Viwango, and the CSORG were all built for the specific purpose of engagement in regulation and self-regulation.

Third, the pre-existence of infrastructure for self-regulation cannot be counted on to have an influence on regulatory change. In Kenya, the NGO Council had been fulfilling fairly well its self-regulation role though the 1990s but was then subject to political interference that, combined with other vulnerabilities in the sector following the Second Liberation election, meant the sector was unable to contribute to Sessional Paper No. 1's development. Later, in wave three, the self-regulation initiative offered by Viwango helped shape a PBO Act that allowed for various voluntary self-regulation options. But 
come wave four, the impression left by the amendment attempts and stalled PBO Act implementation was that no amount of self-regulation would stave off a regulatory threat that was not technical but political in its origins. Granted, Viwango did not prove a viable self-regulation scheme given limited uptake by the sector, likely due in part to the obstacle posed by CSOs' dependency on DAC/G funding and thus focus on the accountability relationship with DAC/Gs as discussed above. A strong apex body to promote Viwango might have helped with uptake, but the sector is far from being so cohesive. Despite Viwango's success in its broad outreach to CSOs through its development, or the CSORG's successes in reaction to the GoK's proposed PBO Act amendments, the competition among CSOs for funds and visibility, limit the sector's ability to form a strong apex body (Kanyinga, 2015a, p. 6). Still, it is unlikely that an apex body would have avoided being caught, as was Viwango, in a vicious circle whereby the state regulatory change - or lack thereof in the form of PBO Act nonimplementation - combined with ever-restrictive implementation of the NGOs Coordination Act and a pervasive official anti-CSO narrative, posed a disincentive to selfregulate.

The existence of CSO infrastructure and even self-regulation therefore do influence, and sometimes drive, regulatory change. However, pre-existing infrastructure is not a pre-condition for change, and pre-existing self-regulation can have no effect if what is driving state regulatory change cannot be addressed by self-regulation as a technical exercise of enhancing CSO accountability. 


\section{DAC/G Funding and Policy Engagement}

In LMI countries, DAC/Gs have played a prominent role that is not paralleled in $\mathrm{HI}$ countries. Their regulatory change role has been both a direct and an indirect one that has been manifest in many ways, driving and influencing CSO regulatory change.

When it comes to DAC/G's role in regulatory change, most straightforward is $\mathrm{DAC} / \mathrm{Gs}$ ' funding to regulation and self-regulation initiatives, in Kenya through funding of the NGO Network in wave one (which became the NGO Council); the KCS-CSP (which became Viwango); and the CSORG that designed and negotiated the PBO Act to fruition (if not implementation). DAC/Gs have also played a role through their policy engagement with LMI country governments on the regulation subject. In Kenya this included DAC/Gs' policy pressure on the GoK to consider CSO proposals in relation to the NGOs Co-ordination Act, and later, DAC/G interventions against the GoK's various PBO Act amendment proposals. In both of these endeavours - funding of regulatory change initiatives and policy engagement - DAC/Gs' financial support to their domestic or international CSOs operating in Kenya in partnership with Kenyan CSOs, as well as direct DAC/G support to Kenyan CSOs, has been an element of their influence.

In other ways DAC/Gs' LMI country involvement has been a more indirect driver of regulatory change. That is, $\mathrm{DAC} / \mathrm{Gs}$ ' involvement has come to bear on other regulatory change drivers.

Of note is the DAC/G practice that launched in the 1980s and continues through to today, of applying aid conditionalities leading to suspensions of funding to LMI country governments, while funding CSOs as an alternate provider of social, economic and 
democratic development. This modus operandi has not made governments into fans of CSO sectors. Writing on Africa, Ndegwa (1996) described the situation thus: "the decline of official aid to states in Africa and the more recent withdrawal or conditionality of the remainder have not endeared NGOs to states that view them as competitors", which in turn led African governments to pursue regulation of the CSO sector (p. 22). States' jealousy of DAC/G funding to CSOs in LMI countries is echoed elsewhere as a source fuelling state regulatory reform aimed at gaining control of this funding as seen elsewhere in Africa and in other regions and countries (Bratton, 1989, p. 578; Gugerty, 2010, p. 1091; Dunn et al., 2017, p. 228).

The competition has been an economic one for $\mathrm{DAC} / \mathrm{G}$ financial resources, though economic with a political angle where such resources are desired for political patronage purposes. It has also been a more overtly political one given that $\mathrm{DAC} / \mathrm{G}$ funding has contributed substantially to CSOs' civic and political engagement activities, themselves a driver of state regulation. The growth of LMI countries' CSO sectors has also come about as a product of the availability of DAC/G funding on which CSOs are largely dependent. Further, aspects of DAC/Gs' funding practices including the tendency to fund CSOs for DAC/G-defined priority areas and application of rigid performance management requirements, posed challenges for CSOs in balancing DAC/G needs with CSOs' own mandates and priorities, and relationships of domestic accountability. All told, DAC/Gs' funding to CSOs has acted as an indirect driver of regulatory change, influencing the driving factors of sector growth, CSO activities, CSO mismanagement issues, and government's political agendas (the latter discussed further below). 
Of consideration in this equation is also the changing nature of the relationship of influence between DAC/Gs and LMI country governments. DAC/Gs' role as influencers has been waning in recent years, with LMI countries pushing back against it, including against DAC/G democracy promotion efforts (Carothers \& Brechenmacher, 2014, pp. 2425). This has been further upended due to the growing influence of, and $\mathrm{DAC} / \mathrm{G}$ competition with, other states including China. Further, DAC/Gs' many and competing interests in LMI countries are leading at times to inconsistent approaches and stances that undermine their long-term overall influence - for better or for worse. Strong DAC/G interest in private sector development and in counter-terror (discussed also under Security and Terror Concerns below) appear to be making them less inclined to engage in the kind of policy influencing they traditionally utilized to advance issues of human rights, democracy and accountability, all pertinent to the regulation of CSOs. In as much as the shared anti-terror agenda chips away at DAC/Gs' willingness to defend enabling regulation for the CSO sector, this constitutes an aspect of the "securitization" of aid and development on the rise since 9/11 (Abrahamsen, 2015; Sidel, 2010b, pp. 101-102). In the words of Gyimah-Boadi (2015), these concerns have created a "new "scramble for Africa" in which "Western powers are readjusting their established governance benchmarks in order to stay competitive" with the security and anti-terror push also "erode[ing] the liberal political values that have guided Western foreign policy since the end of the Cold War" (p. 109).

Relatedly, DAC/Gs' contradictory approaches, and increasingly "illiberal acts" (Gyimah-Boadi, 2015, p. 110) domestically and on the global scene are exploitable by 
LMI country governments that, as in Kenya, are inclined to play an anti-West, antiforeign interference card as a means to bolster their own questionable legitimacy while silencing DAC/G criticism. Thus, the significance Gugerty (2014, pp. 10, 16-17 \& 27; Gugerty, 2010, p. 1098 citing Ndegwa, 1996) attributed to DAC/Gs' funding and policy influence in support of the NGOs Co-ordination Act amendments and establishment of the NGO Council in Kenya in 1991 cannot be assumed to apply today.

DAC/Gs are the primary external driver of regulatory change in LMI countries. They have played a direct influencing role through policy dialogue with governments and financial support for CSO state and self-regulation initiatives, though that role is changing as the development landscape changes. That DAC/Gs are "far from neutral actors" (Branch, 2011, p. 299) is evident, even in relation to $\mathrm{DAC} / \mathrm{G}$ actions not necessarily intended as overt policy or political influencing. Their funding relationship with CSOs has inadvertently over time contributed to regulatory backlash against CSO sectors. In various ways $\mathrm{DAC} / \mathrm{Gs}$ have driven regulatory change via their influence on other drivers.

\section{Status of State Regulation}

This research confirms the obvious - that the status of state regulation can drive change in both state and self-regulation. It also provides some observations on the limits of this driver and directions of change that it can provoke that, while not specific to LMI countries may be more pronounced there. The absence or weakness of existing state regulation can drive changes both to state and self-regulation, the latter especially when anticipation of state regulatory change is felt by the CSO sector as a threat. A state 
regulation weakness can be due to a problem with the regulation itself or in the wider regulatory framework in which it is situated, or, it can be a product of poor or nonimplementation of a regulation.

Problems in implementation of existing regulation tend to be more common in LMI countries than $\mathrm{HI}$ ones. This is due in part to capacity challenges that regulators face in the form of insufficient financial resources and the associated shortage of staff, particularly skilled, technical staff, and infrastructure. In the Kenya case, the NGOs Coordination Act did contain weaknesses such that revising it as called for in Sessional Paper No. 1 was due. However, when it came to the Board's 2009 national survey of the sector intended to provide an evidence base for regulatory reform, a key take-away was the Board's own admission that it lacked the capacity to implement the Act adequately and appropriately, citing as examples its staff shortage, its centralized operations, and its inability to play an educating, guiding role for registrants (or potential registrants). Weakness in the Act provided a driver of regulatory change, but beyond issues with the Act itself were deficiencies in implementation that made it difficult to even obtain a full grasp of the Act's gaps. In wave four, the Board's over-reaching implementation of the Act may not have driven changes to state or self-regulation per se. But the wave four implementation experience reinforces that "beyond the formal provisions of law.... attention must be paid as well to the way in which laws are enforced" (Salamon \& Toepler, 2000, p. 2), and such enforcement can be particularly challenging in LMI countries. 
In Salamon and Toepler's (2000) study of CSO legal frameworks they remind us that "legal provisions affecting non-profit organizations can be scattered widely throughout national legal systems" (p. 2). This statement applies equally to HI and LMI countries' legal and regulatory frameworks for CSOs. What it means however is that the kind of weaknesses in regulation or its implementation more prominent in LMI countries - such as capacity issues - will be multiplied across the different regulations and regulators. LMI countries may also be saddled with a regulatory framework from colonial times in which the CSO form was seen as legitimate in as much as it served social and economic development - or 'charitable' - purposes only. ${ }^{148}$ Such regulatory frameworks did little to nothing to address the CSO civic and political engagement/public benefit boundary question, never mind from a more contemporary understanding of CSOs as "more than providers of services" but with a "legitimate role as participants in policy development" (Phillips, 2006, p. 29).

In the Kenya case, a driver of regulatory change apparently behind the NGOs Coordination Act, as reflected also in Sessional Paper No. 1, and then in the PBO Act's design, was to address the regulatory weakness manifest in the existence of multiple regulations covering varied CSO types. However, as revealed in the fourth wave, the various GoK bodies with responsibility for the various regulations did not necessarily

148 The colonial legacy affect on legislation and regulation in Kenya and other LMI countries is not limited to CSO regulation. Legislation criminalizing homosexuality as exists in Kenya is another example of enduring colonial era legislation that is slow to reform (though in 2018 India decriminalized sexual intercourse between homosexuals (Suri, 2018)), as is legislation allowing the death penalty (Wolfe-Robinson \& Bowcott, 2012). 
have a shared interest in harmonizing the varied regulatory regimes. They maintained that each of the existing regulations met a certain specific CSO form that the PBO Act did not. Instead the preference was to maintain the status quo. For a section of the CSO sector too there was interest in maintaining the status quo. For the same reasons that CSOs had continued to register under alternate regulation options after enactment of the NGOs Coordination Act - their particular CSO form, minimizing GoK interference, lighter touch regulation requirements, even as extra regulatory steps would be required to obtain tax exempt status - some were less keen to see harmonization. In a way therefore, a weakness in the existing, non-harmonized regulatory framework for CSOs contributed to regulatory stasis versus change. Absent harmonization, addressing capacity gaps could have gone some way to enhancing the type of outreach, education, and monitoring of registered CSOs to render the various Acts' implementation more effective, or to foster information-sharing and coordination across the regulators. The Kenya case further demonstrated how, at least in the case of the NGOs Co-ordination Board, maintenance of the status quo served its interest as it eliminated uncertainties regarding job security, and, allowed for the continuation of rent-seeking behaviours by Board management and staff.

The history and associated complexity of the regulatory framework for CSOs in Kenya was also thus a confounding factor. For example, the PBO Act sought to move away from the elective approach to tax exemptions for registrants as a significant way to enable their public benefit contributions, incentivize private giving, and reduce the sector's offending reliance on foreign funding. That the elective tax exemptions were regulated under the Income Tax Act would have also required coordination, and 
agreement, on these aims which, given the 2014 amendment attempt to revert back to an elective approach, may have been absent. Competing aims, on the one hand enablement of the sector through improved financial sustainability, on the other, tax collection, were not easily reconcilable, compounded by the multiple regulations covering CSOs. The colonial legacy of a fragmented regulatory framework covering CSOs hindered the emergence of a cohesive understanding of and vision for the sector.

This research confirmed that CSOs facing or fearing pending state regulatory change will indeed turn to self-regulation, as predicted by Dunn et al. (2017), and as seen with the KNCSS's effort in face of the NGOs Co-ordination Act, then later with the KCSCSP. However, subsequent threat of stricter state regulation and overall uncertainty is a disincentive for self-regulation, as demonstrated in wave four following the creation of the apex organization, Viwango.

All of this suggests that the status of state regulation is unreliable as a predictor of regulatory change in LMI countries. It also points to the importance of looking beyond the content of regulatory text, to its implementation, and to its situation in a broader regulatory framework.

\section{Political Agendas}

Regulatory change can be driven by the political agendas of a government in power. Though this political agendas driver can be influenced by a government's discomfort with CSOs' civic and political engagement activities, attributing the political agendas behind regulatory change to CSOs' activities alone would be an over-simplification. And while this driver is present in both HI and LMI countries, in the latter, especially in LMI 
countries prone to authoritarianism; where CSOs are used as a political tool; where the government-CSO relationship is an uneasy one; and where an LMI government also has bones to pick with the primary funder of CSOs, the DAC/Gs, the political agendas driver holds significant weight.

Certainly CSOs' civic and political engagement activities inform this driving factor. Regulatory change can be turned to by governments, using the guise of the need for increased CSO transparency and accountability "as a pretext to silence critics" (UNSR, 2013, para. 38). As seen, this driver is more likely the case in LMI countries than is the imperative of regulating to ensure a $\mathrm{CSO}$ is operating in keeping with the nondistribution principle, or in the public benefit in order to protect financial contributions from domestic sources.

Especially where an LMI country is tending toward authoritarianism, a government will be inclined, by its nature and tenuous legitimacy to "suppress opposition and centralize political power" as a matter of "political survival” (Appe \& Barraga, 2017, p. 1814 citing ICNL, 2006 \& 2009; Dupuy et al., 2015a, p. 306). In such countries, where democratic institutions are limited in depth and durability, or in the words of the incoming Prime Minister Abiy of Ethiopia, there is a "lack of a mature democratic system" (York, 2018a, para. 13), CSOs have and continue to play a key role in bringing about democratic reforms detrimental to authoritarian leaders. In Kenya one can look back to CSO activism that, even under extreme duress, found ways to advance the independence movement. Thereafter, again under duress, CSO civic and political engagement contributed critically to the transition from a single to a multi-party state 
only twenty-five years ago. More recently in Kenya one can look to CSOs' role in the Second Liberation transition, then in reaction to the ICC indictees' candidatures in the 2013 elections, or in monitoring and calling out weaknesses in the 2017 elections. In countries "where the state continues to resist full democratisation", being a civic and politically engaged CSO "necessarily entails being part of the political opposition" and thus felt as a threat by the government in power (Orvis, 2003, p. 266). A government's discomfort with CSOs' civic and political role is exacerbated when, as in the Kenya case, the line between small "p" politics in the form of civic and political engagement and large "p" partisan politics is sometimes blurred, for example by individuals" use of the CSO form for their own political advancement purposes.

Further, the possibility for political agendas to bear on regulatory change is exacerbated in LMI country contexts where a regulator may lack independence from political pressures. A regulator's independence is of concern in HI and LMI countries alike. However, the possibility of politicization is heightened in LMI countries where the type of high level political manoeuvring seen in Kenya is less subject to scrutiny. A regulator's lack of "insulation" may not be simply insulation from the "political winds" (Owens, 2017, p. 82) of prevailing governments, but from outright political interference. In Kenya, the fluctuating placement of the NGOs Co-ordination Board in the GoK hierarchy was indicative of this. It began close to the President's Office (Internal Security) in wave one, with the President's Office itself even having abruptly taken over responsibility for drafting of the NGOs Co-ordination Act. In the second wave it was found slightly further afield in the Ministry of Home Affairs, then was moved to the 
Ministry of National Heritage and Culture in wave three. When this Ministry (amongst others) was dissolved in wave four the Board was first placed under the quite centralized Ministry of Devolution and Planning, then pulled to Internal Security under the President's Office at the peak of wave four contentions.

An independent legal and judicial system can play a significant role in arbitrating for neutral regulatory decision-making that also upholds rights. However, to revert to the judicial system citizens must be able to trust that the rule of law will prevail. In Kenya prior to the fourth wave, little use was made of the judicial system when it came to issues of CSO regulation. Backed by the 2010 Constitution alongside a growing perception that the country has a "strong and vibrant judiciary upholding rights" (I25_GoK), the system began to be put to more use, but the outcomes were still subject to political agendas. Even faced with court rulings, the GoK failed to implement the necessary steps toward PBO Act implementation. While much was made of the landmark Supreme Court decision annulling the first round of the 2017 national elections, the Court, under threat, was cowed following the second election round and so did not rule so courageously.

The Kenya case demonstrates characteristics of the political agendas driver and its prevalence in regulatory change, or regulatory stasis in the case of the PBO Act's nonimplementation and amendment attempts. The NGOs Co-ordination Act was in part a product of the GoK's consternation at CSOs' civic and political activism for democracy reforms, but it was also a product of competition for resources for political patronage purposes. The driver behind the regulatory change in the form of undermining the NGO Council and its self-regulation was in part due to an incoming GoK's interest in stymying 
CSOs' civic and political activism (ironically the same activism that had helped this GoK come to power) and distracting it from calling out government corruption, but was also due to political ambitions of the incoming Council Chair. Notably, the introduction of the PBO Act by the CSO sector and its presidential assent was thereafter possible due to the then GoK's (somewhat) reformist and conciliatory political agenda. Then, its nonimplementation and amendment attempts were a product of myriad political factors. Yes, these included animosity toward the sector due to its civic and political activism in relation to the ICC cases and more broadly such as CSOs' monitoring of GoK governance shortfalls including corruption and accountability standards under the new Constitution and devolution. But they were also part of a wider political effort to silence any critical voice and; political positioning vis-à-vis CSOs' DAC/G funders including a stand against their long-standing pro-democracy, pro-CSO agenda; and, politicians' reluctance to see regulatory reform that might jeopardize their use of CSOs as a political tool. The Kenya case shows how political agendas can amount to the use of "political interference" as a "management tool", or in the context of this research, a regulatory tool (Kanyinga, 2016, para. 69).

Strangely, although as seen in the political backdrop of each of Kenya's regulatory waves, Kenyan politics are "ethnic laden" (Ndegwa 1996, p. 37), ethnicity was not a driver of regulatory change in and of itself. But, ethnicity shaped the broader political agendas associated with competition for political power, as may also be the case in other LMI countries where ethnic divisions are a feature of the landscape. Formal politics in Kenya is seen "as a zero-sum competition for preference" between ethnic groups 
(Hornsby, 2012, p. 628), yet any form of CSO challenge to political power holders may risk being subject to the GoK's political agendas regardless of its ethnic origins, if it has any.

True that there was a hint in Kenya's first regulatory wave of then President Moi's ethnic re-balancing as a motivating factor behind regulatory change, and CSOs have been on different sides of ethnic divides - for example in the 2005 constitutional debate in Kenya where support for the (defeated) status quo constitution tended to come from the Kikuyu/President Kibaki side versus support for a reformist constitution from the Luo/opposition/Odinga side (Wanyande, 2009, p. 17). At the same time however, politicians' "instrumentalization of ethnic identity" led them to accuse CSOs of ethnic bias when CSOs' policy positions were not embraced by said politicians (Njongu, 2018, p. 14). Over time, the CSO landscape became more ethnically diverse such that, by the fourth wave, it could not be said that regulatory over-reach by the GoK was driven by or targeting a particular corner of the CSO sector dominated by a particular ethnic group. As noted by an interviewee: "you can't say the backlash is against a certain ethnic group" (I56_Other). Kanyinga (2015b) has pointed out that the current GoK and CSOs "cannot be expected to be comfortable bedfellows" as the current GoK leaders and CSOs have since the 1990s consistently been on opposite sides of political transition battles (paras. 20-22), which themselves tend to fall along ethnic lines. But while for the political leaders the battles were ethnic laden, for CSOs the battles - whether in constitutional debates or for a change in government - were for reform, for a change from the status quo. Certainly this may read as an over-simplification of a very complicated landscape. 
The main point is, regulatory change or over-reach cannot either be simplified to being about GoK backlash against CSOs dominated by any particular ethnic group.

All told therefore, the political agendas driver bears considerable weight in LMI countries. Noteworthy also is that the intricacies of political agendas in context can make it difficult to predict regulatory change. In Kenya, the nature of the incoming Second Liberation GoK would not have anticipated the regulatory changes and challenges of wave two. Equally, in wave four, politicians' resistance to a PBO Act with strong potential to strengthen regulation of the sector could not have been readily predicted. As noted by Minogue and Cariño (2006a), "regulatory policy making in developing countries" is of a "deeply political nature" (p. 12), more so still under authoritarianleaning regimes with questionable legitimacy and tendencies toward corruption. The intimation of Walzer's (1990) and then Foley and Edwards' (1996) "civil society argument", that it is the prevailing politics of regimes in power that define parameters for CSO operations, continues to resonate.

\section{Public Management Agendas}

Regulatory change can be brought about by the pursuit of particular public management models, with, for example, a state-centred planning and administration model overtaken by NPM and more recently morphing into a regulatory governance model. Public management agendas are present as drivers in both HI and LMI countries. However, in LMI countries their pursuit by governments is less significant relative to the other driving factors of this conceptual framework. LMI country governments do pursue specific public management agendas, whether independently-motivated, or in taking up 
the "management message conveyed by donors" such that, for example, "many of the principles (more or less appropriated) of NPM are to be found in LMI countries" (Naudet, 2012, p. 11). As a driver of change in CSO regulation however, it is primarily the public management agendas as pursued by $\mathrm{DAC} / \mathrm{Gs}$ that indirectly influence regulatory change.

As discussed above under External Actors, in LMI countries DAC/Gs have brought their policy influence, and thus their public management agendas, along with their aid funds. While there is a dearth of literature linking trends in aid management and public management, linkages are evident, at least when it comes to the application of NPM (Naudet, 2012, p. 13). In Kenya and elsewhere, in the early days of NPM DAC/G policy conditionalities focused on privatization and rolling back the state. Privatization also meant increasing funding for CSOs especially to undertake social and economic development services in the state's stead. The affects included the proliferation of CSOs, sometimes alongside suspended or otherwise reduced funding to LMI country governments. DAC/Gs' pursuit of NPM also informed their tendency to fund CSOs for DAC/G-defined priorities, and to impose performance measurement requirements. As a result, DAC/Gs' pursuit of particular models of public management have an influencing effect on other driving factors: sector growth; political agendas where there is perturbation with the growth of this relatively independent sector and its access to $\mathrm{DAC} / \mathrm{G}$ funds; and an undercutting of the relationships of domestic accountability so important to CSOs' legitimacy. As DAC/Gs adopted a governance model their influence 
included emphasizing, and sometimes requiring, the participation of CSOs in the public policy realm.

Less a driver in and of itself therefore, public management agendas especially as pursued by $\mathrm{DAC} / \mathrm{Gs}$ provide an indirect influence on CSO regulatory change in as much as they influence other driving factors.

\section{Security and Terrorism Concerns}

Security and terrorism concerns have become a more prominent driver of state regulatory change in both $\mathrm{HI}$ and LMI countries in recent decades as countries worldwide have faced specific terror incidences and the global counter terror movement has expanded in reach and importance. The security driver has some characteristics particularly pronounced, though not exclusive to LMI countries, which relate to authoritarian politics, to the capacity challenges of regulators, and to the relationship with DAC/Gs.

In LMI countries, especially with authoritarian leaning governments bent on silencing civic and politically engaged CSOs, the balance between security and the freedoms of association and assembly so critical to CSOs will already be tenuous. In such environments, the state can be quick to turn to national security and the terror threat as rationale for regulatory change. This was the case in Kenya going back to the first wave's development of the NGOs Co-ordination Act when President Moi accused the CSO sector of being a threat to national security, really a threat to his reign. More recently, the issue of terrorism provided the GoK with a handy veil of justification "for either clamping down on the sector or proposing certain provisions that would in a way curtail 
the sector" (I61_Other). As a driver of regulatory change therefore, security and terror concerns may be used as easy veneer to mask politically motivated agendas.

Further, the features of regulators in these LMI country contexts inform the use and appearance of this driver of regulatory change. A non-independent, politicized regulator will not resist the push by a government bent on restricting CSOs through regulation, or intimidation, to use the terror-CSO narrative as rationale for regulatory change. Regulators' capacity challenges are an exacerbating element particularly given the proliferation across multiple ministries and agencies of "wide-ranging regulation under the rubric of anti-terrorism law and policy" that increasingly "supplement" states' CSO regulations (Sidel, 2010b, p. 133). Deficiencies in information sharing and coordination across regulators, as well as in the implementation of existing regulations, seem to increase the chance that terror becomes a misplaced driver of regulatory change.

The 2015 experience of MUHURI and Haki Africa in Kenya are illustrative, though not so much of terror as a driver of regulatory change but of its influence on changes in the application of regulation. The two CSOs were included on a list of entities suspected of association with terrorism issued by the Inspector General of Police under the Prevention of Terrorism Act (2012). With the issuance being in breach of this Act for a variety of reasons (KNCHR, 2015a, paras. 7-8), the two CSOs filed a court case that found them to be illegitimately on the list. Following the CSOs' court filing the NGOs Co-ordination Board began (unsuccessful) steps to deregister them based on also unfounded non-compliance with the NGOs Co-ordination Act. Both of these instances point to a sort of regulatory change in the form of implementation over-reach that was 
shown to have little to do with any sort of security or terror threat posed by these CSOs. Also noteworthy were the general statements from the NGOs Co-ordination Board associating CSOs with terrorism, and references to an unspecified terror-CSO link as justification for PBO Act amendments.

The requirement for states to comply with FATF standards also shapes the Security and Terror Concerns driver, in both HI and LMI countries. The Global Non-Profit Organization Platform on FATF's consistent call for an evidence-based approach to eliminate or revise Recommendation 8, noting that non-profits are "not a significant source of terrorist financing" and that "the frequency and severity of such abuses is very low" (Global NPO Coalition on FATF, 2014, p. 2), met with success at least in revising the Recommendation (Global NPO Coalition on FATF, n.d.-b, para. 1). Still, that the terror-CSO link proposition was "accepted and embraced by many national governments", influenced regulatory regimes for CSOs in a number of countries, and will not be quickly undone (Hayes, 2012, pp. 27 \& 30-35). In the words of McGregorLowndes and Wyatt (2017a): "Non-democratic nations have relished the opportunity to use its broad and uncompromising principles to stifle dissenting civil society organizations in their own domestic spheres" (p. 276).

Particular to LMI countries is the mixed bag of the $\mathrm{DAC} / \mathrm{G}$ influence in this arena as already mentioned. DAC/Gs' commitment to maintaining relationships with LMI country governments as strategic allies in the counter-terror effort may in a sense empower, or "give space" to the latter to turn to terror concerns as a justification for over-reach in the regulation of CSOs (Abrahamsen, 2015, p. 2). Carothers and Brechenmacher (2014) 
point to a "counterterrorism spillover" occurring as DAC/Gs" implementation of legal and regulatory restrictions domestically in the name of counter-terrorism signal the value and legitimacy in doing so (p. 29).

As a driver of regulatory change therefore, security and terror concerns are present, but need to be viewed with caution. On the surface they may appear as a significant driver, but in country contexts where political motivations prevail as the main driver of regulatory change, security/terror concerns can provide an excuse for regulatory change rather than an evidence-based rationale.

This research has found that the factors driving regulatory change are many, interlinked, and all present in Kenya to varying degrees. Further, it has found that characteristics particularly prevalent in LMI countries inform how these drivers are shaped, while giving weight to some drivers over others. The types of activities CSOs are active in drives regulatory change due to states' political agendas, whether more open and collaborative political agendas such as seen in Kenya in wave three, or rather more closed and punitive ones such as seen in waves one and four in particular. That DAC/Gs are so prevalent in LMI countries, both as providers of ODA to CSOs and governments and as policy influencers, makes them an important driving factor. Moreover, their influence spans across virtually all of the other driving factors.

The conceptual framework of this research has provided a lens through which to probe, in a comprehensive way, what drives regulatory change and how to recognize the drivers in LMI country contexts. Figure 6 illustrates the framework of regulatory change 
drivers, with the most relevant LMI characteristics shaping each driver noted by number beside the driver.

Figure 6: Conceptual Framework - Drivers of Regulatory Change with LMI Country Characteristics

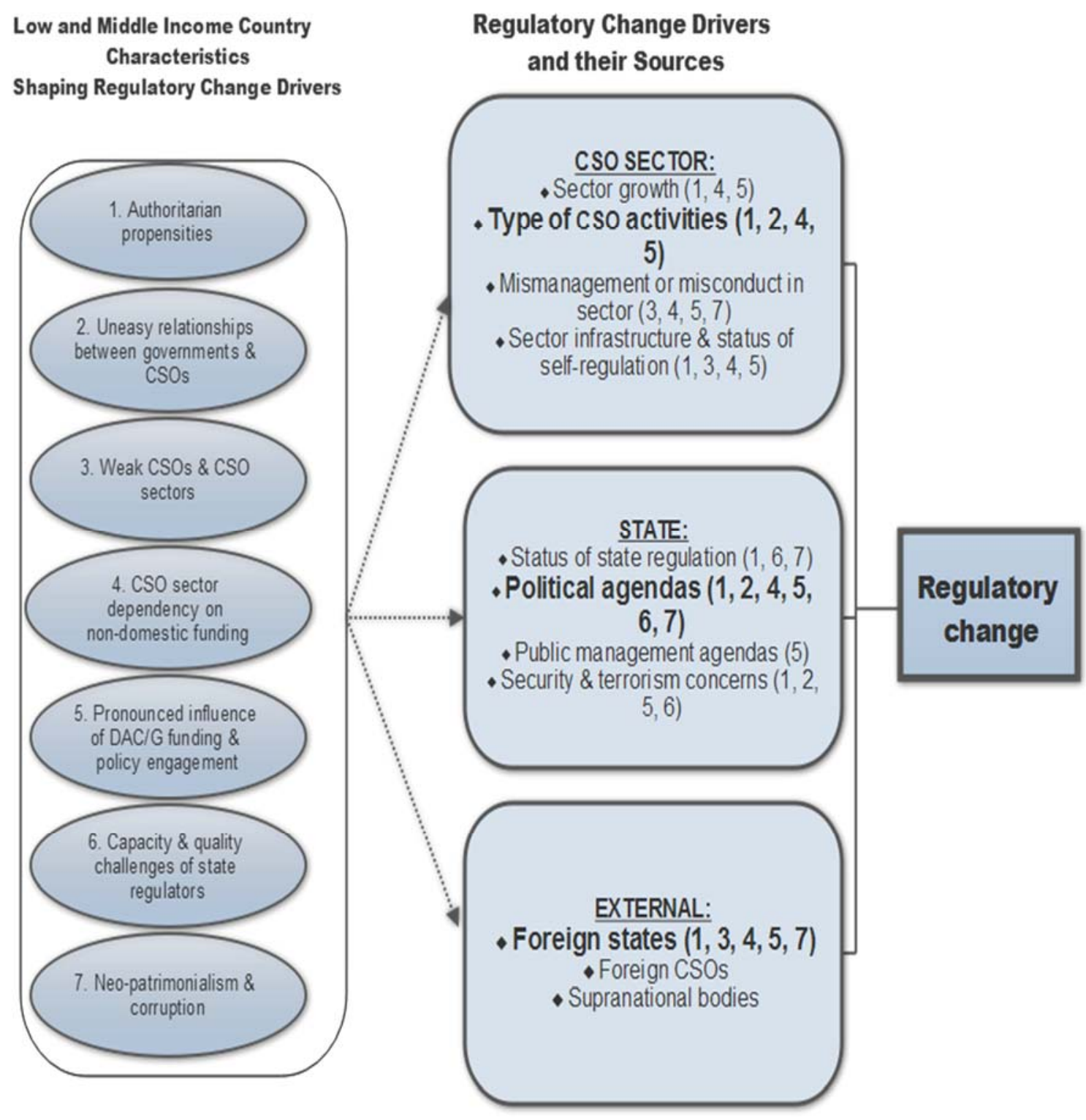




\section{Implications for the State and Self-regulation Relationship, Accountability and the Paradox}

What this analysis of the drivers of regulatory change points to is that the notion of a trade-off between state and self-regulation, and an ensuing wave-like pattern between the two, cannot be counted on to predict when change in one or the other forms of regulation will occur. Certainly regulatory change occurs in what can be called 'waves', with peaks and valleys of regulation and/or self-regulation's initiation, implementation, review, reform, or stasis. But, rather than a straightforward interplay between state and selfregulation, it is the myriad of other drivers of regulatory change and their interplay that have the most predictive power. To understand or attempt to predict regulatory change, the state and self-regulation relationship is not the first place to look; the push and pull of the various factors driving regulatory change obfuscate the state and self-regulation relationship. This is in keeping with the conclusion ultimately reached by Dunn et al. (2017), that state and self-regulation are influenced more by the relationship between states and CSOs, and by their respective strengths or weaknesses, than by the regulatory form (state or self) (p.228). This research goes further by enhancing our understanding of a variety of factors driving regulatory change.

None of this is to say that LMI country states and CSO sectors should cease efforts at "getting the right mix" (Morris, 2011, p. 60) of state and self-regulation. A long-term perspective is needed recognizing that relationships evolve and that remedying confounding challenges such as a regulator's lack of independence, or a CSO sector's financial dependency on foreign funding, will not occur overnight. Moreover, the drivers of regulatory change suggest the inadequacy of purely regulatory fixes. 
In LMI countries, particularly with authoritarian tendencies, the key driver of political agendas is not readily resolved with a technical fix of state or self-regulation. Equally, in LMI country contexts, some of the driving factors have features the nature of which render them also not readily resolvable with a technical response of CSO regulation or self-regulation. Mismanagement or misconduct in the sector; corruption and rent-seeking behaviours in both the CSO sector and in government; regulators' capacity and independence gaps; the veil provided by the reality of security and anti-terror concerns; and the web of DAC/G direct and indirect influence, alongside CSOs' and governments' reactions to it, are cases in point. This further raises questions about the regulation and accountability relationship. If state and self-regulation are called for to provide technical fixes to CSO accountability gaps, other gaps revealed by the drivers - gaps that could be construed as gaps in the accountability of states doing the regulating, or of DAC/Gs' providing funding to CSOs and LMI country governments - are not addressed. Thus, whereas the "long-standing debate" about CSO accountability might provide an ingredient to the "potent cocktail of justifications" (Rutzen, 2015b, p. 30) for regulatory change, especially of the restrictive nature, CSOs' accountability gaps are but one piece of the regulatory change puzzle.

While DAC/G influence is changing, the legacy of decades of funding to CSOs, despite the sector's sense of its diminishment, is ongoing and likely to remain an important driving factor. In LMI country contexts with authoritarian tendencies, state regulatory change will also continue to be driven by political agendas, especially but not exclusively related to CSO civic and political engagement activities. The convenience of 
the terror threat, and its significance as a shared, global concern including of the DAC/Gs, suggests authoritarian leaning governments will continue to "skilfully deploy[ed] the legitimating discourse of terrorism" in their use of regulation and other means to control the sector (Howell et. al., 2008, p. 86). When it comes to the key trend of concern behind this research, that of the growing incidence of state regulatory change that is shrinking the space available for CSOs to operate, the perception that "the real motivation is always political" is not far off the mark (WMD \& ICNL, 2012, p. 10). Such regulatory change may well fundamentally aim at "protecting those in power from scrutiny and accountability", or as seen in the Kenya case, penalizing the CSO sector (WMD \& ICNL, 2012, p. 10). This puts in question a state and self-regulation trade off. At the same time, application of the conceptual framework of regulatory change drivers has also shown that political agendas, while prominent, are not the only factor of consideration in understanding regulatory change.

This analysis of the presence and recurrence of the driving factors in Kenya over a thirty-year period also sheds some light on the paradox in which CSOs are at once recognized for their contribution, while also restricted through regulation. Even as the sector's contribution may be well understood, states and the self-regulating CSO sector are nonetheless faced with various issues - the driving factors - for which regulatory change may be turned to as a solution, even if it may not necessarily be the best, only, or sufficent means to address these issues. The trend of shrinking CSO space through regulation cannot be explained as simply a political backlash by authoritarian-leaning LMI country governments against CSOs' civic and political (or social and economic) 
activism. This is easy logic for the growing anti-'shrinking space' movement comprised largely of CSOs and $\mathrm{DAC} / \mathrm{Gs}$, and, cynically, provides a convenient defense when questions are raised about these actors' practices. Yet it is fair to say that there is also an element of LMI states, and CSOs, working, however disjointedly or worse, antagonistically, through their relationship, the balance between their roles, and the necessary features of a contemporary regulatory framework. While from the post-Cold War era many LMIs experienced the unfolding of what Bloodgood and Tremblay-Boire (2018) refer to as a "Wild West" or "anything goes" period of sector growth and diversification, at present a process of "maturation and regularization" of CSO regulation may be underway (p. 4). Yes, the regulation of CSOs has become a target of LMI (and other) states' repressive tendencies, and a better understanding of the reasons why this is the case, as this research has helped reveal, is important toward helping turn the tide on this phenomenon. Without diminishing the importance of the shrinking space issue, it is necessary to temper our understanding and approaches to addressing it by recalling the long-term, up-and-down nature of struggles for change. At the risk of sounding patronizing - the CSO sector's struggles around the PBO Act in Kenya are certainly real, but the environment for CSOs, both in regulation and in practice, is certainly more enabling than it was prior to and during Kenya's first regulatory wave.

This chapter has served to revisit the conceptual framework of chapter two in ways that highlight how the drivers of regulatory change are manifest in LMI countries, their relative importance, and the implications for the state and self-regulation relationship. Of course, each LMI country will have a different regulatory change story, and caution is 
needed in generalizing from the Kenya case. Nonetheless, this research has shown how the conceptual framework, enhanced with LMI country context considerations, can broaden our understanding of CSO regulatory change drivers. 


\section{CONCLUSION}

The contribution of this research has been to at once broaden and deepen the study of CSO-related policy and regulation, which has been dominated by coverage of $\mathrm{HI}$ countries, with an in-depth LMI country case covering thirty years. This research adds to the nascent scholarly treatment of state and self-regulation of CSOs together, and of their interactions. It offers a conceptual framework incorporating driving factors behind regulatory change gleaned from the literature, while highlighting and illustrating previously un- or insufficiently articulated driving factors and their characteristics that apply especially, though not exclusively, in LMI country contexts.

The regulation literature argues that regulation is pursued as a means of accountability, and that there is a trade-off relationship between state and self-regulation in which one can provide an alternate for the other. This notion of trade-off informs the idea that countries' regulatory regimes undergo waves of alternating emphasis on one or the other of state or self-regulation. One way to investigate the relationship between state and self-regulation of CSOs, and between regulation and accountability, is to consider the array of factors that the literature and empirical evidence suggest drive regulatory change. This research has done so by developing, then applying, a conceptual framework of drivers of regulatory change to the case of Kenya over a thirty-year period. The framework's regulatory change drivers include those emanating from the CSO sector, from the state, and from external sources. Specifically the driving factors are: sector growth; type of CSO activities; mismanagement or misconduct in the sector; sector infrastructure and status of self-regulation; status of state regulation; political agendas; 
public management agendas; security and terrorism concerns; foreign states, CSOs and supranational bodies, the latter dominated by $\mathrm{DAC} / \mathrm{G}$ funding and policy engagement in LMI countries.

In applying the conceptual framework, this research has demonstrated its relevance, while illustrating how our understanding of the drivers can be framed and enriched for application in LMI countries. The characteristics of the drivers, their inter-twined and sometimes mutually reinforcing (or undermining) nature, and their relative significance will differ between LMI countries and the HI countries that the bulk of the scholarly literature on CSO regulation has tended to address.

Of course, the characteristics, linkages and significance of the regulatory change drivers will differ across LMI countries as well. This research has covered only one country case, and each country's story will be distinct in its configuration of drivers. However, where countries share some of the generalized LMI country characteristics as outlined in chapter two, the lessons from the Kenya case will have broader applicability. Further nuanced research applying the conceptual framework on a country-by-country basis would help verify the conceptual framework's relevance and provide opportunities to refine it.

This research has found that in LMI countries the most important driver of regulatory change is the political agendas of governments and their leaders. The political agenda driver goes-hand-in-hand with that of the types of CSO activities, with political agendas particularly geared toward reining in CSOs' civic and political engagement activities. This is unlikely to come as a surprise. Still, the various LMI country characteristics 
shaping and giving weight to these drivers can guide us in detecting them and understanding their full complexity. Moreover, the external driver of $\mathrm{DAC} / \mathrm{Gs}$ is highly pertinent in, and particular to LMIs. These actors may have a direct regulatory change role, but also, an important indirect role in that their funding of CSOs and of LMI country governments, and their policy engagement, shapes so many of the other regulatory change drivers.

Further, the drivers of regulatory change help demonstrate that in LMI country contexts, the anticipated logic in which there is a wave-like interplay between state and self-regulation does not hold true; there are too many other drivers of change that trump the theorized state and self-regulation relationship. Regulatory change occurs in 'waves', but, rather than any interplay between state and self-regulation, it is the varied drivers of regulatory change and their interplay that move and shape the waves along. Further, that state and self-regulation of CSOs offer a technical fix, and a narrow one that cannot readily resolve the issues contained in the driving factors, calls into question the relationship between state and self-regulation.

What the drivers of regulatory change also show us is that while some of them, to some degree, reflect issues of CSO accountability, others are only nominally or not at all about CSO accountability. Just as regulation, whether by states or self-regulation, "can only be part of the answer" to the challenge of CSO accountability (PAGVS, 1999, p. 12), interest in addressing CSO accountability only partly answers why there is regulatory change. Understanding this can help us be aware of the risk that accountability 
arguments can be used as a pretext for other regulatory change rationales. There are far too many factors at play to conflate them into a single issue of CSO accountability.

Applying the framework of regulatory change drivers, does not fully answer the question as to why there a paradox in which the significant contribution of CSOs is recognized, and efforts are made to enable it, while simultaneously space for the sector's functioning is also being restricted. It does, however, give clues, by shedding light on the myriad drivers, their complexity and their interaction. To illustrate, when, in the early years of my studies I expressed interest in investigating the drivers behind shrinking CSO space through regulation, a colleague suggested that I need only count the number of civic and politically engaged CSOs in a country to understand the trend. Clearly CSO civic and political activism, and states' political agendas of quelling that activism, are driving factors, but are far from the only ones at play. Equally, the need for greater accountability from mismanaged or corrupt CSOs is also an over-simplification of regulatory change rationales that only tells part of the story.

What is also evident from this research is that understanding regulation and its change requires a more in-depth look than at what is found in legislative and regulatory text. Implementation is key, especially in contexts where a regulator, and its political patrons, has administrative and political room to manoeuvre, as are extra-regulatory measures.

This analysis generates at least two recommendations for future research. The first concerns the conceptual framework of this research. While it has provided an organizing analytical tool, as with all such tools, the framework merits application in other country contexts, and further refinement. As regards the latter, toward completion of this research 
it became evident that while each of the conceptual framework's drivers of regulatory change were present and relevant in Kenya, some elements of the drivers might have warranted treatment as separate drivers. Even if in so doing the conclusions on the primary driving factors are not anticipated to have altered much, separate treatment would have usefully informed the analysis, though would also have necessitated additional data collection on these topics.

Specifically, the judiciary stands out for its growing role in interpreting CSO-relevant legislation, which, even as it did not actually change the course of the PBO Act's nonimplementation in wave four, was an important site of contestation on CSO regulatory matters. Also, the financial implications of CSOs - at once contributors to the economy, including but not limited to the $\mathrm{DAC} / \mathrm{G}$ financing flowing through them, but also a cost to the economy where tax and other benefits are accorded them - would benefit from more fine-tuned analysis. Additionally, though the role of DAC/Gs quickly rose to the surface as the key external driving factor in this research, a more fulsome picture of external drivers could be provided with separate attention to other external sources. This could include other foreign governments including 'like-minded' governments with authoritarian propensities such as Ethiopia, which itself placed foreign funding restrictions on CSOs in 2009. It could also include foreign CSOs' as potential external drivers, though in this research their role would have been difficult to separate from the driving factors (sector growth, activities, etc.) emanating from CSOs. That said, each of these additional potential drivers would merit research studies of their own. 
The second future research consideration pertains to the ways in which research seeks to understand CSO regulation. Scholarly interest in the subject of shrinking regulatory space for CSOs has been on the rise in recent years, evidenced for example in the number of presentations on the topic at the 2018 International Society for Third Sector Research conference. Ambitious initiatives that seek to quantify and rank regulation across the globe are found within this growing body of study (e.g. see Bloodgood \& TremblayBoire, 2018; DeMattee, 2018). These are extremely valuable, for the academic rigour they bring to the study of CSO regulation, and for their ability to both provide a macrolevel view of the state of CSO regulation worldwide while also allowing for comparative study. However, the current research on Kenya has helped to show the limitations of such approaches if the text of regulation is abstracted from the wider context, regulatory and otherwise, in a country, and regulation's implementation. A look at the NGOs Coordination Act text out of context would not have anticipated, for example, its back-stop use in wave four to attempt to shut down two CSOs unjustifiably accused of terror links, or in the 2017 election year to curtail the activities of other CSOs not even registered under the Act. Nor would it have captured the various capacity challenges faced by the NGOs Co-ordination Board in implementation of the Act as the sector grew and grew, nor the demise of self-regulation as required under the Act.

Regulation can be assessed as more or less restrictive or enabling on paper, but such assessments will not capture the ins and outs and inconsistencies of interpretation. Nor will assessments of legal text capture a state's extra-regulatory measures that have a regulating effect, such as seen in Kenya with, for example, political interference in both 
state and self-regulation, or in the state's anti-CSO public relations narrative. As noted by

ICNL (2015b), when seeking to understand a country's regulatory requirements, it is "extremely important to look beyond the text and consider the legislative and interpretive context" (p. 3).

The findings of this research have policy implications for LMI country governments, for CSOs, and for DAC/Gs. An over-arching implication is that, in as much as the drivers of regulatory change emanate from each of these three key actors, regulatory regimes for CSOs can be seen as a shared responsibility. ${ }^{149}$ Actions to address the paradox of valuing, and indeed benefitting from CSOs while shrinking space for their operation through regulatory restrictions thus need to come from these three actors.

The stickiest action area can be said to lie with LMI country governments and fundamentally whether there is interest, especially by authoritarian-leaning governments, in enabling CSO sectors through regulation (and otherwise). Under the new and stillevolving global geo-political balance of power the tendencies seen in Kenya represent a new normal. Though admittedly a facile recommendation, perhaps it is dialogue between LMI country governments and others, CSOs and DAC/Gs in particular, which could help

${ }^{149}$ This 'shared responsibility' approach to understanding enabling environments for CSOs has been gaining traction in the field of international development cooperation, reflected in the work of the Task Team on CSO Development Effectiveness and Enabling Environment, with which this dissertation's author has been working in a senior policy and strategy advisory role since its 2009 inception (e.g. see Task Team, 2016a \& 2016b), The Task Team's work helped inspire the Global Partnership for Effective Development Cooperation's four-part, shared responsibility framework of their biennially-monitored Indicator 2: Civil society operates in an environment that maximizes its engagement in and contribution to development (GPEDC, 2015). 
stem the flow of restrictive regulatory change. Dialogue might help to move these actors toward a common understanding of what enabling regulatory frameworks might look like, and what CSOs and DAC/Gs can also do to increase a government's comfort level with the CSO sector. Whether in contexts such as Kenya's today the government would initiate such a dialogue seems an unlikely prospect. If it did, it might well be up to the CSO sector, with the support of researchers, to come to the table with an evidence base on the sector's contributions to social and economic development, which is where the interest and felt legitimacy of authoritarian-leaning LMIs tends to lie. Human rights rationales for promoting and protecting the rights of CSOs can be called on but they are not sufficient to make the case. This is especially so in countries where, even if constitutional commitments to rights exist domestically, rights activism is projected as a foreign agenda. ${ }^{150}$

Also needed is dialogue within governments toward coherent rather than contradictory aims and associated coherence in regulatory frameworks. Though Kenya's case of regulatory complexity may be considered extreme, it has helped to illustrate the importance of "meta-policy", of over-arching policy frameworks needed to shape the government-CSO relationship and associated policies and regulations (Phillips \& Smith, 2014, p. 1143). Such frameworks cannot come from a single regulator, nor a President's office. Moreover, even a coherent regulatory framework based on a solid vision of and

${ }^{150}$ As an example of resistance to CSO civic and political activism and 'foreign' ideas of rights, when Saudi Arabia (not an LMI country but an authoritarian one) legalized driving by women, authorities apparently told activist groups "Don't take credit for this" (Clark, 2018, p. A12). 
for the CSO sector will flounder in the absence of trust in its coherent and transparent implementation. Speaking to the use of tax deduction regulations as a means to promote private philanthropy in Kenya for example, Ochido (2013) notes the challenge of "convincing the giving public that the state can be trusted to mediate the gift relationship through regulation. In a nation where the state is generally associated with the betrayal of the public trust, and where agencies are continually engulfed in financial scandals, this will be a hard sell” (p. 70).

In a related idealistic vein, CSOs could also take steps toward constructive relationships with LMI country governments. In this regard the avoidance of partisanship is critical and one that Kenyan CSOs learned somewhat in relation to the 2007/08 PEV. On the one hand, that CSOs had become "progressively partisan" rather than 'issue based" in the years of divisive politics leading up to the 2007/08 elections meant the sector had come to be seen as a non-neutral contributor to "political polarization" (KNCHR, 2008, paras. $89 \&$ 94). On the other, the PEV crisis provided a (tragic) opportunity for the sector to shine due to its critical contributions in the humanitarian response, in advocating for an end to the violence, and in the reconciliation thereafter. Practically as well, productive relationships can be advanced by CSOs, at least those working in social and economic development, that seek ways to share information about their programming and coordinate with governments. Certainly, as seen in Kenya's first wave, the need to 'coordinate' CSOs can be used as an excuse for 'control'. Yet, constructive relationships between CSOs and LMI country governments are not helped 
when governments have limited knowledge of what thousands of largely foreign-funded CSOs are undertaking and contributing to development.

There are other practical matters that CSOs could attend to to address actual and perceived accountability gaps and "legitimacy vulnerabilities" (Brechenmacher \& Carothers, 2018, p. 38), individually as well as within self-regulation schemes. Brechenmacher and Carothers (2018) summarize many of these succinctly in a recent examination of CSO legitimacy in the context of restrictions on CSOs (pp. 34-39), while there is also ample ongoing effort to articulate and promote them by CSOs globally and in specific country contexts (e.g. see Global Standard for CSO Accountability, 2017), though evidence of the breadth of their uptake is not easy to come by.

Strengthening relationships of domestic accountability - with governments but also with constituencies, beneficiaries, and the public, is paramount. CSOs need to (re)connect with those they seek to serve or represent, using various tools - participatory approaches, social audits, inclusive boards - of which there is ample coverage in the CSO accountability literature. In this way CSOs can go a long way to (re)build their base and legitimacy toward "a stronger and more outspoken base of domestic support" (Christensen \& Weinstein, 2013, pp. 89-90) to help protect the sector from restrictive space measures, though evidence shows that in countries inclined to authoritarianism, a base is not adequate protection (Bullain \& Rutzen, 2018, p. 32). It can also be an important step toward addressing CSOs' dependency on DAC/G funding, for local philanthropy will not take hold where CSOs' accountability focus is external. 
On that note, it is dis-heartening that the need for CSO income diversification has been a topic of concern for some time (e.g. see Edwards \& Hulme, 1996), and various trainings on financial sustainability offered to LMI country CSOs over the years have not, nor could they be expected to, resolve the challenge. Alternative sources need to be available, whether from domestic philanthropy - that governments can help facilitate through appropriate regulation - or alternative funding arrangements that are "more insulated from the politics of bilateral relations" such as endowments or corporate sources (Christensen \& Weinstein, 2013, p. 87). Building local philanthropy has not received much attention in the international development arena nor LMI countries though this may be changing, seen for example in the recent OECD publication Private Philanthropy for Development (OECD, 2018c), or in the recent establishment of a Chair in African Philanthropy at the Wits Business School in South Africa (University of Witwatersrand, 2018). Still, in LMI countries where disposable income levels are relatively low, local philanthropy, even if increased by tapping into traditions of "mutual help, with accountability resting on traditional value systems" (Ochido, 2013, p. 70), will never substitute for the vast amounts of DAC/G funding CSOs have received over many years.

When it comes to DAC/Gs, there are also things they could do differently in their funding and policy engagement in LMIs. Again somewhat disheartening is that many of the issues regarding how DAC/Gs fund CSOs are not new (see Edwards \& Hulme, 1996a). But the stakes of DAC/G policy and practice in this regard may be getting higher in the context of a new LMI country normal where DAC/G funding has some deleterious 
affects on government attitudes towards and relations with CSOs. If DAC/G governments retain a belief in the value of democracy and the role of vibrant CSO sectors in promoting and upholding it, whether or not DAC/Gs opt explicitly to pursue democracy promotion, how they fund CSOs, and which CSOs or broader civil society movements they support, contribute to the sector's vibrancy and credibility. Guidance exists for DAC/Gs' CSO support, such as the OECD's, 2012 Partnering with Civil Society publication, while their own evaluations point to pitfalls of their CSO funding and ways to address them to be less distorting of the sector (e.g. see Nilsson et al., 2013; Abuom et al., 2012). ${ }^{151}$ It seems though that $\mathrm{DAC} / \mathrm{Gs}$ are eternally challenged to square the circle of their need to demonstrate development results and their own accountability for taxpayer dollars domestically in DAC/G countries with the need to support genuinely locally-rooted CSOs able to focus on their own domestic accountability relationships.

The DAC/Gs also need to be thinking differently about how they engage at the policy level with LMI country governments. Their ODA continues to be an important source of development finance but it does not have the leverage it once did that allowed DAC/Gs to use it as carrot and stick in an earlier era. Moreover, the inconsistencies in DAC/Gs' approach whereby they would for example sacrifice a principled stand on issues of corruption or human rights for economic growth, stability and security have become even starker and this leaves them vulnerable, especially as nationalism and other less-thandemocratic tendencies rear their heads in $\mathrm{DAC} / \mathrm{G}$ countries. That "shadows are falling

${ }^{151}$ In June 2018 the OECD announced to DAC/Gs in an International Donor Group on Civil Society its intent to update the Partnering with Civil Society guidance in 2019 to reflect more current realities. 
over the international enterprise" of democracy diffusion and promotion (Haggard \& Kaufman, 2016, p. 137) is all the more reason, in this author's view, for DAC/Gs to aim for greater consistency and coherence in their foreign policy inclusive of development, security and defense, and democracy.

There is also a growing body of guidance available to $\mathrm{DAC} / \mathrm{Gs}$ and other international donors on how they can more strategically address the paradox of closing CSO space including in their policy engagement with LMI country governments (e.g. see ICNL, 2018; ARIADNE, European Foundation Centre, \& International Human Rights Funders Group, n.d.). However, further creative thinking is warranted to equip willing DAC/Gs to navigate the new normal. 'Willing' is an important qualifier here given political shifts in some HI countries whereby populism, nationalism and less-liberal democratic ideals are gaining legitimacy, such that the policy-makers and delivers of DAC/G ODA and foreign policy more broadly already have a tough job of simply protecting development cooperation.

There is much more that has been written about ways to improve the practices of LMI country governments, CSOs, and DAC/Gs, which go beyond the purview of this research paper. In looking at some examples that the Kenya narrative indicates as influential, the point is to reiterate that the drivers of regulatory change are manifold and stem from different sources. Still, the Kenya case reminds us that LMI country political agendas are at the forefront of regulatory change. Thus, while recognizing a degree of shared responsibility for CSO regulatory change, as Bullain and Rutzen (2018) highlight, 
conflating good practice with regulatory requirements is best avoided so that concerns about CSO or DAC/G practice are not used as a pretext for regulatory restrictions (p. 33).

Regulatory change can happen rapidly, or imperceptibly slowly. Keeping an eye on the regulatory change drivers can help predict change, and understand it in context. At the same time, giving consideration to the full gamut of drivers can aid practitioners and policy makers - from LMI country governments, DAC/G governments, and CSOs - to see their place and role in influencing the regulatory environment, directly or indirectly. 


\section{APPENDICES}

\section{Appendix A: Research Participant Breakdown}

\begin{tabular}{|c|c|c|}
\hline & Number & Percent \\
\hline TOTAL NUMBER INTERVIEWS & 63 & 100 \\
\hline Number GoK interviews & 15 & 24 \\
\hline Number Elected interviews & 4 & 6 \\
\hline Number DAC/G interviews & 11 & 17 \\
\hline Number CSO interviews & 23 & 37 \\
\hline Number Other interviews & 10 & 16 \\
\hline Number organizations represented in interviews & 53 & \\
\hline $\begin{array}{l}\text { Interviews attended by at least one individual with at minimum } 15 \\
\text { years confirmed experience in/observation of CSO regulation/self- } \\
\text { regulation in Kenya }\end{array}$ & 23 & 43 \\
\hline Total interviews in Kenya & 56 & 89 \\
\hline $\begin{array}{l}\text { - of which Nairobi-based } \\
\text { - of which outside Nairobi }\end{array}$ & $\begin{array}{l}28 \\
17\end{array}$ & $\begin{array}{l}73 \\
27\end{array}$ \\
\hline Total interviews outside of Kenya & 7 & 11 \\
\hline Total interviews with Kenyans & 53 & 84 \\
\hline $\begin{array}{l}\text { GoK interviews: } \\
\text { - of which national } \\
\text { - of which sub-national }\end{array}$ & $\begin{array}{c}11 \\
4 \\
\end{array}$ & $\begin{array}{c}17 \\
6 \\
\end{array}$ \\
\hline $\begin{array}{l}\text { Elected interviews: } \\
\text { - of which national } \\
\text { - of which sub-national }\end{array}$ & $\begin{array}{l}1 \\
3 \\
\end{array}$ & $\begin{array}{l}2 \\
5 \\
\end{array}$ \\
\hline $\begin{array}{l}\text { DAC/G interviews: } \\
\text { - of which DAC/G } \\
\text { - of which multilateral }\end{array}$ & $\begin{array}{l}9 \\
2\end{array}$ & $\begin{array}{c}14 \\
3 \\
\end{array}$ \\
\hline $\begin{array}{l}\text { CSO interviews: } \\
\text { - of which Kenyan CSO } \\
\text { - of which Kenyan chapter of non-Kenyan CSO } \\
\text { - of which Non-Kenyan CSO }\end{array}$ & $\begin{array}{c}16 \\
4 \\
3\end{array}$ & $\begin{array}{l}25 \\
6 \\
5\end{array}$ \\
\hline $\begin{array}{l}\text { Other interviews: } \\
\text { - of which autonomous national institutions/commissions } \\
\text { - of which media } \\
\text { - of which academic } \\
\text { - of which other }\end{array}$ & $\begin{array}{l}3 \\
1 \\
3 \\
3\end{array}$ & $\begin{array}{l}5 \\
2 \\
5 \\
5\end{array}$ \\
\hline
\end{tabular}

Notes:

- Six interviews were attended by more than one person, while 4 were second interviews with the same individual. Thus the total number of individuals interviewed was 68 .

- $\quad$ GoK $=$ Government of Kenya. Both national and sub-national government officials are included in this category. 
- $\quad$ Electeds = Individuals elected nationally (MP) or at sub-national levels (Member of County Assembly).

- $\quad$ DAC/Gs = Governments that are members of the OECD DAC (including EU institutions). An IFI also interviewed is included in the DAC/G interview tally.

- $\quad \mathrm{CSO}=$ civil society organization.

- When an organization is considered a Kenyan chapter of non-Kenyan CSO it has a Kenyan Board and staff. An example is the Kenyan Red Cross (not interviewed for this research).

- $\quad$ Non-Kenyan CSO = International CSO or CSO headquartered outside of Kenya.

- Other = Includes national institutions/commissions categorized as 'autonomous', e.g. established by Acts of Parliament and reporting to Parliament; media; academia; others.

- Interviews considered as 'in Kenya' include two by phone or Skype with individuals in Kenya. 


\section{Appendix B: DAC/G Official Development Assistance Disbursements}

Table B1: DAC/G ${ }^{1}$ ODA Disbursements ${ }^{2}$ to Recipient Country Categories and Kenya (constant 2016 USD millions), $1986-1996$

\begin{tabular}{|c|c|c|c|c|c|c|c|c|c|c|}
\hline \multirow[b]{2}{*}{$\begin{array}{l}\text { Recipient country } \\
\text { category }\end{array}$} & 1986 & 1987 & 1988 & 1989 & 1990 & 1991 & 1992 & 1993 & 1994 & 1995 \\
\hline & & & & & & & & & & \\
\hline All LMIs ${ }^{3}$ & 51797.9 & 51469.1 & 53913.8 & 55430.1 & 58012.7 & 63518.2 & 60271.1 & 56796.7 & 57689.9 & 51310.3 \\
\hline Least Developed & 14636.8 & 14229.1 & 15490.9 & 15095.0 & 15251.7 & 14181.1 & 14643.3 & 13859.6 & 14500.1 & 12589.9 \\
\hline Other Low-income & 1185.5 & 1279.1 & 1437.8 & 1467.8 & 1499.7 & 1296.8 & 1513.7 & 1123.0 & 1114.9 & 1087.0 \\
\hline Kenya & 787.8 & 796.0 & 1040.6 & 1067.6 & 1070.6 & 801.0 & 759.9 & 583.9 & 526.5 & 546.8 \\
\hline $\begin{array}{l}\text { Lower-middle } \\
\text { Income }\end{array}$ & 14942.1 & 13894.8 & 15310.7 & 16006.3 & 18130.3 & 20943.7 & 18406.6 & 15674.5 & 16720.9 & 13192.6 \\
\hline $\begin{array}{l}\text { Upper-middle } \\
\text { Income }\end{array}$ & 7059.4 & 7703.4 & 7377.6 & 8230.9 & 9270.0 & 11482.5 & 8500.9 & 9288.9 & 9400.6 & 10108.4 \\
\hline
\end{tabular}

\begin{tabular}{|c|c|c|c|c|c|c|c|c|c|c|}
\hline & 1986 & 1987 & 1988 & 1989 & 1990 & 1991 & 1992 & 1993 & 1994 & 1995 \\
\hline \multicolumn{11}{|l|}{$\begin{array}{l}\text { Recipient country } \\
\text { category }\end{array}$} \\
\hline All LMIs ${ }^{3}$ & 1.1 & 1.1 & 1.2 & 1.1 & 1.1 & 1.2 & 1.2 & 1.0 & 1.0 & 0.8 \\
\hline Least Developed & 7.2 & 7.5 & 8.3 & 7.8 & 8.4 & 7.7 & 9.4 & 8.3 & 9.8 & 8.1 \\
\hline Other Low-income & 4.5 & 5.3 & 6.0 & 5.8 & 5.6 & 5.3 & 7.3 & 6.5 & 6.0 & 5.9 \\
\hline Kenya & 5.6 & 6.2 & 8.5 & 8.6 & 9.4 & 8.0 & 7.8 & 8.7 & 6.5 & 6.0 \\
\hline $\begin{array}{l}\text { Lower-middle } \\
\text { Income }\end{array}$ & 1.5 & 1.3 & 1.5 & 1.5 & 1.8 & 2.3 & 2.0 & 1.7 & 1.7 & 1.3 \\
\hline $\begin{array}{l}\text { Upper-middle } \\
\text { Income }\end{array}$ & 0.2 & 0.3 & 0.3 & 0.3 & 0.3 & 0.4 & 0.3 & 0.3 & 0.3 & 0.3 \\
\hline
\end{tabular}

Source: DAC database, DAC2a - ODA disbursements to countries and regions, stats.OECD.org. Last accessed Oct. 8, 2018.

${ }^{1}$ The DAC/Gs include EU institutions, which are considered by the OECD as DAC members.

${ }^{2}$ The DAC2a data is available as total net ODA disbursements. Total net ODA is the gross amount of ODA disbursed minus repayments of the principal on previous years' loans, forgiven debt, and recoveries made on grants. See FAQ 3.2 at http://www.oecd.org/dac/financing-sustainabledevelopment/development-finance-data/faq.htm

"LMIs" is the term used in this research to denote OECD "developing countries" including the categories: Least Developed; Other Low-income; Lower-

middle income; and Upper-middle income. 
Table B1: DAC/G ${ }^{1}$ ODA Disbursements ${ }^{2}$ to Recipient Country Categories and Kenya (constant 2016 USD millions), 1996-2005

\begin{tabular}{|c|c|c|c|c|c|c|c|c|c|c|}
\hline & 1996 & 1997 & 1998 & 1999 & 2000 & 2001 & 2002 & 2003 & 2004 & 2005 \\
\hline \multicolumn{11}{|l|}{$\begin{array}{l}\text { Recipient country } \\
\text { category }\end{array}$} \\
\hline All LMIs ${ }^{3}$ & 52615.5 & 48161.5 & 52553.9 & 54675.7 & 54595.3 & 57570.9 & 62573.6 & 67716.7 & 69314.6 & 98743.9 \\
\hline Least Developed & 11176.2 & 11531.7 & 11787.8 & 11334.9 & 12485.2 & 13306.2 & 16615.7 & 22494.4 & 20182.5 & 20183.6 \\
\hline Other Low-income & 936.7 & 917.3 & 905.3 & 929.7 & 807.6 & 982.6 & 1204.5 & 878.4 & 1078.8 & 1134.9 \\
\hline Kenya & 439.2 & 427.3 & 402.8 & 326.0 & 402.2 & 482.7 & 431.0 & 403.5 & 580.1 & 673.4 \\
\hline $\begin{array}{l}\text { Lower-middle } \\
\text { Income }\end{array}$ & 14090.1 & 12471.6 & 14156.0 & 14569.7 & 13703.8 & 16523.3 & 15447.9 & 14004.2 & 12802.8 & 22614.4 \\
\hline $\begin{array}{l}\text { Upper-middle } \\
\text { Income }\end{array}$ & 8858.6 & 8457.0 & 10173.7 & 11325.7 & 10746.3 & 11176.7 & 12207.2 & 13011.5 & 15168.3 & 34212.9 \\
\hline
\end{tabular}

Table B2: DAC/G ${ }^{1}$ ODA to GNI Ratio by Recipient Country Categories and Kenya (percentage), 1996-2005

\begin{tabular}{|c|c|c|c|c|c|c|c|c|c|c|}
\hline & 1996 & 1997 & 1998 & 1999 & 2000 & 2001 & 2002 & 2003 & 2004 & 2005 \\
\hline \multicolumn{11}{|l|}{$\begin{array}{l}\text { Recipient country } \\
\text { category }\end{array}$} \\
\hline All $\mathrm{LMIs}^{3}$ & 0.8 & 0.6 & 0.7 & 0.8 & 0.7 & 0.7 & 0.8 & 0.9 & 0.8 & 1.0 \\
\hline Least Developed & 6.3 & 5.5 & 5.5 & 5.2 & 4.6 & 4.9 & 5.9 & 8.2 & 7.1 & 6.1 \\
\hline Other Low-income & 3.8 & 3.3 & 3.3 & 3.6 & 3.1 & 3.4 & 4.4 & 3.4 & 4.2 & 4.0 \\
\hline Kenya & 3.3 & 2.7 & 2.3 & 2.1 & 2.5 & 2.7 & 2.5 & 2.3 & 3.3 & 3.4 \\
\hline $\begin{array}{l}\text { Lower-middle } \\
\text { Income }\end{array}$ & 1.2 & 0.9 & 1.1 & 1.1 & 1.0 & 1.1 & 0.9 & 0.9 & 0.7 & 1.1 \\
\hline $\begin{array}{l}\text { Upper-middle } \\
\text { Income }\end{array}$ & 0.2 & 0.2 & 0.2 & 0.2 & 0.2 & 0.2 & 0.2 & 0.2 & 0.3 & 0.5 \\
\hline
\end{tabular}

Source: DAC database, DAC2a - ODA disbursements to countries and regions, stats.OECD.org. Last accessed Oct. 8, 2018.

${ }^{1}$ The DAC/Gs include EU institutions, which are considered by the OECD as DAC members.

${ }^{2}$ The DAC2a data is available as total net ODA disbursements. Total net ODA is the gross amount of ODA disbursed minus repayments of the principal on previous years' loans, forgiven debt, and recoveries made on grants. See FAQ 3.2 at http://www.oecd.org/dac/financing-sustainable-

development/development-finance-data/faq.htm

3"LMIs" is the term used in this research to denote OECD "developing countries" including the categories: Least Developed; Other Low-income; Lower-

middle income; and Upper-middle income. 
Table B2: DAC/G ${ }^{1}$ ODA Disbursements ${ }^{2}$ to Recipient Country Categories and Kenya (constant 2016 USD millions), 2006-2016

\begin{tabular}{|c|c|c|c|c|c|c|c|c|c|c|c|}
\hline & 2006 & 2007 & 2008 & 2009 & 2010 & 2011 & 2012 & 2013 & 2014 & 2015 & 2016 \\
\hline \multicolumn{12}{|l|}{$\begin{array}{l}\text { Recipient country } \\
\text { category }\end{array}$} \\
\hline All LMIs ${ }^{3}$ & 91007.9 & 81988.2 & 91945.0 & 92176.7 & 97185.7 & 99472.6 & 96253.8 & 98386.6 & 99826.1 & 107515.3 & 119942.7 \\
\hline Least Developed & 21314.1 & 22489.2 & 25751.9 & 27068.6 & 30912.5 & 31253.4 & 28533.4 & 30844.4 & 27959.8 & 28422.3 & 28690.3 \\
\hline Other Low-income & 1311.1 & 1573.0 & 1952.9 & 2214.9 & 2057.6 & 2366.0 & 2714.8 & 2888.8 & 2436.4 & 2341.4 & 2247.3 \\
\hline Kenya & 877.3 & 944.2 & 1007.2 & 1305.2 & 1244.6 & 1595.2 & 1795.4 & 2128.4 & 1675.0 & 1623.7 & 1535.2 \\
\hline $\begin{array}{l}\text { Lower-middle } \\
\text { Income }\end{array}$ & 26296.2 & 16220.8 & 16323.7 & 19437.2 & 20440.8 & 17990.0 & 18786.9 & 19707.8 & 18893.5 & 19462.2 & 20999.6 \\
\hline $\begin{array}{l}\text { Upper-middle } \\
\text { Income }\end{array}$ & 20351.1 & 18602.5 & 20442.2 & 13984.9 & 11323.8 & 16153.5 & 14525.7 & 12509.1 & 13898.5 & 14053.0 & 18854.5 \\
\hline
\end{tabular}

Table B2: DAC/G ${ }^{1}$ ODA to GNI Ratio by Recipient Country Categories and Kenya (percentage), 2006-2016

\begin{tabular}{|c|c|c|c|c|c|c|c|c|c|c|c|}
\hline \multirow{2}{*}{\multicolumn{12}{|c|}{$\begin{array}{l}\text { Recipient country } \\
\text { category }\end{array}$}} \\
\hline & & & & & & & & & & & \\
\hline All $\mathrm{LMIs}^{3}$ & 0.8 & 0.6 & 0.6 & 0.6 & 0.6 & 0.5 & 0.5 & 0.4 & 0.4 & 0.4 & 0.5 \\
\hline Least Developed & 5.6 & 5.3 & 5.1 & 4.9 & 5.0 & 4.6 & 3.9 & 4.0 & 3.3 & 3.1 & 3.4 \\
\hline Other Low-income & 3.7 & 4.0 & 4.5 & 4.5 & 3.8 & 4.2 & 4.0 & 3.9 & 3.1 & 2.7 & 2.4 \\
\hline Kenya & 3.2 & 3.0 & 2.9 & 3.5 & 3.2 & 4.1 & 3.8 & 4.2 & 3.0 & 2.6 & 2.2 \\
\hline $\begin{array}{l}\text { Lower-middle } \\
\text { Income }\end{array}$ & 1.1 & 0.6 & 0.6 & 0.7 & 0.5 & 0.4 & 0.4 & 0.4 & 0.4 & 0.4 & 0.4 \\
\hline $\begin{array}{l}\text { Upper-middle } \\
\text { Income }\end{array}$ & 0.3 & 0.2 & 0.2 & 0.1 & 0.1 & 0.1 & 0.1 & 0.1 & 0.1 & 0.1 & 0.1 \\
\hline
\end{tabular}

Source: DAC database, DAC2a - ODA disbursements to countries and regions, stats.OECD.org. Last accessed Oct. 8, 2018.

${ }^{1}$ The DAC/Gs include EU institutions, which are considered by the OECD as DAC members.

${ }^{2}$ The DAC2a data is available as total net ODA disbursements. Total net ODA is the gross amount of ODA disbursed minus repayments of the principal on previous years' loans, forgiven debt, and recoveries made on grants. See FAQ 3.2 at http://www.oecd.org/dac/financing-sustainable-development/development-financedata/faq.htm

3"LMIs" is the term used in this research to denote OECD "developing countries" including the categories: Least Developed; Other Low-income; Lower-middle income; and Upper-middle income. 


\section{Appendix C: DAC/G ODA Disbursements for CSOs}

Table C1: DAC/G ${ }^{1}$ ODA Disbursements ${ }^{2}$ for CSOs to LMI countries (constant 2016 USD million)

\begin{tabular}{|c|c|c|c|c|c|c|c|c|c|c|c|c|c|c|c|}
\hline & $2002^{*}$ & 2003 & 2004 & 2005 & 2006 & 2007 & 2008 & 2009 & 2010 & 2011 & 2012 & 2013 & 2014 & 2015 & 2016 \\
\hline $\begin{array}{l}\text { Total for } \\
\text { CSOs }\end{array}$ & 860 & 1173 & 3975 & 5223 & 9210 & 13339 & 15952 & 18776 & 19414 & 19569 & 19340 & 20100 & 21604 & 22868 & 22992 \\
\hline $\begin{array}{l}\text { For CSOs } \\
\text { as } \% \text { of } \\
\text { ODA }\end{array}$ & $1.5 \%$ & $1.7 \%$ & $5.6 \%$ & $5.0 \%$ & $9.2 \%$ & $14.4 \%$ & $15.3 \%$ & $18.6 \%$ & $17.9 \%$ & $17.5 \%$ & $18.0 \%$ & $17.5 \%$ & $18.9 \%$ & $18.8 \%$ & $17.2 \%$ \\
\hline $\mathrm{To}^{3} \mathrm{CSOs}$ & 858 & 1172 & 1679 & 1206 & 1858 & 2864 & 2477 & 2196 & 2016 & 1931 & 1994 & 2313 & 2791 & 3332 & 3159 \\
\hline $\begin{array}{l}\text { To as } \% \text { of } \\
\text { for CSOs }\end{array}$ & $99.8 \%$ & $99.9 \%$ & $42.2 \%$ & $23.1 \%$ & $20.2 \%$ & $21.5 \%$ & $15.5 \%$ & $11.7 \%$ & $10.4 \%$ & $9.9 \%$ & $10.3 \%$ & $11.5 \%$ & $12.9 \%$ & $14.6 \%$ & $13.7 \%$ \\
\hline $\begin{array}{l}\text { Through } \\
\text { CSOs }\end{array}$ & 1 & 1 & 2296 & 4016 & 7352 & 10475 & 13475 & 16580 & 17397 & 17638 & 17346 & 17787 & 18812 & 19536 & 19833 \\
\hline $\begin{array}{l}\text { Through } \\
\text { as \% of } \\
\text { for CSOs }\end{array}$ & $0.2 \%$ & $0.1 \%$ & $57.8 \%$ & $76.9 \%$ & $79.8 \%$ & $78.5 \%$ & $84.5 \%$ & $88.3 \%$ & $89.6 \%$ & $90.1 \%$ & $89.7 \%$ & $88.5 \%$ & $87.1 \%$ & $85.4 \%$ & $86.3 \%$ \\
\hline
\end{tabular}

Source: OECD Creditor Reporting System (CRS) database, https://stats.oecd.org/qwids/. Last accessed Oct. 8, 2018.

Note: The DAC maintains two datasets known as the DAC and the CRS datasets. DAC data as in Appendix B [from DAC2a] is focused on high-level data, while the CRS data used in Appendix C goes down to the individual project level. Though in principle the DAC and CRS data should match there are acknowledged discrepancies. See FAQ 4.3 at http://www.oecd.org/dac/financing-sustainable-development/development-finance-data/faq.htm

* Data on flows to and through CSOs is considered by the OECD to be of good quality from 2010 onward (DAC Statistician, personal communication, Aug. 12018 ). Prior years are shown here though they do not inform the research narrative.

${ }^{1}$ The DAC/Gs include EU institutions, which are considered by the OECD as DAC members.

${ }^{2}$ The CRS database provides data in gross bilateral ODA disbursements, which is the amount a donor spends in a given year. See FAQ 3.2 at

http://www.oecd.org/dac/financing-sustainable-development/development-finance-data/faq.htm

${ }^{3}$ Disbursements "For" CSOs represents total combined flows "to" and "through" CSOs. "To" CSOs: Core contributions and contributions to programmes. These aid funds are programmed by the CSOs. "Through" CSOs: Funds channelled through CSOs and other private bodies to implement donor-initiated projects (earmarked funding) (OECD, 2018a, p. 1). 
Table C2: DAC/G ${ }^{1}$ ODA Disbursements ${ }^{2}$ for CSOs to Kenya (constant 2016 USD million)

\begin{tabular}{|c|c|c|c|c|c|c|c|c|c|c|c|c|c|c|c|}
\hline & $2002^{*}$ & 2003 & 2004 & 2005 & 2006 & 2007 & 2008 & 2009 & 2010 & 2011 & 2012 & 2013 & 2014 & 2015 & 2016 \\
\hline $\begin{array}{l}\text { Total for } \\
\text { CSOs }\end{array}$ & 12 & 15 & 43 & 73 & 84 & 224 & 258 & 400 & 376 & 467 & 546 & 615 & 494 & 497 & 499 \\
\hline $\begin{array}{l}\text { For CSOs } \\
\text { as } \% \text { of } \\
\text { ODA }\end{array}$ & $3.1 \%$ & $3.1 \%$ & $7.4 \%$ & $10.3 \%$ & $9.1 \%$ & $21.1 \%$ & $23.0 \%$ & $28.8 \%$ & $27.7 \%$ & $27.4 \%$ & $25.8 \%$ & $27.1 \%$ & $27.3 \%$ & $27.8 \%$ & $28.6 \%$ \\
\hline $\mathrm{To}^{3} \mathrm{CSOs}$ & 12 & 15 & 19 & 21 & 7 & 54 & 25 & 18 & 28 & 23 & 25 & 37 & 34 & 56 & 36 \\
\hline $\begin{array}{l}\text { To as } \% \\
\text { of for } \\
\text { CSOs }\end{array}$ & $100 \%$ & $100 \%$ & $43.5 \%$ & $29.0 \%$ & $8.8 \%$ & $24.3 \%$ & $9.7 \%$ & $4.5 \%$ & $7.5 \%$ & $5.0 \%$ & $4.6 \%$ & $6.0 \%$ & $6.8 \%$ & $11.3 \%$ & $7.2 \%$ \\
\hline $\begin{array}{l}\text { Through } \\
\text { CSOs }\end{array}$ & - & - & 24 & 52 & 77 & 169 & 233 & 382 & 348 & 444 & 521 & 578 & 460 & 441 & 463 \\
\hline $\begin{array}{l}\text { Through } \\
\text { as \% of } \\
\text { for CSOs }\end{array}$ & - & - & $56.5 \%$ & $71.0 \%$ & $91.2 \%$ & $75.7 \%$ & $90.3 \%$ & $95.5 \%$ & $92.5 \%$ & $95.0 \%$ & $95.4 \%$ & $94.0 \%$ & $93.2 \%$ & $88.7 \%$ & $92.8 \%$ \\
\hline
\end{tabular}

Source: OECD Creditor Reporting System (CRS) database, https://stats.oecd.org/qwids/. Last accessed Oct. 8, 2018.

Note: The DAC maintains two datasets known as the DAC and the CRS datasets. DAC data as in Appendix B [from DAC2a] is focused on high-level data, while the CRS data used in Appendix $C$ goes down to the individual project level. Though in principle the DAC and CRS data should match there are acknowledged discrepancies. See FAQ 4.3 at http://www.oecd.org/dac/financing-sustainable-development/development-finance-data/faq.htm

* Data on flows to and through CSOs is considered by the OECD to be of good quality from 2010 onward (DAC Statistician, personal communication, Aug. 12018 ).

Prior years are shown here though they do not inform the research narrative.

${ }^{1}$ The DAC/Gs include EU institutions, which are considered by the OECD as DAC members.

${ }^{2}$ The CRS database provides data in gross bilateral ODA disbursements, which is the amount a donor spends in a given year. See FAQ 3.2 at

http://www.oecd.org/dac/financing-sustainable-development/development-finance-data/faq.htm

${ }^{3}$ Disbursements "For" CSOs represents total combined flows "to" and "through" CSOs. "To" CSOs: Core contributions and contributions to programs;

aid funds are programmed by the CSOs. "Through" CSOs: Funds channelled through CSOs to implement donor-initiated projects (earmarked funds)

(OECD, 2018a, p. 1). 


\section{BIBLIOGRAPHY}

Abdi, H. S. (2015a). Press release: Taskforce on the proposed amendments to the Public Benefits Organizations Act, 2013.

Abdi, H. S. (2015b). Public notice on PBOs Act, 2013. Retrieved from http://www.ngobureau.or.ke/?wpdmpro=media-advert-pbos-act-ammendment-bychair-pbo-taskforce

Abdullahi, A. (2017, November 8). Kenya, again, represses civil society [Blog post]. Kenya Elections 2017. Retrieved from https:/www.hrw.org/blog-feed/kenyaelections-2017

AbouAssi, K. (2015). Testing resource dependency as a motivator for NGO selfregulation: Suggestive evidence from the global South. Nonprofit and Voluntary Sector Quarterly, 44(6), 1255-1273. http://doi.org/10.1177/0899764014556774

Abrahamsen, R. (2015). Sacrificing democracy for security? The dangers of securitizing development in Africa. Presentation to the Africa Study Group, Nov. 25, 2015, Ottawa, CA. Retrieved from http://africastudygroup.ca/wpcontent/uploads/2014/08/ASG-meeting-minutes-November-25-2015.pdf

Abuom, A., Alemu, K., Evensmo, I., Hafild, E., Kruse, S. E., \& Riddell, R. C. (2012). An exploratory study of the wider effects of Norwegian civil society support to countries in the South. Oslo, NO: Norwegian Agency for Development Cooperation. Retrieved from https://www.norad.no/globalassets/import-2162015-80434am/www.norad.no-ny/filarkiv/vedlegg-til-publikasjoner/tracking-impact-anexploratory-study-of-the-wider-effects-of-norwegian-civil-society-support-tocountries-in-the-south.pdf 
Accountable Now. (n.d.). About Accountable Now. Retrieved from https://accountablenow.org/about-accountable-now/

Achieng, E. (2017, July 24). This is a petition to office of the Attorney General and Department of Justice [Blog post]. Retrieved from https://emalineachieng.wordpress.com/2017/07/24/re-petition-to-office-of-theattorney-general-and-department-of-justice-to-act-in-public-interest-and-promoteprotect-and-uphold-the-rule-of-law-with-respect-to-commencement-of-the-publicbenefit-o/

Achuka, V. (2018, January 13). Cost of the war in Somalia. Standard Digital. Retrieved from https://www.standardmedia.co.ke/business/article/2001265865/cost-of-thewar-in-somalia

Affa'a-Mindzie, M. (2014, July 23). Leaders agree on immunity for themselves during expansion of African court. International Peace Institute Global Observatory. Retrieved from http://theglobalobservatory.org/2014/07/leaders-agree-immunityexpansion-african-court/

Africa Centre for Open Governance. (2017, October 26). Kenya' s electoral dysfunction: Fear and boycott affects turnout. Retrieved from https://africog.org/kenyas-electoraldysfunction-fear-and-boycott-affects-turnout/

African Development Bank Group, Organisation for Economic Co-Operation and Development, \& United Nations Development Programme. (2016). African economic outlook 2016. Retrieved from http://www.oecd.org/countries/namibia/1826046.pdf African Union. (2014). The report, the draft legal instruments and recommendations of 
the Specialized Technical Committee on Justice and Legal Affairs (No.

EX.CL/846(XXV)). Executive Council Twenty-Fifth Ordinary Session, 20-24 June

2014. Retrieved from http://justsecurity.org/wp-content/uploads/2014/07/Legal-

Instruments-Adopted-in-Malabo-July-2014.pdf

Allison, S. (2016, April 19). Think again: In adversity there is opportunity for the International Criminal Court. Institute for Security Studies. Retrieved from https://www.issafrica.org/iss-today/think-again-in-adversity-there-is-opportunityfor-the-international-criminal-court

Amutabi, M. N. (2006). The NGO factor in Africa: The case of arrested development in Kenya. New York, NY: Routledge.

Appe, S., \& Barraga, D. (2017). Policy windows for CSOs in Latin America: Looking outside legal and regulatory frameworks. Voluntas, 28(4), 1812-1831. http://doi.org/10.1007/s11266-015-9666-z

Appe, S., \& Pallas, C. L. (2017). Aid reduction and local civil society: Causes, comparisons, and consequences. Voluntas, 29(2), 1-18.

http://doi.org/10.1007/s11266-017-9846-0

ARIADNE, European Foundation Centre, \& International Human Rights Funders Group. (n.d.). Challenging the closing space for civil society: A practical starting point for funders. Retrieved from http://www.ariadne-network.eu/wpcontent/uploads/2015/03/Ariadne_ClosingSpaceReport-Final-Version.pdf

Armstrong, P. (2006). The limits and risks of regulation: The case of the World Banksupported Draft Handbok on Good Practices for Laws Relating to NGOs. In L. Jordan \& P. van Tuijl (Eds.), NGO accountability: Politics, principles and 
innovations (pp. 61-80). London, UK: Earthscan.

Arowosegbe, J. O. (2014). African studies and the bias of eurocentricism. Social Dynamics, 40(2), 308-321. http://doi.org/10.1080/02533952.2014.942074

Atia, M., \& Herrold, C. E. (2018). Governing through patronage: The rise of NGOs and the fall of civil society in Palestine and Morocco. Voluntas. Advance online publication. http://doi.org/10.1007/s11266-018-9953-6

Aulick, K. (2013). Learning agenda mini-case \#12: Kenya Viwango. Retrieved from http://www.developmentiscapacity.org/sites/default/files/12-Viwengo-Kenya-LA Mini Case.pdf

Australian Government the Treasury. (2012). Australian Charities and Not-for-Profits Commission Implementation Report. Canberra, AU: The Australian Government. Retrieved from http://acnctaskforce.treasury.gov.au/content/publications/implementationreport/dow nloads/ACNC_ir.pdf

Ayres, I., \& Braithwaite, J. (1992). Responsive regulation: Transcending the deregulation debate. New York, NY: Oxford University Press.

Baird, M. (2017). The challenges of charity regulation. Presentation at The Future of Charity Regulation conference, April 28, 2017, Carleton University, Ottawa, CA. Baldwin, R., Cave, M., \& Lodge, M. (2010). Introducing regulation - The field and the developing agenda. In R. Baldwin, M. Cave, \& M. Lodge (Eds.), The Oxford handbook of regulation (pp. 3-16). Oxford, UK: Oxford University Press.

Baldwin, R., Scott, C., \& Hood, C. (1998). Introduction. In R. Baldwin, C. Scott, \& C. Hood (Eds.), A reader on regulation (pp. 1-55). New York, NY: Oxford University 
Press.

Barker, S. (2017). Reflections on regulatory accountability. In M. McGregor-Lowndes \& B. Wyatt (Eds.), Regulating charities: The inside story (pp. 183-208). New York, NY: Routledge.

Bater, P. (2000). Evaluating tax incentives for donations to public benefit organizations. The International Journal of Not-for-Profit Law, 3(2). Retrieved from http://www.icnl.org/research/journal/vol3iss2/art_2.htm

BBC News. (2013, February 8). Claims of witnesses in Kenya ICC trial disappearing. Retrieved from http://www.bbc.com/news/world-africa-21382339

BBC News. (2014, December 18). Kenya security bill: MPs brawl as measures approved. Retrieved from http://www.bbc.com/news/world-africa-30530423

BBC News. (2015, June 11). Kenya court rules HakiAfrica and MHR not terrorists. Retrieved from http://www.bbc.com/news/world-africa-33092786

Bearak, M., \& Ombuor, R. (2018, April 3). Gay Kenyans sense they may be on the brink of a historic legal triumph. The Washington Post. Retrieved from https://www.washingtonpost.com/world/africa/gay-kenyans-sense-they-may-be-onthe-brink-of-a-historic-legal-triumph/2018/04/02/a2a370e4-2965-11e8-a227$\mathrm{fd} 2 \mathrm{~b} 009466 \mathrm{bc} \_$story.html?noredirect $=$on\&utm_term $=.68 \mathrm{~b} 612 \mathrm{f} 8 \mathrm{c} 860$

Beeby, D. (2018a, July 17). CRA loses court challenge to its political-activity audits of charities. $C B C$ News. Retrieved from https://www.cbc.ca/news/politics/charitypolitical-audits-cra-lebouthillier-farha-poverty-environmental-gray-liberal1.4750295

Beeby, D. (2018b, August 15). Liberals promise to repeal restriction on charities' 
political activity. $C B C$ News. Retrieved from http://www.cbc.ca/news/politics/cracourt-charities-political-activity-1.4786818

Beer, C. T., Bartley, T., \& Roberts, W. T. (2012). NGOs: Between advocacy, service provision, and regulation. In D. Levi-Faur (Ed.), Oxford handbook of governance (pp. 325-338). New York, NY: Oxford University Press.

Berg, B. L. (2001). Qualitative research methods for the social sciences (4th ed.). Needhan Heights, MA: Pearson Education Company.

Berman, S. (1997). Civil society and the collapse of the Weimar Republic. World Politics, 49(3), 401-429. http://doi.org/10.1353/wp.1997.0008

Bies, A. L. (2010). Evolution of nonprofit self-regulation in Europe. Nonprofit and Voluntary Sector Quarterly, 39(6), 1057-1086. http://doi.org/10.1177/0899764010371852

Biggs, S. D., \& Neame, A. D. (1996). Negotiating room to maneuver: Reflections concerning NGO autonomy and accountability within the new policy agenda. In M. Edwards \& D. Hulme (Eds.), Beyond the magic bullet: NGO performance and accountability in the post-Cold War world (pp. 40-52). West Hartford, CT: Kumarian Press.

Blee, K. M., \& Taylor, V. (2002). Semi-structured interviewing in social movement research. In B. Klandermans \& S. Staggenborg (Eds.), Methods of social movement research (pp. 92-117). Minneapolis, MN: University of Minnesota Press.

Bloodgood, E. A. (2013). When accountability kills: Alternative accountability mechanisms and NGO demise. Paper presented at the 2013 Annual Meeting of the American Political Science Association, August 28-31, 2013, Chicago, IL. Retrieved 
from http://papers.ssrn.com/sol3/papers.cfm?abstract_id=2299733\#\#

Bloodgood, E. A., \& Tremblay-Boire, J. (2011). International NGOs and national regulation in an age of terrorism. Voluntas, 22(1), 142-173.

http://doi.org/10.1007/s11266-010-9148-2

Bloodgood, E. A., \& Tremblay-Boire, J. (2018). NGO regulatory backlash? Examining internal and external explanations for $N G O$ regulation. Paper presented at the 13th International Conference of the International Society for Third Sector Research, July 10-13, 2018, Amsterdam, NL. Retrieved from https://convention2.allacademic.com/one/istr/istr18/index.php?cmd=Online+Progra m+View+Paper\&selected_paper_id=1360591\&PHPSESSID=1564eoq543a9bk8rcs4 d $97 \mathrm{pb} 75$

Bloodgood, E. A., Tremblay-Boire, J., \& Prakash, A. (2014). National styles of NGO regulation. Nonprofit and Voluntary Sector Quarterly, 43(4), 716-736. http://doi.org/10.1177/0899764013481111

Blumberg, M. (2017a, March 27). Blumberg's snapshot of the Canadian charity sector 2015. Retrieved from http://www.globalphilanthropy.ca/images/uploads/Blumbergs_Canadian_Charity_Se ctor_Snapshot_2015.pdf

Blumberg, M. (2017b, June 11). Total revenue received from all sources outside Canada by Canadian registered charities in 2015. Retrieved from http://www.globalphilanthropy.ca/images/uploads/Total_revenue_received_from_all _sources_outside_Canada_by_Canadian_Charities_in_2015.pdf Blumberg, M. (2018, October 31). Finance changes to political activities and Canadian 
charities. Retrieved from

https://www.globalphilanthropy.ca/images/uploads/Finance_Changes_to_Political_ Activities_and_Canadian_charities.pdf

Bode, I. (2011). Creeping marketization and post-corportist goverance. In S. D. Phillips \& S. R. Smith (Eds.), Governance and regulation in the third sector: International perspectives (pp. 115-141). New York, NY: Routledge.

Bode, I., \& Brandsen, T. (2014). State-third sector partnerships: A short overview of key issues in the debate. Public Management Review, 16(8), 1055-1066. http://doi.org/10.1080/14719037.2014.957344

Boris, E. T., \& Lott, C. M. (2017). Reflections on challenged regulators. In M. McGregor-Lowndes \& B. Wyatt (Eds.), Regulating charities: The inside story (pp. 97-115). New York, NY: Routledge.

Boru Halakhe, A. (2014, February 7). Does the ICC have an Africa problem? Kenya trials key to future of court's relations with continent. Aljazeera America. Retrieved from http://america.aljazeera.com/opinions/2014/2/kenya-trialskeytoiccafricarelations.html

Bowcott, O. (2014, December 5). ICC drops murder and rape charges against Kenyan president. The Guardian. Retrieved from http://www.theguardian.com/world/2014/dec/05/crimes-humanity-charges-kenyapresident-dropped-uhuru-kenyatta

Braithwaite, J. (2006). Responsive regulation and developing economies. World Development, 34(5), 884-898. http://doi.org/10.1016/j.worlddev.2005.04.021 Braithwaite, J. (2017). Types of responsiveness. In P. Drahos (Ed.), Regulatory theory: 
Foundations and applications (pp. 117-132). Acton, AUS: Australian National University Press. Retrieved from http://press-

files.anu.edu.au/downloads/press/n2304/pdf/book.pdf?referer=2304

Braithwaite, V. (2012). A regulatory approach for the Australian Charities and Not-forprofit Commission: A discussion paper (Regulatory Institutions Network, Australian National University, Canberra No. 19). Canberra, AU. Retrieved from http://regnet.anu.edu.au/sites/default/files/publications/attachments/201505/ROP19_0.pdf

Branch, D. (2011). Kenya: Between Hope and Despair, 1963-2011. London, UK: Yale University Press.

Brass, J. N. (2010). Surrogates for government? NGOs and the state in Kenya (Unpublished doctoral dissertation). University of California, Berkeley, CA. Retrieved from http://digitalassets.lib.berkeley.edu/etd/ucb/text/Brass_berkeley_0028E_10920.pdf

Brass, J. N. (2012). Blurring boundaries: The integration of NGOs into governance in Kenya. Governance: An International Journal of Policy, Administration, and Institutions, 25(2), 209-235. http://doi.org/10.1111/j.1468-0491.2011.01553.x

Bratton, M. (1989). The politics of government-NGO relations in Africa. World Development, 17(4), 569-587. http://doi.org/10.1016/0305-750X(89)90263-5

Bratton, M. (1994). Civil society and political transitions in Africa. In J. W. Harbeson, D. Rothchild, \& N. Chazan (Eds.), Civil society and the state in Africa (pp. 51-81). Boulder, CO: Lynne Rienner Publishers, Inc.

Brechenmacher, S., \& Carothers, T. (2018). The legitimacy menu. In S. Brechenmacher 
\& T. Carothers (Eds.), Examining civil society legitimacy (pp. 34-39). Washington, DC: Carnegie Endowment for International Peace. Retrieved from https://carnegieendowment.org/files/Civil-Society-Legitimacy_FINAL.pdf

Breen, O. B., Dunn, A., \& Sidel, M. (2017a). Regulatory waves: An introduction. In O. B. Breen, A. Dunn, \& M. Sidel (Eds.), Regulatory waves: Comparative prspectives on state regulation and self-regulation policies in the nonprofit sector (pp. 1-20). Cambridge, UK: Cambridge University Press.

Breen, O. B., Dunn, A., \& Sidel, M. (Eds.). (2017b). Regulatory waves: Comparative perspectives on state regulation and self-regulation policies in the nonprofit sector. Cambridge, UK: Cambridge University Press.

Brody, E. (2002). Accountability and public trust. In L. M. Salamon (Ed.), The state of nonprofit America (pp. 471-498). Washington, DC: Brookings Institution Press.

Brody, E. (2006). The legal framework for nonprofit organizations. In W. Powell \& R. Steinberg (Eds.), The nonprofit sector: A research handbook (Second, pp. 243-266). New Haven, CT: Yale University Press.

Brown, S. (2001). Authoritarian leaders and multiparty elections in Africa: How foreign donors help to keep Kenya's Daniel arap Moi in power. Third World Quarterly, 22(5), 725-739. http://doi.org/10.1080/01436590120084575

Bullain, N., \& Rutzen, D. (2018). All for one and one for all. In S. Brechenmacher \& T. Carothers (Eds.), Examining civil society legitimacy (pp. 31-33). Washington, DC: Carnegie Endowment for International Peace. Retrieved from https://carnegieendowment.org/files/Civil-Society-Legitimacy_FINAL.pdf Burger, R. (2012). Reconsidering the case for enhancing accountability via regulation. 
Voluntas, 23(1), 85-108. http://doi.org/10.1007/s11266-011-9238-9

Burger, R., \& Seabe, D. (2014). NGO accountability in Africa. In E. Obadare (Ed.), The handbook of civil society in Africa (pp. 77-107). London, UK: Springer.

Burke, J. (2017, July 31). Kenyan election official "tortured and murdered" as fears of violence grow. The Guardian. Retrieved from https://www.theguardian.com/world/2017/jul/31/kenyan-election-officialchristopher-msando-dead-before-national-vote on Nov 12, 2017

Busan Partnership for Effective Development Cooperation. (2011). Fourth High Level Forum on Aid Effectiveness, Busan, SKR, 29 November-1 December, 2011. Retrieved from http://www.oecd.org/dac/effectiveness/49650173.pdf

Cabinet Secretary Ministry of Devolution and Planning. (2016). Press release on matters relating to the NGO Coordination Board. Retrieved from http://www.devolutionplanning.go.ke/?news=press-releaseonhttps://www.khrc.or.ke/images/docs/ResponsetofakeDelphinepetition-1.pdf

Callamard, A. (2006). NGO accountability and the Humanitarian Accountability Partnership: Towards a transformative agenda. In L. Jordan \& P. van Tuijl (Eds.), NGO accountability: Politics, principles and innovations (pp. 183-194). London, UK: Earthscan.

Canada Without Poverty v. AG Canada, 2018 ONSC 4147 (2018). Retrieved from http://www.imaginecanada.ca/sites/default/files/canada_without_poverty_v_ag_cana da_20180716.pdf

Canadian Council for International Cooperation. (2009). Code of ethics and operational standards. Ottawa, CA. Retrieved from 
http://www.ccic.ca/_files/en/about/001_code_of_ethics_booklet_e.pdf

Canadian Council for International Cooperation. (2018). CCIC leaders' pledge on preventing and addressing sexual misconduct. Retrieved from https://gallery.mailchimp.com/5b5b20c0f419d201ae76973b4/files/3b24db7c-e4544253-b32a-f5eb3fdc3b3e/CCIC_Leaders_Pledge_Official.01.pdf

Carothers, T. (2013). Democracy without illusions. Foreign Affairs, 76(1), 85-99. http://doi.org/10.2307/20047911

Carothers, T., \& Brechenmacher, S. (2014). Closing space: Democracy and human rights support under fire. Washington, DC: Carnegie Endowment for International Peace. Retrieved from http://carnegieendowment.org/files/closing_space.pdf

Carothers, T., \& Ottaway, M. (2000). The burgeoning world of civil society aid. In M. Ottaway \& T. Carothers (Eds.), Funding virtue: Civil society aid and democracy promotion (pp. 3-17). Washington DC: Carnegie Endowment for International Peace.

Casey, J. (2016). The nonprofit world: Civil society and the rise of the nonprofit sector. Boulder, CO: Kumarian Press.

Charmaz, K. (2008). Grounded theory in the 21st Century: Applications for advancing social justice studies. In N. K. Denzin \& S. Lincoln, Yvonna (Eds.), Strategies of qualitative inquiry (3rd ed., pp. 203-241). Thousand Oaks, CA: Sage Publications, Inc.

Charnovitz, S. (2006). Accountability of NGOs in global governance. In L. Jordan \& P. van Tuijl (Eds.), NGO accountability: Politics, principles and innovations (pp. 2142). London, UK: Earthscan. 
Christensen, D., \& Weinstein, J. M. (2013). Defunding dissent: Restrictions on aid to NGOs. Journal of Democracy, 24(2), 77-91. http://doi.org/10.1353/jod.2013.0026

CIVICUS. (2011). Bridging the gaps: Citizens, organisations and dissociation - Civil Society Index summary report 2008-2011. Johannesburg, SA. Retrieved from http://www.civicus.org/downloads/Bridging the Gaps - Citizens Organisations and Dissociation.pdf

CIVICUS. (2015a). Attacks on civil society undermining democracy and development in Kenya. Johannesburg, SA. Retrieved from http://civicus.org/images/Kenya Policy Action Brief.pdf

CIVICUS. (2015b). State of civil society report 2015. Johannesburg, SA. Retrieved from http://civicus.org/images/StateOfCivilSocietyFullReport2015.pdf

CIVICUS. (2016). State of civil society report 2016. Johannesburg, SA. Retrieved from http://www.civicus.org/index.php/en/socs2016

Clark, C. (2018, August 11). MBS: The next-generation royal is now a leader who can reach around the world. The Globe and Mail, pp. A12-A13.

Clifford, B. (2011). Civil and uncivil society. In M. Edwards (Ed.), The Oxford handbook of civil society (pp. 209-219). Oxford, UK: Oxford University Press.

Coglianese, C., \& Mendelson, E. (2010). Meta-regulation and self-regulation. In R. Baldwin, M. Cave, \& M. Lodge (Eds.), The Oxford handbook of regulation (pp. 146-167). Oxford, UK: Oxford University Press.

Collier, D., \& Mahoney, J. (2010). Insights and pitfalls: Selection bias in qualitative research. World Politics, 49(1), 56-91. http://doi.org/10.1353/wp.1996.0023

Commission of Inquiry into Post-Election Violence. (2008). Report of the Commission of 
Inquiry into Post-Election Violence. Nairobi, KE:eKLR. Retrieved from http://kenyalaw.org/Downloads/Reports/Commission_of_Inquiry_into_Post_Electio n_Violence.pdf

Committee of Experts on Constitutional Review. (2009). The Preliminary Report of the Committee of Experts on Constitutional Review - Issued on the publication of the harmonised draft Constitution. Nairobi, KE. Retrieved from http://katibainstitute.org/Archives/images/17-11-2009_Preliminary_Report.pdf

Committee to Protect Journalists. (2013, December 5). Kenya parliament passes draconian media laws. Retrieved from https://cpj.org/2013/12/kenya-parliamentpasses-draconian-media-laws.php

Companies Act, Chapter 486 of 1962. eKLR. Retrieved from http://www.kenyalaw.org:8181/exist/kenyalex/actview.xql?actid=CAP. 486

Constitution of Kenya Review Act, No. 13 of 1997. eKLR. Retrieved from http://www.constitutionnet.org/sites/default/files/KEL97-005.pdf

Core Humanitarian Standard. (n.d.). History. Retrieved from https://corehumanitarianstandard.org/the-standard/history

Coston, J. M. (1998). A model and typology of government-NGO relations. Nonprofit and Voluntary Sector Quarterly, 27(3), 358-382. http://doi.org/10.1177/0899764098273006

Council of Europe. European Convention for the Protection of Human Rights and Fundamental Freedoms, as amended by Protocols Nos. 11 and 14 (1950). Retrieved from http://www.echr.coe.int/Documents/Convention_ENG.pdf

Council on Foundations. (2017). Kenya. Retrieved from 
https://www.cof.org/sites/default/files/Kenya-201804.pdf

County Governments Act, No. 17 of 2012. eKLR. Retrieved from

http://www.kenyalaw.org:8181/exist/kenyalex/actview.xql?actid=No. 17 of 2012

CSO Reference Group. (2013). What is the likely impact of the Statute Law

(Miscellaneous Amendments Act 2013) on Kenya? Nairobi, KE. Retrieved from http://www.penkenya.org/UserSiteFiles/public/Miscellaneous Amendments Act 2013 Bill Statement.pdf

CSO Reference Group. (2014a). A PBO voluntary service charter for citizens. Nairobi, KE.

CSO Reference Group. (2014b). Briefing note on the memorandum to the Public Benefits Act 2013. Nairobi, KE.

CSO Reference Group. (2014c). The Public Benefit Organisations Act, 2013 - A guide (1st ed.). Nairobi, KE. Retrieved from http://www.civilsocietyrg.org/resources/pboact-2013/file/102-a-guide-to-the-public-benefit-organizations-act-2013.html

CSO Reference Group. (2015a). Shadow report on Sophia Abdi Task Force on PBO Act 2013 Amendments. Nairobi, KE. Retrieved from http://www.scribd.com/doc/266224018/Shadow-Report-Sofia-Abdi-TaskForce\#scribd

CSO Reference Group. (2015b, July 2). \#PBOActNow \#WhatThePeopleSaid (Facebook post). Retrieved from https://www.facebook.com/PBOAct2013/videos/725028667608125/

CSO Reference Group. (2017). The civil society calls on the Government of Kenya to stop forthwith its incessant attacks. Nairobi, KE. Retrieved from 
http://www.khrc.or.ke/images/docs/CSORG.pdf

Customs and Excise Act, Chapter 472 of 1978. eKLR. Retrieved from

http://kenyalaw.org/lex//actview.xql?actid=CAP. 472\#part_XX

Dearden, L. (2018, February 12). British charities face government crackdown as Oxfam sexual exploitation scandal widens. The Independent. Retrieved from https://www.independent.co.uk/news/uk/home-news/oxfam-sexual-exploitationscandal-haiti-prostitutes-latest-government-funding-unit-dfid-mordaunta8207531.html

Deloffre, M. Z. (n.d.). Abductive Inferential Logic in Qualitative Content Analysis. Unpublished manuscript.

DeMattee, A. (2018). Catching the tail of the "closing space" phenomenon: Finally, a typology of CSO regulatory regimes. Presentation at the 13th International Conference of the International Society for Third Sector Research, July 10-13, 2018, Amsterdam, The Netherlands. Retrieved from https://convention2.allacademic.com/one/istr/istr18/index.php?cmd=Online+Progra m+View+Paper\&selected_paper_id=1360853\&PHPSESSID=qo623a1596937g8rdo9 voj2917

Department of Finance Canada. (2018, October 31). Government recognizes the valuable role charities play in building a strong and caring Canada. Retrieved from https://www.canada.ca/en/department-finance/news/2018/10/governmentrecognizes-the-valuable-role-charities-play-in-building-a-strong-and-caringcanada.html

Development Partners Group. (2015). Written submission of Development Partners to 
Hon. Sophia Abdi Noor. Nairobi, KE.

Diamond, L. (2015). Facing up to the democratic recession. Journal of Democracy, 26(1), 141-155. http://doi.org/10.1353/jod.2015.0009

Dicklitch, S. (2002). NGOs and democratization in transitional societies: Lessons from Uganda. In D. N. Nelson \& L. Neack (Eds.), Global society in transition: An international politics reader (pp. 15-36). The Hague, NL: Kluwer Law International.

Dobbin, F., Garrett, G., \& Simmons, B. (Eds.). (2008). The global diffusion of markets and democracy. New York, NY: Cambridge University Press.

Doern, B. G., \& Johnson, R. (2006). Concepts, context and key issues. In B. G. Doern \& R. Johnson (Eds.), Rules, rules, rules, rules: Multilevel regulatory governance (pp. 3-26). Toronto, CA: University of Toronto Press.

Dolowitz, D. P., \& Marsh, D. (2000). Learning from abroad: The role of policy transfer in contemporary policy-making. Governance, 13(1), 5-23. http://doi.org/10.1111/0952-1895.00121

Driscoll, L. (2017). The reforming regulator. In M. McGregor-Lowndes \& B. Wyatt (Eds.), Regulating charities: The inside story (pp. 37-57). New York, NY: Routledge.

Dunn, A., Breen, O. B., \& Sidel, M. (2017). Regulatory waves: A conclusion. In O. B. Breen, A. Dunn, \& M. Sidel (Eds.), Regulatory waves: Comparative perspectives on state regulation and self-regulation policies in the nonprofit sector (pp. 221-243). Cambridge, UK: Cambridge University Press.

Dunn, A., Spencer, E., \& Sidel, M. (2012). Law, regulation and the nonprofit sector: 
New developments and comparative perspectives [Abstract]. Abstract for panel presentation for the 10th International Conference of the International Society for Third Sector Research, July 10-13, 2012, Siena, IT. Retrieved from http://www.istr.org/general/custom.asp?page=SienaAbstracts

Dupuy, K. E., Ron, J., \& Prakash, A. (2015). Who survived? Ethiopia's regulatory crackdown on foreign-funded NGOs. Review of International Political Economy, 22(2), 419-456. http://doi.org/10.1080/09692290.2014.903854

Dupuy, K., Ron, J., \& Prakash, A. (2015). Hands off my regime! Governments' restrictions on foreign aid to non-governmental organizations in poor and middleincome countries. World Development, 84(August), 299-311. http://doi.org/10.1016/j.worlddev.2016.02.001

Eastern and Southern Africa Anti-Money Laundering Group. (2011a). Mutual Evaluation Report, Anti-Money Laundering and Combating the Financing of Terrorism Republic of Kenya. Dar es Salaam, TZ. Retrieved from http://www.esaamlg.org/userfiles/Kenya_Mutual_Evaluation_Detail_Report(2).pdf Eastern and Southern Africa Anti-Money Laundering Group. (2011b). Mutual Evaluation Report, Anti-Money Laundering and Combating the Financing of Terrorism Republic of Kenya Executive Summary. Dar es Salaam, TZ. Retrieved from http://www.esaamlg.org/userfiles/Kenya_MER_Executive_Summary(2).pdf

Ebole, R., \& Odhiambo, M. (2016). Governance assessment Kenya: January 2013 - July 2016. Freedom House. Retrieved from https://freedomhouse.org/sites/default/files/Governance Assessment Kenya 2016.pdf Ebrahim, A. (2003). Accountability in practice: Mechanisms for NGOs. World 
Development, 31(5), 813-829. http://doi.org/10.1016/S0305-750X(03)00014-7

Eckstein, H. (1992). Case study and theory in political science. In Regarding politics:

Essays on political theory, stability, and change (pp. 117-176). Berkeley, CA:

University of California Press.

Edelman Trust. (2017). Edelman trust barometer 2017 annual global study - Executive summary. Retrieved from http://www.edelman.com/executive-summary/

Edwards, M. (1998). Are NGOs overrated? Why and how to say "no." Current Issues in Comparative Education, 1(1), 55-61. Retrieved from https://www.tc.columbia.edu/cice/pdf/25630_1_1_Edwards.pdf

Edwards, M. (2009). Civil society (2nd ed.). Cambridge, UK: Polity Press.

Edwards, M. (2011). Introduction: Civil society and the geometry of human relations. In M. Edwards (Ed.), The Oxford handbook of civil society (pp. 3-14). New York, NY: Oxford University Press.

Edwards, M., \& Hulme, D. (Eds.). (1996a). Beyond the magic nullet: NGO performance and accountability in the post-Cold War world. West Hartford, CT: Kumarian Press.

Edwards, M., \& Hulme, D. (1996b). Introduction: NGO performance and accountability. In M. Edwards \& D. Hulme (Eds.), Beyond the magic bullet: NGO performance and accountability in the post-Cold War world (pp. 1-20). West Hartford, CT: Kumarian Press.

Epstein, H. (2017, August). Kenya: The election \& the cover-up. The New York Review of Books. Retrieved from http://www.nybooks.com/daily/2017/08/30/kenya-theelection-and-the-cover-up/?printpage=true

Eric Gitari v Attorney General \& another, Petition No. 150 of 2016. (2016). High Court 
of Kenya at Nairobi: eKLR. Retrieved from

http://kenyalaw.org/caselaw/cases/view/122862/

Eric Gitari v NGOs Coordination Board \& 4 others, Petition No. 440 of 2013 (2015).

High Court of Kenya at Nairobi: eKLR. Retrieved from

http://kenyalaw.org/caselaw/cases/view/108412/

Estache, A., \& Wren-Lewis, L. (2010). On the theory and evidence on regulation of network industries in developing countries. In R. Baldwin, M. Cave, \& M. Lodge (Eds.), The Oxford handbook of regulation (pp. 371-406). Oxford, UK: Oxford University Press.

Etherington, S. S. (2017). Reflections on modernizing and reforming regulation. In M. McGregor-Lowndes \& B. Wyatt (Eds.), Regulating charities: The inside story (pp. 59-77). New York, NY: Routledge.

Everatt, D., \& Kanyinga, K. (2007). Kenya: Governance, Justice, Law and Order Sector (GJLOS) programme: Fourth programme review final report. Nairobi, KE. Retrieved from https://sarpn.org/documents/d0002961/Kenya_GJLOS_2007.pdf

Farrelly, J. (2017). The Charities Regulatory Authority: The future of charity regulation, an Irish perspective. Presentation at The Future of Charity Regulation conference, April 28, 2017, Carleton University, Ottawa, CA.

FIDH: World Movement for Human Rights. (2015, April 14). Kenya $\mathrm{Q}$ Human rights organisations are not terrorist organizations. Retrieved from https://www.fidh.org/International-Federation-for-HumanRights/Africa/kenya/kenya-human-rights-organisations-are-not-terroristorganizations 
FIDH: World Movement for Human Rights. (2017, May 18). Kenya: Last warning from the court to implement the PBO Act 2013 within 30 days. Retrieved from https://www.fidh.org/en/issues/human-rights-defenders/kenya-last-warning-fromthe-court-to-implement-the-pbo-act-2013

Financial Action Task Force. (n.d.). History of the FATF. Retrieved from http://www.fatf-gafi.org/about/historyofthefatf/

Financial Action Task Force. (2012). International standards on combating money laundering and the financing of terrorism \& proliferation - The FATF recommendations. Paris, FR. Retrieved from http://www.fatfgafi.org/media/fatf/documents/recommendations/pdfs/FATF_Recommendations.pdf

Finch, C., \& Omolo, A. (2015). Building public participation in Kenya's devolved government (Kenya School of Government \& Centre for Devolution Studies, Working Paper Series Kenya Devolution No. 1). Nairobi, KE. Retrieved from http://documents.worldbank.org/curated/en/2015/02/24079761/summary-overview

Fisher, J. (1998). Nongovernments: NGOs and the political development of the third world. West Hartford, CT: Kumarian Press.

Fisher, J. (2013). Importing democracy: The role of NGOs in South Africa, Tajikistan, and Argentina. Dayton, OH: Kettering Foundation Press.

Flyvbjerg, B. (2006). Five misunderstandings about case-study research. Qualitative Inquiry, 12(2), 219-245. http://doi.org/10.1177/1077800405284363

Foley, M. W., \& Edwards, B. (1996). The paradox of civil society. Journal of Democracy, 7(3), 38-52. http://doi.org/10.1353/jod.1996.0048

Forests Act, No. 7 of 2005. eKLR. Retrieved from 
http://www.kenyaforestservice.org/images/MMMB/forests act no.7 of 2005.pdf

Fowler, A. (1994). Non-governmental organisations and the promotion of democracy in Kenya (Unpublished doctoral dissertation). University of Sussex, UK. Retrieved from https://ethos.bl.uk/OrderDetails.do?did=1\&uin=uk.bl.ethos.357791

Fowler, A. (2012). Measuring civil society: Perspectives on Afro-centrism. Voluntas, 23(1), 5-25. http://doi.org/10.1007/s11266-011-9239-8

Freedom House. (2016, September 9). Kenya: Freedom House welcomes decision to implement PBO Act 2013. Retrieved from https://freedomhouse.org/article/kenyafreedom-house-welcomes-decision-implement-pbo-act-2013

Freedom House. (2017). Freedom in the world 2017. Washington, DC. Retrieved from https://freedomhouse.org/sites/default/files/FH_FIW_2017_Report_Final.pdf

Freedom House. (2018). Aggregate Category and Subcategory Scores, 2003-2018. Retrieved from https://freedomhouse.org/content/freedom-world-data-and-resources Frumkin, P. (2002). On being nonprofit: A conceptual and policy primer. Cambridge, MA: Harvard University Press.

Gariyo, Z. (1996). NGOs and development in East Africa: A view from below. In M. Edwards \& D. Hulme (Eds.), Beyond the magic bullet: NGO performance and accountability in the post-Cold War world (pp. 156-165). West Hartford, CT: Kumarian Press.

Garrett, T. (2017). The evanescent regulator. In M. McGregor-Lowndes \& B. Wyatt (Eds.), Regulating charities: The inside story (pp. 159-182). New York, NY: Routledge.

George, A. L., \& Bennett, A. (2005). Case studies and theory development in the social 
sciences. Cambridge, MA: MIT Press.

Gerring, J. (2004). What is a case study and what is it good for? The American Political Science Review, 98(2), 341-354. http://doi.org/10.1017/S0003055404001182

Gerring, J. (2007). Is there a (viable) crucial-case method ? Comparative Political Studies, 40(3), 231-253. http://doi.org/10.1177/0010414006290784

Gibelman, M., \& Gelman, S. R. (2004). A loss of credibility: Patterns of wrongdoing among nongovernmental organizations. Vountas, 15(4), 355-381. http://doi.org/10.1007/s11266-004-1237-7

Githae, W. (2017, October 2). Kenya cuts ties with NGO over judiciary. Daily Nation. Retrieved from http://www.nation.co.ke/news/Kenya-cuts-ties-with-NGO-overJudiciary/1056-4120622-14mmilu/index.html

Gleckman, H. (2018, January 11). 21 Million taxpayers will stop taking the charitable deduction under the new tax law. Forbes. Retrieved from https://www.forbes.com/sites/beltway/2018/01/11/21-million-taxpayers-will-stoptaking-charitable-deductions-under-the-new-tax-law/\#4d77ebfd238f

Global NPO Coalition on FATF. (n.d.-a). Achievements. Retrieved from http://fatfplatform.org/achievements/

Global NPO Coalition on FATF. (n.d.-b). Impact on civil society. Retrieved from http://fatfplatform.org/impact-on-civil-society/

Global NPO Coalition on FATF. (2014). Recommendations: Financial Action Task Force typology review. Retrieved from http://fatfplatform.org/wpcontent/uploads/2015/02/NPO-Sector-Typology-Position-Paper-FATF.pdf Global NPO Coalition on FATF. (2015). Counter-terrorism regimes are obstructing 
NGOs from doing their vital work. Retrieved from

http://www.icnl.org/globalforum2015/wp-content/uploads/2015/05/FATF-

Engagement.pdf

Global Partnership for Effective Development Co-operation. (2015). Monitoring guide

2015-2016: Monitoring the effective development co-operation commitments.

Retrieved from http://effectivecooperation.org/wp-content/uploads/2016/08/2015-

2016-GPEDC-Monitoring-Guide.pdf

Global Partnership for Effective Development Cooperation. Nairobi Outcome Document (2016). Retrieved from http://effectivecooperation.org/hlm2-outcome-doc-thirddraft-14-nov-16/

Global Standard for CSO Accountability. (2017). 12 commitments for dynamic accountability: Guidance materials. Retrieved from http://www.csostandard.org/wpcontent/uploads/2017/11/2017_Global-Standard-Guidance-Material.pdf

Goldsmith, B. (2015, January 21). Why is trust in NGOs falling? World Economic Forum. Retrieved from https://www.weforum.org/agenda/2015/01/why-is-trust-inngos-falling/

Government of Kenya. (2003). Economic recovery strategy for wealth and employment creation 2003-2007. Nairobi, KE. Retrieved from siteresources.worldbank.org/KENYAEXTN/Resources/ERS.pdf

Government of the Republic of Kenya. (2007). Kenya Vision 2030 - The Popular Version. Nairobi, KE. Retrieved from http://www.vision2030.go.ke/cms/vds/Popular_Version.pdf

Guerrero, D. M. (2004). The growing role of civil society organizations in the third world 
and government policies toward them. In P. Bater, F. Hondius, \& P. Kessler Lieber (Eds.), The tax treatment of NGOs: Legal, ethical and fiscal frameworks for promoting NGOs and their activities (pp. 211-229). The Hague, NL: Kluwer Law International.

Gugerty, M. K. (2010). The emergence of nonprofit self-regulation in Africa. Nonprofit and Voluntary Sector Quarterly, 39(6), 1087-1112. http://doi.org/10.1177/0899764010372972

Gugerty, M. K. (2014). Nonprofit regulatory waves in sub-Saharan Africa: Cooperation, contestation and crackdown. Paper presented at the 43rd annual Association for Research on Nonprofit Organizations and Voluntary Action conference, November 2014, Denver, CO.

Gugerty, M. K., \& Prakash, A. (2010). Voluntary regulation of NGOs and nonprofits: An introduction to the club framework. In M. K. Gugerty \& A. Prakash (Eds.), Voluntary regulation of NGOs and nonprofits: An accountability club framework (pp. 3-38). Cambridge, MA: Cambridge University Press.

Gugerty, M. K., Sidel, M., \& Bies, A. L. (2010). Introduction to mini symposium: Nonprofit self-regulation in comparative perspective - Themes and debates. Nonprofit and Voluntary Sector Quarterly, 39(6), 1027-1038. http://doi.org/10.1177/0899764010372971

Gyimah-Boadi, E. (2015). Africa's waning democratic commitment. Journal of Democracy, 26(1), 101-113. http://doi.org/10.1353/jod.2015.0000

Haggard, S., \& Kaufman, R. R. (2016). Democratization during the third wave. Annual Review of Political Science, 19 (Advance online publication), 125-144. 
http://doi.org/10.1146/annurev-polisci-042114-015137

Hammad, L., \& Morton, B. (2011). Greater influence, greater responsibility: Are INGOs' self-regulatory accountability standards effective? Ottawa, CA: The NorthSouth Institute. Retrieved from http://www.nsi-ins.ca/wpcontent/uploads/2012/10/2011-Greater-Influence-Greater-Responsibility-areINGOs-Self-Regulatory-Accountability-Standards-Effective.pdf

Hanmer, L., Ikiara, G., Eberlei, W., \& Abong, C. (2003). Kenya. In D. Booth (Ed.), Fighting poverty in Africa. Are PRSPs making a difference? (pp. 91-117). London, UK: Overseas Development Institute. Retrieved from https://www.odi.org/sites/odi.org.uk/files/odi-assets/publications-opinionfiles/8032.pdf

Hannan, L. (2015). Kenya: A guidebook to impunity [Online video]. Nairobi, KE: InformAction. Retrieved from http://www.informaction.tv/index.php/filmlist/item/454-kenya-a-guidebook-to-impunity

Hansmann, H. B. (1980). The role of nonprofit enterprise. The Yale Law Journal, 89(5), 835-901. http://doi.org/10.1021/ja804069n

Harrow, J. (2016). Accountability in 4-D: Changing approaches in contemporary philanthropy. In T. Jung, S. D. Phillips, \& J. Harrow (Eds.), The Routledge companion to philanthropy (pp. 482-500). New York, NY: Routledge.

Hayes, B. (2012). Counter-terrorism, "policy laundering” and the FATF: Legalising surveillance, regulating civil society. Amsterdam, NL; London, UK: Transnational Institute and Statewatch. Retrieved from http://www.statewatch.org/analyses/no171-fafp-report.pdf 
Hayman, R., Crack, A., Okitoi, J., Lewis, S., Pratt, B., Bakri, S., \& Popplewell, R. (2014). Legal frameworks and political space for non-governmental organisations: An overview of six countries: Phase II. European Institute of Development Research and Training Institutes Policy Paper Series. Retrieved from http://www.intrac.org/data/files/resources/801/Legal-Frameworks-and-PoliticalSpace-for-NGOs-an-overview-of-six-countries-Phase-II.pdf

Heinrich, V. F., \& Fioramonti, L. (Eds.). (2008). CIVICUS global survey of the state of civil society volume 2: Comparative perspectives. Bloomfield, CT: Kumarian Press. Hellinger, S., Hellinger, D., \& O’Regan, F. M. (1988). Aid for just development: Report on the future of foreign assistance. Boulder, CO: Lynne Rienner Publishers, Inc. Retrieved from http://www.developmentgap.org/uploads/2/1/3/7/21375820/aid_for.pdf

Hood, C. (1991). A public management for all seasons? Public Administration, 69(spring), 3-19. http://doi.org/10.1111/j.1467-9299.1991.tb00779.x

Hood, C. (1995). The "new public management" in the 1980s: Variations on a theme. Accounting, Organizations and Society, 20(2/3), 93-109. http://doi.org/10.1016/0361-3682(93)E0001-W

Hope, K. R. (2013). Managing the public sector in Kenya: Reform and transformation for improved performance. Journal of Public Administration and Governance, 2(4), 128. http://doi.org/10.5296/jpag.v2i4.2751

Hornsby, C. (2012). Kenya: A history since independence. London, UK: I.B. Tauris \& Co Ltd.

Houghton, I. (2015, March 9). The real issues over changes to PBO Act. The Star. 
Retrieved from http://www.the-star.co.ke/article/real-issues-over-changes-pboact\#sthash.qyX76sc2.dpbs

Houghton, I., \& Muchai, S. (2014, March 31). Protecting civic space against \#NGOMuzzle laws in Kenya [Blog post]. Retrieved from https://irunguh.wordpress.com/2014/03/31/protecting-civic-space-againstngomuzzle-laws-in-kenya/

Howell, J., Ishkanian, A., Obadare, E., Seckinelgin, H., \& Glasius, M. (2008). The backlash against civil society in the wake of the long war on terror. Development in Practice, 18(1), 82-93. http://doi.org/10.1080/09614520701778884

Howell, J., \& Pearce, J. (2000). Civil society: Technical instrument or social force for change? In D. Lewis \& T. Wallace (Eds.), New roles and relevance: Development $N G O s$ and the challenge of change. Hartford, CT: Kumarian.

Hulme, D., \& Edwards, M. (1997). NGOs, states and donors: An overview. In D. Hulme \& M. Edwards (Eds.), NGOs, states and donors: Too close for comfort? (pp. 3-22). New York, NY: St. Martin's Press.

Human Rights Watch. (2013a, October 4). Kenya: Rights defenders under attack. Retrieved from https://www.hrw.org/news/2013/10/04/kenya-rights-defendersunder-attack

Human Rights Watch. (2013b, November 11). Kenya: New laws would undermine basic rights. Retrieved from http://www.hrw.org/news/2013/11/11/kenya-new-lawswould-undermine-basic-rights

Huntington, S. P. (1991). The third wave: Democratization in the late twentieth century. Norman, OK: University of Oklahoma Press. 
Hyden, G., Court, J., \& Mease, K. (2004). Making sense of governance: Emperical evidence from 16 developing countries. Boulder, CO: Lynne Rienner Publishers, Inc.

Igunza, E. (2012, August 3). Witness protection fears in Kenya. Institute for War and Peace Reporting. Retrieved from https://iwpr.net/global-voices/witness-protectionfears-kenya

Income Tax (Charitable Donations) Regulations, L.N. 100A/2007, Corr. No. 37/2007. eKLR. Retrieved from http://kenyalaw.org/lex/sublegview.xql?subleg=CAP. 470\#KE/LEG/EN/AR/I/CHAPTER 470/SUBLEG/HC_24

Income Tax Act, Chapter 470 of 1973. eKLR. Retrieved from hhttp://kenyalaw.org/lex//actview.xql?actid=CAP. 470\#part_XV

Independent Sector. (2015). Principles for good governance and ethical practice: A guide for charities and foundations, 2015 edition. Washington, DC. Retrieved from http://www.independentsector.org/wp-content/uploads/2016/11/Principles2015Web-1.pdf

InformAction. (2015). Prosecuting crimes against humanity episode 4: Lessons learnt; "unprecedented" bribery and loss of witnesses [Online video]. Nairobi, KE: InformAction. Retrieved from https://www.youtube.com/watch?v=7WARAkj5VZw InterAction. (2018). CEO pledge on preventing sexual abuse, exploitation and harassment by and of NGO staff. Washington, DC. Retrieved from https://www.interaction.org/sites/default/files/ceo_pledge_on_preventing_sexual_ha rassment_and_abuse_by_and_of_ngo_staff_1.pdf International Center for Not-for-Profit Law. (2006). Recent laws and legislative proposals 
to restrict civil society and civil society organizations. The International Journal of Not-for-Profit Law, 8(4), 76-85. Retrieved from

http://www.icnl.org/research/journal/vol8iss4/art_1.htm

International Center for Not-for-Profit Law. (2009). Global trends in NGO law, 1(1).

Retrieved from http://www.icnl.org/research/trends/trends1-1.pdf?pdf=trends1-1

International Center for Not-for-Profit Law. (2013). NGO law monitor: Kenya.

Washington, DC. Retrieved from http://www.icnl.org/research/monitor/kenya.html

International Center for Not-for-Profit Law. (2014). NGO law monitor: Kenya.

Washington, DC. Retrieved from http://www.icnl.org/research/monitor/kenya.html

International Center for Not-for-Profit Law. (2015a). NGO law monitor: Kenya.

Washington, DC. Retrieved from http://www.icnl.org/research/monitor/kenya.html

International Center for Not-for-Profit Law. (2015b). Statement of the International

Center for Not-for-Profit Law (ICNL) to the Task Force on Proposed Amendments

to the Public Benefit Organisations (PBO) Act, 2013.

International Center for Not-for-Profit Law. (2016). Survey of trends affecting civic space: 2015-2016. Global Trends in NGO Law, 7(4). Retrieved from

http://www.icnl.org/research/trends/trends7-4.pdf?pdf=trends7-4

International Center for Not-for-Profit Law. (2017). Civic freedom monitor: Kenya.

Washington DC. Retrieved from

http://www.icnl.org/research/monitor/kenya.html\#top

International Center for Not-for-Profit Law. (2018). Effective donor responses to the challenge of closing civic space. Washington, DC. Retrieved from http://www.icnl.org/news/2018/Effective donor responses FINAL 1 May 2018.pdf 
International Center for Not-for-Profit Law, \& United Nations Development Programme. (2009). The role of legal reform in supporting civil society: An introductory primer. Retrieved from http://www.undp.org/content/dam/undp/documents/partners/civil_society/additional _documents/The_role_http://www.undp.org/content/undp/en/home/librarypage/civil _society/the_role_of_legalreforminsupportingcivilsocietyanintroductorypri.html International Criminal Court. (2015). Case information sheet: Situation in the Republic of Kenya, the Prosecutor v. Uhuru Muigai Kenyatta. The Hague, NL. Retrieved from https://www.icc-cpi.int/kenya/kenyatta/Documents/KenyattaEng.pdf

International Criminal Court. (2016). Case information sheet: Situation in the Republic of Kenya, the Prosecutor v. William Samoei Ruto and Joshua Arap Sang. The Hague, NL. Retrieved from https://www.icccpi.int/kenya/rutosang/Documents/RutoSangEng.pdf International Institute for Democracy and Electoral Assistance. (2017). The global state of democracy: Exploring democracy's resilience (1st ed.). Stockholm, SE. Retrieved from https:/www.idea.int/gsod/files/IDEA-GSOD-2017-REPORT-EN.pdf

Irish, L. E., Kushen, R., \& Simon, K. W. (2004). Guidelines for laws affecting civic organizations (2nd ed.). New York, NY: Open Society Institute. Retrieved from https://www.opensocietyfoundations.org/sites/default/files/guidelines_laws_english. pdf

Irvin, R. A. (2005). State regulation of nonprofit organizations: Accountability regardless of outcome. Nonprofit and Voluntary Sector Quarterly, 34(2), 161-178. http://doi.org/10.1177/0899764004272189 
Jacinto, L. (2013, March 8). Kenyatta blasts UK - with a little help from British PR. France 24. Retrieved from http://www.france24.com/en/20130307-kenyatta-blastsuk-with-little-help-british-pr-firm

Jamah, A. (2014, December 17). Kenya Jobs to go as Uhuru adminstration revokes registrations of 525 NGOs in Kenya, freezes their accounts. Standard Digital News. Retrieved from http://standardmedia.co.ke/article/2000144966/govt-revokesregistrations-of-510-ngos-freezes-theiraccounts?articleID $=2000144966 \&$ story_title=jobs-to-go-as-uhuru-adminstrationrevokes-registrations-of-525-ngos-in-kenya-freezes-their-accounts\&pageNo=1

Jillo, R. A. (2009). NGO law reform in Kenya: Incorporating best practices. The International Journal of Not-for-Profit Law, 11(4), 39-54. Retrieved from http://www.icnl.org/research/journal/voll1iss4/vol1 1iss4.pdf

Jordan, L., \& van Tuijl, P. (2006). Rights and responsibilities in the political landscape of NGO accountability: Introduction and overview. In L. Jordan \& P. van Tuijl (Eds.), NGO acountability: Politics, principles and innovations. London, UK: Earthscan.

Jubilee Coalition. (2013). Transforming Kenya: Securing Kenya's prosperity 2013-2017. Nairobi, KE. Retrieved from http://www.presidency.go.ke/images/jubilee-coalitionmanifesto.pdf

Jung, T., \& Phillips, S. D. (2017). Introduction: A new "new" philanthropy: From impetus to impact. In T. Jung, S. D. Phillips, \& J. Harrow (Eds.), The Routledge companion to philanthropy (pp. 5-34). New York, NY: Routledge.

Jung, T., Phillips, S. D., \& Harrow, J. (Eds.). (2017). The Routledge companion to philanthropy. New York, NY: Routledge. 
Kaberia, T. (2014, November 3). Bill on NGO funding proposes to take us back to the Kanu days of intolerance. Daily Nation. Retrieved from http://www.nation.co.ke/oped/Opinion/NGO-Funding-Bill-Civil-SocietyGovernment/-/440808/2509212/-/view/printVersion/-/9f53pu/-/index.html Kakah, M. (2017, December 7). Court blocks Fazul Mahamed's new tenure. Daily Nation. Retrieved from http://www.nation.co.ke/news/NGO-Board-barredextending-Fazul-Mahamed-contract-/1056-4219096-t8fxliz/index.html

Kamau, J. (2016, December 8). Kidero foundation under probe over unexplained cash in its bank accounts. Daily Nation. Retrieved from http://www.nation.co.ke/news/Sh27-billion-in-Kidero-link-bank-account/1056-3478884-p0m1gjz/

Kameri-Mbote, P. (2000). The operational environment and constraints for NGOs in Kenya: Strategies for good policy and practice (International Environmental Law Research Center Working Paper No. 2000-2). Geneva, CH. Retrieved from http://www.ielrc.org/content/w0002.pdf

Kamstra, J., Pelzer, B., Elbers, W., \& Ruben, R. (2016). Constraining is enabling? Exploring the influence of national context on civil society strength. Voluntas, 27(3), 1023-1044. http://doi.org/10.1007/s11266-016-9697-0

Kanyinga, K. (1995). The changing development space in Kenya: Socio-political change and voluntary development agencies. In P. Gibbon (Ed.), Markets, civil society and democracy in Kenya (pp. 69-120). Uppsala, SE: Nordiska Afrikainstitutet.

Kanyinga, K. (1998). Contestation over political space: The state and the demobilisaton of opposition politics in Kenya. In A. O. Olukoshi (Ed.), The politics of opposition in contemporary Africa (pp. 39-90). Uppsala, SE: Nordiska Afrikainstitutet. 
Kanyinga, K. (2004). Civil society formations in Kenya: A growing role in development and democracy. In D. Okello (Ed.), Civil society in the third republic (pp. 9-25). Nairobi, KE: The National Council of NGOs.

Kanyinga, K. (2015a). Political economy analysis of civil society in Kenya. Nairobi, KE. Kanyinga, K. (2015b, February 28). Evolution of Kenya's civil society. Daily Nation. Retrieved from http://www.nation.co.ke/news/Evolution-of-Kenya-civilsociety/1056-2639170-31ubm9/index.html

Kanyinga, K. (2016, January 16). Self interests have ruined institutions. Daily Nation. Retrieved from http://www.nation.co.ke/oped/opinion/Self-interests-have-ruinedinstitutions/440808-3036582-f2xlb1z/index.html

Kanyinga, K., \& Mitullah, W. (2007). The non-profit sector in Kenya: What we know and what we don't know. Nairobi, KE: Institute for Development Studies, University of Nairobi. Retrieved from http://www.akdn.org/publications/civil_society_kenya_nonprofit_popular.pdf Karl, T. L. (1995). The hybrid regimes of Central America. Journal of Democracy, 6(3), 72-85. http://doi.org/10.1353/jod.1995.0049

Katana, K. (2015, June 13). Is this why these NGOs had to go? The Star. Retrieved from https://www.the-star.co.ke/news/2015/06/13/is-this-why-these-ngos-had-togo_c1150122

Katumanga, M. (2004). Civil society and the Government: Conflict or cooperation? In D. Okello (Ed.), Civil society in the third republic (pp. 43-53). Nairobi, KE: The National Council of NGOs.

Kenya Citizenship and Immigration Act, No. 12 of 2011. eKLR. Retrieved from 
http://www.kenyalaw.org/lex//actview.xql?actid=No. 12 of 2011

Kenya Human Rights Commission. (2017, August 15). The Kenya Human Rights

Commission Denounces Attempt of Illegal De-registration by the NGO

Coordination Board. Nairobi, KE. Retrieved from

http://www.khrc.or.ke/images/docs/TheKenyaHumanRightsCommissiondenouncesa ttemptofillegalde-registrationbythengocoordinationboard.pdf

Kenya Information and Communications Act, No. 2 of 1998. eKLR. Retrieved from http://kenyalaw.org/lex//actview.xql?actid=No. 2 of 1998

Kenya National Commission on Human Rights. (2008). On the brink of the precipice: A human rights account of Kenya's Post-2007 election violence. Nairobi, KE. Retrieved from https://file.wikileaks.org/file/full-kenya-violence-report-2008.pdf Kenya National Commission on Human Rights. (2015a). Statement on gazettement of civil society organizations. Nairobi, KE. Retrieved from http://www.knchr.org/Portals/0/PressStatements/Press_Statement_on_Gazettement_ of_CSOs.pdf

Kenya National Commission on Human Rights. (2015b). "The error of fighting terror with terror": Preliminary report of KNCHR investigations on human rights abuses in the ongoing crackdown against terrorism. Nairobi, KE. Retrieved from http://www.knchr.org/Portals/0/CivilAndPoliticalReports/Final Disappearances report pdf.pdf

Kenya Transitional Justice Network. (2013). Summary: Truth, Justice and Reconciliation Commission Report. Nairobi, KE. Retrieved from https://www.africaportal.org/publications/kenya-transitional-justice-network- 
summary-truth-justice-and-reconciliation/

Kiai, M. (2013, December 18). In Kenya, averting a move to strangle civil society with the financial noose. Open Democracy. Retrieved from http://www.opendemocracy.net/openglobalrights/maina-kiai/in-kenya-avertingmove-to-strangle-civil-society-with-financial-noose

Kiai, M. (2015, January 30). Focus on masterminds of the 2007 violence, not human righst activists. Daily Nation. Retrieved from http://mobile.nation.co.ke/blogs/Focus-on-masterminds-of-the-2007-violence//1949942/2608104///format/xhtml/item/1///dpmoee/-/index.html

Kiai, M. (2017, November 17). When rights are treated as gifts, you're in a dictatorship. Daily Nation. Retrieved from http://www.nation.co.ke/oped/opinion/rights-aretreated-as-gifts--you-re-in-a-dictatorship/440808-4191536-cfl2f6z/index.html

Kiai, M. (2018, March 23). Analytica has shown what Jubilee, diplomats stand for. Daily Nation. Retrieved from https://www.nation.co.ke/oped/opinion/Analytica-exposedJubilee-and-diplomats/440808-4354548-123tyfy/index.html

Kikechi, B. (2015, February 1). Kenyan team in Addis leads push for African alternative to ICC. Standard Digital News. Retrieved from http://www.standardmedia.co.ke/?articleID=2000150054\&story_title=Kenyakenyan-team-in-addis-leads-push-for-african-alternative-to-icc

Kimutai, C., \& Okumu, P. (2017, August 12). Uhuru Kenyatta got 8.2 million votes against Raila's 6.7 million. Standard Digital. Retrieved from https://www.standardmedia.co.ke/article/2001251033/uhuru-kenyatta-got-8-2million-votes-against-raila-s-6-7-million 
Kindornay, S., \& Reilly-King, F. (2013). Promotion and partnership: Bilateral donor approaches to the private sector. In Private sector development - Business plan or development strategy? (pp. 31-38). Vienna, AT: Österreichische Forschungsstiftung für Internationale Entwicklung. Retrieved from http://www.oefse.at/Downloads/publikationen/oeepol/Artikel2013/3_Kindornay_Rei lly.pdf

King, A., \& Lenox, M. (2000). Industry self-regulation without sanctions: The chemical industry's responsible care program. Academy of Management Journal, 43(4), 698716. http://doi.org/10.5465/1556362

Kiplagat, S. (2014, October 27). 100,000 jobs at risk over Law on NGO financing. The Star. Retrieved from https://www.the-star.co.ke/news/2014/10/27/100000-jobs-atrisk-over-law-on-ngo-financing_c1026689

Kisinga, F. (2009). The process of reviewing the NGO Coordination Act, 1990: A stepby-step roadmap. International Journal of Not-for-Profit Law, 11(4). Retrieved from http://www.icnl.org/research/journal/vol11 iss4/vol11iss4.pdf

Kisinga Gitonga, F. (2010). Kenya. The International Journal of Not-for-Profit Law, 12(2), 21-38. Retrieved from http://www.icnl.org/research/journal/vol12iss2/ijnl_vol12iss2.pdf Koech, G. (2014, February 20). Kenya: NGO Council suspends national chairperson. The Star. Retrieved from http://allafrica.com/stories/201402201205.html

Koesel, K. J., \& Bunce, V. J. (2013). Diffusion-proofing: Russian and Chinese responses to waves of popular mobilizations against authoritarian rulers. Perspectives on Politics, 11(3), 753-768. http://doi.org/10.1017/S1537592713002107 
Kofi Annan Foundation. (2009). The Kenya National Dialogue and Reconciliation: One year later. Retrieved from http://www.kofiannanfoundation.org/in-the-news/thekenya-national-dialogue-and-reconciliation-one-year-later/

Koskei, S., \& Ollinga, M. (2015, January 25). Why carrying an ICC witness tag is a risky and deadly affair. Standard Digital. Retrieved from http://www.standardmedia.co.ke/?articleID=2000149140\&story_title=Kenya-whycarrying-an-icc-witness-tag-is-a-risky-and-deadly-affair

Kuti, É. (2011). Government-nonprofit sector relations in Hungary. In S. D. Phillips \& S. R. Smith (Eds.), Governance and regulation in the third sector: International perspectives (pp. 142-163). New York, NY: Routledge.

Laing, A. (2015, July 8). Kenyan politicians tell Barack Obama to leave "gay rights" talk at home. The Telegraph. Retrieved from http://www.telegraph.co.uk/news/worldnews/barackobama/11721249/Kenyanpoliticians-tell-Barack-Obama-to-leave-gay-rights-talk-at-home.html

Land Act, No. 6 of 2012. eKLR. Retrieved from http://www.kenyalaw.org/k1/fileadmin/pdfdownloads/Acts/Land_Act__No_6_of_2 012___.pdf

Lanser, T. R. (2012). Countries at the crossroads 2012: Kenya. Retrieved from https://freedomhouse.org/sites/default/files/Kenya - FINAL.pdf

Levitsky, S., \& Way, L. A. (2002). The rise of competitive authoritarianism. Journal of Democracy, 13(2), 51-65. http://doi.org/10.1353/jod.2002.0026

Lewis, D. (2002). Civil society in African contexts: Reflections on the usefulness of a concept. Development and Change, 33(4), 569-586. http://doi.org/10.1111/1467- 
7660.00270

Lewis, D., \& Opoku-Mensah, P. (2006). Moving forward research agendas on international NGOs: Theory, agency and context. Journal of International Development, 18(5), 665-675. http://doi.org/10.1002/jid

Lipschutz, R. D. (2005). Power, politics and global civil society. Millennium: Journal of International Studies, 33(3), 747-769.

http://doi.org/10.1177/03058298050330030401

Lloyd, R., \& Casas, L. De. (2005, December 1). NGO self-regulation: Enforcing and balancing accountability. Alliance. Retrieved from hhttp://www.alliancemagazine.org/analysis/ngo-self-regulation-enforcing-andbalancing-accountability/

Long, J. D., Kanyinga, K., Ferree, K. E., \& Gibson, C. (2013). Choosing peace over democracy. Journal of Democracy, 24(3), 140-155. http://doi.org/10.1353/jod.2013.0048

Mackintosh, M. (2002). Questioning the state. In M. Wuyts, M. Mackintosh, \& Y. Hewitt (Eds.), Development policy and public action (pp. 61-89). Oxford, UK: Oxford University Press.

Maeda, K. (2010). Two modes of democratic breakdown: A competing risks analysis of democratic durability. Journal of Politics, 72(4), 1129-1143.

http://doi.org/10.1017/S0022381610000575

Mahamad, F. (2017, November 6). Official communication to the lobby groups Kura Yangu Sauti Yangu and We The People over allegations of illegally operating in Kenya [Tweet]. Retrieved from 
https://twitter.com/ngoboardkenya/status/927498517446365184

Maina, W. (1998). Kenya: The state, donors and the politics of democratization. In A. Van Rooy (Ed.), Civil society and the aid industry (pp. 134-167). London, UK: Earthscan.

Makabila, S. (2014, April 27). Undermine state at your own peril, new NGO Council boss tells groups. Standard Digital. Retrieved from http://www.standardmedia.co.ke/mobile/?articleID=2000110342\&story_title=under mine-state-at-your-own-peril-new-ngo-council-boss-tells-groups

Malingha Doya, D. (2015, July 7). Kenyan firms cry foul as Chinese company building \$3.8-bn railway imports cement into country. Mail \& Guardian Africa. Retrieved from http://mgafrica.com/article/2015-07-07-kenyan-firms-cry-foul-as-chinesecompany-building-38-billion-railway-imports-cement-into-country

Martin, S. (2017, December 15). Revered poet wrote mind-expanding verse. The Globe and Mail. Retrieved from https://www.theglobeandmail.com/arts/books-andmedia/don-coles-90-a-revered-poet-who-wrote-mind-expandingverse/article37352399/

Masinde, J. (2015a, May 26). Kenya attracts Sh115bn in investment, defying security worries. Business Daily. Retrieved from http://www.businessdailyafrica.com/Kenyaattracts-Sh115-billion-in-investment/-/539546/2731068/-/12i2ko4z/-/index.html

Masinde, J. (2015b, August 23). Kenya eyes Sh200bn in foreign investment. Daily Nation. Retrieved from http://www.nation.co.ke/business/Kenya-eyes-Sh200bn-inforeign-investment/-/996/2843746/-/68b6f0z/-/index.html Matanga, F. K. (2000). Civil society and politics in Africa: The case of Kenya. Paper 
presented at the 4th International Conference of the International Society for Third Sector Research, Trinity College, Dublin, IE. Retrieved from http://c.ymcdn.com/sites/www.istr.org/resource/resmgr/working_papers_dublin/mat anga.pdf

Matara, E., \& Mwajefa, M. (2014, October 27). NGOs fault foreign funding rule. Daily Nation. Retrieved from http://www.nation.co.ke/news/NGO-Council-KevinnahLoyatum-Law-Moses-Kuria-Amendment/-/1056/2501684/-/ygmdaxz/-/index.html McGregor-Lowndes, M., \& Wyatt, B. (2017a). Conclusion. In M. McGregor-Lowndes \& B. Wyatt (Eds.), Regulating charities: The inside story (pp. 261-292). New York, NY: Routledge.

McGregor-Lowndes, M., \& Wyatt, B. (2017b). Introduction. In M. McGregor-Lowndes \& B. Wyatt (Eds.), Regulating charities: The inside story (pp. 1-14). New York, NY: Routledge.

McGregor-Lowndes, M., \& Wyatt, B. (Eds.). (2017c). Regulating charities: The inside story. New York, NY: Routledge.

Media Council Act, No. 46 of 2013. eKLR. Retrieved from http://kenyalaw.org/lex//actview.xql?actid=No. 46 of 2013

Menya, W. (2011, April 5). Poll: 61pc of Kenyans prefer ICC trials. Daily Nation. Retrieved from http://www.nation.co.ke/news/politics/1064-1139102gc2ynr/index.html

Menya, W. (2014, October 25). State targeting us over support for Hague cases, civil society protests. Daily Nation. Retrieved from http://mobile.nation.co.ke/news/CivilSociety-ICC-Hague-Cases-Jubilee-Government///1950946/2499628/- 
/format/xhtml/-/15mi3qz/-/index.html

Ministry of Devolution and Planning. (2016). Issuance of work permit to expatriates in accordance with the NGOs Co-ordination Act, Circular No. NGOB2904/2016/ED, April 21, 2016. Retrieved from http://www.ngobureau.or.ke/?wpdmpro=circularnumber-ngob29042016ed

Ministry of Lands. (2009). Sessional Paper No. 3 of 2009 on National Land Policy. Nairobi, KE. Retrieved from http://www1.uneca.org/Portals/lpi/CrossArticle/1/Land Policy Documents/Sessional-paper-on-Kenya-National-Land-Policy.pdf

Minogue, M. (2004). Public management and regulatory governance: problems of policy transfer to developing countries. In P. Cook, C. Kirkpatrick, M. Minogue, \& D. Parker (Eds.), Leading issues in competition, regulation and development (pp. 165181). Cheltenham, UK: Edward Elgar Publishing.

Minogue, M. (2006). Apples and oranges: Comparing international experiences in regulatory reform. In M. Minogue \& L. V. Cariño (Eds.), Regulatory governance in developing countries (pp. 61-81). Cheltenham, UK: Edward Elgar Publishing.

Minogue, M., \& Cariño, L. V. (2006a). Introduction: Regulatory governance in developing countries. In M. Minogue \& L. V. Cariño (Eds.), Regulatory governance in developing countries (pp. 3-16). Cheltenham, UK: Edward Elgar Publishing.

Minogue, M., \& Cariño, L. V. (Eds.). (2006b). Regulatory governance in developing countries. Cheltenham, UK: Edward Elgar Publishing.

Miriri, D. (2017, October 30). Kenya elections: President Uhuru Kenyatta wins $98 \%$ of re-run vote. Independent. Retrieved from http://www.independent.co.uk/news/world/africa/kenya-elections-latest-today- 
uhuru-kenyatta-won-repeat-vote-board-rules-raila-odinga-opposition-a8027646.html Mirza, S., \& Obrecht, A. (2013). Collective accountability in civil society: The African picture (One World Trust Briefing Papers No. 133). London, UK. Retrieved from http://oneworldtrust.org/index.php?option $=$ com_docman\&task $=$ cat_view $\&$ gid $=68 \&$ Itemid $=55$

Mohammed, H. (2015, October 30). Devolution CS Waiguru revokes deregistration of NGOs. Citizen Digital. Retrieved from http://citizentv.co.ke/news/devolution-cswaiguru-revokes-deregistration-of-ngos-104570/

Moore, D., \& Zenn, J. (2013). The legal and regulatory framework for civil society: Global trends in 2012. In State of civil society 2013: Creating an enabling environment. The synthesis report (pp. 73-79). Johannesburg, SA: CIVICUS. Retrieved from http://socs.civicus.org/wpcontent/uploads/2013/04/2013StateofCivilSocietyReport_full.pdf

Moore, J. (2017a, October 28). Violence flares and tensions rise after Kenya Presidential vote. The New York Times. Retrieved from https://www.nytimes.com/2017/10/28/world/africa/kenya-election-uhuru-kenyattaraila-odinga.html

Moore, J. (2017b, November 20). Kenya court upholds President's election. The New York Times. Retrieved from https://www.nytimes.com/2017/11/20/world/africa/kenya-supreme-courtruling.html?ribbon-ad$\mathrm{idx}=2 \& \mathrm{rref}=$ world/africa\&module=Ribbon \&version=context\&region=Header \&acti on $=$ click\&contentCollection $=$ Africa\&pgtype $=$ article 
Moore, J. (2018, March 14). Victims of political violence want more than handshake from Kenyan leaders. The New York Times. Retrieved from https://www.nytimes.com/2018/03/14/world/africa/kenya-odinga-kenyatta-policeviolence.html?rref=collection $\% 2$ Fbyline $\% 2$ Fjinamoore $\&$ action $=$ click $\&$ contentCollection $=$ undefined $\&$ region $=$ stream $\&$ module $=$ strea m_unit\&version=latest\&contentPlacement=1\&pgtype $=$ collection

Morris, D. (2011). The case of England and Wales: Striking the right balance of "hard" law versus "soft” law. In S. D. Phillips \& S. R. Smith (Eds.), Governance and regulation in the third sector: International perspectives (pp. 37-68). New York, NY: Routledge.

Morris, D. (2016). Legal limits on political campaigning by charities: drawing the line. Voluntary Sector Review, 7(1), 109-115. http://doi.org/10.1332/204080516X14558747391154

Muhindi, S. (2016, February 10). NGO staff sue Fazul for "illegal tenure." The Star. Retrieved from https:/www.the-star.co.ke/news/2016/02/10/ngo-staff-sue-fazul-forillegal-tenure_c1292073

Muslims for Human Rights (MUHURI) \& another v Inspector General of Police \& 5 others, Petition No. 19 of 2015 (2015). High Court of Kenya at Mombasa: eKLR. Retrieved from http://kenyalaw.org/caselaw/cases/view/116382/

Mutai, E. (2012, May 13). PS questions civil society's use of donor funds. Business Daily. Retrieved from http://www.businessdailyafrica.com/PS+questions +civil +society+use+of +donor+fun ds++/-/539546/1405192/-/8fejb1z/-/index.html 
Mutai, L. (2017, August 17). Kenya government cracks down on rights groups [Blog post]. Kenya Elections 2017. Retrieved from https:/www.hrw.org/blog-feed/kenyaelections-2017

Mutambo, A. (2016, November 10). Ombudsman urges banning of Fazul Mahamed from public office. Daily Nation. Retrieved from http://www.nation.co.ke/news/BanFazul-Mahamed-from-public-office-says-CAJ/1056-3448190-ehjrfsz/index.html

Mutheu, J. (2014, March 12). Kenya: Launching standards that build strong, transparent, and accountable civil society organizations [Blog post]. Management Sciences for Health Global Health Impact Blog. Retrieved from https://www.msh.org/blog/2014/03/12/kenya-launching-standards-that-build-strongtransparent-and-accountable-civil

Mwiti, B. (2014, January 9). Kenya's withdrawal from the ICC: A get out of jail free card? Fair Observer. Retrieved from http://www.fairobserver.com/region/africa/kenyas-withdrawal-icc-get-out-jail-freecard/

Naidoo, K. (2004). The end of blind faith? Civil society and the challenges of accountability, transparency and legitimacy. Accountability Forum, 2, 14-25. Retrieved from http://www.lasociedadcivil.org/wpcontent/uploads/2014/11/the_end_of_blind_faith.pdf

Nairobian Reporter. (n.d.). Uhuru and Waiguru: I suspect there's more than meet the eye - Prof Makau Mutua. The Nairobian. Retrieved from https://www.sde.co.ke/thenairobian/article/2000182998/uhuru-and-waiguru-isuspect-there-s-more-than-meet-the-eye-prof-makau-mutua 
Najam, A. (1996). Understanding the third sector: Revisiting the prince, the merchant, and the citizen. Nonprofit Management \& Leadership, 7(2), 203-219. http://doi.org/10.1002/nml.4130070210

Najam, A. (2000). The four-C's of third sector-government relations: Cooperation, confrontation, complementarity, and co-optation. Nonprofit Managment \& Leadership, 10(4), 375-396. http://doi.org/10.1002/nml.10403

National Council for Voluntary Organizations. (2017). UK civil society almanac 2017, Income data. Retrieved from https://data.ncvo.org.uk/a/almanac17/income-data/ National Council of NGOs. (2004a). Civil society in the third republic. (D. Okello, Ed.). Nairobi, KE: The National Council of NGOs.

National Council of NGOs. (2004b). Synthesis of the main issues emerging from the NGO Council Conference on "Civil Society in the Third Republic", 15th-16th December 2003, Panafric Hotel - Nairobi. In D. Okello (Ed.), Civil society in the third republic (pp. 89-94). Nairobi, KE: The National Council of NGOs.

National Council of NGOs. (n.d.). Membership. Retrieved July 17, 2015, from http://www.thengocouncilkenya.org/index.php/membership.html National Council of Non-Governmental Organisations v Wilson Kipkazi \& another, Suit No. 231 of 2014 (2017). High Court of Kenya at Nairobi. Retrieved from http://kenyalaw.org/caselaw/cases/view/133719/

Naudet, J.-D. (2012). Development aid reforms in the context of new public management (Agence Française de Développement Working Paper No. 119). Paris, FR. Retrieved from https://www.afd.fr/en/development-aid-reforms-context-new-publicmanagement 
Ndegwa, S. N. (1996). The two faces of civil society: NGOs and politics in Africa. West Hartford, CT: Kumarian Press.

Ndegwa, S. N. (2003). Kenya: Third time lucky? Journal of Democracy, 14(3), 145-158. http://doi.org/10.1353/jod.2003.0060

NGOs Co-ordination Board. (2009). National survey of NGOs 2009. Nairobi, KE.

NGOs Co-ordination Board. (2015). Annual NGO sector report 2013/14 - Popular version. Nairobi, KE.

Nilsson, A., Holmberg, A., Modéer, P., Mogen, M. B., Christoplos, I., \& Rothman, J. (2013). Review of civil society support modalities at Sida HQ and Swedish embassies final report. Stockholm, SE: Swedish International Development Cooperation Agency. Retrieved from https://www.sida.se/contentassets/a3dc882f93664d85bcde92d336f1a749/review-ofcivil-society-support-modalities-at-sida-hq-and-swedish-embassies---finalreport_3475.pdf

Nizam, R., Muriu, A. R., \& International Budget Partnership. (2015). Basic requirements for public participation in Kenya's legal framework (Kenya Devolution No. 2). Retrieved from https://openknowledge.worldbank.org/bitstream/handle/10986/21664/94498.pdf?seq uence $=1 \&$ is Allowed $=\mathrm{y}$

Njongu, K. (2018). Confronting paristanship and divisions in Kenya. In S. Brechenmacher \& T. Carothers (Eds.), Examining civil society legitimacy (pp. 1415). Washington, DC: Carnegie Endowment for International Peace. Retrieved from https://carnegieendowment.org/files/Civil-Society-Legitimacy_FINAL.pdf 
Non-Governmental Organizations Co-ordination Regulations, Chapter 134 of 1992. eKLR. Retrieved from http://www.kenyalaw.org:8181/exist/kenyalex/sublegview.xql?subleg=CAP. 134\#KE/LEG/EN/AR/N/CHAPTER 134/SUBLEG/HC_3

Non-Governmental Organizations Code of Conduct, L.N. 306/1995. eKLR. Retrieved from http://www.kenyalaw.org:8181/exist/kenyalex/sublegview.xql?subleg=CAP. 134\#KE/LEG/EN/AR/N/CHAPTER 134/SUBLEG/HC_3

Obadare, E. (2011). Civil society in sub-Saharan Africa. In M. Edwards (Ed.), The Oxford handbook of civil society (pp. 183-194). New York, NY: Oxford University Press.

Obadare, E. (2014). Introduction: Turning the table on Gellner: Alternative discourses of civil society in Africa. In E. Obadare (Ed.), The handbook of civil society in Africa (pp. 1-3). New York, NY: Springer.

Obala, L. (2014). The myths and realities of Kenya's turning to the East. Doha, QA: Al Jazeera Centre for Studies. Retrieved from http://studies.aljazeera.net/ResourceGallery/media/Documents/2014/5/22/20145221 2924830734Kenya and China.pdf

Obong'o, S. O. (2009). Implementation of performance contracting in Kenya. International Public Management Review, 10(2), 66-84. http://doi.org/10.5296/jpag.v2i4.2751

Obong'o, S. O. (2013). Particularistic exchanges and pacts of domination in Africa: Examining how patronage appointments may have increased resistance to public sector reforms in Kenya. International Public Management Review, 14(1), 27-46. 
http://doi.org/10.1002/fut.21631

Obura, F. (2018, February 27). Fazul Mohamed quits as CEO of NGOs Board. Standard Digital. Retrieved from https://www.standardmedia.co.ke/business/article/2001271251/fazul-quits-as-ceoof-ngos-board

Ochido, H. O. (2013). My brother's keeper: Challenges in gifting in the Kenyan context. The International Journal of Not-for-Profit Law, 15(1), 68-71. http://doi.org/10.1177/0278364909104276

Office of the Prosecutor of the International Criminal Court. (2014, December 5). Statement of the Prosecutor of the International Criminal Court, Fatou Bensouda, on the withdrawal of charges against Mr. Uhuru Muigai Kenyatta. Retrieved from http://www.icc-cpi.int/en_menus/icc/press and media/press releases/Pages/otpstatement-05-12-2014-2.aspx

Office of the Vice President, \& Ministry of Home Affairs. (2006). Sessional Paper No 1 of 2006 on Non Governmental Organisations. Nairobi, KE. Retrieved from http://www.penkenya.org/UserSiteFiles/public/SessionalPaper.pdf

Okopu-Mensa, P. Y. (2009). Whither Africa's civil society? (Development, Innovation and International Political Economy Research (DIIPER) Series No. 18). Aalborg, DK. Retrieved from http://vbn.aau.dk/files/17778380/DIIPER_wp_18.pdf

Okumu, E. (2015, April 6). Devolution CS Anne Waiguru resigns, cites poor health and attacks against family. The Star. Retrieved from https://www.thestar.co.ke/news/2015/11/21/devolution-cs-anne-waiguru-resigns-cites-poor-healthand-attacks_c1246960 
Ong'wen, O. (2004, May 26). Civil society in trouble as NARC raids council. East African Standard. Retrieved from http://www.sarpn.org/newsflash.php?news_id=1468\&archive=1

Onoma, A. K. (2010). The contradictory potential of institutions: The rise and decline of land documentation in Kenya. In J. Mahoney \& K. Thelen (Eds.), Explaining institutional change: Ambiguity, agency and power (pp. 63-93). New York, NY: Cambridge University Press.

Onyando, J. (2015, October 3). NGO Board audit. The Star. Retrieved from https://www.the-star.co.ke/news/2015/10/03/ngo-board-audit_c1215180

Open Forum for CSO Development Effectiveness. (2010). The Istanbul principles for CSO development effectiveness. Retrieved from http://csopartnership.org/wpcontent/uploads/2016/01/hlf4_72.pdf

Organisation for Economic Co-operation and Development. (n.d.-a). DAC list of ODA recipients. Retrieved from http://www.oecd.org/dac/financing-sustainabledevelopment/development-finance-standards/daclist.htm

Organisation for Economic Co-operation and Development. (n.d.-b). DAC list of ODA recipients effective for reporting on 2014, 2015, 2016 and 2017 flows. Retrieved from https://www.oecd.org/dac/stats/documentupload/DAC_List_ODA_Recipients2014to 2017_flows_En.pdf

Organisation for Economic Co-operation and Development. (n.d.-c). Frequently asked questions. Retrieved from http://www.oecd.org/dac/financing-sustainabledevelopment/development-finance-data/faq.htm 
Organisation for Economic Co-operation and Development. (n.d.-d). History of DAC lists of aid recipient countries. Retrieved from http://www.oecd.org/dac/stats/historyofdaclistsofaidrecipientcountries.htm Organisation for Economic Co-operation and Development. (n.d.-e). Net ODA. Retrieved from https://data.oecd.org/oda/net-oda.htm

Organisation for Economic Co-operation and Development. (1996). Shaping the 21st century: The contribution of development co-operation. Paris, FR. Retrieved from https://www.oecd.org/dac/2508761.pdf

Organisation for Economic Co-operation and Development. (2010). Civil society and aid effectiveness: Findings, recommendations and good practice. Paris, FR. Retrieved from http://www.oecd-ilibrary.org/content/book/9789264056435-en

Organisation for Economic Co-operation and Development. (2011). How DAC members work with civil society organisations: An overview. Paris, FR. Retrieved from http://www.oecd.org/dac/peer-reviews/48843465.pdf

Organisation for Economic Co-operation and Development. (2012). Partnering with civil society: 12 lessons from DAC peer reviews. Paris, FR. Retrieved from http://www.oecd.org/dac/peer-reviews/12 Lessons Partnering with Civil Society.pdf Organisation for Economic Co-operation and Development. (2018a). Aid for civil society organisations. Paris, FR. Retrieved from http://www.oecd.org/dac/financingsustainable-development/development-finance-topics/Aid-for-Civil-SocietyOrganisations-2015-2016.pdf

Organisation for Economic Co-operation and Development. (2018b). List of DAC members. Retrieved from http://www.oecd.org/dac/financing-sustainable- 
development/development-finance-standards/dacandcrscodelists.htm

Organisation for Economic Co-operation and Development. (2018c). Private

philanthropy for development. Paris, FR. Retrieved from https://read.oecd-

ilibrary.org/development/private-philanthropy-for-development_9789264085190-

en\#page 1

Organization of African Unity. African Charter on Human and Peoples' Rights (1981).

Retrieved from https://au.int/sites/default/files/treaties/7770-treaty-0011_-

_african_charter_on_human_and_peoples_rights_e.pdf

Orvis, S. (2003). Kenyan civil society: bridging the urban-rural divide? The Journal of Modern African Studies, 41(2), 247-268.

http://doi.org/10.1017/s0022278x03004245

Osborne, S. P. (2010). The (new) public governance: A suitable case for treatment? In S. P. Osborne (Ed.), The new public governance? Emerging perspectives on the theory and practice of public governance (pp. 1-16). London, UK: Routledge.

Otini, R. (2012, May 27). Donors raise funding for NGOs ahead of polls. Business Daily. Retrieved from http://www.businessdailyafrica.com/Donors-raise-funding-forNGOs-ahead-of-polls--/539546-1414728-sk2a84/index.html

Otwala, J. (2017, May 14). High Courts orders Nkaissery to implement pro-civil society law. Kenya Free Press. Retrieved from http://www.kenyafreepress.com/topstories/national/2022/high-courts-orders-nkaissery-to-implement-pro-civil-societylaw

Owens, M. (2017). Challenged regulators. In M. McGregor-Lowndes \& B. Wyatt (Eds.), Regulating charities: The inside story (pp. 81-96). New York, NY: Routledge. 
Owino, S. (2017, October 8). Government hard hit by own move to shut down IDLO. Daily Nation. Retrieved from http://www.nation.co.ke/news/State-hard-hit-by-ownmove-to-shut-prolific-donor-NGO-/1056-4129896-5g8cy4/index.html

Owiti, J., Aluoka, O., \& Oloo, A. G. R. (2004). Civil society in the new dispensation: Prospects and challenges. In D. Okello (Ed.), Civil society in the third republic (pp. 71-88). Nairobi, KE: The National Council of NGOs.

Pajas, P. (1999). Recognition of public benefit in legal systems of several nations. International Journal of Not-for-Profit Law, 2(1). Retrieved from http://www.icnl.org/research/journal/vol2iss1/s_1.htm\#2

Panel on Accountability and Governance in the Voluntary Sector. (1999). Building on strength: Improving governance and accountability in Canada's voluntary sector. Ottawa, CA. Retrieved from http://sectorsource.ca/sites/default/files/resources/files/2458_Book.pdf

Parachin, A., Breen, O., Barber, P., Farwell, M., Phillips, S. D., \& Smith, S. R. (2014). Regulatory waves 2: Comparative perspectives on state regulation and selfregulation policies in the nonprofit sector [Abstract]. Abstract for panel presentation for the 11th Conference of the International Society for Third Sector Research, July 22-25, 2014, Muenster, DE. Retrieved from https://c.ymcdn.com/sites/istr.siteym.com/resource/resmgr/MunsterAbstracts/Pane19_Regulatory_Waves_2-_C.pdf

Paris Declaration on Aid Effectiveness. (2005). Paris, FR. Retrieved from http://www.oecd.org/document/18/0,3343,en_2649_3236398_35401554_1_1_1_1,0 0.html\%5Cnhttp://scholar.google.com/scholar?hl=en\&btnG=Search\&q=intitle:The + Paris + Declaration + on + Aid + Effectiveness + and + the + Accra + Agenda + for + Action\# 6 
Pascoe, S. (2017). The digital regulator. In M. McGregor-Lowndes \& B. Wyatt (Eds.), Regulating charities: The inside story (pp. 211-232). New York, NY: Routledge.

PBO Taskforce. (2015). Taskforce report on the Public Benefit Organizations Act, 2013 (PBOs Act, 2013). Nairobi, KE: Ministry of Devolution and Planning. Retrieved from http://www.ngobureau.or.ke/?wpdmpro=final-task-force-2014-15-report-onthe-pbos-act-2013

Penal Code, Chapter 63 of 1930. eKLR. Retrieved from http://www.kenyalaw.org:8181/exist/kenyalex/actview.xql?actid=CAP. 63

Persons With Disabilities Act, No. 14 of 2003. eKLR. Retrieved from http://kenyalaw.org/lex//actview.xql?actid=No. 14 of 2003

Peter Ntoyian Ole Mesei \& 11 others v Non Governmental Organizations Council, Civil Appeal No. 31 of 2016 (2016). High Court of Kenya at Nairobi: eKLR. Retrieved from http://kenyalaw.org/caselaw/cases/view/120274/

Peterson, L. E., \& Gallus, N. (2007). International treaty protections for not-for-profit organizations. The International Journal of Not-for-Profit Law, 10(1), 47-76. Retrieved from http://www.icnl.org/research/journal/vol10iss1/ijnl_vol10iss1.pdf Phillips, S. D. (2006). Balancing acts: Multilevel regulation of Canada's voluntary sector. In B. G. Doern \& R. Johnson (Eds.), Rules, rules, rules: Multilevel regulatory governance (pp. 124-154). Toronto, CA: University of Toronto Press.

Phillips, S. D. (2011). Incrementalism at its best, and worst: Regulatory reform and relational governance in Canada. In S. D. Phillips \& S. R. Smith (Eds.), Governance and regulation in the third sector: International perspectives. New York, NY: Routledge. 
Phillips, S. D. (2012a). Canadian leapfrog: From regulating charitable fundraising to coregulating good governance. Voluntas, 23(3), 808-829. http://doi.org/10.1007/s11266-011-9237-x

Phillips, S. D. (2012b). The new citizenship and governance: Alternative intersections. In D. Levi-Faur (Ed.), Oxford handbook of governance (pp. 485-497). New York, NY: Oxford University Press.

Phillips, S. D., \& Smith, S. R. (2011a). Between governance and regulation: Evolving government-third sector relationships. In S. D. Phillips \& S. R. Smith (Eds.), Governance and regulation in the third sector: International perspectives (pp. 136). New York, NY: Routledge.

Phillips, S. D., \& Smith, S. R. (Eds.). (2011b). Governance and regulation in the third sector: International perspectives. New York, NY: Routledge.

Phillips, S. D., \& Smith, S. R. (2014). A dawn of policy convergence? Third sector policy and regulatory change among the "Anglo-Saxon" cluster. Public Management Review, 16(8), 1141-1163. http://doi.org/10.1080/14719037.2014.965272

Phillips, S. D., \& Smith, S. R. (2016). Public policy for philanthropy. Catching the wave or creating a backwater? In T. Jung, S. D. Phillips, \& J. Harrow (Eds.), The Routledge companion to philanthropy (pp. 213-228). New York, NY: Routledge. Polidano, C., \& Hulme, D. (1999). Public management reform in developing countries. Public Management Review, 1(1), 121-132. http://doi.org/10.1080/14719037800000007

Political Parties Act, No. 11 of 2011. eKLR. Retrieved from http://www.kenyalaw.org/lex//actview.xql?actid=No. 11 of 2011 
Pollitt, C. (2010). 30 years of public management reforms: Has there been a pattern? (A background paper for the World Bank consultation exercise). Leuven, BE. Retrieved from siteresources.worldbank.org/EXTGOVANTICORR/Resources/Politt.doc\%0A

Pousadela, I. M., \& Cruz, A. (2016). The sustainability of Latin American CSOs: Historical patterns and new funding sources. Development in Practice, 26(5), 606618. http://doi.org/10.1080/09614524.2016.1188884

Poverty Eradication Network. (2007a). Enhancing the competence and sustainability of high quality CSOs in Kenya. Nairobi, KE. Retrieved from http://www.akdn.org/publications/civil_society_kenya_competence.pdf

Poverty Eradication Network. (2007b). Examining government and CSO collaborations in Kenya: A study of selected successful case stories: What can we learn? Nairobi, KE. Retrieved from http://www.akdn.org/publications/civil_society_kenya_cso.pdf Poverty Eradication Network. (2014). State of civil society in Kenya: Challenges and opportunities. Nairobi, KE. Retrieved from http://penkenya.org/upgrade/wordpress/wp-content/uploads/2018/06/csos-leadersdialogue-report2015.pdf

Prakash, A., \& Gugerty, M. K. (2010). Trust but verify? Voluntary regulation programs in the nonprofit sector. Regulation \& Governance, 4(1), 22-47. http://doi.org/10.1111/j.1748-5991.2009.01067.x

President of Kenya. (2014). Speech by His Excellency Hon. Uhuru Kenyatta, C.G.H., President and Commander-in-Chief of the Defense Forces of the Republic of Kenya during the Fifth Mashujaa Day, 20th October 2014. Nairobi, KE. Retrieved from http://allafrica.com/stories/201410202625.html 
President of Kenya. (2016). President Kenyatta's Jamhuri Day Speech, December 12, 2016. Nairobi, KE. Retrieved from http://www.mygov.go.ke/president-kenyattasjamhuri-day-speech-december-12-2016/

Prevention of Terrorism Act, No. 30 of 2012. eKLR. Retrieved from http://www.kenyalaw.org/lex//actview.xql?actid=No. 30 of 2012

Proceeds of Crime and Anti-Money Laundering Act, No. 9 of 2009. eKLR. Retrieved from http://www.kenyalaw.org/lex//actview.xql?actid=No. 9 of 2009

Public Audit Act, No. 34 of 2015. eKLR. Retrieved from http://kenyalaw.org/lex//actview.xql?actid=No. 34 of 2015

Public Benefit Organizations Act, No. 18 of 2013. eKLR. Retrieved from http://www.kenyalaw.org:8181/exist/kenyalex/actview.xql?actid=No. 18 of 2013

Public Finance Management Act, No. 18 of 2012. eKLR. Retrieved from http://kenyalaw.org/lex//actview.xql?actid=No. 18 of 2012

Public Order Act, Chapter 56 of 1950. eKLR. Retrieved from http://kenyalaw.org/lex//actview.xql?actid=CAP. 56

Rajab, R., \& Awich, L. (2017, August 16). State cracks down on civil society. The Star. Retrieved from https://www.the-star.co.ke/news/2017/08/16/state-cracks-down-oncivil-society_c1617387

Ratcliffe, R. (2017, August 24). "The boss wants to talk to you": Former UN rights expert on Kenya airport ordeal. The Guardian. Retrieved from https://www.theguardian.com/global-development/2017/aug/24/boss-wants-to-talkto-you-former-un-human-rights-expert-maina-kiai-detained-kenya-airport-ordeal Reichard, C. (2010). New public management. In H. K. Anheier \& S. Toepler (Eds.), 
International encyclopedia of civil society (pp. 1030-1034). Berlin, DE: Springer.

Reimann, K. D. (2006). A view from the top: International politics, norms and the worldwide growth of NGOs. International Studies Quarterly, 50(1), 45-68. http://doi.org/10.1111/j.1468-2478.2006.00392.x

Republic of Kenya. (2007). Governance, Justice, Law and Order Sector (GJLOS) Reform Programme: Administrative data collection and analysis report. Nairobi, KE. Retrieved from http://acjr.org.za/resource-centre/governance-justice-and-law-andorder-sector-reform-programme-administrative-data-collection-and-analysis-report Republic v Commission on Administrative Justice Ex parte Yusuf Mahamed Fazul, Misc. Civil Application No. 517 of 2016 (2017). High Court of Kenya at Nairobi: eKLR. Retrieved from http://kenyalaw.org/caselaw/cases/view/139462/ Republic v Fazul Mahamed and 3 others, Miscellaneous Application No. 617 of 2017 (2017). High Court of Kenya at Nairobi: eKLR. Retrieved from http://kenyalaw.org/caselaw/cases/view/142705/

Republic v Non-Governmental Organisations Co-ordination Board EX Parte Okiya Omtatah Okoiti \& 2 others, Miscellaneous Application No. 654 of 2016 (2017). High Court of Kenya at Nairobi: eKLR. Retrieved from http://kenyalaw.org/caselaw/cases/view/140715/

Risley, A. (2015). Civil society organizations, advocacy, and policy making in Latin American democracies. New York, NY: Palgrave MacMillan.

Robbins, K. C. (2006). The nonprofit sector in historical perspective. In W. W. Powell \& R. Steinberg (Eds.), The nonprofit sector: A research handbook (2nd ed., pp. 1431). New Haven, CT: Yale University Press. 
Robinson, M. (1997). Privatising the voluntary sector: NGOs as public service contractors? In D. Hulme \& M. Edwards (Eds.), NGOs, states and donors: Too close for comfort? (pp. 59-78). New York, NY: St. Martin's Press.

Rogers, D. (2018, January 13). GOP tax law a one-two punch to charities - and American giving. Politico. Retrieved from https:/www.politico.com/story/2018/01/13/goptax-law-charities-giving-339039

Rutzen, D. (2011). Global perspectives on the legal framework for civil society and relational governance. In S. D. Phillips \& S. R. Smith (Eds.), Governance and regulation in the third sector: International perspectives (pp. 260-276). New York, NY: Routledge.

Rutzen, D. (2015a). Aid barriers and the rise of philanthropic protectionism. International Journal of Not-for-Profit Law, 17(1), 5-44. Retrieved from http://www.icnl.org/research/journal/vol17ss1/Rutzen.pdf

Rutzen, D. (2015b). Civil society under assault. Journal of Democracy, 26(4), 28-39. http://doi.org/10.1353/jod.2015.0071

Rutzen, D., \& Shea, C. (2006). The associational counter-revolution. Alliance, 11(3), 2728. Retrieved from http://ecbiz108.inmotionhosting.com/ icnlor5/research/resources/dcs/alliance2006.p df

Salamon, L. M. (1994). The rise of the nonprofit sector. Foreign Affairs, 73(4), 109-122. http://doi.org/10.2307/20046747

Salamon, L. M. (2010). Putting the civil society sector on the economic map of the world. Annals of Public and Cooperative Economics, 81(2), 167-210. 
http://doi.org/10.1111/j.1467-8292.2010.00409.x

Salamon, L. M., Anheier, H. K., List, R., Toepler, S., \& Wojciech Sokolowski, S. (Eds.). (1999). Global civil society: Dimensions of the nonprofit sector. Baltimore, MD:

The Johns Hopkins Center for Civil Society Studies. Retrieved from http://ccss.jhu.edu/wp-content/uploads/downloads/2011/08/Global-Civil-SocietyI.pdf

Salamon, L. M., Sokolowski, W., \& Associates, A. (Eds.). (2004). Global civil society: Dimensions of the nonprofit sector, volume two. Bloomfield, CT: Kumarian Press. Retrieved from http://ccss.jhu.edu/wpcontent/uploads/downloads/2011/08/Global_Civil_Soiciety_2_TOC.pdf

Salamon, L. M., \& Toepler, S. (2000). The influence of the legal environment on the development of the nonprofit sector (Center for Civil Society Studies Working Paper Series No. 17). Baltimore, MD. Retrieved from http://ccss.jhu.edu/wpcontent/uploads/downloads/2011/09/CCSS_WP17_2000.pdf

Salamon, L. M., Wojciech Sokolowski, S., \& List, R. (2004). Global civil society: An overview. In L. M. Salamon, S. Wojciech Sokolowski, \& and Associates (Eds.), Global civil society: Dimensions of the nonprofit sector, volume two (pp. 3-60). Bloomfield, CT: Kumarian Press. Retrieved from http://ccss.jhu.edu/wpcontent/uploads/downloads/2011/08/Global_Civil_Soiciety_2_TOC.pdf

Schoeman, R. E. (2008). The public policy impact of the changing official development assistance programme in financing the HIV/AIDS response in Southern Africa (Unpublished doctoral dissertation). University of Pretoria, SA. Retrieved from https://repository.up.ac.za/bitstream/handle/2263/24284/Complete.pdf?sequence=10 
Seawright, J., \& Gerring, J. (2008). Case selection techniques in case study research: A menu of qualitative and quantitative options. Political Research Quarterly, 61(2), 294-308. http://doi.org/10.1177/1065912907313077

Sidel, M. (2005). The guardians guarding themselves: A comparative perspective on nonprofit self-regulation. Chicago-Kent Law Review, 80, 803-835. Retrieved from http://www.cklawreview.com/wp-content/uploads/vol80no2/Sidel.pdf

Sidel, M. (2006). The third sector, human security, and anti-terrorism: The United States and beyond. Voluntas, 17(3), 199-210. http://doi.org/10.1007/s11266-006-9017-1

Sidel, M. (2010a). Maintaining firm control: Recent developments in nonprofit law and regulation in Vietnam. The International Journal of Not-for-Profit Law, 12(3), 5267. Retrieved from http://www.icnl.org/research/journal/vol12iss3/v12n3 revised.pdf

Sidel, M. (2010b). Regulation of the voluntary sector: Freedom and security in an era of uncertainty. New York, NY: Routledge.

Sidel, M. (2010c). The promise and limits of collective action for nonprofit selfregulation: evidence from Asia. Nonprofit and Voluntary Sector Quarterly, 39(6), 1039-1056. http://doi.org/10.1177/0899764010371514

Sidel, M., Layton, M., Dunn, A., Limor, N., \& Brindt, N. (2014). Regulatory waves 1: Comparative perspectives on state regulation and self-regulation policies in the nonprofit sector [Abstract]. Abstract for panel presentation for the 11th Conference of the International Society for Third Sector Research, July 22-25, 2014, Muenster, DE. Retrieved from http://c.ymcdn.com/sites/www.istr.org/resource/resmgr/MunsterAbstracts/Panel9_R 
egulatory_Waves_1-_C.pdf

Skelcher, C. (2004). Public-private partnerships and hybridity. In E. Ferlie, L. E. Lynn Jr, \& C. Pollitt (Eds.), The Oxford handbook of public management (pp. 347-370). London, UK: Oxford University Press.

Smillie, I. (1995). The alms bazaar: Altruism under fire - non-profit organizations and international development. International Development Research Centre. Ottawa, CA: International Development Research Centre. Retrieved from https://www.developmentbookshelf.com/doi/book/10.3362/9781780446127

Smith, D. H. (2011). Foreword. In C. Corbett (Ed.), Advancing nonprofit stewardship through self-regulation (pp. ix-xx). Sterling, VA: Kumarian Press.

Smith, S. R. (2010). Hybridization and nonprofit organizations: The governance challenge. Policy and Society, 29(3), 219-229. http://doi.org/10.1016/j.polsoc.2010.06.003

Snow, D. A., \& Trom, D. (2002). The case study and the study of social movements. In B. Klandermans \& S. Staggenborg (Eds.), Methods of social movement research (pp. 146-172). Minneapolis, MN: University of Minnesota Press.

Societies Act, Chapter 108 of 1968. eKLR. Retrieved from http://kenyalaw.org/lex//actview.xql?actid=CAP. 108

Solomon, S. (2018, March 22). Cambridge analytica played roles in multiple African elections. Voice of America. Retrieved from https://www.voanews.com/a/cambridge-analytica-played-roles-in-multiple-africanelections/4309792.html

Srauss, A. L., \& Corbin, J. (1998). Basics of qualitative research: Techniques and 
procedures for developing grounded theory (2nd ed.). Thousand Oaks, CA: Sage Publications, Inc.

Stephens, U. (2017). Reflections on birthing a regulator. In M. McGregor-Lowndes \& B. Wyatt (Eds.), Regulating charities: The inside story (pp. 233-257). New York, NY: Routledge.

Strauss, A., \& Corbin, J. (1994). Grounded theory methodology: An overview. In N. K. Denzin \& Y. S. Lincoln (Eds.), Handbook of qualitative research (pp. 273-285). Thousand Oaks, CA: Sage Publications, Inc.

Suarez, D., \& Gugerty, M. K. (2016). Funding civil society? Bilateral government support for development NGOs. Voluntas, 27(6), 2617-2640. http://doi.org/10.1007/s11266-016-9706-3

Suddaby, R. (2006). From the editors: What grounded theory is not. Academy of Management Journal, 49(4), 633-642. http://doi.org/10.5465/amj.2006.22083020

Suri, M. (2018, September 6). India's top court decriminalizes gay sex in landmark ruling. $C N N$. Retrieved from https://www.cnn.com/2018/09/06/asia/india-gay-sexruling-intl/index.html

Task Team on CSO Development Effectiveness and Enabling Environment. (2011). CSO development effectiveness and enabling environment: A review of the evidence. Stockholm, SE. Retrieved from https://taskteamcso.files.wordpress.com/2014/02/evidence-of-progress-on-aaaen_d1813.pdf

Task Team on CSO Development Effectiveness and Enabling Environment. (2016a). Development of guidance on Indicator Two: An invitation to engage. The Hague, 
NL. Retrieved from https://taskteamcso.files.wordpress.com/2016/11/developmentof-guidance-for-indicator-two.pdf

Task Team on CSO Development Effectiveness and Enabling Environment. (2016b). Key messages for the Global Partnership for Effective Development Cooperation 2016 second High Level Meeting in Nairobi. The Hague, NL. Retrieved from https://taskteamcso.files.wordpress.com/2016/11/key-messages.pdf

Taylor, B. (2013). Kenya's Green Belt Movement: Contributions, conflict, contradictions, and complications in a prominent environmental non-governmental organization (ENGO). In L. Trägårdh, N. Witoszek, \& B. Taylor (Eds.), Civil society in the age of monitory democracy (pp. 180-207). New York, NY: Berghahn Books.

Taylor, R., Torugsa, N. A., \& Arundel, A. (2018). Leaping into real-world relevance: An "abduction" process for nonprofit research. Nonprofit and Voluntary Sector Quarterly, 47(1), 206-227. http://doi.org/10.1177/0899764017718635

Tenbensel, T., Dwyer, J., \& Lavoie, J. (2014). How not to kill the golden goose:

Reconceptualizing accountability environments of third-sector organizations. Public Management Review, 16(7), 925-944.

http://doi.org/10.1080/14719037.2013.770054

The Constitution of Kenya, 2010. eKLR. Retrieved from http://www.kenyalaw.org:8181/exist/kenyalex/actview.xql?actid=Const2010 The Constitution of Kenya Review Act, No. 9 of 2008. eKLR. Retrieved from http://www.kenyalaw.org/Downloads/Acts/The_Constitution_of_Kenya_Review_A ct_2008.pdf 
The Immigration Act, Chapter 172 of 1985. eKLR. Retrieved from http://kenyalaw.org/k1/fileadmin/pdfdownloads/RepealedStatutes/ImmigrationActCa p172.pdf

The Kenya Gazette, Vol. CXVII - No. 36, Notice No. 2326, The Kenya Gazette 807-808 (2015). Nairobi, Kenya. Retrieved from http://puntlandi.com/wpcontent/uploads/2015/04/TERROR-LIST.pdf

The Non-governmental Organizations Co-ordination Act, No. 19 of 1990. eKLR.

Retrieved from http://kenyalaw.org/kl/fileadmin/pdfdownloads/Acts/NonGovernmentalOrganizationsCo-ordinationAct_No19of1990_.pdf

The Public Benefit Organizations (Amendment) Bill, National Assembly Bills No. 9, 2016. eKLR. Retrieved from http://kenyalaw.org/k1/fileadmin/pdfdownloads/bills/2016/Public_Benefits_Organiz ations__Amendment__Bill_2016.pdf

The Security Laws (Amendment) Act, No. 19 of 2014. eKLR. Retrieved from http://kenyalaw.org/k1/fileadmin/pdfdownloads/AmendmentActs/2014/SecurityLaw s_Amendment_Act_2014.pdf

The Statute Law (Miscellaneous Amendments) Act, No. 7 of 2007. eKLR. Retrieved from http://kenyalaw.org/k1/fileadmin/pdfdownloads/AmendmentActs/2007/the_statute_1 aw_miscellaneous_amendments_act_2007.pdf

The Statute Law (Miscellaneous Amendments) Bill, 2013, Bills No. 32. Laws of Kenya. Retrieved from http://kenyalaw.org/kl/fileadmin/pdfdownloads/bills/2013/TheStatuteLaw(Miscellan 
eousAmendments)Bill2013.pdf

The Statute Law (Miscellaneous Amendments) Bill, 2014, Bills No. 24. eKLR. Retrieved from

http://kenyalaw.org/kl/fileadmin/pdfdownloads/bills/StatutesLawMiscellaneous(Am endments)Bill20I4.pdf

Thomas, P. (2015). Trust and the role of independent parliamentary agencies. Ottawa, CA: Office of the Public Sector Integrity Commissioner of Canada. Retrieved from http://www.psic-ispc.gc.ca/eng/content/dr-paul-thomas-paper

Transition to Devolved Government Act, No. 1 of 2012. eKLR. Retrieved from http://kenyalaw.org/lex//actview.xql?actid=No. 1 of 2012

Transparency International. (1998). Corruption perceptions index 1998: Results. Retrieved from https://www.transparency.org/research/cpi/cpi_1998/0

Transparency International. (2002). Corruption perceptions index 2002: Results. Retrieved from https://www.transparency.org/research/cpi/cpi_2002/0

Transparency International. (2007). Corruption perceptions index 2007: Results. Retrieved from https://www.transparency.org/research/cpi/cpi_2007/0

Transparency International. (2008). Corruption perceptions index 2008: Results. Retrieved from https://www.transparency.org/research/cpi/cpi_2008/0\#results Transparency International. (2012). Corruption perceptions index 2012: Results. Retrieved from https://www.transparency.org/cpi2012/results Transparency International. (2013). Corruption perceptions index 2013: Results. Retrieved from https://www.transparency.org/cpi2013/results Transparency International. (2017). Corruption perceptions index 2016. Berlin, DE. 
Retrieved from

https://www.transparency.org/whatwedo/publication/corruption_perceptions_index_ 2016

Transparency International. (2018a). Corruption perceptions index 2017. Berlin, DE. Retrieved from https://www.transparency.org/news/feature/corruption_perceptions_index_2017

Transparency International. (2018b). Corruption perceptions index 2017: Full data set. Retrieved from https://www.transparency.org/news/feature/corruption_perceptions_index_2017\#tab le

Tremblay-Boire, J., Prakash, A., \& Gugerty, M. K. (2016). Regulation by reputation: Monitoring and sanctioning in nonprofit accountability clubs. Public Administration Review, 76(5), 712-722. http://doi.org/10.1111/puar.12539

Trusted Society of Human Rights Alliance v Cabinet Secretary Devolution and Planning and 3 others, Petition No. 351 of 2015 (2016). High Court of Kenya at Nairobi: eKLR. Retrieved from http://kenyalaw.org/caselaw/cases/view/128172/

Trusted Society of Human Rights Alliance v Cabinet Secretary for Devolution and Planning \& 3 others, Petition No. 351 of 2015 (2017). High Court of Kenya at Nairobi: eKLR. Retrieved from http://kenyalaw.org/caselaw/cases/view/135653

Trustees (Perpetual Succession) Act, Chapter 164 of 1923. eKLR. Retrieved from http://www.kenyalaw.org/lex//actview.xql?actid=CAP. 164

Truth, Justice and Reconciliation Act, No. 6 of 2008. eKLR. Retrieved from http://kenyalaw.org/lex//actview.xql?actid=No. 6 of 2008 
Truth, Justice and Reconciliation Commission. (2013). Report of the Truth, Justice and Reconciliation Commission - Abridged version. Nairobi, KE.

Turner, M., \& Hulme, D. (1997). Governance, administration and development. West Hartford, CT: Kumarian Press.

United Nations. Universal Declaration of Human Rights (Resolution 217 A) (1948). Retrieved from http://www.un.org/en/universal-declaration-human-rights/ United Nations. General Declaration on the Right and Responsibility of Individuals, Groups and Organs of Society to Promote and Protect Universally Recognized Human Rights and Fundamental Freedoms (A/RES/53/144) (1998). Retrieved from https://www.ohchr.org/EN/ProfessionalInterest/Pages/RightAndResponsibility.aspx/ 89/pdf/N9977089.pdf?OpenElement

United Nations. (2015). Transforming our World: The 2030 Agenda for Sustainable Development. New York, NY. Retrieved from http://www.un.org/pga/wpcontent/uploads/sites/3/2015/08/120815_outcome-document-of-Summit-foradoption-of-the-post-2015-development-agenda.pdf

United Nations Special Rapporteur on the rights to freedom of peaceful assembly and of association. (2013). Report of the Special Rapporteur on the rights to freedom of peaceful assembly and of association, Maina Kiai (A/HRC/23/39). Geneva, $\mathrm{CH}$. Retrieved from http://freeassembly.net/wpcontent/uploads/2013/09/A.HRC_.23.39_EN-annual-report-April-2013.pdf United Nations Special Rapporteur on the rights to freedom of peaceful assembly and of association. (2014). Report of the Special Rapporteur on the rights to freedom of peaceful assembly and of association, Maina Kiai (A/HRC/26/29). Geneva, CH. 
Retrieved from http://freeassembly.net/wp-content/uploads/2014/05/A-HRC-2629_en.pdf

United Nations Special Rapporteur on the rights to freedom of peaceful assembly and of association. (2017). Report of the Special Rapporteur on the rights to freedom of peaceful assembly and of association, Maina Kiai (A/HRC/35/28). Geneva, CH. Retrieved from http://freeassembly.net/wpcontent/uploads/2017/05/A.HRC_.35.28.English.pdf

United States Agency for International Development. (2010). 2009 NGO sustainability index for sub-Saharan Africa. Washington, DC. Retrieved from http://pdf.usaid.gov/pdf_docs/Pnadw488.pdf

United States Agency for International Development. (2013a). 2012 CSO Sustainability Index for Central and Eastern Europe and Eurasia. Washington, DC. Retrieved from http://www.usaid.gov/sites/default/files/documents/1863/2012CSOSI_0.pdf

United States Agency for International Development. (2013b). 2012 CSO sustainability index for sub-Saharan Africa. Washington, DC. Retrieved from http://www.usaid.gov/sites/default/files/documents/1860/CSOSI_AFR_2012.pdf

United States Agency for International Development. (2014). 2013 CSO sustainability index for sub-Saharan Africa. Washington, DC. Retrieved from http://www.usaid.gov/sites/default/files/documents/1866/2013_Africa_CSOSI.pdf United States Agency for International Development. (2016). 2015 CSO sustainability index for sub-Saharan Africa. Washington, DC. Retrieved from https://www.usaid.gov/sites/default/files/documents/1866/2015_Africa_CSOSI.pdf United States Agency for International Development. (2017a). 2016 CSO sustainability 
index for Asia. Washington, DC. Retrieved from

https://www.usaid.gov/sites/default/files/documents/1868/2016-Asia-CSOSIReport.pdf

United States Agency for International Development. (2017b). 2016 CSO sustainability index for Central and Eastern Europe and Eurasia. Washington, DC. Retrieved from https://www.usaid.gov/sites/default/files/documents/1866/CSOSI_Report_728-17.pdf

United States Agency for International Development. (2017c). 2016 CSO sustainability index for sub-Saharan Africa. Washington, DC. Retrieved from https://www.usaid.gov/sites/default/files/documents/1866/2016_Africa_CSOSI__508.pdf

United States Agency for International Development. (2017d). 2016 CSO sustainability index for the Middle East and North Africa. Washington, DC. Retrieved from https://www.usaid.gov/sites/default/files/documents/1866/2016_MENA_CSOSI__508.pdf

University of Witwatersrand. (2018). Chair in African philanthropy fact sheet. Johannesburg, SA: The Wits Business School. Retrieved from http://www.wbs.ac.za/media/wits-business-school/content-assets/documents/WBSChair-in-African-Philanthropy-fact-sheet.pdf

Urban Areas and Cities Act, No. 13 of 2011. eKLR. Retrieved from http://kenyalaw.org/lex//actview.xql?actid=No. 13 of 2011

Value Added Tax Act, Chapter 476 of 1993. eKLR. Retrieved from http://kenyalaw.org/kl/fileadmin/pdfdownloads/Acts/ValueAddedTaxActCap476.pd 
Van Rooy, A. (1998). Civil society as idea: An analytical hatstand? In A. Van Rooy (Ed.), Civil society and the aid industry (pp. 6-30). London, UK: Earthscan.

Van Rooy, A., \& Robinson, M. (1998). Out of the ivory tower: Civil society and the aid system. In A. Van Rooy (Ed.), Civil society and the aid industry (pp. 31-70). London, UK: Earthscan.

Vernon, R. (2009). Closing the door on aid. The International Journal of Not-for-Profit Law, 11(4), 5-29. Retrieved from http://www.icnl.org/research/journal/vol11iss4/special_1.htm

Viwango. (n.d.). Certification process. Retrieved from http://www.viwango.org/index.php?option=com_content\&view=article\&id=22:certi fication-process $\&$ catid $=1$ :certificaton $\&$ Itemid $=20$

Viwango. (2011a). The Kenya civil society organisations capacity assessment tool. Nairobi, KE.

Viwango. (2011b). The Kenya civil society organisations code of practice. Nairobi, KE. Viwango. (2011c). The Kenya civil society organisations standards. Nairobi, KE. Voluntary Sector Initiative. (2002). A code of good practice on policy dialogue: Building on an Accord between the Government of Canada and the voluntary sector. Ottawa, CA. Retrieved from http://www.vsi-isbc.org/eng/policy/pdf/codes_policy.pdf Wacker, J. (1998). A definition of theory: Research guidelines for different theorybuilding research methods in operations management. Journal of Operations Management, 16(4), 361-385. http://doi.org/10.1016/S0272-6963(98)00019-9 Wafula, C. (2015, July 3). NGOs board on the spot over proposed changes on PBO Act. 
Daily Nation. Retrieved from http://www.nation.co.ke/news/Civil-societies-disownchanges-on-PBO-Act/-/1056/2774040/-/auk0b6z/-/index.html

Walzer, M. (1990). The civil society argument. Gunnar Myrdal Lecture, October 1990, University of Stockholm, Stockholm, SE. Retrieved from http://cts.lub.lu.se/ojs/index.php/st/article/viewFile/2863/2427

Wamucii, P. (2014). Civil society organizations and the state in East Africa: From the colonial to the modern era. In E. Obadare (Ed.), The handbook of civil society in Africa (pp. 109-124). New York, NY: Springer.

Wamucii, P., \& Idwasi, P. (2010). The legislative environment for civil society in Kenya. In B. Moyo (Ed.), (Dis)enabling the public sphere: Civil society regulation in Africa (Volume 1) (pp. 247-270). Midrand, SA: Southern Africa Trust.

Wanyande, P. (2009). Civil society and transition politics in Kenya: Historical and contemporary perspectives. In P. Wanyande \& M. A. Okebe (Eds.), Discourses on civil society in Kenya (pp. 8-19). Nairobi, KE: African Research and Resource Forum. Retrieved from http://erepository.uonbi.ac.ke/bitstream/handle/11295/38988/CIVIL SOCIETY AND TRANSITION POLITICS.pdf?sequence $=1 \&$ isAllowed $=\mathrm{y} \#$ page $=19$

Wanyeki, M. (2015). See no evil: Reform and observation of Kenya's 2013 presidential elections. In F. Otieno (Ed.), New constitution, same old challenges: Reflections on Kenya's 2013 elections (pp. 18-46). Nairobi, KE: Society for International Development Nairobi Office with Uraia Trust. Retrieved from https://profiles.uonbi.ac.ke/patrick_asingo/files/elections_book_2013.pdf Wanzala, O. (2015, October 29). NGOs given 14 days to submit audited accounts or be 
deregistered. Daily Nation. Nairobi, Kenya. Retrieved from http://www.nation.co.ke/news/-/1056/2934696/-/1315mr6z/-/index.html

Wapner, P. (2002). Introductory essay: Paradise lost? NGOs and global accountability. Chicago Journal of International Law, 3(1), 155-160. Retrieved from https://chicagounbound.uchicago.edu/cgi/viewcontent.cgi?referer=https://www.goog le.ca/\&httpsredir $=1 \&$ article $=1178 \&$ context $=$ cjil

Warren, S., Lloyd, R., \& Lingan, J. (2009, December 1). The growth of CSO selfregulation. Alliance. Retrieved from http://www.alliancemagazine.org/analysis/thegrowth-of-cso-self-regulation/

Wiepking, P., \& Handy, F. (2015a). Introduction. In P. Wiepking \& F. Handy (Eds.), The Palgrave handbook of philanthropy (pp. 3-8). New York, NY: Palgrave Macmillan. Wiepking, P., \& Handy, F. (Eds.). (2015b). The Palgrave handbook of global philanthropy. New York, NY: Palgrave Macmillan.

Wiepking, P., \& Handy, F. (2015c). The practice of philanthropy: The facilitating factors from a cross-national perspective. In P. Wiepking \& F. Handy (Eds.), The Palgrave handbook of philanthropy (pp. 597-623). New York, NY: Palgrave Macmillan.

Williams, A. P., \& Taylor, J. A. (2013). Resolving accountability ambiguity in nonprofit organizations. Voluntas, 24(3), 559-580. http://doi.org/10.1007/s11266-012-9266-0

Witness Protection Act, No. 16 of 2006. eKLR. Retrieved from http://kenyalaw.org/lex//actview.xql?actid=No. 16 of 2006

Wolfe-Robinson, M., \& Bowcott, O. (2012, May 6). The global fight to end capital punishment. The Guardian. Retrieved from https://www.theguardian.com/world/2012/may/06/global-fight-end-capital- 
punishment

Wood, J. (2016). Unintended consequences: DAC governments and shrinking civil society space in Kenya. Development in Practice, 26(5), 532-543. http://doi.org/10.1080/09614524.2016.1188882

World Bank. (n.d.-a). World Bank country and lending groups. Retrieved from https://datahelpdesk.worldbank.org/knowledgebase/articles/906519-world-bankcountry-and-lending-groups

World Bank. (n.d.-b). Worldwide governance indicators. Retrieved from http://info.worldbank.org/governance/wgi/\#reports

World Bank. (2014, September 30). Kenya: A bigger, better economy. Retrieved from http://www.worldbank.org/en/news/feature/2014/09/30/kenya-a-bigger-bettereconomy

World Economic Forum. (2013). The future role of civil society. Geneva, CH. Retrieved from http://www3.weforum.org/docs/WEF_FutureRoleCivilSociety_Report_2013.pdf World Movement for Democracy, \& International Center for Not-for-Profit Law. (2012). Defending civil society report. Washington, DC. Retrieved from http://www.icnl.org/research/resources/dcs/DCS_Report_Second_Edition_English.p df

Wyatt, B. (2016). Reflections on the long and winding road of regulation. In M. McGregor-Lowndes \& B. Wyatt (Eds.), Regulating charities: The inside story (pp. 139-155). Cheltenham, UK: Routledge.

York, G. (2015a, June 27). Racked by violence, Kenya struggles to hold its economic 
lead. The Globe and Mail. Retrieved from

https://secure.globeadvisor.com/servlet/ArticleNews/story/gam/20150627/RBIBKE NYAECONOMY

York, G. (2015b, July 2). Anti-terror tactics targeting Muslim leaders provoking tensions in Kenya. The Globe and Mail. Retrieved from http://www.theglobeandmail.com/news/world/anti-terror-tactics-targeting-muslimleaders-provoking-tensions-in-kenya/article25236344/

York, G. (2018a, April 13). New Ethiopian leader Abiy Ahmed, youngest in Africa, sparks hope of reform. The Globe and Mail. Retrieved from https://www.theglobeandmail.com/world/article-new-ethiopian-leader-abiy-ahmedyoungest-in-africa-sparks-hope-of/

York, G. (2018b, September 21). Kenyan court releases acclaimed gay-themed film from censors' grip. The Globe and Mail. Retrieved from https://www.theglobeandmail.com/world/article-kenyan-court-releases-acclaimedgay-themed-film-from-censors-grip/

Zakaria, F. (1996). The rise of illiberal democracy. Foreign Affairs, 76(6), 22-43. http://doi.org/10.2307/20048274 